\title{
POLITÉCNICA
}

UNIVERSIDAD POLITÉCNICA DE MADRID

TESIS DOCTORAL

DEPARTAMENTO DE ENERGÍA Y COMBUSTIBLES

Escuela Técnica Superior de Ingenieros de Minas y Energía

\section{HERRAMIENTA DE DIAGNOSIS PARA EVALUAR EL ESTADO DE ACEITES DIELÉCTRICOS BIODEGRADABLES}

\author{
Autor: FRANCISCO SANZ PÉREZ \\ Titulación: Licenciado en Ciencias Químicas \\ PROGRAMA DIMARMA (RD 99/2011) \\ Junio 2017
}

Dirigido por:

JOSE LAUREANO CANOIRA LOPEZ

ALBERTO RAMOS MILLÁN 
Tesis doctoral

DIMARMA 


\section{AGRADECIMIENTOS}

Con estas líneas, quiero mostrar mi más sincero agradecimiento a todas y cada una de las personas que durante estos años han estado a mi lado: mi pareja, mi familia, mis amigos y compañeros de trabajo. Estoy seguro que sin su apoyo incondicional y su ayuda, este proyecto nunca se hubiera llevado a cabo.

Quisiera mostrar especialmente mi más sincero agradecimiento a mis directores de tesis, D. Laureano Canoira López y D. Alberto Ramos Millán y concretamente, a Laureano, el cual me dio los consejos necesarios para que dicha tesis llegara a buen puerto. De corazón, muchas gracias, te estaré eternamente agradecido.

A mi familia, especialmente a mi madre y a mi padre. Gracias por todo el esfuerzo que habéis hecho para conseguir que hoy esté donde he llegado.

A Patxi, mi parte complementaria. Gracias por todas esas horas que me has escuchado, tranquilizado, apoyado y comprendido. Sabes perfectamente que esta tesis doctoral también lleva una parte de ti.

A Jorge Insa y Jesús Sánchez Caba, todo el conocimiento adquirido durante estos años os lo debo a vosotros. Os estaré eternamente agradecido por la paciencia y el interés mostrado. Me habéis demostrado que, aunque haya perdido a unos jefes, he ganado unos magníficos amigos.

A Ernesto Iván Diestre Redondo, ya que durante estos años de investigación, hemos trabajado codo con codo en el laboratorio, él desde el Centro de Tecnología de Repsol y yo desde el Laboratorio de Combustibles y Petroquímica.

Y por último, a todos mis compañeros del laboratorio de Combustibles y Petroquímica. Juntos hemos levantado uno de los mejores laboratorios de investigación y desarrollo. 


\section{ÍNDICE}

RESUMEN

ABSTRACT 11

CAPÍTULO 1. INTRODUCCIÓN 13

1.1. Los transformadores eléctricos: principios de funcionamiento 14

1.2. Partes de un transformador 20

1.3. Tipos de transformador 27

1.4. Los aceites dieléctricos 29

1.5. Propiedades físico químicas de los aceites dieléctricos 39

1.6. Binomio papel / Aceite dentro del transformador 80

1.7. Especificaciones técnicas de los aceites dieléctricos y su legislación 93

1.8. Aceites sintéticos 99

$\begin{array}{lll}\text { 1.9. } & \text { Estudio de patentes } & 104\end{array}$

1.10. Mejora en las propiedades químicas y físico químicas de los aceites: uso $\begin{array}{ll}\text { de aditivos } & 115\end{array}$

1.11. Biodegradabilidad y ecotoxicidad de los aceites biodegradables 133

CAPÍTULO 2: EQUIPOS Y MÉTODOS DE ENSAYO 137

2.1. Estudio de las propiedades en frio

$\begin{array}{ll}\text { 2.1.1. Winterización/desparafinado } & 138\end{array}$

2.1.2. Estudio de la acción de depresores del punto de congelación en aceites

2.2. Estudio de las propiedades de solubilidad

2.2.1. Determinación de las curvas de saturación de humedad en aceites 152

2.2.2. Determinación de las curvas de solubilidad de aire en aceites $\quad 159$

2.3. Estudio de los procesos de degradación térmica

2.3.1. Estudio de las propiedades de transferencia térmica 165

2.3.2. Estudio de la degradación térmica de aceites de origen vegetal 169

$\begin{array}{ll}\text { 2.3.3. Ensayo de oxidación en película fina } & 177\end{array}$

2.3.4. Desarrollo de planta piloto de generación de puntos calientes $\quad 178$

2.4. Estudio de compatibilidad química

2.4.1. Compatibilidad de aceites con aislantes celulósicos 
2.4.2. Compatibilidad de los aceites vegetales con los materiales del transformador

2.4.3. Compatibilidad de aceites en presencia de ácidos grasos

2.5. Ecotoxicidad de los aceites vegetales

CAPÍTULO 3: RESULTADOS Y DISCUSIÓN

3.1. Comportamiento del aceite vegetal frente a bajas temperaturas

3.1.1. Desparafinado del aceite vegetal A

3.1.2. Estudio de la acción de depresores del punto de congelación en aceites

3.2. Propiedades de solubilidad en el aceite dieléctrico vegetal

3.2.1. Determinación experimental de la tendencia a la saturación de humedad

3.2.2. Resultados de las curvas de solubilidad de aire en aceite

3.3. Resultados de los procesos de degradación termo-oxidativa

3.3.1. Resultados obtenidos en el estudio de las propiedades de transferencia térmica

3.3.2. Estudio de la degradación térmica de aceites de origen vegetal 246

3.3.3. Ensayo de oxidación en película fina 256

3.3.4. Triángulo de Duval para el aceite A 257

3.4. Estudio de compatibilidad química

3.4.1. Compatibilidad de aceites con aislantes celulósicos

3.4.2. Compatibilidad de los aceites vegetales con los materiales del transformador

3.4.3. Compatibilidad en presencia de ácidos grasos

3.5. Estudio de ecotoxicidad en lombrices y lechuga común 
Tesis doctoral

DIMARMA 
Tesis doctoral

DIMARMA

RESUMEN 


\section{RESUMEN}

En la sociedad actual en la que vivimos, existe una demanda creciente por crear nuevas metodologías que permitan sustituir el petróleo y los productos petrolíferos por otros de origen no fósil. Dicha necesidad se fundamenta en la disminución de reservas de petróleo a nivel mundial así como las posibles consecuencias que pueden acontecer por rivalidades geopolíticas entre diferentes países. La tendencia natural es el desarrollo de nuevos productos, tanto combustibles (biodiesel, bioetanol,...) como no combustibles (biolubricantes, aceites dieléctricos de origen vegetal).

Unos de los productos de origen petrolífero que se está actualmente sustituyendo por otro de origen vegetal es el aceite aislante o dieléctrico ubicado dentro de la cuba de los transformadores de distribución y potencia.

Desde hace más de medio siglo, la tendencia fue emplear matrices orgánicas de origen petrolífero como agentes aislantes líquidos en aceites de transformador. Seleccionando el tipo de base necesaria para esta aplicación y adicionando aditivos mejoradores de sus propiedades físicas, se consiguió un fluido de bajo coste relativo, excelentes prestaciones y fácil disponibilidad. Pero dichos aceites, además de su origen petrolífero, requieren la mejora de otras propiedades tales como una elevada resistencia a incendios o una total biodegradabilidad. De esta forma, se evitarían incendios como los acontecidos en el año 2006 simultáneamente en cuatro transformadores de potencia de diferentes subestaciones eléctricas ubicadas en Madrid.

Hasta hace unos años, se han estado usando como agentes aislantes líquidos los famosos policlorobifenilos o PCB's. Este fluido sintético dotaba al aislante líquido de unas características dieléctricas excepcionales. Pero en contrapartida, poseía una elevada ecotoxicidad tanto acuática como terrestre, haciendo del mismo uno de los productos sintéticos con mayor poder carcinogénico conocidos, además de una muy escasa biodegradabilidad. 
Por todas estas razones, ha sido necesario el desarrollo de nuevos productos líquidos aislantes con una mínima ecotoxicidad, una elevada biodegradabilidad y unas características fisicoquímicas frente a la inflamabilidad, mejoradas con respecto a sus homólogos minerales.

Actualmente existen en el mercado aceites aislantes biodegradables de origen vegetal. El problema al que se enfrenta la sociedad actual es llegar a conocer el comportamiento de estos fluidos frente a requerimientos térmicos y eléctricos, así como predecir su comportamiento con herramientas de diagnosis del estado de los mismos. Para fluidos de origen mineral existen una amplia gama de herramientas de diagnóstico del estado del transformador mediante análisis químicos y fisicoquímicos. Dichas herramientas no pueden ser extrapoladas y usadas para los nuevos aceites biodegradables, ya que su matriz orgánica es completamente diferente y, como consecuencia, su comportamiento físico y químico es diferente también. El desarrollo de una herramienta de diagnosis evitará el deterioro prematuro del aceite y generará marcadores de fallos térmicos y eléctricos dentro del transformador. Todo esto conllevará un ahorro económico en el mantenimiento del transformador así como una seguridad aumentada frente a explosiones e incendios de los mismos. 
Tesis doctoral

DIMARMA 
Tesis doctoral

DIMARMA

ABSTRACT 


\begin{abstract}
In our actual society, there is a growing demand to create new methodologies to replace oil and petroleum products by other of non-fossil origin. This requirement is based on the decline in oil reserves worldwide and the possible consequences that may occur by geopolitical rivalities between different countries. The natural tendency is to develop new products, both fuels (biodiesel, bioethanol ...) and oils (bio-lubricants, dielectric oils of vegetable origin).

One of the products of petroleum origin which is currently replaced by another of vegetable origin is insulating or dielectric oil located within the distribution cuba and power transformers.

For over half a century, the trend was to use organic matrices of petroleum origin as insulating fluids in transformers. Selecting the type of base required for this application and adding improvers of their physical properties, a fluid of relatively low cost, easy availability and excellent performance was achieved. But these oils, in addition to its petroleum origin, require improving other properties such as high resistance to fire and total biodegradability. Thus, fires would be avoided as occurred in 2006 simultaneously in four different power transformer substations located in Madrid, Spain.
\end{abstract}

Until recent years, they have been used as insulating fluids the polychlorinated biphenyls or PCBs agents. This synthetic fluid endowed the liquid insulation exceptional dielectric properties. But in contrast, it had a much higher aquatic ecotoxicity, making it one of the most known synthetic carcinogenics.

For all these reasons, it has been necessary to develop new insulating liquid products with a low ecotoxicity, a high biodegradability and compared physicochemical characteristic, such as improved flammability properties relative to their mineral counterparts.

Actually, there are on the market biodegradable insulating oils of vegetable origin. The problem facing technics today is to understand the behavior of these fluids against thermal and electrical stress, as well as to have tools to predict their behavior that state the same diagnosis. For fluids of mineral origin there are a wide range of tools for diagnosis of the transformer by chemical and physicochemical analysis. These tools can not be extrapolated and used for new biodegradable oils, because their organic matrix is completely different and, therefore, their physical and chemical behavior is different too. The development of a diagnostic tool to prevent premature deterioration of the oil and generate markers of thermal and electrical faults within the transformer is the aim of this thesis. This diagnosis tool will lead to cost savings in the transformer maintenance and increased security against explosions and fires in them. 
CAPÍTULO 1: INTRODUCCIÓN 


\section{CAPÍTULO 1: INTRODUCCIÓN}

\subsection{Los transformadores eléctricos: principios del funcionamiento}

Los transformadores son equipos encargados de convertir un voltaje de entrada en otro de salida. Los transformadores se encuentran presentes tanto en la generación de energía eléctrica como en su transmisión y distribución. También, su uso se extiende al campo de las telecomunicaciones y en aplicaciones domésticas. El papel que desempeñan es de gran importancia económica debido a las graves consecuencias que pueden derivarse de los fallos de estos equipos.

En su forma más simple, un transformador consiste en un núcleo de hierro dulce que lleva en dos regiones del mismo dos devanados que constituyen los circuitos primarios y secundarios [1]. El devanado que recibe la potencia eléctrica es el primario, y el devanado secundario es el encargado de entregarla a una red exterior.

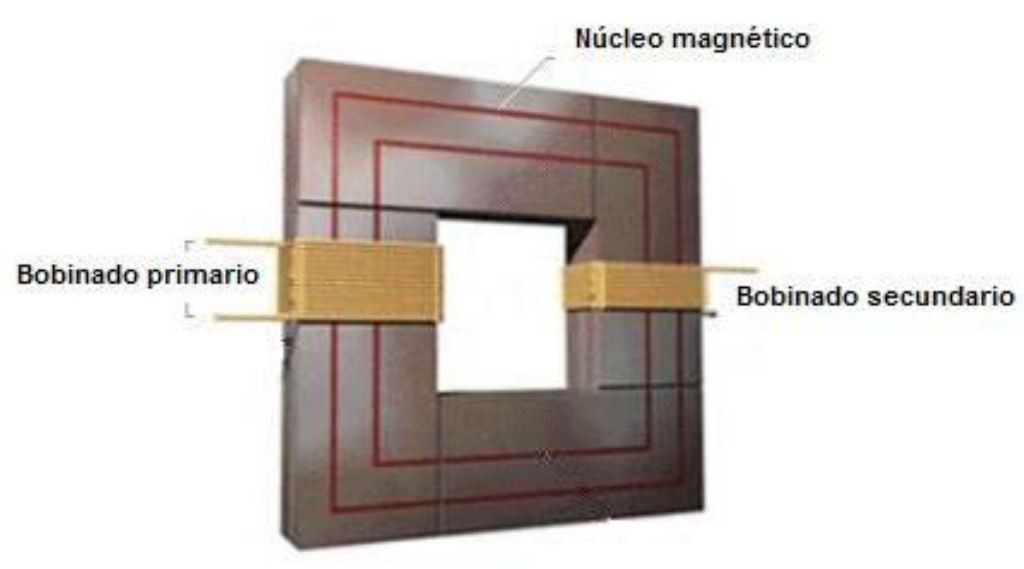

Figura 1: Núcleo de un transformador monofásico (Fuente: mailxmail.com)

En la figura 1 se observan las tres partes mencionadas:

a) Una bobina primaria conectada a una fuente de corriente alterna

b) Una bobina secundaria

c) Un núcleo laminado de hierro dulce. 
A veces, como ocurre en muchos transformadores de teléfonos y radiofrecuencia, no hay núcleo alguno y se dice que se trata de un transformador con núcleo de aire.

El mecanismo de operación de una transformador es el siguiente: conforme se aplica una corriente alterna (en adelante c.a.) en el bobinado o devanado primario, por inducción electromagnética se genera una c.a. en el devanado secundario. La relación entre el voltaje del bobinado primario y el voltaje inducido en el bobinado secundario es función directa del número de vueltas o arrollamientos de cada bobinado.

$$
\frac{V_{p}}{V_{s}}=\frac{N_{p}}{N_{s}}
$$

donde $V_{p}$ es el voltaje de entrada o voltaje en el bobinado primario, $V_{s}$ es el voltaje de salida o voltaje en el bobinado secundario, $\mathrm{N}_{\mathrm{p}}$ es el número de vueltas en el bobinado primario y $\mathrm{N}_{\mathrm{s}}$ es el número de vueltas en el bobinado secundario.

De la fórmula anterior se puede concluir que, si el número de arrollamientos del bobinado primario es mayor que el secundario, el voltaje de salida en el transformador es menor que el voltaje de entrada, por lo tanto, se tiene una reducción de voltaje. Pero, si por el contrario el número de arrollamientos del devanado secundario es mayor que el número de arrollamientos del bobinado primario, el voltaje de salida es mayor que el de entrada y se tiene un incremento del voltaje.

Pero, ¿cómo funciona un transformador? ¿En qué ley se basa? El mecanismo de funcionamiento de un transformador tiene su origen en la ley de inducción de Faraday. Para explicar dicha ley, empezaremos describiendo dos experimentos sencillos que demuestran que una corriente puede ser producida por un campo magnético cambiante [2]. Sea una espira de alambre conectada a un galvanómetro como aparece en la figura 2.

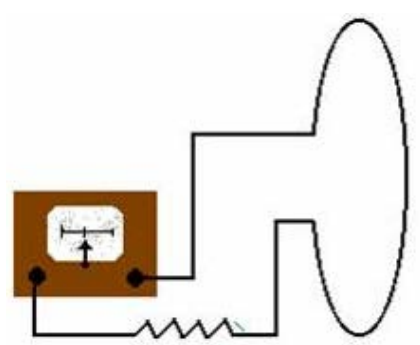

Fig. 2: Galvanómetro unido a una espera metálica 
Si un imán se mueve hacia la espira, de la aguja del galvanómetro se desviará en una dirección, como se muestra en la figura 3. Si el imán se mueve alejándose de la espira, la aguja del galvanómetro se desviará en dirección opuesta, tal y como muestra la figura 4. Si el imán se mantiene estacionario en relación a la espira, no se observa desviación en la aguja del galvanómetro. A partir de estas experiencias, se puede concluir que siempre que exista un movimiento relativo entre el imán y el circuito de la espira, se generará una corriente en el circuito.

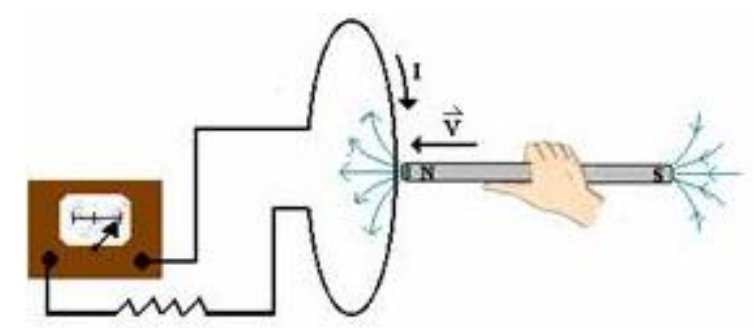

Figura 3: Imán acercándose a la espira

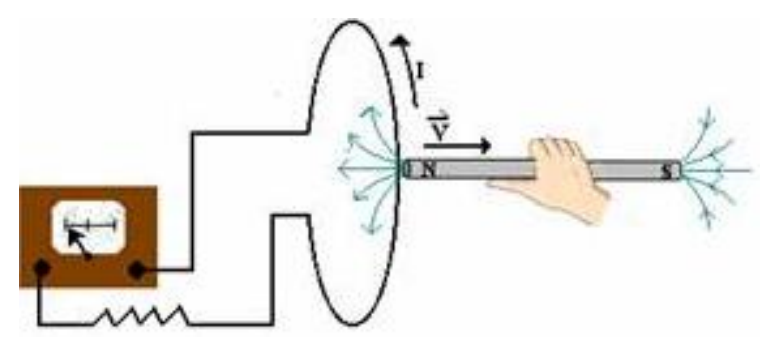

Figura 4: Imán alejándose de la espira

Esta corriente generada sin existencia alguna de baterías en el circuito se le conoce como Corriente Inducida ya que está generada por una fuerza electromotriz inducida o fem inducida.

Para ver cómo funciona un transformador, se describirá el siguiente experimento. El montaje consta de una bobina conectada a una batería y a un interruptor. La bobina que 
una ambas partes la denominaremos bobina primaria y su correspondiente circuito, circuito primario. La bobina se devana o se enrolla alrededor un núcleo de hierro para intensificar el campo producido por la corriente a través de la bobina. Una segunda bobina también se devana alrededor del anillo metálico en la posición opuesta al devanado primario. La segunda bobina se conecta a un galvanómetro. Nos referiremos a esta segunda bobina como bobina secundaria y a su correspondiente circuito, como circuito secundario. El único propósito de este circuito secundario es detectar cualquier corriente que pueda ser producida por un cambio en el campo magnético.

Para comenzar con el experimento, se acciona el interruptor del circuito primario y se observa que el galvanómetro del circuito secundario se desvía en una dirección y regresa a cero. Cuando se abre el interruptor, el galvanómetro se desvía hacia la otra dirección para acabar en cero otra vez. Faraday, después de observar dichos fenómenos, enunció que una corriente no puede ser producida por un campo magnético estable, ya que la corriente que se genera en el circuito secundario ocurre sólo en el instante en que el campo magnético a través de la bobina secundaria está cambiando. Por lo tanto, la fem o fuerza electromotriz es producida en el circuito secundario por los cambios en el campo magnético y es directamente proporcional a la rapidez de cambio de flujo magnético a través del circuito.

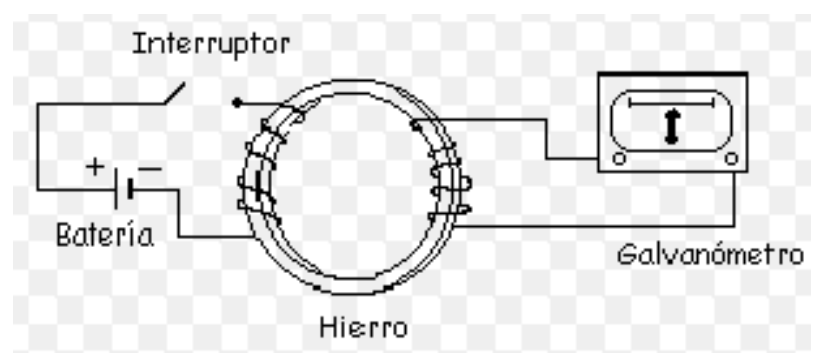

Figura 5: Aplicación de la ley de Faraday

Por lo tanto, y por similitud entre los circuitos de la figura 1 y los circuitos de la figura 5 podemos explicar cómo funciona un transformador en términos eléctricos.

Si el devanado primario del transformador se somete a una tensión eléctrica $\left(\mathrm{V}_{1}\right)$, circulará por él una corriente $\left(\mathrm{I}_{1}\right)$. La corriente primaria dará lugar, al pasar por el devanado primario a un flujo magnético $(\phi)$. Dicho flujo magnético, al atravesar el 
interior de las espiras del devanado secundario, dará lugar a una corriente en el devanado secundario $\left(\mathrm{I}_{2}\right)$ y a una tensión eléctrica $\left(\mathrm{V}_{2}\right)$ en sus extremos.

Desarrollando el aparato matemático para un transformador ideal, en el que se suponen que tanto las pérdidas en el circuito magnético como las pérdidas en los devanados son nulas, tendremos que el flujo magnético vendrá dado por la expresión:

$$
\varnothing=\emptyset_{\max } \sin \omega \cdot t
$$

(Ecuación 2)

Si en cada uno de los devanados hay $\mathrm{N}$ espiras, las tensiones inducidas en el circuito primario y circuito secundario serán:

$$
\begin{aligned}
& E_{1}=N_{1} \frac{d \emptyset}{d t}=N_{1} \emptyset_{\text {max }} \omega \cos \omega t \\
& E_{2}=N_{2} \frac{d \emptyset}{d t}=N_{2} \emptyset_{\text {max }} \omega \cos \omega t
\end{aligned}
$$

(Ecuación 4)

Teniendo en cuenta valores eficaces de $\mathrm{E}_{1}=4,44 \mathrm{~N}_{1} \phi_{\max } f \quad$ y $\quad \mathrm{E}_{2}=4,44 \mathrm{~N}_{2} \phi_{\max } f$ se obtiene la denominada Relación de Transformación o relación de espiras:

$$
\frac{E_{1}}{E_{2}}=\frac{N_{1}}{N_{2}}
$$

(Ecuación 5)

Si la resistencia óhmica de los devanados es nula y no hay flujo de dispersión, la tensión aplicada es igual a la tensión inducida, por lo que:

$$
\frac{E_{1}}{E_{2}}=\frac{N_{1}}{N_{2}}=\frac{V_{1}}{V_{2}}
$$

En el circuito secundario existe una carga Z, de acuerdo con la ley de Ampere: 


$$
N_{1} i_{1}-N_{2} i_{2}=\int_{c} H d l=\check{\mathrm{R}} \emptyset(t)
$$

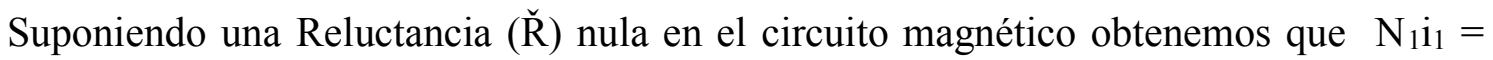
$\mathrm{N}_{2} \mathrm{i}_{2}$ que en valores eficaces da lugar a la expresión:

$$
\frac{I_{1}}{I_{2}}=\frac{N_{2}}{N_{1}}
$$

En el caso de que en el secundario tengamos una impedancia $Z_{2}$, con un factor de potencia $\cos \varphi$, la potencia consumida será $\mathrm{P}_{2}=\mathrm{V}_{2} \mathrm{I}_{2} \cos \varphi$. Dado que las tensiones e intensidades del circuito primario y secundario están en fase (debido a que no hay pérdidas en el transformador), la potencia en el circuito primario será $\mathrm{P}_{1}=\mathrm{V}_{1} \mathrm{I}_{1} \cos \varphi$, con lo que:

$$
P_{1}=V_{2} \frac{N_{1}}{N_{2}} I_{2} \frac{N_{2}}{N_{1}} \cos \varphi=V_{2} I_{2} \cos \varphi
$$

Por lo que la potencia de entrada al circuito primario del transformador es igual a la potencia de salida del transformador.

Pero no todos los transformadores se comportan idealmente en la vida real. El rendimiento de un transformador se define como la relación entre la potencia de salida respecto a la potencia de entrada. Teniendo en cuenta que la potencia eléctrica es igual al producto del voltaje por la corriente, el rendimiento o eficaciones de un transformador viene dado por la expresión:

$$
\varepsilon=\frac{V_{s} I_{s}}{V_{p} I_{p}}
$$

(Ecuación 10)

donde $I_{s}$ e $I_{p}$ son las corrientes en las bobinas del circuito primario y secundario, respectivamente. La mayor parte de los transformadores eléctricos son diseñados por obtener rendimientos muy altos, generalmente superiores al $90 \%$. 


\subsection{Partes componentes de un transformador}

Las principales partes que componen un transformador son clasificadas en cuatro grandes grupos [3]:

- Circuito magnético (núcleo)

- Circuito eléctrico (devanados)

- Sistema de aislamiento

- Tanque y accesorios

\subsubsection{El circuito magnético (núcleo)}

El circuito magnético es la parte componente del transformador que servirá para conducir el flujo magnético generado, el cual concatenará magnéticamente los circuitos eléctricos del transformador. El circuito magnético se conoce comúnmente como núcleo. Este núcleo se encuentra formado por láminas de acero al silicio de grano orientado de bajas pérdidas y una alta permeabilidad magnética.

Todas las láminas están aisladas en ambas caras por medio de un aislante inorgánico llamado carlite que consiste en una capa especial aislante aplicada en el proceso final de planchado y recocido del acero.

En la actualidad se tienen cuatro tipos de lámina de grano orientado, cuyas características se encuentran recogidas en la tabla 1:

Tabla1: Pérdidas dieléctricas en el acero al silicio a $60 \mathrm{~Hz}$ y $50 \mathrm{~Hz}$

\begin{tabular}{|c|c|c|c|c|c|}
\cline { 3 - 6 } \multicolumn{2}{c|}{} & \multicolumn{2}{c|}{$\mathbf{6 0 ~ H z}$} & \multicolumn{2}{c|}{$\mathbf{5 0 ~ H z}$} \\
\hline Grado de & \multirow{2}{*}{$\begin{array}{c}\text { Espesor } \\
\text { orientación }\end{array}$} & \multicolumn{2}{c|}{$W / \mathbf{k g}$} & \multicolumn{2}{c|}{ W/ kg } \\
\cline { 3 - 6 } & $\mathbf{m m})$ & $1,5 \mathrm{~T}$ & $1,7 \mathrm{~T}$ & $1,5 \mathrm{~T}$ & $1,7 \mathrm{~T}$ \\
\hline M-2 & 0,18 & 0,93 & - & 0,70 & - \\
\hline M-3 & 0,23 & 1,01 & - & 0,77 & - \\
\hline M-4 & 0,28 & 1,12 & 1,63 & 0,85 & 1,24 \\
\hline M-5 & 0,35 & 1,46 & 2,07 & 1,11 & 1,57 \\
\hline
\end{tabular}


Las pérdidas en la lámina a $50 \mathrm{~Hz}$ comparadas con las pérdidas a $60 \mathrm{~Hz}$ tienen la siguiente equivalencia:

\section{Pérdidas a $50 \mathrm{~Hz}=0,76$ x pérdidas a $60 \mathrm{~Hz}$}

El tipo de lámina más usado en la fabricación de núcleos para transformadores es la M4.

\subsubsection{El circuito eléctrico (devanados)}

Los devanados son la parte que componen los circuitos eléctricos del transformador (devanados primarios y secundarios). Los devanados se fabrican en diferentes tipos de metales, dependiendo de las necesidades del diseño, y los materiales que se utilizan, básicamente, son el cobre y el aluminio.

La función de los devanados primarios es crear un flujo magnético para inducir en los devanados secundarios una fuerza electromotriz o fem, y transferir potencia eléctrica del primario al secundario mediante el principio de inducción electromagnética. Este proceso se desarrolla con unas pérdidas de energía muy pequeñas conocidas como pérdidas magnéticas por corrientes de Foucault.

Aunque el cobre tenga una baja resistencia específica, su mayor coste comparado con el coste del aluminio ha dado lugar a un incremento del uso de aluminio (usado por primera vez en 1952), especialmente en la construcción de transformadores de distribución y pequeña potencia.

A la hora de diseñar la fabricación de un transformador, se deben considerar determinadas características particulares tanto del cobre como del aluminio. Las ventajas que ofrece el cobre frente al aluminio son:

- Su elevada resistencia mecánica

- Su buena conductividad eléctrica por lo que el dimensionado de la bobina será más pequeño

Por otro lado, las ventajas de las bobinas de aluminio frente a las de cobre son: 
- Su estabilidad en el coste del suministro

- Una eficiente disipación de calor en devanados en banda

- Una considerable reducción del peso

Los devanados de aluminio en el circuito de baja tensión son construidos únicamente en banda. Sin embargo, los devanados de cobre pueden ser construidos con conductores redondos, forrados con papel o esmaltados, o la combinación de ambos aislamientos dependiendo del tipo de transformador, tensión y potencia del mismo.

Tabla 2: Comparación de las propiedades físicas del aluminio y del cobre

\begin{tabular}{|l|c|c|}
\hline Propiedad & Aluminio & Cobre \\
\hline Conductividad eléctrica a $20^{\circ} \mathrm{C}$ & $62 \%$ & $100 \%$ \\
\hline Peso específico $\left(\mathrm{g} / \mathrm{cm}^{3}\right)$ a $20^{\circ} \mathrm{C}$ & 2,70 & 8,89 \\
\hline Calor específico $\left(\mathrm{J} / \mathrm{g} .{ }^{\circ} \mathrm{C}\right)$ & 0,21 & 0,09 \\
\hline Punto de fusión $\left({ }^{\circ} \mathrm{C}\right)$ & 660 & 1083 \\
\hline Conductividad térmica a $20^{\circ} \mathrm{C}(\mathrm{W} / \mathrm{m} . \mathrm{K})$ & 205,0 & 385,0 \\
\hline Esfuerzo mecánico a la tensión $\left(\mathrm{kg} / \mathrm{mm}^{2}\right)$ & 16 & 25 \\
\hline $\begin{array}{l}\text { Peso total de un transformador de } 2500 \mathrm{kVA}(\mathrm{kilo} \text { Voltio } \\
\text { Amperio) con devanado de A.T. a } 44 \mathrm{kV}(\mathrm{kg})\end{array}$ & 6318 & 6682 \\
\hline
\end{tabular}

\subsubsection{Sistemas de aislamiento}

Los transformadores llevan incorporados una serie de materiales aislantes, los cuales, juntos forman el sistema de aislamiento. Este sistema incluye diferentes materiales como los que se citan a continuación:

- Cartón prensado de celulosa (pressboard)

- Papel kraft normal o tratado con resinas epoxi

- Papel corrugado

- Cartón prensado de alta densidad

- Collares de cartón prensado y aislamientos finales

- Partes de cartón prensado laminado 
- Esmaltes y barnices

- Recubrimientos orgánicos e inorgánicos para la laminación del núcleo

- Porcelana

- Recubrimientos de polvo epóxico

- Madera de arce para armados

- Fibra vulcanizada

- Algodón (hilos, cintas)

- Plásticos, telas y cintas adhesivas

- Cintas de fibra de vidrio

- Fluido líquido dieléctrico que pueden ser aceites minerales, silicónicos o vegetales.

El sistema de aislamiento aisla los devanados del transformador entre ellos, y a tierra, así como las partes cercanas al núcleo y a las partes de acero que forma la estructura. Es por ello que el aislamiento es mucho más que solamente un medio mecánico para conservar los alambres separados.

Los primeros catorce materiales forman el sistema de aislamiento sólido que debe de cumplir con tres importantes funciones:

1) Soportar las tensiones relativamente altas, sucedidas en servicio normal (esfuerzos dieléctricos). Esto incluyen ondas de impulso y transitorias.

2) Soportar esfuerzos mecánicos y térmicos los cuales, generalmente acompañan un cortocircuito.

3) Prevenir excesivas acumulaciones de calor.

Sin embargo, el aislante líquido dieléctrico es el material aislante clave del transformador. Los fluidos dieléctricos, o aceites aislantes, o "líquidos electrotécnicos" son fluidos necesarios para la generación, transmisión, distribución y utilización industrial de energía eléctrica [4]. Las propiedades de estos líquidos, junto con las de las de los materiales sólidos son criterios importantes en el diseño del equipo así como para proporcionar un menor impacto ambiental y durabilidad del equipo al mínimo coste aceptable. Por esta causa, un cambio de naturaleza del fluido, de mineral a éster, sea sintético o natural, o mezcla de cualesquiera de ellos supone para el fabricante del 
equipo la necesidad de disponer de la máxima información acerca de sus propiedades y de su compatibilidad con el resto de materiales del transformador.

Las propiedades deseadas para el fluido aislante ideal serían las siguientes:

- Elevada rigidez dieléctrica

- Bajo factor de pérdidas dieléctricas

- Alta resistividad volumétrica

- Elevado calor específico

- Excelente estabilidad termo-oxidativa

- Buenas propiedades de absorción de gases

- Fluencia a baja temperatura

- Baja viscosidad

- Buenas propiedades de extinción de arcos

- Alta temperatura de inflamabilidad

- Mínimo coste

- No tóxico

- Rápida degradabilidad en el ambiente

Aunque se estén llevando a cabo investigaciones y desarrollos de nuevos fluidos dieléctricos, lamentablemente no existe actualmente ningún fluido, tanto mineral como sintético, que cumpla con todos y cada uno de los requisitos expuestos anteriormente. Por dicha razón, el fabricante del equipo y productor del fluido deben tomar un compromiso entre todas ellas cuando se realiza una selección o un nuevo desarrollo. Los criterios de compromiso serán los económicos, los diseños del equipo, la potencia del transformador, el factor crítico de una interrupción de su operación así como consideraciones de seguridad y medio ambiente.

Pero, ¿porque se usa aceite mineral, sintético o vegetal como aislante? Las pérdidas en los devanados, en el núcleo, y en otros elementos motivan el calentamiento del transformador, las cuales, hemos de evitar. Los principales medios refrigerantes que se utilizan, en contacto con los arrollamientos, son el aire y el aceite (tanto mineral, sintético y vegetal). El uso de aceite, frente al aire, está justificado dado que tiene una mejor conductividad térmica y posee un mayor calor específico. La función del aceite es doble, actúa como aislante y como refrigerante. 
La parte activa del transformador suele ir sumergida en aceite, esta parte está en el interior de un tanque o caja. Esta caja puede tener una superficie de refrigeración considerable, compuesta por tubos, aletas o radiadores adosados. Este sistema de refrigeración, puede efectuarse por convección natural, o bien forzada.

La potencia de un transformador viene limitada por su valor máximo de calentamiento, por tanto, la ventilación forzada y buen aislante líquido puede ser un medio eficaz para aumentar la potencia.

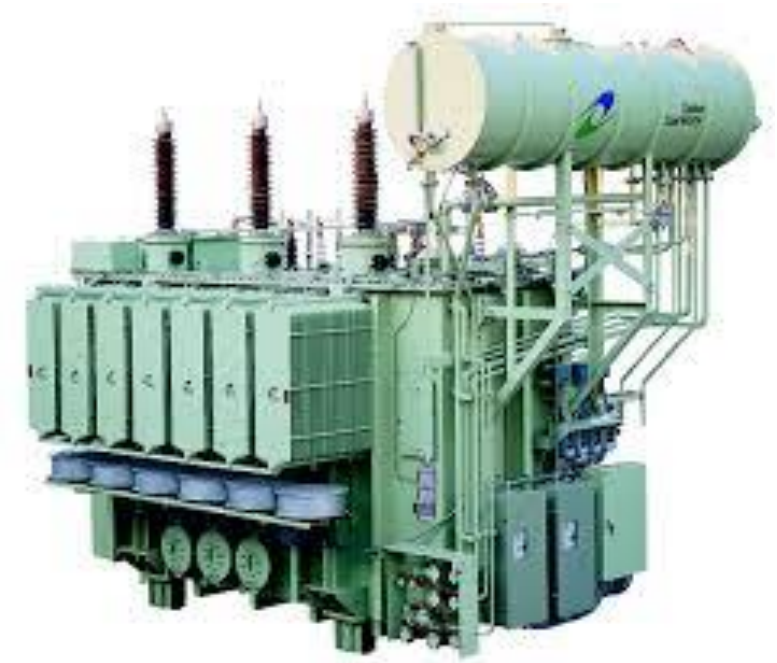

Figura 6: Transformador de potencia (Fuente: Web ADIMRA)

\subsubsection{Tanque y accesorios}

Los transformadores que emplean refrigeración por líquido deben tener sus núcleos y devanados necesariamente encerrados en tanques que eviten las pérdidas del refrigerante. A este sistema formado por el núcleo, devanados y tanque se le conoce como la parte activa del transformador. Estos tanques están construidos por chapas (láminas) lisas de aceros, soldadas entre sí y pueden tener forma redonda, ovalada, elíptica o rectangular.

Estos tanque deben tener una holgura suficiente para permitir la dilatación y contracción térmica del aceite. En los transformadores de distribución es corriente utilizar un tanque hermético con una cámara de aire suficiente entre la tapa y el aceite que permita que éste comprima o dilate el aire encerrado. En los transformadores de potencia, existe una cámara de expansión unida a un relé de Buchholz. Dependiendo del modelo, el relé 
puede detectar varios tipos de fallos dieléctricos del transformador. En caso de una acumulación lenta de gas, posiblemente debida a una ligera sobrecarga eléctrica, el gas producido por el craqueo térmico del aceite aislante se acumula en la parte superior del relé y provoca el descenso del nivel de aceite. Un interruptor de nivel de aceite ubicado en el relé dispara una señal de alarma. Se abre el relé y el gas pasa al tanque de expansión, evitando así las sobrepresiones en la cuba o tanque del transformador. Este mismo tanque sirve para tomar muestra de gases y ser analizadas por cromatografía gaseosa. En función de los gases detectados, y con la ayuda de diferentes herramientas de diagnosis e interpretación de fallos dieléctricos, podemos saber qué tipo de fallo ha ocurrido dentro del tanque sin tener que dejar fuera de servicio el transformador.

Con respecto a los accesorios del transformador, se pueden diferencias varias categorías:

- Herrajes: Son los elementos que permiten la conexión al transformador de los cables de acometida, generalmente de cobre tal y como se ha citado anteriormente.

- Pintura: El tipo de pintura depende del sitio de instalación del transformador. Las pinturas anticorrosivas y los esmaltes empleados para el acabado final son de origen sintético. Para transformadores de potencia ubicados en lugares agresivos y/o salinos, se emplean pinturas tipo epóxica y para transformadores de distribución, tipo alquídica. El método de limpieza de los equipos, antes de pintarlos, es por chorro de arena (sand blasting).

- Empaques: Se emplean para asegurar la hermeticidad o sellado entre el tanque y los herrajes. Se fabrican de caucho sintético apto especialmente para aplicaciones que requieran resistencia a los aceites derivados del petróleo, sin llegar a contaminarlos. Poseen buena resistencia a los ácidos y las bases, excepto cuando tengan un fuerte efecto oxidante; además tienen buena resistencia al envejecimiento térmico, a la rotura por cargas de choque, baja deformación y buena resistencia eléctrica y a la abrasión.

- Radiadores: Se emplean cuando la superficie del tanque no es suficiente para disipar el calor o pérdidas de energía generadas en el transformador. Estos elementos son planos y vienen fijamente soldados al tanque. 
Además de estos componentes básicos, los transformadores vienen equipados con otros elementos y con accesorios tales como los dispositivos de protección contra sobrepresiones (relé de Buchholz), sobretensiones, cortocircuitos, indicadores de nivel de aceite, etc., cuyo uso depende de la potencia del transformador y del grado de protección y confianza que se requiera en el sistema.

\subsection{Tipos de transformadores}

Los transformadores se clasifican en función de la red de suministro de energía a la cual se conecten o en función del medio aislante que usen:

- Dependiendo de la red de suministro de energía a la cual se conecte el transformador se distinguen básicamente tres grupos:

- Transformadores de distribución: Se fabrican en potencias normalizadas desde 25 hasta $1000 \mathrm{kVA}$. Se puede variar la tensión desde 13,2 hasta $35 \mathrm{kV}$ empleando un conmutador exterior de accionamiento sin carga.

- Transformadores tipo subestación: Opera con potencias de 225 a 2.000 kVA $\mathrm{y}$ tensiones hasta de $35 \mathrm{kV}$. Se usan en montajes de plataformas especialmente construidas.

- Transformadores de potencia: Se construyen en potencias normalizadas desde 1,25 hasta 20 MVA, en tensiones de 13,2, 33, 66 y $132 \mathrm{kV}$ y frecuencias de 50 a $60 \mathrm{~Hz}$. Normalmente las características técnicas están coordinadas con los requerimientos específicos de cada proyecto.

- Dependiendo del medio aislante y refrigerante, se clasifican en:

- Transformadores sumergidos en aceite: Pueden ser con ventilación natural o con ventilación forzada, ésta última aplicable por costos de fabricación, a transformadores con potencias superiores a $2.000 \mathrm{kVA}$. Cuando por especificaciones muy particulares en el diseño o empleo se requieran sistemas especiales, se pueden construir transformadores en los que por 
medio de bombas exteriores, el aceite circula forzadamente a través de radiadores ventilados adecuadamente.

- Transformadores tipo seco: Son de fabricación especial y se caracterizan porque el núcleo y los devanados no están sumergidos en un líquido aislante y refrigerante. Las bobinas están fabricadas con arrollamientos de aluminio y el aislamiento está constituido por una mezcla de resina epóxica y harina de cuarzo, siendo un material resistente a la humedad e ignífugo.

Los transformadores tipo seco se utilizan bajo techo, y ocupan normalmente un espacio más reducido que un transformador sumergido en aceite. Son apropiados para operar en sitios con alto riesgo de incendio o explosión.

La refrigeración puede ser natural o forzada por medio de ventiladores controlados por temperatura con lo cual se logra un incremento de la potencia hasta un $40 \%$ para servicio permanente.

Pero de acuerdo con las exigencias del servicio se requieren transformadores con construcciones no convencionales. Dentro de estos casos se encuentran los siguientes:

- Transformadores tipo Pedestal o Pad Mounted: Dichos transformadores están diseñados para montaje sobre una base en concreto y son aptos para instalaciones a la intemperie. Las características constructivas de este tipo de transformadores permiten su instalación en lugares donde haya circulación de personas y/o donde el reducido espacio impida el montaje de una subestación tradicional.

- Transformadores de frecuencia variable: Especialmente diseñados para el accionamiento de motores de velocidad variable tales como los utilizados en equipos de exploración de petróleo.

- Transformadores autoprotegidos: Incluyen interruptores o switches automáticos para desconectar el transformador cuando está sometido a una sobrecarga que conduce a sobrecalentamiento o para separar el transformador de la red secundaria cuando ocurre un cortocircuito en ésta. Estos transformadores también vienen equipados con pararrayos. 


\subsection{Categorías de equipos}

Con el fin de tener en cuenta las diferentes exigencias de los usuarios, los equipos han sido clasificados en diferentes categorías:

- CATEGORÍA 0: Transformadores de potencia para sistemas de tensiones superiores a $420 \mathrm{kV}$.

- CATEGORÍA A: Transformadores de potencia para sistemas de tensiones superiores a $170 \mathrm{kV}$ y hasta $420 \mathrm{kV}$. Igualmente, están incluidos los transformadores de potencia, cualquiera que sea la tensión asegurada, cuya continuidad de servicio es vital y los equipos similares para aplicaciones especiales de trabajan en condiciones de costos elevados.

- CATEGORIA B: Transformadores de potencia para sistemas con tensiones superiores a $72,5 \mathrm{kV}$ y hasta $170 \mathrm{kV}$ (y aquellos que no pertenezcan a la categoría A).

- CATEGORÍA C: Transformadores de potencia para sistemas con tensiones hasta $72,5 \mathrm{kV}$ (aquellos que no pertenezcan a la categoría A). Interruptores en aceite, selectores y reguladores de corriente alterna blindados.

- CATEGORÍA D: Transformadores de medida para sistemas con tensiones superiores a $170 \mathrm{kV}$.

- CATEGORÍA E: Transformadores de medida para sistemas con tensiones hasta $170 \mathrm{kV}$.

- CATEGORÍA F: Conmutadores de derivación bajo carga sumergidos en aceite.

- CATEGORÍA G: Disyuntores sumergidos en aceite.

\subsection{LOS ACEITES DIELÉCTRICOS}

\subsubsection{Los aceites dieléctricos de origen mineral}

El aceite mineral como medio refrigerante y aislante en los transformadores no supone ninguna novedad: de hecho, se ha utilizado ya durante más de un siglo [4]. Siempre ha ofrecido el mejor compromiso entre los costes y las prestaciones, además de su excelente compatibilidad con los materiales del transformador. Otros líquidos bastantes más costosos, tales como aceite de silicona, determinados tipos de ésteres sintéticos, 
etc., se reservan para aplicaciones en las que sus aplicaciones específicas puedan justificar un precio más elevado.

Los tipos de aceites minerales utilizados actualmente no son muy distintos, en su estructura química básica, de los aceites utilizados hace cien años. Se ha mejorado, sin embargo, enormemente la calidad de los aceites gracias a los adelantos en las técnicas de refinado y debido a que ahora se conocen mejor los requisitos necesarios en las aplicaciones de los transformadores.

Pero, ¿por qué utilizar aceites de mejor calidad? Para comenzar a responder a esta pregunta, compararemos el volumen relativo de aceite que una determinada fuente de energía eléctrica utiliza actualmente con el volumen que utilizaba en el pasado. La necesidad de una mejor calidad se hace obvia.

$\begin{array}{ll}\text { Año } & \text { Litros de aceite/kVA } \\ 1930 & \text { Aprox. } 3,5 \\ 1960 & 1,0 \\ 1980 & 0,25\end{array}$

La mayor carga térmica del aceite de transformadores exige una mejor estabilidad frente a la oxidación. La decisión de utilizar aceites de mejor calidad para transformadores también se justifica por la influencia de los costes y la fiabilidad en caso de avería del transformador, independientemente de si la misma se debe a un aislamiento deficiente por la formación de sedimentos o por un electroaislamiento de papel deteriorado.

En la actualidad se estima que la vida útil de un transformador puede alcanzar hasta los 40 años, y para un aceite de alta calidad para transformadores rigen las mismas expectativas.

En este contexto es interesante señalar que, si se ha elegido un aceite de baja calidad, durante algún tiempo -aproximadamente 10 años- no se harán patentes las prestaciones del aceite, y para entonces ya habrá expirado el periodo de garantía del transformador. Es fácil comparar los costes ocasionados por una vida de servicio más corta del transformador y/o las paradas prolongadas, con los costes adicionales relativamente bajos de un aceite de alta calidad. Dado que la vida de servicio del papel depende de la estabilidad del aceite (cuando el aceite se deteriora, se acelera la degradación de las 
fibras de celulosa), es evidentemente preferible utilizar desde el principio un aceite de buena calidad en lugar de esperar a que el papel de deteriore, un daño que es irreversible.

Un estudio realizado por las compañías de inspección y seguros de los EEUU [4] mostró que:

- Un $10 \%$ del total de averías en transformadores eléctricos de debían al deterioro del material aislante.

- Las averías internas por sobrecarga en los arrollamientos de alta tensión eran ocasionadas por sedimentos de material.

Por estas y otras razones es importante entender la influencia de los distintos parámetros del aceite cuando se van a seleccionar aceites para equipos eléctricos, especialmente transformadores.

La calidad o prestaciones de un aceite dieléctrico dependen principalmente de la estructura química de este y de los aditivos mejoradores de las propiedades físico químicas que posea dicho fluido.

Un aceite mineral de transformador se compone principalmente de carbono e hidrógeno en moléculas que presentan diferentes estructuras. Las estructuras típicas se presentan en la figura 7:

Parafinas<smiles>CCCCCCCCC</smiles>

Isoparafinas

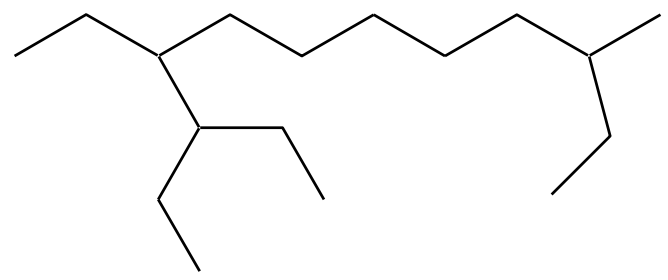

Naftenos

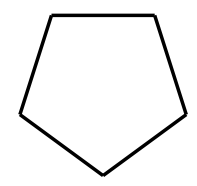<smiles>C1CCCCC1</smiles><smiles>C1CCCCCC1</smiles> 
Aromáticos<smiles>Cc1ccc(C)c(C)c1</smiles>

Poliaromáticos<smiles></smiles>

Figura 7: Estructura de los hidrocarburos básicos del aceite mineral

Las tres letras que conforman la estructura básica de un aceite mineral de transformadores son:

$\mathbf{P}$ por las estructuras parafínicas. Este grupo de moléculas puede ser tanto de cadena lineal como de cadena ramificada. Los alcanos normales (n-alcanos) de cadena lineal son conocidos como parafinas. Si los aceites que contienen n-alcanos son enfriados, se impide su libre flujo. Estos aceites no son newtonianos por debajo de su punto de turbidez, siendo necesario reducir su contenido de n-alcanos antes de poder utilizarlos en un clima frío. Las moléculas de este tipo presentan asimismo una baja solubilidad para el agua y los productos de oxidación. Esto puede ocasionar problemas, en forma de sedimentos precipitados en los conductos del transformador.

$\mathbf{N}$ por las estructuras nafténicas. Las moléculas de este grupo son también conocidas como cicloalcanos. Las propiedades que presentan a bajas temperaturas son excelentes, y tienen mejor capacidad de solubilidad que los n-alcanos. Existen 5, 6, o 7 carbonos en la estructura anular, predominando los anillos de 6 átomos de carbono.

A por las estructuras aromáticas. Todos los aceites del transformador contienen moléculas aromáticas, siendo este probablemente el grupo más importante a tratar. Las moléculas aromáticas contienen un mínimo de un anillo de seis átomos de carbono. Son totalmente distintas de las moléculas parafínicas y nafténicas, tanto química como físicamente. 
Pero, ¿cómo influyen las moléculas aromáticas en las propiedades del aceite del transformador? Los monoaromáticos de los aceites de transformador son siempre alquilados, y por lo general cuentan con buenas propiedades eléctricas, siendo asimismo absorbentes del gas.

Los hidrocarburos aromáticos policíclicos, PAH, pueden haber sido producidos durante el proceso de refino o existir previa y naturalmente en el aceite. Cuando se aumenta la gama de destilación, normalmente también aumenta el contenido en PAH.

Los PAH presentan las propiedades siguientes:

\section{Deseables}

- Inhibidores de la oxidación: durante el proceso de oxidación se producen fenoles que actúan como inhibidores de la formación de radicales. En los aceites de transformador que ya cuentan con cierta vida de servicio, se pueden medir los fenoles aparecidos como productos de oxidación.

○ Alta absorción de gases, superior a la de los monoaromáticos.

\section{Indeseables}

- En un campo eléctrico, las moléculas aromáticas ejercen un efecto negativo sobre propiedades eléctricas tales como la ruptura por impulsos y la carga del flujo.

- Se sabe que algunas de estas moléculas son cancerígenas.

Pero, ¿cuáles son las típicas moléculas hipotéticas que podemos encontrar en el aceite? Solo los poliaromáticos y los n-alcanos aparecen en el aceite como moléculas simples. Todas las demás se presentan combinadas en estructuras moleculares de diversos tipos, produciendo la combinación de las tres letras anteriormente citadas.

La figura 3 presenta una molécula típica de aceite. Una manera de caracterizar los aceites consiste en analizar los tipos de carbono. Existen distintos métodos para determinar los tipos de carbono. Uno de ellos es la espectroscopía de infrarrojos, la cual 
mide el carbono enlazado a la estructura aromática y el carbono enlazado a la estructura parafínica.

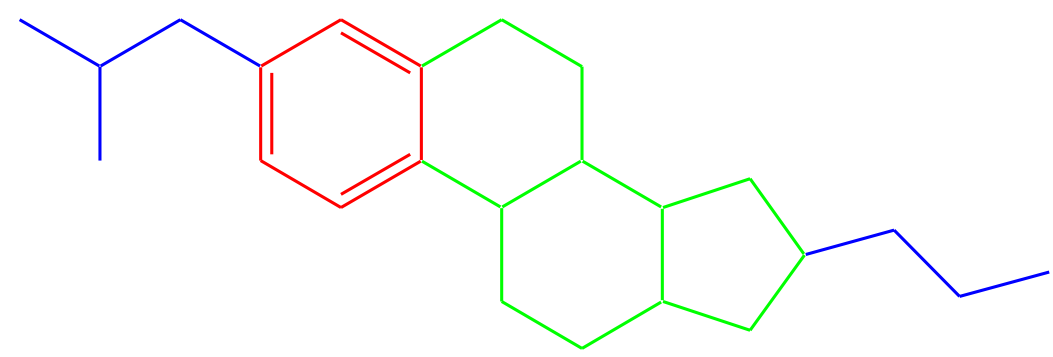

Figura 8: Estructura de una molécula típica del aceite mineral

La molécula posee un $32 \%$ de carbonos parafínicos, un $44 \%$ de carbonos nafténicos y un $24 \%$ de carbonos aromáticos.

Además de las estructuras hidrocarbonadas, todos los aceites contienen un pequeño porcentaje (en número) de moléculas que incluyen en su estructura otros átomos tales como nitrógeno, azufre y oxígeno. Casi todos los heteroátomos de un aceite están enlazados a las estructuras aromáticas, por lo que si se extraen todos los aromáticos mediante separación física, se extraerá igualmente todo el azufre, nitrógeno y oxígeno.

Tipo carbazol<smiles>[X]c1ccccc1-c1ccccc1</smiles>

$$
\mathrm{X}=\mathrm{S}, \mathrm{N}, \mathrm{O}
$$

Tipo fenol

Tipo tetrahidroquinolina<smiles>CCCCCc1cccc(O)c1</smiles><smiles>CCCCCC1CCc2nc(CCCC)ccc2C1</smiles>

Figura 9: Heteroátomos en el aceite mineral 
El tipo de aceite que se empleará para su uso como dieléctrico dependerá del crudo empleado, y la cantidad total después del refino variará de uno a otro proceso. A continuación se muestra la tabla 3 con la variación de los destilados y con la cantidad de diferentes hidrocarburos necesarios para la producción del aceite para transformador.

Tabla 3: Composición porcentual en función del grado de refino

\section{Tipo}

n-alcanos $(\% \mathrm{~m} / \mathrm{m})$ [por el método IR]

$\mathrm{C}_{\mathrm{P}}, \mathrm{C}$ que forma parte de parafinas [por el método IR]

$\mathrm{C}_{\mathrm{N}}, \mathrm{C}$ que forma parte de nafténicos [por el método IR]

$\mathrm{C}_{\mathrm{A}}, \mathrm{C}$ que forma parte de aromáticos [por método IR]

PAH $(\% \mathrm{~m} / \mathrm{m})[$ HPLC]

Azufre $(\% \mathrm{~m} / \mathrm{m})$

Nitrógeno (ppm)

Acidez total $(\mathrm{mg} \mathrm{KOH} / \mathrm{g})$

\section{Cantidad}

$0,05-15 \%$

$42-65 \% *$

Diferencia hasta $100 \%$

$14-25 \%$

$>2 * *$

$1,0-2,0$

$70-600$

$0,05-2,0$

(*) Los aceites con Cp entre 42 - $50 \%$ son considerados como aceites nafténicos, entre un 50 - $56 \%$ como aceites intermedios y entre $56-67 \%$ como aceites parafínicos. Estos niveles no están definidos exactamente, pero pueden ser usados como directrices. Algunos aceites hidrocraqueados tienen más de un $67 \%$ en $\mathrm{Cp}$ (no ocurre de forma natural).

(**) El nivel es normalmente tan alto que el aceite de alimentación ha de ser considerado como cancerígeno. Un punto de ebullición más elevado proporciona un valor más alto. El método por HPLC se describe en la sección referida a los requisitos de los aceites de transformador. 


\subsubsection{Los aceites dieléctricos de origen vegetal}

La utilización de aceites vegetales dieléctricos frente a los actuales aceites minerales derivados del petróleo, o siliconas derivadas de procesos petroquímicos, supone ventajas importantes desde el punto de vista medio ambiental y desde el punto de vista de la seguridad. Los incendios en transformadores de distribución han sido frecuentes en los últimos años en España, sobre todo en situaciones de elevada demanda eléctrica y condiciones ambientales desfavorables. En los últimos veranos ha habido incendios en transformadores en ciudades tan significativas como Madrid, Barcelona o Sevilla que han generado una importante alarma entre los vecinos e importantes pérdidas materiales.

La palabra aceite (del árabe az-zait, el jugo de la aceituna, y éste del arameo zayta) es un término genérico para designar numerosos líquidos grasos de orígenes diversos que no se disuelven en el agua y que tienen menor densidad que ésta.

Los aceites vegetales están formados principalmente por triglicéridos (TGC) derivados de la reacción que se produce entre la molécula de glicerol con tres moléculas de ácidos grasos iguales o diferentes. Dependiendo del origen del aceite (palma, soja, colza, etc) la longitud media de la cadena de los ácidos grasos (normalmente de 12 a 24 carbonos) y el número de insaturaciones que muestran, pueden varían de forma significativa.

En la Figura 10 se representa la estructura química de un triglicérido. Como se puede observar, el esqueleto común en la molécula, trazado en color azul, es el procedente del alcohol (glicerol). En color negro se dibuja el fragmento variable de los ácidos grasos.

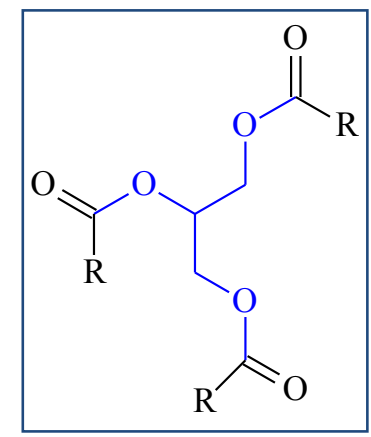

Figura 10: Estructura de un triglicérido, donde R representa la cadena alifática de los ácidos grasos 
La reacción de formación de estos TGC es la mostrada en la Figura 11:

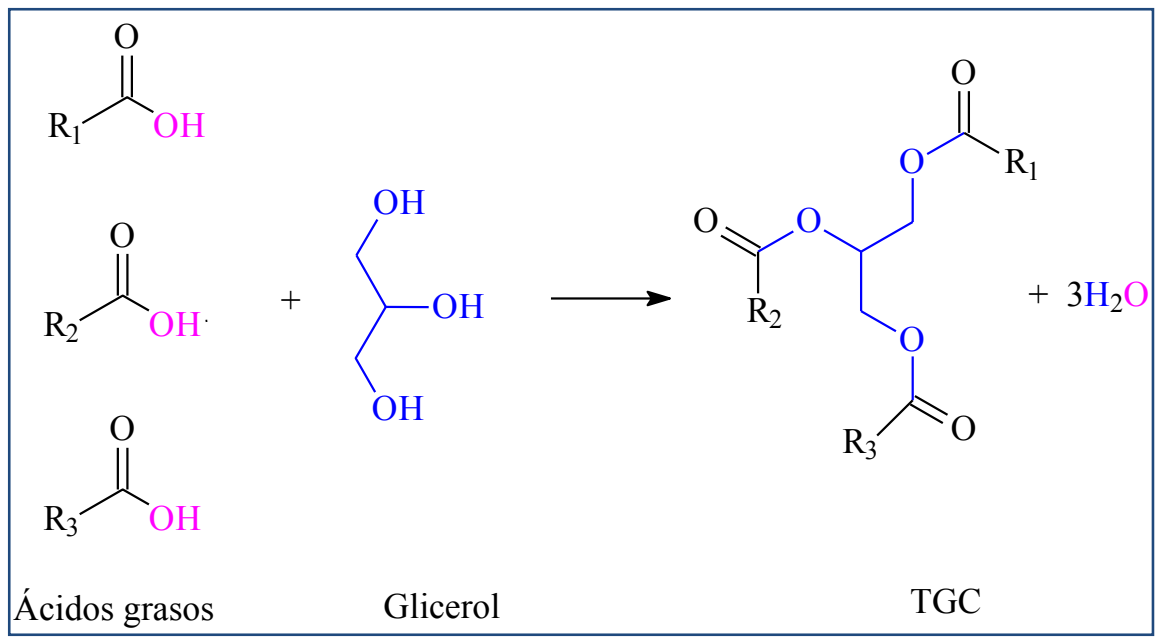

Figura 11: Reacción de sintesis de los TGC

Los ácidos grasos pueden tener desde 10 carbonos de cadena hasta 22 y 24 carbonos de extensión de cadena. Existen en la naturaleza al menos 50 ácidos grasos. En la tabla 4 se muestran algunos de los ácidos grasos más comunes en la naturaleza.

Tabla 4: Ácidos grasos más comunes

Nombre común

Cáprico

Láurico

Mirístico

Palmítico

Esteárico

Araquídico

Behénico

Lignocérico

Palmitoleico

Oleico

Gadoleico

Cetoleico

Erúcico

Nervónico

Linoleico

$\alpha$-Linolénico
Nombre sistemático

Decanoico

Dodecanoico

Tetradecanoico

Hexadecanoico

Octadecanoico

Eicosanoico

Docosanoico

Tetracosanoico

9-hexadecenoico

9-octadecenoico

11-eicosaenoico

11-docasaenoico

13-docasaenoico

15-tetracosaenoico

9,12-octadecadienoico

9,12,15-octadecatrienoico
Abreviatura

10:0

12:0

14:0

16:0

18:0

20:0

22:0

24:0

16:1

18:1

20:1

22:1

22:1

24:1

18:2

18:3 


\begin{tabular}{lll}
\hline $\boldsymbol{\gamma}$-Linolénico & $6,9,12$-octadecatrienoico & $18: 3$ \\
\hline Dihomo- $\boldsymbol{\gamma}$-linolénico & $8,11,14$-eicosatrienoico & $20: 3$ \\
\hline Araquidónico & $5,8,11,14$-eicosatetraenoico & $20: 4$ \\
\hline AEP & $5,8,11,14,17$-eicosapentaenoico & $20: 5$ \\
\hline Adrénico & $7,10,13,16$-docosatetraenoico & $22: 4$ \\
ADP & $4,7,10,13,16$-docosapentaenoico & $22: 5$ \\
ADH & $4,7,10,13,16,19$-docosahexaenoico & $22: 6$ \\
\hline
\end{tabular}

Para el caso de los aceites los triacilglicéridos contienen ácidos grados insaturados o con enlaces dobles, que le dan la característica líquida a temperatura ambiente. En función de la concentración de los diferentes ácidos grasos, nos encontramos con diferentes tipos de aceite en la naturaleza. A continuación se muestra una tabla con algunos de los aceites vegetales más comunes:

Tabla 5: Composición química de los aceites más comunes

\begin{tabular}{|c|c|c|c|c|c|}
\hline \multicolumn{2}{|l|}{ TIPO DE ACEITE } & \multirow{2}{*}{$\begin{array}{l}\text { ACEITE DE } \\
\text { PALMA }\end{array}$} & \multirow{2}{*}{$\begin{array}{l}\text { ACEITE DE } \\
\text { GIRASOL }\end{array}$} & \multirow{2}{*}{$\begin{array}{c}\text { ACEITE } \\
\text { DE SOJA }\end{array}$} & \multirow{2}{*}{$\begin{array}{c}\text { ACEITE } \\
\text { DE COLZA }\end{array}$} \\
\hline Propiedad & Unidades & & & & \\
\hline Densidad $\left(20^{\circ} \mathrm{C}\right)$ & $\mathrm{g} / \mathrm{cm}^{3}$ & 0,9121 & 0,9195 & 0,9198 & 0,9181 \\
\hline Indico de yodo & $\begin{array}{l}\text { g Yodo } \\
/ 100 \mathrm{~g}\end{array}$ & 53,2 & 137,2 & 136,6 & 125,9 \\
\hline \multicolumn{6}{|l|}{ Composición de ácidos grasos } \\
\hline Ácido Laúrico (C12:0) & \multirow{15}{*}{$\%$} & 0,14 & $<0,01$ & $<0,01$ & 0,01 \\
\hline Ácido Mirístico (C14:0) & & 0,98 & 0,07 & 0,07 & 0,06 \\
\hline Ac. Palmítico (C16:0) & & 44,79 & 6,27 & 10,49 & 4,43 \\
\hline Ac. Palmitoleico (C16:1) & & 0,17 & 0,12 & 0,12 & 0,25 \\
\hline Ácido Margárico (C17:0) & & 0,09 & 0,04 & 0,09 & 0,05 \\
\hline Ácido Margaroleico (C17:1) & & 0,02 & 0,02 & 0,04 & 0,05 \\
\hline Ácido Esteárico (C18:0) & & 4,44 & 3,67 & 3,34 & 1,60 \\
\hline Ácido Oleico (C18:1) & & 38,64 & 25,53 & 24,89 & 56,89 \\
\hline Ácido Linoleico (C18:2) & & 9,88 & 62,92 & 53,3 & 22,63 \\
\hline Ácido Linolénico (C18:3) & & 0,14 & 0,06 & 6,38 & 11,95 \\
\hline Ácido Araquídico (C20:0) & & 0,44 & 0,25 & 0,36 & 0,51 \\
\hline Ácido Gadoleico (C20:1) & & 0,11 & 0,14 & 0,26 & 1,12 \\
\hline Ácido Behénico (C22:0) & & 0,06 & 0,65 & 0,49 & 0,29 \\
\hline Ácido Erúcico (C22:1) & & $<0,01$ & $<0,01$ & $<0,01$ & 0,03 \\
\hline Ácido Lignocérico (C24:0) & & 0,09 & 0,24 & 0,16 & 0,12 \\
\hline Fórmula cadena media & - & $\mathrm{C}_{17,1} \mathrm{H}_{33,6} \mathrm{O}_{2}$ & $\mathrm{C}_{17,9} \mathrm{H}_{32,7} \mathrm{O}_{2}$ & $\mathrm{C}_{17,8} \mathrm{H}_{32,5} \mathrm{O}_{2}$ & $\mathrm{C}_{18,0} \mathrm{H}_{33,0} \mathrm{O}_{2}$ \\
\hline Peso molecular del triglicérido & $\mathrm{g} / \mathrm{mol}$ & 848,7 & 878,6 & 874,9 & 881,0 \\
\hline
\end{tabular}


Antes de utilizar estos aceites vegetales como dieléctricos, tienen que ser sometidos a un proceso de refino. Los aceites crudos se almacenan en grandes tanques de acero inoxidable. Naturalmente estos aceites contienen tocoferoles, gomas y otros antioxidantes naturales. Pero el grado de acidez libre que presenta, unido a las sustancias naturales los hacen poco aptos para aplicaciones electrotécnicas, y es necesario refinarlos.

El refino consta de varias fases:

Neutralización y desgomado: El refino comienza con la neutralización de la acidez libre de la materia prima que se realiza en unas lavadoras centrifugadoras, donde se añade ácido fosfórico e hidróxido de sodio. El ácido fosfórico retira las gomas (fosfoglicéridos) del aceite, y el hidróxido de sodio neutraliza la acidez libre.

Desodorización: Luego, el aceite neutralizado y desgomado es conducido a las torres de desodorización, donde caen por gravedad, en medio de bandejas sometidas a alta temperatura, aquellas sustancias volátiles y aldehídos, que emigran del cuerpo del aceite y son condensados, para su disposición final. Estudios más recientes han determinado que la desodorización activa el aceite, predisponiéndolo a su rancidez. Por este motivo, se recomienda que se adicionen, de inmediato, derivados de guayatecol y otros. Un aceite se considera rancio cuando su índice de peróxido supera los 5 meq peróxido/g. Se le adiciona al aceite colorantes naturales tales como el betacaroteno y antioxidantes para su preservación.

\subsection{PROPIEDADES FÍSICO QUÍMICAS DE LOS ACEITES DIELÉCTRICOS.}

Cuando se comparan entre sí diferentes aceites dieléctricos que cumplen una determinada especificación, sus propiedades físico-químicas son relativamente próximas entre ellos bajo el punto de vista del diseño del transformador, es decir su viscosidad es próxima, su constante dieléctrica parecida, su actividad frente a celulosa equivalente, etc ya que se trata de hidrocarburos con distribución de pesos moleculares parecidos y, salvo un nivel de calidad superior de unos respecto a otros por un mejor 
grado de refino, el diseñador del transformador dispone de una gran cantidad de datos que le permiten efectuar cambios en el diseño sin necesidad de una gran cantidad de experimentación sobre el aceite.

En la presente tesis se analizarán por tanto algunas de estas propiedades, las que se considera deberían ser evaluadas por causa de un cambio de naturaleza del fluido: de mineral a tipo éster.

\subsubsection{Propiedades de transferencia térmica}

La disipación del calor generado en los equipos eléctricos es una de las funciones principales de los aceites aislantes. Así, una transferencia térmica eficiente por el fluido reduce la temperatura en los devanados, lo que prolonga la vida del transformador, minimizando la velocidad de degradación de la celulosa.

La disipación del calor en el transformador se realiza fundamentalmente por la convección natural o forzada del aceite a través de los pasos incorporados en los arrollamientos. Por tanto, el conocimiento de la conductividad térmica, calor específico, coeficiente de expansión y densidad a diferentes temperaturas es fundamental en la ingeniería de diseño de transformadores para decidir así los aspectos básicos siguientes:

- Tipo de circulación

- Bombas

- Tamaño y configuración de los pasos de aceite

- Constantes térmicas del equipo en condiciones de operación normal y sobrecarga

\section{a) Conductividad térmica}

Es una medida de la capacidad del aceite para transferir energía en forma de calor en ausencia de fenómenos de transporte de masa. En el caso de los aceites minerales se determina mediante la norma ASTM-D2717, midiendo el gradiente de temperatura producido a través del aceite por una cantidad de energía introducida en una célula de vidrio calentada mediante una resistencia eléctrica de platino $(\mathrm{Pt})$. Se expresa en 


\section{$\mathrm{W} / \mathrm{m} . \mathrm{K}$}

Los esquemas indicados en la figura 11 dan una idea del método, también llamado THW (Transient Hot Wire), para determinar esta propiedad en un amplio margen de temperatura. Estos equipos básicos permiten establecer curvas de evolución de la conductividad térmica en intervalos entre $-30^{\circ} \mathrm{C}$ y $+190^{\circ} \mathrm{C}$.
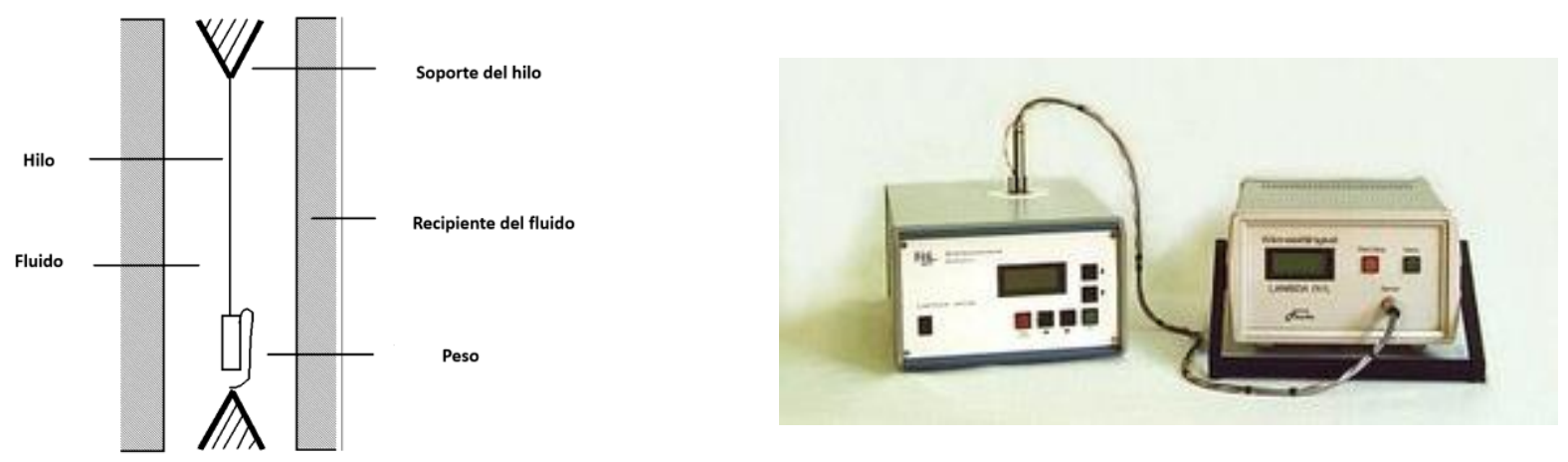

LAMBDA System 1 de PSL Systemtechnik

Figura 11: Conductímetro térmico

La mayor parte de los líquidos presentan valores de 0,3 a $0,045 \mathrm{~W} \mathrm{~m}^{-1} \mathrm{~K}^{-1}$. Una ecuación de utilidad para aceites minerales es la siguiente y que posiblemente pueda ser aplicable a algunos fluidos tipo éster:

$$
\lambda=0.00028(1-0.0054 T) d^{-1}
$$

(Ecuación 11)

En donde $\lambda$ es la conductividad que depende de la temperatura (T) y la densidad (d).

Aunque será necesario determinar esta propiedad en el/los fluidos desarrollados en esta tesis, una estimación general comparativa entre distintos fluidos dieléctricos se indica en la figura 12: 


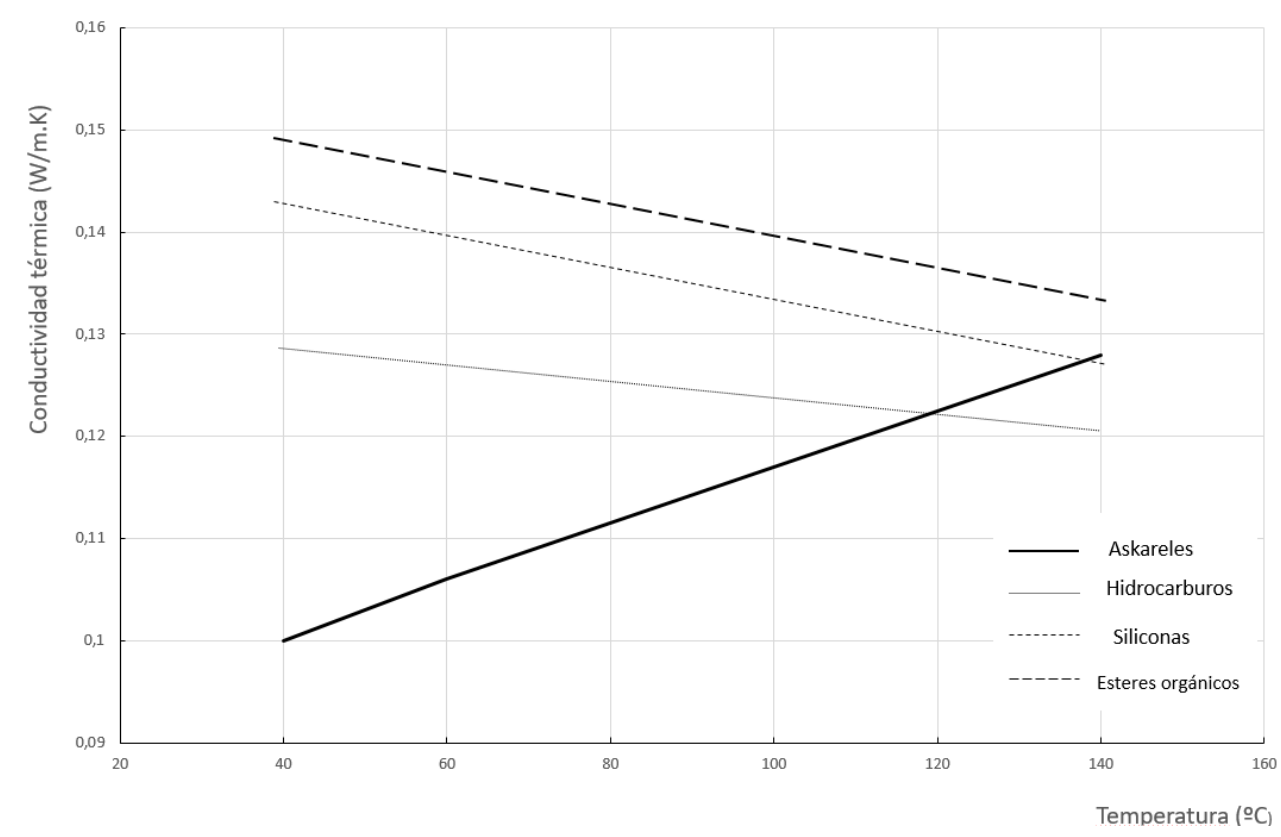

Figura 12: Valores de conductividad para diferentes tipos de aceite

\section{b) Calor específico}

El calor específico es una propiedad termodinámica que indica la cantidad de energía requerida para elevar la temperatura de una unidad de masa de una sustancia un grado. La norma ASTM D2766, supone el empleo de un calorímetro y son valores típicos para aceites aislantes los valores indicados en la Figura siguiente:

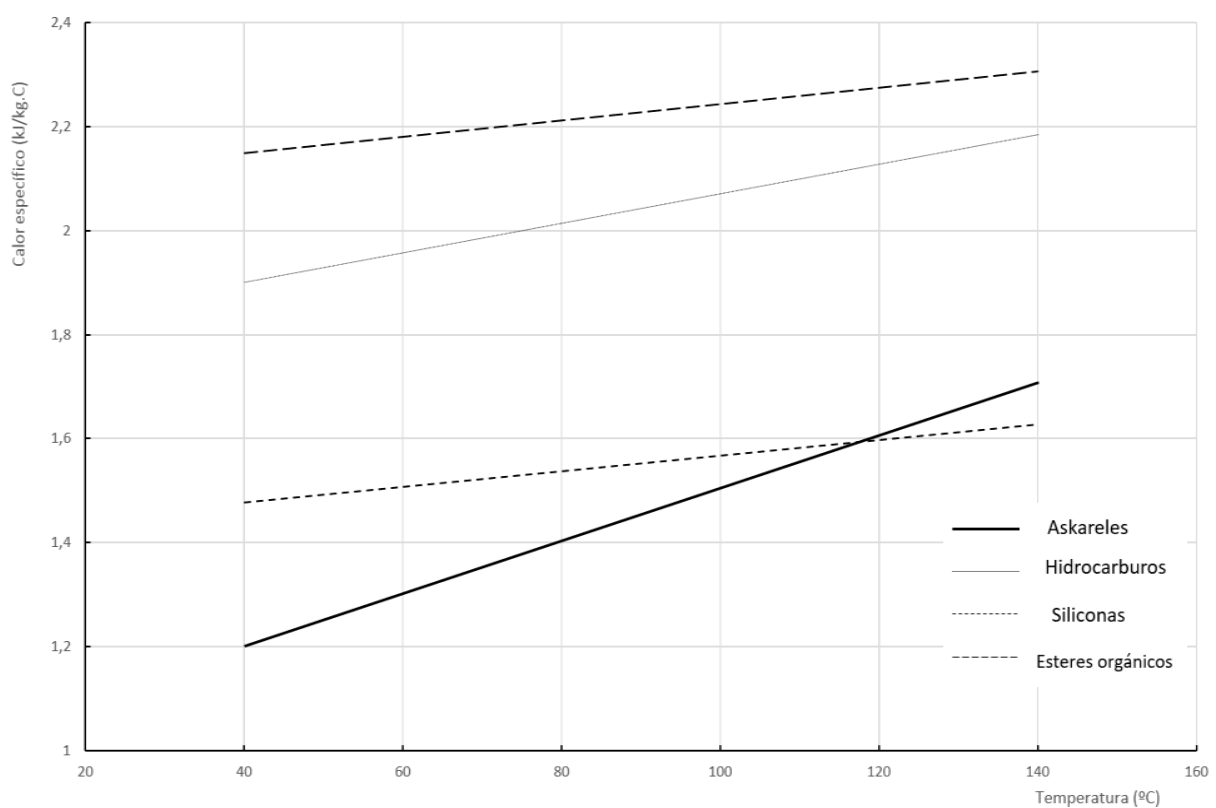

Figura 13: Valores de calor específico para diferentes tipos de aceite 


$$
\mathrm{Cp}=(0,43+0.008 \mathrm{~T}) \mathrm{d}^{-1 / 2}
$$

(Ecuación 12)

La ecuación 12, la cual relaciona la densidad (d), la temperatura (T) y el calor específico (Cp) permite, para aceites minerales, un cálculo de su valor a partir de la densidad a 20 ${ }^{\circ} \mathrm{C}$. La técnica PDSC (Calorimetría Diferencial de Barrido con módulo de alta presión), es una excelente herramienta para determinar esta propiedad.

\section{c) Coeficiente de expansión térmica}

Este coeficiente representa el cambio en volumen del fluido por unidad de volumen y grado de temperatura. Se evalúa midiendo la densidad a diferentes temperaturas y se expresa en $\mathrm{K}^{-1}$ en un determinado rango de ésta.

$$
\alpha=\frac{\left(d_{0}-d_{1}\right)}{d_{0}\left(T_{o}-T_{1}\right)}
$$

Siendo $\mathrm{d}_{0}$ la densidad a la temperatura más baja, $\mathrm{T}_{0} \mathrm{y} \mathrm{d}_{1}$ la densidad a temperatura de medida más alta, $\mathrm{T}_{1}$.

Este parámetro es importante para determinar el tamaño de la cuba del transformador que permita acomodar una determinada cantidad de aceite en un amplio rango de temperaturas.

\section{d) Densidad}

La densidad en el caso de los aceites aislantes se utiliza para calcular la masa de un determinado volumen de aceite y como parámetro en numerosos cálculos de flujo en el transformador.

También puede ser importante en aplicaciones específicas tales como equipo eléctrico en climas fríos donde se puede formar hielo en transformadores fuera de servicio expuestos a temperaturas por debajo de $0{ }^{\circ} \mathrm{C}$. Se debe asegurar en tales casos, y por esta 
razón se fija un valor máximo en las especificaciones, que la densidad del aceite sea siempre inferior a la del hielo para evitar que éste flote y alcance contactos eléctricos en la superficie. En la figura adjunta se indican valores de densidad para aceites minerales comparada con la del hielo-agua:

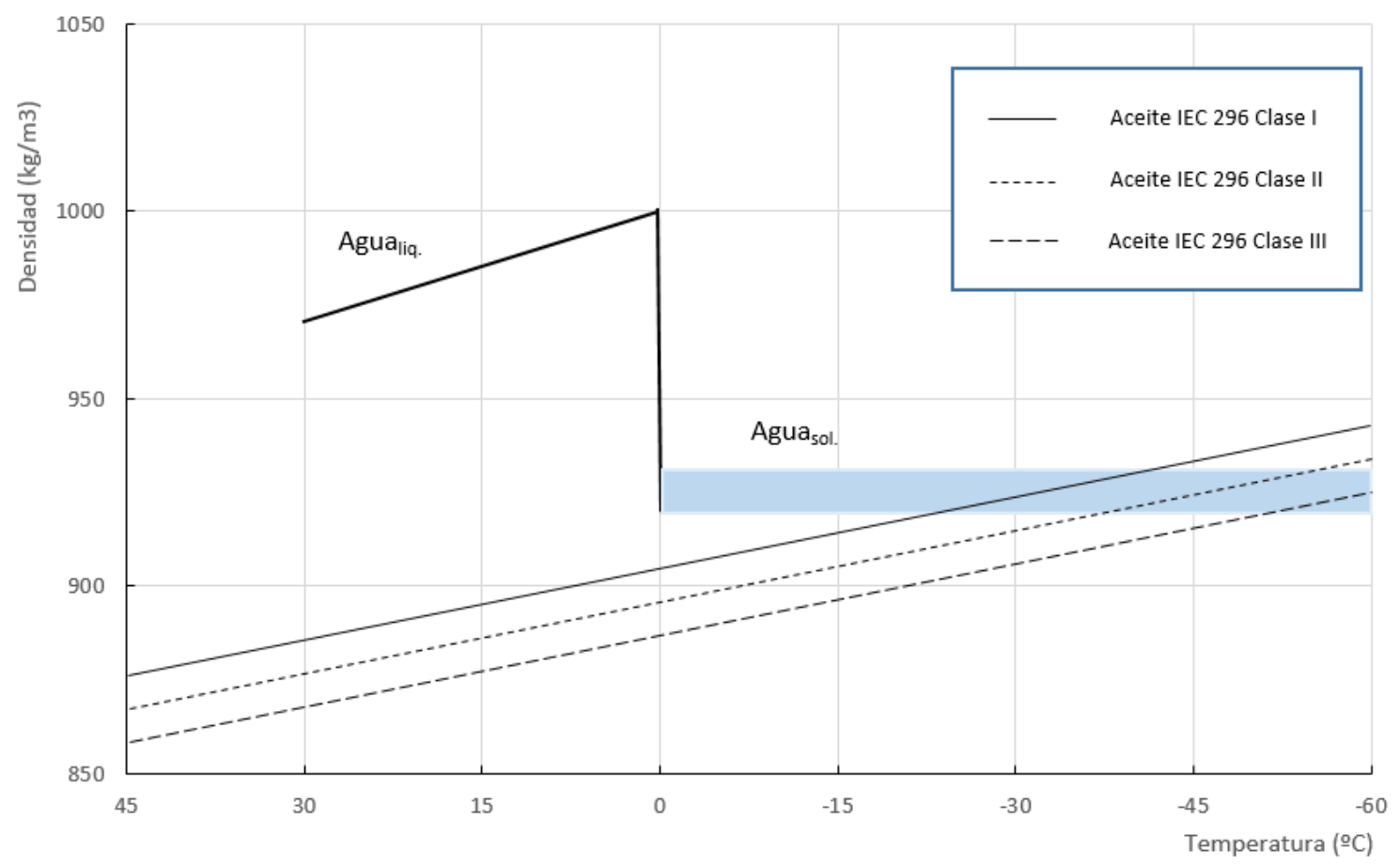

Figura 14: Valores de densidad para diferentes tipos de aceite dieléctricos

Dado que a igualdad de viscosidad, los ésteres poseen densidades más elevadas que los aceites minerales, será necesario también conocer esta propiedad en función de la temperatura y compararla a la del agua en un amplio rango de temperaturas.

\section{e) Viscosidad-Fluencia}

Es la propiedad más importante en la transmisión de calor por convección y es por tanto el parámetro primordial para determinar la eficiencia de la transferencia térmica en los equipos eléctricos.

Los fluidos dieléctricos presentan comportamiento newtoniano (es decir, fluyen) en un amplio rango de temperatura y su viscosidad está limitada en las diferentes 
especificaciones, aun cuando se expresa también en forma indirecta a través del punto de niebla y punto de vertido (también conocido como punto de congelación).

Dado que los ésteres vegetales poseen, en general, temperaturas de congelación más altas que las de los aceites minerales, esta propiedad deberá ser objeto de especial atención en el desarrollo de la presente tesis. Además, su estabilidad a temperaturas próximas a la congelación es bastante deficiente precipitando parte de los componentes más saturados del aceite, algunos de los cuales son incluso difícilmente solubilizados al elevar la temperatura después de haber pasado por una etapa de congelación.

La incorporación de aditivos depresores se tratará en el apartado correspondiente, aunque conviene mencionar que en algunos casos su eficacia puede decrecer en presencia del papel aislante. Para ello, se diseñó la norma IEC- 61065 "Método para evaluar las propiedades de fluidez a baja temperatura de aceites minerales aislantes después del envejecimiento" en el que se determina la congelación del aceite después de un período de oxidación, empleando para ello el equipo clásico de la norma IEC 61125, aunque enrollando, además del hilo de cobre, una tira de papel Kraft (50 cm x 1,5 cm de acuerdo con la Norma CEI 554-3-1, densidad aparente $0,8 \mathrm{~kg} / \mathrm{dm}^{3}$ y espesor $0,10 \mathrm{~mm})$.

\section{f) Criterio de refrigeración}

La literatura recoge parámetros y curvas de comparación de diferentes fluidos aislantes bajo el punto de vista de su capacidad de transferencia térmica. Uno de ellos es el denominado parámetro “P”, también llamado Criterio de Refrigeración:

$$
P=\frac{C_{p} \cdot \lambda \cdot \alpha}{\vartheta}
$$

Donde $C_{p}$ es el calor específico, $\lambda$ es la conductividad térmica, $\alpha$ es el coeficiente de expansión térmica y $\vartheta$ es la viscosidad cinemática. 
Un valor más elevado de $\mathrm{P}$ señalará una mejor transferencia térmica. Mediante el citado valor $\mathrm{P}$ a diferentes temperaturas se puede comparar la eficiencia de distintos fluidos, siendo la viscosidad cinemática la que mayor influencia ejerce y el coeficiente de expansión térmica el de menor incidencia.

Las gráficas adjuntas [5] reflejan una comparación de un aceite mineral frente a un éster y un aceite de silicona al utilizar el citado criterio:

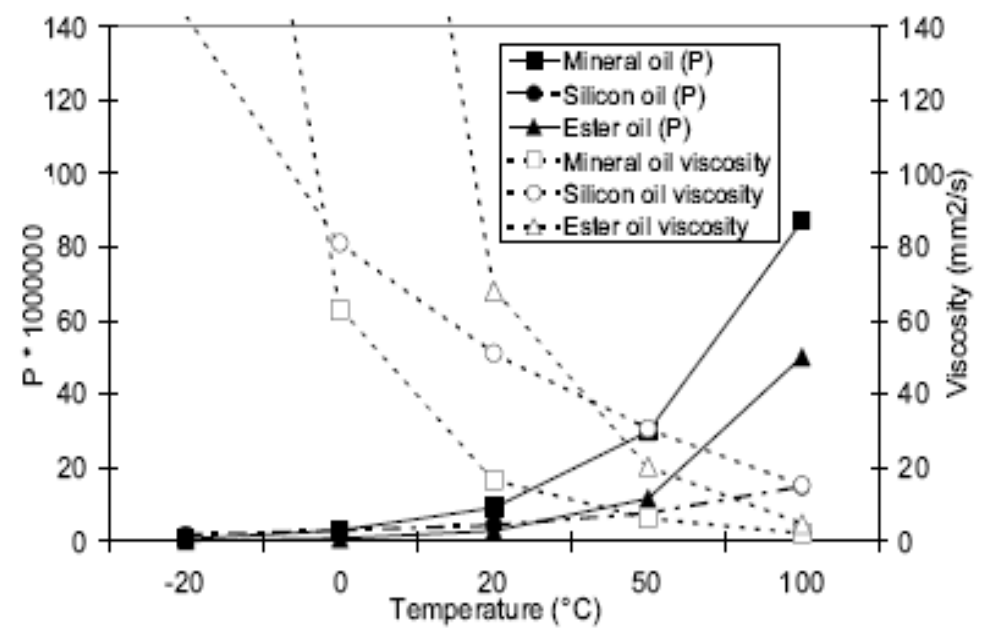

Figura 15: Valores de P y viscosidad cinemática para diferentes aceites [Ref. 5]

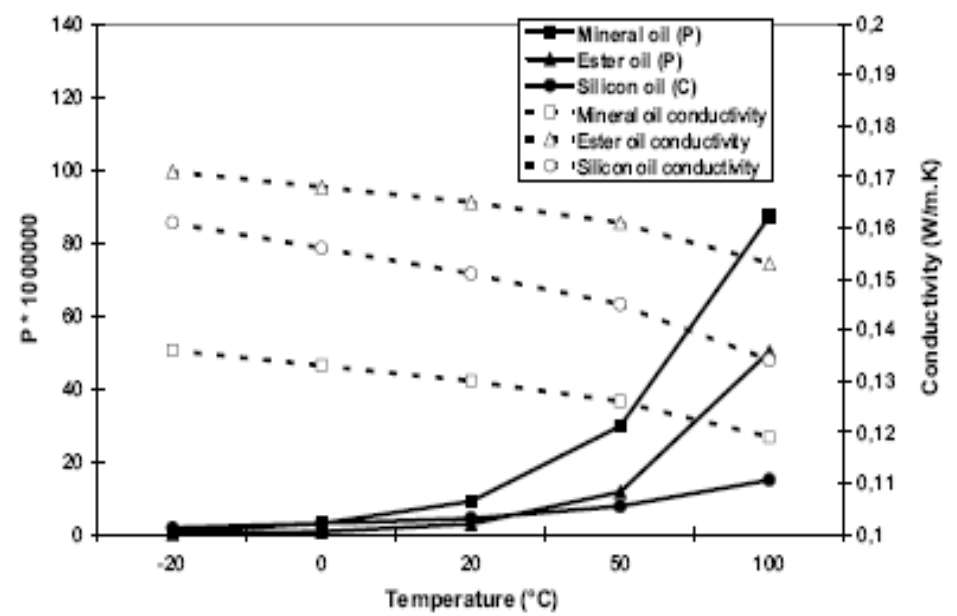

Figura 16: Valores de P y conductividad para diferentes tipos de aceite [Ref.5] 
Los ésteres son en general de mayor viscosidad cinemática que los aceites minerales por lo que su eficiencia en la transmisión de calor será algo inferior y no siempre será compensada por sus valores más altos de densidad y calor específico. Se entenderá por tanto la importancia de determinar estos parámetros en el desarrollo de la presente tesis.

\subsubsection{Propiedades dieléctricas}

No se pretende en esta recopilación bibliográfica hacer un análisis de las propiedades fundamentales de los aceites para cumplir su misión como dieléctricos. Se trata solamente hacer alguna mención a la necesidad de su determinación y hacer hincapié en algún matiz derivado del cambio de naturaleza del fluido, ya que los ésteres naturales presentan algunas peculiaridades.

\section{a) Resistividad volumétrica}

Cuando se aplica un potencial eléctrico a través de un aislamiento, el flujo de corriente estará limitado por la resistencia u oposición que impone este material. La resistividad volumétrica se define como la resistencia eléctrica encontrada cuando se aplica un potencial eléctrico entre las caras opuestas de un cubo. Se mide en Ohm.cm

Bajo condiciones de baja densidad de carga $(<500 \mathrm{~V} / \mathrm{mm})$ la resistividad de los aceites depende fundamentalmente de la medida en que puedan disociarse y formar iones. Los contaminantes tales como agua, ácidos y materiales sólidos de carácter polar son la causa habitual de una baja resistividad.

La resistividad se asocia a la libertad de movimiento o movilidad de los transportadores de carga. Así, por ejemplo, la movilidad electrónica decrece en los alcanos a medida que aumenta su peso molecular, la ramificación aumenta la movilidad electrónica y el mayor valor se encuentra en carbonos cuaternarios. En los cicloalcanos es mayor que en los correspondientes alcanos y la introducción de un doble enlace puede incrementarla en algunos casos. Los ésteres naturales poseen en general una menor resistividad que los aceites minerales tal y como puede observarse en la tabla siguiente: 
Tabla 6: Valores de resistividad volumétrica

\begin{tabular}{|c|c|}
\hline & Resistividad volumétrica , 210C \\
\hline Alquil benceno & $1 \times 10^{15}$ \\
\hline Polibuteno & $8 \times 10^{14}$ \\
\hline Aceite de ricino & $3 \times 10^{10}$ \\
\hline Dibutil sebacato & $5 \times 10^{12}$ \\
\hline Estearato de butilo & $4 \times 10^{12}$ \\
\hline
\end{tabular}

Esta propiedad, además de la tangente del ángulo de pérdidas dieléctricas o Tang $\delta$ y la constante dieléctrica $\varepsilon$, juntas o por separado son importantes indicadores de la calidad intrínseca y del grado de contaminación o envejecimiento del líquido aislante. Pueden utilizarse por tanto para interpretar la desviación de las características dieléctricas deseadas e influencia sobre el comportamiento del equipo.

La norma EN 60247 recoge el método para su determinación.

Se entiende por tanto, la importancia que tiene el grado de refino de los aceites de origen vegetal y la eliminación de vestigios de impurezas y especialmente compuestos ácidos ya que, como se ha indicado, las características dieléctricas decrecen con el contenido de grupos nucleófilos.

\section{b) Constante dieléctrica}

La permitividad relativa, también llamada Constante Dieléctrica $(\varepsilon)$ de un material aislante es la relación entre la capacidad $\mathrm{C}$ de un condensador en el que el espacio entre electrodos está ocupado por un material dieléctrico, a la capacidad del mismo en la que el espacio entre electrodos está el vacío, $\mathrm{C}_{0}$.

$$
\varepsilon=\frac{C}{C_{0}}
$$

En aplicaciones dieléctricas, una buena constante dieléctrica así como una baja disipación de energía son las características deseadas. En un material dieléctrico ideal, 
como es el vacío, no existe pérdida de energía debido a la ausencia de moléculas que pudieran ser polarizadas, mientras que en los dieléctricos, el momento dipolar puede ser un factor de mayor o menor importancia según su naturaleza. La constante dieléctrica será por tanto una medida de la ineficiencia del material como dieléctrico. Por tanto, cuanto menor sea su valor, mejores serán sus prestaciones como aislante.

La exposición de un material a un campo eléctrico produce normalmente tres tipos de polarización dentro del líquido: electrónica, atómica y de orientación. Sin embargo, un cuarto tipo ocurre en las interfases entre materiales distintos, como es el caso PapelAceite. Es la Polarización Interfásica.

La constante dieléctrica o permitividad relativa de los fluidos aislantes está determinada por la polarizabilidad de sus moléculas, así como por su peso molecular y densidad, es decir, la constante dieléctrica depende de la estructura electrónica y su grado de polarización al someterse a un campo eléctrico.

Normalmente la contribución de la polarización atómica es pequeña y a la suma de ésta con la polarización electrónica se llama también Polarización por Deformación. La de orientación es debida a la formación de dipolos en el campo eléctrico por causa de la distribución asimétrica de cargas electrónicas en las moléculas, y dado que ésta es sensible a la temperatura, la constante dieléctrica de un material será más sensible a cambios de temperatura en el caso de moléculas que contengan grupos éster.

En el caso de los aceites minerales, la constante dieléctrica presenta valores en el entorno de 2,1-2,3 dependiendo de su estructura y su peso molecular. Por ejemplo,

Tabla 7: Valores de constante dieléctrica en función de la composición

\begin{tabular}{|c|c|c|c|c|c|}
\hline & A & B & C & D & $\mathbf{E}$ \\
\hline \multicolumn{6}{|l|}{ Composición } \\
\hline$\% \mathrm{C}_{\mathrm{A}}$ [Aromático] & 21.5 & 15.0 & 0 & 12.0 & 11.0 \\
\hline$\% C_{N}$ [Nafténico] & 36.5 & 40.0 & 45 & 38.5 & 36.0 \\
\hline \% C $P$ Parafínico] & 42.0 & 45.0 & 55 & 49.5 & 53.0 \\
\hline Peso Molecular (g/mol) & 335 & 350 & 410 & 535 & 212 \\
\hline$\varepsilon @ 27$ oC, $100 \mathrm{~Hz}$ & 2.28 & 2.20 & 2.09 & 2.22 & 2.14 \\
\hline
\end{tabular}


En el caso de los ésteres, la constante dieléctrica es más elevada, por lo que su determinación será un dato de interés para el fabricante del equipo en la medida en que esta propiedad afecta a las condiciones de operación.

A continuación se muestran los valores de constante dieléctrica para diferentes moléculas que contienen grupos éster:

Tabla 8: Valores de constante dieléctrica para diferentes tipos de esteres

\begin{tabular}{|c|c|}
\hline & $\boldsymbol{\varepsilon}$ @ 25 $\mathbf{~ o}, \mathbf{6 0} \mathbf{~ H Z}$ \\
\hline Oleato de butilo & 2,9 \\
\hline Benzoato de bencilo & 4,5 \\
\hline Benzoato de iso-propilo & 5,0 \\
\hline Estearato de butilo & 3,3 \\
\hline Laurato de butilo & 3,0 \\
\hline Dibutil-sebacato & 4,4 \\
\hline Dietil-hexil adipato & 4,1 \\
\hline Metil-ricino oleato & 4,3 \\
\hline Aceite de ricino & 3,7 \\
\hline
\end{tabular}

Cooper Power Systems, en su producto comercial FR3 con un valor de 3,2 (éster natural que fabrican), sugieren que al acercarse al valor 4,4 de la celulosa, el valor neto del aislamiento global puede ser mejor que con aceite mineral al existir menor discontinuidad.

\section{c) Tangente delta $(\delta)$}

En el caso de la tangente del ángulo de pérdidas dieléctricas o más conocida como tang $\delta$, existe un buen conocimiento de su significado.

Cuando se aplica un voltaje alterno a un condensador, el dieléctrico queda sometido a tensiones y desplazamientos periódicos. Si el material fuera perfectamente elástico, no habría pérdida de energía a causa de que la energía almacenada durante los periodos de aumento de la tensión serían cedidos al circuito cuando disminuyese ésta. Pero la elasticidad eléctrica de los dieléctricos sólidos y líquidos no es perfecta, de modo que el voltaje aplicado tiene que vencer fricciones moleculares además de las fuerzas elásticas. Este trabajo de fricción se transforma en calor y representa una pérdida de energía utilizable. Este fenómeno se asemeja a la histéresis magnética en algunos aspectos. 
Esta no es solo la única causa de la pérdida de energía atribuible a un dieléctrico en un condensador. Además de las fricciones propias de las moléculas del dieléctrico, existen las de los iones asociados intentando orientarse bajo la acción del campo eléctrico alternante y la principal de todas, es la producida por las corrientes de conducción de un electrodo a otro. Esta última viene afectada profundamente por la humedad y la temperatura.

Cuando estas pérdidas de energía no son excesivas, la elevación de temperatura del dieléctrico es moderada (del orden de 3 a $5{ }^{\circ} \mathrm{C}$ ), lo que está dentro de la zona de seguridad del aparato eléctrico; pero si estas pérdidas se elevan, la temperatura interna puede subir hasta $50{ }^{\circ} \mathrm{C}$, con lo que se favorecen modificaciones en el dieléctrico que pueden llevar a fallos prematuros del condensador. Por eso, la medida de esta energía o el cambio de alguna magnitud con ella relacionada se usan actualmente para determinar el deterioro debido a la humedad, materiales extraños, envejecimiento en los dieléctricos y daños mecánicos del aparato. También se usa para anticipar fallos en servicio de ambos.

Normalmente es costumbre expresar las pérdidas en un condensador por su factor de potencia (power factor). En un circuito eléctrico, el factor de potencia viene dado por la razón entre la energía actual del circuito en Watios y la energía aparente (producto de voltios por amperios del mismo). Considerando el caso particular de un voltaje sinusoidal aplicado a un condensador perfecto, las ondas de la intensidad de corriente de carga llevan a las de voltaje una diferencia de fase de $90{ }^{\circ} \mathrm{C}$, es decir, que la intensidad de corriente está en un máximo cuando el voltaje es cero y este desplazamiento de fase entre voltaje e intensidad permanece constante mientras no haya ninguna influencia externa sobre el circuito.

Representando estas magnitudes sobre un diagrama vector, obtenemos la siguiente figura. 


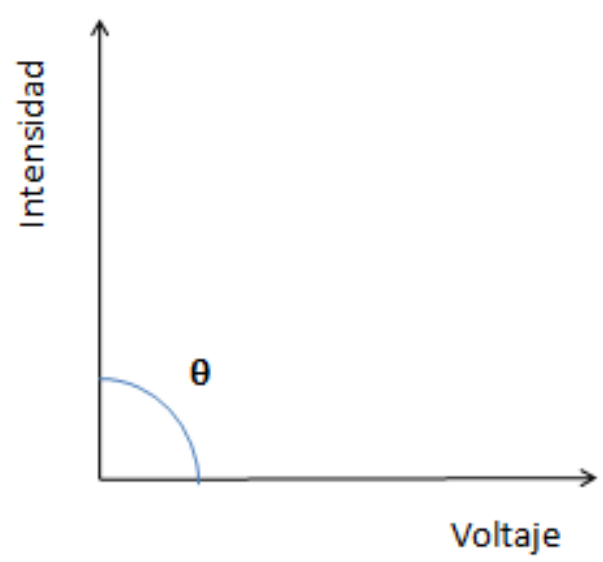

Figura 17: Representación vector intensidad frente a vector voltaje

Un condensador perfecto tiene un consumo de energía igual a cero y por lo tanto no hay pérdidas de energía; de aquí se deduce que factor de potencia es cero.

En la práctica, a causa de que los dieléctricos son imperfectos, una cantidad de energía relativamente pequeña se disipa en el condensador y el ángulo de fase $\theta$ entre ambos vectores se hace inferior a $90{ }^{\circ} \mathrm{C}$ y el factor de potencia será igual a $\cos \theta$ (ver figura 18).

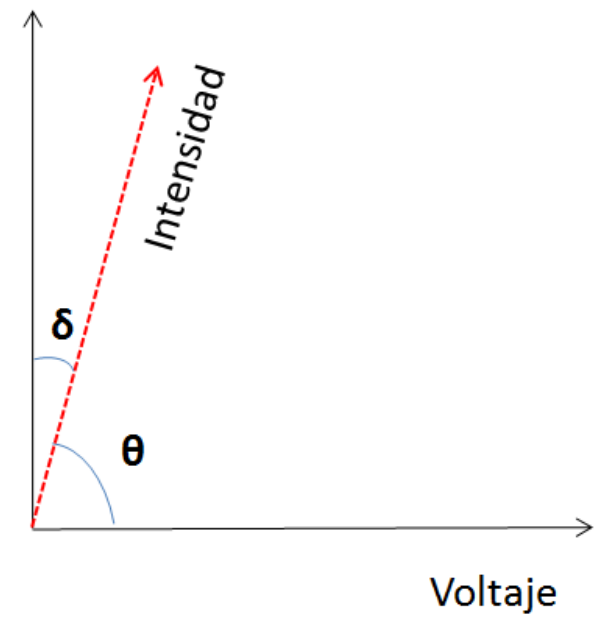

Figura 18: Representación vectores intensidad y voltaje en dieléctricos reales 
Si consideramos el ángulo $\delta$, denominado "ángulo de pérdidas dieléctricas", tenemos que:

$$
\begin{gathered}
\delta=90-\theta \\
\operatorname{Cos} \theta=\operatorname{Sin} \delta
\end{gathered}
$$

Para valores del factor de potencia $(\theta<0,05)$, se tiene que:

$$
\operatorname{Sin} \delta=\operatorname{tg} \delta \sim \delta
$$

(Ecuación 16)

Siendo las unidades de $\delta$ en radianes. El nombre dado a $\operatorname{tg} \delta$ es el de "factor de disipación" para evitar confusión de ideas con el factor de potencia al que se considera usualmente con valores próximos a la unidad.

Si representamos un condensador con una capacitancia $C$ (Faradios) en serie con una resistencia $R$ y se aplica un voltaje sinusoidal de frecuencia $f$, el factor de disipación viene dado por la fórmula $\mathrm{D}=\operatorname{tg} \delta=2 \pi \mathrm{fCR}$.

La pérdida de energía para un voltaje E viene dado por:

$$
\mathrm{P}=\mathrm{nfCE}^{2} \sin 2 \delta
$$

(Ecuación 17)

Si $\delta$ es pequeño, como es usual para aceites de transformador, $\mathrm{P}=2 \mathrm{nfCE}^{2} \operatorname{tg} \delta$, es decir:

$$
P=w C E^{2} D
$$

Donde $\mathrm{D}$ es el factor de disipación, $\mathrm{C}$ es la capacitancia, E es el voltaje, $\mathrm{P}$ es la pérdida de energía y w es la frecuencia.

De aquí se deduce que la energía disipada en el dieléctrico es directamente proporcional al ángulo de pérdidas dieléctricas y aparte de adicionarse a los costes de marcha del equipo, aparece como una adicional pérdida de calor. Si el valor del factor de disipación o ángulo de pérdidas dieléctricas es alto, puede llevar a una gran elevación de la temperatura con la consiguiente disminución de la estabilidad del dieléctrico.

En el laboratorio, la $\operatorname{tg} \delta$ se mide a diversas temperaturas, aunque lo habitual es realizarlo a $25{ }^{\circ} \mathrm{C}$ y $90{ }^{\circ} \mathrm{C}$. Un resultado satisfactorio a esta última temperatura, pero 
deficiente a $25{ }^{\circ} \mathrm{C}$, señala normalmente la presencia de compuestos contaminantes polares precipitables en frío o por ejemplo, agua condensada.

Factores tales como el tamaño molecular, la composición química, la orientación específica y la configuración electrónica afectan también a la tg $\delta$, sin embargo, a altas frecuencias y una temperatura suficientemente elevada, las pérdidas pueden atribuirse exclusivamente a la conductividad del líquido, es decir, a la presencia de portadores de cargas libres en el líquido. Así pues, la medida de las propiedades dieléctricas en líquidos aislantes es de gran importancia como indicador de la pureza del fluido.

Para una mejor interpretación de estos parámetros se debe comentar que, mientras cantidades relativamente grandes de impurezas producen comparativamente cambios pequeños en la constante dieléctrica, la $\operatorname{tg} \delta$ puede verse fuertemente afectada por trazas de contaminantes disueltos o partículas coloidales. Algunos líquidos son más sensibles a la contaminación que los hidrocarburos debido a su mayor polaridad, lo que resulta a cambio en mayor poder disolvente y capacidad de disociación. Por tanto éstos requieren comparativamente un mayor cuidado en su manipulación que los hidrocarburos.

\subsubsection{Formación de gases}

En este apartado no se pretende entrar en detalle en los fenómenos de formación de gases y métodos de diagnóstico de potenciales defectos a través de los tipos y las relaciones entre los principales gases formados, ya que actualmente la normativa describe en detalle esta metodología.

Solamente se hará mención por tanto a algunos conceptos relacionados con la formación de gases y alguna literatura referente a la comparación entre aceites minerales y ésteres donde se describen brevemente los métodos experimentales empleados.

En un transformador bien diseñado, debidamente secado e impregnado de aceite, es muy difícil que se inicien descargas eléctricas. Sin embargo, éstas pueden producirse por causa de defectos del dispositivo, humedad, partículas, electrificación estática, etc. y pueden dar lugar a fallos en el propio equipo u otros asociados. 
Las Descargas Parciales (DP) o de baja energía pueden tener lugar dentro del aislamiento o ser adyacentes a los conductores. Este tipo de descargas sólo puentea parcialmente el aislamiento entre conductores y se llaman de "efecto corona" cuando la descarga parcial se produce en un medio gaseoso (burbujas de gas) alrededor de conductores alejados de aislamientos sólidos. También se llaman descargas parciales a pequeños arcos de baja energía por causa de partículas metálicas.

Las Descargas Disruptivas se describen como arcos, perforaciones o cortocircuitos. Se utilizan también términos tales como cebado (descarga a través del aceite), perforación (a través del aislamiento sólido), contorneado (en la superficie del aislamiento sólido) etc.

Los Defectos Térmicos se refieren a temperaturas excesivas alcanzadas por el aislamiento, y que pueden ocurrir por refrigeración insuficiente, corrientes circulatorias excesivas en partes metálicas adyacentes como resultado de malos contactos, sobrecalentamientos del devanado interno, etc.

El resultado final de estas descargas de energía es la formación de gases debido a diversas reacciones químicas en el aceite o el aislamiento. No obstante se pueden producir también gases, no como consecuencia de un defecto sino por oxidación u otras reacciones en las que pueden estar involucrados aceros, superficies no protegidas, pinturas, etc. Incluso puede producirse hidrógeno molecular por reacción del acero con agua en la medida que exista oxígeno disuelto o por descomposición de la fina capa de aceite existente entre los laminados del núcleo cuando estos se sobrecalientan.

Como resultado de descargas parciales o defectos térmicos se pueden romper los enlaces $\mathrm{C}-\mathrm{C}$ y $\mathrm{C}-\mathrm{H}$ de los hidrocarburos para dar lugar a radicales libres tipo $\mathrm{H} \cdot \mathrm{CH}_{3}$, $\mathrm{CH}_{2}{ }, \mathrm{CH}^{\cdot}$ ó $\mathrm{C} \cdot$ que se recombinarían rápidamente entre ellos para dar lugar a moléculas gaseosas como serían hidrógeno $\mathrm{H}-\mathrm{H}$, metano $\mathrm{CH}_{3}-\mathrm{H}$, etano $\mathrm{CH}_{3}-\mathrm{CH}_{3}$, etileno $\mathrm{CH}_{2}=\mathrm{CH}_{2}$, acetileno $\mathrm{CH} \equiv \mathrm{CH}$. Otros productos posibles, aunque muy minoritarios, serían hidrocarburos $\mathrm{C} 3$ y $\mathrm{C} 4$, partículas de carbono e incluso polímeros de hidrocarburos.

En el caso de DP, al ser defectos de baja energía favorecen la escisión de enlaces C-H, que son los más débiles y como consecuencia, el hidrógeno sería el principal gas de recombinación. 
Para formarse gases tales como etano, etileno o acetileno se necesitan mayores energías de activación, por lo que estos se formarán preferentemente en descargas de alta energía o en zonas de alta temperatura. Por ejemplo, se favorecerá la formación de etileno sobre metano y etano a temperaturas del orden de $500{ }^{\circ} \mathrm{C}$, mientras que el acetileno requiere unos $800-1200{ }^{\circ} \mathrm{C}$ y un enfriamiento muy rápido para acumularse como gas estable de recombinación. Por tanto, el acetileno se formará preferentemente en arcos. Se conoce también que las partículas carbonosas se forman a temperaturas de $500-800{ }^{\circ} \mathrm{C}$ y que aparecen después de arcos en el aceite o alrededor de puntos muy calientes.

Por oxidación, el aceite puede producir también pequeñas cantidades de $\mathrm{CO}$ y $\mathrm{CO}_{2}$ que pueden acumularse durante largos períodos hasta alcanzar concentraciones importantes.

Las cadenas de polímero de la celulosa contienen un gran número de débiles enlaces $\mathrm{C}-\mathrm{O}$ y glicosídicos que son menos estables que los de los hidrocarburos del aceite y que descomponen a temperaturas inferiores. Para valores mayores de $105^{\circ} \mathrm{C}$ tiene lugar, con velocidad significativa, la escisión de la cadena del polímero y por encima de $300{ }^{\circ} \mathrm{C}$ se produce su completa descomposición y carbonización. Durante este proceso se forman principalmente agua, monóxido de carbono y $\mathrm{CO}_{2}$, en mucha mayor cantidad que durante la oxidación del aceite, así como cantidades menores de hidrocarburos gaseosos y compuestos furánicos.

Un modelo de "gassing" en transformadores podría ser el indicado en el diagrama adjunto tal y como se indica en la referencia [6]. En el mismo, se pueden observar todas las fuentes, tanto internas como externas del transformador que pueden dar lugar a "gassing" en el interior de la cuba del transformador. 


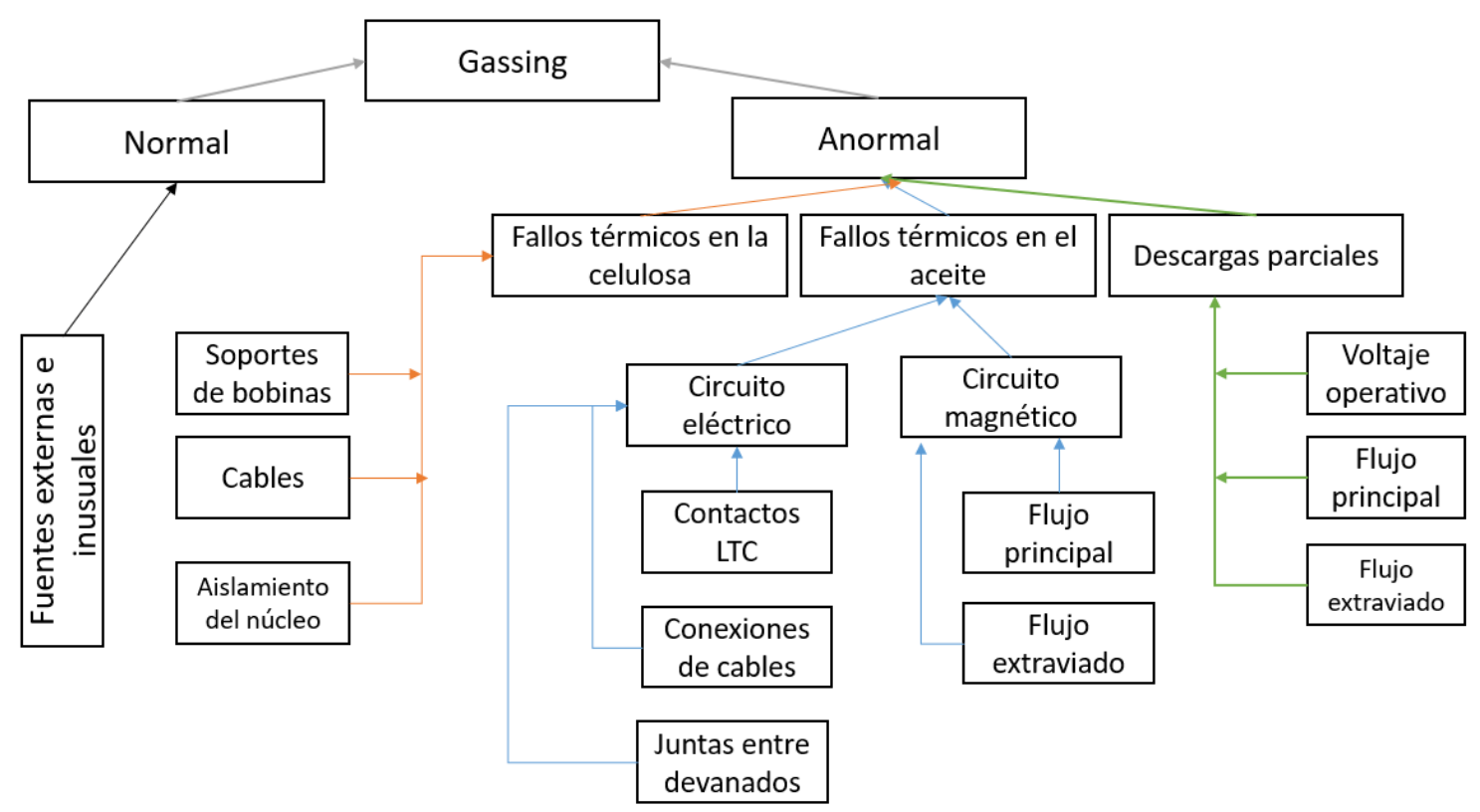

Figura 19: Posibles fallos térmicos y eléctricos dentro de un transformador

La experiencia acumulada durante años de datos analíticos de concentraciones de gases y defectos observados ha permitido, a través de numerosos estudios, clasificar los defectos en función de relaciones tales como las indicadas en la tabla 9 (DoerenburgRogers), pero que pueden resumirse como sigue: un alto nivel de hidrógeno señalaría que pueden tener lugar descargas parciales, la presencia de óxidos de carbono en determinadas relaciones indicaría papel sobrecalentado, gases hidrocarbonados podrían proceder de un defecto térmico y la presencia de acetileno supondría la generación de arcos eléctricos.

Tabla 9: Relaciones de Doerenburg-Rogers

\begin{tabular}{|c|c|c|c|c|}
\hline Caso & Defecto característico & $\frac{\mathrm{C}_{2} \mathrm{H}_{2}}{\mathrm{C}_{2} \mathrm{H}_{4}}$ & $\frac{\mathrm{CH}_{4}}{\mathrm{H}_{2}}$ & $\frac{\mathrm{C}_{2} \mathrm{H}_{4}}{\mathrm{C}_{2} \mathrm{H}_{6}}$ \\
\hline DP & Descargas parciales & $>1$ & $<0,1$ & $<0,2$ \\
D1 & Descargas de baja energía & $0,1-0,5$ & $>1$ \\
$\mathrm{D} 2$ & Descargas de alta energía & $0,6-2,5$ & $0,1-1$ & $>2$ \\
$\mathrm{~T} 1$ & Defecto térmico $\left(\mathrm{t}<300^{\circ} \mathrm{C}\right)$ & & $>1$ & $<1$ \\
$\mathrm{~T} 2$ & Defecto térmico $\left(300^{\circ} \mathrm{C}<\mathrm{t}<700^{\circ} \mathrm{C}\right)$ & $<0,1$ & $>1$ & $1-4$ \\
T3 & Defecto térmico $\left(\mathrm{t}>700^{\circ} \mathrm{C}\right)$ & $<0,2$ & $>1$ & $>4$ \\
\hline
\end{tabular}


Todas estas informaciones permiten, aun considerando la complejidad del problema, disponer de la posibilidad de detectar un defecto o un fallo a efectos de poder tomar una decisión sobre la continuidad en servicio de un transformador antes de un problema catastrófico. Así, el análisis de gases disueltos (DGA) es hoy una herramienta fundamental en el mantenimiento predictivo de transformadores.

Además, es importante considerar la diferencia en la velocidad de generación de gases en diferentes aceites, la migración de aquéllos entre el aceite y la celulosa y otras fuentes inusuales de generación de gas. Por esta causa, el conocimiento de las características de "gassing" en condiciones experimentales de simulación de defectos térmicos, descargas y arcos es fundamental para una posterior interpretación de potenciales fallos del transformador mediante el análisis DGA.

Por otro lado, cuando se produce el gas lentamente por causa, por ejemplo, de un defecto incipiente, el análisis de los gases disueltos en el aceite proporciona más información que el de los gases libres; este análisis de los gases en el aceite es, también, esencial para determinar la velocidad total de formación de gases y, por tanto, para comprobar si el defecto está aumentando, que es en definitiva el aspecto más importante a determinar. Cuando se realiza el análisis de gases libres, es necesario convertir las concentraciones de los diferentes gases en estado libre en sus correspondientes concentraciones equivalentes en disolución utilizando para ello la tabla 10 de coeficientes de Ostwald, antes de aplicar el método de las relaciones de gases de la tabla 9, y compararlas con las concentraciones de los gases disueltos en el aceite del relé y de la cuba principal. Esto permite además comparar las concentraciones reales en el aceite con las equivalentes en el gas libre y obtener así información sobre la velocidad con la que las burbujas han ascendido a través del aceite $\mathrm{y}$, por tanto, de la velocidad de formación de gases.

El cálculo de las concentraciones de gases disueltos equivalentes a las concentraciones de gases libres se realiza aplicando los coeficientes $K$ de Ostwald para cada gas. Para un gas particular, el coeficiente K se define como: 


$$
K\left(\frac{\mu L}{L}\right)=\frac{[\text { Gas en la fase líquida }]}{[\text { Gas en la fase gas }]}
$$

(Ecuación 19)

Tabla 10: Coeficientes de Ostwald de varios gases en aceites minerales aislantes

\begin{tabular}{|c|c|c|}
\hline $\mathrm{Gas}$ & $\mathrm{K} @ 20^{\circ} \mathrm{C}$ & $\mathrm{K} @ 50^{\circ} \mathrm{C}$ \\
\hline $\mathrm{N}_{2}$ & 0,09 & 0,09 \\
$\mathrm{O}_{2}$ & 0,17 & 0,17 \\
$\mathrm{H}_{2}$ & 0,05 & 0,05 \\
$\mathrm{CO}$ & 0,12 & 0,12 \\
$\mathrm{CO}_{2}$ & 1,08 & 1,00 \\
$\mathrm{CH}_{4}$ & 0,43 & 0,40 \\
$\mathrm{C}_{2} \mathrm{H}_{6}$ & 2,40 & 1,80 \\
$\mathrm{C}_{2} \mathrm{H}_{4}$ & 1,70 & 1,40 \\
$\mathrm{C}_{2} \mathrm{H}_{2}$ & 1,20 & 0,9 \\
\hline Nota: Los valores dados en la tabla representan valores medios obtenidos en algunos tipos de corrientes de \\
aceites minerales aislantes para transformador. Los valores reales pueden diferir un poco de estos valores. Sin \\
embargo, los datos indicados pueden utilizarse sin que influyan en las conclusiones deducidas de los resultados \\
de los ensayos recalculados.
\end{tabular}

Además, el conocimiento de la solubilidad de los gases en aceites aislantes es fundamental para entender los fenómenos de sobresaturación (formación de burbujas en la matriz del aceite dieléctrico) que pueden ocurrir por causa de cambios bruscos de temperatura.

La norma americana ASTM D 2780 "Standard Test Method for Solubility of Fixed Gases in Liquids" permite la medida de esta característica a diferentes temperaturas para obtener curvas del tipo indicado en la figura 20: 


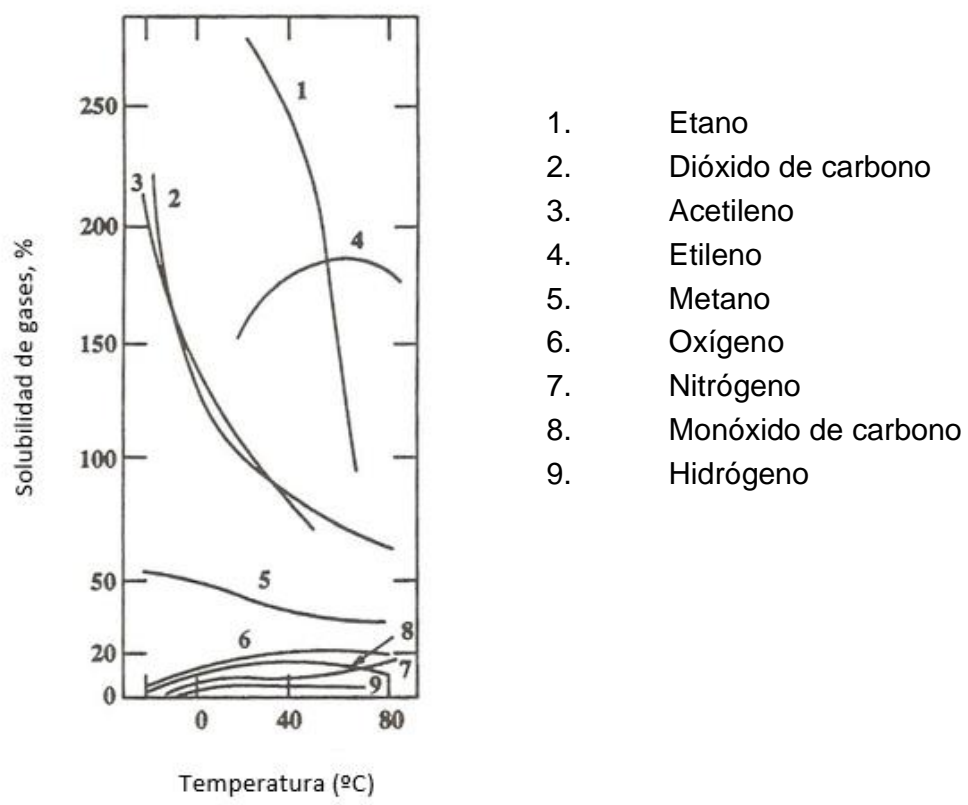

Figura 20: Solubilidad de gases en aceites minerales

En la referencia [7], se compara el comportamiento de un aceite mineral de transformadores Shell Diala D con el ester sintético Midel 7131 bajo el punto de vista de sus prestaciones en formación de gases cuando son sometidos, en laboratorio, a ensayos de formación de gases en una célula especialmente diseñada para simular descargas parciales y arcos a través de unos electrodos inmersos en aceite. La figura siguiente indica un esquema del citado dispositivo:

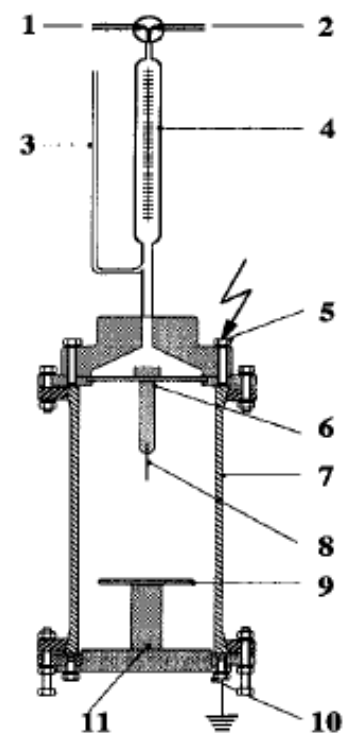
Gas Argón
Al cromatógrafo de gases
Tubo igualador
Bureta
Tapa con conexión de alta tensión
Soporte electrodo alta tensión
Recipiente de vidrio cilíndrico
Electrodo en forma de aguja
Electrodo en forma de plato
Fondo con conexión a tierra

Figura 21: Generador de gases por descargas eléctricas 
De esta forma comprobaron que bajo el estrés eléctrico aplicado, el éster genera mayor cantidad de gases que el aceite mineral. La gráfica siguiente refleja esta diferencia, a nivel de ejemplo, para el volumen de gases no disueltos en función de la energía de las descargas:

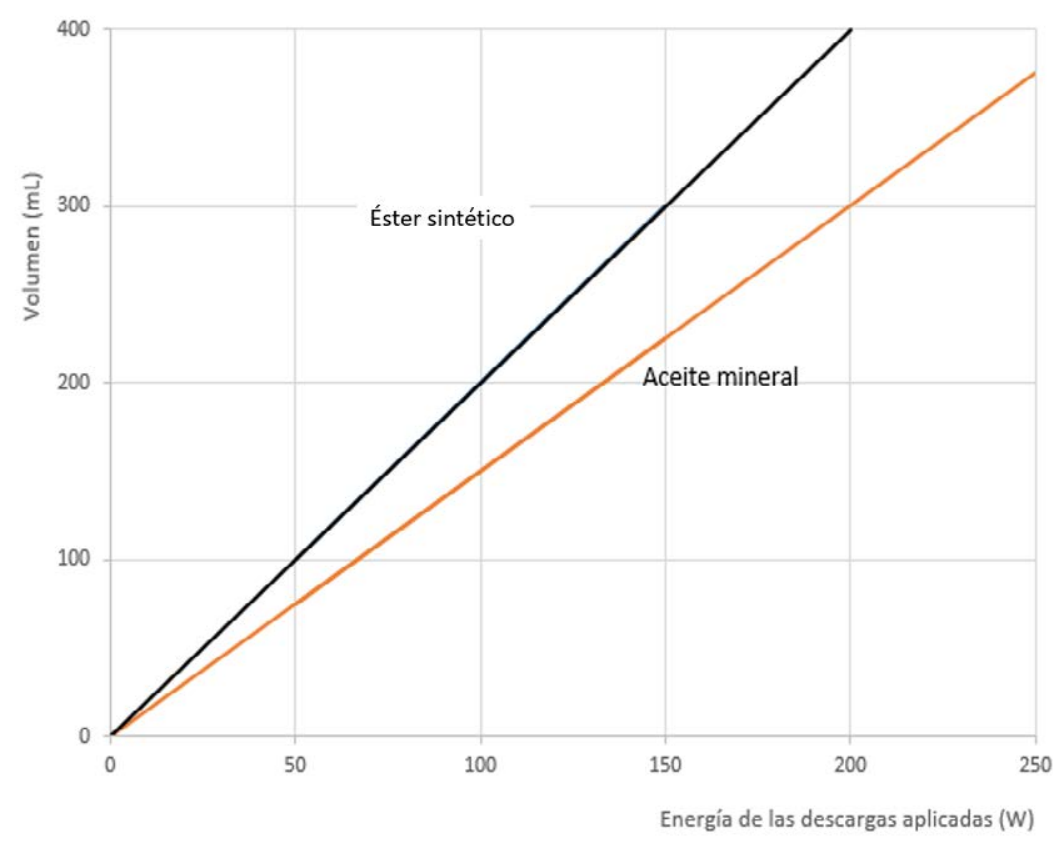

Figura 22: Comparación gases generados por descargas eléctricas

De la misma forma se simularon condiciones de defecto térmico hasta temperaturas de $1000{ }^{\circ} \mathrm{C}$ utilizando una célula como la indicada en la figura 23, pero introduciendo en ella una resistencia de Konstantan para producir el foco térmico o punto caliente. La temperatura en el líquido alrededor del alambre caliente se medía con una sonda de NiCrNi y el sistema permitiría regular la temperatura en un amplio rango y los autores [7] asumen que alrededor del alambre hay una región de temperatura constante. 


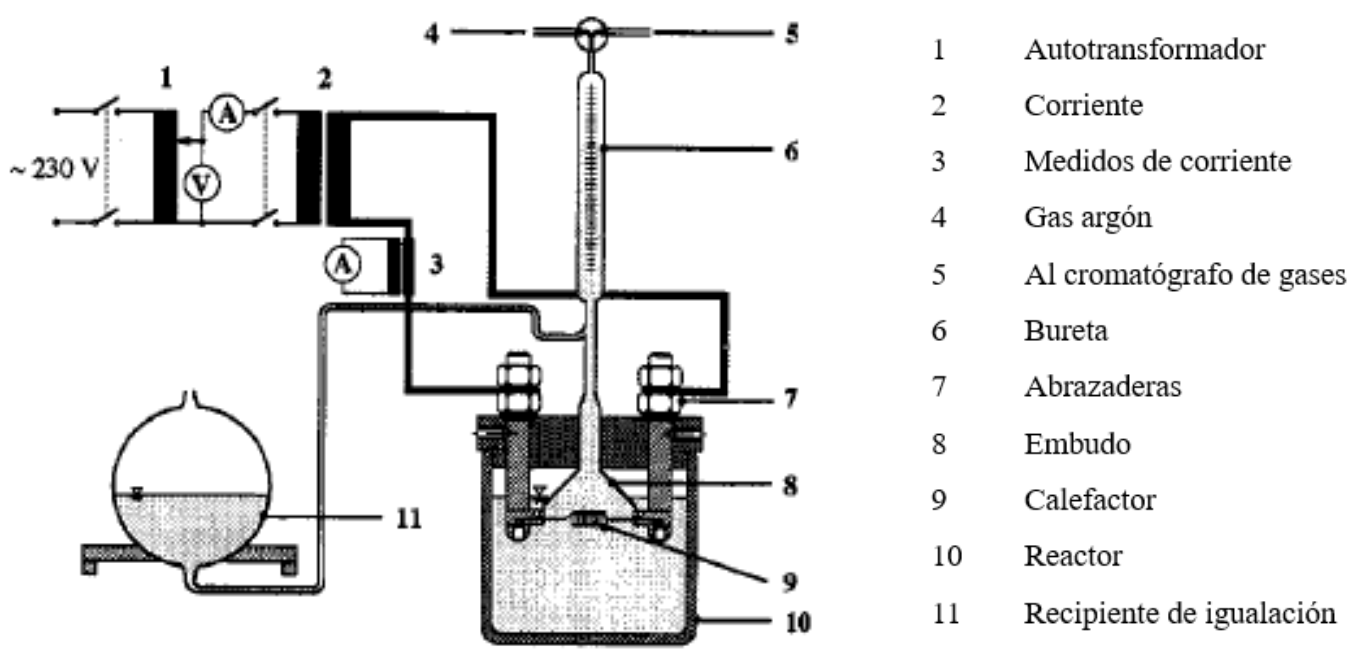

Figura 23: Generador de gases por puntos calientes

En este caso la generación de gases no disueltos fue la indicada en la gráfica 24, donde puede observarse que los principales gases generados fueron $\mathrm{H}_{2}, \mathrm{CH}_{4}$ y $\mathrm{C}_{2} \mathrm{H}_{4}$ y que sus concentraciones fueron similares para el aceite mineral que para el éster:

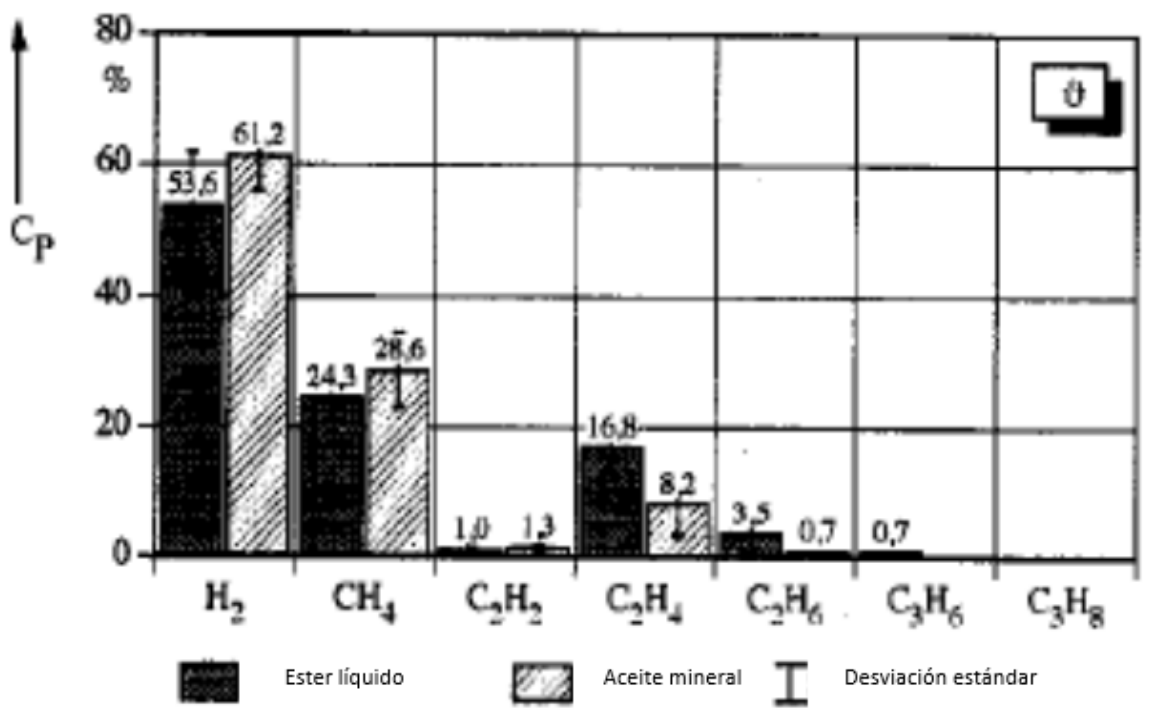

Figura 24: Gases generados por puntos calientes 
Por otro lado, en la referencia [8], diferentes autores comparan las características de formación de gases de un aceite mineral, el mismo éster sintético Midel 7131 y el aceite vegetal FR3. La experimentación en este caso se llevó a cabo con dos equipos distintos.

Para el caso de simular condiciones de descargas parciales (PD) y arcos se empleó una célula con una configuración de electrodos aguja - disco separados $15 \mathrm{~mm}$. Se encontró, sin embargo, que la generación de gases disueltos en ésteres era inferior a la de los aceites minerales (ver figura 11):

Tabla 11: Comparativa de gases generados por descargas eléctricas en diferentes aceites

\begin{tabular}{|l|c|c|c|c|c|c|c|c|c|}
\hline & \multicolumn{4}{|c|}{ Aceite Mineral } & \multicolumn{3}{c|}{ Ester sintético } & \multicolumn{3}{c|}{ Aceite Vegetal } \\
\hline Test & C & LEDT & CDT & C & LEDT & CDT & C & LEDT & CDT \\
\hline $\mathrm{H}_{2}$ & 5 & 901 & 20 & 7 & 97 & 5 & 8 & 191 & 23 \\
\hline $\mathrm{CH}_{4}$ & 1 & 145 & 2 & 0 & 9 & 2 & 1 & 14 & 2 \\
\hline $\mathrm{C}_{2} \mathrm{H}_{6}$ & 0 & 24 & 0 & 01 & 2 & 0 & 2 & 10 & 1 \\
\hline $\mathrm{C}_{2} \mathrm{H}_{4}$ & 1 & 270 & 2 & 0 & 26 & 0 & 1 & 63 & 2 \\
\hline $\mathrm{C}_{2} \mathrm{H}_{2}$ & 1 & 1540 & 2 & 9 & 126 & 0 & 6 & 280 & 2 \\
\hline $\mathrm{CO}$ & 18 & 6 & 2 & 37 & 37 & 2 & 6 & 51 & 8 \\
\hline Total & 26 & 2886 & 28 & 17 & 297 & 9 & 24 & 609 & 38 \\
\hline
\end{tabular}

Para la condición de simulación de este tipo de defectos eléctricos, el acetileno era el gas clave para descargas de baja energía mientras que el hidrógeno lo era para las descargas parciales. Concluyen también que los métodos de interpretación de defectos eléctricos de baja energía por análisis de gases identifican bien el fenómeno, pero las relaciones de gases y porcentajes de éstos deberían ser revisados en las correspondientes guías de mantenimiento de aceites de transformador en uso (Guías IEC, de sus letras en ingles "Comité Internacional de Electrotecnia").

El estudio de la formación de gases simulando defectos térmicos fue realizado en condiciones de $\mathrm{T} 1\left(\mathrm{t}<300^{\circ} \mathrm{C}\right)$ empleando para ello recipientes de vidrio donde se introducían los fluidos con papel Kraft previamente acondicionado en relación 20:1 y se ensayaban a temperaturas de $90^{\circ} \mathrm{C}, 150^{\circ} \mathrm{C}$ y $200^{\circ} \mathrm{C}$ por períodos de tiempo de hasta 14 días. Los resultados sugieren que en defectos térmicos $\mathrm{T} 1$, los ésteres producen también menos gases que los aceites minerales y el aceite vegetal sin embargo, parece generar mayor cantidad de etano y este podría ser el gas clave, junto a $\mathrm{CO}$ y $\mathrm{CO}_{2}$, para este tipo de diagnosis. 
Podría indicarse, como comentario, que el método ASTM D 7150 "Standard Test for the Determination of Gassing Characteristics of Insulating Liquids Under Thermal Stress at Low Temperature" empleado como procedimiento de evaluación de aceites en el artículo [9], podría ser de utilidad en el trabajo a realizar en el desarrollo del producto objeto de esta tesis, sin embargo para temperaturas más elevadas que $120{ }^{\circ} \mathrm{C}$ el sistema de jeringa empleado podría ser inadecuado y menos aún para condiciones de defecto térmico $\mathrm{T} 2>300^{\circ} \mathrm{C}$.

En este último caso podrían ser utilizados también sistemas parecidos al referido en la norma ASTM D 2300 "Gassing of Electrical Insulating Liquids Under Electrical Stress and Ionization (Modified Pirelli Method)" o al indicado en el esquema siguiente en el que podría emplearse algún tipo de resistencia para generar el flujo térmico en lugar de producir una descarga eléctrica.

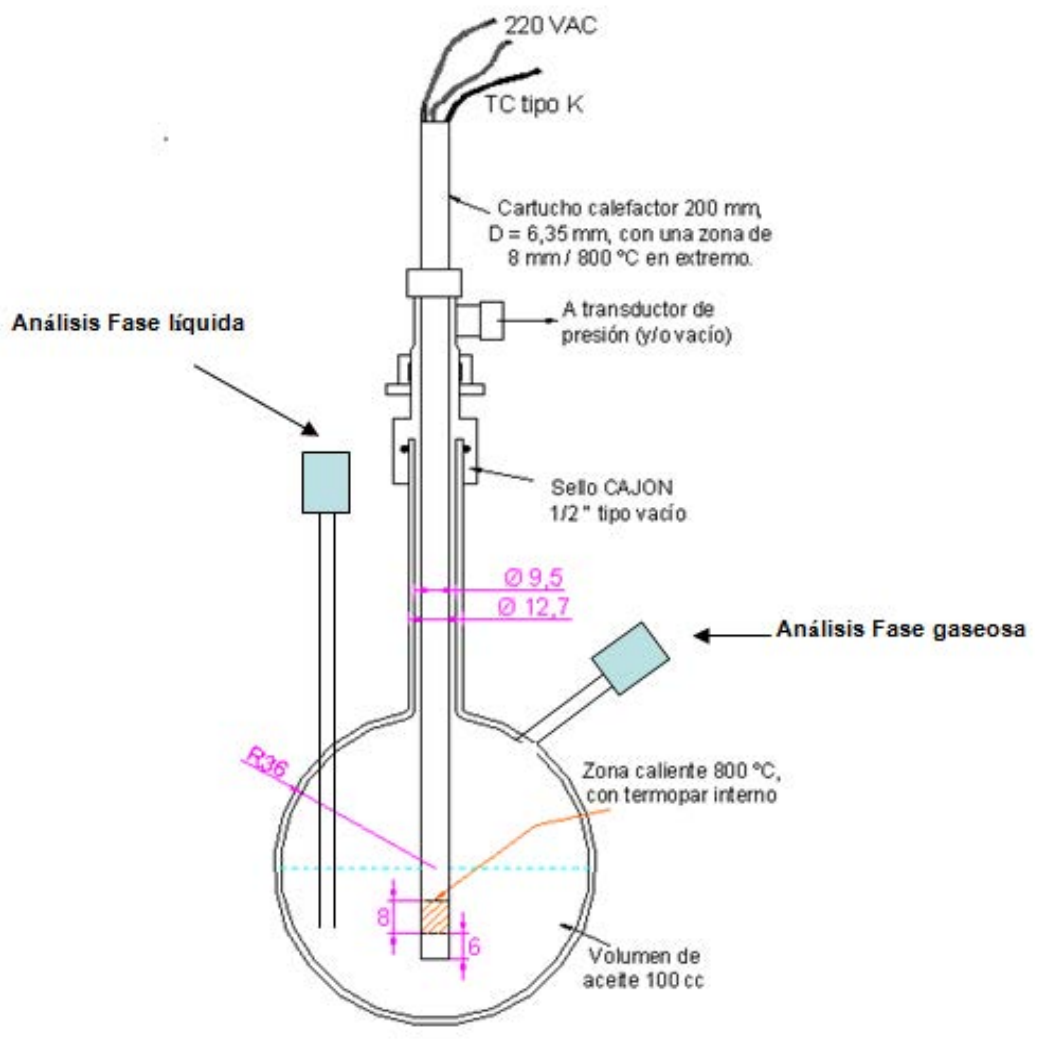

Figura 25: Generador de gases por puntos calientes

Hasta la fecha, y dado que no son muchos los transformadores rellenos de aceite vegetal, las oportunidades de medir gases disueltos en el fluido no son comparables a las de décadas de análisis de éstos en aceites minerales y mucho menos la 
disponibilidad de correlaciones con miles de fallos. No existe, por tanto, la misma calidad de diagnóstico en el caso de los ésteres. En principio parece ser que las líneas base de concentraciones de hidrógeno y $\mathrm{CO}_{2}$ son mayores en el caso de los ésteres y que las relaciones de Doerenburg-Rogers no se conocen bien ni son tan precisas como para determinar la condición de los transformadores en servicio. No obstante, las medidas disponibles hasta ahora, en transformadores operando sin problemas no han mostrado niveles anormales de gases.

\subsubsection{Tendencia a la formación de carga electrostática (ECT)}

La ECT (Electrostatic Charge Tendency) de un aceite es una propiedad importante para ciertos diseños de transformadores de alto voltaje y extra alto voltaje con refrigeración forzada que tienen velocidades de bombeo del aceite que pueden dar lugar a la formación de cargas electrostáticas. Estas cargas pueden producir una descarga de energía causando un fallo en el transformador.

La ECT es un requisito específico para aceites que no consta en general en las especificaciones IEC ó ASTM, aunque sin embargo, en el caso de transformadores de potencia refrigerados tipos OF u OD (IEC 60076-2) con alta velocidad de la circulación del aceite, suele determinarse esta propiedad y acordar un límite entre el comprador y el fabricante.

En principio, en relación a esta tesis, y teniendo en cuenta que la primera aplicación del nuevo tipo de fluidos a desarrollar está dirigida a transformadores sellados sin circulación de aceite, podría obviarse esta propiedad. Sin embargo, noticias recientes señalan que han empezado a utilizarse estos fluidos vegetales en transformadores de potencia. Los más recientes de los que se tiene noticia son:

- Uno en Luton, UK, para la Compañía EDF Energy Networks fabricado por Areva T\&D que utiliza Envirotemp FR3 suministrado por Cooper Power Systems. Se trata de un transformador de $132 \mathrm{kV}$ y $30 \mathrm{t}$ de fluido con ligeras modificaciones para adaptarlo a este dieléctrico. Se ha publicado además que EDF está cooperando con la School of Electrical and Electronic Engineering de la Universidad de Manchester y con Areva T\&D para comparar las 
prestaciones de este transformador equipado con aceite vegetal con las de un segundo transformador del mismo tipo pero equipado con aceite mineral.

- En el segundo caso, Waukesha Electric Systems ha renovado recientemente la carga de cinco transformadores de 167 MVA (top rating), $230 \mathrm{kV}$ y 17,200 galones por unidad, también con Envirotemp FR3.

La generación de carga electrostática tiene lugar en transformadores de potencia si dos materiales similares, uno el aceite aislante y el otro el conductor ó el aislante sólido se encuentran en contacto y en movimiento relativo. La generación de carga puede ocurrir en cualquier interfase liquido-sólido y puede producirse en el flujo de aceite en tuberías, pasos, filtros, etc. También puede ocurrir por causa del movimiento de un aislante o conductor sólido en un líquido estacionario.

Generalmente el aceite se carga positivamente y el material aislante negativamente.

En los transformadores con circulación forzada el aceite es dirigido, por razones de refrigeración, hacia el fondo de los arrollamientos y conducido a la parte superior del equipo. Las cargas eléctricas que se generan son así transportadas por el flujo de aceite a través de los aislamientos, generando nubes de carga que afectan a la rigidez dieléctrica especialmente en el espacio ocupado por el aceite. Se pueden generar ahí arcos eléctricos provocando un fallo del transformador. El grado de electrificación por fricción determina si esta propiedad puede conducir a una ruptura dieléctrica.

Se ha descrito en la literatura que la electrificación estática en transformadores puede verse afectada por diversos factores, entre los que se encuentran:

- La temperatura del aceite, aumentando con ésta

- La humedad: ECT disminuye al aumentar el contenido en agua

- La velocidad de flujo y su turbulencia

- La naturaleza del aceite

- La rugosidad del aislamiento sólido

- La energización del sistema. Posiblemente la electrificación estática sea proporcional al campo eléctrico 
- La rigidez dieléctrica del aceite en movimiento, aunque no bien conocido su efecto

- La migración del agua en el sistema papel-aceite

- Los sistemas mecánicos tales como bombas, orificios, pasos de aceite, válvulas...

En principio, la ECT se describe como la propiedad de un aceite para cargarse eléctricamente cuando se desplaza sobre una superficie sólida, y se define como la densidad de carga generada por unidad de volumen de aceite y se mide en $\mu \mathrm{C} / \mathrm{m}^{3}$.

$$
\rho=\frac{i \phi}{V} 10^{12}=\left[\frac{i}{(V / \phi)}\right] 10^{12}
$$

Siendo $\boldsymbol{i}$ la intensidad de corriente en amperios, $\boldsymbol{\Phi}$ el flujo de aceite y $\boldsymbol{V}$ volumen en $\mathrm{mL}$.

En un aceite, incluso de elevado valor de resistividad, existen cantidades pequeñas o muy pequeñas de compuestos iónicos que pueden disociarse mediante calor en sus correspondientes iones:

$$
\mathrm{AB} \leftrightarrow \mathrm{A}^{+}+\mathrm{B}^{-}
$$

Las cargas iónicas proceden de impurezas disociables y éstas, forman una doble capa débilmente enlazada a las superficies sólidas tal y como se indica en la figura 26. El resultado de esta doble capa débilmente enlazada es la generación de una interfase electrificada. 


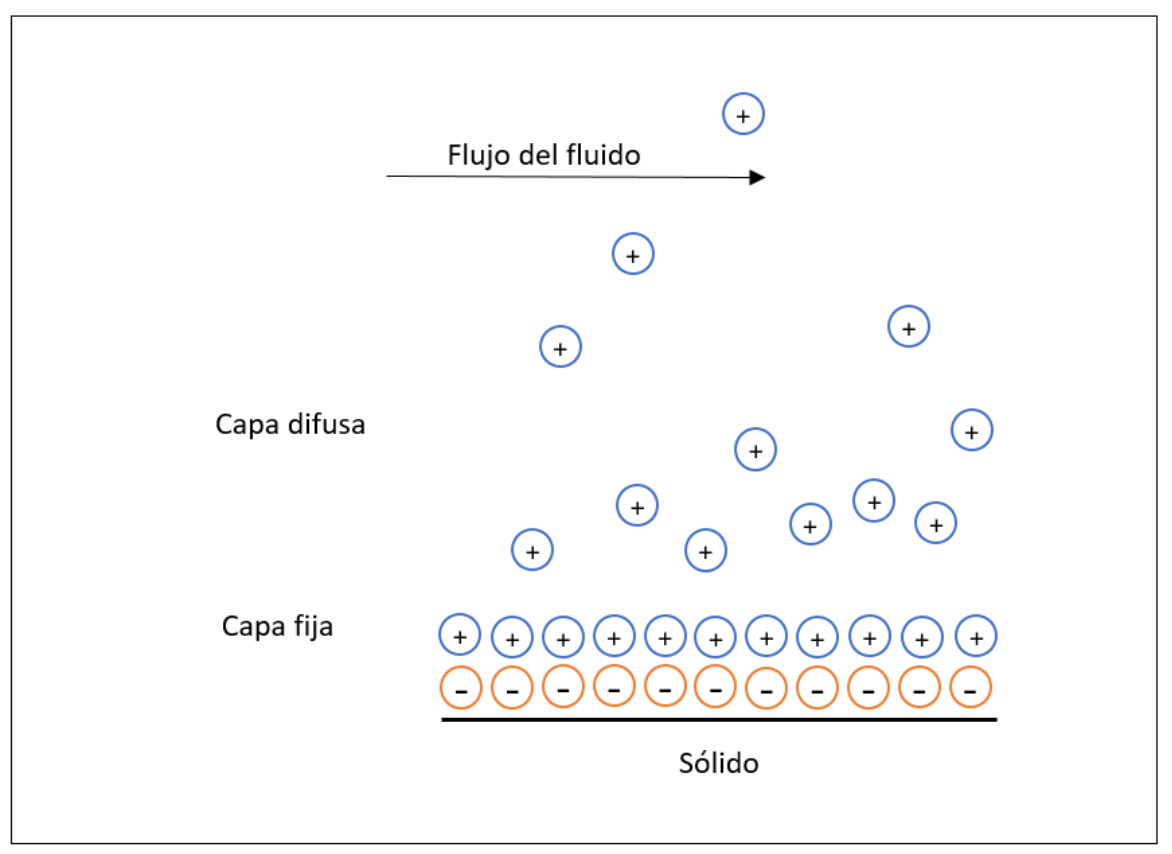

Figura 26: Diagrama de formación de la interfase electrificada

Si el movimiento del fluido es capaz de arrancar iones de esta doble capa y transportarlos en la corriente, el resultado será una separación de cargas entre las enlazadas sobre la superficie y las que están en movimiento, generando así una diferencia de potencial.

Si las concentraciones de iones $\mathrm{A}^{+}$y $\mathrm{B}^{-}$son iguales no existe cambio de carga, pero si hay un exceso de uno de ellos, se detectará como una carga electrostática en el sistema.

En los transformadores cargados con aceites minerales, donde los sólidos (celulosa) son orgánicos, el aceite se cargará positivamente, aunque si los sólidos son partículas metálicas el aceite podrá cargarse negativamente. La razón es que la molécula de celulosa contiene en su cadena las unidades básicas de glucosa, las cuales disponen de 6 grupos hidróxido $(\mathrm{OH})$ cada una, y los átomos de oxígeno en los $\mathrm{OH}$ poseen una de las mayores electronegatividades en iones. Por esta causa, la nube electrónica que forma el enlace $\mathrm{O}-\mathrm{H}$ está desplazada hacia el átomo de oxígeno, quedando éste con carga parcial negativa y el hidrógeno, con positiva.

La superficie de las fibras de celulosa del papel aislante se llega a cubrir de los hidrógenos positivamente polarizados, los cuales tendrán afinidad por los iones 
negativos existentes en el aceite adsorbiéndolos sobre el papel y resultando así una carga negativa sobre el papel y consecuentemente positiva en el aceite.

Así, el agua afectará sensiblemente a la $E C T$ ya que para un sistema celulosa-aceite habrá un reparto de agua entre ambas fases que dependerá fuertemente de la temperatura y la naturaleza del fluido aislante.

Respecto a los sistemas de medida, en la referencia [10] se hace una exhaustiva revisión de los numerosos métodos empleados en el sector para medir esta característica de los aceites y estudiar la influencia de las variables que afectan esta propiedad. CIGRE ha propuesto un método para medir la ECT [11].

Finalmente, son dos los sistemas que más se están empleando en la industria para medir la ECT:

1- El denominado SDA (Spinning Disc Apparatus) también llamado $R D C$ (Rotating Disc Apparatus)

2- El MCT (Ministatic Charge Tester)

El $R D C$ consiste en un disco de $150 \mathrm{~mm}$ de diámetro y $6 \mathrm{~mm}$ de espesor cubierto, en sus dos caras, por papel especial de transformadores e inmerso en un recipiente metálico de unos cuatro litros de capacidad donde puede girar gracias a un pequeño motor. Un electrómetro permite medir la corriente eléctrica creada sobre el disco y que se conduce hacia "tierra". El conjunto se introduce en una caja de Faraday para poder medir la ECT (figura 27).

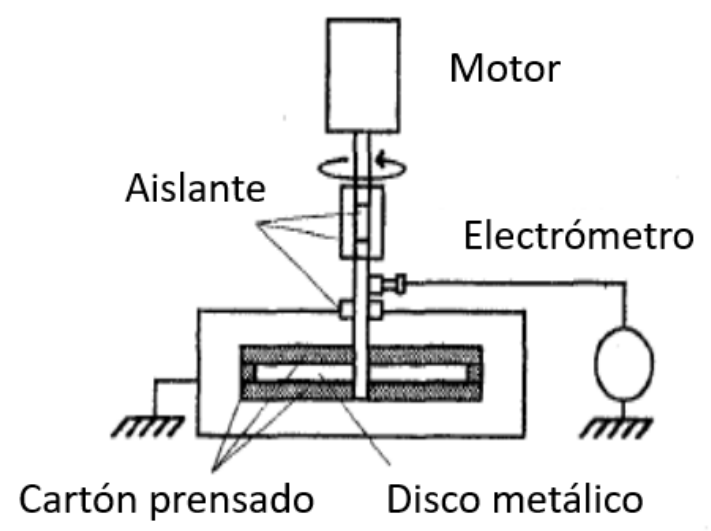

Figura 27: Esquema método RDC 
Algunos autores que han trabajado con esta técnica advierten de la sensibilidad de la medida y señalan que la ECT está muy influenciada por la temperatura y el tipo de material empleado en el disco. En la referencia [12] se hace alusión a este fenómeno detectado:

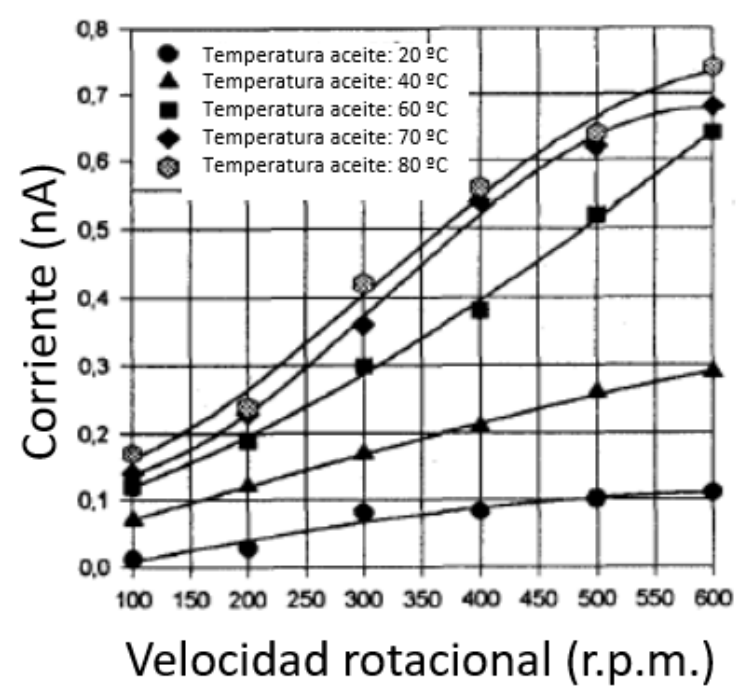

Figura 28: Influencia de la temperatura en el método RDC

El método $M C T$ consiste básicamente en un recipiente de vidrio equipado con un filtro de celulosa altamente poroso de 3 micras. El sistema funciona forzando al aceite, en principio eléctricamente neutro, a través del filtro, lo que determina una separación de cargas en la interfase aceite-filtro. El aceite se carga positivamente y el filtro negativamente. Las medidas se realizan con un electrómetro o cualquier sistema electrónico capaz de medir la carga sobre un anillo metálico que rodea el filtro. El conjunto está introducido también en una caja de Faraday. Este sistema ha sido adaptado por numerosos laboratorios con mayores o menores modificaciones, como por ejemplo la indicada en la figura 29 para cartón prensado y que podría ser también de interés para el caso de evaluación de fluidos de viscosidad elevada: 


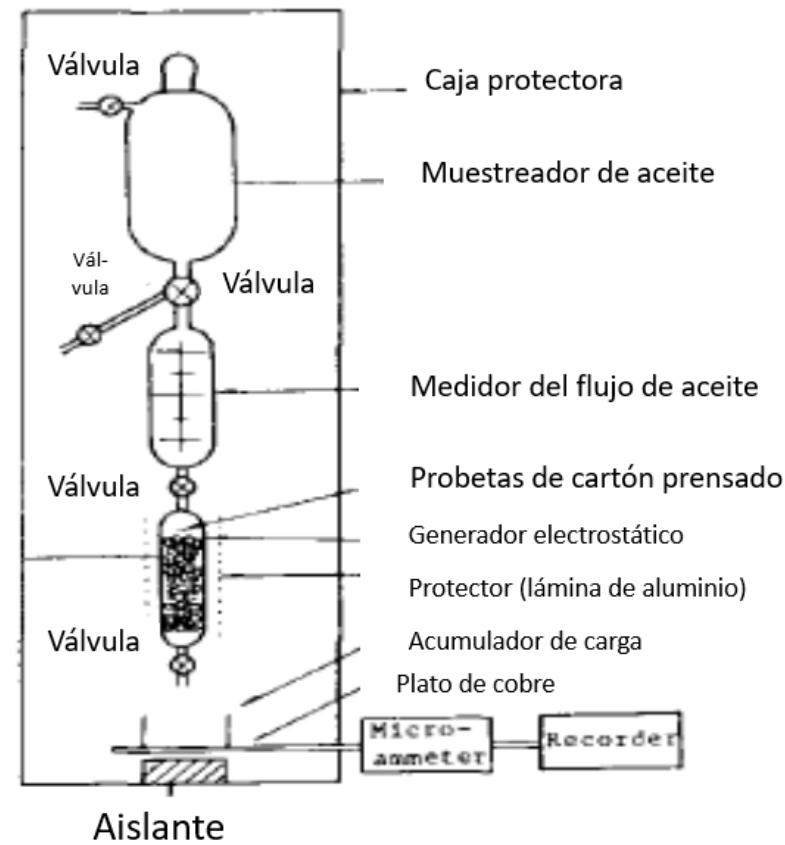

Figura 29: Esquema método MCT

La supresión de la electricidad estática se ha llevado a cabo en transformadores en los últimos años mediante el empleo de aditivos. El más innovador trabajo en este sentido se realizó utilizando para ello pequeñas concentraciones de compuestos nitrogenados.

Una explicación para este efecto supresor de carga radicaría en que los átomos de nitrógeno poseen un par de electrones solitarios que exhiben ciertas características de insaturación. Así, compuestos con múltiples átomos de nitrógeno, tales como el BTA (1,2,3-Benzotriazol) son fácilmente atraíbles por el papel aislante, fijándose a él tal y como se indica en la figura 30:<smiles>c1ccc2[nH]nnc2c1</smiles>

Figura 30: Estructura química del BTA 


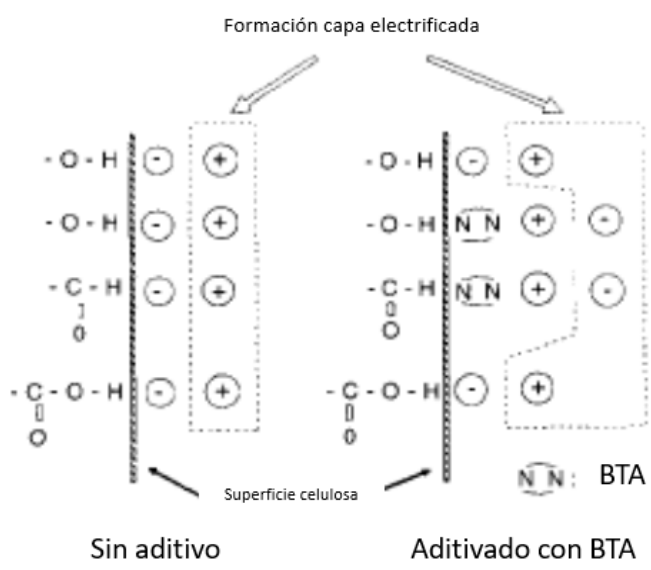

Figura 31: Esquema supresión de electricidad estática

El BTA contiene tres átomos de nitrógeno por molécula y al adsorberse, crea sobre la superficie una nueva distribución de cargas, por lo que las cargas iónicas transportadas por el aceite lo serán en mucha menor cuantía disminuyendo o eliminando la carga positiva de éste. Esta situación explicaría a su vez el efecto de mayor eficacia de las moléculas de mayor contenido nitrogenado en la supresión de la ECT tal y como se refleja en la figura 22:

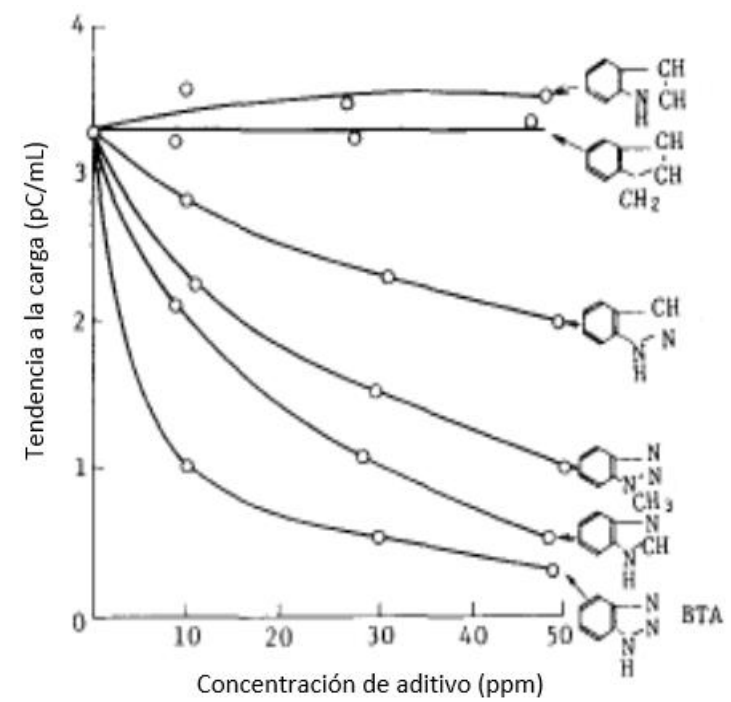

Figura 32: Efectividad del aditivo en función de número de nitrógeno por molécula 
Se observa que el BTA es el más eficaz de la serie y podría explicarse la menor capacidad supresora de carga del metil-BTA (molécula inmediatamente superior) por el impedimento estérico del grupo metilo.

Cabría recordar en este apartado algunos aspectos básicos sobre estos aditivos:

- La solubilidad reducida del BTA en aceites parafínicos

- Que moléculas no nitrogenadas o con un solo átomo de nitrógeno no ejercen efecto alguno en la ECT

- Que para la supresión de la electrificación son necesarios al menos dos átomos de nitrógeno por molécula y que el efecto aumenta en función de la posición en que estos se localicen

- Que existe competitividad superficial o reparto de estos aditivos sobre la celulosa y las superficies de cobre donde actúa como pasivante.

Por esta causa, gráficas como la indicada a continuación, en la que según mediciones de laboratorio una concentración de 10 ppm de BTA comienza a ser efectiva, habría que ponerla en entredicho bajo un punto de vista práctico ya que no se tendría en cuenta el pasivante que habría podido quedar fijado sobre el cobre de los conductores.

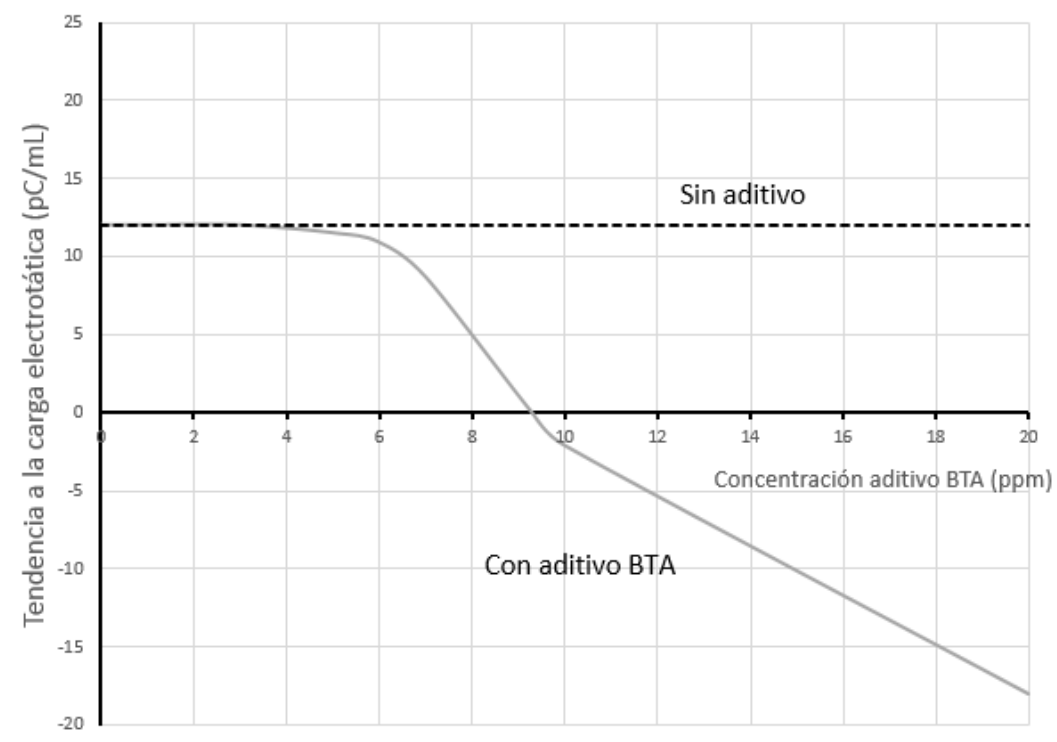

Figura 33: Efectividad de la molécula de BTA 
Algunas informaciones sobre la ECT en fluidos diferentes de los aceites minerales se han recogido en una serie de artículos [5]. En dichos artículos, se estudia la influencia de la humedad sobre la ECT para diferentes fluidos así como la correlación entre la resistividad y la densidad de carga (la resistividad fue determinada según norma IEC 60247 y la ECT mediante el MCT previamente descrito). Las características de los aceites empleados se recogen en la tabla 12 :

Tabla 12: Propiedades fisicoquímicas de los aceites empleados en el estudio

\begin{tabular}{|l|c|c|c|c|}
\hline \multicolumn{1}{|c|}{ Tipo de aceite } & $\begin{array}{c}\text { Mineral } \\
\text { nafténico (A) }\end{array}$ & $\begin{array}{c}\text { Ester sintético } \\
(\mathbf{B}) *\end{array}$ & $\begin{array}{c}\text { Ester sintético } \\
(\mathbf{C})^{*}\end{array}$ & $\begin{array}{c}\text { Silicónico } \\
\text { (D) }\end{array}$ \\
\hline Densidad $\left(20^{\circ} \mathrm{C}\right), \mathrm{g} / \mathrm{cm}^{3}$ & 0,89 & 0,97 & 0,99 & 0,96 \\
\hline Viscosidad $\left(40^{\circ} \mathrm{C}\right), \mathrm{mm}^{2} / \mathrm{s}$ & 8,09 & 30 & 33 & 35 \\
\hline Punto de congelación $\left({ }^{\circ} \mathrm{C}\right)$ & -57 & -48 & -51 & -50 \\
\hline $\begin{array}{l}\text { Conductividad térmica }\left(20^{\circ} \mathrm{C}\right), \\
\mathrm{W} / \mathrm{m} . \mathrm{K}\end{array}$ & 0,13 & 0,16 & 0,14 & 0,15 \\
\hline $\begin{array}{l}\text { Punto de inflamación }(\text { Método } \\
\text { PM), }{ }^{\circ} \mathrm{C}\end{array}$ & 148 & 257 & $>250$ & 305 \\
\hline Factor de disipación $\left(90^{\circ} \mathrm{C}\right)$ & $<0,001$ & 0,004 & 0,02 & $<0,001$ \\
\hline Constante dieléctrica $\left(20^{\circ} \mathrm{C}\right)$ & 2,2 & 3,2 & 3,3 & 2,7 \\
\hline Rigidez dieléctrica, $\mathrm{kV}$ & $>70$ & $>75$ & $>75$ & 200 \\
\hline $\begin{array}{l}\text { Max. Solubilidad de agua }\left(25^{\circ} \mathrm{C}\right), \\
\text { ppm }\end{array}$ & 70 & 2500 & 2500 & 250 \\
\hline
\end{tabular}

(*)Los tipos B y C son tetraésteres de pentaeritritol.

Los autores determinaron que los ésteres producen una mayor electrificación electrostática que los aceites minerales y que cuanto mayor es la resistividad, menor es la tendencia a la formación de carga electrostática. Posteriormente, cuando se deshidrataron las muestras, se compararon los valores de los aceites desecados con los húmedos y encontraron que efectivamente el agua ejerce también una influencia, aunque no demasiado importante al menos a los niveles estudiados:

Tabla 13: Contenido en agua de los aceites antes y después de la deshidratación

\begin{tabular}{|l|c|c|c|c|}
\hline Aceites & $\begin{array}{c}\text { Mineral } \\
\text { nafténico (A) }\end{array}$ & $\begin{array}{c}\text { Ester sintético } \\
\text { (B) }\end{array}$ & $\begin{array}{c}\text { Ester sintético } \\
\text { (C) }\end{array}$ & $\begin{array}{c}\text { Silicónico } \\
\text { (D) }\end{array}$ \\
\hline $\begin{array}{l}\text { Agua, ppm (antes del } \\
\text { tratamiento) }\end{array}$ & 29 & 277 & 168 & 76 \\
\hline $\begin{array}{l}\text { Agua, ppm (después del } \\
\text { tratamiento) }\end{array}$ & 13 & 168 & 96 & 27 \\
\hline
\end{tabular}




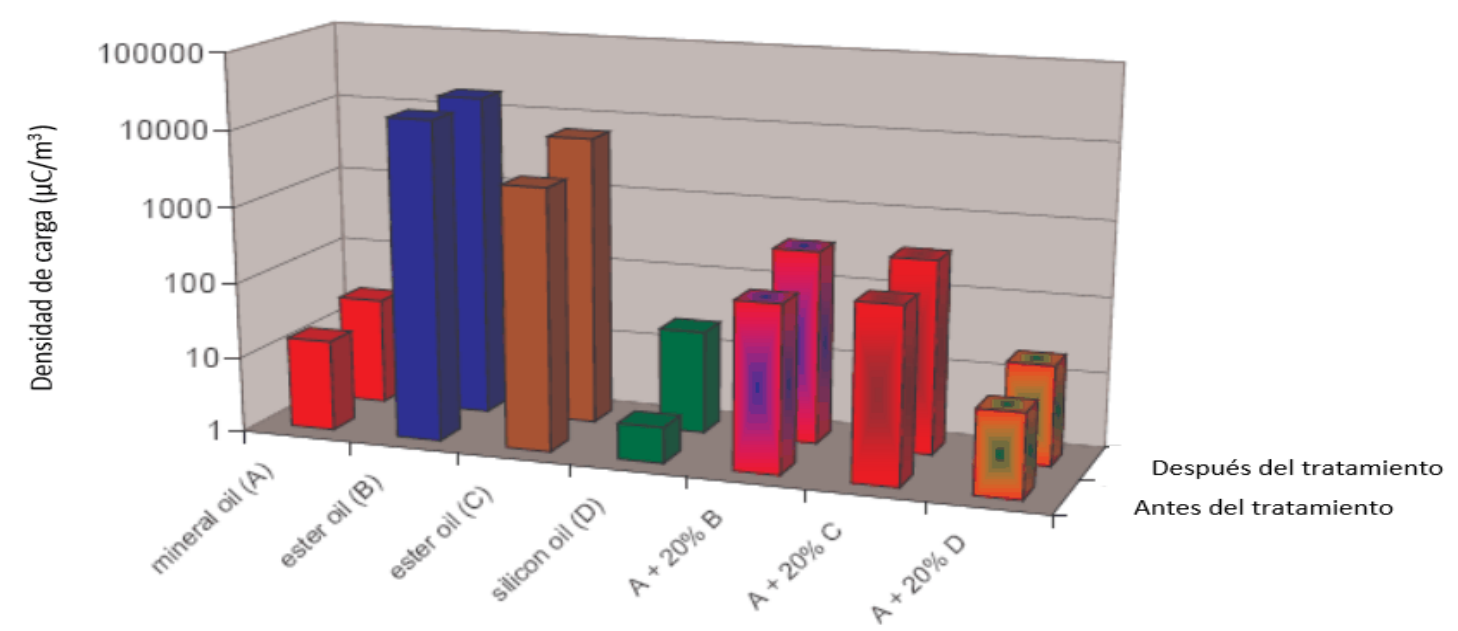

Figura 34: ETC en función de la naturaleza del aceite y de su contenido en agua

Como último punto a tratar dentro de este capítulo, sería conveniente hacer una pequeña relación entre los procesos de electrificación y los parámetros característicos del aceite.

Se sabe que los procesos de electrificación que sufre un transformador por dentro son transferencia de carga, separación de carga y relajación de carga, mientras que ECT, factor de disipación y resistividad específica son parámetros característicos del aceite aislante. A continuación se indican las relaciones entre todos estos procesos:

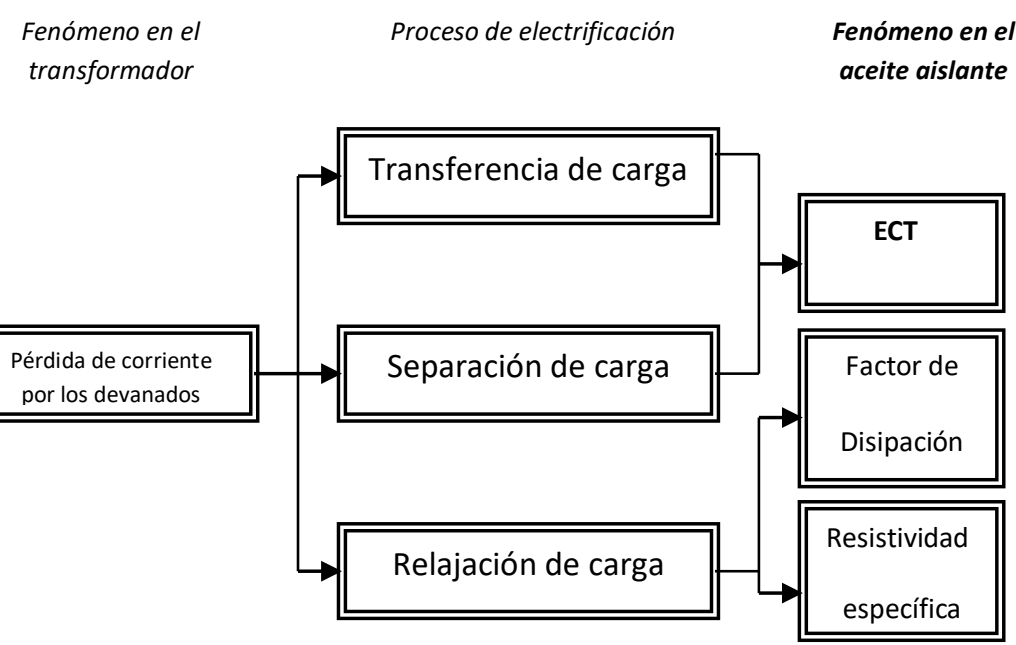

Figura 35: Relación de procesos de electrificación del transformador y del aceite aislante 
Como se tiene conocimiento, la transferencia de carga y la separación de carga generan electricidad estática y esta puede ser evaluada a través de una medida de ECT. También se sabe de la relación mutua entre el factor de disipación $(\operatorname{tg} \delta)$ y la transferencia de carga, lo que da lugar a poder realizar medidas de las pérdidas de corriente en los devanados en transformadores de alto voltaje. Pero hay un inconveniente, y es que dichas medidas no pueden realizarse con el transformador energizado. Por lo tanto, se usan las medidas de ECT y factor de disipación como medidas indirectas para la diagnosis de transformadores.

Cabe concluir por tanto que la faceta de electrificación debe ser considerada al estudiar los nuevos dieléctricos teniendo en cuenta las variables mencionadas, es decir considerar al menos el tipo y dosis de pasivante, humedad y grado de envejecimiento.

\subsubsection{Miscibilidad y compatibilidad}

Investigar estas facetas, y en este caso la miscibilidad, es de interés en el caso de los aceites de transformadores por razones diversas:

- Por cuanto un fluido puede ser diseñado por mezcla de diversos fluidos. Por ejemplo, de ésteres de distinto origen ya que puede ser necesario para modificar una propiedad deficiente, abaratarlo, etc, o incluso ser necesario para ajustar el producto a una especificación concreta: por ejemplo cuando una de las materias es de cierta variabilidad en viscosimetría (vegetal) y se requiere un mayor o menor porcentaje de otro éster para ajustarla.

- También porque, en ocasiones, un fluido podría ser empleado en operaciones de relleno de un transformador que contiene otro de naturaleza distinta ("retrofilling"). En este caso podría considerarse por ejemplo la situación de rellenar con éster un transformador que operase con aceite mineral.

En la literatura [14] se reflejan estudios de mezclas de aceite mineral con ésteres en porcentajes que suelen llegar al $50 \%$, y se analizan como parámetros de investigación la saturación con agua, $\operatorname{tg} \delta$, constante dieléctrica, rigidez dieléctrica, viscosidad, etc. 
El grado de saturación con agua se considera de gran importancia, ya que los ésteres presentan elevada higroscopicidad, que puede ser incluso 40 veces mayor que la de los aceites minerales. Se comentará en el apartado dedicado a la celulosa cómo gracias a esta higroscopicidad se reduce el contenido en agua del aislamiento sólido debido a la difusión de ésta desde el sólido al líquido sin mermar de propiedades dieléctricas del aislante. En las figuras siguientes [15] se indican los límites de saturación de un aceite mineral, un éster y sus mezclas en función de la temperatura:

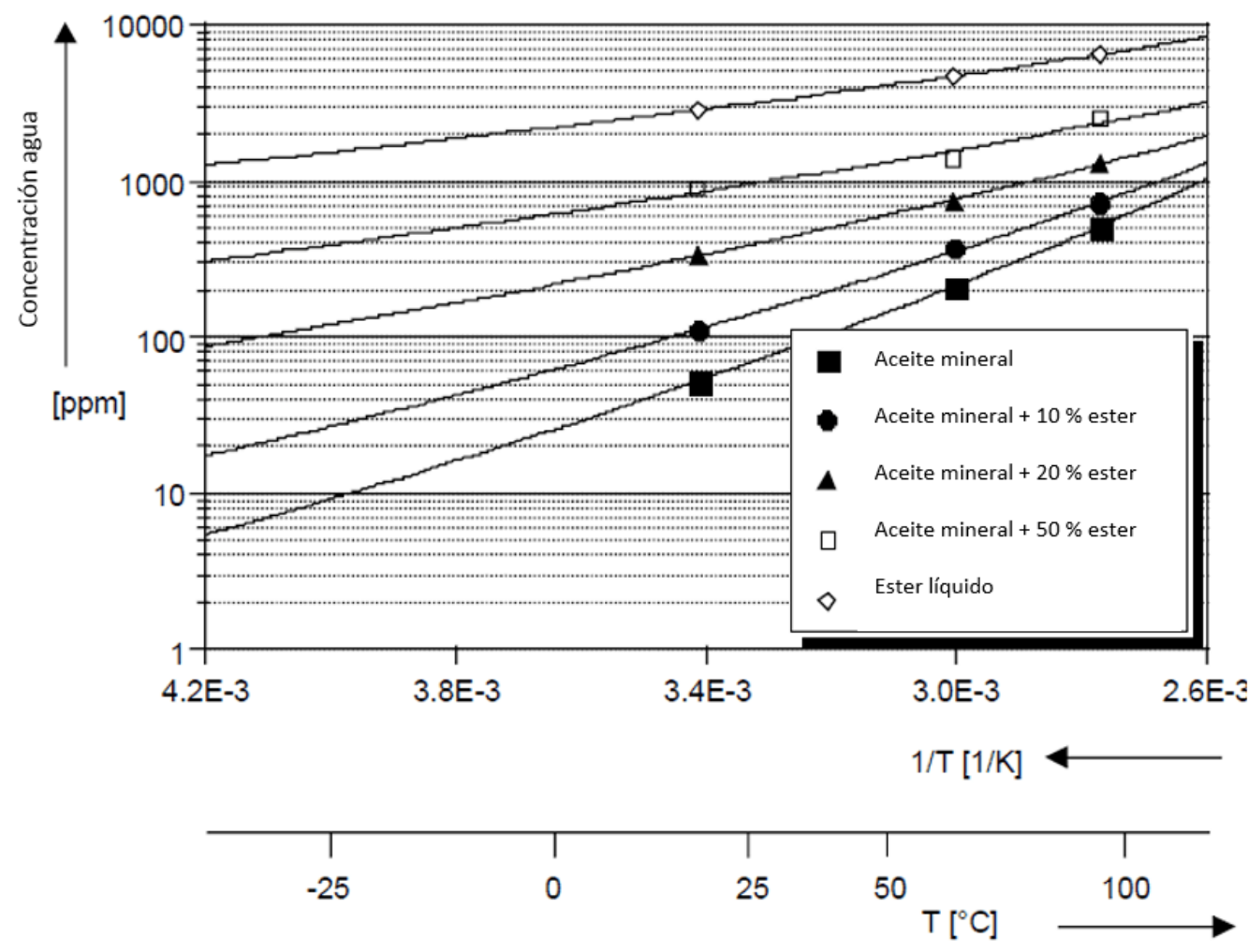

Figura 36: Saturación de agua en función de la temperatura 


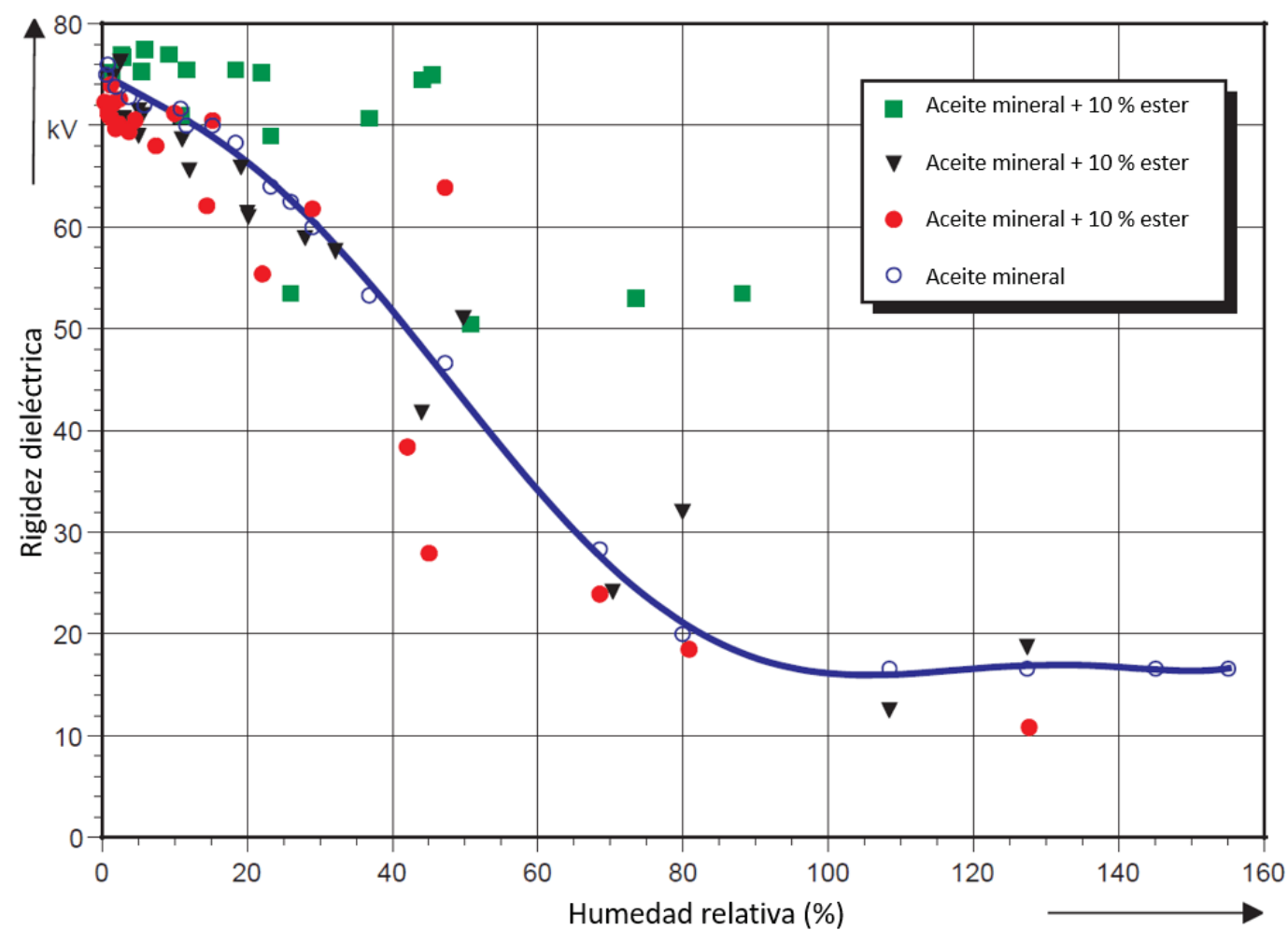

Figura 37: Rigidez dieléctrica en función del contenido en agua

En cuanto a la compatibilidad debe señalarse que las juntas juegan un papel fundamental en el sellado de transformadores y sus materiales pueden ser más o menos sensibles a los aceites dieléctricos. Suelen emplearse materiales elásticos que evitan la contaminación del fluido, que han de soportar contracciones y expansiones, vibraciones, cambios térmicos etc. es decir una importante función que no debe ser alterada por contacto con el fluido aislante. La mayor parte de la información sobre compatibilidad proviene de trabajos realizados con aceites minerales y es práctica habitual realizar estos ensayos en el desarrollo de cualquier fluido dieléctrico con los materiales empleados en la construcción del transformador y no sólo las juntas sino con el conjunto de éstos. Si se tiene en cuenta que los ésteres poseen un mayor poder disolvente que los aceites minerales, la compatibilidad debe ser objeto de un completo estudio. No se ha localizado en este caso información específica para fluidos dieléctricos de este tipo con materiales de transformador, pero con carácter genérico que algunos materiales tales cauchos nitrílicos de polipropileno, vinílicos y Tygon pueden ser vulnerables en mayor o menor medida. A nivel de ejemplo se indica en la tabla 14 un resumen de compatibilidad de oleato de metilo con diversos materiales: 
Tabla 14: Compatibilidad de diferentes elastómeros con oleato de metilo

\begin{tabular}{l|c}
\hline Elastómero & $\begin{array}{c}\text { Clasificación de } \\
\text { compatibilidad }\end{array}$ \\
\hline Nitrilo NBR & 4 \\
Nitrilo hidrogenado HNBR & 4 \\
Copo. Etileno-Propileno EPDM & 2 \\
Fluorocarbono FKM & 1 \\
Hifluor FKM & 1 \\
Perfluoroelastómero FFKM & 1 \\
Aflas (TFE/Propileno) FEPM & $\mathrm{X}$ \\
Neopreno/cloropreno CR & 4 \\
Estireno-butadieno SBR & 4 \\
Poliacrilato ACM & $\mathrm{X}$ \\
Poliuretano EU & $\mathrm{X}$ \\
Butilo IIR & 2 \\
Butadieno BR & 4 \\
Isopreno IR & $\mathrm{X}$ \\
Caucho natural NR & 4 \\
Hypalon CSM & 4 \\
Fluorosiliconas FVMQ & 2 \\
Silicona MQ & $\mathrm{X}$ \\
\hline
\end{tabular}

1.- Satisfactorio

2.- Favorable (pasa para juntas estáticas)

3.- Dudoso (a veces pasa para juntas estáticas)

4.-No satisfactorio

X.- Datos insuficientes 


\subsection{BINOMIO PAPEL/ACEITE DENTRO DEL TRANSFORMADOR}

El conocimiento de la vida remanente de los transformadores, especialmente los de potencia, es un factor decisivo para gestionar el riesgo asociado a la fiabilidad de la red de transmisión eléctrica. La evaluación de la vida de estos equipos tiene relación con su proceso de envejecimiento, ya que la máquina está expuesta a demandas térmicas, mecánicas y eléctricas en mayor o menor grado. Por ello, la evaluación de la condición en que se encuentra un transformador mediante métodos de supervisión, en y fuera de línea, es una estrategia clave en el mantenimiento de los equipos y la red.

En general, los transformadores de potencia son diseñados para un mínimo de 25 años de vida para temperaturas de operación entre 60 y $95^{\circ} \mathrm{C}$.

El papel impregnado de aceite dieléctrico es el medio más utilizado en el aislamiento de los devanados y ésta es la razón por la que en la industria eléctrica rige la premisa de que "La vida del papel es la vida del transformador". Sin embargo, este tipo de aislamiento es el eslabón más débil en la cadena de transmisión de energía.

El aislamiento papel/aceite se degrada con el tiempo, y el proceso depende de las demandas térmicas y eléctricas, de la presencia y cantidad de agua y oxígeno, así como fallos externos, sobretensiones, etc. La degradación del papel acaba en fallos que pueden ser encontrados en causas diversas:

- El papel puede romperse y salir fuera de los devanados bloqueando los pasos de aceite impidiendo la circulación y consiguiente refrigeración.

- El agua procedente de la degradación del papel y la ingresada del exterior puede fijarse superficialmente al papel reduciendo su resistividad.

- Una carbonización local del papel puede incrementar la conductividad eléctrica y causar sobrecalentamientos o fallos.

El aislante sólido (papel, cartón prensado, algodón etc....) utilizado en transformadores está hecho de celulosa, y su principal fuente es la madera. En condición seca, la madera contiene del orden de un 40-50\% de celulosa, $20-30 \%$ de lignina y $10-30 \%$ de hemicelulosa y polisacáridos. 
La celulosa es un polímero lineal compuesto de moléculas de glucosa unidas por enlace $\beta(1 \rightarrow 4)$ a través de un enlace glicosídico, tal y como se indica en la estructura siguiente:
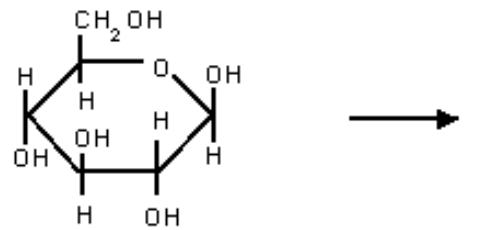

Figura 38: Estructura química de la celulosa

Los papeles aislantes, también llamados Kraft, están disponibles en el mercado en una amplia variedad de formas y de grados de polimerización según el tratamiento especial dado al papel para el uso específico al que se dedique. Por ejemplo, el papel recubierto con resina epoxi a uno o ambos lados para mejorar su resistencia a la temperatura, o los papeles mejorados térmicamente como Permacel (GEE) o Insuldur (Westinghouse).

Los papeles mejorados térmicamente se fabrican por modificación de las cadenas de celulosa haciendo reaccionar los grupos $\mathrm{OH}$ por acetilación o ciano-acetilación o bien por incorporación de estabilizantes (aminas, dicianoamidas) para inhibir la formación de agua. El papel se considera térmicamente mejorado si cumple el criterio de vida establecido en 50\% retención de TS (Resistencia a la Tracción) después de 65.000 h a $110^{\circ} \mathrm{C}$ en tubo sellado o cualquier otro valor Tiempo/Temperatura dado por la Guía IEEE C57.100.

El cartón prensado se fabrica a partir de láminas contiguas de papel sometidas a presión y temperatura. Tanto el papel como el cartón absorben bien al aceite y debido a su bajo precio y facilidad de fabricación pueden considerarse materiales idóneos para esta aplicación.

Al número de unidades de monómero de $\beta$-glucosa en el polímero de celulosa es conocido como Grado de Polimerización $\left(D P_{v}\right)$ y muy frecuentemente, éste es medido por el método viscosimétrico descrito en la norma ASTM D 4243 [16].

En cualquier caso, el valor de $\mathrm{DP}_{\mathrm{v}}$ está críticamente relacionado con la rigidez mecánica del papel. Debe tenerse en cuenta que, durante la fabricación del papel, el $\mathrm{DP}_{\mathrm{v}}$ se 
encuentra entre 1000 - 1300 aproximadamente, el secado del transformador lo reduce a $950-1000$ y el envejecimiento en servicio lo reduce todavía más.

Para un $\mathrm{DP}_{\mathrm{v}}$ entre 950 - 500 la rigidez mecánica, $T S$ es aproximadamente constante, pero en el margen 500 - 200 el valor de TS decrece en proporción directa a su $\mathrm{DP}_{\mathrm{v}}$. Para un valor de $\mathrm{DP}_{\mathrm{v}}$ aproximado de 150 , la rigidez mecánica se reduce a un $20 \%$ de su valor original y por debajo de esta cifra el papel no tiene rigidez mecánica alguna, por lo que en la industria se considera que debajo de un $\mathrm{DP}_{\mathrm{v}}$ igual a 200 , el papel ha perdido sus propiedades mecánicas y el equipo es susceptible de daños.

El método viscosimétrico de determinación del $\mathrm{DP}_{\mathrm{v}}$ está descrito en las normas ASTM D 4243 [16] y EN-60450 [17] y consiste en determinar la viscosidad específica $(V S)$ de una disolución de papel en Cuen (disolución $1 \mathrm{~mol} / \mathrm{l}$ de hidróxido de bis-etilendiamina de cobre II) y a partir de ésta se deduce la viscosidad intrínseca $(V)$, mediante la cual se calcula el grado de polimerización mediante las ecuaciones descritas en el procedimiento (ver diferencias entre las viscosidades en la normativa citada).

El artículo [18] es un interesante trabajo sobre el procedimiento analítico, consideraciones sobre el método y precauciones a tener en cuenta en esta determinación relativamente delicada.

De acuerdo con la literatura, la humedad, el nivel de oxígeno y la temperatura afectan al DP y por consiguiente a la vida del equipo. Los aceites minerales y los esteres naturales o sintéticos responden de forma diferente por lo que un conocimiento de la compatibilidad de los nuevos fluidos a desarrollar con papel debe ser un ejercicio necesario, en el que será también fundamental el conocimiento de las mencionadas variables a nivel comparativo.

Debe tenerse precaución en la extrapolación de resultados para cualquiera de los modelos que pudiera utilizarse en el estudio de la compatibilidad y por ende el envejecimiento de transformadores. La experiencia descrita en la literatura con fluidos dieléctricos minerales utilizando los métodos clásicos Lockie Test (IEEE C57.91-1999) y de Tubo sellado (IEC 354) han proporcionado datos interesantes muy apreciados en el sector acerca de estimaciones de la vida del transformador a partir de datos de DP. 


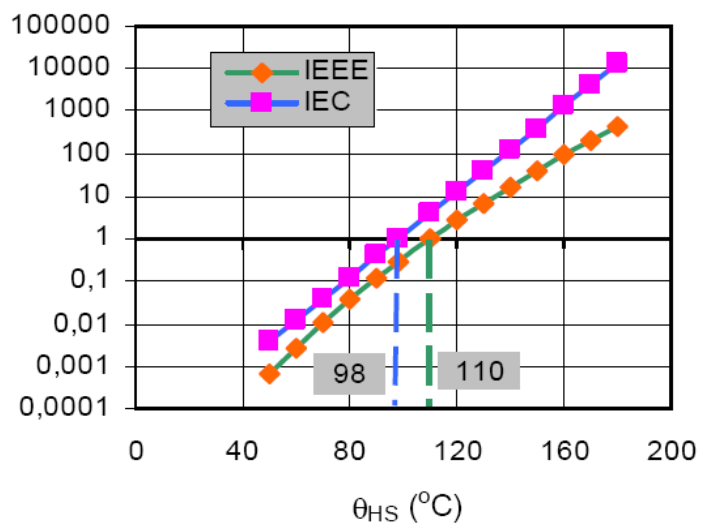

Figura 39: Temperatura del punto caliente $(\boldsymbol{\theta H} \boldsymbol{S})$

Lo mismo ocurre con el modelo Dual [19] en el que se sugiere también que el final de la vida de los sistemas de aislamiento de Kraft mejorado térmicamente son próximos a los indicados en la Guía IEEE C57.91-1999. Ésta proporciona una vida del aislamiento de 180.000 horas para una temperatura de punto caliente de $110{ }^{\circ} \mathrm{C}$, en contraste con la vida de 65.000 horas cuando se realiza el estudio en tubo sellado. Un valor de DP igual a 200 correlaciona bien con el $50 \%$ de reducción de resistencia a la tracción y ésta a su vez está en concordancia con lo indicado en la citada Guía IEEE.

La causa primaria de la degradación del papel y en general el envejecimiento de éste sigue la cinética de la ley de Arrhenius, pudiendo tomarse como índice que cada $10{ }^{\circ} \mathrm{C}$ de elevación de la temperatura, la vida del papel se reduce a la mitad.

El efecto del agua en el envejecimiento es muy significativo y la velocidad de degradación es directamente proporcional al contenido de ésta. Por ejemplo, decreciendo el contenido de agua en el papel de $1 \%$ a $0,5 \%$, se duplica la vida de éste. Tal y como se dijo al principio, el Kraft mejorado térmicamente es menos sensible a los efectos del agua.

El oxígeno influye también en la degradación de la celulosa aunque no en la misma medida que sobre el aceite. Se ha sugerido que las consecuencias de una concentración alta de $\mathrm{O}_{2}$, comparadas a las de un bajo nivel de éste, pueden ser del orden de 2,5 a 1 sobre el envejecimiento del papel. 
La degradación de las moléculas de celulosa se traduce en formación de gases, principalmente monóxido y dióxido de carbono, así como glucosa lo que finalmente se traduce en la generación de compuestos furánicos. Existe abundante literatura que trata este tema a efectos de medir la concentración de estos compuestos relacionándola con el DP de la celulosa. Existen correlaciones en base a datos de laboratorio y transformadores en servicio. Una de ellas es la indicada a continuación para Kraft no mejorado térmicamente:

$$
\log _{10}(2 F A L)=1,51-0,0035 \cdot D P v
$$

Donde 2FAL es la concentración de 2-furfural y $\mathbf{D P}_{\mathbf{v}}$ es el grado de polimerización medio viscosimétrico. Para los casos de papel mejorado térmicamente la ecuación anterior se transformaría en:

$$
\log _{10}(2 F A L)=1,5655-0,0035 \cdot D P v
$$

(Ecuación 22)

Se indica en la figura 40 un ejemplo típico de correlación en transformadores:

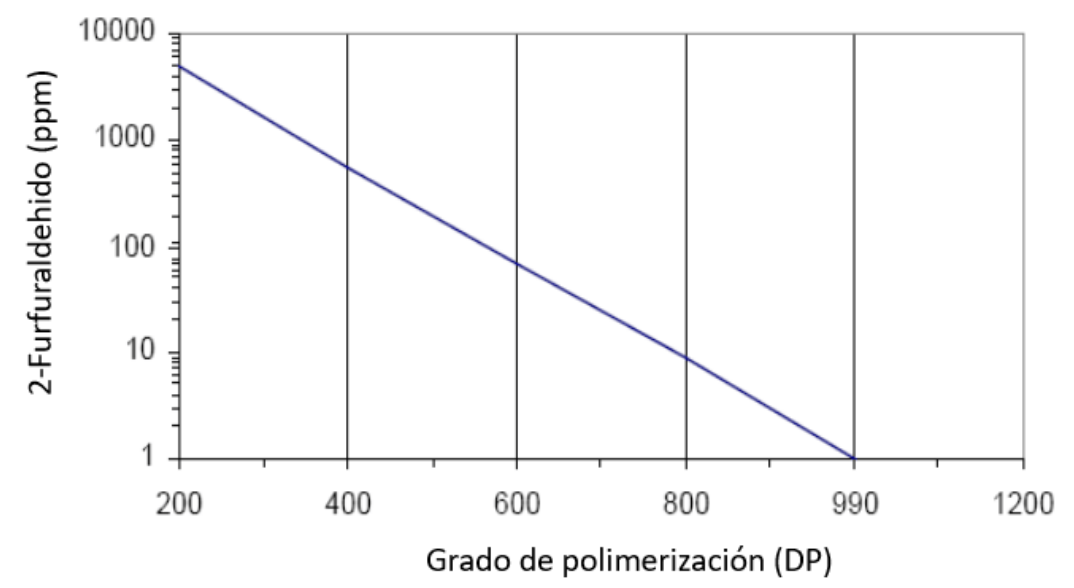

Figura 40: Correlación entre el grado de polimerización y el contenido en furfuraldehido

Trabajos recientes de Siemens [20] han demostrado que aunque se asume que la temperatura es el factor más importante del envejecimiento, la humedad ejerce una mayor influencia que aquella cuando se trata de transformadores de respiración libre en condiciones normales de servicio $\left(75-95^{\circ} \mathrm{H}_{\mathrm{R}}\right)$, ya que el mecanismo hidrolítico de 
degradación del aislamiento sólido requiere una menor energía de activación que el mecanismo pirolítico por el que también se forma 2-furfural.

El mecanismo pirolítico de formación de furanos ocurre a temperaturas superiores a $130^{\circ} \mathrm{C}$ y es el más importante para el caso de puntos calientes anormales en el transformador. Este fenómeno parece ocurrir a través de la formación de levo-glucosano y ha sido relativamente bien investigado.

El mecanismo hidrolítico transcurre según el siguiente mecanismo:

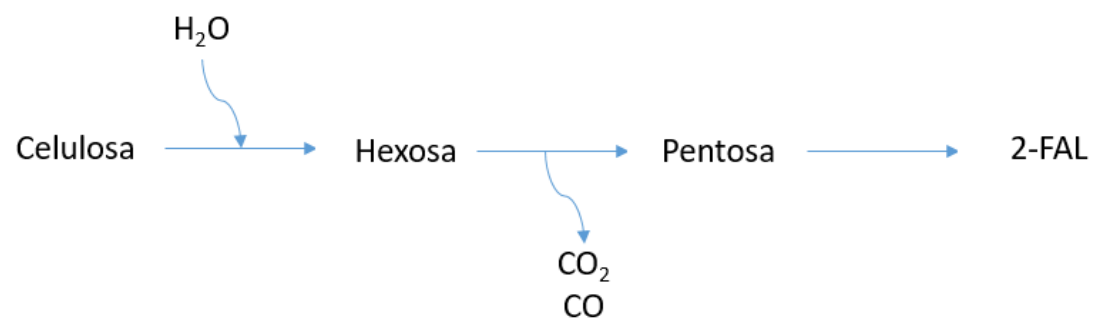

Figura 41: Mecanismo de degradación hidrolítica de la celulosa

En condiciones ácidas, la hexosa (glucosa) produce 2-Hidroxi-Metil-Furfural (2-HMF), que puede a su vez degradarse según el esquema siguiente:

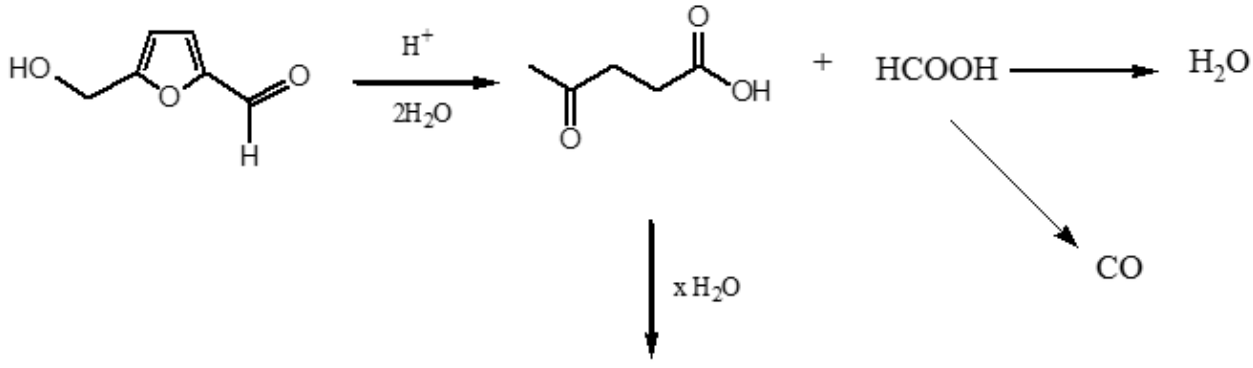

Polímero ácido marrón

Figura 42: Mecanismo de degradación ácida del 2-HMF 
En este caso la experimentación se llevó a cabo en matraces de vidrio con cartón prensado de diferente grado de humedad con tapón de plástico en estufas de temperatura controlada a 75 y $95^{\circ} \mathrm{C}$ simulando la condición de un transformador de respiración libre. Con muestras de cartón de diferente contenido en agua y un aceite nafténico, se determinó la humedad en el cartón, el DP y variación de compuestos furánicos a lo largo de 12 meses siguiendo normas IEC.

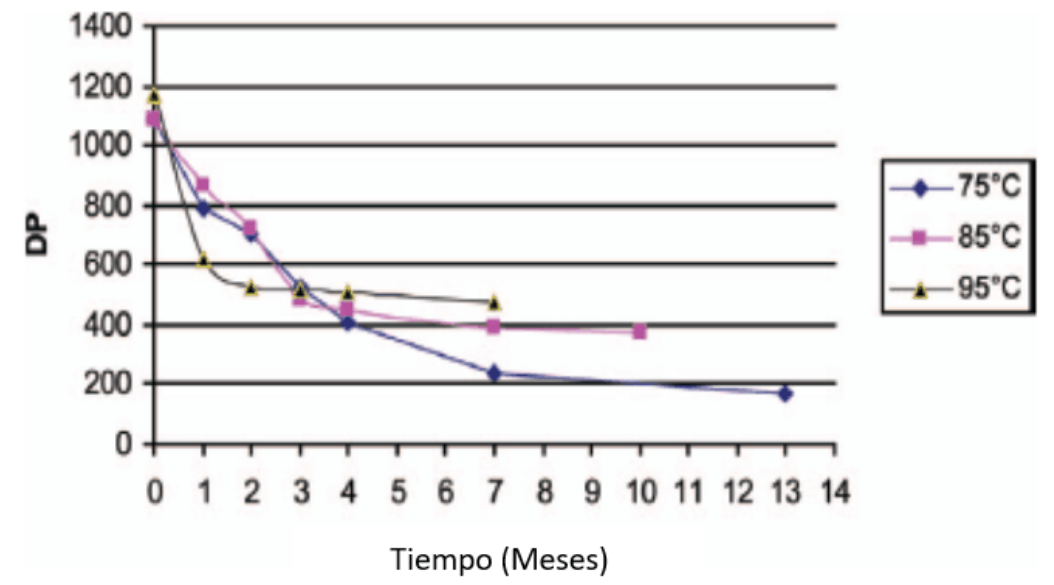

Figura 43: Variación del grado de polimerización en función de la temperatura

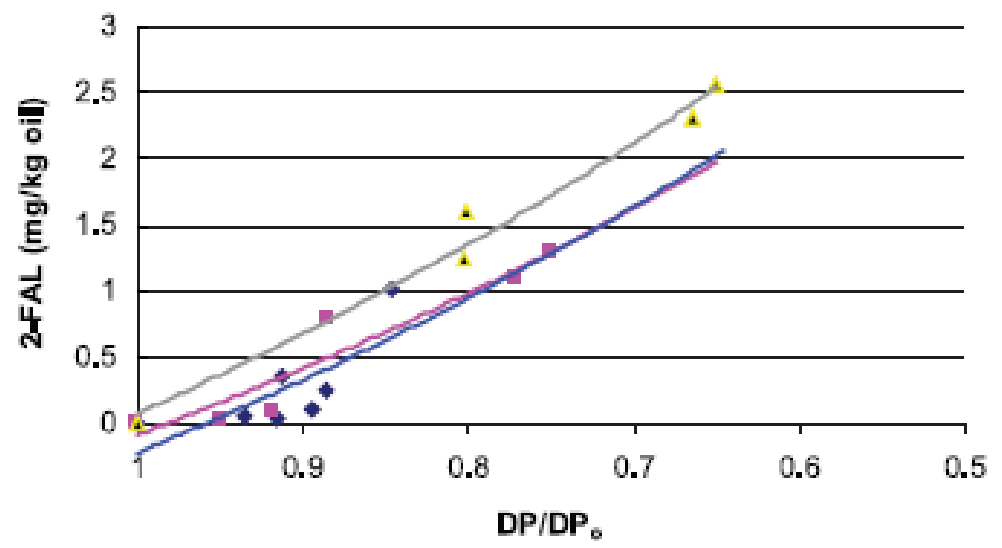

Figura 44: Variación del grado de polimerización con el contenido en 2-FAL 
Algunos artículos describen la metodología para controlar el nivel de humedad en el papel para poder realizar con mayor seguridad la experimentación sobre la influencia de esta variable [21]. A continuación se indica el tipo de recipiente utilizado.

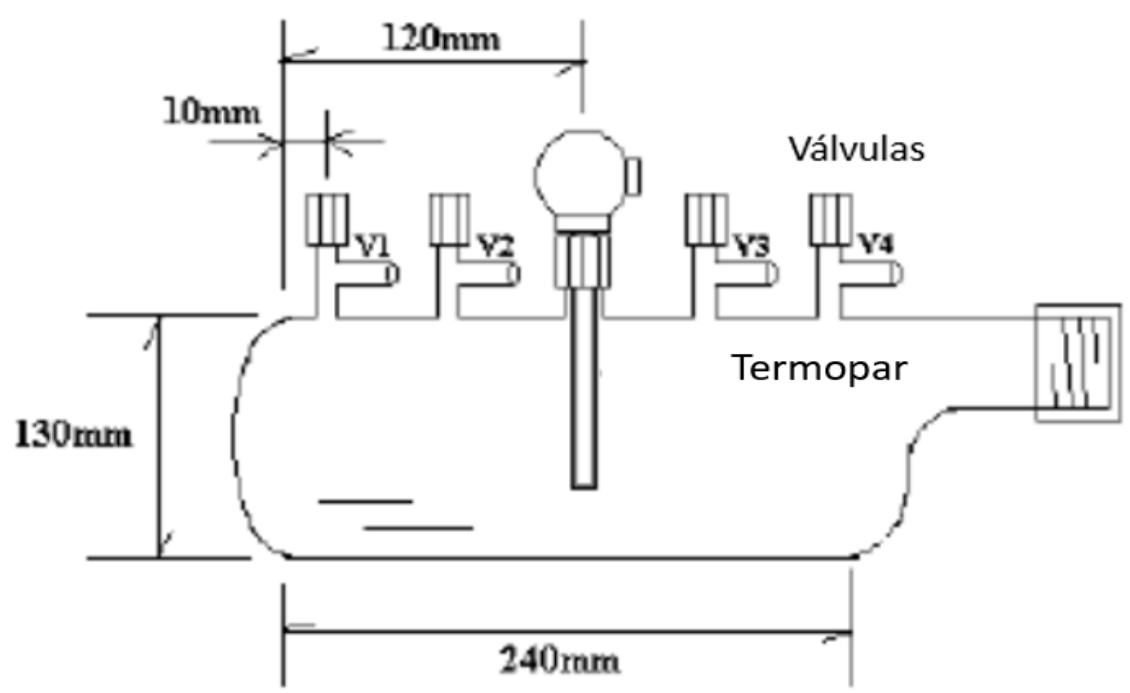

Figura 45: Equipo diseñado para mantener una humedad constante de valor conocido

Las curvas de partición de humedad en el papel son de utilidad para conocer las condiciones de equilibrio entre aceite y papel. Para el caso de los aceites minerales estas curvas son bien conocidas y cuando el transformador está en equilibrio, proporcionan una información rápida para estimar el contenido de agua del papel a partir del análisis de esta en el aceite. Con esta información y las guías de carga se puede obtener una estimación interesante de la vida residual del transformador o potencialidad de fallos por degradación del papel. Algunas de las gráficas típicas son la de Oommen, donde la línea continua corresponde a las curvas de adsorción de agua y las discontinuas a las de desorción: 


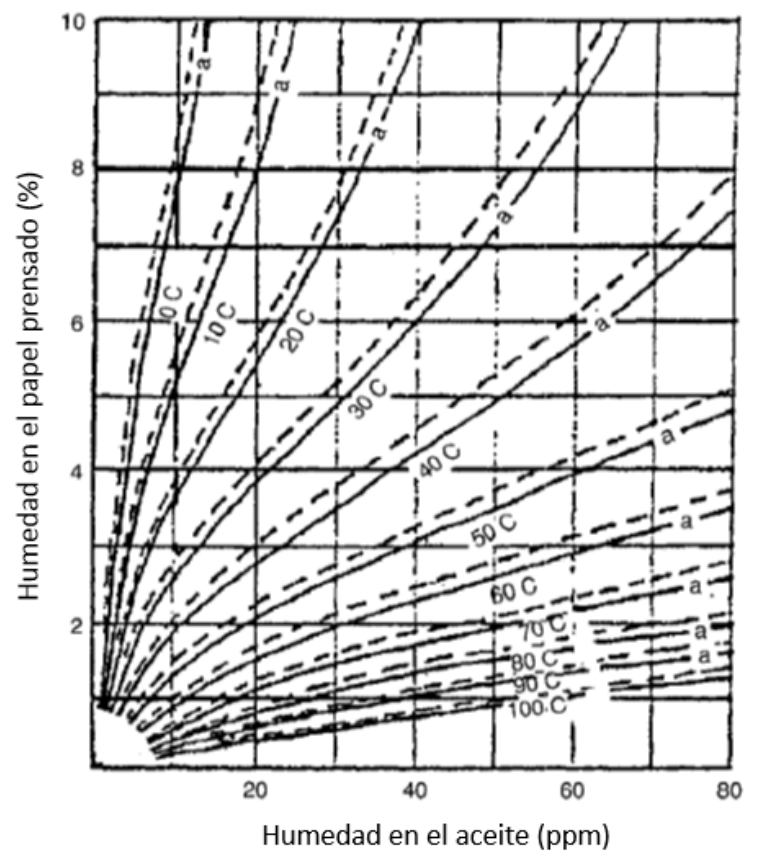

Figura 46: Distribución de agua en el binomio papel/aceite en función de la temperatura

Se explica por tanto la importancia que van a jugar las variables de temperatura, humedad y tiempo cuando se utilicen fluidos dieléctricos tipo éster. En este sentido, los trabajos de Cooper Power Systems [22] son una interesante referencia para comparar este tipo de productos con los aceites minerales. Bajo el punto de vista del papel, los autores concluyen que el Kraft mejorado térmicamente envejece de forma mucho más lenta en el éster que en el aceite mineral: el éster tarda unas 5-8 veces más de tiempo para llegar a su punto final de vida a $170^{\circ} \mathrm{C}$ y unas 2,5 veces a unos $110^{\circ} \mathrm{C}$.

Esto, en teoría al menos, debería permitir temperaturas de operación más altas en el transformador o niveles de sobrecarga más elevadas que las mencionadas en las citadas guías IEEE e IEC.

Como mecanismo proponen que la mejora en el envejecimiento térmico de la celulosa en éster natural es el resultado de dos formas de protección: que el agua es capturada por el éster ya que éste puede retener mucha mayor concentración hasta la saturación que los aceites minerales (1000 ppm frente a $60 \mathrm{ppm}$ ) y ya se ha comentado la influencia que esta ejerce en la degradación. La segunda forma sería por protección hidrolítica, es decir, debido a las reacciones de transesterificación entre los grupos éster 
y los $\mathrm{OH}$ de la celulosa. De esta última forma, grupos voluminosos moleculares del éster estabilizarían la molécula aumentando su resistencia térmica.

Un trabajo de corte similar para estudio de aceites minerales fue realizado por Nynas [4] con su aceite nafténico $11 \mathrm{EN}$ pero aditivado para el estudio con $0,3 \%$ wt. de $B H T$ (Butilhidroxitolueno) y $25 \mathrm{ppm}$ de benzotriazol. El aceite fue ensayado en viales sellados a la llama en una progresión de temperaturas hasta $180^{\circ} \mathrm{C}$ y realizando sobre las muestras de aceite análisis de gases y compuestos furánicos y sobre el papel, su valor de $\mathrm{DP}_{\mathrm{v}}$. Utilizaron como catalizador hilo plano de cobre con arrollamiento de papel.

No observaron 2-FAL hasta que la temperatura alcanzó $130{ }^{\circ} \mathrm{C}$ aunque la despolimerización del papel empezó a $\operatorname{los} 120^{\circ} \mathrm{C}$. Se detectó también 5-Hidroxi-MetilFurfural (5-HMF). La correlación entre 2-FAL y 5-HMF y el valor $\mathrm{DP}_{\mathrm{v}}$ del papel indicaron que la producción de furánicos no comenzó hasta alcanzar un valor de $\mathrm{DP}_{\mathrm{v}}$ aproximadamente de 450. Se encontró también que los contenidos en compuestos furánicos en el papel eran de unas 150 veces mayor que el analizado en el aceite, lo que sugiere que los coeficientes de partición de estos compuestos entre papel y aceite son mucho más favorables al papel, aunque esta absorción se va desplazando hacia el aceite a medida que aumenta la temperatura.

De este trabajo cabe deducir que los coeficientes de partición de los furanos pueden diferir bastante al emplear ésteres en lugar de aceites minerales y, que en un análisis en servicio, al valorar el 2-FAL, las tablas de diagnosis basadas en aceites minerales pudiesen dar lugar a conclusiones erróneas.

En la bibliografía y normas la mayor parte de los estudios de degradación de celulosa han sido realizados tomando como base medidas de viscosidad para determinar el grado de ruptura molecular y consecuentemente el DP del material. Sin embargo, estos valores no siempre reflejan una panorámica clara del proceso, ya que la celulosa es una mezcla compleja de diferentes polímeros con una distribución relativamente amplia de sus pesos moleculares. Se ha comprobado que las medidas por cromatografía GPC (Gel Permeation Chromatography) son más precisas para el seguimiento de este proceso al proporcionar no sólo el peso molecular sino también la distribución de éstos. En la referencia [23] se hace mención a esta técnica, estudiándose el proceso de degradación 
de muestras de papel Kraft sumergidos en aceite a diferentes temperaturas y tiempos. Se emplearon para este trabajo ampollas de vidrio, que tras su desgasificado fueron selladas al vacío.

La figura 47 muestra los cromatogramas para papeles nuevos y envejecidos indicando claramente la utilidad de la técnica analítica:

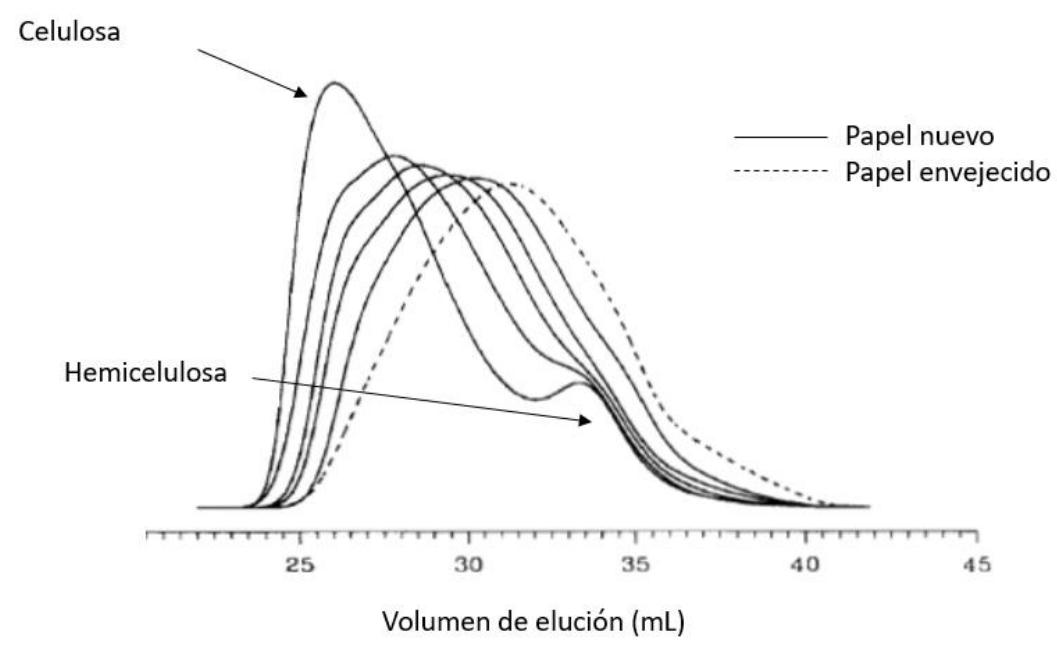

Figura 47: Distribución de pesos moleculares de celulosa nueva y envejecida térmicamente

Se indican también cálculos para determinar el número de cadenas de polímeros en función del tiempo de degradación, así como cálculos de la velocidad de rotura en ausencia de humedad:

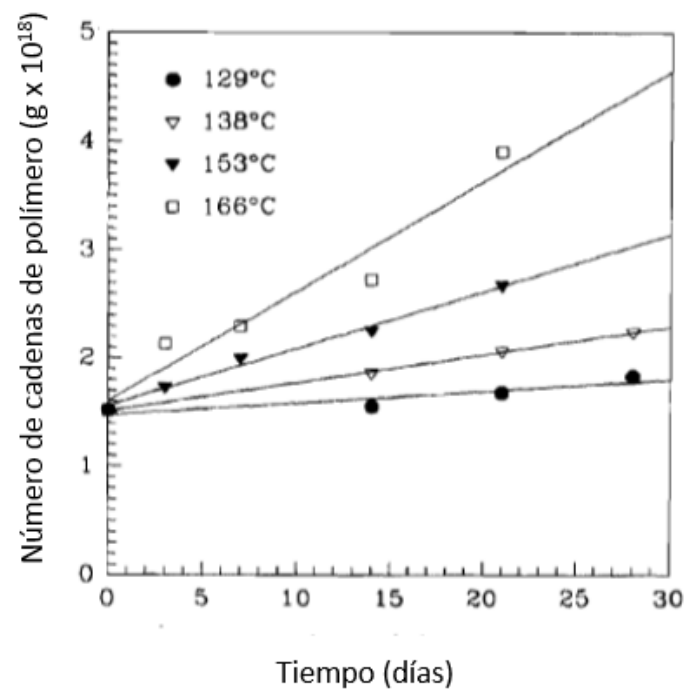

Figura 48: Isotermas de degradación de las cadenas de polímero 
Los mismos autores, utilizando el mismo tipo de experimentación [24], realizaron en paralelo estudios de evolución de la Resistencia a la Tracción (TS) según ASTM D202, y habiendo tratado los papeles conforme a la norma ASTM D685 y TAPPI T402. Encontraron interesantes relaciones entre DP y TS tal y como se indica en la figura 49, pero especialmente con el número de cadenas del polímero de celulosa en los procesos de envejecimiento:
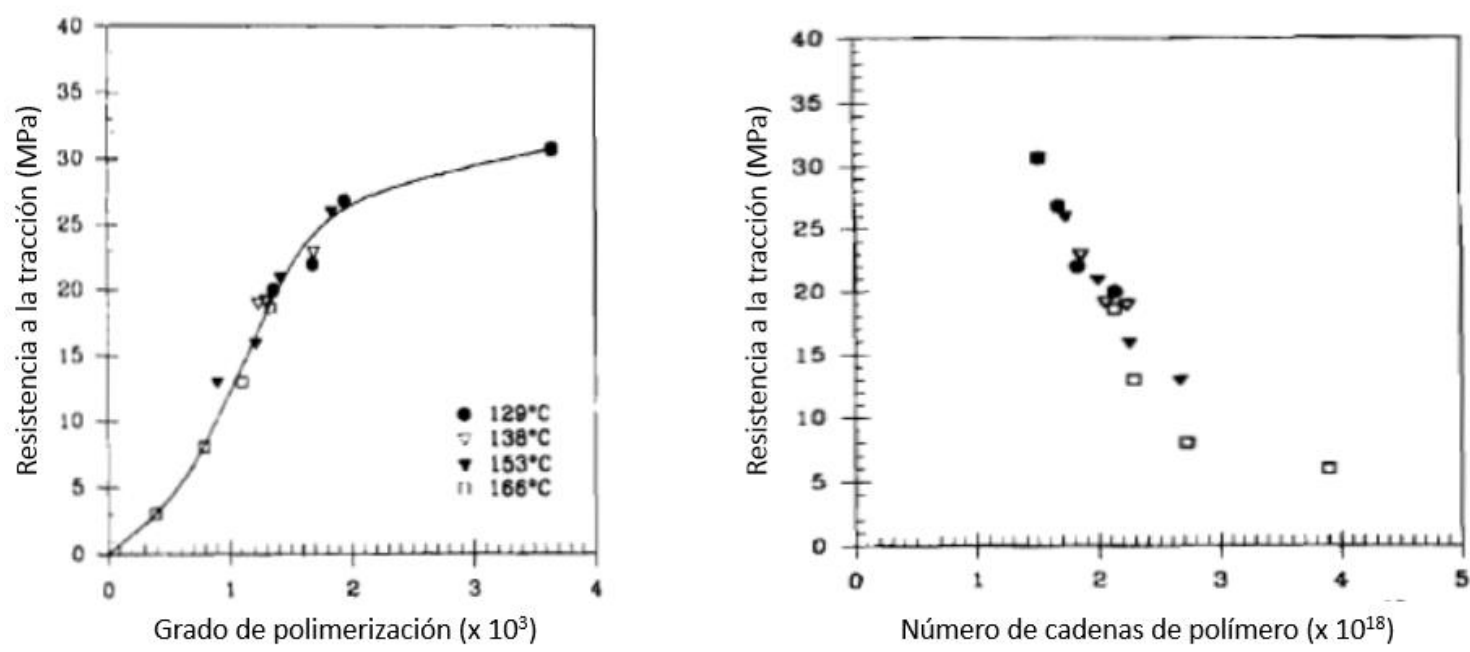

Figura 49: TS frente al DP y al número de cadenas de polímero de celulosa

En este trabajo [24] utilizaron para el envejecimiento acelerado un conductor plano de cobre envuelto en papel aislante en forma parecida a las experiencias de Nynas. Después de desgasificar y secar el aceite y las muestras de conductor, los especímenes se introdujeron en ampollas de vidrio que fueron posteriormente sellados al vacío. Las experiencias se realizaron a diferentes temperaturas y tiempos. Debe señalarse aquí que este tipo de probetas de conductor envuelto en cobre son utilizadas también para ensayos de corrosión. Respecto al efecto del oxígeno, aunque ya se mencionó anteriormente, no hay mucha información respecto a su influencia y casi siempre ha sido estudiado en forma conjunta al del agua. En la serie de artículos [25-28] se hace mención a este factor concluyendo que existen interacciones antagonistas entre el oxígeno y el agua con la temperatura, con el resultado de una reducción de la velocidad de envejecimiento a bajos niveles de agua y bajas temperaturas $\left(120^{\circ} \mathrm{C}\right)$ cuando la 
concentración de oxígeno en el aceite aumenta desde 400 ppm a $1 \%(\mathrm{~m} / \mathrm{m})$. Los autores observaron que tanto el agua como el oxígeno incrementan la velocidad de formación 2FAL, pero el agua era más efectiva.

Se podrían extraer algunos comentarios sobre este apartado bajo el punto de vista de la compatibilidad éster o aceite mineral frente al papel:

- El equilibrio del agua es diferente en la celulosa frente ambos tipos de fluidos

- Parámetros como DP ó TS podrían verse afectados de forma muy diferente en función del tiempo

- El coeficiente de partición del 2-FAL para las fases papel-fluido podrían ser distintos y en consecuencia la metodología de diagnosis de aceites en servicio

- La técnica de GPC será de importancia cada vez mayor por su precisión, simpleza y emplear menores cantidades de muestra

- La utilización de conductores de cobre envueltos en papel está ganando en importancia para ensayar la compatibilidad de fluidos con celulosa

- Nuevas técnicas de análisis del papel nuevo o degradado por IR ó por DRX y microscopia electrónica de barrido para ver la integridad y tamaño de las fibras de papel

- Escasas referencias a la degradación del NOMEX ${ }^{(1)}$ en presencia de ésteres.

(1) Sustituto del papel de celulosa fabricado con fibras de poliaramida para aplicaciones a alta temperatura (Ej. $240^{\circ} \mathrm{C}$ en conductor, $130^{\circ} \mathrm{C}$ en aceite) [29] 


\subsection{ESPECIFICACIONES TÉCNICAS DE LOS ACEITES DIELÉCTRICOS Y SU LEGISLACIÓN.}

Los aceites dieléctricos, como hemos visto, juegan un papel fundamental en el buen funcionamiento y tiempo de vida útil de un transformador. No es de extrañar entonces que estos fluidos estén altamente regulados por especificaciones internacionales estrictas en cuanto a las prestaciones que debe de cumplir en servicio. Es por ello que el Comité Internacional de Electrotecnia (IEC) haya publicado unas especificaciones para este tipo de fluidos.

En dichas especificaciones, aparecen los límites mínimos y máximos que debe de cumplir el aceite después de ser cargado en la cuba del transformador y antes de ser energizado el transformador. Debido al elevado número de aceites dieléctricos presentes en el mercado y a sus diferentes naturalezas químicas, IEC ha elaborado una especificación para aceites dieléctricos de origen mineral, otra para los aceites dieléctricos de origen vegetal y unas últimas para los aceites dieléctricos a base de ésteres sintéticos.

\subsubsection{Especificaciones para aceites dieléctricos de origen mineral}

Tabla 15: Especificaciones para aceites de origen mineral

\begin{tabular}{|c|c|c|}
\hline Propiedad & Normativa & Límites \\
\hline \multicolumn{3}{|l|}{ 1.- Funcional } \\
\hline Viscosidad cinemática a $40^{\circ} \mathrm{C}$ & ASTM D 445 & Max. $12 \mathrm{~mm}^{2} / \mathrm{s}$ \\
\hline Viscosidad cinemática a $-30{ }^{\circ} \mathrm{C}$ & ASTM D 445 & Max. $1800 \mathrm{~mm}^{2} / \mathrm{s}$ \\
\hline Punto de congelación & ASTM D 97 & Max. $-40^{\circ} \mathrm{C}$ \\
\hline Contenido en agua & IEC 60814 & Max. 30 mg/kg (ppm) \\
\hline Rigidez dieléctrica & IEC 60156 & Min. $30 \mathrm{kV}$ \\
\hline Densidad a $20{ }^{\circ} \mathrm{C}$ & ASTM D 4052 & Max. $0,895 \mathrm{~g} / \mathrm{cm}^{3}$ \\
\hline Tangente $\delta$ a $90^{\circ} \mathrm{C}, 50 \mathrm{~Hz}$ & IEC 60247 & Max. 0,005 \\
\hline \multicolumn{3}{|c|}{ 2.- Estabilidad/grado de refino } \\
\hline Apariencia & - & Libre de sedimentos y material en suspensión \\
\hline Acidez & ASTM D 974 & Max. 0,01 mg KOH/g \\
\hline Tensión interfacial & ISO 6295 & Según fabricante \\
\hline
\end{tabular}




\begin{tabular}{|c|c|c|}
\hline Contenido total de azufre & ISO 14596 & Según fabricante \\
\hline Azufre corrosivo & DIN 51353 & No corrosivo \\
\hline Aditivos antioxidantes & IEC 60666 & Aceites inhibidos: $0,08-0,40 \% \mathrm{wt}$. \\
\hline Contenido en 2-furfural & IEC 61198 & Máx. $0,1 \mathrm{mg} / \mathrm{kg}$ \\
\hline \multicolumn{3}{|l|}{ 3.- Rendimiento } \\
\hline $\begin{array}{l}\text { Estabilidad a la oxidación } \\
\text { - Acidez total } \\
\text { - Lodos } \\
\text { - Tangente } \delta \text { a } 90^{\circ} \mathrm{C}\end{array}$ & IEC 61125 (met.C) & $\begin{array}{l}\text { Duración test: } 164 \text { horas } \\
\text { Max. } 1,2 \mathrm{mg} \mathrm{KOH} / \mathrm{g} \\
\text { Max. } 0,8 \% \\
\text { Max. } 0,5\end{array}$ \\
\hline \multicolumn{3}{|l|}{ 4.- Salud y medioambiente } \\
\hline Punto de inflamación & ASTM D 92 & Min. $135^{\circ} \mathrm{C}$ \\
\hline Contenido en PCA & BS 2000 Part 346 & Máx. 3 \% wt. \\
\hline Contenido en PCB & IEC 61619 & No detectado \\
\hline
\end{tabular}

Actualmente, existe una guía de mantenimiento de aceites de transformador en operación: la IEC 60422 [30]

\subsubsection{Especificaciones para aceites dieléctricos de origen vegetal}

Tabla 16: Especificaciones para aceites de origen vegetal

\begin{tabular}{|l|c|c|}
\hline \multicolumn{1}{|c|}{ Propiedad } & Normativa & Límites \\
\hline 1.- Físicas & ASTM D 445 & Max. $50 \mathrm{~mm}^{2} / \mathrm{s}$ \\
\hline Viscosidad cinemática a $40^{\circ} \mathrm{C}$ & ASTM D 445 & Max. $500 \mathrm{~mm}^{2} / \mathrm{s}$ \\
\hline Viscosidad cinemática a $0{ }^{\circ} \mathrm{C}$ & ASTM D 97 & Max. $-10^{\circ} \mathrm{C}$ \\
\hline Punto de congelación & IEC 60814 & Max. $200 \mathrm{mg} / \mathrm{kg}(\mathrm{ppm})$ \\
\hline Contenido en agua & IEC 60156 & Min. $30 \mathrm{kV}$ \\
\hline Rigidez dieléctrica & ASTM D 4052 & Max. $0,960 \mathrm{~g} / \mathrm{cm}^{3}$ \\
\hline Densidad a $15^{\circ} \mathrm{C}$ & IEC 60247 & Max. 0,2 \\
\hline Tangente $\delta$ a $90^{\circ} \mathrm{C}, 50 \mathrm{~Hz}$ & - & Libre de sedimentos y material en suspensión \\
\hline 2.- Estabilidad/grado de refino & ASTM D 974 & Max. 0,06 mg KOH/g \\
\hline Apariencia & \multicolumn{2}{|c|}{} \\
\hline Acidez &
\end{tabular}




\begin{tabular}{|c|c|c|}
\hline Azufre corrosivo & DIN 51353 & No corrosivo \\
\hline \multicolumn{3}{|l|}{ 3.- Salud y medioambiente } \\
\hline Punto de inflamación & ASTM D 92 & Min. $275^{\circ} \mathrm{C}$ \\
\hline Punto de combustión & ASTM D 92 & Min. $300^{\circ} \mathrm{C}$ \\
\hline Contenido en PCB & IEC 61619 & No detectado \\
\hline \multicolumn{3}{|c|}{ 4.- Información para el diseño del transformador } \\
\hline Coeficiente de expansión & ASTM D 1903 & 0,0007 a $0,0008{ }^{\circ} \mathrm{C}^{-1}$ \\
\hline Constante dieléctrica, $25^{\circ} \mathrm{C}$ & ASTM D 924 & 3,1 a 3,3 \\
\hline Calor específico, $20^{\circ} \mathrm{C}$ & ASTM D 2766 & 0,45 a $0,60 \mathrm{cal} / \mathrm{g}$ \\
\hline Conductividad térmica & ASTM D 2717 & $0,00045 \mathrm{cal} / \mathrm{cm} . \mathrm{s} .{ }^{\circ} \mathrm{C}$ \\
\hline
\end{tabular}

Con respecto al ensayo de estabilidad a la oxidación según IEC 61125 método C, después de haber participado en Round Robin Test con otros países de la Unión Europea, se llegó a la conclusión de que el tiempo de ensayo debería ser solo de 48 horas debido a que a las 164 horas se produce la polimerización del aceite dieléctrico vegetal y los valores de repetibilidad y reproducibilidad no eran buenos.

\subsubsection{Significado de los ensayos citados en las especificaciones}

El significado de cada uno de los parámetros especificados en la tabla superior se muestra a continuación:

- Viscosidad cinemática. Es un importante factor en el control de la disipación del calor. El envejecimiento y la oxidación del aceite tienden a incrementar la viscosidad. La temperatura también afecta a la viscosidad. El envejecimiento y oxidación normales del aceite no afectarán significativamente la viscosidad. Esto puede suceder si el aceite está bajo condiciones extremas de descargas tipo corona u oxidación.

- Punto de congelación. Es una medida de la capacidad del aceite para fluir a baja temperatura. No existen evidencias que sugieran que esta propiedad se vea afectada durante el deterioro normal del aceite. Los cambios en el punto de congelación pueden normalmente interpretarse como resultado del rellenado con un tipo diferente de aceite. 
- Contenido en agua. Dependiendo de la cantidad de agua, la temperatura del sistema de aislamiento y el estado del aceite, el contenido en agua del aceite aislante influye en:

○ La rigidez dieléctrica del aceite

○ El aislamiento sólido

○ La tendencia al envejecimiento del líquido y del aislamiento sólido

El contenido en agua del aislamiento líquido y sólido tiene, por tanto, un impacto significativo en las condiciones reales y en la vida útil del transformador.

- Rigidez dieléctrica. La rigidez dieléctrica es una medida de la capacidad del aceite para soportar solicitaciones eléctricas. La medida de la rigidez dieléctrica sirve principalmente para indicar la presencia de contaminantes como agua o partículas. Un bajo valor de rigidez dieléctrica puede indicar que uno o más de estos contaminantes están presentes. Sin embargo, un valor elevado de rigidez dieléctrica no indica necesariamente la ausencia de todo contaminante.

- Densidad. La densidad puede ser útil para identificar el tipo de aceite. En climas fríos, la densidad del aceite puede ser importante para determinar la idoneidad de su uso. Por ejemplo, los cristales de hielo formados a partir de agua libre pueden flotar en aceites de alta densidad y conducir a contorneamiento durante la posterior fusión. Sin embargo, la densidad no es significativa para comparar la calidad de diferentes muestras de aceite. No existen evidencias de que la densidad se vea afectada por el deterioro normal del aceite.

- Factor de pérdidas dieléctricas $(F P D, \operatorname{tg} \delta$ ). Este parámetro es muy sensible a la presencia de contaminantes polares solubles, productos de envejecimiento o coloides en el aceite. Se pueden controlar los cambios en los niveles de contaminantes midiendo este parámetro incluso cuando la contaminación es tan ligera que está cerca del límite de detección química. Puede obtenerse información adicional útil midiendo la tangente del ángulo de pérdidas tanto a temperatura ambiente como a una temperatura más elevada como $90{ }^{\circ} \mathrm{C}$. En el caso de transformadores de medida de muy alta tensión $(>400 \mathrm{kV})$, debe 
prestarse especial atención a la tan $\delta$ pues se ha descrito que elevados valores pueden conducir a embalamientos térmicos con fallo del transformador.

- Aspecto y color. El color de un aceite aislante se expresa con un número obtenido por comparación con una serie de colores normalizados. No es una propiedad crítica, pero puede ser útil para una evaluación comparativa. Un incremento rápido o un número de color elevado pueden indicar degradación o contaminación del aceite. Además del color, al aspecto del aceite puede mostrar turbidez o sedimentos que pueden indicar la presencia de agua libre, lodos insolubles, carbón, fibras u otros contaminantes.

- Acidez. La acidez o índice de neutralización del aceite es una medida de los constituyentes o contaminantes ácidos del aceite. La acidez de un aceite usado se debe a la formación de productos de oxidación ácidos. Los ácidos y otros productos de oxidación, junto con el agua y los contaminantes sólidos, afectarán las propiedades dieléctricas y otras del aceite. Los ácidos tienen impacto en la degradación de los materiales celulósicos y también pueden ser responsables de corrosión de partes metálicas del transformador. La velocidad de incremento de la acidez de un aceite en servicio es un buen indicador de la velocidad de envejecimiento.

- Azufre corrosivo. El azufre está presente en aceites refinados formando moléculas que contienen azufre. La cantidad depende de los procesos de refino del aceite, el grado de refino y el tipo de crudo. Debido a un pobre refino, a contaminación o a las condiciones de trabajo del propio transformador, estas moléculas se pueden descomponer dando lugar a especies que pueden provocar corrosión a las temperaturas de trabajo.

- Punto de inflamación. La rotura del aceite causada por descargas eléctricas o por exposición prolongada a muy altas temperaturas puede producir cantidades suficientes de hidrocarburos de bajo peso molecular para reducir el punto de inflamación del aceite. Un bajo punto de inflamación puede indicar la presencia de productos combustibles volátiles en el aceite. Esto puede deberse a contaminación con un disolvente pero, en algunas ocasiones, se ha observado que la causa eran chispas eléctricas. 
- Tensión interfacial. La tensión interfacial entre el aceite y al agua proporciona un medio para detectar contaminantes polares solubles y productos de degradación. Esta característica cambia muy rápidamente durante las etapas iniciales del envejecimiento pero se estabiliza cuando el deterioro es todavía moderado. Un rápido descenso de la tensión interfacial puede también indicar problemas de compatibilidad entre el aceite y algunos materiales del transformador (barnices, juntas), o una contaminación accidental durante el llenado del transformador con el aceite.

- Contenido en inhibidor. Los aditivos más comúnmente utilizados en aceites aislantes son 2,6-ditercbutil-p-cresol (DBPC) y 2,6-ditercbutil-fenol (DBP).

Los aceites inhibidos tienen una forma de oxidación diferente a la de los aceites no inhibidos. Al principio de su vida en servicio, se consume el inhibidor sintético con escasa formación de productos de oxidación. Esto se conoce como periodo de inducción. Una vez que se ha consumido el inhibidor, la velocidad de oxidación está determinada, principalmente, por la estabilidad a la oxidación del aceite base.

- Derivados furánicos. El análisis de derivados furánicos es una herramienta muy útil para determinar el envejecimiento del aislamiento celulósico. Este análisis se realiza según lo estipulado en el método B de la norma UNE EN 61198.

- Estabilidad a la oxidación. Se denomina estabilidad a la oxidación a la capacidad del aceite mineral aislante eléctrico para resistir a la oxidación bajo solicitaciones térmicas y en presencia de oxígeno y un catalizador de cobre. Proporciona información general acerca de la esperanza de vida del aceite en las condiciones de servicio en equipos eléctricos. IEC define esta propiedad como la resistencia a la formación de compuestos ácidos, lodos y compuestos que influyen en el Factor de Disipación Dieléctrica bajo ciertas condiciones.

- Compatibilidad de aceites aislantes. Para rellenar el transformador o mantener niveles, se debe utilizar un aceite que cumpla con la norma IEC 60296 y sea del mismo tipo. Los aceites no usados, que sean conformes con dicha norma y que no contengan o contengan los mismos aditivos, se consideran compatibles entre 
sí y pueden mezclarse en todas los proporciones. La experiencia de campo indica que, normalmente, no se observan problemas cuando se añade un pequeño porcentaje, por ejemplo un $5 \%(\mathrm{~m} / \mathrm{m})$ de un aceite no usado a aceites usados clasificados como "buenos", aunque adiciones superiores a aceites fuertemente envejecidos puede ocasionar la precipitación de lodos. En estos casos, puede ser necesario realizar un ensayo de compatibilidad para determinar la viabilidad de las mezclas de aceites no usados de diferentes orígenes, con aceite en servicio.

- Recuento de partículas. La presencia de partículas en el aceite aislante de equipos eléctricos puede tener diferentes orígenes. El propio equipo puede contener partículas del proceso de fabricación y el aceite puede contener partículas de su almacenamiento y manipulación, si no se filtra adecuadamente. El desgaste y el envejecimiento del aceite y materiales sólidos pueden producir partículas durante la vida en servicio del equipo. Calentamientos localizados por encima de los $500{ }^{\circ} \mathrm{C}$ pueden formar partículas de carbón. Las partículas de carbón producidas en el conmutador del cambiador de tomas en carga pueden migrar por fugas a la cuba principal y contaminar los componentes sumergidos en aceite del transformador. Una fuente típica de partículas metálicas es el desgaste de los cojinetes de las bombas.

\subsection{ACEITES SINTÉTICOS}

\subsubsection{La problemática de los bifenilos policlorados (PCB)}

Los $\boldsymbol{P C B}$ o bifenilos policlorados son una serie de compuestos organoclorados que constituyen una serie de 209 isómeros, los cuales se forman mediante la cloración de diferentes posiciones del bifenilo, 10 en total.

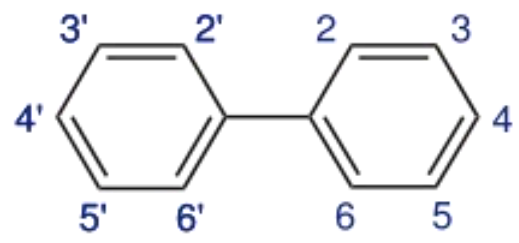

Figura 50: Estructura química de una molécula de bifenilo 
Cada posición puede ser sustituida por un átomo de cloro. Si las posiciones 2,2',6 y 6' no tienen ningún cloro, los bifenilos se mantienen coplanares hablando por tanto de PCB's coplanares o no-orto. Si tenemos una posición sustituida en cada lado, son PCB's mono-orto sustituidos, y el resto son los PCB's no coplanares. Su fórmula empírica es $\mathrm{C}_{12} \mathrm{H}_{10-\mathrm{n}} \mathrm{Cl}_{\mathrm{n}}$, donde $\mathrm{n}$ puede variar entre 1 y 10 , siendo mayoritarios los isómeros con 2 a 7 cloros.

Los PCB's coplanares tienen importancia medioambiental y analítica debido a su toxicidad, parecida a la de las dibenzodioxinas policloradas (PCDD) y dibenzofuranos policlorados (PCDF), posiblemente debido a la coplanaridad de la molécula.

Las propiedades fisicoquímicas de estos compuestos dependen del grado de cloración y de si son no-orto, mono-orto o no coplanares. Así, la presión de vapor disminuye con el grado de cloración, y lo mismo con su estabilidad en el medio ambiente. El periodo de semivida puede variar desde 10 días a un año y medio; por lo general estos compuestos son termoestables, no los ataca la luz y son difícilmente biodegradables.

La primera síntesis de PCB's fue realizada por Schmitt-Schulz en Alemania en 1881, iniciándose su producción a nivel industrial por la empresa Monsanto en 1929. El máximo de producción tuvo lugar a final de la década de 1970, con unas 610.000 toneladas anuales estimadas.

Las principales aplicaciones de estos compuestos son como intercambiadores de calor y fluidos dieléctricos en sistemas eléctricos, como transformadores o estaciones rectificadoras. En principio, estos compuestos fueron bienvenidos debido a su alta estabilidad térmica y a su baja inflamabilidad, por lo cual su uso se fue extendiendo.

A partir de varias investigaciones, los fabricantes de PCB's reconocieron su toxicidad ambiental, pero debido a la forma de uso y sus aplicaciones industriales, reconocieron además la imposibilidad práctica de controlar las emisiones al medio ambiente de estos productos. Debido a esto, los PCB's se encuentran hoy ampliamente difundidos en el medio ambiente, ya sea por vertido directo a partir de industrias que los utilizan o por combustión y vertido a ríos y aguas marinas de desechos contaminados. 
Debido a su amplia difusión ambiental, se han encontrado PCB's en diferentes productos como leche y sus derivados, tejido adiposo (humano y animal) y otros órganos con contenido graso como el cerebro y el hígado.

\subsubsection{Efectos biológicos}

Las principales vías de ingestión de PCB's en los humanos son la inhalación y la alimentación, sobre todo en alimentos propensos a estar contaminados como pescados y mariscos y en otros productos hidrobiológicos, ya que estos desechos poseen gran adhesión en el agua y los animales.

Inhalación: Debido a la baja presión de vapor de estos compuestos (Presión de vapor: $0,2-1.33 \times 10^{-3} \mathrm{~Pa}$ ), sólo un $25 \%$ aproximadamente del total ingerido es por esta vía.

- Cadena alimenticia: La entrada en la cadena alimenticia se da en el mar, cuando el plancton puede asimilar PCB's desde los sedimentos marinos. Como ocurre con la mayoría de contaminantes, mediante el proceso de bioamplificación o biomagnificación se va incrementando la concentración de PCB's a lo largo de la cadena alimenticia (plancton, marisco, pescado pequeño, mamíferos marinos), y usualmente el hombre, al ser el último de la cadena, es el que recibe mayores cantidades de PCB's. Debido al origen marino, la principal fuente de ingestión de PCB's en la dieta humana es el pescado en general y especialmente el expuesto a mayores concentraciones, el cual puede llegar a ser el 4-5\% del total.

Los PCB's, una vez ingeridos, se acumulan principalmente en tejidos ricos en lípidos, como puede ser el tejido adiposo, el cerebro, hígado, etc. Se produce una transferencia de la madre al feto durante la gestación, y esta contaminación del feto puede dar lugar a una ralentización del neurodesarrollo y afectar a la función tiroidea al situarse en receptores específicos para estas hormonas. Se especula con la posibilidad de efectos adversos incluso en niveles no tóxicos para el resto de la población adulta.

El grado de toxicidad de los PCB's es directamente proporcional al grado de cloración de la molécula, y dentro de esta escala los PCB's coplanares son más tóxicos que sus congéneres no coplanares, como se indica en la tabla 17, donde PCB's coplanares con 
menos átomos de cloro (126 y 169) son más tóxicos que un isómero no coplanar con 7 cloros (PCB 170).

Tabla 17: Factor de Equivalencia Tóxica (TEF) para algunos PCB's

\begin{tabular}{|l|c|c|}
\hline \multicolumn{3}{|c|}{ TEF según la OMS para algunos PCBs coplanares } \\
\hline PCB & Fórmula & TEF (OMS, 1994) \\
\hline PCB-77 & $3,3^{\prime}, 4,4^{\prime}$-Tetraclorobifenilo & 0,005 \\
\hline PCB-126 & $3,3^{\prime}, 4^{\prime}, 4^{\prime}, 5$-Pentaclorobifenilo & 0,1 \\
\hline PCB-169 & $3,3^{\prime}, 4^{\prime}, 4^{\prime}, 5,5^{\prime}$ '-Hexaclorobifenilo & 0,01 \\
\hline PCB-170 & $2,2^{\prime}, 3,3^{\prime}, 4,4^{\prime}, 5$-Heptaclorobifenilo & 0,00001 \\
\hline
\end{tabular}

Se define el TEF como el Toxic Equivalency Factor o Factor de Equivalencia Tóxica. Estos factores se refieren al compuesto de referencia 2,3,7,8-TCDD, una tetraclorodibenzodioxina. Un factor de toxicidad de, por ejemplo, 0,5 indica que para un determinado compuesto el efecto tóxico producido por $10 \mathrm{ng}$ es el mismo que el producido por $5 \mathrm{ng}$ de 2,3,7,8-TCDD.

Los síntomas derivados de una intoxicación por PCBs son náuseas, vómitos, pérdida de peso, dolores en el bajo vientre, incremento de secreciones oculares, ictericia, edemas, cansancio, pigmentación de las uñas, etc., además de efectos hepatotóxicos a medio y largo plazo. También se está investigando su relación con trastornos del desarrollo en niños expuestos a los PCB's de forma prenatal, con la observación de coeficientes de inteligencia menores frente a niños sometidos a menores niveles de PCB's. En la fauna los PCB's pueden producir carcinogénesis y efectos mutagénicos y teratogénicos (malformaciones del feto). En las plantas, los efectos se refieren principalmente a una disminución de la velocidad de la división celular y la fijación de $\mathrm{CO}_{2}$ en algas, además de una inhibición del crecimiento.

\subsubsection{Comportamiento medioambiental}

El carácter más volátil de los $\mathrm{PCB}$ 's permite su paso desde el suelo a la atmósfera, donde pueden volver otra vez al suelo o a la hidrosfera, o pasar a formar parte de la 
cadena alimenticia por inhalación. Su estabilidad permite que se difundan grandes distancias antes de ser asimilados o degradados.

- Hidrosfera: Los PCB's pueden llegar a la hidrosfera por solubilización de restos en sedimentos, excreción de organismos marinos y por deposición húmeda o seca desde la atmósfera.

- Atmósfera: Estos compuestos llegan a la atmósfera por evaporación desde el suelo en zonas contaminadas, donde pueden adherirse a la superficie de aerosoles y dispersarse o volver al suelo o a la hidrosfera. El grado de evaporación depende del tipo de suelo y de su humedad, normalmente a suelo más seco se evaporan más rápidamente.

- Suelo: Se acumulan en el humus debido a su carácter lipófilo, desde donde pueden movilizarse con dificultad hacia la atmósfera o el agua. Su persistencia aumenta con el grado de cloración.

Estos compuestos son muy estables, por lo que no son modificados químicamente por la acción de ácidos ni bases fuertes. En la atmósfera, pueden ser atacados por radicales hidroxilo dando lugar a compuestos de degradación, y si son irradiados con radiación UV de la longitud de onda adecuada, pueden perder sus cloros aumentando su velocidad de degradación.

Dentro de los productos de descomposición tenemos compuestos oxigenados (alcoholes), productos de desdoblamiento y clorobenzoatos. El final de la degradación es $\mathrm{HCl}$, agua y $\mathrm{CO}_{2}$. 


\subsection{ESTUDIO DE PATENTES}

Para la defensa de la presente tesis se han estudiado 89 patentes, de las cuales han resultado útiles $51 ; 28$, por el contrario, no han aportado información relevante pero también se han incluido en el informe de tesis. Finalmente, aproximadamente 10 no han sido incluidas por su antigüedad.

Tratamos de encontrar un fluido cuyas propiedades, si son antagónicas, lo sean en grado mínimo. El ejemplo de los hidrocarburos es bueno: su punto de inflamación (PI) y su punto de vertido (PP) dependen del peso molecular (PM), y si aumentamos el PM mejora el PI, pero empeora el PP. Y viceversa, ambas de forma muy acusada. Por tanto, interesan fluidos en los que la modificación de una propiedad no altere (empeore) drásticamente otra propiedad. Y en caso de que esto ocurra, debe existir un aditivo que contrarreste el efecto negativo.

\subsubsection{Lista de patentes consultadas}

ABB

\begin{tabular}{|l|l|l|}
\hline $\mathrm{N}$ & REFERENCIA & TíTULO \\
\hline 11 & US2006/030499 & $\begin{array}{l}\text { ELECTRICAL TRANSFORMER WITH VEGETABLE OIL DIELECTRIC } \\
\text { FLUID }\end{array}$ \\
\hline 34 & US-1999-5949017 & $\begin{array}{l}\text { ELECTRICAL TRANSFORMERS CONTAINING ELECTRICAL } \\
\text { INSULATION FLUIDS COMPRISING HIGH OLEIC ACID OIL } \\
\text { COMPOSITIONS }\end{array}$ \\
\hline 74 & US-2001-6312623 B1 & $\begin{array}{l}\text { HIGH OLEIC ACID OIL COMPOSITIONS AND METHODS OF } \\
\text { MAKING AND ELECTRICAL INSULATION FLUIDS AND DEVICES } \\
\text { COMPRISING THE SAME }\end{array}$ \\
\hline 77 & US-2006-0030499 A1 & $\begin{array}{l}\text { ELECTRICAL TRANSFORMER WITH VEGETABLE OIL DIELECTRIC } \\
\text { FLUID }\end{array}$ \\
\hline
\end{tabular}

CHEVRON

\begin{tabular}{|l|l|l|}
\hline N & REFERENCIA & TíTULO \\
\hline 59 & WO2006/060269 & DIELECTRIC FLUIDS AND PROCCESSES FOR MAKING SAME \\
\hline 42 & $\begin{array}{l}\text { US-2006-0113512 } \\
\text { A1 }\end{array}$ & DIELECTRIC FLUIDS AND PROCESSES FOR MAKING SAME. \\
\hline 80 & $\begin{array}{l}\text { WO-2006-060269 } \\
\text { A2 }\end{array}$ & DIELECTRIC FLUIDS AND PROCESSES FOR MAKING SAME \\
\hline
\end{tabular}




\section{COOPER}

\begin{tabular}{|l|l|l|}
\hline $\mathrm{N}$ & REFERENCIA & TíTULO \\
\hline 3 & US2003/0164479A1 & $\begin{array}{l}\text { DIELECTRIC FLUID HAVING DEFINED CHEMICAL COMPOSITION FOR } \\
\text { USE IN ELECTRICAL APPARATUS }\end{array}$ \\
\hline 4 & US2005/0040375A1 & $\begin{array}{l}\text { VEGETABLE OIL BASED DIELECTRIC FLUID AND METHODS OF USING } \\
\text { SAME }\end{array}$ \\
\hline 12 & WO2005/030679A2 & ADDITIVE FOR DIELECTRIC FLUID \\
\hline 28 & $\begin{array}{l}\text { EP-1992-0499359 } \\
\text { A1 }\end{array}$ & FIRE RESISTANT DIELECTRIC FLUID. \\
\hline 57 & US-1998-5766517 & DIELECTRIC FLUID FOR USE IN POWER DISTRIBUTION EQUIPMENT \\
\hline 37 & $\begin{array}{l}\text { US-2004-6726857 } \\
\text { B2 }\end{array}$ & $\begin{array}{l}\text { DIELECTRIC FLUID HAVING DEFINED CHEMICAL COMPOSITION FOR } \\
\text { USE IN ELECTRICAL APPARATUS. }\end{array}$ \\
\hline 40 & $\begin{array}{l}\text { US-2001-6184459 } \\
\text { B1 }\end{array}$ & VEGETABLE OIL BASED DIELECTRIC COOLANT \\
\hline 75 & $\begin{array}{l}\text { US-2002-6352655 } \\
\text { B1 }\end{array}$ & VEGETABLE OIL BASED DIELECTRIC FLUID \\
\hline 47 & $\begin{array}{l}\text { WO-2002-084673 } \\
\text { A1 }\end{array}$ & DIELECTRIC FLUID \\
\hline
\end{tabular}

EMHART INDUSTRIES

\begin{tabular}{|l|l|l|}
\hline $\mathrm{N}$ & REFERENCIA & TÍTULO \\
\hline 22 & US-1985-4538208 & ALTERNATING CURRENT CAPACITOR \\
\hline 24 & US-1987-4642731 & DIELECTRIC FLUID FOR A CAPACITOR \\
\hline
\end{tabular}

\section{ETHYL PETROLEUM ADDITIVES}

\begin{tabular}{|l|l|l|}
\hline $\mathbf{N}$ & REFERENCIA & TÍTULO \\
\hline 56 & EP-1998-1006173 A1 & LUBRICANT COMPOSITIONS EXHIBITING EXTENDED OXIDATION STABILITY. \\
\hline 50 & US-2006-0205615 A1 & $\begin{array}{l}\text { ADDITIVES AND LUBRICANT FORMULATIONS FOR IMPROVED } \\
\text { ANTIOXIDANT PROPERTIES. }\end{array}$ \\
\hline
\end{tabular}

\section{EXXON}

\begin{tabular}{|l|l|l|}
\hline $\mathrm{N}$ & REFERENCIA & TÍTULO \\
\hline 13 & EP1991/0458574A2 & $\begin{array}{l}\text { PROCESS FOR PRODUCING TRANSFORMER OIL FROM A } \\
\text { HYDROCRACKED STOCK }\end{array}$ \\
\hline 69 & US-1978-4124489 & $\begin{array}{l}\text { PRODUCTION OF TRANSFORMER OIL FEED STOCKS FROM WAXY } \\
\text { CRUDES }\end{array}$ \\
\hline 35 & US-2000-6083889 & $\begin{array}{l}\text { HIGH TEMPERATURE, HIGH EFFICIENCY ELECTRICAL AND } \\
\text { TRANSFORMER OIL }\end{array}$ \\
\hline
\end{tabular}

GENERAL ELECTRIC

\begin{tabular}{|l|l|l|}
\hline $\mathrm{N}$ & REFERENCIA & TÍTULO \\
\hline 64 & US1960/2922938 & $\begin{array}{l}\text { ELECTRIC CAPACITOR AND STABILIZED DIELECTRIC MATERIAL } \\
\text { THEREFOR }\end{array}$ \\
\hline
\end{tabular}




\begin{tabular}{|l|l|l|}
\hline 65 & US1974/3833978 & STABILIZED ESTER IMPREGNANT \\
\hline 67 & US-1975-3925221 & STABILIZED ESTER IMPREGNANT \\
\hline 30 & GB 2378320A & POWER CAPACITOR CONTAINING THIXOTROPIC DIELECTRIC FLUID. \\
\hline
\end{tabular}

MONSANTO

\begin{tabular}{|l|l|l|}
\hline $\mathrm{N}$ & REFERENCIA & TÍTULO \\
\hline 19 & US-1976-3948787 & $\begin{array}{l}\text { CAPACITOR AND DIELECTRIC IMPREGNANT COMPOSITION } \\
\text { THEREFOR }\end{array}$ \\
\hline
\end{tabular}

\section{NIPPON PETROCHEMICALS}

\begin{tabular}{|l|l|l|}
\hline $\mathrm{N}$ & REFERENCIA & TÍTULO \\
\hline 23 & US-1986-4621302 & $\begin{array}{l}\text { ELECTRICAL INSULATING OIL AND ELECTRICAL APPLIANCES } \\
\text { IMPREGANTED WITH THE SAME }\end{array}$ \\
\hline 26 & US-1991-5017733 & ELECTRICAL INSULATING OIL COMPOSITION. \\
\hline
\end{tabular}

\section{RENEWABLE LUBRICANTS}

\begin{tabular}{|l|l|l|}
\hline N & REFERENCIA & TíTULO \\
\hline 44 & WO-2006-116502 & $\begin{array}{l}\text { HIGH TEMPERATURE BIOBASED LUBRICANT COMPOSITIONS } \\
\text { COMPRISING BORON NITRIDE }\end{array}$ \\
\hline 58 & $\begin{array}{l}\text { US-2003-6534454 } \\
\text { B1 }\end{array}$ & BIODEGRADABLE VEGETABLE OIL COMPOSITIONS \\
\hline 49 & $\begin{array}{l}\text { WO-2005-026300 } \\
\text { A1 }\end{array}$ & $\begin{array}{l}\text { VEGETABLE OIL LUBRICANT COMPRISING ALL-HYDROPROCESSED } \\
\text { SYNTHETIC OILS }\end{array}$ \\
\hline
\end{tabular}

SHELL OIL

\begin{tabular}{|l|l|l|}
\hline N & REFERENCIA & TÍTULO \\
\hline 63 & EP1995/0668342A1 & LUBRICATING BASE OIL PREPARATION PROCESS \\
\hline 78 & $\begin{array}{l}\text { WO-2002-064710- } \\
\text { A2 }\end{array}$ & BASE OIL COMPOSITION \\
\hline 55 & US-1969-3449249 & LUBRICANT COMPOSITIONS \\
\hline
\end{tabular}

\section{SIGCO RESEARCH}

\begin{tabular}{|l|l|l|}
\hline N & REFERENCIA & TÍTULO \\
\hline 71 & US-1986-4627192 & SUNFLOWER PRODUCTS AND METHODS FOR THEIR PRODUCTION \\
\hline 72 & US-1988-4743402 & $\begin{array}{l}\text { NOVEL SUNFLOWER PRODUCTS AND METHODS FOR THEIR } \\
\text { PRODUCTION. }\end{array}$ \\
\hline
\end{tabular}

SPRAGE ELECTRIC

\begin{tabular}{|l|l|l|}
\hline N & REFERENCIA & TÍTULO \\
\hline 5 & US1978/4121275 & $\begin{array}{l}\text { ESTER DIELECTRIC FLUID CONTAINING TERT-BUTYL } \\
\text { ANTHRAQUINONE }\end{array}$ \\
\hline
\end{tabular}




\begin{tabular}{|l|l|l|}
\hline 17 & US1973/3740625 & ELECTRICAL CAPACITORS WITH ESTER IMPREGNANTS \\
\hline 66 & US1974/3855508 & $\begin{array}{l}\text { ELECTRICAL CAPACITORS HAVING SUBSTITUTED ESTER } \\
\text { IMPREGNANTS }\end{array}$ \\
\hline
\end{tabular}

\section{VARIOS}

\begin{tabular}{|c|c|c|c|}
\hline $\mathrm{N}$ & REFERENCIA & TÍTULO & PROPIEDAD \\
\hline 1 & US1981/4259708 & CAPACITOR WITH ESTER DIELECTRIC FLUID & $\begin{array}{l}\text { Westingho } \\
\text { use }\end{array}$ \\
\hline 52 & WO2005/014762A1 & A FUNCTIONAL FLUID AND THE USE THEREOF & Rohmax \\
\hline 8 & JP2005317259A & $\begin{array}{l}\text { ELECTRICAL EQUIPMENT AND OIL-CONTAINING } \\
\text { TRANSFORMER WHICH USE ELECTRICAL INSULATION } \\
\text { OIL }\end{array}$ & Hitachi \\
\hline 61 & EP2005/1559867A1 & $\begin{array}{l}\text { METHODS AND COMPOSITIONS FOR TREATING } \\
\text { SUBTERRANEAN FORMATIONS WITH GELLED } \\
\text { HYDROCARBON FLUIDS }\end{array}$ & Halliburton \\
\hline 14 & FR-1965-1412610 & $\begin{array}{l}\text { DIELÉCTRICOS A BASE DE ÉSTERES DE ÁCIDO } \\
\text { CAMFÓRICO Y DE ÁCIDO CICLOHEXANONA-2,2,6,6- } \\
\text { TETRACARBOXÍLICO }\end{array}$ & Hoechst \\
\hline 16 & GB1980/2063909 & HIGH FLASHPOINT HYDRAULIC FLUID & Mobil Oil \\
\hline 53 & US1972/3673093 & $\begin{array}{l}\text { LIQUID DIELECTRIC COMPOSITION OF ALKYLBENZENE } \\
\text { AND AN ANTIOXIDANT STABILIZER }\end{array}$ & $\begin{array}{l}\text { Montecatin } \\
\text { o Edison }\end{array}$ \\
\hline 54 & US-1978-4082866 & $\begin{array}{l}\text { METHOD OF USA AN ELECTRICAL EQUIPMENT } \\
\text { UTILIZING ISULATING OIL CONSISTING OF A } \\
\text { SATURATED HYDROCARBON OIL }\end{array}$ & RTE \\
\hline 68 & US-1973-3759827 & LUBRICANT COMPOSITIONS & $\begin{array}{l}\text { Dow } \\
\text { Corning }\end{array}$ \\
\hline 70 & US1980/4206066 & $\begin{array}{l}\text { HIGH IMPACT - ARC TRACK AND WEATHER } \\
\text { RESISTANT POLYMER INSULATOR AND COMPOSITION } \\
\text { INCLUDING EPOXIDIZED CASTOR OIL } \\
\end{array}$ & A.B. Chance \\
\hline 21 & US-1982-4355346 & $\begin{array}{l}\text { ELECTRICAL APPARATUS HAVING AN IMPROVED } \\
\text { DIELECTRIC SYSTEM }\end{array}$ & $\begin{array}{l}\text { McGraw- } \\
\text { Edison }\end{array}$ \\
\hline 25 & US-1987-4697043 & $\begin{array}{l}\text { PERCHLOROETHYLENE DIELECTRIC FLUID } \\
\text { CONTAINING ALIPHATIC HYDROCARBONS }\end{array}$ & $\begin{array}{l}\text { Occidental } \\
\text { Electroche } \\
\text { mical }\end{array}$ \\
\hline 27 & $\begin{array}{l}\text { EP-1988-0292025 } \\
\text { A2 }\end{array}$ & FIRE-RETARDANT ELECTRIC DEVICE. & Nippon Oil \\
\hline 29 & $\begin{array}{l}\text { EP-2005-1637580 } \\
\text { A1 }\end{array}$ & $\begin{array}{l}\text { VISCOSITY INDEX MODIFYING ADDITIVES FOR } \\
\text { LUBRICATING COMPOSITIONS. }\end{array}$ & $\begin{array}{l}\text { Afton } \\
\text { Chemical }\end{array}$ \\
\hline 32 & US-1994-5336847 & $\begin{array}{l}\text { STATIONARY INDUCTION APPARATUS CONTAINING } \\
\text { UNINFLAMMABLE INSULATING LIQUID. }\end{array}$ & Fuji Electric \\
\hline 33 & US-1999-5912215 & FOOD GRADE DIELECTRIC FLUID & $\begin{array}{l}\text { Electric } \\
\text { Fluids LLC }\end{array}$ \\
\hline 36 & $\begin{array}{l}\text { US-2002-6391228 } \\
\text { B1 }\end{array}$ & $\begin{array}{l}\text { DIELECTRIC COMPOSITION HAVING AN IMPROVED } \\
\text { GAS ABSORPTION }\end{array}$ & Atofina \\
\hline 38 & $\begin{array}{l}\text { US-2004-6790386 } \\
\text { B2 }\end{array}$ & DIELECTRIC FLUID & $\begin{array}{l}\text { Petro } \\
\text { canada }\end{array}$ \\
\hline 76 & US-2002-0141135 & CAPACITOR DIELECTRIC FLUID & North \\
\hline
\end{tabular}




\begin{tabular}{|c|c|c|c|}
\hline & A1 & & $\begin{array}{l}\text { American } \\
\text { Capacitor }\end{array}$ \\
\hline 43 & $\begin{array}{l}\text { US-2006-0276353 } \\
\text { A1 }\end{array}$ & LUBRICATING OIL COMPOSITION & Infineum \\
\hline 79 & WO-1999-53314 & $\begin{array}{l}\text { METHOD AND APPARATUS FOR MONITORING } \\
\text { GAS(ES) IN A DIELECTRIC FLUID }\end{array}$ & Spyrotec \\
\hline 45 & $\begin{array}{l}\text { WO-2006-065344 } \\
\text { A1 }\end{array}$ & $\begin{array}{l}\text { LUBRICANT COMPOSITIONS STABILIZED WITH } \\
\text { MULTIPLE ANTIOXIDANTS }\end{array}$ & Chemtura \\
\hline 46 & $\begin{array}{l}\text { US-2006-0116301 } \\
\text { A1 }\end{array}$ & $\begin{array}{l}\text { LIQUID PHENOLIC SULPHUR-CONTAINING } \\
\text { ANTIOXIDANTS }\end{array}$ & CIBA \\
\hline 48 & $\begin{array}{l}\text { WO-2004-108871 } \\
\text { A2 }\end{array}$ & $\begin{array}{l}\text { LIQUID COMPOSITIONS THAT ARE BASED ON } \\
\text { MODIFIED OLEIC RAPESEED OIL AND ARE USED AS } \\
\text { INSULATING LIQUIDS AND HEAT TRANSFER LIQUIDS, } \\
\text { AND ELECTRICAL DEVICES CONTAINING SAID LIQUID } \\
\text { COMPOSITIONS }\end{array}$ & $\begin{array}{l}\text { Electricite } \\
\text { de France- } \\
\text { Service } \\
\text { National }\end{array}$ \\
\hline 50 & $\begin{array}{l}\text { WO-2005-078054 } \\
\text { A1 }\end{array}$ & $\begin{array}{l}\text { LUBRICANT COMPOSITIONS COMPRISING AN } \\
\text { ANTIOXIDANT BLEND }\end{array}$ & Crompton \\
\hline 7 & JP2005/135989A & $\begin{array}{l}\text { ELECTRIC EQUIPMENT AND ITS MANUFACTURING } \\
\text { METHOD }\end{array}$ & Toshiba \\
\hline 20 & US-1974-3812407 & CAPACITOR & $\begin{array}{l}\text { Nichicon } \\
\text { Capacitor }\end{array}$ \\
\hline 41 & $\begin{array}{l}\text { US-2001-6245726 } \\
\text { B1 }\end{array}$ & $\begin{array}{l}\text { SOYBEAN BASED TRANSFORMER OIL AND } \\
\text { TRANSMISSION LINE FLUID }\end{array}$ & Waverly \\
\hline 51 & $\begin{array}{l}\text { WO-2005-119702 } \\
\text { A1 }\end{array}$ & $\begin{array}{l}\text { HIGH PERFORMANCE DIELECTRIC OIL AND THE USE } \\
\text { THEREOF IN HIGH VOLTAGE ELECTRIC EQUIPMENT }\end{array}$ & Areva T\&D \\
\hline
\end{tabular}

PROPIEDAD: PARTICULARES

\begin{tabular}{|l|l|l|}
\hline $\mathrm{N}$ & REFERENCIA & TÍTULO \\
\hline 2 & US2002/0139962A1 & DIELECTRIC FLUID \\
\hline 6 & EP2006/1623785A1 & $\begin{array}{l}\text { USE OF AN ESTER OF A FATTY ACID AS DIELECTRIC FLUID FOR } \\
\text { ELECTRICAL DISCHARGE MACHINING }\end{array}$ \\
\hline 60 & US2006/0054281A1 & $\begin{array}{l}\text { HYDROCARBON DIELECTRIC HEAT TRANSFER FLUIDS FOR } \\
\text { MICROWAVE PLASMA GENERATORS }\end{array}$ \\
\hline 62 & EP2005/1598410A2 & $\begin{array}{l}\text { PROCESS AND DEVICE FOR REMOVING POLYCHLORINATED } \\
\text { BIPHENYLS (PCBS) FROM DIELECTRIC REFRIGERANT FLUIDS (FDRs) } \\
\text { CONTAINED IN ELECTRICAL EQUIPMENT }\end{array}$ \\
\hline 10 & US2002/0049145A1 & $\begin{array}{l}\text { VEGETABLE-BASED TRANSFORMER OIL AND TRANSMISSION LINE } \\
\text { FLUID }\end{array}$ \\
\hline 15 & GB1974/1490581 & CAPACITOR \\
\hline 18 & US1973/3754173 & STABILIZED ESTER IMPREGNATED CAPACITOR \\
\hline 39 & $\begin{array}{l}\text { US-2005-0072964 } \\
\text { A1 }\end{array}$ & ADDITIVE FOR DIELECTRIC FLUID \\
\hline
\end{tabular}




\subsubsection{Bases}

Actualmente se contemplan cuatro posibilidades: aceite mineral, éster natural, éster sintético y mezclas. Los aceites minerales, a su vez, pueden tener diferentes bases: parafínica, nafténica, aromática y mezclas. Sus propiedades son muy diferentes y dependen de la proporción de cada componente. Por ejemplo, una base parafínica produce bajos puntos de congelación y propiedades de gassing negativas. En general, los aceites minerales son más inflamables, aunque también son mejores aislantes. Durante su uso generan diversos gases, pero tienen mayor capacidad de absorción de hidrógeno, en caso de que haya suficiente número de insaturaciones.

En esta tesis se está especialmente interesado en los ésteres naturales; son más baratos y más biodegradables que los sintéticos, y tienen ventajas respecto a los aceites minerales que iremos viendo. Los ésteres tienen, en general, mejor comportamiento frente al gassing. Son fuente, principalmente, de $\mathrm{CO}_{2}$ y $\mathrm{CO}$ procedente de la hidrólisis del grupo éster. Son más sensibles al agua y se hidrolizan produciendo ácidos carboxílicos. Tienen un mayor punto de inflamación, pero son menos aislantes. Si tienen origen vegetal, llevan inhibidores naturales de la oxidación, que son irremplazables y actúan sinérgicamente.

\subsubsection{Hidrólisis}

Para que un aceite con base de éster sea menos hidrolizable, es necesario sustituir el éster de forma que el grupo carbonilo quede impedido estéricamente. Es particularmente interesante el grupo terc-butilo. La hidrólisis de ésteres produce ácidos, por lo que estos aceites presentan por lo general un número ácido más alto que los aceites minerales.

\subsubsection{Propiedades de corona}

El efecto corona se mejora introduciendo un aceptor de hidrógeno, como la $\beta$-metil antraquinona; mejor resultado cuanto más soluble sea este aceptor. En general, la presencia de ésteres de ftalato, y otros compuestos aromáticos (terc-butil-antraquinona) mejora las propiedades de corona, mientras que los grupos alifáticos lo empeoran. Una baja tendencia al gassing implica una alta resistencia al efecto corona y que el aceite es un absorbedor neto de hidrógeno. 


\subsubsection{Resistencia al fuego}

Se puede obtener una alta resistencia al fuego eligiendo cuidadosamente la base y empleando aditivos. Respecto a la base, la resistencia al fuego es mayor cuando tiene una baja presión de vapor, lo cual se consigue empleando moléculas de, al menos, 35 átomos de carbono. Y por otra parte, a mayor conductividad, el calentamiento más lento y la ignición es más difícil. La disipación de calor, en el rango de temperaturas de trabajo, es función de la viscosidad, el calor específico, la conductividad térmica y el coeficiente de expansión.

\subsubsection{Viscosidad cinemática}

Como se ha mencionado, la viscosidad tiene mucha importancia en la disipación de calor: cuanto menos viscoso, mejor circula y elimina calor el aceite. En principio, lo hace por convección, luego por conducción y finalmente por radiación. Es sabido que la viscosidad aumenta con el peso molecular, pero también lo hace la resistencia al fuego; por tanto, aquí tenemos dos propiedades antagónicas, y no es el único ejemplo.

La variación de la viscosidad con la temperatura es mayor para los ésteres que para los aceites minerales, es decir: a baja temperatura es más fluido un aceite mineral, pero su viscosidad no disminuye tan rápidamente como la del éster. A la temperatura de trabajo, ambos tienen una viscosidad parecida.

\subsubsection{Rigidez dieléctrica y agua}

Uno de los factores más problemáticos del transformador es la humedad, procedente de la hidrólisis de la celulosa que constituye el papel aislante (como ya se ha mencionado, este papel está impregnado en aceite y rodea totalmente a ambos bobinados del transformador). La presencia de agua tiene varios efectos:

- Degradación del papel aislante mediante hidrólisis de la celulosa

- Hidrólisis de los ésteres componentes del aceite base

- Empeoramiento de la rigidez dieléctrica

Ésteres vegetales y aceites minerales tienen un comportamiento muy diferente, debido a su distinta composición química. Para todos los fluidos dieléctricos, la tensión de 
ruptura decae rápidamente cuando se alcanza el 40-50\% de la saturación relativa de agua; lo importante es que este valor se alcance lo más tarde posible, es decir, aunque se forme agua, que ésta no esté en su forma libre sino "disuelta", requisito que satisfacen los ésteres mucho mejor que los aceites minerales. Resulta más útil comparar valores de saturación relativa, que el contenido absoluto en $\mathrm{mg} / \mathrm{kg}$. Hay que mencionar que el índice de saturación con agua de un aceite disminuye con la temperatura.

Otra cuestión importante en este apartado es la polaridad, es decir, la presencia de grupos funcionales polares que aumenta la conductividad. Por tanto, los esteres siempre tendrán una constante dieléctrica más baja que los aceites minerales. No es la única consecuencia de la polaridad del grupo éster, ya que cuanto más polar la molécula, hay un valor más alto de factor de disipación, por lo que aumentan las pérdidas energéticas y el riesgo de sobrecalentamiento. Para evitar el problema de la presencia de agua, tradicionalmente se ha recurrido a un proceso de regeneración del aceite que, además, elimina los ácidos que se han ido formando. Esto se realiza mediante percolación a través de un lecho de tierras Fuller tipo atapulgita o similar.

\subsubsection{Gases}

A consecuencia de descargas eléctricas imprevisibles, en algunos puntos del fluido se pueden alcanzar temperaturas instantáneas muy superiores a las de trabajo. Es estas condiciones, parte del fluido se vaporiza, produciendo una serie de gases, principalmente hidrógeno y óxidos de carbono. El gas hidrógeno formado causa la hidrogenación de dobles enlaces, lo cual puede alterar sensiblemente las propiedades del aceite: disminuye la resistencia a la oxidación y modifica la viscosidad (inversa al grado de insaturación). Por otra parte, es muy importante que el aceite sea capaz de absorber todo ese hidrógeno, dado que se trata de un gas muy inflamable. Lo interesante es lograr que sus propiedades no cambien a pesar de que pueda absorber mucho gas.

Cuando se emplean ésteres de ácidos grasos, éstos debe tener al menos una insaturación; el resultado es un buen balance entre la tendencia a la oxidación (mayor, cuantas más instauraciones) y la reducción de la evolución del hidrógeno formado. Se prefieren los ésteres procedentes de ácidos mono-insaturados, porque se oxidan menos que los poliinsaturados. 
Como ya se ha dicho, una baja tendencia al gassing implica una alta resistencia al efecto corona, y que el aceite es un absorbedor neto de hidrógeno.

Los ésteres son fuente de $\mathrm{CO}$ y $\mathrm{CO}_{2}$, que también se producen durante la ruptura térmica de la celulosa, mientras que por hidrólisis, producen ácidos de cadena larga. Mediante aditivos aromáticos y olefínicos se puede disminuir la tendencia al gassing; así, los compuestos aromáticos sustituidos son agentes donantes de hidrógeno y producen una tendencia negativa al gassing.

\subsubsection{Grado de insaturación-oxidación-hidrogenación}

La hidrogenación de dobles enlaces mejora la estabilidad a la oxidación, dado que los dobles enlaces constituyen el principal punto de ataque del oxígeno. De hecho, es un proceso que se lleva a cabo habitualmente en las plantas de refino. Pero al realizarlo, hay que tener en cuenta que este proceso también afecta a otras propiedades, como la viscosidad. A menor grado de instauración, más facilidad para que el aceite solidifique (punto de congelación más alto). Por otra parte, a mayor número de insaturaciones, mayor facilidad para captar hidrógeno; así que, de nuevo, el cambio en una determinada propiedad tiene dos efectos antagónicos. Interesaría que el gas sea un captador neto de hidrógeno, pero que su hidrogenación no cambie estas propiedades (algo teóricamente imposible).

Un caso muy referido en la literatura es el del ácido oleico, considerado "inestable" porque tiene una instauración. Esto lo hace susceptible de oxidación, pero también lo capacita para captar hidrógeno; en general, altos grados de poliinsaturación dan lugar a mayor capacidad para absorber hidrógeno, pues los enlaces dobles pasan a sencillos. En resumen: los enlaces dobles pueden sufrir oxidación, en presencia de oxígeno (a triple enlace, con desprendimiento de agua) o reducción (hidrogenación, en presencia de hidrógeno) a enlace sencillo, con los correspondientes cambios en diversas propiedades.

\subsubsection{Aditivos}

Los aditivos empleados para mejorar las propiedades del aceite se pueden clasificar como sigue:

- Antioxidantes

- Depresores del punto de congelación 
- Modificadores de la viscosidad.

- Desactivadores de metales

- Scavengers

- Elevadores del punto de inflamación

- Antioxidantes:

Naturales o sintéticos, actúan atrapando radicales libres durante el periodo de inducción de la reacción en cadena (por radicales libres) que constituye la oxidación. Los antioxidantes actúan alargando el periodo de inducción; una vez comenzada la fase de propagación, ya no son capaces de detenerla.

Existe amplia bibliografía sobre el tema, e incluso puede acudirse al mundo de los polímeros y al de la tecnología de alimentos; dado que el problema es idéntico (oxidación de aceite, de polímero, y enrranciamiento de grasa, son básicamente lo mismo), lo escrito es válido para todos con la salvedad de que los aceites van a estar expuestos a una temperatura de trabajo de $45-95^{\circ} \mathrm{C}$, e incluso hay momentos en que la temperatura alcanza valores mucho más altos. Pero el sustrato es el mismo.

Hay muchos tipos de antioxidantes; entre los más citados se encuentran los fenoles impedidos estéricamente, ciertas aminas aromáticas, etc., con mecanismos de acción diferentes.

En los aceites naturales se encuentra una cierta cantidad (trazas) de una enzima que comienza la oxidación por radicales libres: es la enzima lipooxidasa. Por lo tanto, los aceites naturales están más inclinados a la oxidación que otros, sintéticos. Para contrarrestar esta característica, también son portadores de antioxidantes naturales (irreemplazables y que actúan sinérgicamente). En los aceites naturales pueden encontrarse compuestos de azufre que corroen al cobre, lo cual es una fuente de este metal que pasa a estar disponible para catalizar oxidaciones.

- Depresores del punto de congelación:

Es aconsejable un punto de congelación inferior a los $-40^{\circ} \mathrm{C}$. Por lo general se emplean polímeros (polivinilos y polimetacrilatos). 
- Modificadores de la viscosidad:

Dado que los propios ésteres se emplean como plastificantes (disolventes) en la industria de polímeros, no se les suele añadir nada para modificar esta propiedad.

- Desactivadores de metales:

Las reacciones de oxidación y de hidrólisis son catalizadas por cobre (procedente de los bobinados) y por hierro (procedente del material con que está fabricado el transformador). Los desactivadores empleados son, por lo general, agentes que forman compuestos de coordinación como el EDTA, benzotriazol, etc. 


\subsection{MEJORA EN LAS PROPIEDADES QUÍMICAS Y FÍSICO QUÍMICAS DE LOS ACEITES: USO DE ADITIVOS.}

Los aditivos juegan un papel fundamental en la protección del aceite dieléctrico y también en algunos casos, mejorando alguna característica deficiente del aceite como pueden ser sus propiedades de flujo o viscosimétricas a baja temperatura, o actuando como protectores de los materiales constructivos del transformador. Aunque existen muchos tipos de aditivos con funciones muy específicas, en esta tesis solamente se mencionarán tres tipos de productos:

- Antioxidantes.

- Depresores del punto de congelación.

- Desactivadores de metales.

\subsubsection{Antioxidantes}

En numerosas ocasiones, la vida del aceite dieléctrico suele estar limitada por el envejecimiento del propio aceite base. Al llegar a su límite de vida, se observa cambio en la coloración, formación de depósitos (más conocidos como lodos o sludges), mal olor, desarrollo de acidez etc... Este proceso, llamado envejecimiento oxidativo, es inducido por el oxígeno del aire, el calor, las superficies metálicas que actúan de catalizador, etc, y puede ser retrasado por la presencia de aditivos antioxidantes.

Los fenómenos que pueden ocurrir durante este proceso conducen a toda una serie de productos que en líneas generales son perjudiciales para un buen funcionamiento del aceite.

El esquema adjunto indica, en forma resumida, las consecuencias de los fenómenos oxidativos que tienen lugar en el aceite: 


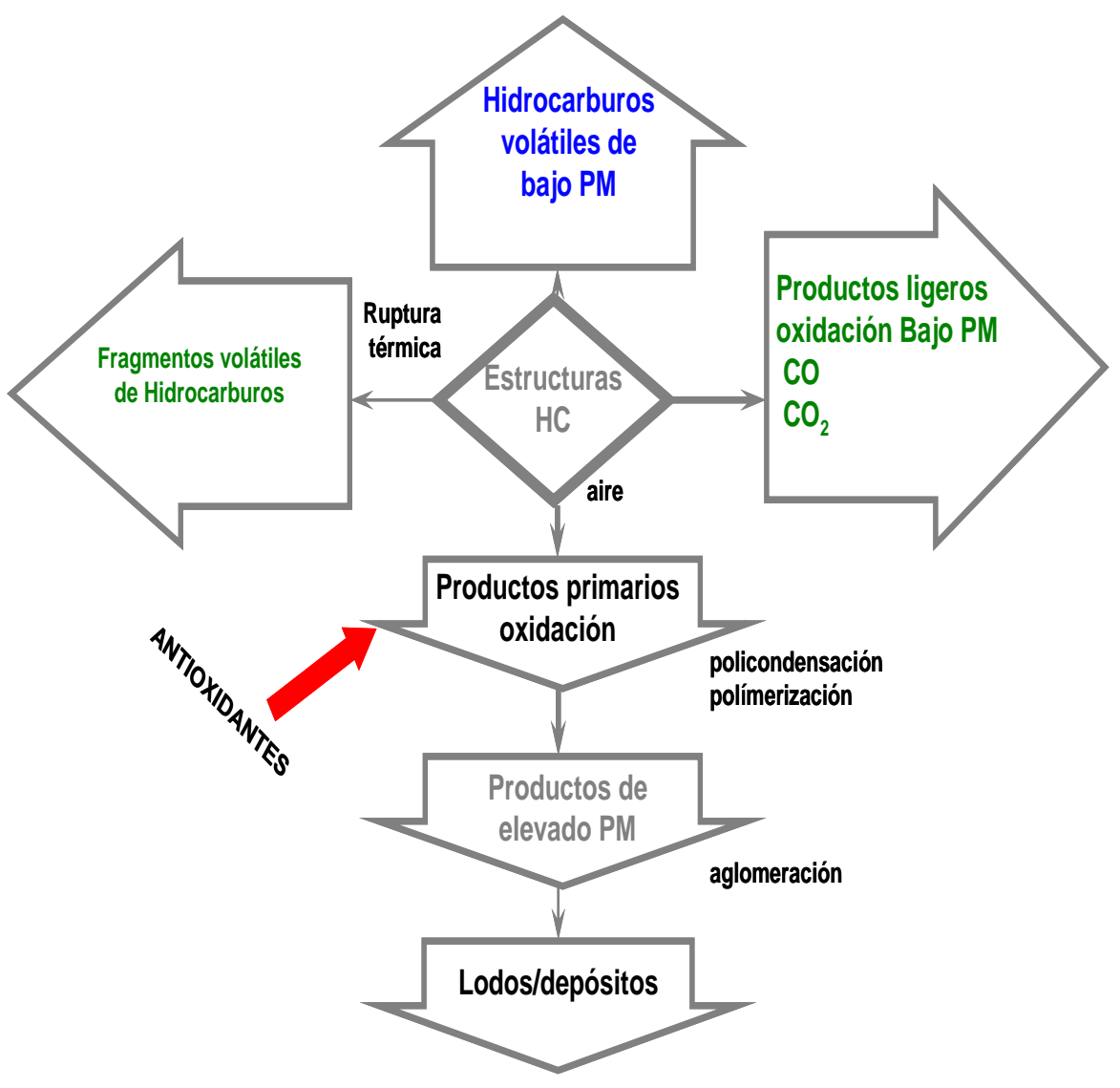

Figura 51: Productos de oxidación del aceites minerales y vegetales

En el caso particular de los aceites dieléctricos, estos procesos acaban dando lugar a agua, moléculas polares como ácidos y cetonas, lodos, metales disueltos, etc., que modifican sustancialmente las características dieléctricas del material o interfieren en la refrigeración del sistema por obstrucción de conductos o pasos de aceite si se depositan lodos.

En función del tiempo, la siguiente gráfica indica en qué medida transcurre la oxidación de un aceite mineral, así como sus consecuencias en algunas propiedades: 


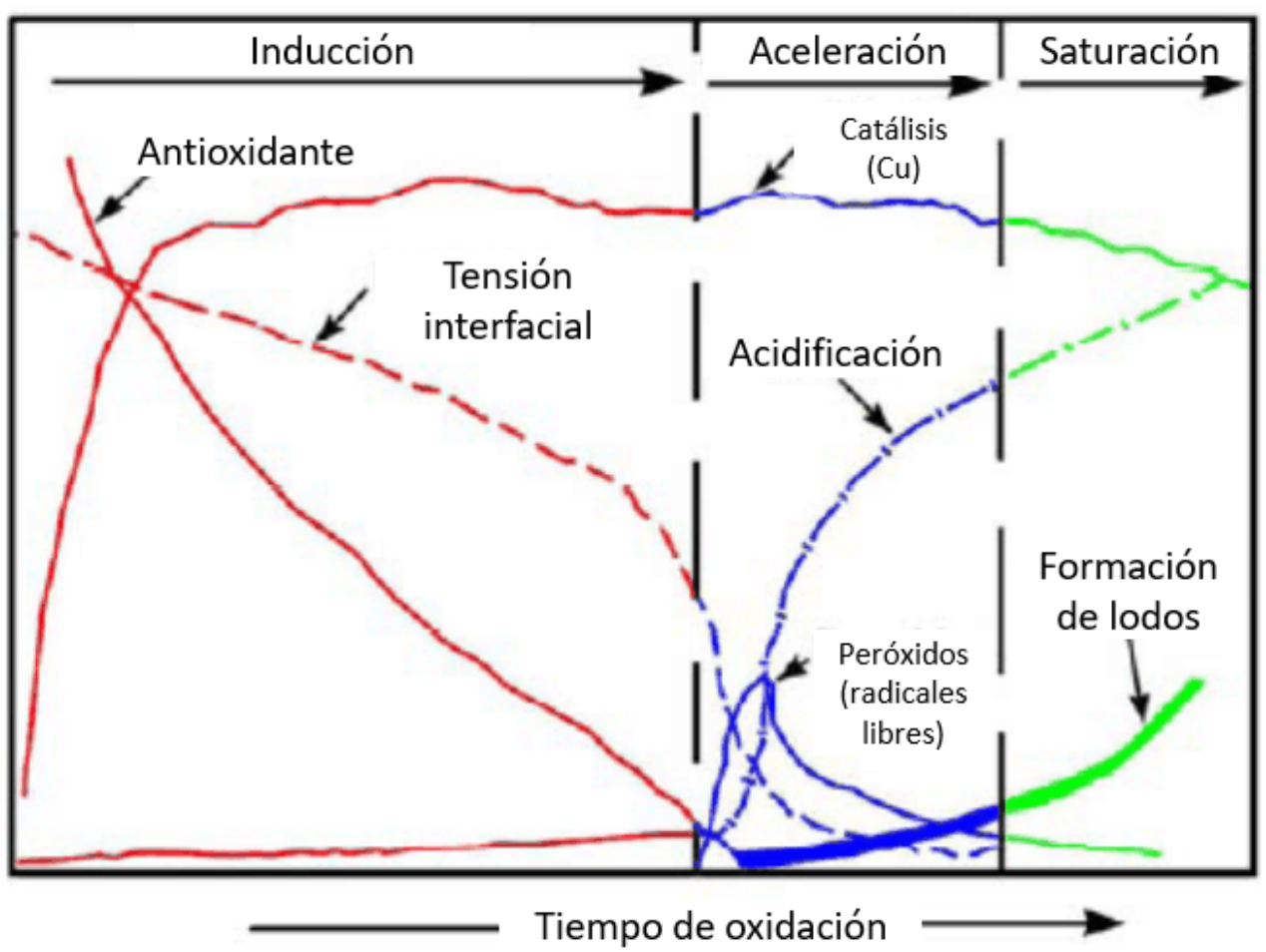

Figura 52: Proceso de oxidación de un aceite

Existe amplia bibliografía acerca de los aditivos antioxidantes, e incluso puede acudirse al mundo de los polímeros o al de la tecnología de alimentos; dado que el problema es idéntico (oxidación de aceite, de polímero, y enrranciamiento de grasa, son básicamente lo mismo). La salvedad es que los aceites dieléctricos van a estar expuestos a una temperatura de trabajo entre $45-95{ }^{\circ} \mathrm{C}$, aunque hay momentos en que la temperatura alcanza valores mucho más altos.

La bibliografía señala que los procesos y mecanismos de oxidación para ésteres son los mismos que los descritos para aceites minerales con la peculiaridad de que estos pueden contener puntos de ataque oxidativo en cierto modo más sensibles. La figura adjunta marca algunos de ellos, aunque las reacciones químicas de oxidación pueden tener lugar en cualquier enlace, pero preferentemente en los enlaces dobles o triples, anillos aromáticos, hidrógenos en posición alfa, en enlaces polarizables, hidrógenos en carbonos terciarios, etc. 


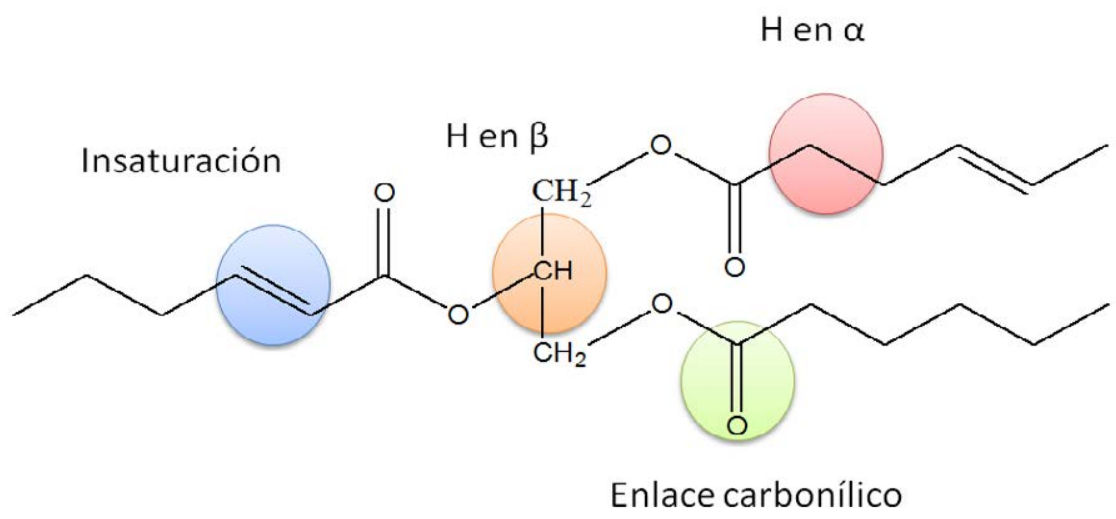

Figura 53: Puntos de ataque de una molécula de triglicérido

Otra salvedad es que en los aceites naturales se encuentra una cierta cantidad (trazas) de un enzima que comienza la oxidación por radicales libres: el enzima lipooxidasa. Por lo tanto, los aceites naturales están más inclinados a la oxidación que otros sintéticos, aunque para contrarrestar esta característica, también son portadores de antioxidantes naturales (irreemplazables y que actúan sinérgicamente).

Es conocido por la comunidad científica que la oxidación en los aceites minerales tiene lugar a través de unos mecanismos de reacción de tipo "radicales libres", los denominados radicales alquilo $(\mathrm{R} \cdot)$ y peroxídico $(\mathrm{ROO} \cdot)$. De esta forma, después de un cierto período de inducción, que depende del tipo de base o de la presencia de inhibidores naturales de oxidación, algunos átomos de hidrógeno son eliminados por acción de iniciadores químicos, el calor o la radiación: es lo que se conoce como Etapa de Iniciación, pero que a través de distintas etapas generará un proceso autooxidativo en el que a modo de resumen, podrían definirse los siguientes pasos:

1. - Iniciación: Por causa de la radiación y/ o el calor:

$$
\mathrm{R}-\mathrm{H}+\mathrm{O}_{2} \rightarrow \mathrm{R} \cdot+\mathrm{HOO} \cdot
$$


2. - Propagación, donde el radical alquílico $\mathrm{R} \cdot$ puede reaccionar con oxígeno para formar un radical peroxídico ROO· y éste, al reaccionar con otro hidrocarburo produce un hidroperóxido y un nuevo radical, el cual puede reiniciar el proceso reaccionando con oxígeno tal y como se ha indicado al principio:

$$
\begin{gathered}
\mathrm{R} \cdot+\mathrm{O}_{2} \rightarrow \mathrm{ROO} \cdot \\
\mathrm{ROO} \cdot+\mathrm{R}-\mathrm{H} \rightarrow \mathrm{ROOH}+\mathrm{R} \cdot
\end{gathered}
$$

3. - Ramificación o Extensión de la reacción: Los hidroperóxidos, por acción de la radiación o el calor, generan nuevos radicales y diferentes especies químicas oxidadas:

$$
\begin{gathered}
\mathrm{ROOH}+\mathrm{h} v \rightarrow \mathrm{RO} \cdot+\mathrm{OH}^{\bullet} \\
\mathrm{RO}^{\bullet}+\mathrm{RH} \rightarrow \mathrm{ROH}+\mathrm{R}^{\bullet} \\
\mathrm{OH}^{\bullet}+\mathrm{RH} \rightarrow \mathrm{H}_{2} \mathrm{O}+\mathrm{R}^{\bullet}
\end{gathered}
$$

4.- La fase de Terminación, que tiene lugar cuando dos radicales se recombinan entre sí para dar una especie no reactiva

$$
\begin{gathered}
2 \mathrm{R} \cdot \rightarrow \mathrm{R}-\mathrm{R} \\
\mathrm{R} \cdot+\mathrm{ROO} \cdot \rightarrow \mathrm{ROOR} \\
2 \mathrm{ROO} \cdot \rightarrow \mathrm{ROOR}+\mathrm{O}_{2}
\end{gathered}
$$


Los productos típicos de la oxidación que pueden formarse a través de los mencionados procesos son alquilhidroperóxidos $(\mathrm{ROOH})$, dialquilperóxidos (ROOR'), alcoholes $(\mathrm{ROH})$, aldehídos $(\mathrm{RCHO})$, cetonas (R-CO-R'), ácidos carboxílicos $(\mathrm{RCOOH})$, ésteres (R-COO-R'), etc. Posteriormente, reacciones de polimerización de los citados productos conducen a materiales insolubles que se depositan como barnices, lacas y lodos. Los productos de oxidación de carácter ácido pueden provocar problemas de corrosión, así como también los citados alquil-peroxi-radicales.

El diagrama indicado a continuación recoge el conjunto de reacciones que tienen lugar en el fenómeno de oxidación, también llamado de "autoxidación", por cuanto ésta tiene lugar automáticamente en cuanto el material orgánico es expuesto a la atmósfera.

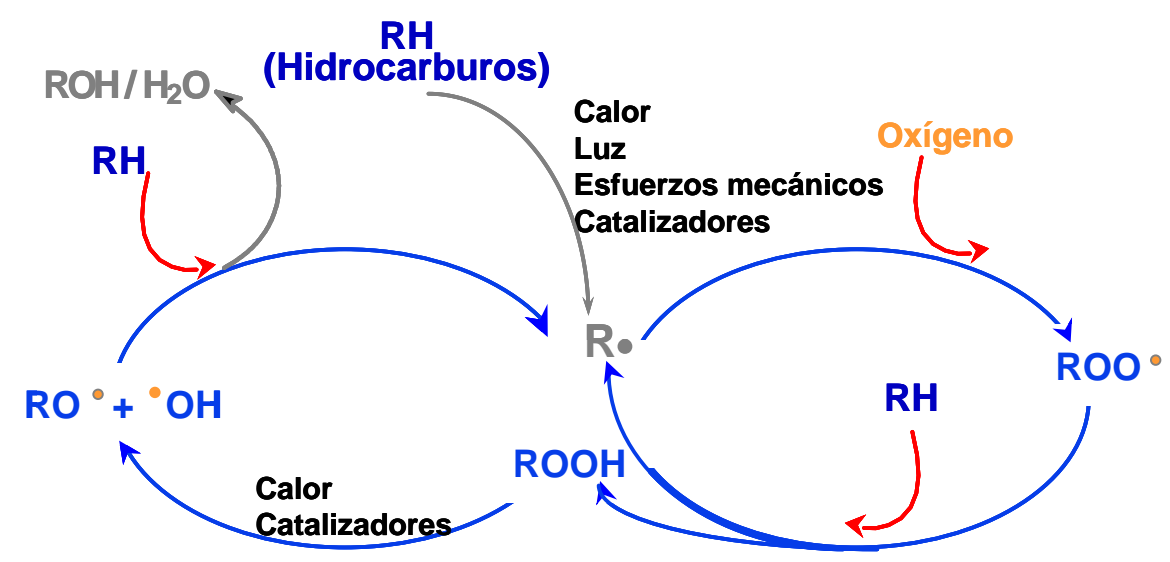

Figura 54: Reacciones de autoxidación de un aceite

Los fenómenos oxidativos son tremendamente influenciados por la temperatura, de forma que a medida que ésta aumenta, la velocidad de degradación se incrementa proporcionalmente. Como regla empírica se habla de que cada $7-10{ }^{\circ} \mathrm{C}$, la velocidad de oxidación de los aceites se duplica y esta es la causa por la que se vigila y diseña especialmente la temperatura de operación del transformador.

Dada la naturaleza compleja de los fenómenos oxidativos, afectando a los miles de estructuras químicas diversas presentes en los aceites base y a las diferentes velocidades de reacción, así como a la influencia del resto de factores como temperatura, presencia de oxígeno u otros gases, humedad, catalizadores, etc, hace que su control sea difícil en la práctica. Se dispone, no obstante, de diferentes tipos de aditivos inhibidores también 
llamados antioxidantes, y estos, empleados solos o en combinaciones, se utilizan en dosis adecuadas para obtener un retraso óptimo del envejecimiento del aceite.

La principal función de los antioxidantes será la de estabilizar a los aceites base controlando la proliferación de las especies químicas responsables de la oxidación, es decir los peroxi-radicales (ROO·) y los hidroperóxidos (ROOH).

Los aditivos antioxidantes se pueden clasificar en dos tipos, según su forma de actuación:

1 - Primarios o Captadores de Radicales (scavengers) tales como los fenoles estéricamente impedidos y las aminas aromáticas.
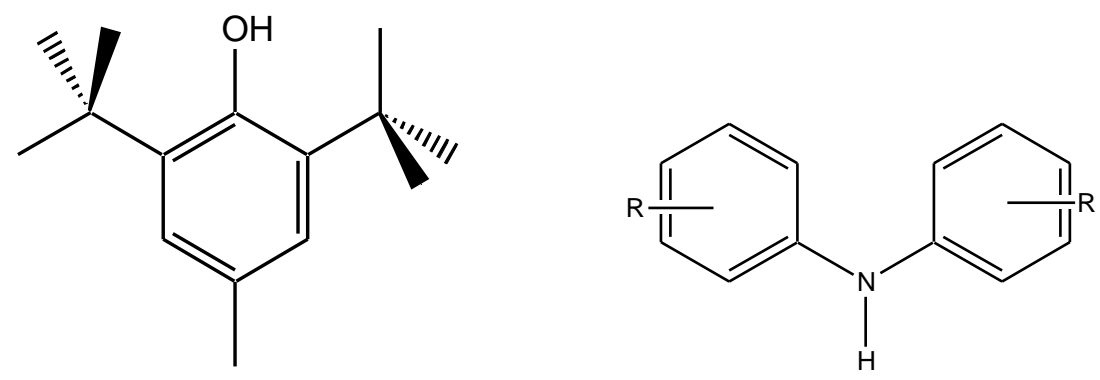

Figura 55: BHT (izquierda) y amina aromática (derecha)

2 - Secundarios o Rompedores de Hidroperóxidos (decomposers) como son determinados compuestos de azufre, fósforo, fenoles etc. Los derivados de fósforo, sin embargo, no son empleados en este sector.
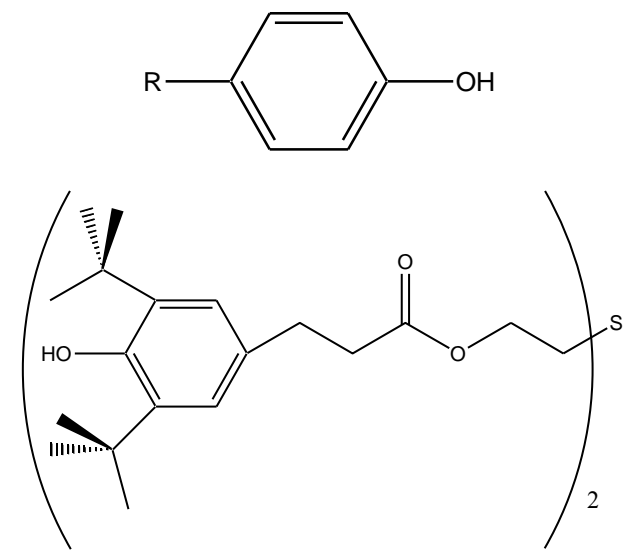

Figura 56: Fenol (arriba) y tiobisfenol (abajo) 
Los antioxidantes primarios actúan donando un $\mathrm{H}^{\bullet}$ radical al peroxiradical formado en la degradación del aceite. Debido al impedimento estérico, el aditivo antioxidante en forma radical-resonante creado según la reacción indicada a continuación, ya no ataca a las moléculas de aceite en los enlaces $\mathrm{R}-\mathrm{H}$ y consecuentemente la cadena de reacción se termina :

$$
\mathrm{ROO}+\mathrm{AOx}-\mathrm{H} \rightarrow \mathrm{R}-\mathrm{OOH}+\mathrm{AOx} \cdot
$$

En la figura 57 se indica un ejemplo de control de la oxidación empleando un antioxidante derivado del 2,6 di-terc-butil-fenol:

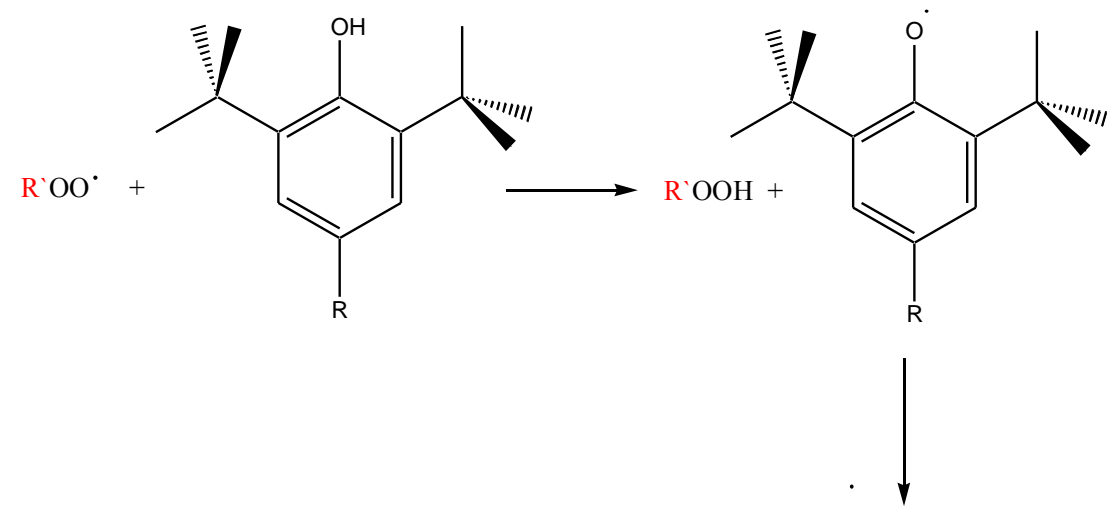

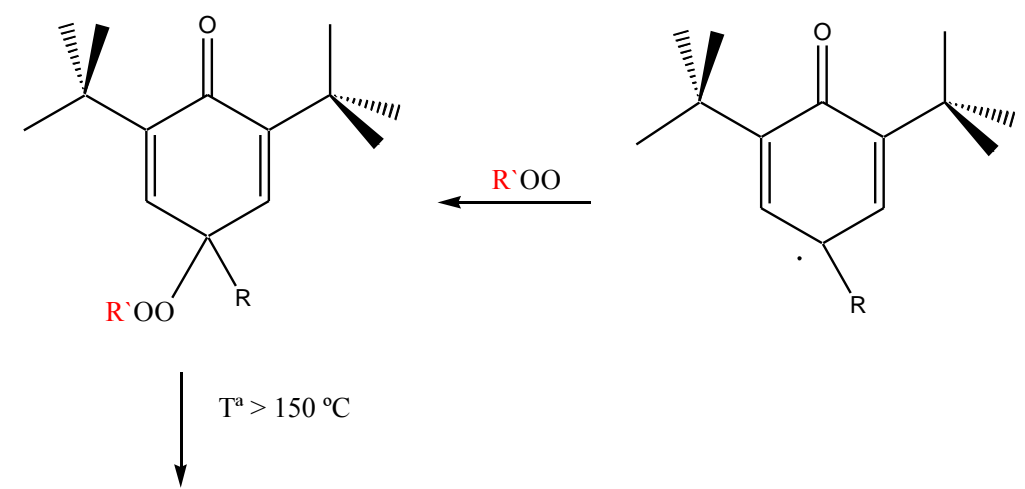

Productos no radicálicos

Figura 57: Mecanismo de actuación de un antioxidante primario

Existen una gran cantidad de aditivos de este tipo, de los cuales se indican a continuación algunas de sus fórmulas. 
$\underline{\text { Fenoles estéricamente impedidos: }}$
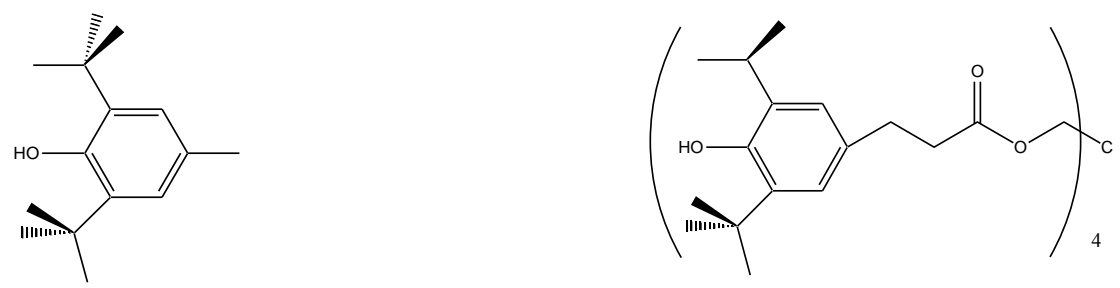<smiles>Cc1c(C)c2c(c(C)c1O)CC[C@@](C)(C(C)(C)CCC(C)CCC(C)C)O2</smiles>

Figura 58: Estructura química de la vitamina E (abajo) entre otras

Son también ejemplos la TBHQ (Terc-butil-hidroquinona), PG (Propilgalato) y BHA (butilhidroxianisol) ampliamente utilizados en el sector alimentario, especialmente con aceites vegetales.

Aminas aromáticas:

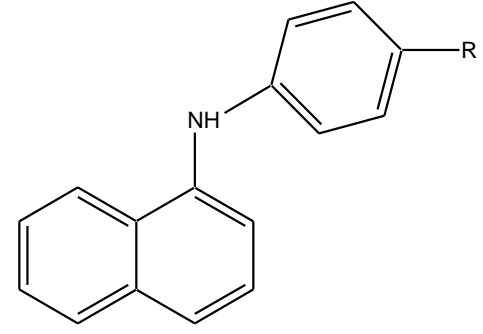

N-Fenil Naftil amina (PANA)<smiles>Cc1cccc(Nc2ccccc2)c1</smiles>

Difenil amina (DPA)

Figura 59: Estructura química de aminas aromáticas

Con respecto a los antioxidantes secundarios, estos convierten los hidroperóxidos en productos no-radicales deteniendo así la cadena de propagación. A continuación se indican ejemplos del modo de acción de dialquilsulfuro, fenol, alquil-fosfitos y tio- 
éteres: descomposición de los hidroperóxidos en productos No-Radicales y de los radicales peroxídicos en oxirradicales menos reactivos.

$$
\begin{array}{lll}
\mathrm{ROOH}+\text { sec. } \mathrm{AOx} & \longrightarrow & \mathrm{ROH}+\text { ox. sec. Aox } \\
\mathrm{ROO}+\text { sec. AOx } & \longrightarrow & \mathrm{RO}+\text { ox. sec. Aox }
\end{array}
$$

Se indica a continuación como ejemplo la forma de desactivación de hidroperóxidos por los tioéteres.

$$
\begin{array}{lll}
\mathrm{R}-\mathrm{S}-\mathrm{R}+\mathrm{ROOH} & \mathrm{R}-\mathrm{SO}-\mathrm{R}+\mathrm{ROH} \\
\mathrm{R}-\mathrm{SO}-\mathrm{R}+\mathrm{ROOH} & \longrightarrow & \mathrm{R}-\mathrm{SO}_{2}-\mathrm{R}+\mathrm{ROH} \\
\mathrm{R}-\mathrm{S}-\mathrm{R}+2[\mathrm{ROO} \cdot] & \longrightarrow & \mathrm{R}^{-\mathrm{SO}_{2}-\mathrm{R}}+2[\mathrm{RO} \cdot]
\end{array}
$$

Donde $\mathbf{R}$ son radicales alquilo o arilo.

En aplicaciones de dieléctricos, este tipo de aditivos sulfurados producen sulfóxidos y sulfonas que elevan fuertemente la tangente del ángulo de pérdidas por lo que no deben utilizarse. Lo mismo ocurre con el DBDS (dibencil-disulfuro), sólo que en este caso, además, el producto se descompone sobre los conductores de cobre generando sulfuro de cobre, que es altamente conductor.

En aceites minerales aislantes, los únicos admitidos hasta la fecha son el DBPC (ditercbutil-p-cresol) y el BPC (butil-p-cresol) que incluso figuran en especificaciones internacionales. Sin embargo el reciente empleo de ésteres y ausencia de legislación, ha propiciado el empleo de otros sistemas como por ejemplo las combinaciones de TBHQ /Fenilaminas.

En la práctica, la combinación de antioxidantes depende del objetivo deseado, de las especificaciones a cumplir, de la vida útil del aceite, de la naturaleza de la base, etc. El complemento con otros productos tales como inhibidores de la corrosión y herrumbre capaces de desactivar o reducir la acción catalítica pro-oxidante de los metales, proporciona un sinergismo que el laboratorio debe de estudiar para determinar la combinación óptima de aditivos para una determinada formulación.

Los aditivos antioxidantes se estudian en ensayos de laboratorio de tipo diverso según las condiciones que se pretenda simular, pero en todos ellos el objetivo es el de someter 
a los aceites a condiciones severas de temperatura, aporte de oxígeno o aire y presencia de catalizadores metálicos de cobre $(\mathrm{Cu})$, hierro $(\mathrm{Fe})$, aluminio (Al), agua, celulosa, etc, para evaluar la estabilidad a la oxidación en períodos de tiempo mucho más reducidos que la vida útil real.

\subsubsection{Inhibidores de la corrosión o pasivadores}

Estos tipos de aditivos se utilizan para proteger las superficies metálicas del ataque de agentes agresivos como el oxígeno, la humedad, los productos de la oxidación del propio aceite dieléctrico o los que contaminan a éste.

En general actúan generando películas formadas por moléculas densamente empacadas sobre la superficie a proteger. Su adsorción sobre las superficies se debe al carácter polar de las moléculas y tiene lugar a través de fenómenos de interacción física o química. Por su mecanismo de acción, compiten sobre las superficies con otros aditivos como los pasivadores por lo que pueden reducir su actividad.

- moléculas de aditivo

- moleculas de aceite base
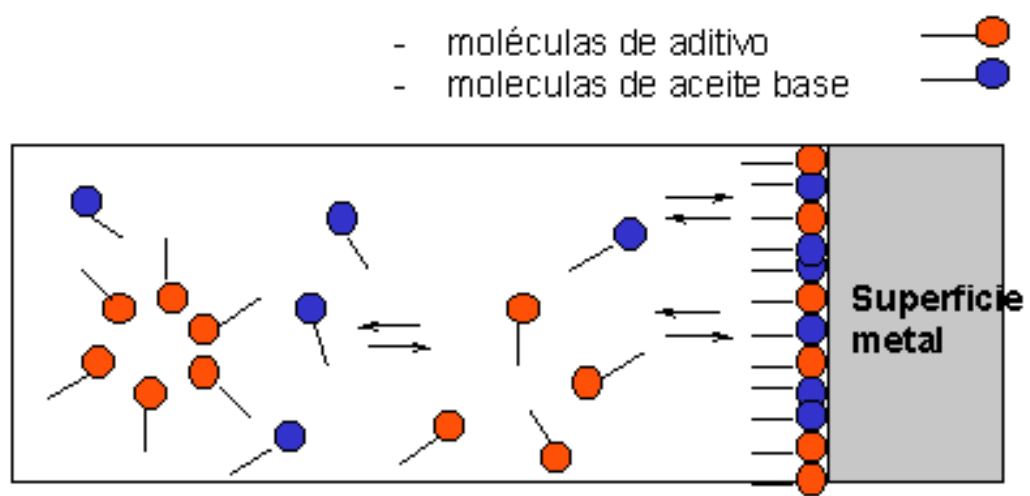

Figura 60: Mecanismo de actuación de los pasivadores

Sin embargo, por su forma de acción, no son realmente efectivos en tanto no se alcanza la Concentración Micelar Crítica, punto a partir del cual existe suficiente concentración de moléculas libres para poder inhibir la corrosión.

Pequeñas cantidades de agua son inevitables en los aceites. El agua llega a los aceites dieléctricos por contaminación, degradación de aceite o por condensación. Si el agua no es eliminada, desplazará al fluido de la superficie y será adsorbida sobre éste, en 
particular en las superficies de hierro. Cuando hay oxígeno presente, se crea una interfase electroquímica entre el metal (ánodo) y su capa de óxido que genera corrosión.

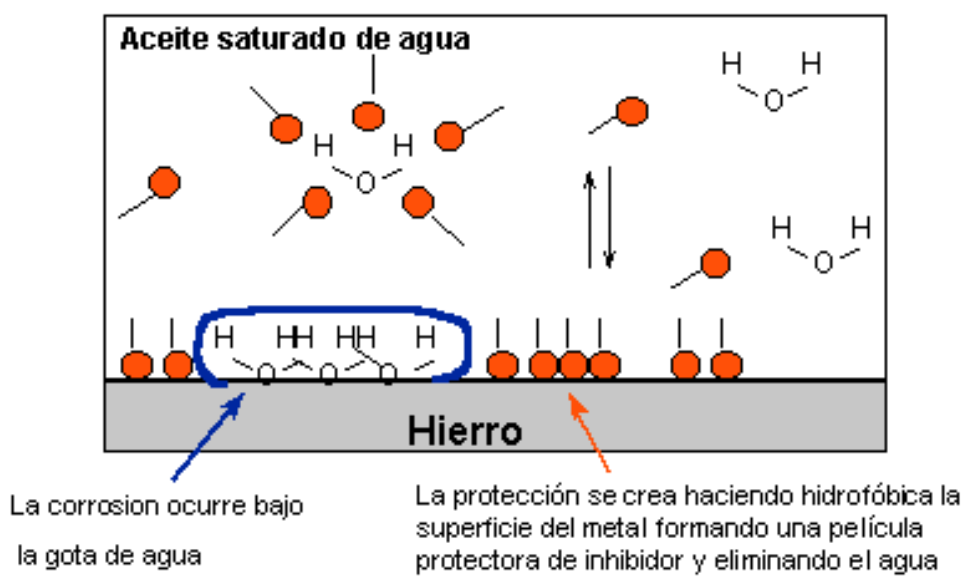

Figura 61: Mecanismo de formación de interfase electroquímica por adsorción de agua sobre el metal

La protección anticorrosiva de metales férreos se conoce como antiherrumbre, mientras que en los metales no-férreos se conoce como pasivado.

En el primero de los casos se utilizan sulfonatos de petróleo o de origen sintético como los mono o dialquilbencenos, sulfonatos de calcio y sodio, así como otros productos tales como sales de ácidos grasos de lanolina, parafinas oxidadas, naftenatos de cinc, ácidos succínicos alquilados, ácido nonilfenoxiacético... Se indica a continuación alguna de las fórmulas de productos anticorrosivos no metálicos (ashless) que son los únicos que han llegado ocasionalmente a ser utilizados en aceites aislantes y que no están contemplados en las especificaciones ni es bien conocida su influencia en las propiedades dieléctricas.

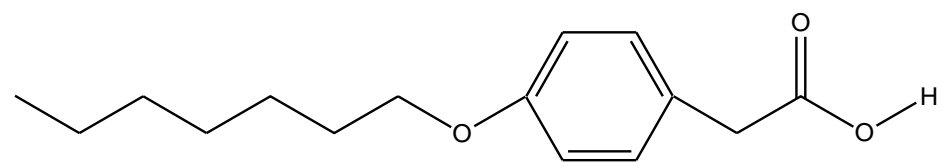

Figura 61: Estructura del ácido nonilfenoxiácético (NPA) 
En el caso de los pasivadores metálicos se distinguen:

a) Los capaces de formar película protectora de superficie "pasivándola" frente a un ataque posterior, y entre los que se encuentran la serie de aditivos derivados de triazol:
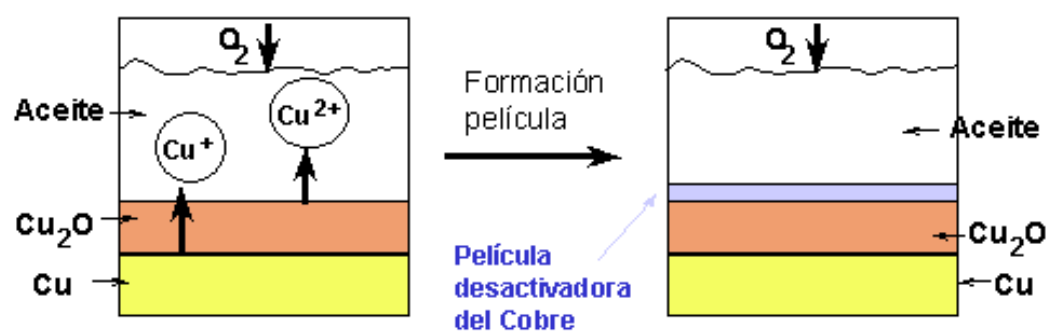

Figura 62: Mecanismo de actuación de pasivantes<smiles>c1ccc2[nH]nnc2c1</smiles>

Benzotriazol<smiles>Cc1ccc2nnn(C)c2c1</smiles>

Tolutriazol<smiles>N#Cn1cncn1</smiles>

Triazol (Liquido)

Figura 63: Estructura química de aditivos derivados del triazol

b) Los que actúan formando "quelatos" con los iones metálicos inhibiendo así la formación de óxido de cobre e impidiendo su acción catalítica pro-oxidante. Es el caso de las disaliciléndialquilendiaminas.

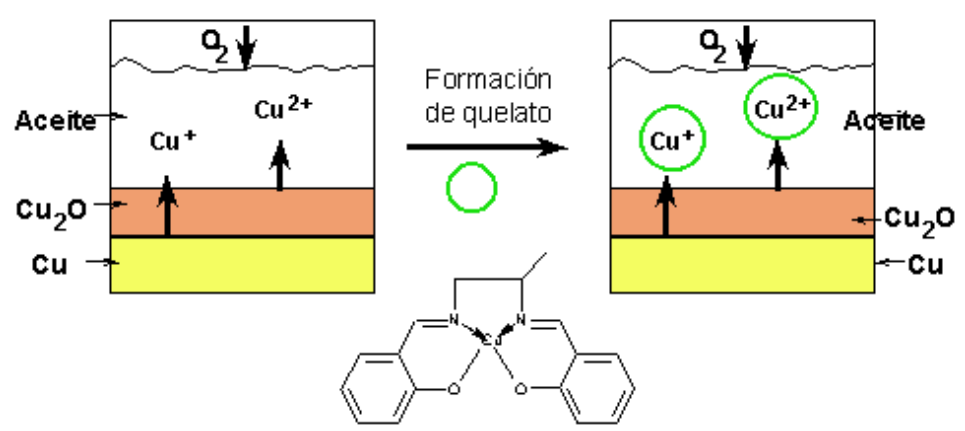

Figura 64: Mecanismo de formación de quelatos 
El caso de los benzotriazoles, es un ejemplo de un aditivo en dieléctricos que cumple simultáneamente otra función, que es la de actuar como supresor de carga electrostática $(E C T)$. Se ha comentado también que este tipo de triazoles pueden generar algún aumento de la generación de gases. Este es el caso señalado en la tabla 18 obtenida para un aceite mineral pasivado con Irgamet 39 y ensayado según procedimiento de Stray Gassing $\left(168 \mathrm{~h} \mathrm{a} 120^{\circ} \mathrm{C}\right)$.

Tabla 18: Aumento de la concentración de gases (en ppm) usando Irgamet 39 (triazol)

\begin{tabular}{|l|c|c|c|c|c|c|c|c|}
\hline & \multicolumn{2}{|c|}{ Sin Irgamet 39 } & \multicolumn{2}{c|}{ Con Irgamet 39 } & \multicolumn{2}{c|}{ Sin Irgamet 39 } & \multicolumn{2}{c|}{ Con Irgamet 39 } \\
\hline Gas analizado & \multicolumn{2}{|c|}{ Atmósfera de $\mathbf{N}_{\mathbf{2}}$} & \multicolumn{2}{c|}{ Atmósfera de $\mathbf{~}_{\mathbf{2}}$} & \multicolumn{2}{c|}{ Atmósfera de aire } & \multicolumn{2}{c|}{ Atmósfera de aire } \\
\hline Hidrógeno & 51 & 55 & 293 & 179 & 234 & 247 & 1575 & 1495 \\
\hline Oxígeno & 516 & 460 & 163 & 214 & 123 & 369 & 372 & 817 \\
\hline Nitrógeno & 77.400 & 77.500 & 76.600 & 77.000 & 61.800 & 64.400 & 62.100 & 64.400 \\
\hline Metano & 15 & 14 & 15 & 13 & 108 & 108 & 79 & 79 \\
\hline $\mathrm{CO}$ & 29 & 25 & 39 & 28 & 208 & 206 & 220 & 229 \\
\hline Etano & 14 & 11 & 12 & 10 & 78 & 78 & 64 & 63 \\
\hline $\mathrm{CO}_{2}$ & 189 & 158 & 262 & 230 & 391 & 394 & 1020 & 1033 \\
\hline Etileno & 1 & 0,7 & 0,9 & 0,9 & 2 & 2 & 1,8 & 2 \\
\hline Acetileno & 0 & 0 & 0 & 0 & 0 & 0 & 0 & 0 \\
\hline $\begin{array}{l}\text { Total gases } \\
\text { combustibles }\end{array}$ & 110 & 107 & 360 & 231 & 630 & 641 & 1940 & 1868 \\
\hline
\end{tabular}

Se observó un claro aumento de hidrógeno y oxígeno, lo que de darse en el transformador, podría dar a una mala interpretación de los análisis de gases diagnosticando erróneamente algún problema de descargas parciales.

Igualmente en un trabajo de Siemens [31] buscando la influencia del pasivante sobre propiedades del aceite, detectaron incrementos de hidrógeno y $\mathrm{CO}_{2}$, pero no de oxígeno, al ensayar los aceites a $140{ }^{\circ} \mathrm{C}$ y 48 h en una modificación del ensayo de corrosión al cobre.

No se han localizado otras publicaciones al respecto, por lo que no se ha podido detectar en aceites vegetales que contienen este tipo de aditivos si se están produciendo estos efectos. 


\subsubsection{Depresores del punto de congelación}

Existe un tipo de aditivos poliméricos que modifican las características de flujo de los aceites dieléctricos pero muy especialmente la fluencia a baja temperatura. Son los llamados Depresores de Congelación (PPD de sus siglas en inglés Pour Point Depressant). La mayor diferencia con respecto a otros aditivos es la concentración óptima de empleo y aquí el peso molecular o el efecto espesante juegan un papel reducido, ya que a dosis de $0,1-1 \%(\mathrm{~m} / \mathrm{m})$ estas características apenas afectan a las propiedades viscosimétricas en caliente.

Los aditivos PPD interfieren el proceso de formación de los cristales de parafina que se producen al disminuir la temperatura, evitando así la creación de una gran red cristalina que daría lugar a la congelación de la masa de aceite. Estos aditivos no impiden que las moléculas de parafina solidifiquen y cristalicen, lo que hacen es cocristalizar con ellas impidiendo, por razones estéricas, la formación de grandes cristales. Se producen numerosos cristales de pequeño tamaño, pero estos pueden moverse unos respecto a otros y el resultado final es que la masa de aceite, aunque viscosa, mantiene cierta movilidad y puede fluir cuando se somete a un cierto esfuerzo. Se consiguen con estos aditivos disminuir las propiedades de congelación en valores de -10 a $-40{ }^{\circ} \mathrm{C}$ según el tipo de aceite, su proceso de congelación natural, su viscosidad, etc.

En la figura adjunta trata de representar la situación anteriormente descrita:

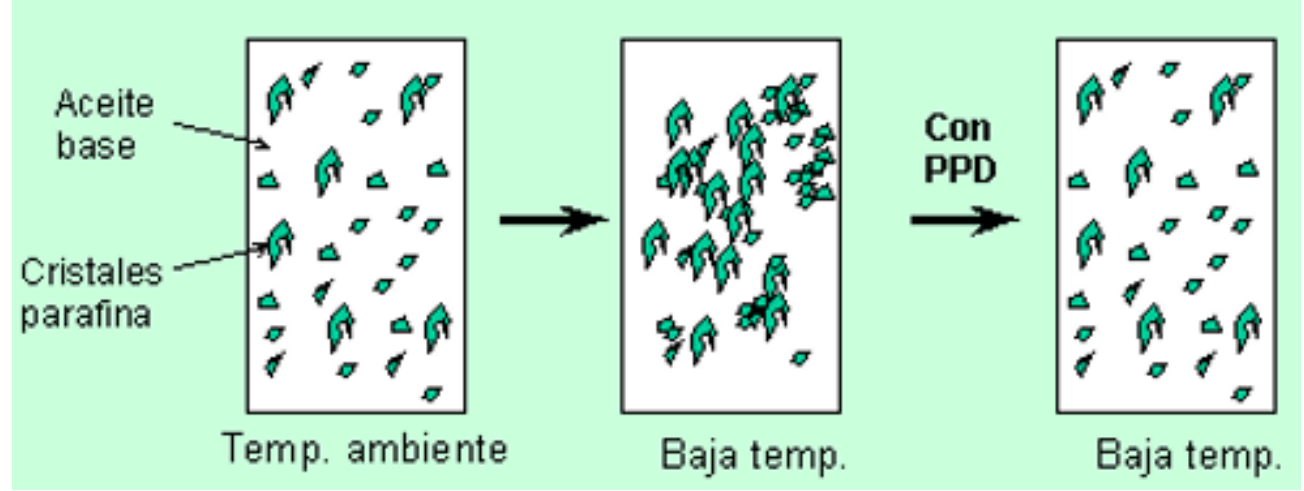

Figura 64: Mecanismo de actuación de aditivos PPD 
En ocasiones, como es el caso de los aceites dieléctricos, se requieren PPD's especiales que no modifiquen las características de tensión interfacial o tangente del ángulo de pérdidas y que los aceites retengan durante largos períodos de tiempo las características modificadas de congelación.

Entre los diversos tipos empleados como PPD son los polialquilmetacrilatos los más utilizados. No obstante, se citan a continuación algunas otras de las especies químicas más empleadas:

- Ftalatos

- Tetraparafinfenol

- Fumaratos

- Estirenos alquilados

- Etilvinilacetatos

- Esteres de acetato de vinilo-fumarato

Estos aditivos que son, en general, de eficacia probada en aceites minerales, no lo son tanto en aceites vegetales. Se están desarrollando nuevos polímeros en estos últimos tiempos, no tanto por su aplicabilidad a aceites dieléctricos sino al biodiesel, de donde se esperan avances en los próximos años.

Una nueva familia de reciente aparición son los copolímeros de ésteres de estirenoanhídrido maleico (nombre comercial L 7671) del que se indican a continuación algunos datos sobre su capacidad de mejorar las propiedades en frío de aceites de colza y soja hiperoleica.

Tabla 19: Mejora de las propiedades en frio en varios aceites vegetales

\begin{tabular}{|c|c|c|}
\cline { 2 - 3 } \multicolumn{1}{c|}{} & \multicolumn{2}{c|}{ Ensayo punto de congelación (ASTM D 97), o-C } \\
\hline Concentración L 7671 & Aceite soja hiperoleica & Aceite de colza \\
\hline $0 \%$ & -12 & -18 \\
\hline $1 \%$ & -24 & -36 \\
\hline
\end{tabular}


Sigue también sin resolverse claramente el problema de la estabilidad en frío de los aceites vegetales aditivados con PPD al almacenamiento prolongado incluso a temperaturas claramente superiores a las de su punto de congelación. En la siguiente tabla, además del empleo del aditivo depresor se ha recurrido a un disolvente mineral para mejorar sus propiedades.

Tabla 20: Mejora de las propiedades en frio en varios aceites vegetales

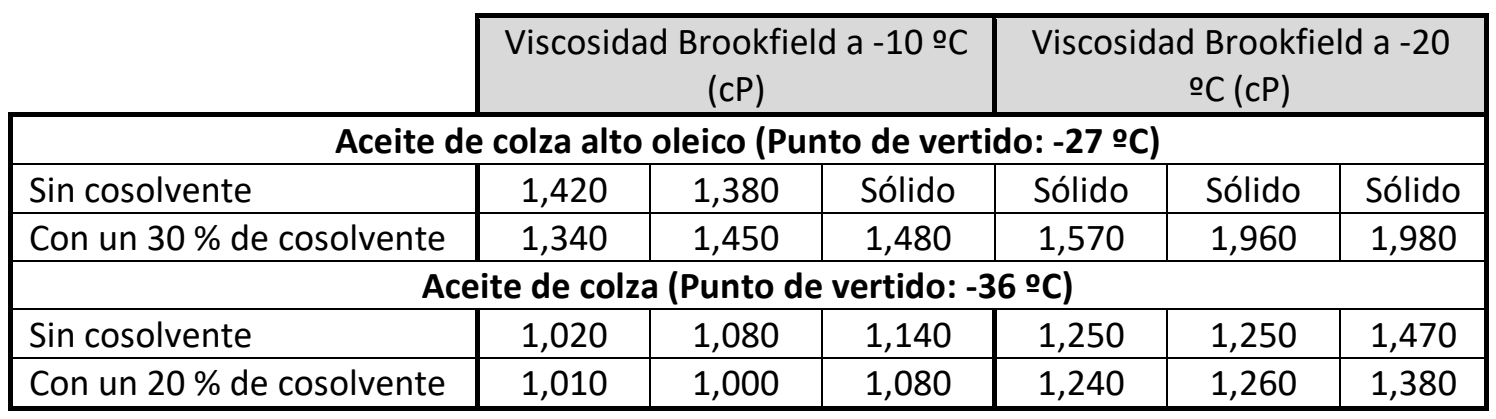

Este aspecto de estabilidad de las propiedades en frío es muy importante en aceites de transformador ya que estos pueden estar desenergizados largos periodos de tiempo en condiciones atmosféricas de baja temperatura. Si hubiese deposición de material se interrumpiría la circulación de aceite pudiendo generar sobrecalentamientos locales con consecuencias catastróficas.

Es obvio, por tanto, que esta propiedad deberá ser bien evaluada al aditivar los futuros aceites de base vegetal, para los que también habrá la necesidad del emplear aditivos PPD específicos en función del origen del éster.

\subsubsection{Otros aditivos}

Existen también algunos tipos de productos específicos para modificar, en aceites dieléctricos, las características de "Gas Absorbing-Gas Evolving” y cuya misión es la de ser aceptores de hidrógeno. Se encuentran entre ellos distintos productos con mayor o menor grado de aromaticidad, es decir, de insaturación. Dado que en principio, el hidrógeno que se genera en el transformador lo hace en estado naciente, es capaz de saturar los dobles enlaces. 
Se utilizan para esta aplicación alquilbencenos, alquilnaftalenos, difenilalcanos, pmetilantraquinona, etc. Aunque en bajas cantidades (normalmente inferiores a un $2 \%$ $(\mathrm{m} / \mathrm{m})$, siendo su empleo cada vez más limitado. 


\subsection{BIODEGRADABILIDAD Y ECOTOXICIDAD DE LOS ACEITES VEGETALES}

Con respecto a la evaluación medio ambiental de estos nuevos aceites dieléctricos biodegradables, las propiedades del aceite dieléctrico ecológico, con una biodegradabilidad según OECD 301 B próxima al $90 \%$ (frente a valores inferiores al 50 $\%$ en aceites minerales y aún inferiores en siliconas sintéticas) y una ecotoxicidad frente a algas, daphnias y peces superior a $1000 \mathrm{mg} / \mathrm{L}$ son argumentos suficientes para asegurar que un vertido accidental del fluido no tendrá consecuencias dañinas para el medio ambiente.

En línea con este razonamiento el EcoLabel europeo, reconocimiento a aquellos fluidos de características amigables con el medio ambiente, es concedido a compuestos que entre otros requisitos muestran valores de biodegradabilidad superiores al $60 \%$ según OECD $301 \mathrm{~B}$ y valores de ecotoxicidad frente a algas, daphnias y peces (según OECD 201, 202 y 203 respectivamente) superiores a $100 \mathrm{mg} / \mathrm{L}$.

Es necesario aclarar que en la actualidad existen numerosos métodos estandarizados para medir la biodegradabilidad de compuestos. De forma general, todos consisten en someter a incubación el producto a ensayar en medio acuoso, junto con un determinado tipo de bacterias, en unas condiciones específicas. La principal diferencia entre cada método consiste en que, según el tipo de análisis de resultados, se obtienen datos de biodegradabilidad diferentes:

- Biodegradabilidad total: Cuando se mide la cantidad de $\mathrm{CO}_{2}$ desprendido (medida directa) o el consumo de oxígeno (medida indirecta) durante el periodo de incubación. El compuesto es transformado en su totalidad en $\mathrm{CO}_{2}$, agua, sales minerales y biomasa.

- Biodegradabilidad primaria: Cuando se mide la cantidad de hidrocarburo desaparecido (degradado) durante el periodo de incubación. Alteración de la estructura química del compuesto, resultando en la pérdida de alguna de sus propiedades específicas.

Igualmente, la biodegradabilidad se puede clasificar como inherente o rápida según el tipo de ensayo: 
- Inherente: El ensayo se realiza bajo condiciones que favorecen la biodegradación (alta concentración de biomasa y de microorganismos en relación a concentración de sustancia de ensayo, aclimatación previa de los microorganismos a la sustancia de ensayo, periodo de incubación largo).

- Rápida: El ensayo se realiza bajo condiciones relativamente desfavorables a la biodegradación (pequeña concentración de microorganismos en relación a concentración de sustancia de ensayo, SIN aclimatación previa de los microorganismos a la sustancia de ensayo, periodo de incubación corto).

Es importante destacar que el método OECD 301 B cuantifica la biodegradabilidad total (conversión total a $\mathrm{CO}_{2}$, agua, sales minerales y biomasa) y rápida (se realiza bajo condiciones relativamente desfavorables a la biodegradación). Por tanto, asegura el metabolismo completo del compuesto en condiciones similares a las que se pueden dar en un vertido accidental en medio acuoso.

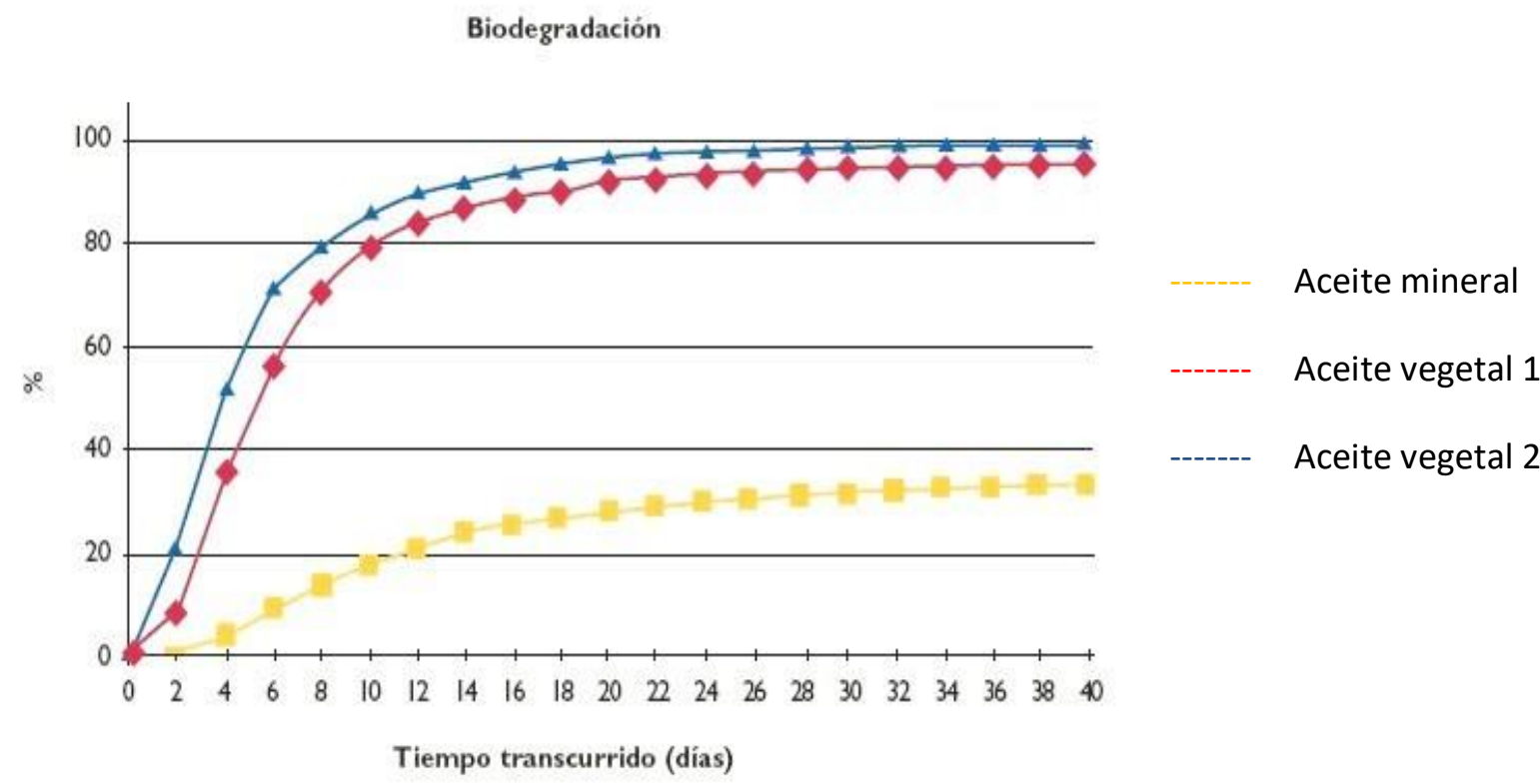

Figura 65: Biodegradación de los aceites vegetales frente a los aceites minerales 
El mecanismo de degradación hidrotérmica de los aceites vegetales se muestra a continuación en la figura 66:

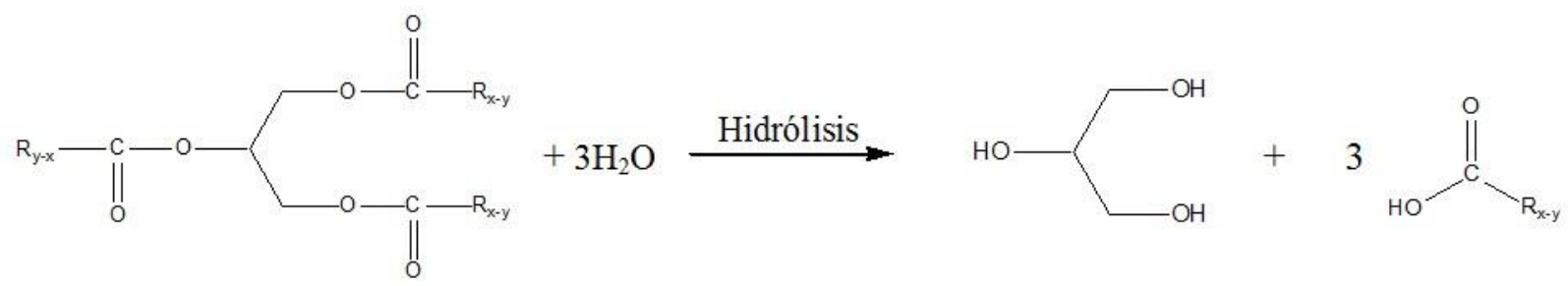

Figura 66: Mecanismo de degradación hidrolítica de un triglicérido

El glicerol se degrada según mecanismos de tautomerización, deshidratación, condensación,... mientras que los ácidos grasos sufren una descarboxilación según el mecanismo de reacción siguiente:<smiles>[R17]C(=O)O</smiles>

\section{Descarboxilación}

$$
\mathrm{R}_{\mathrm{x}-\mathrm{y}}+\mathrm{CO}_{2}
$$

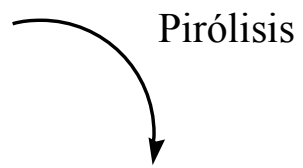

$\mathrm{R}_{\mathrm{m}-\mathrm{a}}^{\prime}+\mathrm{R}^{\prime \prime}{ }_{\mathrm{n}-\mathrm{b}}$

Figura 67: Biodegradación de los ácidos grasos presentes en la molécula de triglicérido

Donde $\mathrm{R}_{\mathrm{x}-\mathrm{y}}, \mathrm{R}_{\mathrm{m}-\mathrm{a}}$, $\mathrm{R}^{\text {” }}$ n-b son cadenas hidrocarbonadas productos de degradación de los ácidos grasos, $\mathrm{x}, \mathrm{m}, \mathrm{n}$ es el número de átomos de carbono $(1,2,3, \ldots ; \mathrm{x}>\mathrm{m}, \mathrm{n})$ e y,a,b son el número de insaturaciones $(0,1,2,3, \ldots ; \mathrm{y}>\mathrm{a}, \mathrm{b})$. 
Otro de los motivos de cambiar la naturaleza del fluido aislante para transformadores es conseguir un mejor comportamiento frente al fuego. El aceite dieléctrico ecológico tiene un excelente comportamiento ante el fuego reduciendo el riesgo de que se produzca un incendio y minimizando las consecuencias de este en caso de producirse. Tales afirmaciones están corroboradas por el hecho de que el aceite dieléctrico ecológico presenta un punto de combustión superior a $350^{\circ} \mathrm{C}$ (inferior a $250^{\circ} \mathrm{C}$ en el caso de los aceites minerales) y es clasificado según la norma UNE 61100 como un fluido de clase $\mathrm{K}$, es decir, es un fluido de seguridad aumentada lo que evita la necesidad de instalar sistemas fijos de extinción de incendios en los centros de transformación.

Por otra parte, en ensayos realizados bajo la norma ISO 5660-1 el aceite dieléctrico ecológico ha mostrado una mucho mayor resistencia a inflamarse que los aceites minerales con tiempos de ignición 4 veces superiores a los aceites minerales. Además, una vez producida la ignición, las tasas de emisión de humos y las velocidades de emisión de calor han sido un $50 \%$ inferiores a los aceites minerales. 
CAPÍTULO 2: EQUIPOS Y MÉTODOS DE ENSAYO 
Como hemos podido ver en el capítulo 1, el desarrollo de un nuevo aceite dieléctrico así como una herramienta de diagnosis para la evaluación de fallos eléctricos y térmicos ocurridos dentro de un transformador de distribución, es una tarea que requiere el estudio de muchas propiedades químicas, físico-químicas, de compatibilidad y de ecotoxicidad.

Por esta razón, en el presente capítulo se expondrán de forma sencilla los métodos desarrollados en el laboratorio para poder evaluar y cuantificar dichas propiedades.

\subsection{ESTUDIO DE LAS PROPIEDADES EN FRIO}

\subsubsection{Winterización / desparafinado}

\subsubsection{Introducción}

La winterización es un proceso termomecánico de separación donde los componentes triglicéridos de las grasas y aceites cristalizan desde un fundido o líquido. La cristalización fraccionada en dos componentes viene acompañada de una solidificación parcial y separación de los componentes de triglicéridos de mayor temperatura de fusión. Los triglicéridos precipitables pueden tener uno, dos o los tres ácidos grasos, que pueden ser del mismo tipo o diferente y en cualquier posible configuración, dependiendo de la fuente de la que proceden.

Según la literatura, la cristalización de los triglicéridos ocurre en dos etapas: (1) nucleación, y (2) crecimiento cristalino. La velocidad de nucleación depende de la composición de triglicéridos, la velocidad de enfriamiento del aceite, la temperatura de nucleación y la agitación. La velocidad de crecimiento de los cristales depende de la temperatura de cristalización, el tiempo y la agitación. Así pues una cuidadosa selección de las variables de proceso es muy importante para un aceite en particular.

\subsubsection{Diseño de experimentos}

Se había leído en literatura y observado en el laboratorio, que algunos aceites vegetales que presentan puntos de congelación relativamente bajos, congelan sin embargo a 
temperaturas más altas cuando se les deja reposar durante un cierto período de tiempo. Por ejemplo, el aceite de soja presenta un punto de congelación de $-26^{\circ} \mathrm{C}$, pero si se almacenaba a $-18^{\circ} \mathrm{C}$ durante 24 horas, al cabo de este período, el aspecto del aceite era el de una masa sólida blanca. Por lo tanto, parecía de interés que se estudiase algún método para eliminar parte del material cristalizado con el objetivo de garantizar que el aceite no congelase en esas circunstancias.

En los siguientes apartados de la presente tesis se hacen resúmenes de algunos procesos recogidos de distintas fuentes, presentando con carácter previo alguna información de definición de los términos descerado/winterización/fraccionamiento.

Finalmente, se recoge al final del presente apartado la definición del ensayo de "Cold test" muy utilizado en la industria y que se considera puede ser de interés para trabajos futuros. También se expone una propuesta del empleo de este método como fase previa a la definición de las condiciones de winterización en laboratorio.

De las referencias bibliográficas consultadas, se pueden extraer las siguientes conclusiones:

a) Se puede leer reiteradamente en la bibliografía que tanto la nucleación como el crecimiento cristalino dependen de la composición del aceite que se vaya a desparafinar y que los distintos triglicéridos para un aceite dado, fraccionarán en el orden siguiente:

\section{Trisaturados, $\mathrm{S} 3$}

2. Disaturados monoinsaturado, S2U

3. Monosaturado diinsaturado, SU2

4. Triinsaturados, U3

Aunque una parte menor de los glicéridos de mayor punto de fusión permanecerán en el líquido como resultado de la formación de mezclas eutécticas y equilibrios de solubilidad.

Por cuanto la mezcla de triglicéridos en un aceite es demasiado compleja como para predecir su separación de fases, unas determinadas condiciones de winterización solo son aplicables para un tipo de aceite en particular. 
b) Dado que los procedimientos tradicionales de winterización requieren de bastante tiempo y dan bajos rendimientos, los que utilizan disolventes pueden resultar los más adecuados especialmente cuando se requieren aceites de bajo punto de congelación y elevado Cold Test.

c) Se han empleado numerosos disolventes en la winterización dependiendo del tipo de aceite, aunque algunos de los más citados son el n-hexano, la acetona y las mezclas de ambos, aunque el n-hexano en bajas concentraciones (10\%) y temperaturas próximas a $0{ }^{\circ} \mathrm{C}$, tiende a dar disoluciones gelatinosas con algunos aceites.

Por ejemplo, una mezcla muy citada para baja temperatura es 50/50 (v/v) de aceite/nhexano con un período de agitación de 1 hora a $10 \mathrm{rpm}$, con un enfriamiento progresivo a $-5{ }^{\circ} \mathrm{C},-12^{\circ} \mathrm{C}$ y finalmente $-20^{\circ} \mathrm{C}$. Otros disolventes citados son: metiletilcetona, metilisobutilcetona, acetato de etilo, acetato de isopropilo, dietil éter, disoluciones de dimetil formamida, etc.

d) Se observa en general que los tiempos de cristalización recomendables en los procesos de winterización son más elevados que los que habitualmente se emplean en el desparafinado de productos petrolíferos y pueden llegar incluso a más de 24 horas.

e) El empleo del Cold Test o sistema similar es una determinación de gran interés que puede ayudar a seleccionar las condiciones de operación en la winterización, especialmente para fijar la temperatura o tiempo de enfriamiento en el proceso. También resulta de interés y es utilizado en algunos casos el método de Calorimetría Diferencial de Barrido ( $D S C$ ) para determinar el inicio de la cristalización y proceder así a la winterización a partir de la temperatura COT (Crystallization Onset Temperature).

f) En el caso de esta tesis, se propondrá un método previo o de screening para la selección de variables que posteriormente se optimizarán en la winterización. Este podría resumirse en las siguientes etapas:

1. Preparación de unos $20 \mathrm{~mL}$ de disoluciones de aceite en n-hexano en proporciones de $1 / 1$ y $3 / 1(\mathrm{v} / \mathrm{v})$ de disolvente/aceite

2. Preparación de unos $20 \mathrm{~mL}$ de disoluciones de aceite en acetona en proporciones de $1 / 1$ y $3 / 1(\mathrm{v} / \mathrm{v})$ de disolvente/aceite 
3. Preparación de unos $20 \mathrm{~mL}$ de disoluciones de aceite y mezcla de disolventes en proporción 85/15 de acetona/n-hexano.

4. Introducción de tubos de ensayo o viales de las disoluciones y del aceite sin disolvente en chiller a $0{ }^{\circ} \mathrm{C}$ y disminución de la temperatura a una velocidad de enfriamiento de $0,3{ }^{\circ} \mathrm{C} / \mathrm{min}$ (una hora aproximadamente para alcanzar $-20^{\circ} \mathrm{C}$ en el baño).

5. Mantener las disoluciones durante 5 horas a $-20^{\circ} \mathrm{C}$ observando visualmente la aparición de precipitados.

6. Seleccionar la condición más adecuada en función de la cantidad de estearina precipitada y la no aparición de geles.

La winterización es una etapa de fraccionamiento seco que proporciona dos productos a partir del mismo material original. Cuando se aplica a triglicéridos, se obtienen dos fracciones de diferente punto de fusión que se separan por su diferente solubilidad en el aceite a una temperatura determinada.

La separación de las fases se lleva a cabo, en general, por filtración opcionalmente aplicando algún tipo de presión. Y el principal problema encontrado en la separación de fases es la inclusión de fracción oleína liquida en la fracción de estearina sólida. La fracción de oleína se retiene en los espacios internos y entre la masa de cristales de la fracción de estearina. De esta forma la separación del solido a partir de la fracción liquida es solamente parcial. El contenido en sólidos de la fracción de estearina se conoce como eficacia de la separación. Por ejemplo, para el fraccionamiento en seco de aceite de palma, la eficacia raramente sobrepasa el $50 \%$ en peso.

Originalmente se aplicaba este proceso al aceite de semillas de algodón para la eliminación de los triglicéridos de alto punto de fusión sometiendo al aceite a una cristalización lenta de los productos de mayor peso molecular en tanques al exterior durante el invierno, de aquí se obtiene el término winterización.

En las figura 68 se muestra el resultado de un proceso de winterización realizado en laboratorio, en el que un aceite se ha enfriado a $10{ }^{\circ} \mathrm{C}$ durante $6 \mathrm{~h}$ y se ha filtrado mediante papel de Whatman 41 mediante un sistema como el indicado a continuación: 


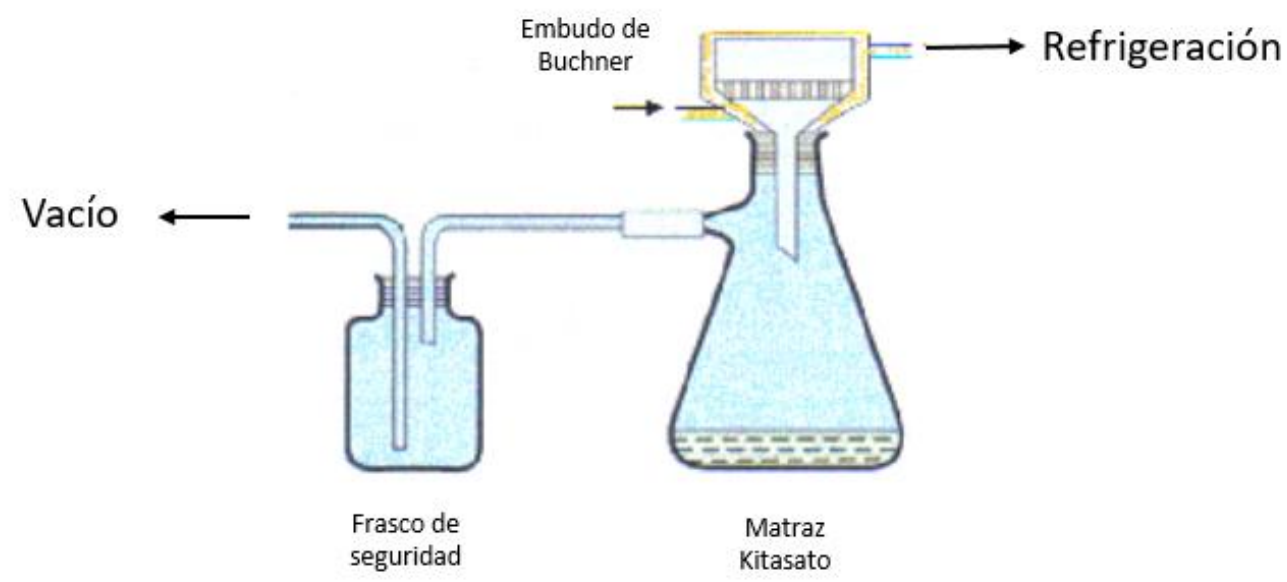

Las fracciones resultantes serían:

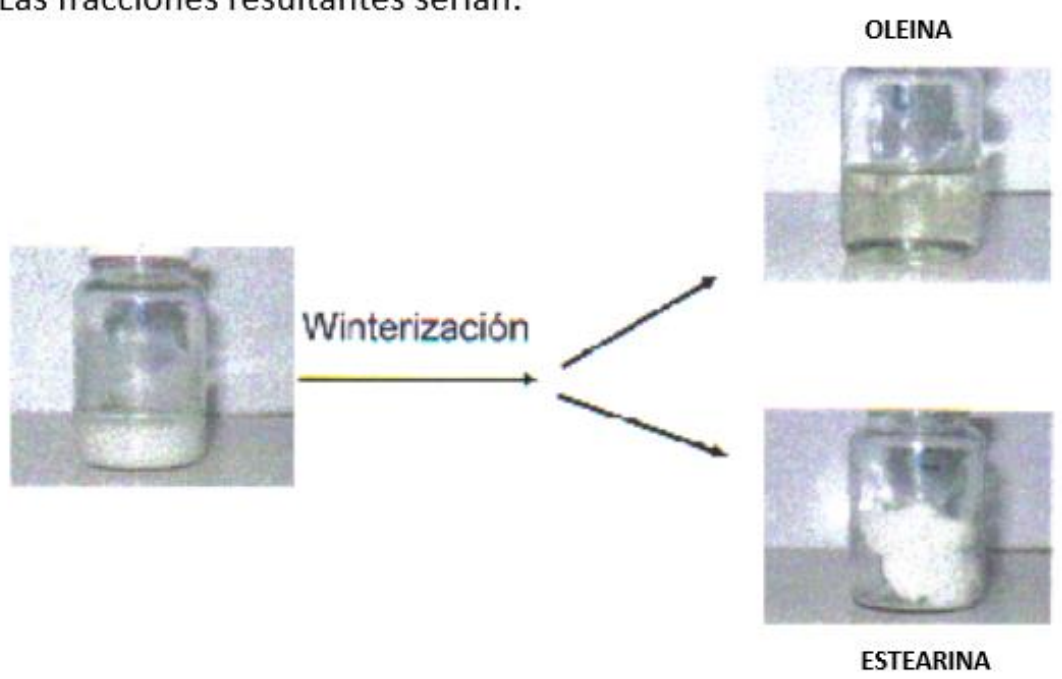

Figura 68: Obtención de oleína y estearina después de un proceso de winterización

Hoy en día, lógicamente, en el proceso industrial se utiliza la refrigeración mecánica y es esencial que ésta sea controlada para ajustar la temperatura de enfriamiento y el tiempo de maduración de los cristales. Generalmente se realiza por enfriamiento rápido del aceite con agua fría o equipos frigoríficos, con lo que se consigue la cristalización de los compuestos que se quieren eliminar. Estos sólidos, llamados "estearinas" se separan de las "oleínas", o fase líquida, por filtración o centrifugación.

Las etapas del proceso son: enfriamiento gradual y cuidadoso del aceite o mezcla aceite/disolvente hasta sobresaturación y formación de núcleos de crecimiento de los cristales, maduración y separación de los cristales por centrifugación o filtración en filtros herméticamente sellados. Se emplea por ejemplo, con aceites de girasol y de salvado de arroz. 


\subsubsection{Fraccionamiento de ácidos grasos}

Esta tecnología, que engloba a los procesos anteriores, se encuentra en uso industrial desde hace más de un siglo, y consiste también en la separación mecánica de los componentes líquidos (oleína) que forman una grasa o aceite, de los componentes sólidos (estearina) cristalizados. La separación de la fracción líquida de la sólida depende de la temperatura a que se realiza la cristalización, y el número de fracciones obtenidas dependerá del número de etapas de fraccionamiento.

Este proceso se utiliza principalmente para mejorar las propiedades "líquidas" de la fracción principal o para producir una fracción sólida más "pura". La complejidad de aceites y grasas implica que las fracciones obtenidas serán a su vez una mezcla de varios triglicéridos, pero enriquecidas en componentes de alto o bajo punto de fusión de la mezcla original. La solidificación de grasas es un proceso bastante complicado, que conlleva la formación de cristales mixtos, lo que hace difícil predecir cuál será el comportamiento en términos de fusión de las fracciones obtenidas.

El fraccionamiento suele ser utilizado como un proceso en sí mismo, durante el refinado de aceite o como parte de procesos de modificación de grasas y aceites, combinado con hidrogenación, interesterificación, etc.

En el caso del fraccionamiento hay que tener presente que el valor de la fracción o fracciones secundarias puede tener un importante papel en rentabilidad final de la producción.

Tipos de fraccionamiento:

A.- Sedimentación por gravedad y por refrigeración indirecta. Se empleaba antes de la aparición del fraccionamiento industrial; la separación de las distintas fracciones mediante la sedimentación por gravedad de los sólidos, conllevaba una gran pérdida de aceite. La refrigeración indirecta del aceite seguido de filtración o centrifugación es por tanto una winterización.

B.- Adición de agentes de superficie activa y centrifugación. Se comenzaron a usar a nivel industrial a mediados del siglo XX agentes de superficie activa para ayudar en la 
separación de la grasa cristalizada de la fracción líquida, así como las centrífugas de disco, de alta eficacia.

C.- Fraccionamiento en "seco": la grasa/aceite se funde completamente para posteriormente ser enfriada, formándose cristales de los triglicéridos de mayor punto de fusión, que se separan por filtración. En este caso queda bastante oleína presente en la torta de filtrado, por lo que se considera un proceso poco selectivo y es el llamado desparafinado seco. El mayor problema encontrado aquí es la inclusión de una gran cantidad de oleína en la fracción separada de estearina. El fraccionamiento en seco es un procedimiento más barato y ambientalmente más aceptable que el fraccionamiento con disolvente y es en éste donde encuentran interés los aditivos modificadores de la forma cristalina de la estearina.

D.- Fraccionamiento con disolventes: Apareció alrededor de 1950 para la producción de una grasa a partir de aceite de palma, con propiedades de fusión similares a la manteca de cacao y que a su vez fuera compatible con ella. La grasa /aceite a fraccionar se disuelve con un disolvente como acetona o n-hexano, tras lo que se enfría la disolución. La mayor dificultad del proceso reside en conseguir el crecimiento de los cristales del glicérido de forma que al separarlos, retenga la menor cantidad posible de aceite líquido. Por esto, conviene que durante el proceso se formen cristales grandes, bajando lentamente la temperatura. Tras la formación de cristales de los triglicéridos con mayor punto de fusión, se separan por filtración, mientras que las fracciones se recuperan por evaporación del disolvente. El contenido de oleína de la torta de filtrado es mínimo y está diluido en el disolvente.

El proceso es equivalente al empleado en el sector de refino de petróleo para obtener bases lubricantes por desparafinado.

El fraccionamiento con disolventes se caracteriza por:

- Ser un proceso muy eficaz en cuanto al rendimiento de separación, produciéndose una fracción sólida de alta calidad.

- Requiere una elevada inversión.

- Elevado gasto de energía. 
- Presenta problemas de seguridad debido a la inflamabilidad de los disolventes utilizados.

Todo esto hace que el fraccionamiento con disolventes se utilice únicamente para la obtención de fracciones con alto valor añadido. La cristalización fraccionada surge a raíz del aumento de producción de aceite de palma en Malasia e Indonesia alrededor de 1970. La oleína de palma, separada mediante fraccionamiento, se comercializa mucho mejor en el mundo industrializado que el aceite al completo. Para el procedimiento de fraccionamiento de aceite de palma, donde la grasa a fraccionar se cristaliza a partir de, por ejemplo, una disolución de n-hexano o acetona, las eficiencias de la separación pueden ser superiores a un $95 \%$, frente al $50 \%$ antes mencionado.

E.- Fraccionamiento con membranas de filtración. El desarrollo de las tecnologías de membranas para utilizar en la filtración a presión, ha tenido un gran efecto en las tecnologías de fraccionamiento. Este tipo de tecnología está implantándose y permite obtener fracciones de alta pureza, en condiciones de operación suaves y con costes relativamente bajos, estableciéndose como alternativa al fraccionamiento con disolventes y sus desventajas.

Se sabe que se puede interferir la cristalización añadiendo al aceite de cristalización una sustancia modificadora de la cristalización. La presencia de pequeñas cantidades de la citada sustancia o aditivos en el proceso de enfriamiento podría acelerar, retardar o inhibir la cristalización. Los modificadores de cristalización preferidos son por ejemplo esteres de ácidos grasos de glucosa y derivados. Estos modificadores de cristalización son eficaces para la aceleración de la velocidad de cristalización pero no se describen como capaces de incrementar la eficacia de la separación.

Hay actualmente disponibles otros modificadores de las formas cristalinas de manera que después de la cristalización pueda separarse la fase de estearina más eficazmente de la fase liquida: la fase de oleína. Se trata, por ejemplo, de esteres de ácidos grasos de sacarosa, aditivos basados en productos de polimerización de esteres de alcohol vinílico o de un alcohol vinílico sustituido, así como copolímeros esterizados de anhídrido maleico y estireno. Se ha descrito también el uso de derivados de dextrina para el mismo propósito. 


\subsubsection{Selección de las condiciones de ensayo}

En el artículo de Leibovitz [32] se describen tres métodos de winterización de aceite de girasol:

A - El método convencional con separación a través de filtros y que consiste en una cristalización gradual con Kiselgur (Hyflo-supercell), maduración y separación por filtros

B - El de cristalización con un agente coadyuvante de la precipitación, que puede ser agua o jabón. Después de la cristalización, la suspensión de agua se separa por centrifugación.

C - El de winterización en disolvente, que consiste en mezclar el aceite con un volumen determinado de disolvente tal como n-hexano o alcohol isopropílico y después del enfriamiento y cristalización, se separa el sólido mediante filtros, centrifugación o decantadores especiales.

El más interesante, según el desarrollo de sus autores es éste último, donde la cristalización se realiza en alcohol isopropílico empleando un cristalizador en continuo en el que los cristales flotan en la parte superior del medio. Un sistema especial de decantación permite a continuación separar los cristales. Se reconoce que el principal problema del proceso es la energía consumida en la evaporación del disolvente.

Utilizan como método de control el llamado "Cold Test OC" donde el aceite debe permanecer brillante durante un ciclo de 24 horas a $0^{\circ} \mathrm{C}$ y 72 horas a temperatura ambiente.

En cuanto a las ceras eliminadas se trata de esteres de ácidos grasos de $\mathrm{C}_{20}$ a $\mathrm{C}_{28} \mathrm{y}$ alcoholes grasos de $\mathrm{C}_{22}$ a $\mathrm{C}_{30}$ cuyo punto de fusión es de $76-77{ }^{\circ} \mathrm{C}$ y que contienen a su vez triglicéridos de palmítico y esteárico. No se describen en el artículo detalles del proceso ni temperaturas ni relaciones alcohol/aceite etc. 
Por otro lado, en el artículo de Pushpinder [33], el proceso de winterización se aplica a aceites para ensaladas donde estos deben estar transparentes a la temperatura de almacenamiento en frigorífico.

Los autores detallan en qué medida factores tales como la velocidad de refrigeración, la temperatura de cristalización y la movilidad de las moléculas de triglicéridos en la masa son cruciales al jugar un importante papel en la separación de las grasas sólidas en forma de distintos cristales capaces de separarse fácilmente del aceite por filtración.

En el proceso de winterización, el aceite es enfriado desde la temperatura ambiente hasta una temperatura predeterminada de cristalización. El aceite se mantiene a esta temperatura durante un cierto periodo de tiempo previo a la separación de la fase sólida del líquido por filtración.

Los triglicéridos que se encuentran en aceite y grasas son de naturaleza compleja de forma que un simple triglicérido puede contener uno, dos o tres ácidos que pueden ser los mismos o cualquiera de las posibles combinaciones de ellos, por lo que la eliminación de una cierta parte por cristalización fraccionada es un proceso difícil.

El factor determinante de ambos procesos es la sobresaturación, considerando que no ocurre ni nucleación ni crecimiento cristalino en soluciones no sobresaturadas. Una disolución sobresaturada se define como aquella que contiene más soluto que el que podría disolver bajo condiciones de equilibrio y en el caso de grasas y aceites ésta solo se forma reduciendo la temperatura del fundido. Las curvas de saturación pueden determinarse experimentalmente en función de la temperatura y definen tres regiones en el conjunto concentración -temperatura: una región de insaturación donde un cristal de soluto se disolverá, una región metaestable entre la curva de saturación y la de sobresaturación donde puede haber crecimiento cristalino y una región sobresaturada (inestable) donde la nucleación tiene lugar instantáneamente. 


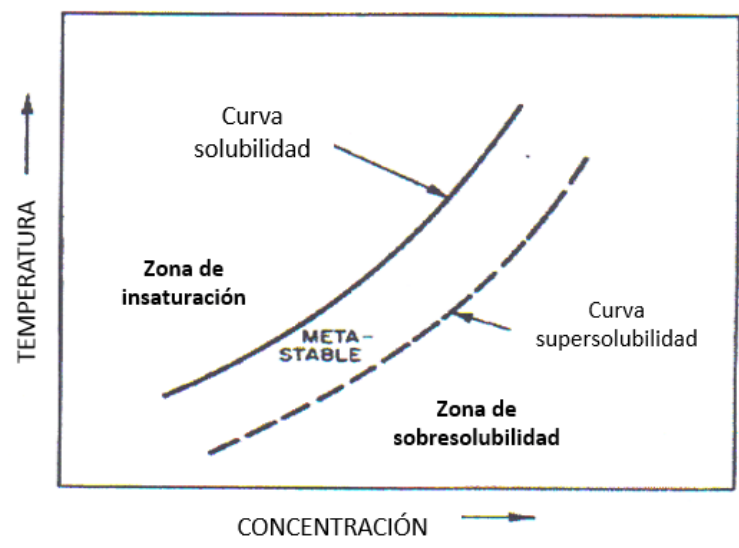

Figura 68: Obtención de oleína y estearina después de un proceso de winterización

La nucleación puede ser estimulada por la introducción de energía mecánica. La acción de agitadores, bombas e impacto sobre las paredes sólidas del recipiente puede iniciar la nucleación. Los otros factores que pueden afectar a la nucleación son el área de la superficie del cristal y la velocidad de enfriamiento.

La nucleación puede también ocurrir cuando materias extrañas actúan como núcleos en los que el soluto puede comenzar a construir un entramado. La presencia de tal material extraño o el propio crecimiento de cristales conduce a un menor grado de sobresaturación. Una vez la nucleación ha tenido lugar en la región sobresaturada a partir de la formación de fase sólida, la concentración de soluto en la disolución disminuirá y si esta concentración se mantiene entonces entre las zonas de saturación y sobresaturación, el núcleo crecerá para formar cristales.

El crecimiento cristalino puede tener lugar por difusión controlada o por integración de partículas. Para un cristalizador sin agitación el crecimiento está controlado por la difusión de partículas y la velocidad de crecimiento de los cristales depende de su tamaño. En un cristalizador agitado, la velocidad de crecimiento viene determinada por la integración de partículas y es por tanto independiente del tamaño de los cristales.

En resumen, la velocidad de nucleación depende de la composición de triglicéridos a winterizar, la velocidad de enfriamiento, la temperatura de nucleación y el tipo de agitación. 
Así pues, una selección cuidadosa de las variables de winterización es muy importante para producir un pequeño número de núcleos alrededor de los cuales crecen en tamaño cada vez mayor a medida que el enfriamiento continúa, ya que si se produjesen un gran número de núcleos habría una gran cantidad de pequeños cristales difíciles de filtrar. Además, si los cristales se agrupasen en forma de pequeños terrones la fase líquida podría quedar ocluida y daría como resultado una mala separación y rendimiento pobre en fracción oleína.

La composición de los triglicéridos condiciona la curva de saturación-sobresaturación y el mecanismo de crecimiento cristalino. En general se admite que los diferentes triglicéridos fraccionarán en el siguiente orden:

Trisaturados $>$ Disaturados y monoinsaturado $>$ Monosaturado y diinsaturados $>$ Triinsaturados

Y, en forma contraria a lo que podría intuirse, algunos glicéridos linoleicos cristalizan en mayor grado, a una misma temperatura, que los correspondientes glicerooleatos. Por ejemplo:

$$
\mathrm{PLP} \sim>\mathrm{POP}, \mathrm{OLP}>\mathrm{LOP} \sim>\mathrm{OOP}
$$

Donde P, O y L significan los grupos palmítico, oleico y linoleico del triglicérido. La velocidad de enfriamiento es crucial en un proceso de winterización, requiriéndose extremo cuidado para obtener una disolución sobresaturada. Si el sobreenfriamiento se lleva acabo demasiado rápido, se formará una masa de cristales muy pequeños y además, como la velocidad de nucleación es muy rápida se formará una masa muy viscosa que impediría el movimiento de los núcleos que no podrían agregarse fácilmente ni crecer por causa de la débil difusión de moléculas existentes en la masa viscosa.

Los autores reportan velocidades de enfriamiento del orden de $1-3{ }^{\circ} \mathrm{C} /$ hora, aunque en determinados aceites parcialmente hidrogenados podrían usarse velocidades de 13$17^{\circ} \mathrm{C} /$ hora $\left(0.2-0.3{ }^{\circ} \mathrm{C} / \mathrm{min}\right)$. 
La temperatura de cristalización es importante bajo el punto de vista de la velocidad de crecimiento de los cristales. Se determina normalmente a partir de las curvas de saturación - insaturación. Si es demasiado baja resultará una viscosidad muy alta y el crecimiento de los cristales será pequeño. Además, siendo el proceso de cristalización ligeramente exotérmico su control es muy importante ya que también intervienen transformaciones de formas cristalinas

Una velocidad de agitación adecuada durante la nucleación y crecimiento cristalino puede minimizar los gradientes de transferencia de masa y de calor evitando nucleaciones localizadas. La velocidad de agitación debería ser la necesaria para mantener uniforme la temperatura y la masa de aceite, provocando un movimiento suave pero suficiente para facilitar el crecimiento de cristales por choque entre ellos. La agitación no deberá ser tampoco elevada para evitar la cizalla de cristales o su rotura.

El tiempo de cristalización juega un papel crucial en el crecimiento cristalino según se infiere de la curva de saturación - insaturación, reportándose que en diseños bien realizados el tiempo podría ser de 6-10 horas

Por otro lado, en la patente europea 95913146.7 [39] se reivindica un procedimiento para el fraccionamiento de aceites de triglicéridos, con el objetivo de mejorar la eficacia de la separación.

Los autores encuentran que se puede mejorar la eficacia de la separación en el fraccionamiento de grasas de triglicéridos, monoglicéridos o diglicéridos de ácidos grasos. De acuerdo con la invención, el procedimiento desarrollado para la separación de material graso solido cristalizado a partir de un aceite de triglicérido comprende las etapas siguientes: a) un calentamiento, b) enfriamiento y cristalización y c) uso de ácido cítrico como ayudante de la separación de estearina y oleína.

\subsubsection{Cold test}

Este ensayo se considera de interés como método adicional al de punto de congelación y al de niebla.

Mide la resistencia del aceite a la cristalización y se utiliza habitualmente como un índice de winterización. Se determina por inmersión de un recipiente conteniendo el 
aceite en un baño de agua con hielo (caso de medir a $0{ }^{\circ} \mathrm{C}$ ) y midiendo al final de 5,5 horas para comprobar si existen nieblas. Se pasa el ensayo cuando el aceite está límpido y brillante al final del ensayo. El ensayo puede ser realizado a otras temperaturas y el método estándar habitual es el AOCS Ce 11-53. Un método alternativo consiste en medir el tiempo al que se genera la turbidez y suele ser norma exigir 10 horas mínimo para los aceites para ensaladas.

\subsubsection{Estudio de la acción de los depresores del punto de congelación en el aceite vegetal A}

\subsubsection{Introducción}

El objetivo de este estudio es evaluar la acción de diferentes depresores de punto de congelación (PPD) en el aceite vegetal A (uno de los aceites aceites objeto de estudio de la presente tesis). El interés de este estudio es debido a que dicho aceite posee muy buenas propiedades como aceite dieléctrico, pero su comportamiento en frío es malo.

Al tratarse de un aceite hiperoleico, la acción de los depresores del punto de congelación se ve muy reducida si se trabaja en concentraciones del orden del 0,5\% $\mathrm{v} / \mathrm{v}$, ya que al llegar a la temperatura de congelación, congela todo el aceite en bloque eclipsando la acción de dichos depresores. Otra opción sería aumentar la concentración de dicho PPD, opción no viable económicamente debido al elevado coste de dichos depresores.

En este estudio, se evaluarán PPD de diferente naturaleza así como de diferente marca comercial. Una nueva familia de reciente aparición son los copolímeros de ésteres de estireno-anhídrido maleico (ver figura 69).

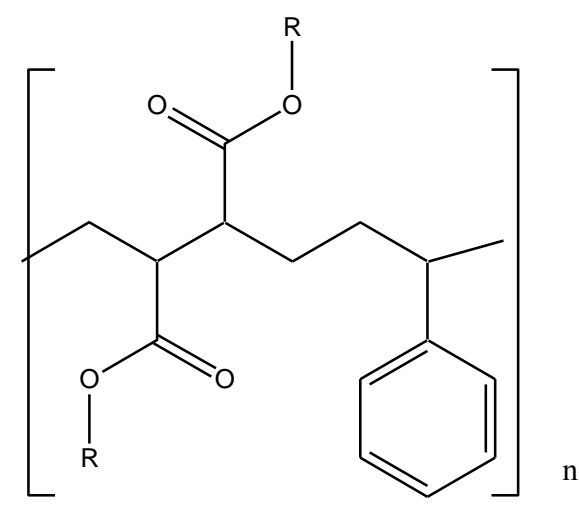

Figura 69: Estructura química del copolímero de estireno-anhídrido maleico 


\subsubsection{Método de evaluación de los depresores del punto de congelación}

Para evaluar el efecto de los depresores del punto de congelación en el aceite A, se llevarán a cabo dos tipos de ensayos:

- Ensayo de comportamiento en frío: Se somete a los aceites junto con los depresores a temperaturas de $-18{ }^{\circ} \mathrm{C}$ durante un periodo determinado de tiempo. Se observa el estado de la mezcla cada hora, durante las cinco primeras horas y luego, cada 24 horas hasta observar su congelación.

- Determinación del punto de vertido por ASTM D 97

\subsection{ESTUDIO DE LAS PROPIEDADES DE SOLUBILIDAD}

\subsubsection{Determinación de las curvas de saturación de humedad en aceites dieléctricos}

\subsubsection{Introducción}

Antes de introducirnos en profundidad sobre el efecto del agua en las propiedades dieléctricas del aceite, es conveniente definir en primer lugar las diferentes formas en que puede encontrarse el agua en los aceites dentro de un transformador:

Agua disuelta: Se encuentra químicamente ligada a las estructuras moleculares a través de enlaces de hidrógeno.

$>$ Agua emulsionada: Se trata de una solución sobresaturada en la que el agua no ha terminado de separarse del aceite confiriendo a éste un aspecto lechoso o turbio.

$>$ Agua libre: Agua en concentración suficientemente alta como para formar gotas de agua capaces de separarse del aceite.

La fuente de dicha humedad puede tener dos orígenes: origen externo, debido a que en los transformadores de respiración libre el aire húmedo pasa a través de un deshidratador con gel de sílice y un mal funcionamiento de éste puede provocar que 
pase el agua atmosférica, y origen interno, donde principalmente el agua proviene del envejecimiento de la celulosa.

El mayor peligro para los equipos eléctricos es el agua dentro de los aislamientos de papel celulósico debido a que dicho agua puede acelerar el proceso de envejecimiento del papel. Además, la concentración de agua en el papel es mucho mayor que en el aceite. Por ejemplo, para una concentración de 10 a 20 ppm de agua en un aceite, el contenido de ésta en el papel podría alcanzar un $2 \%$ en peso. Para un transformador de 600 MVA conteniendo 12 toneladas de papel y 35 toneladas de aceite, habría solo $700 \mathrm{~g}$ de agua en el aceite pero $240 \mathrm{~kg}$ en el papel, influenciando sus características eléctricas, estabilidad química y su durabilidad mecánica.

\subsubsection{Influencia del agua en las propiedades dieléctricas del aceite}

Es conocido bibliográficamente el bajo carácter higroscópico de los aceites dieléctricos de carácter mineral (a temperatura ambiente, la saturación de agua es de unas 60 ppm, valor más o menos diferente según la naturaleza parafínica o nafténica del aceite) mientras que en los ésteres naturales, la saturación de agua a temperatura ambiente es de 1000 ppm aproximadamente [41]. Como muestra en la figura 70, el aceite de naturaleza éster admite mucho más agua que un aceite de origen mineral.

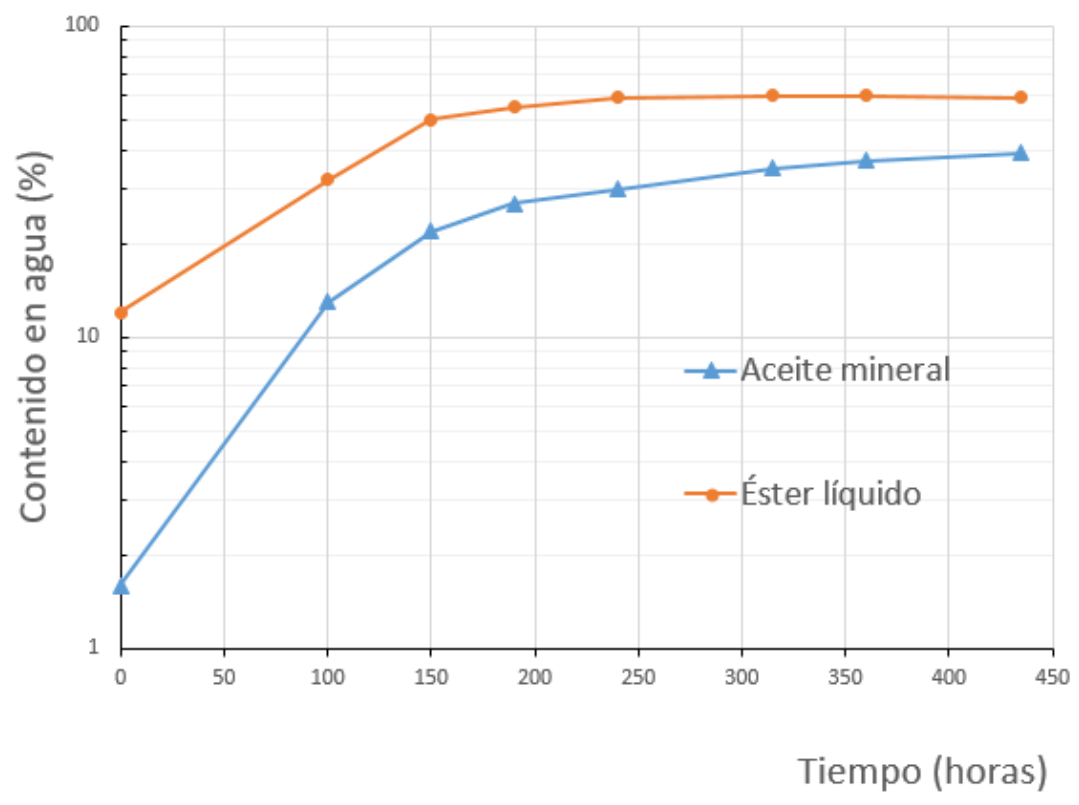

Figura 70: Capacidad de disolución de agua en diferentes tipos de aceite 
En los aceites vegetales dicha saturación de agua varía con la humedad relativa del medio, la temperatura, su naturaleza, la presencia de aditivos en dicho aceite o incluso el estado de oxidación del mismo, ya que los compuestos altamente polares que se producen en dicha oxidación (ácidos orgánicos, aldehídos, cetonas...) facilitan la solubilidad de agua.

Conocer el comportamiento de los aceites de origen vegetal frente al agua es de primera necesidad ya que ésta puede hacer variar en cierto grado algunas propiedades fundamentales de estos aceites como son:

- Rigidez dieléctrica $(R D)$ : En aceites minerales, el límite de saturación de agua es menor y la RD se verá afectada en mayor grado (para unas 100 ppm de agua, la RD decae un $85 \%$ aproximadamente). Para aceites de origen vegetal sin embargo, como la tolerancia al agua es más elevada, la RD no decae tanto y se mantiene constante en un rango más amplio de contenido en agua. Véase por ejemplo la figura 71 donde se representa la $\mathrm{RD}$ frente a la temperatura para un aceite sintético (Proeco) con diferentes concentraciones de agua [42], donde se observa la estabilidad de la RD frente al aumento de concentración de agua en el aceite.

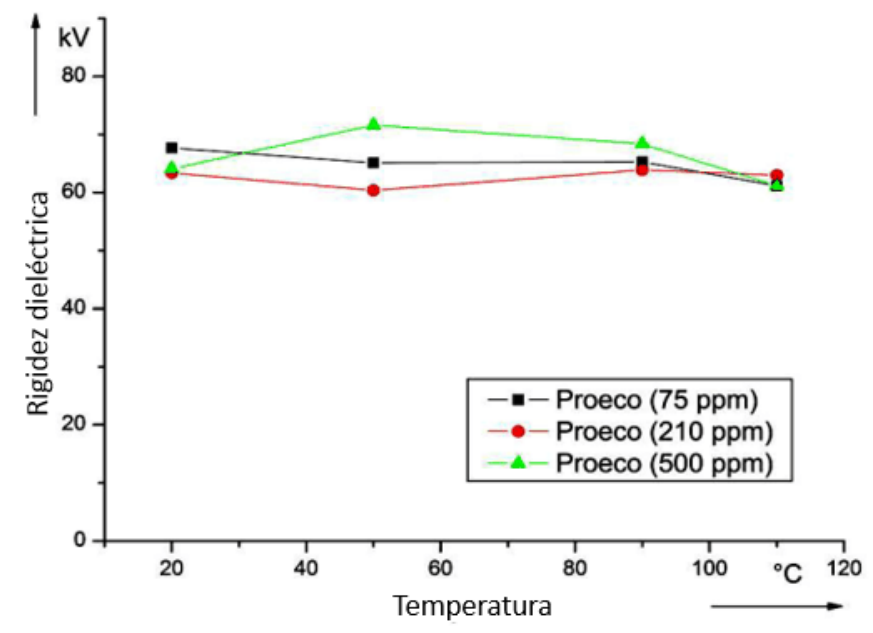

Figura 71: Efecto del agua en la RD en ésteres sintéticos 
- Factor de pérdidas dieléctricas (FPD): Cuando el contenido de agua en un aceite de origen mineral o vegetal excede el límite de saturación o se aproxima a él, el factor de pérdidas dieléctricas aumenta rápidamente, tal y como se cita en el artículo de X. Li [43]. En la figura 72, se representa el porcentaje de la tangente $\delta$ frente a la concentración de agua (wtr). Se observa que a partir de 0,8 $\%$ de agua, la tangente del ángulo de pérdidas aumenta exponencialmente.

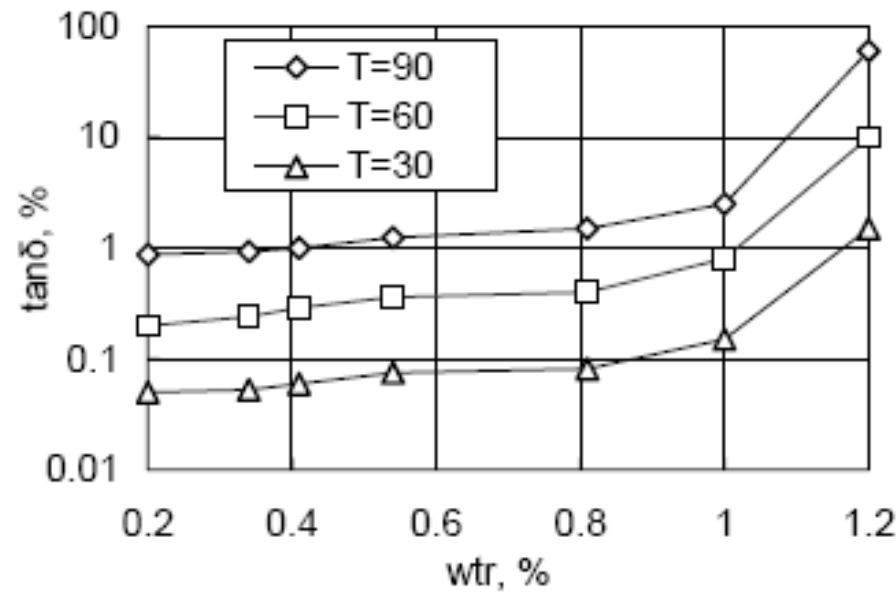

Figura 72: Efecto del agua en la RD en ésteres sintéticos

La solubilidad del agua en aceites puede expresarse por la ley de Arrhenius:

$$
\log X_{w}^{0}=A-\frac{B}{T}
$$

Donde $X_{w}{ }^{o}$ es la solubilidad de agua en aceite en ppm, $T$ es la temperatura en grados Kelvin y $A$ y $B$ son parámetros específicos para cada aceite y se determinan experimentalmente. 
Dicha solubilidad de agua en aceite aislante tiene un límite de saturación que depende, además de la naturaleza del aceite, de su peso molecular. Este límite de saturación se puede determinar experimentalmente según la ecuación:

$$
W_{L}=W_{0} \cdot 10^{\left(-\frac{H}{T}\right)}
$$

Donde $W_{L}$ es el valor límite de saturación, $H$ es una constante específica para cada aceite y se determina experimentalmente, $W_{0}$ es la concentración de agua en aceite cuando la temperatura tiende a infinito y se determina experimentalmente también y $T$ es la temperatura del sistema en grados Kelvin.

\subsubsection{Solubilidad de agua en ésteres naturales}

Tal y como hemos mencionado en el apartado anterior, las solubilidad del agua es mucho mayor en los ésteres vegetales que en los fluidos minerales. Dicha solubilidad tiene una dependencia directamente proporcional con la temperatura, es decir, a mayor temperatura del sistema, mayor es la solubilidad del agua en el fluido.

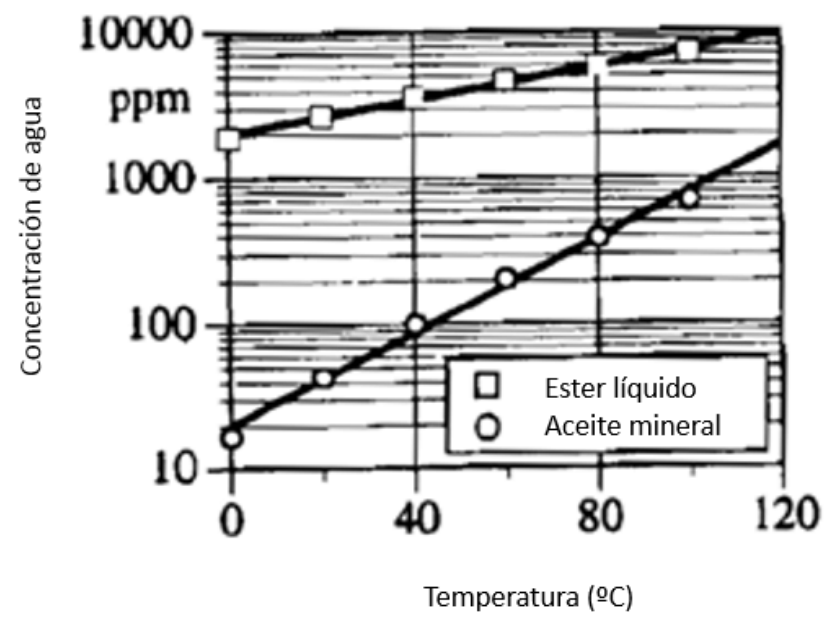

Figura 73: Capacidad de saturación de agua en aceites de diferente origen 
Por otra parte, se ha demostrado (Hilder, [44]) también la relación que existe entre la concentración de agua en el aceite y la presión de vapor que se genera en el equilibrio cuando éste es alcanzado entre el aceite y la fase vapor, de forma que un aumento en la presión de vapor, provoca un aumento de la concentración de agua en el aceite.

Por lo tanto, para poder determinar la solubilidad de agua en nuestro fluido tendremos que variar dos parámetros: la temperatura del sistema y la humedad relativa del medio.

La temperatura se controlará con una estufa de aire forzado que nos proporcionará una temperatura homogénea en toda la cámara. Por otro lado, para obtener en el laboratorio a pequeña escala una humedad relativa conocida, se usarán disoluciones acuosas saturadas de un soluto adecuado. Existen tablas con datos de humedad relativa en función de la temperatura. Los solutos que se usan para recrear una humedad relativa determinada suelen ser sales de naturaleza inorgánica tales como el sulfato de amonio o el carbonato potásico.

Tabla 21: Humedad relativa de disoluciones saturadas con diferentes sales

\begin{tabular}{|l|l|l|l|l|l|l|l|l|l|l|l|}
\hline \multirow{2}{*}{ Disolución saturada de sal } & \multicolumn{10}{|c|}{ Temperatura, oc } \\
\cline { 2 - 12 } & 0 & 5 & 10 & 15 & 20 & 25 & 30 & 35 & 40 & 50 & 60 \\
\hline & \multicolumn{8}{|c|}{ Humedad relativa (\%) } \\
\hline Sulfato potásico & 99 & 98 & 98 & 98 & 98 & 97 & 97 & 97 & 96 & 96 & - \\
\hline Nitrato potásico & 96 & 96 & 96 & 95 & 95 & 94 & 92 & 91 & 89 & 85 & - \\
\hline Cloruro potásico & 89 & 88 & 87 & 86 & 85 & 84 & 84 & 83 & 82 & 81 & 80 \\
\hline Sulfato amónico & 82 & 82 & 82 & 82 & 81 & 81 & 81 & 80 & 80 & 79 & - \\
\hline Cloruro sódico & 76 & 76 & 76 & 76 & 75 & 75 & 75 & 75 & 75 & 74 & 75 \\
\hline Nitrato sódico & - & - & - & - & 65 & 64 & 63 & 62 & 61 & - & - \\
\hline Nitrato amónico & - & - & 75 & 70 & 67 & 64 & 60 & 53 & - & - & - \\
\hline Dicromato sódico & 61 & 59 & 57 & 57 & 55 & 54 & 53 & 51 & 50 & 49 & 47 \\
\hline Nitrato magnésico & 60 & 59 & 57 & 56 & 54 & 53 & 51 & 50 & 48 & 45 & - \\
\hline Carbonato potásico & 43 & 43 & 43 & 43 & 43 & 43 & 43 & - & - & - & - \\
\hline Cloruro magnésico & 34 & 34 & 33 & 33 & 33 & 33 & 32 & 32 & 32 & 31 & 29 \\
\hline Acetato potásico & - & - & 23 & 23 & 23 & 23 & 22 & - & - & - & - \\
\hline Cloruro de litio & 11 & 11 & 11 & 11 & 11 & 11 & 11 & 11 & 11 & 11 & 11 \\
\hline Hidróxido potásico & - & 14 & 12 & 11 & 9 & 8 & 7 & 7 & 6 & 6 & 5 \\
\hline
\end{tabular}


2.2.1.4. Procedimiento para determinar la curva de saturación de humedad en aceites dieléctricos

Las primeras experiencias que tuvieron lugar en el laboratorio se hicieron con el equipo de formación de aeroemulsiones en aceites lubricantes según norma ASTM-D 3427 debidamente modificada. Se inyectó aire saturado de agua en vez de aire seco a un caudal muy inferior al descrito en la norma para no formar aeroemulsiones persistentes.

Se realizó una segunda experiencia en el mismo recipiente de ensayo pero sin el sistema de inyección de aire. El agua se adicionó al aceite en exceso sobre el valor previsto de saturación y el sistema se agitó con un agitador magnético evitando vórtices intensos para no formar emulsiones de agua o aeroemulsiones.

En ambas experiencias, el sistema se calentó hasta los $90^{\circ} \mathrm{C}$ y se fue bajando la temperatura del sistema $10{ }^{\circ} \mathrm{C}$ cada hora hasta alcanzar la temperatura ambiente. Con este método de ensayo, se mantenía controlada la temperatura del sistema pero no la humedad relativa del medio. Para controlar este parámetro, se introdujo dentro de un desecador de vacío un vaso de precipitados con la disolución saturada de un soluto que nos generó la humedad relativa que necesitábamos.

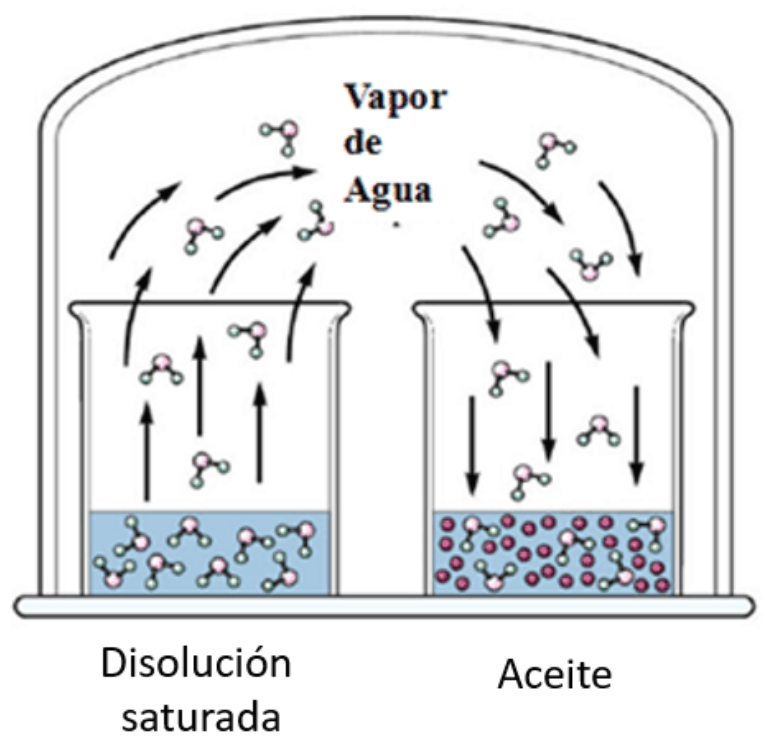

Figura 74: Mecanismo de saturación de agua en aceites usando disoluciones saturadas 
El desecador con la disolución saturada y las muestras de fluido a ensayar se introdujeron en una estufa a una temperatura que se fue aumentando por etapas. De esta manera se controló la temperatura del ensayo y la humedad relativa del medio. No hubo cambios en el estado de las muestras y de la solución saturada cuando se introdujeron dentro de la estufa ya que las temperaturas de ensayo no eran excesivamente elevadas $\left(25,45\right.$ y $\left.65^{\circ} \mathrm{C}\right)$.

Los aceites que se han sometido a ensayo son un aceite dieléctrico denominado ACEITE A facilitado por Repsol y un aceite de soja denominado ACEITE B. Las humedades relativas a las que se trabajó fueron de 43\% y $80 \%$. Para generar una atmósfera del $43 \%$ de $\mathrm{H}_{\mathrm{R}}$, se empleó una disolución saturada de carbonato potásico y para generar la del $80 \%$ de $H_{R}$ se empleó una disolución saturada de sulfato amónico.

Posteriormente se introdujeron las muestras en el desecador de vacío junto con la disolución acuosa saturada la cual nos iba a generar una $H_{R}$ determinada. Inmediatamente se realizó el vacío dentro del desecador para eliminar la humedad procedente del laboratorio. De esta forma, por la ley de Henry, las moléculas de agua pasarán a la fase vapor generando la humedad deseada.

Se determinó las curvas de saturación de agua en ambos aceites para una humedad relativa y temperatura determinada.

\subsubsection{Determinación de las curvas de solubilidad de aire en aceite}

\subsubsection{Introducción}

En transformadores de potencia, las prestaciones que debe cumplir un aceite dieléctrico son más exigentes que las de un aceite dieléctrico para transformadores de distribución. El transformador de potencia posee un sistema formado por un relé de Buchholz/conservador en el cual, una pequeña porción de aceite está en contacto continuo con aire ubicado dentro del conservador. Cuando existen fallos eléctricos o térmicos, se produce un aumento de la temperatura del sistema y como consecuencia, un aumento en la temperatura del aceite aislante. Al aumentar la temperatura del medio, la solubilidad del oxígeno y nitrógeno se ve modificada, y como consecuencia, alguna de sus propiedades físico químicas pueden verse alteradas en cierto grado. 
Para estudiar el efecto que tiene la saturación de aire a diferentes temperaturas en las principales propiedades físico químicas del aceite, se saturaron dos muestras de aceite:

a) Un aceite mineral Aceite $\mathrm{E}$

b) Un aceite vegetal Aceite A

El aire usado para saturar las muestras posee una pureza del 99,999 \% (aire premier). Las temperaturas a las que se saturaron los aceites fueron 30,60 y $80{ }^{\circ} \mathrm{C}$ ya que así se abarca todo el margen en el cual opera un aceite de transformador.

Luego se determinaron las concentraciones de oxígeno y nitrógeno por microcromatografía gaseosa usando el método Shake Test.

\subsubsection{Procedimiento operativo}

Para poder llevar a cabo dicho estudio, se hizo uso del equipo de aeroemulsión (ASTM D 3427) disponible en el laboratorio. Con dicho equipo, se puede modificar la presión de inyección de aire al sistema así como la temperatura del aire usado para la saturación del aceite.

En este caso, se inyectó aire a $28^{\circ} \mathrm{C}$ (temperatura media del aire en la cámara de conservación del transformador) a una presión de 150 mbar. El proceso de saturación del fluido con aire fue de 1 hora mientras el tiempo de desaireación, después de cortar el suministro de aire, fue también de una hora en todos los ensayos. De esta manera se eliminan variables externas que puedan afectar o falsear los datos obtenidos.

Una vez desaireado el sistema, se tomó muestra con una jeringa especial para análisis de gases disueltos y se analizó por micro-cromatografía gaseosa.

\subsubsection{Diseño y desarrollo del experimento}

Los pasos que se llevaron a cabo para la determinación de las curvas de saturación de aire en ambos aceites se detallan a continuación:

a) Deshidratación/desaireación de las muestras de aceite: Con el objetivo de eliminar cualquier fuente de contaminación externa que pudiera falsear los 
resultados, se deshidrataron los aceite y se desairearon sometiendo las muestras a un vacío de 20 mbar y $25^{\circ} \mathrm{C}$. Todo el aire ligado químicamente a la estructura del aceite se eliminó quedando dichas muestras preparadas para el ensayo.

b) Saturación con aire premier: Las muestras fueron introducidas rápidamente en un reactor de vidrio encamisado similar al que aparece en la figura 75 .

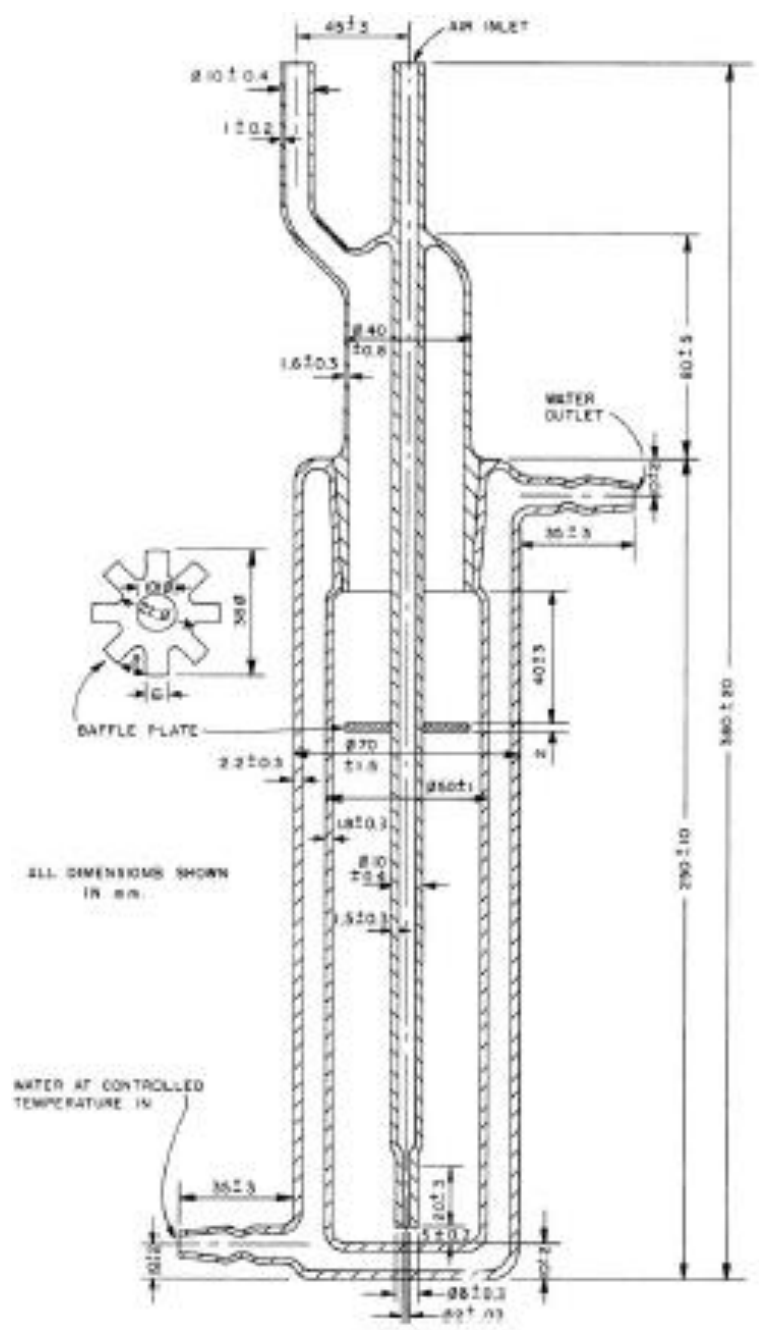

Figura 75: Reactor de vidrio, encamisado

Se insufló aire premier por la entrada superior de la figura 75 a una presión de 150 mbar y $28^{\circ} \mathrm{C}$ durante una hora. El burbujeo fue continuo con presencia de burbujas de elevado volumen tal y como se muestra en la siguiente imagen: 


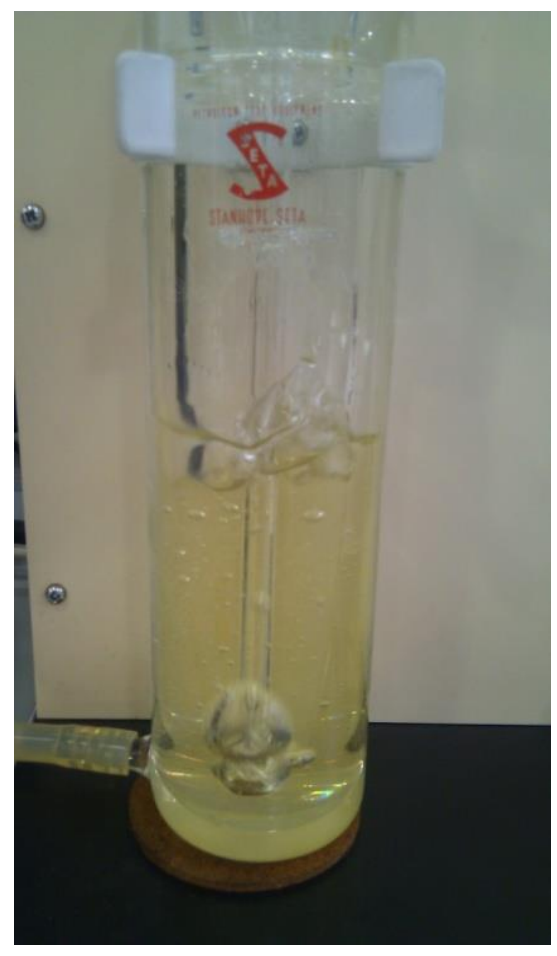

Figura 76: Detalle de las burbujas generadas

Se insufló aire durante una hora. Este ensayo fue llevado a cabo a tres temperaturas diferentes: 30,60 y $80{ }^{\circ} \mathrm{C}$. Dicha temperatura del aceite se alcanza haciendo uso del encamisado del reactor. El encamisado contiene agua destilada que proviene de un calentador o heater ubicado aguas arriba del reactor de vidrio.

c) Desaeración del sistema: Con objeto de eliminar todas las burbujas de aire presentes y que no se han disuelto o ligado al aceite dieléctrico, se dejaron reposar los aceites durante una hora dentro del reactor de vidrio a la temperatura a la que se llevó a cabo el ensayo. 


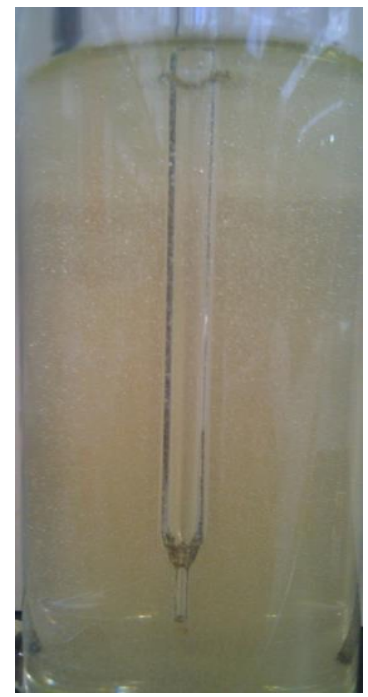

Figura 77: Detalle de las microburbujas durante la desaireación

d) Toma de muestra de aceite para el análisis: Tal y como se ha mencionado anteriormente, las muestras fueron extraídas mediante el uso de válvulas de tres vías, con el objetivo de eliminar el volumen de aire existente entre la cabeza de inyección de aire y el volumen de aceite. Para ello, se montó un sistema de eliminación de fases usando una válvula de tres vías tal y como se muestra a continuación:

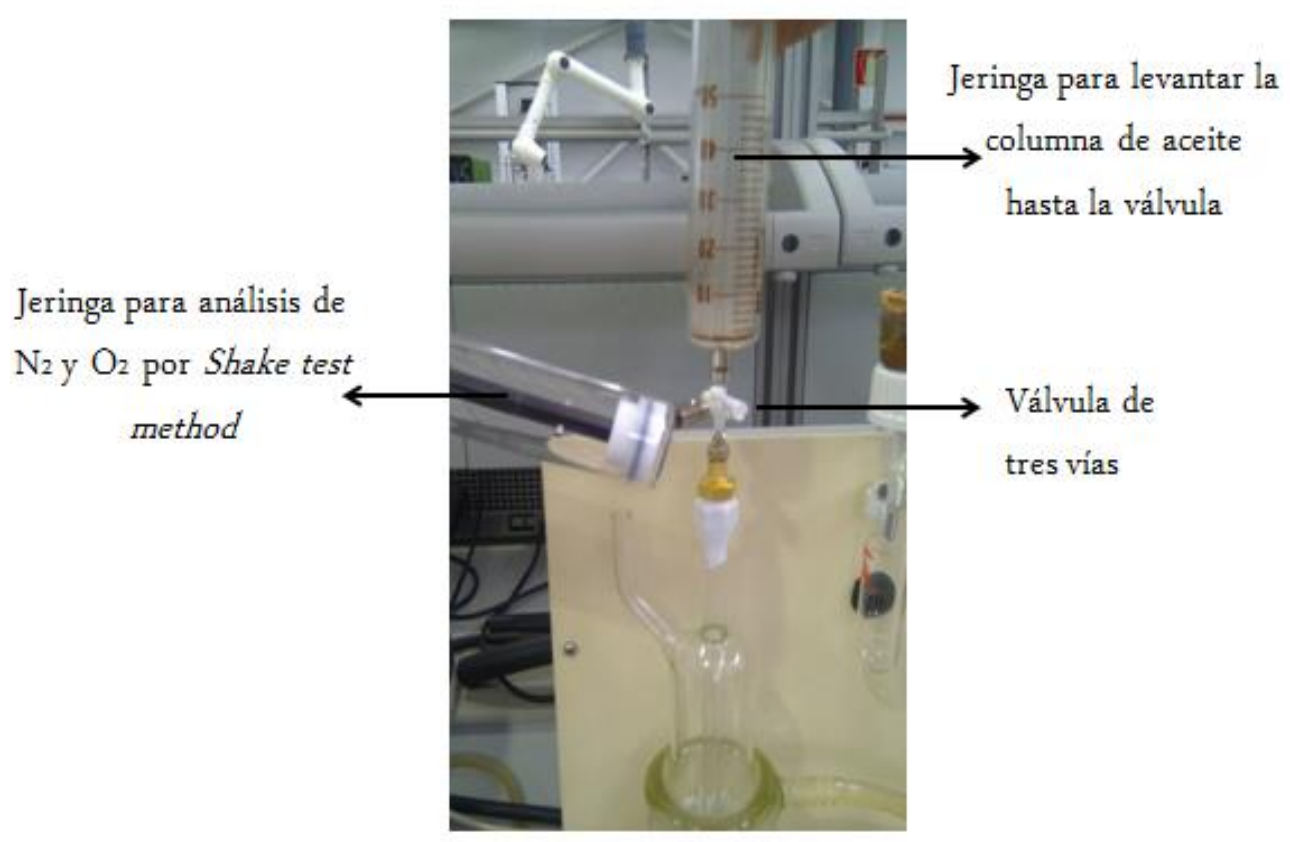

Figura 78: Detalle del montaje llevado a cabo en el laboratorio 
Succionando con la jeringa de vidrio ubicada en la parte superior, se levantó la columna de aceite por el tubo de vidrio hasta alcanzar la altura de la válvula de tres vías. De esta forma, se eliminó toda la fracción de aire ubicada desde la marca del nivel de aceite hasta la válvula de tres vías. Se cerró dicha posición con la válvula y se abrió el canal de la jeringa especial de gases ubicada a la izquierda. Con dicha jeringa se tomaron $100 \mathrm{~mL}$ de muestra. Se cerró la vía de la jeringa de gases y se llevó al micro-cromatógrafo de gases.

e) Análisis de gases disueltos en el aceite: Con un equipo de dilución de gases, se generó un espacio en cabeza o head space de $10 \mathrm{~mL}$ de helio en el interior de la jeringa. Posteriormente, y con un agitador automático, se extrajeron los gases disueltos en el aceite que pasaron al head space de helio. Posteriormente, esa fase de He y oxígeno y nitrógeno, se inyectó mediante un autosampler al micro cromatógrafo. Se obtuvieron los cromatogramas tipo que se muestran a continuación:

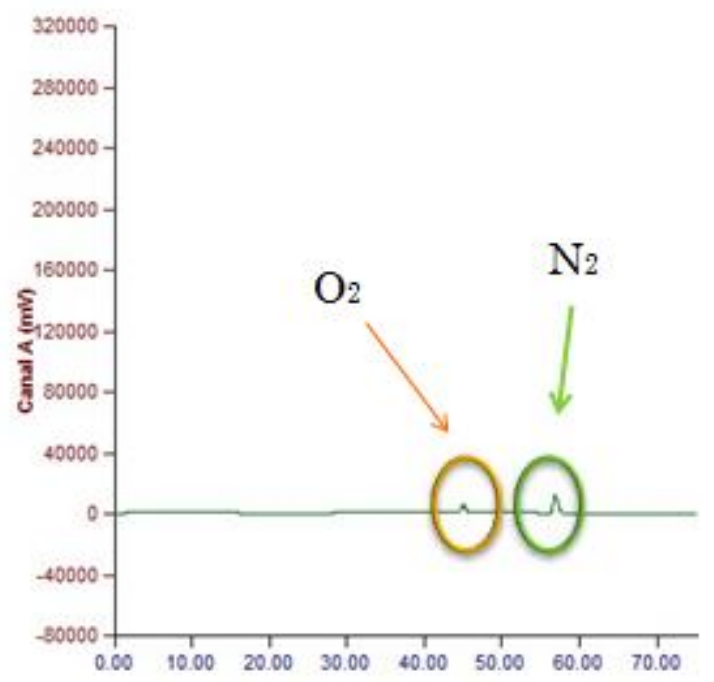

Figura 79: Cromatograma tipo obtenido por micro cromatografía de gases

El software del equipo, teniendo en cuenta el tipo de aceite analizado, aplicó unos coeficientes de solubilidad o coeficientes de Ostwald para determinar, a partir de los gases detectados en el head space, la concentración de gases disueltos en el aceite. 


\subsection{ESTUDIO DE LOS PROCESOS DE DEGRADACIÓN TÉRMICA}

\subsubsection{Estudio de las propiedades de transferencia térmica}

Los fluidos dieléctricos o aceites aislantes son fluidos necesarios para la generación, transmisión, distribución y utilización industrial de la energía eléctrica. Las propiedades de estos líquidos, junto con las de los materiales sólidos son criterios importantes en el diseño del equipo así como para proporcionar un mínimo impacto ambiental y durabilidad del equipo al mínimo coste aceptable. Por esta causa, un cambio de naturaleza del fluido, de mineral a éster, sea sintético o natural, o mezcla de cualesquiera de ellos supone para el fabricante del equipo la necesidad de disponer de la máxima información acerca de sus propiedades.

Cuando se comparan entre sí diferentes aceites de mismo origen (por ejemplo aceite A y aceite $\mathrm{B}$, en estos casos, ambos de origen vegetal) que cumplan una determinada especificación, sus propiedades físico-químicas son relativamente próximas entre ellos bajo un punto de vista del diseño del transformador, es decir su viscosimetría es próxima, su densidad es parecida... ya que se trata de fluidos con distribución de pesos moleculares parecidos y por lo tanto, el diseñador del transformador dispone de una gran cantidad de datos que le permiten efectuar cambios en el diseño sin necesidad de una gran cantidad de experimentación sobre el aceite.

Una de las funciones principales de los aceites aislantes es la disipación del calor generado en los equipos eléctricos. Así, una transferencia térmica eficiente por el fluido reduce la temperatura en los devanados dentro del transformador minimizando la velocidad de degradación de la celulosa.

La disipación del calor en el transformador se realiza fundamentalmente por la convección natural o forzada del aceite a través de los pasos incorporados en los arrollamientos. Por lo tanto, el conocimiento del valor P, parámetro que es directamente proporcional a la conductividad térmica, calor específico y coeficiente de expansión térmica e inversamente proporcional a la viscosidad, es fundamental en la ingeniería del diseño de transformadores para decidir aspectos básicos como el tipo de circulación, 
bombas, constantes térmicas del equipo en condiciones de operación normal y sobrecarga o tamaño y configuración de los pasos de aceite.

\subsubsection{Conductividad térmica}

La conductividad térmica se define como la capacidad del aceite para transferir energía en forma de calor en ausencia de fenómenos de transporte de masa. En el caso de los aceites dieléctricos, se puede determinar mediante la norma ASTM D-2717, midiendo el gradiente de temperatura producido a través del aceite por una cantidad de energía introducida en una célula de vidrio calentada mediante una resistencia eléctrica de platino. Se expresa en W/K.m. En aceites de origen mineral, se observa una dependencia de los valores de conductividad inversamente proporcional a la densidad y directamente proporcional a la temperatura.

\subsubsection{Calor específico}

El calor específico es una propiedad termodinámica que indica la cantidad de energía requerida para elevar un grado la temperatura de una unidad de masa de una sustancia. La norma ASTM D-2766, supone el empleo de un calorímetro para determinar dicho parámetro. En nuestro caso, cuanto mayor sea el valor de $\mathrm{Cp}$, mejor será el valor del parámetro P. El calor específico de dichos aceites fue determinado con el equipo Micro DSC II (Setaram, Francia). El error experimental del ensayo es del 1\%.

\subsubsection{Densidad}

Para la caracterización completa de los aceites dieléctricos de origen vegetal es necesario determinar las densidades del aceite A y B en función de la temperatura, en un rango de temperaturas que comprendiese las que podrían llegar a encontrarse en servicio. Para la elaboración de esta tesis, además de las densidades de los aceites A y $\mathrm{B}$, se determinó la densidad del aceite $\mathrm{E}$ (de origen mineral) para realizar una comparativa entre ellos. 
Teniendo en cuenta que los equipos eléctricos en servicio durante el invierno pueden estar expuestos a bajas temperaturas y que los aceites pueden llegar a contener cantidades apreciables de agua con el paso del tiempo, se propuso comparar cual sería la situación, en el transformador, del hielo formado al bajar la temperatura por debajo de 0 ${ }^{\circ} \mathrm{C}$.

Efectivamente, al bajar la temperatura, la solubilidad del agua en el aceite se reduce de forma que ésta precipita en forma de finas gotas que a temperaturas por debajo de 0 ${ }^{\circ} \mathrm{C}$ congelan en forma de cristales de hielo. En un transformador, los cristales de hielo no deben alcanzar las zonas altas del equipo para evitar descargas eléctricas superficiales, sino que deben hundirse hacia el fondo donde su presencia no es tan peligrosa. La condición esencial es por tanto la de asegurar que la densidad del hielo a temperaturas bajas sea siempre mayor que la del aceite.

Dado que los aceites vegetales tienen una densidad más elevada que los de origen mineral, se decidió investigar sobre la evolución del hielo en el transformador ya que resulta de crucial importancia para determinar en qué condiciones climáticas puede ser empleado un transformador relleno con ése tipo de fluidos, considerando lógicamente otros factores adicionales como los de viscosimetría y factor de refrigeración.

Se determinaron las densidades de los aceites A, B y un aceite E de naturaleza parafínica a cinco temperaturas diferentes abarcando un rango de éstas de 0 a $50{ }^{\circ} \mathrm{C}$. Se ajustaron los valores a una recta por mínimos cuadrados. El equipo con el que se determinó las densidades fue el Densímetro DMA 48 de Anton Paar que fue especialmente recalibrado para esta tesis.

El primer paso del procedimiento operativo para la determinación de las diferentes densidades fue deshidratar los tres aceites calentándolos a $70{ }^{\circ} \mathrm{C}$ durante 3 horas y posteriormente, filtrándolos al vacío sobre membrana de nitrocelulosa de $0,8 \mu \mathrm{m}$ de diámetro de poro. Se introdujeron en un recipiente cerrado y se acondicionaron en neveras y placas calefactoras a las temperaturas a las que había que determinar la densidad para minimizar el error del densímetro.

La media de las concentraciones de agua determinadas por valoración columbimétrica Karl-Fischer en los aceites deshidratados fue: 
- Aceite A: 164,1 ppm

- Aceite B: 173,6 ppm

- Aceite E: 22,63 ppm

\subsubsection{Coeficiente de expansión térmica}

El Coeficiente de Expansión Térmica representa el cambio en volumen del fluido por unidad de volumen y grado de temperatura. Su expresión es:

$$
\alpha=\frac{\left(d_{0}-d_{1}\right)}{d_{0}\left(T_{o}-T_{1}\right)}
$$

Donde $d_{0}$ es la densidad, en $\mathrm{g} / \mathrm{cm}^{3}$ del fluido para una temperatura $\mathrm{T}_{0} \quad \mathrm{y}_{1}$ es la densidad, en $\mathrm{g} / \mathrm{cm}^{3}$ del fluido para una temperatura $T_{1}$.

\subsubsection{Viscosidad cinemática}

Es la propiedad más importante en la transmisión de calor por convección y es por tanto, el parámetro primordial para determinar la eficiencia de la transferencia térmica en los equipos eléctricos.

Los fluidos dieléctricos presentan comportamiento newtoniano en un amplio rango de temperatura y su viscosidad está limitada en las diferentes especificaciones, aun cuando se expresa también en forma indirecta a través del punto de niebla y punto de vertido.

Dado que los ésteres vegetales poseen en general temperaturas de congelación peores que las de los aceites minerales, esta propiedad deberá ser objeto de especial atención. Además, su estabilidad a temperaturas próximas a la congelación es bastante deficiente precipitando parte de algunos de los componentes más saturados del aceite, algunos de los cuales son incluso difícilmente solubilizados al elevar la temperatura después de haber pasado por una etapa de congelación. 
La determinación de la viscosidad cinemática se llevará a cabo según el procedimiento descrito en la normativa americana ASTM D 445, usando los viscosímetros detallados en la normativa ASTM D 446.

\subsubsection{Criterio de refrigeración $\mathrm{P}$}

La literatura recoge parámetros y curvas de comparación de diferentes fluidos aislantes bajo el punto de vista de su capacidad de transferencia térmica. Uno de ellos es el denominado parámetro $P$, también llamado Criterio de Refrigeración. Se define como:

$$
P=\frac{C p \cdot \lambda \cdot \alpha}{\vartheta}
$$

(Ecuación 26)

Donde:

- Cp es el calor específico

- $\lambda$ es la conductividad térmica

- $\alpha$ es el coeficiente de expansión térmica

- $\vartheta$ es la viscosidad cinemática

\subsubsection{Estudio de la degradación térmica de aceites dieléctricos de origen vegetal}

2.3.2.1. Caracterización de la rigidez dieléctrica frente al contenido en agua en aceites de origen vegetal

La rigidez dieléctrica es una medida de la capacidad del aceite para soportar solicitaciones eléctricas. Se define como el cociente de la tensión de perforación (tensión, en $\mathrm{kV}$, por la cual la muestra sufre una perforación) y la distancia de separación entre los electrodos entre los que se aplica la tensión en las condiciones de ensayo prescritas. 


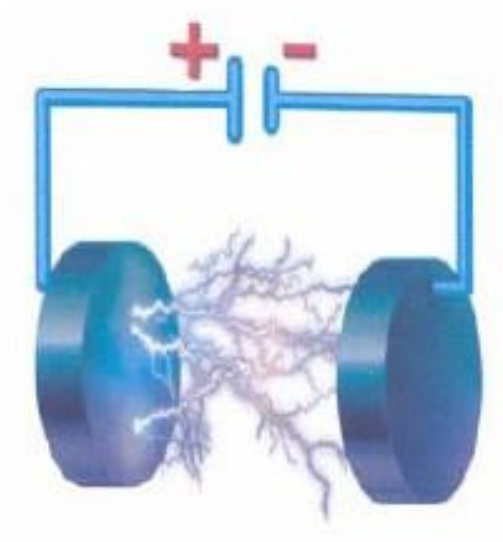

Figura 80: Esquema de mecanismo de ruptura de un dieléctrico

La medida de la rigidez dieléctrica sirve principalmente para indicar la presencia de contaminantes como agua o partículas. Un valor bajo de rigidez dieléctrica puede indicar que uno o más de estos contaminantes están presentes. Sin embargo, un valor elevado de rigidez dieléctrica no indica necesariamente la ausencia de todo contaminante.

Por lo tanto, el contenido en agua del aislamiento líquido y sólido tiene un impacto significativo en las condiciones operativas reales y en la vida útil del transformador. Existen dos fuentes principales de incremento de agua en el aislamiento del transformador:

$\rightarrow$ Ingreso de humedad desde la atmósfera

$\rightarrow$ Degradación de celulosa y aceite

El objetivo de esta tesis será la caracterización de la variación de rigidez dieléctrica en función del contenido de agua en el aceite A cuando la fuente de agua es externa, es decir, procedente de la humedad relativa del medio. 


\subsection{Ensayo de rigidez dieléctrica $(R D)$}

Según la especificación de aceites dieléctricos para transformadores (IEC 296), la evaluación de la rigidez dieléctrica se llevará a cabo según norma IEC 156. Según esta normativa, los electrodos del equipo de $\mathrm{RD}$ deben ser esférico o hemiesféricos separados una distancia de 2,5 $\mathrm{mm}$. El incremento de voltaje por unidad de tiempo (también conocido como tensión) será de $2 \mathrm{kV} \cdot \mathrm{s}^{-1}$.

El equipo de RD que dispone el laboratorio únicamente es capaz de medir hasta los 60 $\mathrm{kV}$. En el caso de los aceites dieléctricos de origen vegetal refinados, la rigidez dieléctrica es superior a $60 \mathrm{kV}$. Por lo tanto, podremos empezar a ver cambios en la RD cuando dicho parámetro esté por debajo de $60 \mathrm{kV}$.

\subsection{Procedimiento operativo}

Las dos muestras evaluadas fueron el aceite A y el aceite B. Se deshidrataron 2 L de cada aceite calentándoles durante 30 minutos a $60-70{ }^{\circ} \mathrm{C}$ y filtrándole posteriormente en membrana de nitrocelulosa de $0,8 \mu \mathrm{m}$ de diámetro de poro. Con este proceso se consiguió deshidratar ambos aceites a valores de contenido en agua inferiores a 50 ppm.

Por otro lado, en un desecador al que se le puede aplicar vacío, se introdujeron $500 \mathrm{~mL}$ de una disolución acuosa de glicerina al 72 \% (dicha solución genera una humedad relativa del $60 \%$ dentro del desecador).

La relación entre la $\mathrm{H}_{\mathrm{R}}$ del aire y el incremento de glicerina está normalizado en la ASTM D5032 “Maintaining constant relative humidity by means of aqueous glycerin”. 


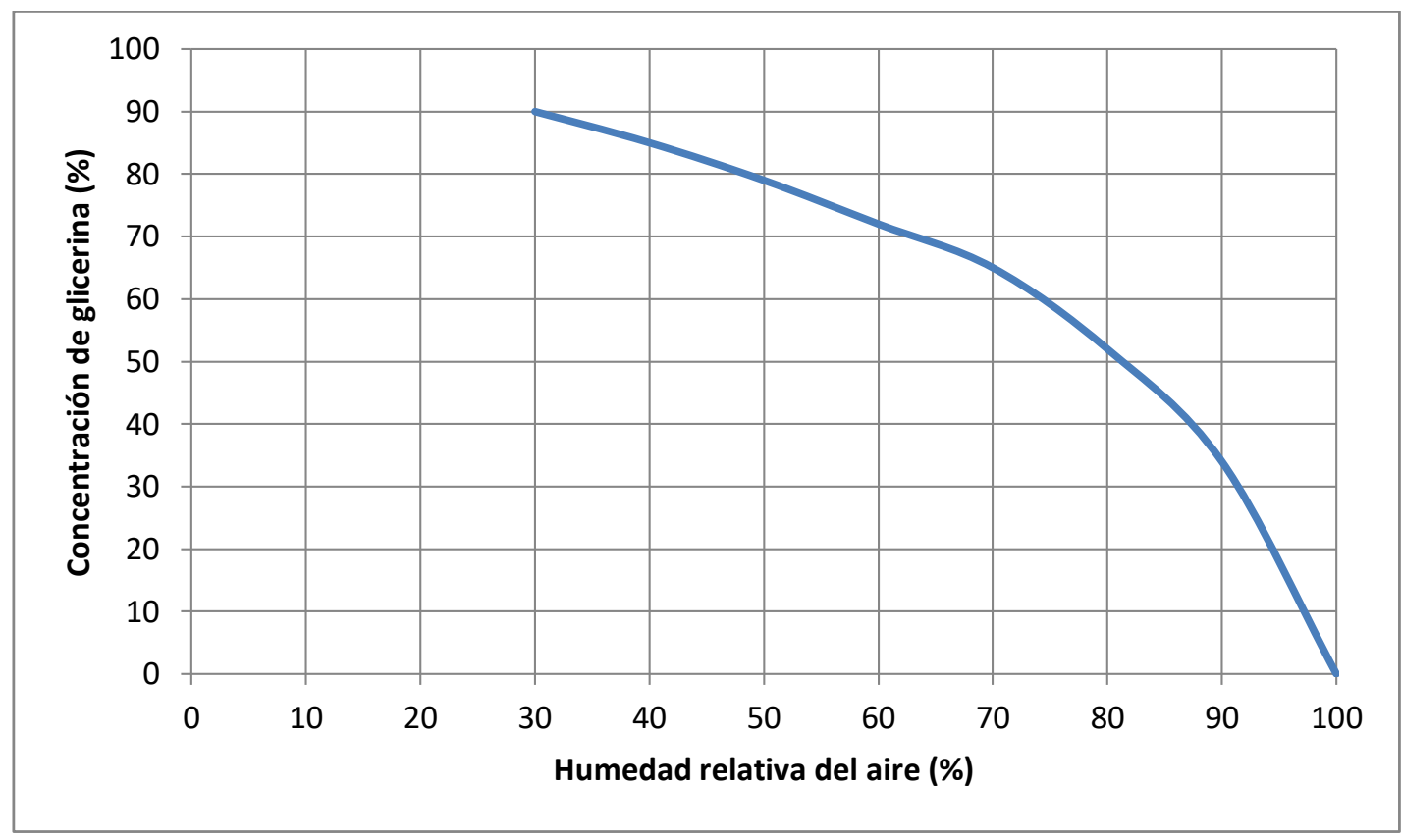

Figura 81: Curva de humedad relativa en función del contenido en glicerina

La expresión analítica de la ecuación de la curva de la figura anterior es:

$$
\begin{gathered}
y=-7 \cdot 10^{-8} x^{5}+10^{-5} x^{4}-0,0013 x^{3}+0,0502 x^{2}-1,3985 x+110,58 \\
R^{2}=0,9998
\end{gathered}
$$

Esta ecuación solo es válida para humedades relativas superiores al $30 \%$. Si se quiere trabajar con $\mathrm{H}_{\mathrm{R}}$ inferiores al $30 \%$, en lugar de agua, se tendrá que introducir gel de sílice dentro del desecador.

Una vez que se ha comprobado que la $H_{R}$ dentro del desecador es del $60 \%$, introducimos 5 vasos de precipitados de $500 \mathrm{~mL}$ y en cada uno de ellos se introducen $350 \mathrm{~mL}$ de un mismo aceite. Primero se harán los ensayos para el aceite A y posteriormente se harán para el aceite $\mathrm{B}$. 


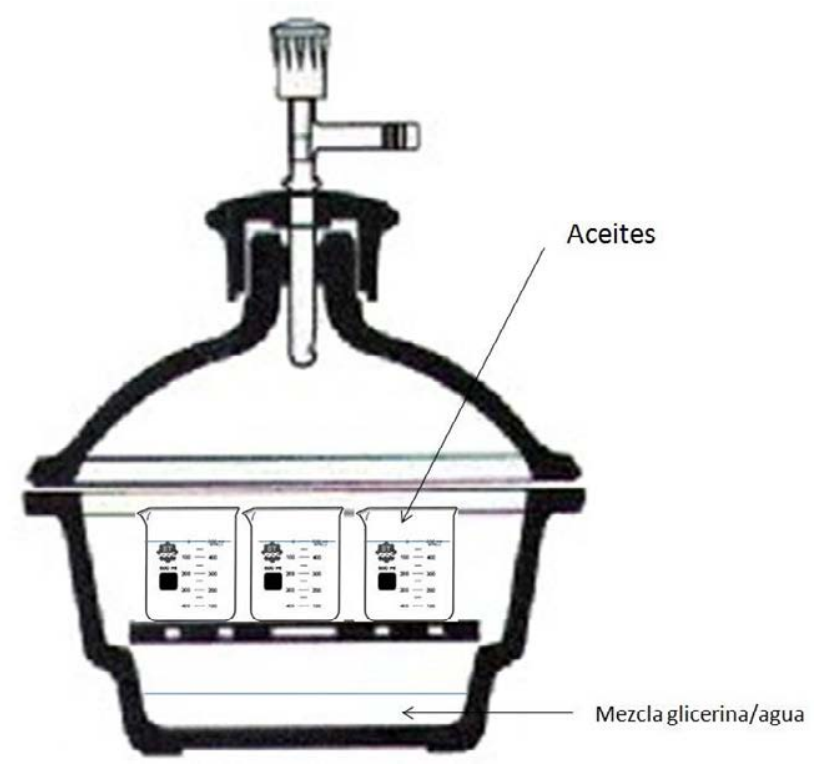

Figura 82: Dispositivo de saturación de muestras usando mezclas de glicerina/agua

La temperatura a la cual se realizó el ensayo fue de $25{ }^{\circ} \mathrm{C}$. Se trabajó con esta temperatura por simplificar el proceso y minimizar el error, ya que no hace falta calefacción. En cuanto a la humedad relativa, se trabajó con una del 60 \% ya que a esta humedad, la cinética de saturación de agua en el aceite, ni es muy rápida ni muy lenta.

2.3.2.2. Caracterización de la rigidez dieléctrica y otras propiedades frente al contenido $\underline{\text { de índice de acidez en aceites de origen vegetal }}$

El objetivo de este ensayo es el de oxidar aceites en condiciones distintas de severidad para obtener aceites de acidez variable y determinar a partir de qué valor de índice de acidez, la rigidez dieléctrica y la tg $\delta$ de un aceite empieza a decaer hasta perder por completo sus propiedades como dieléctrico.

El método consta principalmente de una primera fase de oxidación del aceite según normativa UNE EN $61125 \mathrm{C}$ y posteriormente, una determinación de la RD y la tg $\delta$ a diferentes periodos de tiempo. 


\subsection{Procedimiento operativo}

En primer lugar se acondicionaron los aceites que iban a ser sometidos a oxidación. Para ello, se calentaron dos litros de aceite A durante 40 minutos a $70{ }^{\circ} \mathrm{C}$ en estufa y se aplicó un ligero vacío para favorecer la eliminación de agua disuelta y se filtró posteriormente al vacío a través de membrana de nitrocelulosa de $0,8 \mu \mathrm{m}$.

Se dejó enfriar el aceite en un desecador para evitar en el mayor grado posible su posterior hidratación con la humedad del ambiente. Se determinó la concentración de agua por valoración columbimétrica Karl Fischer y su índice de acidez fresco según normativa ASTM D 974.

Por otro lado, se calentó a $120 \pm 0,5^{\circ} \mathrm{C}$ un baño con silicona. Una vez estabilizada la temperatura en el baño, en tres matraces de tres bocas, se introdujeron $300 \mathrm{~mL}$ de aceite vegetal en cada uno de ellos y se sumergieron completamente en el baño de silicona.

Con respecto a los catalizadores empleados en el proceso de oxidación, se usó hilo de cobre de 1,5 mm de diámetro. Se tuvo que obtener la misma proporción aceite/cobre que la indicada en la normativa UNE EN 61125 C. Según esta normativa, la superficie de catalizador por cada $25 \mathrm{~g}$ de aceite es de $28,6 \mathrm{~cm}^{2}$. Como en este procedimiento el volumen de aceite a oxidar, en cada uno de los matraces, es de $300 \mathrm{~mL}$ se necesitaron $343,2 \mathrm{~cm}^{2}$ de $\mathrm{Cu}$. Esa superficie la generaron 12 espirales de $2 \mathrm{~cm}$ de diámetro y $5 \mathrm{~cm}$ de longitud aproximadamente.

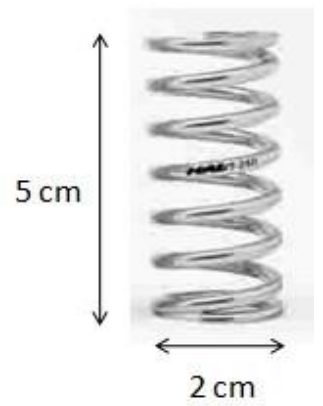

Figura 83: Espiral de cobre usada como catalizador de la reacción de oxidación 
Inmediatamente, antes del uso del catalizador, se pulió la superficie del hilo de $\mathrm{Cu}$ con cinta abrasiva al carburo de silicio de granulometría P220. Las trazas de abrasivo se eliminaron con iso-octano.

En cuanto al flujo de aire premier, se trabajó con un flujo de $10 \mathrm{~L} / \mathrm{h}$ porque aunque tengamos un exceso de atmósfera oxidante, el aceite actuará de reactivo limitante y la reacción de oxidación no incrementará su velocidad de reacción.

\subsection{Montaje y conexiones}

El montaje para la reacción de oxidación con reflujo consta del siguiente equipamiento:

- Baño de silicona capaz de mantener la temperatura a $120 \pm 0,5^{\circ} \mathrm{C}$

- Matraz de tres bocas con base redonda de $1000 \mathrm{~mL}$ de capacidad

- Difusor de aire de vidrio con frita

- Condensador de bolas

- Rotámetros capaces de mantener un flujo de aire de $10 \pm 0,1 \mathrm{~L} / \mathrm{h}$

El esquema del montaje se muestra a continuación:

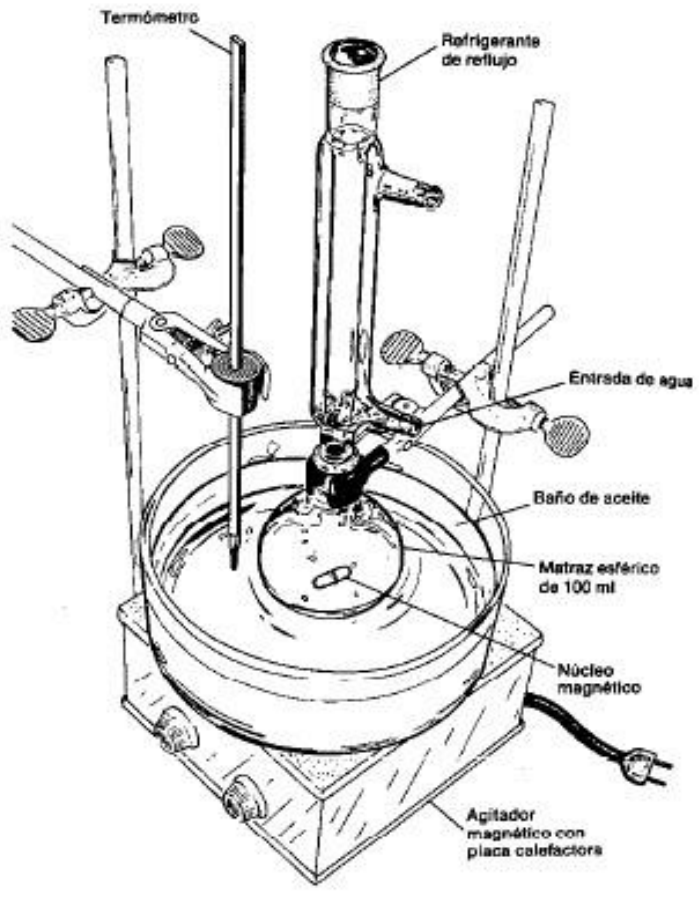

Figura 84: Montaje llevado a cabo para los ensayos de oxidación acelerada 
Se conectaron en serie los tres matraces con sus correspondientes condensadores de bolas. Como líquido refrigerante se usó agua.

\subsection{Extracción y toma de muestras}

El sistema se puso en marcha y se revisó cada hora aproximadamente el flujo de aire que marcaban los rotámetros y la temperatura del baño.

Cada 24 horas aproximadamente, por una de las bocas de cada matraz, se tomaron $2 \mathrm{~mL}$ de aceite oxidado y se determinó el índice de acidez (I.A.). Se realizó esta acción a todos y cada uno de los matraces de tres bocas con objeto de estudiar la repetibilidad de la reacción en cada uno de los matraces. De esta forma, se obtuvieron cada $24 \mathrm{~h}$ tres muestras, una de cada uno de los matraces.

Cuando se observó que la oxidación estaba teniendo lugar en grado notorio, es decir, que el I.A. fuera de $1 \mathrm{mg} \mathrm{KOH} / \mathrm{g}$, se tomaron los primeros $300 \mathrm{~mL}$ del primer matraz. Antes de determinar ningún parámetro, se deshidrató el aceite oxidado con el objetivo de eliminar el agua y las partículas sólidas que se hubieran formado en el proceso de oxidación, ya que estas interfieren en la determinación de la RD y la tg $\delta$. Una vez realizado dicho proceso, se determinaron los siguientes parámetros:

$\checkmark$ Índice de acidez (mg KOH/g)

$\checkmark$ Rigidez dieléctrica $(\mathrm{kV})$

$\checkmark$ Concentración de cobre por ICP-OES (ppm de $\mathrm{Cu}$ )

$\checkmark$ Factor de pérdidas dieléctricas $(\operatorname{tg} \delta)$ a $90^{\circ} \mathrm{C}, 50 \mathrm{~Hz}$

$\checkmark$ Corrosión a la lámina de cobre

Cada 24 horas se siguieron tomando muestras de ambos matraces. Cuando el I.A. fue de $2 \mathrm{mg} \mathrm{KOH} / \mathrm{g}$, se sacó el aceite del segundo matraz, se deshidrató y se determinaron los cinco parámetros anteriormente citados. Por último, cuando el I.A. fue de $3 \mathrm{mg}$ $\mathrm{KOH} / \mathrm{g}$ se sacó el aceite del último matraz. El ensayo se prolongó hasta alcanzar un I.A. de 7,11 mg KOH/g muestra. 
A la hora de determinar los parámetros, se determinaron primero la RD. Después, con ese mismo aceite, se determinó el factor de pérdidas dieléctricas y el contenido en $\mathrm{Cu}$ por ICP-OES. Con el aceite que sobró de la RD (unos $150 \mathrm{~mL}$ aproximadamente), se determinó por último la corrosión a la lámina de cobre.

\subsubsection{Ensayo de oxidación en película fina}

En la interfase aceite/aire del sistema conservador del transformador de potencia, existe una pequeña porción de aceite dieléctrico que está permanentemente en contacto con el aire de la cámara de expansión. Este fenómeno provoca que exista una serie de reacciones de oxidación en dicha interfase, pasando parte del oxígeno de la fase aire a la interfase y que este reaccione con los hidrocarburos que constituyen el fluido dieléctrico.

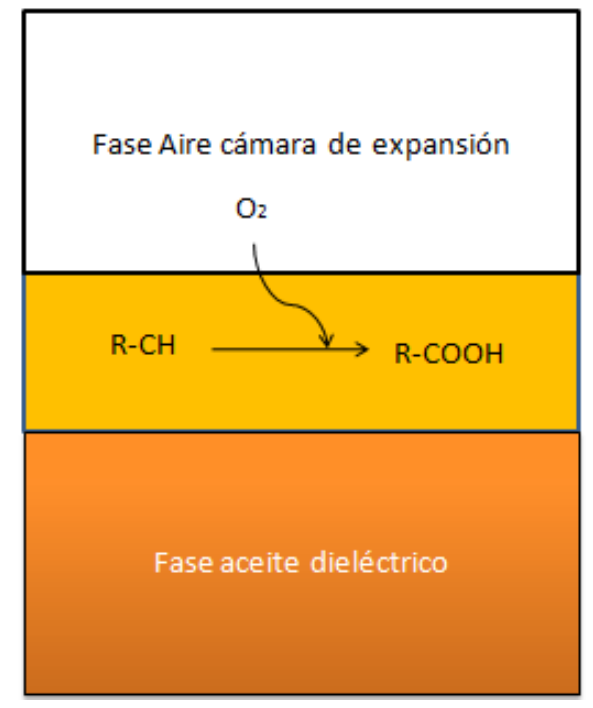

Figura 85: Esquema de los procesos de oxidación en película fina

Por lo tanto, esa pequeña masa de aceite que está en contacto con el oxígeno del aire será el foco donde se concentren mayor cantidad de compuestos oxigenados (ácidos carboxílicos, alcoholes, cetonas...) y por lo tanto, el periodo de inducción de esa pequeña masa de aceite será inferior al periodo de inducción de toda la masa de aceite contenido en el transformador. 
En la actualidad existen muchos ensayos de caracterización de aceites mediante oxidación en película fina (thin film). Uno de los métodos más usados es el Penn State Method. Se diseñó un protocolo de oxidación en película fina haciendo uso de placas Petri.

Se evaluó posteriormente la pérdida de volátiles y el estado físico de los aceites.

\subsubsection{Procedimiento operativo}

Para llevar a cabo dicha caracterización en el laboratorio, se necesitó:

a. Una estufa de ventilación forzada capaz de mantener temperaturas de $120 \pm 1{ }^{\circ} \mathrm{C}$ de la marca SELECTA.

b. Placas Petri de características similares a las usadas para análisis microbiológico.

c. Balanza o granatario con una precisión de $\pm 0,01 \mathrm{~g}$ de la marca IBD.

d. Aceites dieléctricos de origen vegetal (Aceite A y Aceite B) y de origen mineral (Aceite C y Aceite D)

El objeto de dicho estudio es ensayar una pequeña película de aceite, sometiéndola a temperatura de $120{ }^{\circ} \mathrm{C}$ durante 168 horas. Después, se valorará las perdidas por volatilidad así como el estado físico de la muestra.

\subsubsection{Desarrollo de planta piloto de generación de puntos calientes}

Como hemos visto en el capítulo I de la presente tesis, los aceites dieléctricos juegan un papel fundamental en la vida útil del transformador. Si el material aislante, tanto sólido como líquido, sigue un plan de mantenimiento adecuado, el tiempo de vida útil medio de un transformador suele ser de 40 años. Pero factores externos como el agua, las elevadas temperaturas de trabajo, un aumento de la viscosidad del aceite... puedo provocar que dichos aislantes se degraden con el tiempo. Esto da lugar a fallos térmicos y eléctricos dentro del transformador.

Supongamos que por falta de estanqueidad en las juntas del transformador, un cierto volumen de aire entra dentro de la cuba del transformador. Ese aire lleva incorporado 
moléculas de agua que se disuelven en el aceite dieléctrico. Por migración entre fases, el agua disuelta puede ser absorbida por el papel celulósico dando lugar al comienzo de la reacción de hidrólisis de la celulosa.

Tal y como se muestra en el siguiente esquema de reacción, la celulosa se hidroliza dando lugar a productos de bajo peso molecular tales como los furanos citados en el capítulo I.

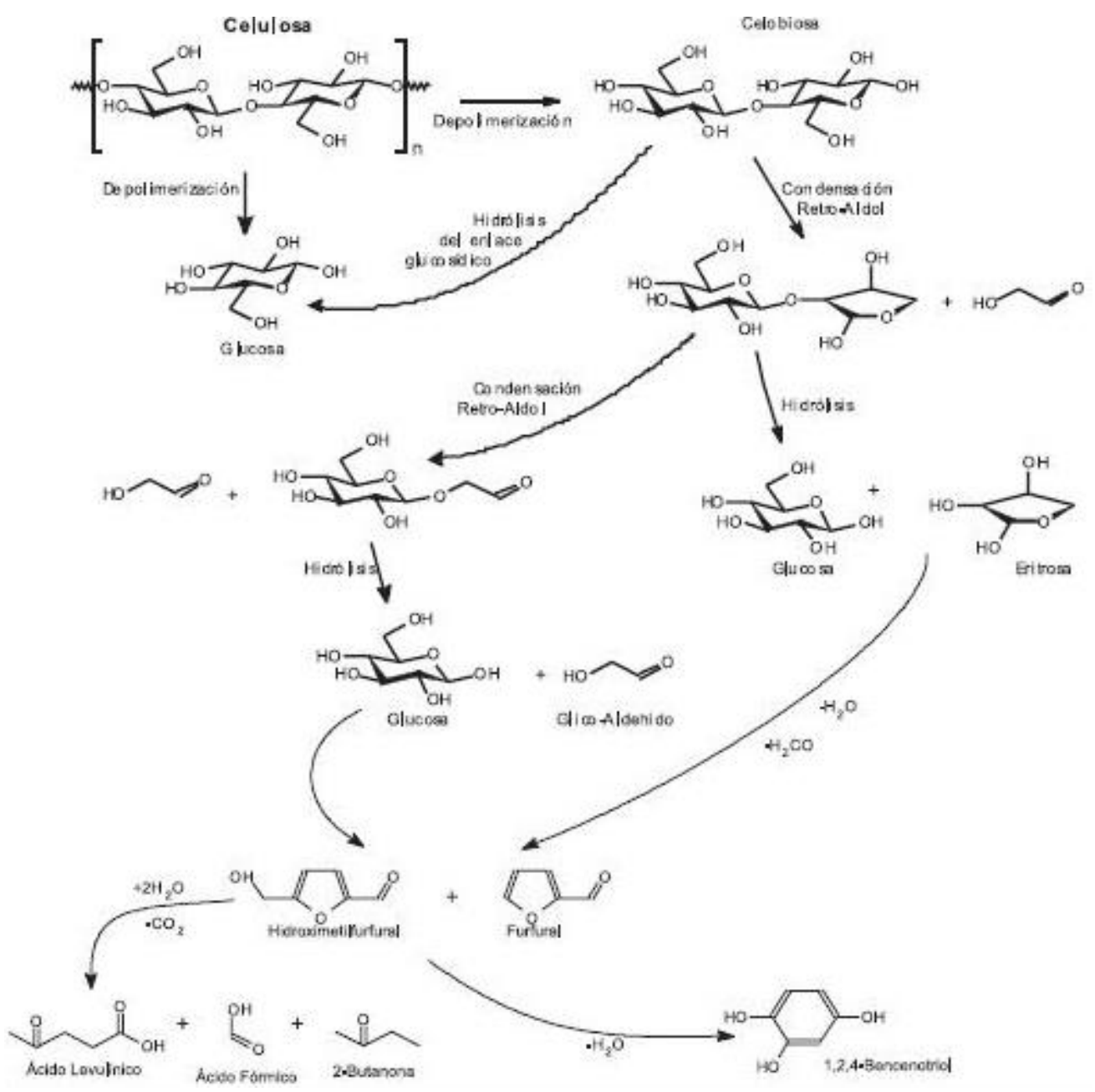

Figura 86: Mecanismo de degradación de la celulosa

Esto se traduce en una disminución de la tracción máxima a la que puede estar sometido el aislante sólido. La hidrólisis total o parcial de la celulosa genera huecos entre los devanados de cobre, quedando estos comunicados entre sí sin ningún tipo de aislante entre ellos. Esto da lugar a arcos eléctricos entre devanados. Un arco eléctrico posee una elevada energía capaz de craquear el aceite aislante, ya que la energía transportada por 
dicho arco es suficientemente elevada como para superar la energía de enlace de las diferentes estructuras químicas por las que está formada el aceite dieléctrico.

A continuación, se expone una secuencia donde se observa el mecanismo de craqueo de las diferentes moléculas [45]:

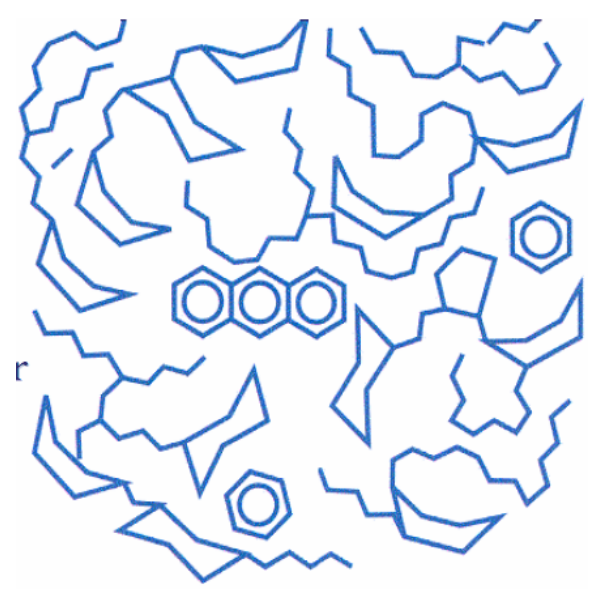

Figura 88: Moléculas tipo de aceite dieléctrico, en reposo

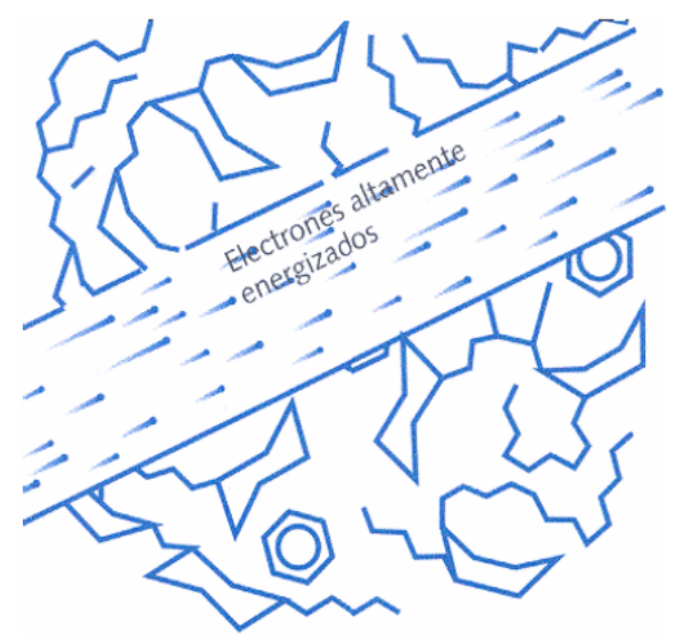

Figura 89: Presencia de un arco eléctrico en la matriz orgánica 


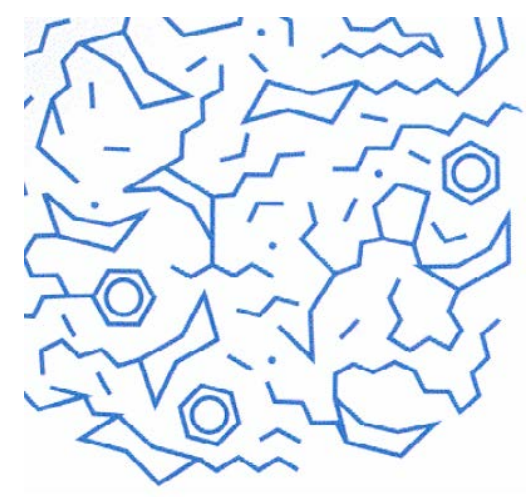

Figura 90: Estado del aceite después. Se observan gases disueltos en la matriz

Como se puede observar en la secuencia de imágenes anteriores, la presencia de un arco eléctrico o un punto caliente origina un craqueo molecular dando lugar a moléculas de bajo peso molecular y a gases disueltos en el aceite.

El análisis de gases disueltos es una potente herramienta para conocer si, el fallo que ha tenido lugar en el interior del transformador es de naturaleza térmica o eléctrica, y si han sido por descargas de baja o alta energía o si los puntos calientes han sido de baja o alta temperatura.

\subsubsection{Análisis de gases disueltos $(D G A)$}

Como se citó en el capítulo 1 de la presente tesis, los aceites minerales están constituidos por un mezcla de diferentes moléculas de hidrocarburos que contienen grupo $\mathrm{CH}_{3}, \mathrm{CH}_{2}$ y $\mathrm{CH}$ unidos por enlaces C-C. Debido a la presencia de fallos térmicos o eléctricos, se pueden romper algunos de estos enlaces, vía radicálica generando radicales libres que se recombinan fácilmente para dar moléculas gaseosas. Los gases generados durante este proceso son generalmente, los mostrados en la siguiente tabla:

Tabla 22: Gases generados durante fallos en el interior del transformador

\begin{tabular}{|l|c|c|c|c|c|c|c|}
\hline Gas & Hidrógeno & $\begin{array}{c}\text { Monóxido de } \\
\text { carbono }\end{array}$ & $\begin{array}{c}\text { Dióxido de } \\
\text { carbono }\end{array}$ & Metano & Etano & Etileno & Acetileno \\
\hline Fórmula & $\mathrm{H}_{2}$ & $\mathrm{CO}$ & $\mathrm{CO}_{2}$ & $\mathrm{CH}_{4}$ & $\mathrm{C}_{2} \mathrm{H}_{6}$ & $\mathrm{C}_{2} \mathrm{H}_{4}$ & $\mathrm{C}_{2} \mathrm{H}_{2}$ \\
\hline
\end{tabular}


Dichos gases, si se producen en baja concentración, se disuelven en el aceite.

Los defectos de baja energía, como son las descargas parciales (descargas tipo corona) favorecen la ruptura del enlace $\mathrm{C}-\mathrm{H}\left(\mathrm{E}_{\text {enlace }}=338 \mathrm{~kJ} \cdot \mathrm{mol}^{-1}\right)$ dando lugar a radicales $\mathrm{H}$. que rápidamente se recombinarán para dar $\mathrm{H}_{2}$ (g). Para poder romper los enlaces C-C se requiere de más temperatura o energía. Esto generará radicales tipo $\mathrm{CH} \cdot, \mathrm{CH}_{2}{ }^{\circ} \mathrm{o} \mathrm{CH}_{3}$. que se recombinaran para dar lugar a nuevos enlaces $\mathrm{C}-\mathrm{C}, \mathrm{C}=\mathrm{C}, \ldots$

La energía de enlace de $\mathrm{C} \equiv \mathrm{C}$ es superior $\left(960 \mathrm{~kJ} . \mathrm{mol}^{-1}\right)$ a la del enlace $\mathrm{C}=\mathrm{C}(720$ $\left.\mathrm{kJ} \cdot \mathrm{mol}^{-1}\right)$ y esta a su vez, superior a la del enlace C-C $\left(607 \mathrm{~kJ} \cdot \mathrm{mol}^{-1}\right)$ por lo que, a temperatura elevadas $\left(500-600{ }^{\circ} \mathrm{C}\right)$ se favorecerá la formación de etileno frente a la formación de metano y etano. De forma similar, la formación de acetileno tendrá lugar a temperaturas superiores a los $800{ }^{\circ} \mathrm{C}$. Por lo tanto, el acetileno será el gas de recombinación de mayor concentración en fallos eléctricos de alta energía (arcos).

En cuanto a la presencia de monóxido de carbono y dióxido de carbono, esta es debida a la descomposición de los monómeros de celulosa por lo que está formado el aislante sólido (Véase Figura 86). Dichos dímeros y monómeros tienen débiles enlaces C-O y enlaces glicosídicos que son más inestables que los enlaces de los hidrocarburos del aceite. Estos enlaces, al superar $\operatorname{los} 105^{\circ} \mathrm{C}$, empiezan a romperse de forma significativa y cuando el sistema alcanza $\operatorname{los} 300{ }^{\circ} \mathrm{C}$, se produce la completa descomposición y carbonización del sólido aislante.

Una de las formas de analizar la presencia de dichos gases disueltos es mediante micro cromatografía gaseosa usando el método de Shake Test para extraer los gases disueltos en el aceite. El equipo que dispone el laboratorio de Combustibles y Petroquímica para llevar a cabo dichos análisis es el equipo Myrkos de Morgan Schaffer,

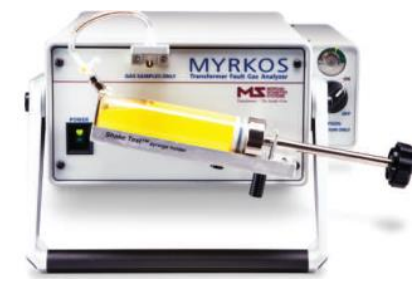

Figura 91: Microcromatógrafo modelo Myrkos 


\subsubsection{Tipos de fallos eléctricos y térmicos}

La experiencia adquirida por la observación de transformadores defectuosos durante varias décadas, ha conducido a las siguientes clases de defectos detectables visualmente:

- Descargas parciales $(\boldsymbol{D P})$. Son del tipo plasma frio o corona y que se pueden producir por la deposición de cera sobre el papel aislante o por chispas eléctricas y que provocan pequeñas perforaciones en el aislante celulósico.

- Descargas de baja energía (D1). Tienen lugar en el aceite o en el papel y originan grandes perforaciones carbonizadas en papel o partículas de carbón en el aceite.

- Descargas de alta energía (D2). Son fallos que generan arcos de potencia que dan lugar a la carbonización del papel, fusión de los metales en los extremos de la descarga o carbonización del aceite.

- Defectos térmicos a baja temperatura (T1). Son puntos calientes de temperatura inferior a $\operatorname{los} 300^{\circ} \mathrm{C}$.

- Defectos térmicos de temperatura elevada (T2). Dan lugar a carbonización del papel celulósico ya que la temperatura de estos puntos calientes es superior a los $300{ }^{\circ} \mathrm{C}$.

- Defectos térmicos de muy altas temperaturas (T3). Son defectos de temperatura superior a los $700{ }^{\circ} \mathrm{C}$ y dan lugar a la carbonización del aceite, coloración de metales o fusión de metales.

Tabla 23: Resumen de las abreviaturas

\begin{tabular}{|l|l|}
\hline DP & Descargas parciales \\
\hline D1 & Descargas de baja energía \\
\hline D2 & Descargas de alta energía \\
\hline T1 & Defecto térmico, $\mathrm{t}<300^{\circ} \mathrm{C}$ \\
\hline T2 & Defecto térmico, $300^{\circ} \mathrm{C}<\mathrm{t}<700^{\circ} \mathrm{C}$ \\
\hline T3 & Defecto térmico, $\mathrm{t}>700^{\circ} \mathrm{C}$ \\
\hline
\end{tabular}




\subsubsection{Triángulo de Duval}

Duval [50], en 1974 utilizó tres gases para clasificar las averías en los transformadores: el metano $\left(\mathrm{CH}_{4}\right)$, el etileno $\left(\mathrm{C}_{2} \mathrm{H}_{4}\right)$ y el acetileno $\left(\mathrm{C}_{2} \mathrm{H}_{2}\right)$. Para ello, representó en un triángulo equilátero el porcentaje de cada uno de los gases detectados por DGA (Análisis de gases disueltos) que vienen dados por las siguientes ecuaciones:

$$
\begin{aligned}
\% C_{4} H_{4} & =\frac{x}{x+y+z} 100 \\
\% C_{2} H_{4} & =\frac{y}{x+y+z} 100 \\
\% C_{2} H_{2} & =\frac{z}{x+y+z} 100
\end{aligned}
$$

Donde $x$ es la concentración de metano en ppm, $y$ es la concentración de etileno y $z$ es la concentración de acetileno en ppm.

A modo de ejemplo, supongamos que llevamos a cabo el análisis de gases disueltos por micro cromatografía gaseosa y obtenemos las siguientes concentraciones de gases: $[$ Metano $]=30 \% \mathrm{v} / \mathrm{v},\left[\right.$ Etileno] $=60 \% \mathrm{v} / \mathrm{v}$ y $[$ Acetileno $]=10 \% \mathrm{v} / \mathrm{v}$. Se traza, para $\mathrm{X}_{\mathrm{p}}$ una recta paralela a $\mathrm{BC}$, para $\mathrm{Y}_{\mathrm{p}}$, una recta paralela a $\mathrm{CA}$ y para $\mathrm{Z}_{\mathrm{p}}$, una recta paralela a AB. Como resultado, obtenemos una intersección de las tres rectas en la ubicación de la avería.

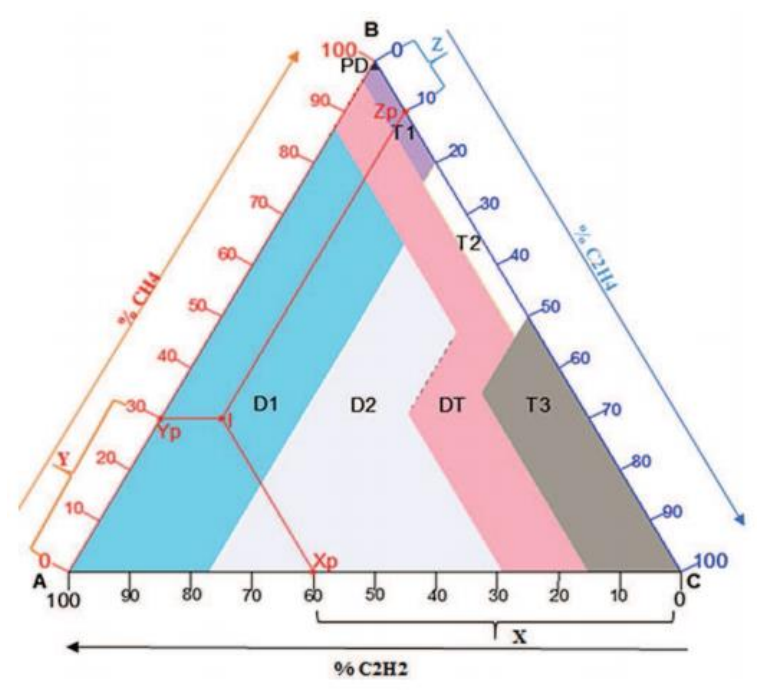

Figura 93: Ubicación de avería en el triángulo de Duval 
En este caso, el fallo asociado a los gases detectados es un fallo eléctrico de baja energía.

En función del aceite usado si es mineral, silicónico, vegetal o sintético, las zonas delimitadas para cada fallo cambiarán. Por esta razón, para el desarrollo de la herramienta de diagnosis del aceite A es necesario recrear fallos eléctricos y térmicos en el laboratorio para "reconstruir" de nuevo el triángulo de Duval para dicho aceite.

\subsubsection{Desarrollo de la planta piloto de generación de puntos calientes}

Como se ha citado, es necesario desarrollar una planta de generación de puntos calientes para recalcular los límites de las zonas T1, T2 y T3 del nuevo aceite desarrollado durante esta tesis.

Para ello, el laboratorio desarrolló un prototipo de planta la cual incluía los siguientes elementos:

1. Autotransformador

2. Indicador de temperatura

3. Dieléctricos

4. Bureta de medida

5. Entrada de argón

6. Salida a análisis

7. Regulador de presión

8. Aros para la colocación del matraz

9. Embudo de vidrio

10. Resistencia (hilo Kanthal)

11. Termopar tipo $\mathrm{K} 1,5 \mathrm{~mm}$

12. Electrodos

13. Soporte

14. Mampara de protección 


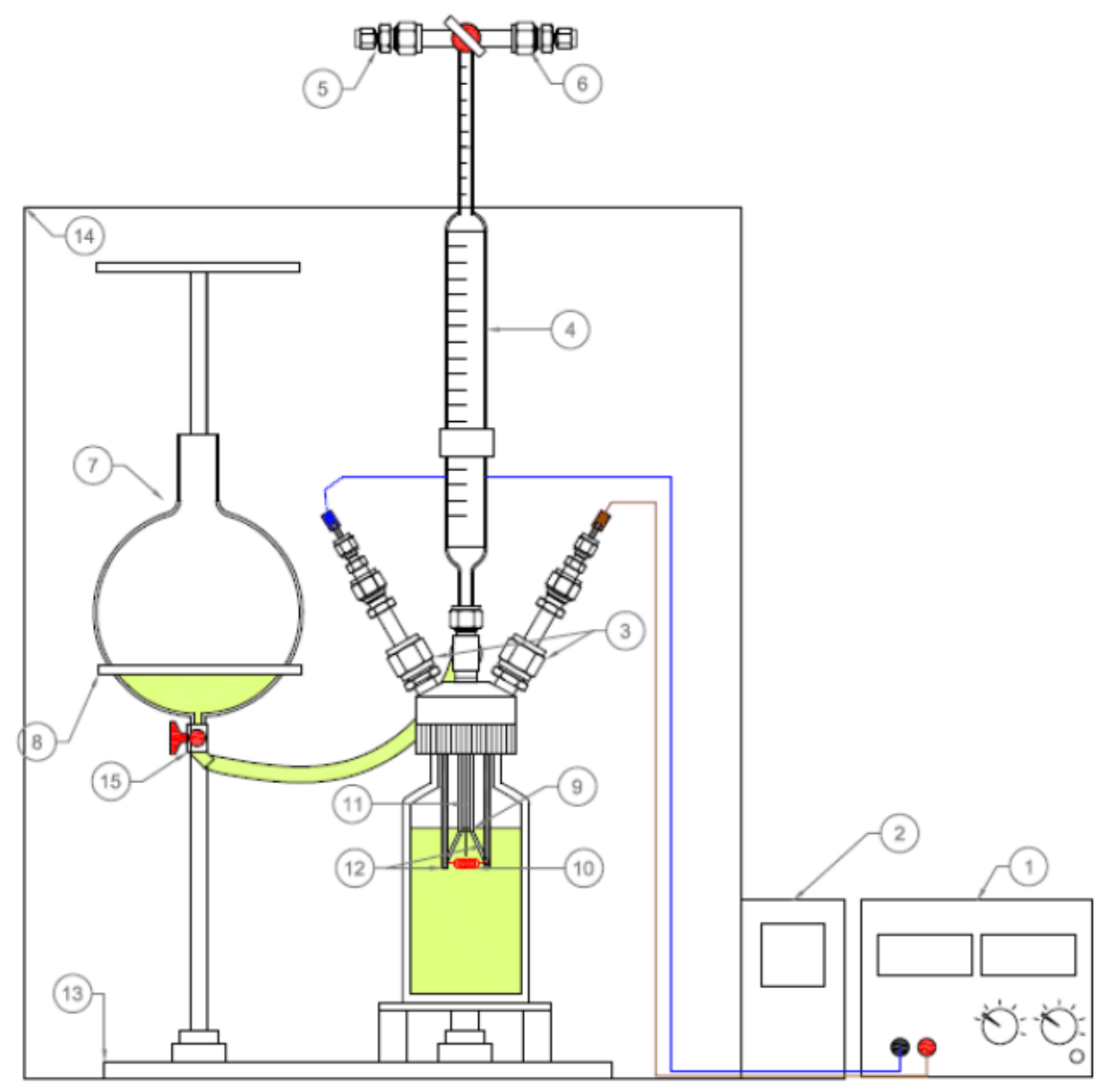

Figura 94: Esquema de la planta piloto de generación de puntos calientes

Como autotransformador se ha empleado una fuente de alimentación de laboratorio EX2020R de la marca Thurbly Thandar Instruments, capaz de suministrar de 0 a $20 \mathrm{~V}$ y de 0 a 20 A. La corriente y tensión de salida se pueden preajustar de forma precisa empleando los controles de la fuente. La resistencia del sistema dependerá de la longitud del hilo Kanthal colocado entre los dos polos. Para conseguir una potencia dada, con una resistencia conocida, el voltaje que hay que aplicar viene dado por la ecuación siguiente:

$$
\operatorname{Voltaje}(V)=\sqrt{\text { Potencia }(W) x \text { Resistencia }(\Omega)}
$$


La fuente dispone de un cruce automático entre corriente constante o tensión constante: si con la tensión de salida ajustada, la corriente es mayor que la que puede circular por la resistencia, la alimentación eléctrica cambiará automáticamente a operación con corriente constante.

En cuanto al indicador de temperatura, se ha colocado un termopar tipo $\mathrm{K}$ junto a la resistencia.

Como el tapón del generador de puntos calientes está fabricado en acero SS304, un material conductor, se han empleado dos dieléctricos. De este modo, no hay conductividad entre el tapón y ninguno de los dos polos.

Una vez generado el punto caliente con el hilo Kanthal, los gases generados se recogen en una bureta de medida de volumen de $100 \mathrm{~mL}$. Está dividida en dos partes: $90 \mathrm{~cm}^{3}$ con graduación $1 / 1$, con diámetro exterior $26 \mathrm{~mm}$ e interior $23,2 \mathrm{~mm}$, y la parte final, con mayor resolución (1/10), de diámetro exterior $13 \mathrm{~mm}$ e interior de $10 \mathrm{~mm}$. La bureta tiene en la parte superior una llave de tres vías, en forma de $\mathrm{T}$ y con paso de 3 mm. La llave tiene una posición que permite comunicar la corriente de argón con el interior de la bureta y la salida de análisis.

Como regulador de presión se ha empleado un matraz de $1000 \mathrm{~mL}$. Variando la posición de éste puede llenarse o vaciarse la bureta (ver figura 95). Dispone de una llave de cierre $\mathrm{CTF}$ en su parte interior. Está conectado a la bureta mediante una manguera flexible de $8 \mathrm{~mm}$.

Para finalizar, el embudo de vidrio lo usaremos para conducir los gases generados por lo puntos calientes desde el recipiente de vidrio hasta la bureta. Dicho embudo se une al tapón mediante una pieza de teflón. El sello en esta pieza es fundamental, puesto que de otro modo, el aire de la cámara del recipiente entraría en la bureta. 

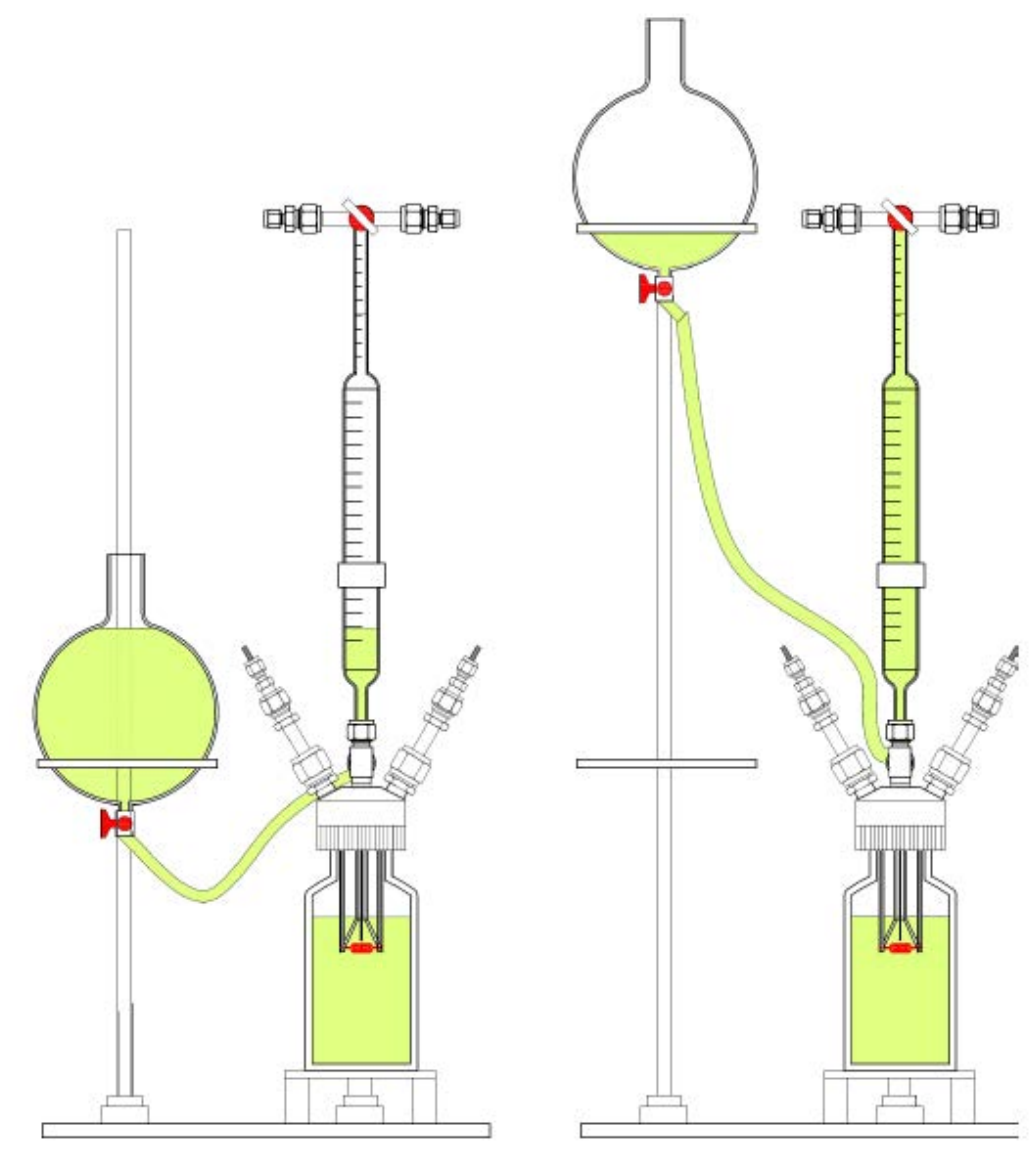

Figura 95: Llenado y vaciado de la bureta mediante cambio de posición del matraz

Dicha planta piloto cumple con las siguientes directivas:

- Directiva 97/23/CE: Equipos de presión

- Directiva 94/9/EC: Aparatos y sistemas de protección para uso en atmósferas potencialmente explosivas

- Directiva 2004/108/EC: Compatibilidad electromagnética

- Directiva 2006/95/EC: Bajo voltaje-Seguridad eléctrica

La "Prueba de seguridad eléctrica" se llevó a cabo en el laboratorio de CATECHOM de la Universidad de Alcalá de Henares, en Madrid (España).

A continuación, se muestras varias imágenes de la planta de generación de puntos calientes, donde se señalan los accesorios citados anteriormente: 


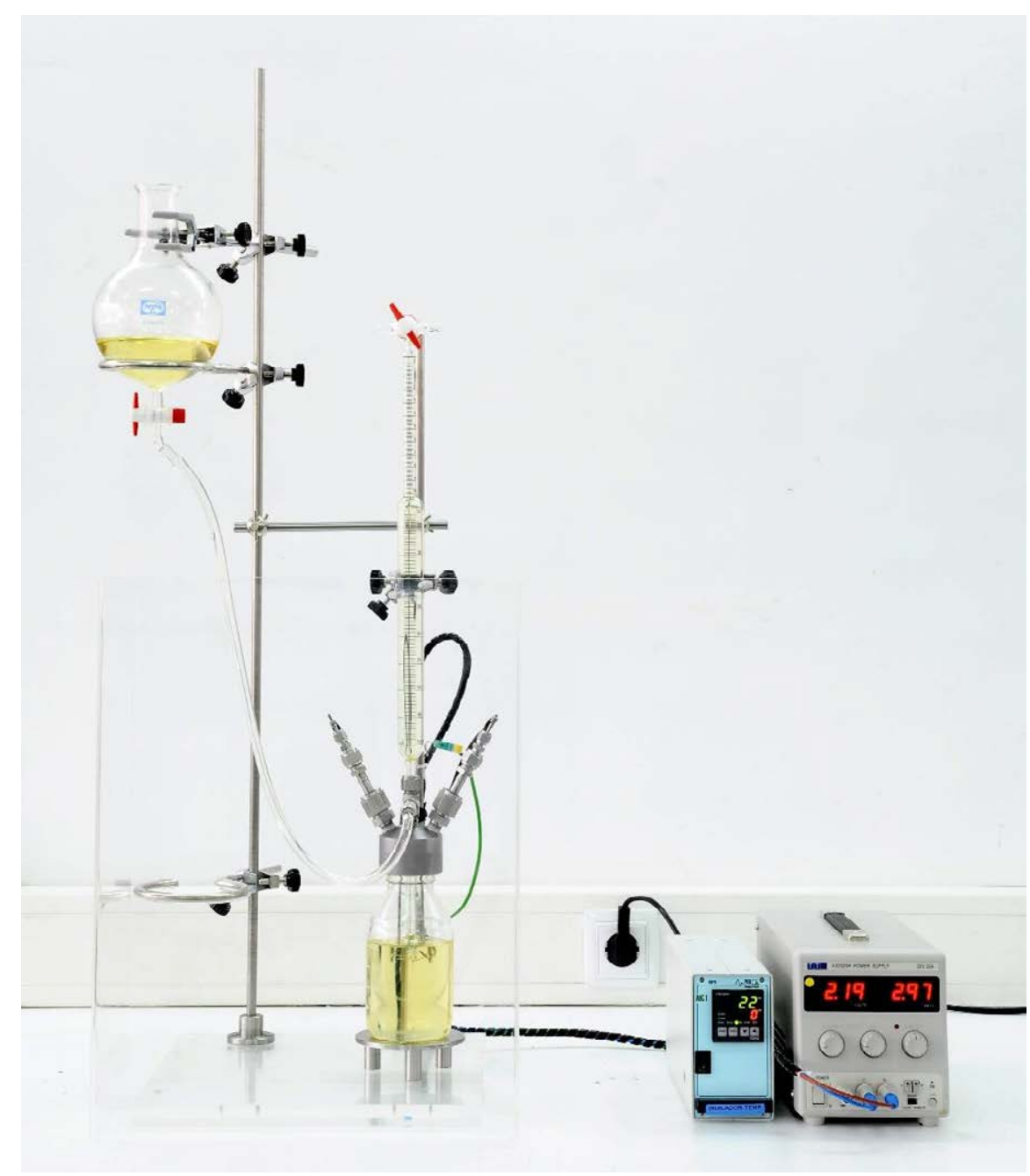

Figura 96:Imagen real de la planta de generación de puntos calientes

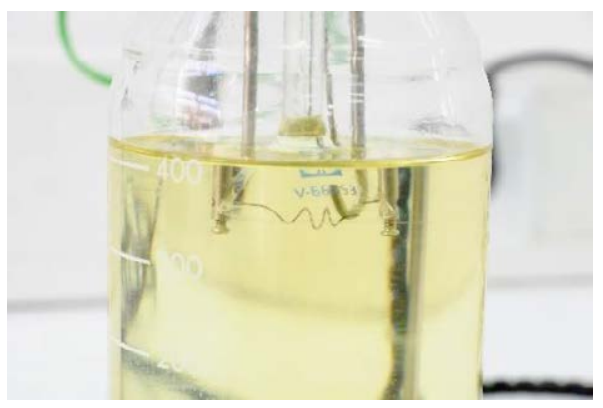

Figura 97: Generador de punto caliente (Resistencia hilo Kanthal) 


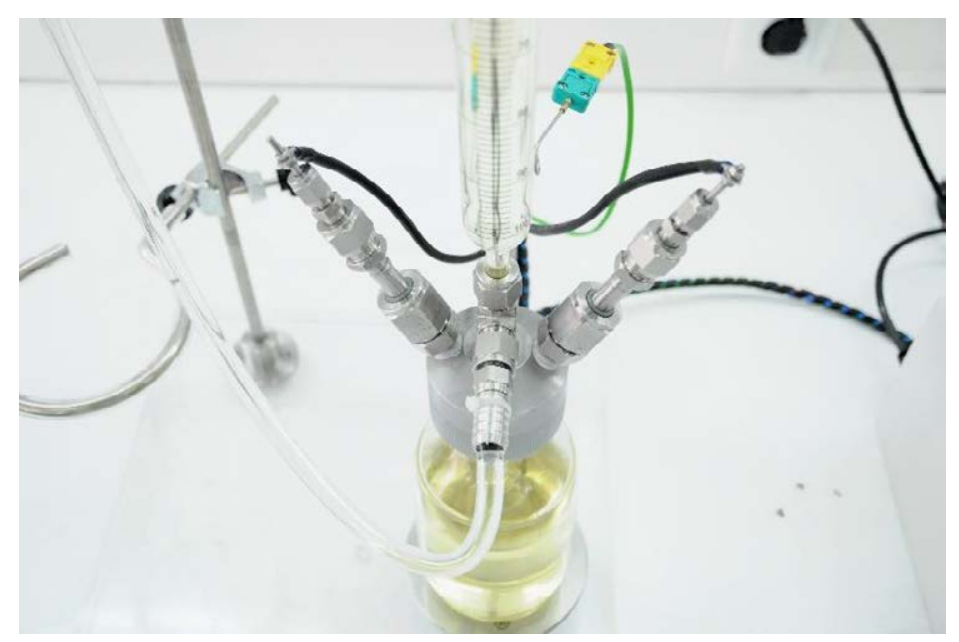

Figura 98: Detalle de los dieléctricos

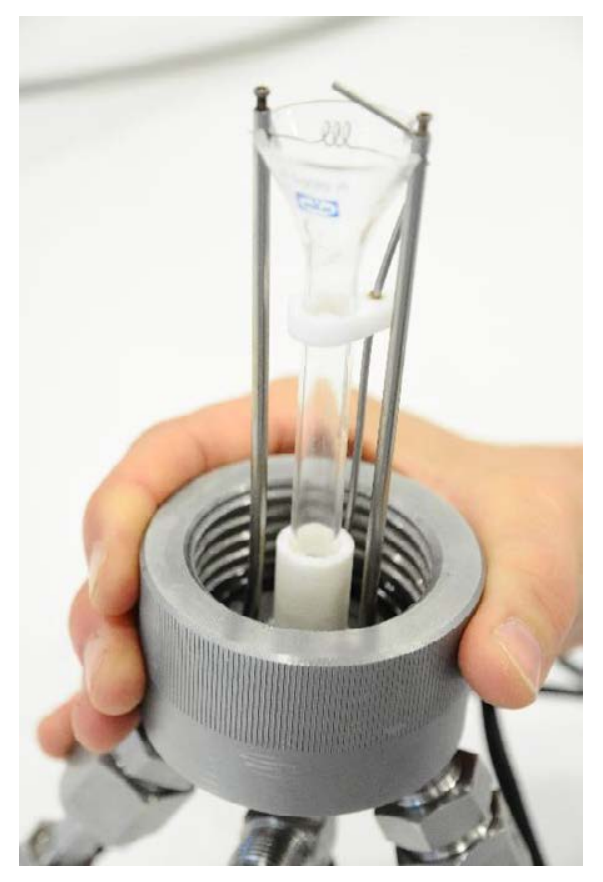

Figura 99: Detalle del cono y del termopar

El objetivo a conseguir con la presente planta es simular los fallos térmicos tipo T1, T2 y T3. Para ello, se jugó con el voltaje y la longitud del hilo Kanthal (resistencia). De esta forma, se consiguieron puntos calientes en un amplio rango de temperaturas (desde los $100^{\circ} \mathrm{C}$ hasta $\operatorname{los} 950{ }^{\circ} \mathrm{C}$ ). Posteriormente, se tomaron muestra de los gases disueltos en el aceite y se llevaron a la representación de Duval con el objetivo de "rediseñar" los límites de dicho triángulo para el aceite $\mathrm{A}$. 


\subsection{ESTUDIO DE COMPATIBILIDAD QUÍMICA}

\subsubsection{Compatibilidad de aceites con aislantes celulósicos}

Es bien conocido, y así se reflejó en el capítulo 1 de la presente tesis, que la degradación de la celulosa reduce el grado de polimerización (DP), destruye los enlaces inter-fibras y causa una pérdida de su resistencia mecánica que conduce a su rasgado y desfibrilación.

El aislamiento papel-aceite se degrada con el tiempo, y el proceso depende de las solicitaciones térmicas y eléctricas, de la presencia de agua y oxígeno, así como fallos externos, sobretensiones, etc. La degradación del papel acaba en fallos que pueden deberse a diversas causas:

- El papel puede romperse y salir fuera de los devanados bloqueando los pasos de aceite impidiendo la circulación y consiguiente refrigeración.

- El agua procedente de la degradación del papel y la ingresada del exterior pueden fijarse superficialmente al papel reduciendo su resistividad.

- Una carbonización local del papel puede incrementar la conductividad eléctrica y causar sobrecalentamiento o fallos.

Para estudiar la compatibilidad de los aceites dieléctricos de origen vegetal con los materiales celulósicos, se han puesto a punto los procedimientos operativos de laboratorio. Para estudiar dicha compatibilidad se determinaron los siguientes parámetros a todas las muestras durante el periodo de degradación que tuvo lugar:

- Grado de polimerización medio viscosimétrico $\left(\overline{D P}_{v}\right)$

- Humedad

- Índice de acidez

- Contenido en agua Karl-Fischer

- Tangente del ángulo de pérdidas dieléctricas

- Contenido de 2-Furfural y familia de furanos

- Espectroscopía FTIR 


\subsubsection{Procedimiento operativo del laboratorio}

Los aceites que fueron sometidos a ensayo para el estudio de la compatibilidad con aislantes celulósicos son:

1. Aceite vegetal aditivado (Aceite A)

2. Aceite vegetal Aditivado (Aceite B)

3. Aceite vegetal de la misma naturaleza que A pero sin aditivar (Aceite $\mathrm{C}$ )

4. Aceite vegetal de la misma naturaleza que B pero sin aditivar (Aceite D)

5. Aceite mineral parafínico (Aceite E)

Para el acondicionamiento y deshidratación de las muestras, se tomaron $300 \mathrm{~mL}$ aproximadamente de cada aceite y se mantuvieron durante una hora a $70^{\circ} \mathrm{C}$. Posteriormente se filtraron al vacío en membrana de nitrocelulosa de $8 \mu \mathrm{m}$ de diámetro de poro. Se fueron depositando en vaso de precipitados de $500 \mathrm{~mL}$ dentro de un desecador para evitar que captasen agua de la atmósfera. Se procedió a determinar el contenido en agua por valoración columbimétrica Karl-Fischer de cada uno de los aceites deshidratados.

Con respecto al cartón (pressboard) se cortaron con tijeras tiras rectangulares de $34 \mathrm{~cm}$ de longitud y 2,5 cm de ancho. De esta manera cada probeta de material celulósico nos proporcionó unos 11 gramos de material celulósico). Las tiras se pesaron posteriormente para conocer la dispersión de pesos. Los resultados son:

Media de las 20 tiras de cartón: 10,3973 g

Desviación típica: $0,2392 \mathrm{~g}$

Tras su pesada, se doblaron por la mitad para obtener una forma de $\mathrm{V}$ ayudándonos con una regla. Se introdujeron a continuación las 20 tiras en una estufa de vacío durante un periodo de 24 horas a $120^{\circ} \mathrm{C}$ y unos 10 mbar para obtener un secado equivalente al que se utiliza industrialmente en transformadores y que deberá proporcionar una humedad en el cartón inferior a $0,5 \% \mathrm{~m} / \mathrm{m}$. Una vez secadas, se mantuvieron en el desecador hasta su posterior empleo. 
En cada uno de los reactores de vidrio diseñados para este ensayo (las dimensiones de los mismos fueron $28 \mathrm{~cm}$ de longitud, $4 \mathrm{~cm}$ de diámetro interior y $5 \mathrm{~mm}$ de espesor de pared), Se introdujeron $250 \mathrm{~mL}$ de aceite deshidratado y dos tiras de cartón que se colocaron en forma de tetraedro. En total se sometieron a ensayo 10 reactores, dos por cada muestra. Los reactores van provistos con un tapón de plástico capaz de resistir, sin deformación, temperaturas de autoclave de hasta $180^{\circ} \mathrm{C}$ (ver figura 100).

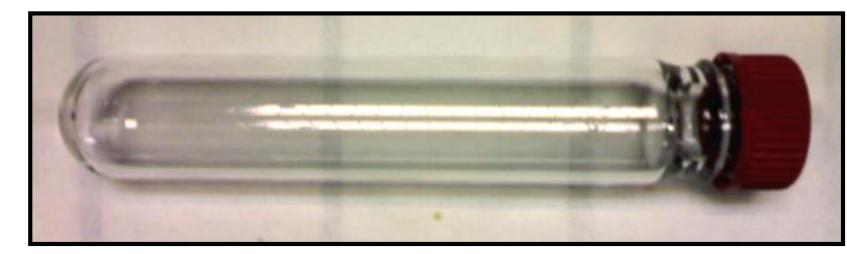

Figura 100: Reactor de vidrio para llevar a cabo ensayos de compatibilidad química

Se introdujeron en la estufa a $55^{\circ} \mathrm{C}$ y 10 mbar de presión durante 24 horas. Una vez transcurrido ese tiempo, se cerraron los reactores y se introdujeron en la estufa a $145^{\circ} \mathrm{C}$ y presión atmosférica.

A las 200 horas aproximadamente, se "aflojaron" los tapones ligeramente para liberar cualquier exceso de presión y se volvió a cerrar inmediatamente. Los tubos se metieron nuevamente en la estufa a la temperatura de $145^{\circ} \mathrm{C}$ y presión atmosférica.

Se fueron recogiendo muestras de aceite y cartón prensado cada 1000 horas durante un periodo total de 4000 horas.

\subsubsection{Compatibilidad de los aceites vegetales con los materiales del transformador}

Uno de los parámetros más significativos a la hora de diseñar un transformador de distribución es determinar la compatibilidad del aceite aislante, en nuestro caso aceite de origen vegetal, con cada uno de los materiales con los que está construido el transformador ya que la magnitud de los cambios en las propiedades eléctricas de los aceites aislantes puede ser de elevada importancia. 
Para evaluar dichos cambios, se evalúan dos tipos de resultados:

- Realizados a los materiales de construcción del transformador donde se determinan los cambios físicos de éstos tales como la dureza, aumento de volumen o la decoloración...

- Realizados al aceite dieléctrico, tales como el color, concentración de metales, índice de acidez...

El objetivo de este ensayo es obtener resultados claros y concisos de la variación de las propiedades de los diferentes materiales para que se tengan en cuenta estas variaciones a la hora de diseñar el transformador.

\subsubsection{Aparatos y equipos}

\subsection{Materiales para llevar a cabo el ensayo de compatibilidad}

1) Horno de ventilación forzada ajustable a $100 \pm 1{ }^{\circ} \mathrm{C}$ y estufa de secado, ajustable a $105 \pm 5^{\circ} \mathrm{C}$ de la marca Selecta

2) Reactor de vidrio, de $2 \mathrm{~L}$ de capacidad con tapadera de vidrio de dos bocas.

3) Desecador de $5 \mathrm{~L}$ de capacidad para acondicionamiento de las muestras

\subsection{Equipos para caracterizar las muestras}

1) Equipo de rigidez dieléctrica de la marca Isotest modelo OT2-60D

2) Balanza analítica con una precisión de $\pm 0,0001 \mathrm{~g}$ de la marca Mettler Toledo

3) Micrómetro y calibre, para medir variación de volumen

4) Equipo de espectroscopía de absorción atómica (ASS) marca Fischer Sci.

5) Equipo de tracción Instron con extensómetro de largo recorrido modelo 3365

6) Material de vidrio: buretas, pipetas, vasos de precipitados... adaptado a la normativa. 


\subsubsection{Materiales que van a ser sometidos a ensayo}

La muestra a ensayar consta de los siguientes materiales:

- Aceite dieléctrico de origen vegetal A y B

- Núcleo de hierro del transformador

- Juntas de goma y cartón

- Corcho laminado

- Madera laminada

- Hilo de cobre

- Placa de cobre

- Canutos de cartón prensado

- Cintas autoadhesivas

\subsubsection{Acondicionamiento de las muestras}

Lo primero que se hizo fue un reconocimiento visual de todos los materiales que se iban a ensayar: detectar fisuras, deformaciones, anomalías en su estructura... Todas las muestras fueron manipuladas con cuidado, nunca se tocaron con las manos. Se hicieron fotografías a cada uno de los materiales antes de ser sometidos a ensayo, que se mostrarán más adelante. Todos los materiales sólidos, excepto el cartón aislante, fueron deshidratados.

Para ello, se mantuvieron durante 16 horas en estufa de ventilación forzada a $105^{\circ} \mathrm{C}$. Se dejaron enfriar en el desecador hasta que alcanzaron la temperatura ambiente.

En cuanto a los canutos de cartón, fueron deshidratados en estufa de vacío, aplicando un ligero vacío ya que así, se evitan efectos de oxigenación que deterioren el estado inicial del material celulósico.

Para deshidratar los aceites se llevó a cabo la misma operación que con el material celulósico. Al igual que los otros materiales anteriormente citados, el aceite se dejó dentro de un desecador hasta que alcanzó la temperatura ambiente. 
La relación de materiales dentro del transformador, deberá seguir el ratio que usan las empresas constructoras de transformadores. Esta es:

- $400 \mathrm{~L}$ de aceite aislante

- $30 \mathrm{~m}^{2}$ de chapa de $\mathrm{Cu}$

- $35 \mathrm{~m}^{2}$ de hilo de $\mathrm{Cu}$ esmaltado

- $180 \mathrm{~m}^{2}$ de material celulósico

- $3 \mathrm{~m}^{2}$ de núcleo de transformador

En la realización de este ensayo, se redujo la escala de las proporciones de los diferentes materiales. El reactor de vidrio donde se va a llevar a cabo la compatibilidad tiene un volumen total de $2 \mathrm{~L}$, por lo que se ensayaron solamente 1,5 $\mathrm{L}$ de aceite. Las relaciones quedaron según la siguiente tabla 24:

Tabla 24: Escalado proporciones materiales para ensayos en laboratorio

\begin{tabular}{lccc}
\hline Material & Ratio Construcción & Ratio LCP & Ratio Ensayo \\
\hline Aceite & $400 \mathrm{~L}$ & $1,5 \mathrm{~L}$ & $\mathbf{1 5 0 0} \mathbf{~ m L}$ \\
Chapa de Cu & $30 \mathrm{~m}^{2}$ & $0,1125 \mathrm{~m}^{2}$ & $\mathbf{1 1 2 , 5} \mathbf{c m}^{\mathbf{2}}$ \\
Hilo de Cu esmaltado & $35 \mathrm{~m}^{2}$ & $0,13125 \mathrm{~m}^{2}$ & $\mathbf{1 3 1 , 2 5} \mathbf{c m}^{\mathbf{2}}$ \\
Material Celulósico & $180 \mathrm{~m}^{2}$ & $0,675 \mathrm{~m}^{2}$ & $\mathbf{6 2 5} \mathbf{c m}^{\mathbf{2}}$ \\
Núcleo transformador & $3 \mathrm{~m}^{2}$ & $0,1125 \mathrm{~m}^{2}$ & $\mathbf{1 1 , 2 5} \mathbf{c m}^{\mathbf{2}}$ \\
\hline
\end{tabular}

En cuanto a los materiales restantes (madera, juntas de goma, corcho laminado...), como son materiales secundarios dentro del transformador, se introdujeron las siguientes proporciones de cada material:

- Probeta de madera de $5 \times 5 \mathrm{~cm}^{2}$

- Probeta de corcho laminado de $5 \times 5 \mathrm{~cm}^{2}$

- Una junta de goma

- Dos tiras autoadhesivas unidas entre si

- Dos canutos de cartón de $15 \mathrm{~cm}$ de longitud 


\subsubsection{Preparación de las probetas}

Para preparar las probetas de cada uno de los materiales que fueron ensayados, se cortaron y prepararon de tal forma que se nos generó la superficie recalculada anteriormente. Las dimensiones de las probetas sometidas a ensayos con los materiales reales recibidos en el laboratorio tienen las siguientes dimensiones:

- Chapa de cobre: Probetas cuadradas de $10,6 \mathrm{~cm}$ de lado

- Hilo de cobre esmaltado: 4 alambres de $40 \mathrm{~cm}$ de longitud

- Material celulósico: Probetas cuadradas de $25 \mathrm{~cm}$ de lado

- Núcleo del transformador: Probetas cuadradas de 3,4 cm de lado

Por lo tanto y en resumen, dentro de cada reactor, deberán ir incluidos las siguientes cantidades de los diferentes materiales:

Tabla 25: Relación de probetas sometidas a ensayos y sus dimensiones

\begin{tabular}{|c|c|c|}
\hline Material & Relación ensayo & Material sometido a ensayo \\
\hline Aceite dieléctrico & $1500 \mathrm{~mL}$ & $1500 \mathrm{~mL}$ \\
\hline Chapa de cobre & $112,5 \mathrm{~cm}^{2}$ & Probeta de $10,6 \times 10,6 \mathrm{~cm}^{2}$ \\
\hline Hilo de cobre esmaltado & $131,25 \mathrm{~cm}^{2}$ & 4 alambres de $40 \mathrm{~cm}$ de 1. \\
\hline Material celulósico & $625 \mathrm{~cm}^{2}$ & $\begin{array}{l}4 \text { probetas de } 10 \times 10 \mathrm{~cm}^{2} \\
+9 \text { probetas de } 5 \times 5 \mathrm{~cm}^{2}\end{array}$ \\
\hline Núcleo del transformador & $11,25 \mathrm{~cm}^{2}$ & Probeta de $3,4 \times 3,4 \mathrm{~cm}^{2}$ \\
\hline Madera & $25 \mathrm{~cm}^{2}$ & Probeta de $5 \times 5 \mathrm{~cm}^{2}$ \\
\hline Corcho laminado & $25 \mathrm{~cm}^{2}$ & Probeta de $5 \times 5 \mathrm{~cm}^{2}$ \\
\hline Junta de goma & - & 2 probetas microhalterio \\
\hline Cinta autoadhesiva ${ }^{(*)}$ & - & 2 unidas entre si \\
\hline Canutos de cartón & - & 2 probetas de $15 \mathrm{~cm}$ \\
\hline
\end{tabular}

${ }^{(*)}$ Antes de someter a ensayo la cinta autoadhesiva, se realizó un breve experimento en el laboratorio. Consistió en juntar dos cintas autoadhesivas y sumergirlas en aceite a $130{ }^{\circ} \mathrm{C}$ durante 3 horas. De esta forma, se observó si era representativo o no estudiar las propiedades de adhesión de las cintas al ser 
sometidas a tan elevadas temperaturas, ya que puede suceder que el poder adherente de dichas cintas desaparezca a elevadas temperaturas. Si vio que después de 3 horas a $130{ }^{\circ} \mathrm{C}$, las cintas autoadhesivas seguían unidas por lo que se decidió someterlas a ensayo.

A continuación se muestran las imágenes con la forma geométrica final de las probetas y el estado final de los materiales una vez fueron introducidos en el reactor junto al aceite.

\section{Aceite A}
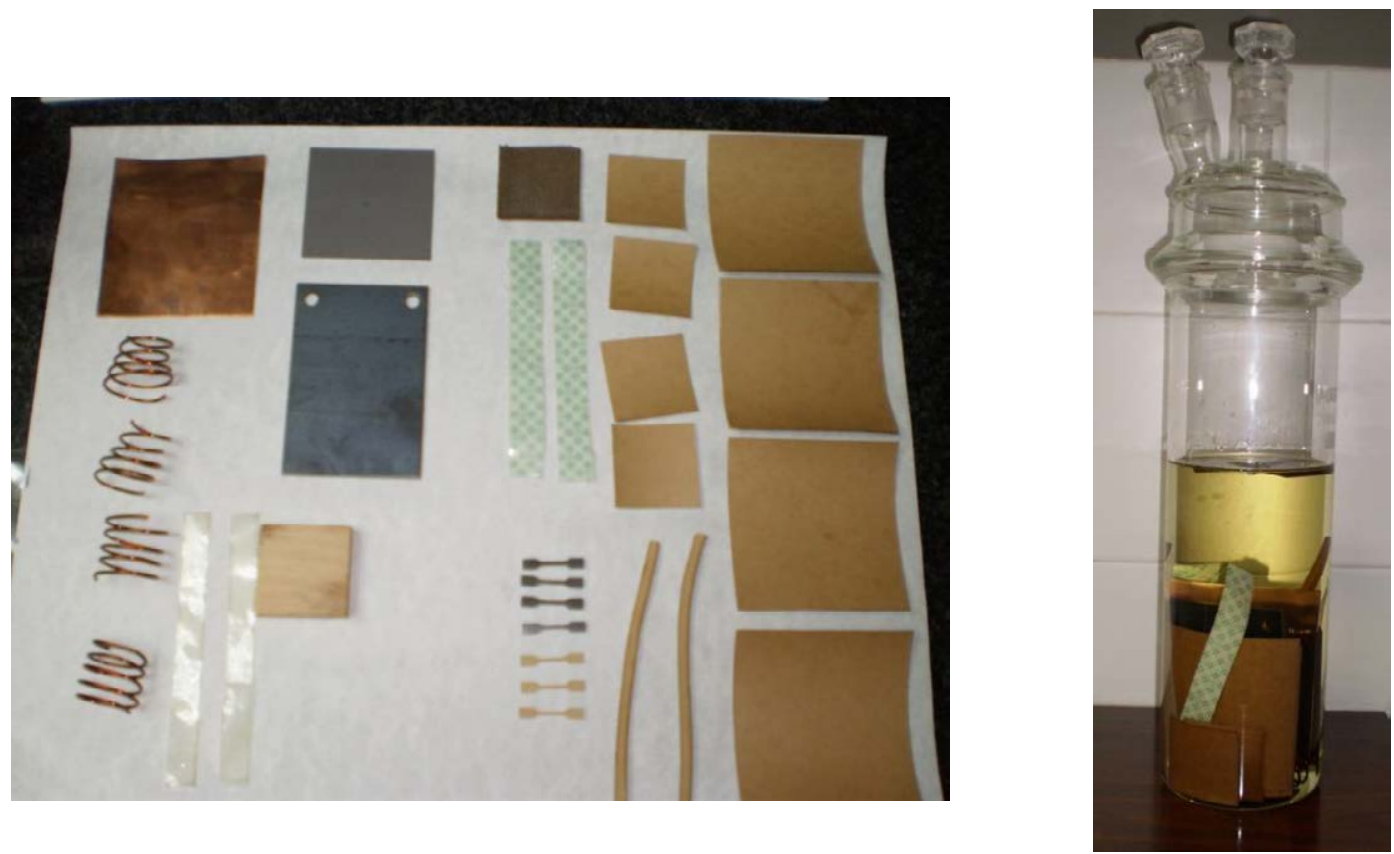

Figura 101: Detalle de las probetas y del reactor cargado con los materiales 


\section{Aceite B}
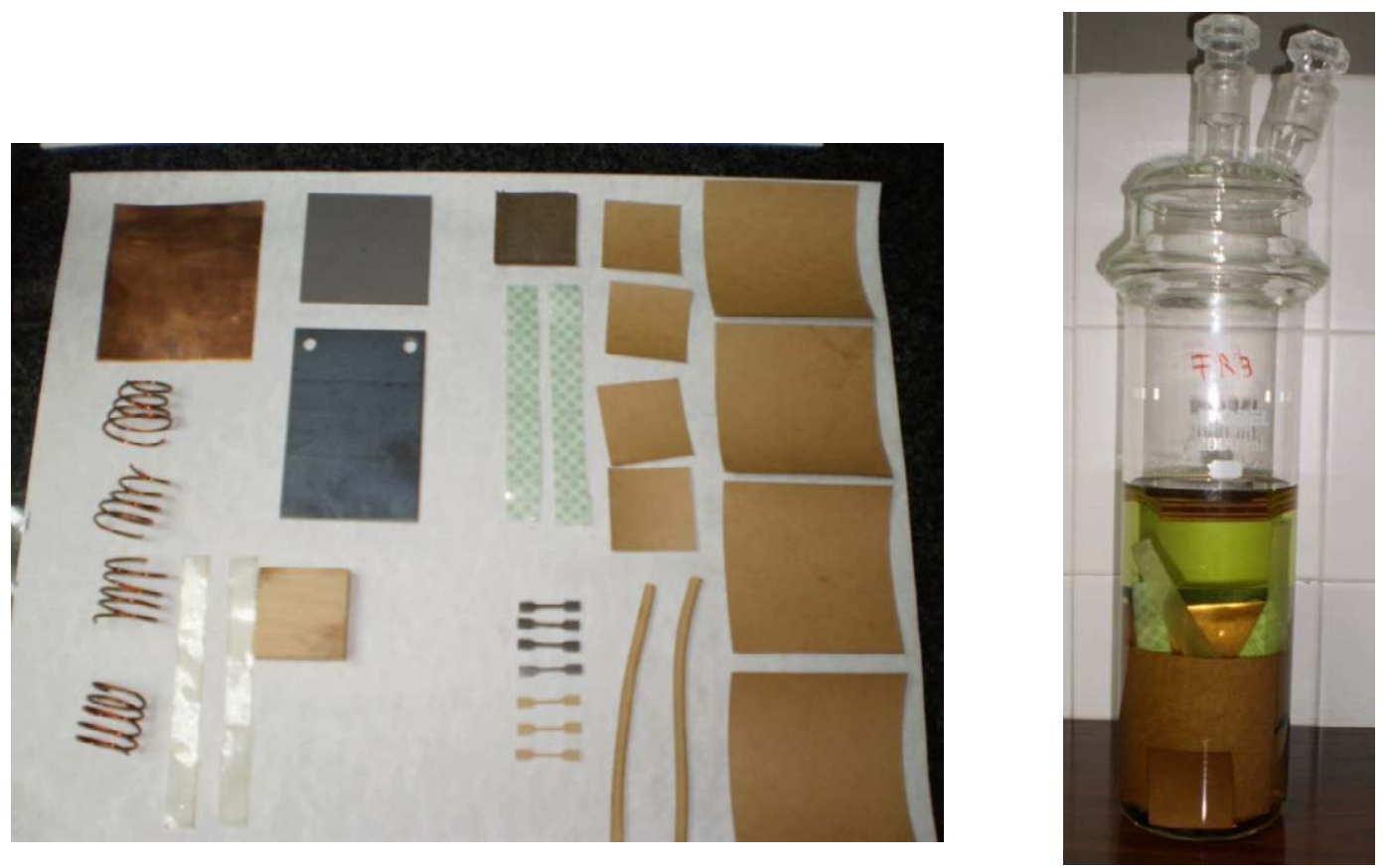

Figura 102: Detalle de las probetas y del reactor cargado con los materiales

A continuación se muestran con más detalle algunas de las probetas de los materiales ensayados:

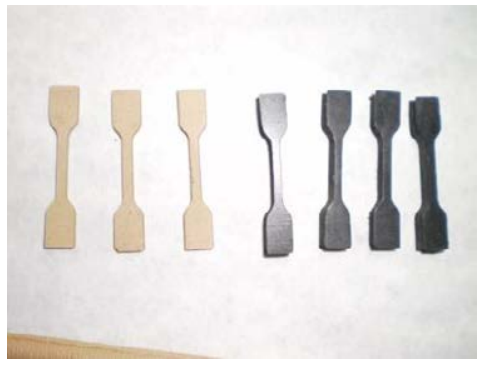

Fig.103: Probetas microhalterio

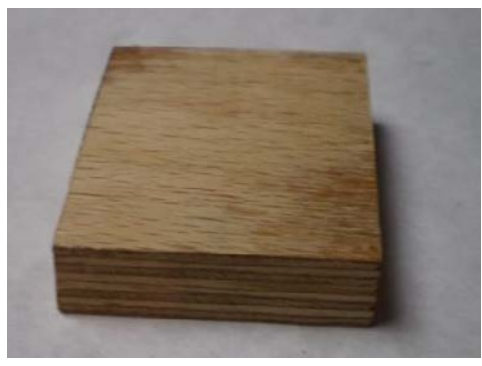

Fig.105: Probeta madera

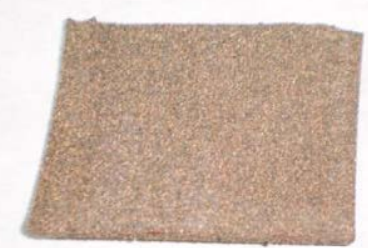

Fig.104: Probeta de corcho

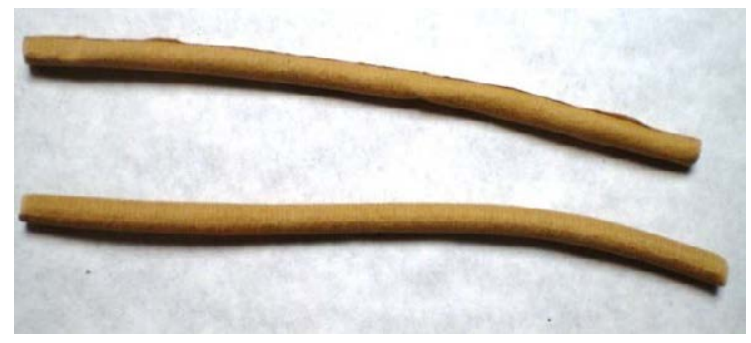

Fig.106: Canuto de cartón 


\subsubsection{Condiciones de ensayo}

Debido a que los aceites vegetales son más estables que los aceites minerales, la temperatura de ensayo fue superior a la temperatura citada en la norma ASTM D 3455 la cual indica que el ensayo de compatibilidad se tiene que llevar a cabo a $100{ }^{\circ} \mathrm{C}$ durante 164 horas. En nuestro caso, la temperatura de ensayo fue de $130 \pm 1{ }^{\circ} \mathrm{C}$. El tiempo de ensayo también se amplió a 672 h, es decir un mes, con el objetivo de observar cambios significativos en las propiedades de los materiales.

\subsubsection{Ensayos a realizar en cada material}

A cada una de los materiales se le determinaron los siguientes parámetros:

$\checkmark$ Evaluación de los resultados en el aceite dieléctrico

○ Rigidez dieléctrica

○ Contenido en agua Karl-Fischer

○ Índice de acidez

○ Factor de pérdidas dieléctricas

- Contenido cobre por ICP-OES

$\checkmark$ Evaluación de los cambios físicos de los materiales a temperatura ambiente

○ Núcleo del transformador

- Aspecto de corrosión

- Variación másica

- Corcho laminado

- Variación volumétrica y lineal

- Variación másica

- Madera:

- Variación volumétrica y lineal

- Variación másica

○ Hilo de cobre:

- Corrosión escala ASTM

- Chapa de cobre:

- Corrosión escala ASTM 
- Canutos de material celulósico:

- Ensayo de tracción hasta la rotura

○ Juntas de goma:

- Ensayo de tracción y alargamiento

- Variación volumétrica

- Variación másica

- Cintas autoadhesivas

- Aspecto final

\subsubsection{Determinación de los parámetros de tracción en el laboratorio}

La muestra de material celulósico con la que vamos a trabajar proviene de un proceso de envejecimiento térmico en aceites de origen vegetal. Como ya se ha descrito anteriormente en el Procedimiento para la determinación del grado de polimerización medio viscosimétrico, la relación de aceite/papel dentro de los reactores de envejecimiento debe ser de $75 \mathrm{~g}$ de aceite por cada $3 \mathrm{~g}$ de papel aislante. Esta masa de papel nos las generan muestras de papel de $1,5 \mathrm{~cm}$ x $150 \mathrm{~cm}$ aproximadamente.

Con estas muestras de papel envejecido térmicamente, obtendremos las probetas necesarias para evaluar la resistencia a la tracción y al alargamiento. Pero antes de pasar a describir el procedimiento del ensayo de resistencia a la tracción y al alargamiento, cabe definir algunos términos considerados oportunos para el total entendimiento del ensayo:

- Resistencia a la tracción: Fuerza de tracción máxima por unidad de anchura que resiste un papel o cartón antes de su rotura, en las condiciones indicadas anteriormente.

- Índice de tracción: Resistencia a la tracción dividida entre el gramaje.

- Alargamiento (elongación): Es el incremento de longitud de una probeta al final del ensayo.

- Deformación: Es la proporción de alargamiento de una probeta frente a la longitud inicial de ensayo. 
- Deformación de rotura: Es la proporción del alargamiento medido en el momento de la rotura de la probeta de papel, al ser ésta sometida a las condiciones definidas en el método estándar de ensayo, frente a la longitud inicial de ensayo.

- Energía absorbida por tracción: Es la cantidad por unidad de superficie de una probeta cuando se somete a su fuerza máxima de tracción.

- Módulo de elasticidad o Módulo de Young: Es la pendiente máxima de la curva de alargamiento multiplicada por la longitud inicial dividida entre la anchura y el grosor de la probeta.

Para el ensayo, las probetas deben tener $1,5 \mathrm{~cm}$ de anchura y $25 \mathrm{~cm}$ de longitud, cortadas en dirección longitudinal, es decir, que su longitud mayor sea paralela al sentido de la máquina del papel. Los resultados así obtenidos definen la resistencia a la tracción en el sentido de la máquina.

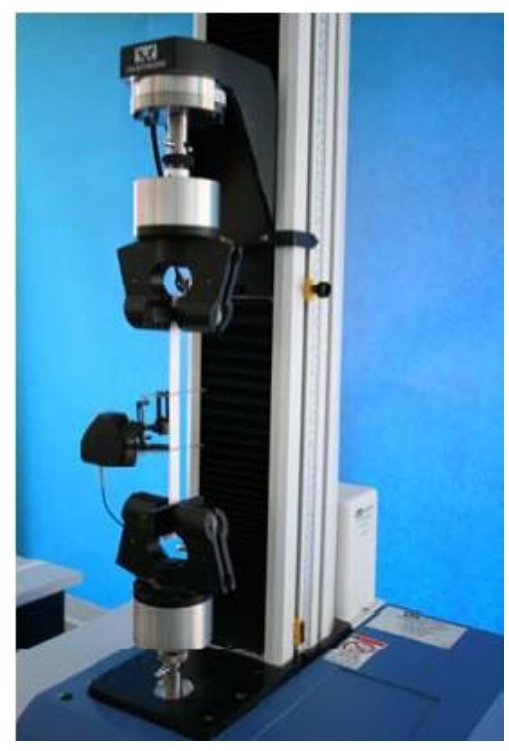

Figura 107: Esquipo de tracción Instron con el que se llevaron a cabo los ensayos

Se ensayarán un número determinado de probetas por aceite $\mathrm{y}$ tiempo de envejecimiento. Las probetas deberán medirse con una precisión de $\pm 0,1 \mathrm{~mm}$ tanto de ancho como de largo. Para determinar la homogeneidad del espesor de las probetas se 
determinará el espesor en la mitad de la probeta utilizando un micrómetro de cuadrante de precisión que aplica a la muestra una carga estática equivalente a $100 \pm 10 \mathrm{kPa}$. Se determinará la media y la desviación estándar por cada muestra para conocer la dispersión de los datos.

En cuanto al equipo de tracción, usaremos el equipo Instron 3365. Este equipo está diseñado para someter una probeta de dimensiones dadas a una velocidad constante de alargamiento. Según normativa UNE EN-ISO 1924-2:2008, la velocidad de elongación es de $20 \mathrm{~mm} / \mathrm{min}$.

La máquina de ensayo de tracción debe tener dos mordazas hidráulicas para fijar las probetas firmemente, pero sin dañarlas o experimentar deslizamiento, a lo largo de una línea recta a través del ancho total de la probeta. Las superficies de las mordazas deben estar en el mismo plano, y alineadas de tal manera que sujeten la probeta en ese mismo plano durante el ensayo.

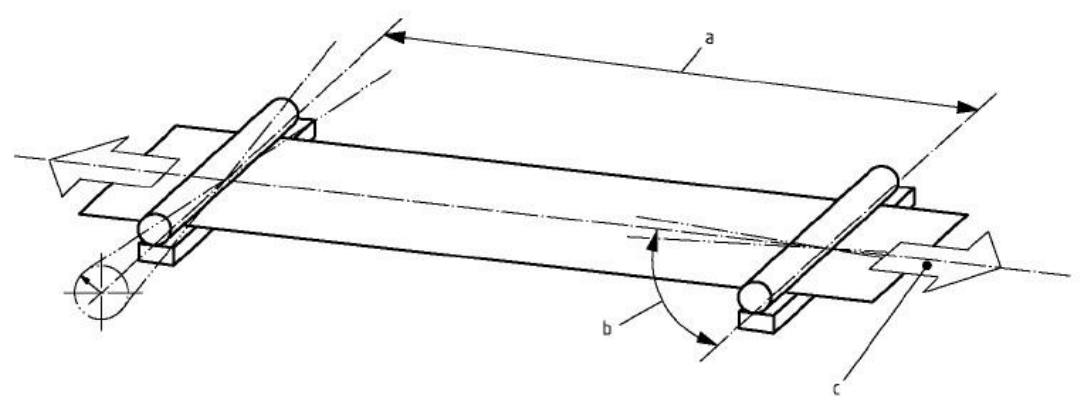

Figura 108: Relación entre las líneas de fijación y las mordazas

Se determinará el módulo de elasticidad, la resistencia a la tracción y el porcentaje de elongación. Estos se definen como:

- Resistencia a la tracción:

$$
\sigma_{\mathrm{T}}^{\mathrm{b}}=\frac{\overline{\mathrm{F}}_{\mathrm{T}}}{\mathrm{b}}
$$

$\overline{\mathrm{F}}_{\mathrm{T}}$ es la media de la fuerza de tracción máxima, en newtons $(\mathrm{N})$

b es la anchura inicial de la probeta, en milímetros (mm) 
- Módulo de elasticidad: Se determina para cada probeta la máxima pendiente de la curva de fuerza-alargamiento, $\mathrm{S}_{\text {máx., }}$ expresada en $\mathrm{N} 7 \mathrm{~mm}$, usando la ecuación

$$
S_{\text {máx }}=\left[\frac{\Delta F}{\Delta \delta}\right]_{\operatorname{máx}}
$$

$\Delta F$ es el incremento de la fuerza en $\mathrm{N}$

$\Delta \delta$ es el incremento del alargamiento en $\mathrm{mm}$

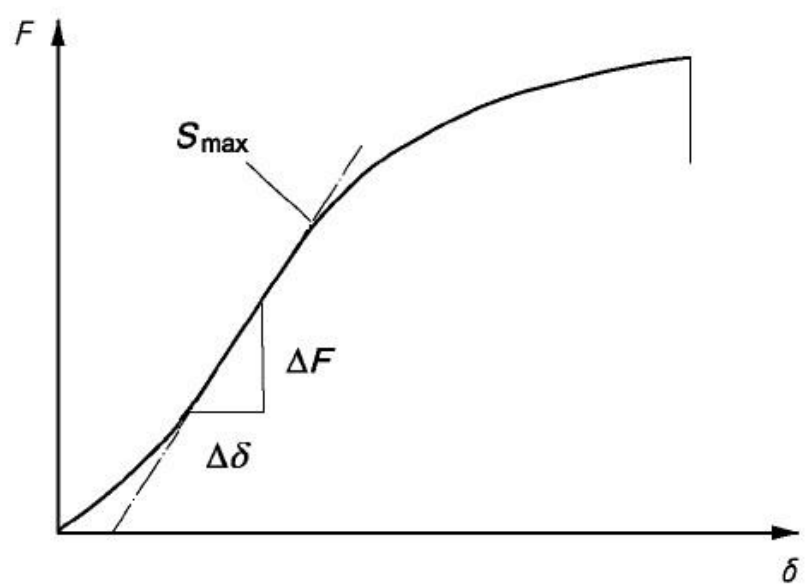

Figura 109: Representación gráfica módulo de elasticidad

Usando la máxima pendiente, $\bar{S}_{\text {máx }}$, se calcula el Módulo de elasticidad, E, expresado en MPa, con la ecuación:

$$
E=\frac{\bar{S}_{\text {máx }} \times l}{b \times t}
$$


1 es la longitud de la probeta en $\mathrm{mm}$

$\mathrm{b}$ es el ancho inicial de la probeta en $\mathrm{mm}$

t es el espesor de la probeta en $\mathrm{mm}$

- Porcentaje de elongación:

$$
\varepsilon_{T}=\frac{\delta}{l} \times 100
$$

$\delta$ es el alargamiento a la rotura, en $\mathrm{mm}$

1 es la longitud inicial de la probeta (separación entre mordazas), en mm

\subsubsection{Compatibilidad de aceites en presencia de ácidos grasos}

En el ensayo anterior llevado a cabo acerca del comportamiento de fluidos dieléctricos, se llevó a cabo la compatibilidad de diferentes materiales por los que está formado el transformador con aceites dieléctricos de origen vegetal.

Sokolov [52] reivindica una serie de premisas a este respecto:

\& Los ácidos formados durante la oxidación de los aceites dieléctricos son adsorbidos por la celulosa y aceleran su proceso de descomposición.

\& El efecto será más intenso en las capas externas del aislamiento sólido.

¿ La adsorción es selectiva y será mayor cuanto menor sea el peso molecular del ácido adsorbido.

\& La acidez total no es un factor determinante en la agresividad al aislamiento por parte del aceite, sino que dependerá de la cantidad de ácidos grasos de bajo peso molecular presentes en el medio.

Tal y como se muestra en la figura siguiente, se ve que el DP de la celulosa será menor cuanto menor sea el tamaño de la cadena hidrocarbonada del ácido adsorbido: 


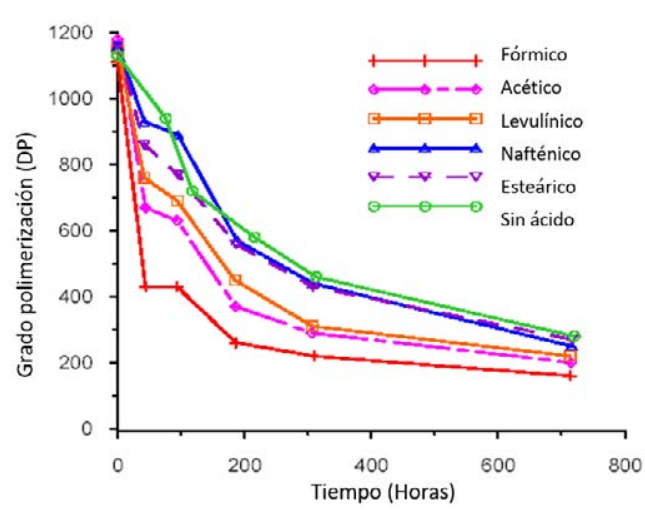

Figura 110: Dependencia del grado de polimerización con la longitud de la cadena

Por esta razón, se decidió estudiar para esta tesis el efecto que tendría la presencia de ácidos sobre el grado de polimerización de material celulósico, cuando se encontraban presenten en la matriz del aceite dos tipos de ácidos grasos: ácido oleico con un tamaño de cadena de 18 átomos de carbono y una insaturación y ácido láurico con una longitud de cadena de 12 átomos de carbono y ninguna insaturación.

Fueron sometidas a ensayo cuatro muestras de aceite de diferente origen, dos de origen vegetal (A y B) y dos de origen mineral ( $\mathrm{E}$ y F). Además, se sometieron a ensayo dos tipos de materiales aislantes sólidos: probetas de papel celulósico y probetas de papel sintético (poliaramida). Se usaron probetas de cobre como agente catalizador de la reacción de oxidación.

Se sometieron a altas temperaturas durante prolongados periodos de tiempo. Al finalizar el ensayo, se evaluaron las propiedades físicoquímicas del aceite, así como las propiedades mecánicas del material aislante sólido.

\subsubsection{Papel aislante sintético de poliaramida}

El papel Nomex es papel aislante no celulósico constituido por cadenas de aramida (figura 111), en concreto, una poliamida aromática. Este papel no está tejido y es obtenido por vía húmeda donde las fibras son poliamidas aromáticas sintéticas y al menos el $85 \%$ de la cadena amida se encuentra unida directamente a dos anillos 
aromáticos. El papel de aramida puede contener materiales con o sin adición de cargas y/o de aglutinantes orgánicos o inorgánicos adecuados.

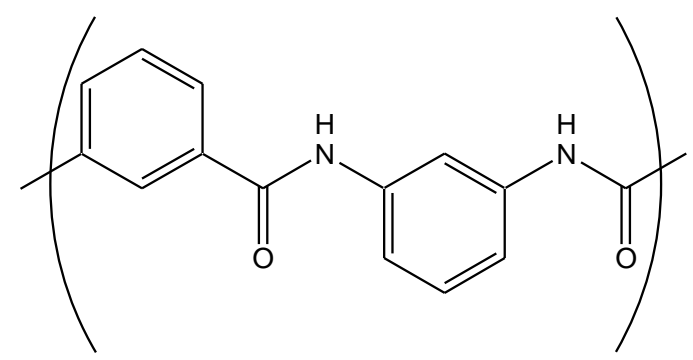

Figura 111: Estructura química de la aramida

Existen 4 tipos principalmente de papel Nomex:

Tipo 410: Calandrado, y proporciona las mejores características mecánicas, y es el más ampliamente utilizado. Tiene aspecto nacarado.

$>$ Tipo 411: No calandrado. Se usa frecuentemente como material de amortiguación suave.

> Tipo 414: Calandrado. Proporciona flexibilidad y es una forma mejorada del tipo 410 y posee más fuerza que el tipo 411.

Tipo 418: Calandrado, este tipo contiene el 50\% en peso de mica inorgánica, y es producido en una gama de grueso entre 0,08 y $0,36 \mathrm{~mm}$. El contenido en mica proporciona una resistencia mejorada de la corona en sus usos como material eléctrico. También posee un buen comportamiento ignífugo (Índice Límite de Oxígeno del $63 \%$ aproximadamente).

El papel Nomex Tipo 410 es el papel más usado en la fabricación de transformadores de distribución. Es un papel satinado de aislamiento que ofrece altos valores inherentes de resistencia dieléctrica, tenacidad mecánica, flexibilidad y resistencia. Es empleado principalmente en la industria eléctrica, en casi todas las aplicaciones conocidas de aislamiento laminar, como aislamiento de fases, fundas de ranuras, etc. 
El papel Nomex con el que vamos a trabajar, según aspecto y dimensiones determinadas en el laboratorio es Tipo 410 con un espesor nominal de 0,05 $\mathrm{mm}$. Este papel posee unas características mecánicas que difieren significativamente de las propiedades del papel celulósico y que le otorgan unas propiedades mucho más resistentes a la hora de actuar como material aislante dentro de un transformador. Éstas se muestran en el siguiente cuadro resumen:

Tabla 27: Comparación propiedades físicas entre Nomex y papel de celulosa

\begin{tabular}{lccc}
\hline Tipo & Unidades & $\mathbf{4 1 0}$ & Celulósico \\
\hline Espesor nominal & $\mathrm{mm}$ & 0,05 & 1,00 \\
Peso específico & $\mathrm{g} / \mathrm{cm}^{3}$ & 0,72 & $0,95-1,00$ \\
Resistencia a la tracción (L) & $\mathrm{N} / \mathrm{cm}$ & 39 & 130 \\
Resistencia a la tracción (T) & $\mathrm{N} / \mathrm{cm}$ & 18 & 53 \\
Elongación (L) a $25^{\circ} \mathrm{C}$ y $50 \% \mathrm{H}_{\mathrm{R}}$ & $\%$ & 9 & 2,5 \\
Elongación (T) a $25^{\circ} \mathrm{C}$ y $50 \% \mathrm{H}_{\mathrm{R}}$ & $\%$ & 6 & - \\
Resistencia al desgarro Elmedorf $(\mathrm{L})$ & $\mathrm{N}$ & 0,8 & - \\
Resistencia al desgarro Elmendorf $(\mathrm{T})$ & $\mathrm{N}$ & 1,6 & - \\
Índice límite de oxígeno $(\mathrm{LOI})$ a $25^{\circ} \mathrm{C}$ & $\%$ & 29 & 16 \\
Conductividad térmica a $150{ }^{\circ} \mathrm{C}$ & $\mathrm{W} / \mathrm{m} \mathrm{K}$ & 0,094 & $0,1-1,4$ \\
\hline
\end{tabular}

Algunas de las propiedades como la elongación (L) a $25{ }^{\circ} \mathrm{C}$ y $50 \%$ de $\mathrm{H}_{\mathrm{R}}$ varían significativamente. La elongación de un material aislante es una medida del ajuste del material aislante al conductor, en nuestro caso, a los devanados de cobre ya que cuanto más ajustado esté al conductor se generará más espacio en los devanados y mejor será la disipación de calor en caso de cortocircuito.

Además de las propiedades mecánicas, también se indican a continuación las propiedades eléctricas más características: 
Tabla 28: Propiedades eléctricas papel Nomex

\begin{tabular}{lcc}
\hline Tipo & Unidades & $\mathbf{4 1 0}$ \\
\hline Espesor nominal & $\mathrm{mm}$ & 0,05 \\
Rigidez dieléctrica & $\mathrm{kV} / \mathrm{mm}$ & 17 \\
Impulso de onda completa & $\mathrm{kV} / \mathrm{mm}$ & 39 \\
Constante dieléctrica & $\mathrm{a} 60 \mathrm{~Hz}$ & 1,6 \\
Factor de disipación & $\mathrm{a} 60 \mathrm{~Hz}\left(\mathrm{x} 10^{-3}\right)$ & 9 \\
\hline
\end{tabular}

\subsubsection{Procedimiento operativo}

Para evaluar el efecto que tendría, sobre las propiedades de tracción del material celulósico la presencia de ácidos grasos libres de diferente tamaño de cadena se introdujeron en un reactor de vidrio como el que se muestra en la figura 112 los siguientes materiales:

a. $100 \mathrm{~g}$ de aceite dieléctrico

b. Una probeta de cobre, previamente lijada y preparada su superficie de $1,0 \times 5,0$ $\mathrm{x} 0,1 \mathrm{~cm}^{3}$.

c. Dos probetas de material celulósico el cual está reforzado con resinas epoxi que se activan con el calor. La longitud media de las probetas introducidas en los reactores fue de $31,4 \pm 0,1 \mathrm{~cm}$. El peso de dichas probetas, individuales, fue de $1,7966 \pm 0,0113 \mathrm{~g}$.

d. Una probeta de material aislante sólido Nomex 410. Su estructura consiste en polímeros de aramida entrelazados dando lugar a una superficie blanca de color satinado. La longitud media de dichas probetas fue de $141,9 \pm 0,3 \mathrm{~cm}$ y su peso medio fue de $1,5501 \pm 0,0157 \mathrm{~g}$.

e. Ácido oleico puro en una concentración de 1000 ppm (ver figura 113)

f. Ácido laúrico puro en una concentración de 1000 ppm (ver figura 114) 


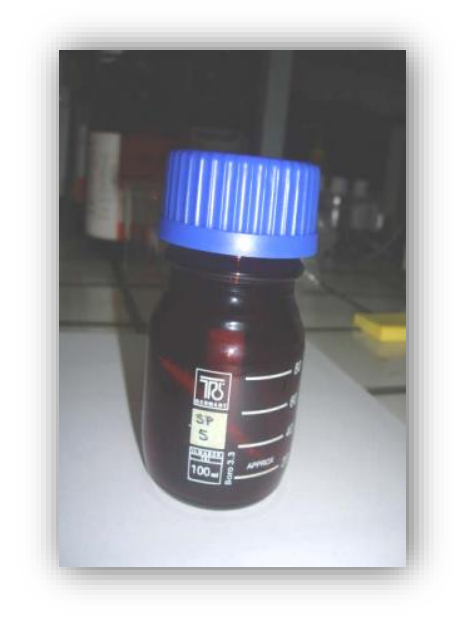

Figura 112: Reactores de vidrio topacio para llevar a cabo los ensayos de compatibilidad

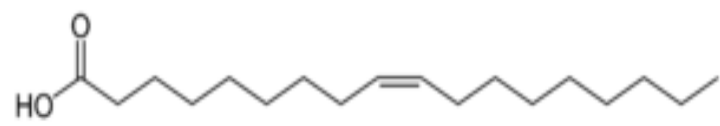

Fig. 113. Estructura química del ácido oleico

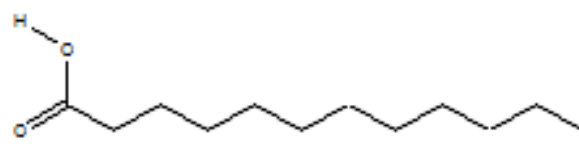

Fig. 114: Estructura química del ácido laúrico

\begin{abstract}
Al final se obtuvieron un total de 16 reactores distribuidos de la siguiente manera: 4 cargados con aceite A, 4 cargados con aceite B, 4 cargados con aceite E y 4 cargados con aceite F. De esta forma se fueron extrayendo de la estufa, cada 1000 horas, un reactor con cada tipo de aceite hasta las 4000 horas, tiempo en el cual se dio por finalizado el ensayo de degradación/compatibilidad.
\end{abstract}

La temperatura a la cual se llevó a cabo el ensayo de compatibilidad fue de $120^{\circ} \mathrm{C}$. Dicha temperatura es superior a la temperatura media a la cual opera un transformador, pero si partimos de la premisa que a $120{ }^{\circ} \mathrm{C}$ el material no se ve afectado, podemos asegurar que a $70-80{ }^{\circ} \mathrm{C}$, el material aislante no sufrirá ningún tipo de daño en su estructura química. 


\subsubsection{Diseño y desarrollo de experimentos}

Tal y como se ha mencionado en el apartado anterior, cada 1000 horas de ensayo se fue extrayendo un reactor de vidrio de cada uno de los aceites dieléctricos ensayados. De esta forma, podremos ver como varían las diferentes propiedades físico-químicas y de tracción de los materiales sometidos a compatibilidad, con el tiempo.

Los ensayos realizados a los materiales se muestran a continuación:

i. Papel Nomex:

ii. Papel celulósico:

iii. Catalizador de cobre:

iv. Aceite dieléctrico:
- Porcentaje de elongación en ruptura

- Carga máxima de ruptura

- Porcentaje de elongación en ruptura

- Carga máxima de ruptura

- Corrosión lámina de cobre

- Viscosidad cinemática a $40{ }^{\circ} \mathrm{C}$

- Análisis de gases disueltos

- Índice de acidez

- Contenido en agua por Karl-Fischer

Para obtener resultados visualmente válidos, una vez extraídos todos los materiales sólidos sumergidos dentro del reactor, se lavaron con iso-octano para desengrasarlos, ya que la presencia de aceite sobre la superficie puede afectar en alguna propiedad de tracción. También se llevó a cabo un análisis fotográfico del estado final de los materiales con el objetivo de mejorar la comprensión de los resultados obtenidos en el laboratorio. 


\subsection{ECOTOXICIDAD DE LOS ACEITES VEGETALES}

2.5.1. Determinación de la toxicidad aguda del aceite dieléctrico A en Eisenia foetida, según guía OECD 207

El objetivo de dicha determinación consiste en evaluar el impacto que tendría sobre el medio terrestre, el vertido de aceite dieléctrico vegetal A. Para ello, y siguiendo instrucción de la guía OECD 207, se usó una población de Eisenia foetida (lombriz de campo) y se determinó el $\mathrm{LC}_{50}$, es decir, se midió la concentración letal del producto que produce la muerte del $50 \%$ de las lombrices al finalizar el periodo de exposición (14 días).

\subsubsection{Principio del método de ensayo}

Las lombrices se mantienen en un sustrato artificial tratado con diferentes concentraciones del producto de ensayo. A los 7 y a los 14 días de la puesta en contacto, se registran la mortalidad y los síntomas visibles presentados por la Eisenia foetida. A los 14 días también se evalúa la pérdida de peso de las lombrices supervivientes.

\subsubsection{Organismo de ensayo}

La especie utilizada en el ensayo es la Eisenia foetida, especie citada y recomendada por la guía OECD 207. Se emplean ejemplares adultos (peso comprendido entre 300 y $600 \mathrm{mg}$ ) acondicionados durante 24 horas antes del ensayo en un sustrato similar al del ensayo. Las condiciones ambientales del acondicionamiento fueron:

- Duración: 24 horas

- Fotoperiodo: luz continua de 400 a 800 lux

- Temperatura: $20 \pm 2^{\circ} \mathrm{C}$

\subsubsection{Condiciones de ensayo}

\subsection{Método de ensayo}

- Duración: 14 días

- Recipientes: vidrio

- Cantidad de sustrato: $750 \mathrm{~g} /$ recipiente

- Carga: 10 lombrices/recipiente 
- Tratamientos: 5 concentraciones crecientes, 1 control y 1 control con sustancia auxiliar (acetona)

- 4 réplicas por tratamiento

\subsection{Sustrato de ensayo}

- Composición: $10 \%$ turba, $20 \%$ arcilla de caolín, $70 \%$ arena

- $\mathrm{pH}=6,45$

- Humedad al inicio del ensayo: $30 \%$

- Humedad al final del ensayo: $39 \%$

\subsection{Aplicación del producto de ensayo}

- Concentraciones ensayadas: 12,$35 ; 37,05 ; 111,15 ; 333,45$ y $1000,35 \mathrm{mg}$ producto/kg de sustrato seco

- Método de administración y justificación: Se simuló un vertido en medio terrestre según lo indicado en la guía OECD 207

\subsubsection{Determinación de la toxicidad agua del aceite dieléctrico A en Lactuca sativa,} según guía OECD 208

El objetivo de dicha determinación consiste en evaluar el impacto que tendría sobre el medio terrestre, el vertido de aceite dieléctrico vegetal A. Para ello, y siguiendo instrucción de la guía OECD 208, se usó una población de Lactuca sativa (lechuga común) para determinar los efectos tóxicos en la germinación y el crecimiento de semillas de plantas terrestres.

\subsubsection{Principio del método de ensayo}

Las semillas se plantan en un sustrato artificial tratado con diferentes concentraciones del producto de ensayo y en sustrato inicial sin producto. Durante 21 días contados a partir de la germinación del $50 \%$ de las semillas plantadas, se registran los daños detectados visualmente (pérdida del color verde, muerte tisular, marchitamiento o 
malformaciones). Al final del periodo, se determinan la altura y el peso seco de todas las plantas germinadas.

\subsubsection{Organismo de ensayo}

La especie utilizada en el ensayo es la Lactuca sativa, especie dicotiledónea recomendada por la guía OECD 208. La especie empleada en los ensayos corresponde con la familia de las Asteráceas y la variedad de lechuga empleada es Maravilla de verano.

\subsubsection{Condiciones de ensayo}

\subsection{Método de ensayo}

- Duración: 25 días desde la puesta en contacto

- Recipientes: macetas de plástico

- Cantidad de sustrato: $1000 \mathrm{~g} /$ recipiente

- Carga: 5 semillas/recipiente

- Tratamientos: 5 concentraciones, 1 control y 1 control con sustancia auxiliar (acetona)

- 4 réplicas por tratamiento

\subsection{Sustrato de ensayo}

- Tipo: franco arenoso

- Composición: $3 \%$ turba esfágnea, $10 \%$ arcilla roja, $87 \%$ arena silícea

- Materia orgánica: 2,7\%

- $\mathrm{pH}=7,40$

- Conductividad: $520 \mu \mathrm{S} / \mathrm{cm}$

\subsection{Aplicación del producto de ensayo}

- Concentraciones ensayadas: 12,$35 ; 37,05 ; 111,15 ; 333,45$ y $1000,35 \mathrm{mg}$ producto/kg de sustrato seco

- Método de administración y justificación: Se simuló un vertido en medio terrestre según lo indicado en la guía OECD 208. 
CAPÍTULO 3: RESULTADOS 


\subsection{COMPORTAMIENTO DEL ACEITE VEGETAL FRENTE A BAJAS TEMPERATURAS}

\subsubsection{WINTERIZACIÓN DEL ACEITE VEGETAL A}

\subsubsection{Ensayos para la optimización de parámetros}

El aceite A que vamos a winterizar posee un elevado contenido en ácido oleico. Se calentaron $600 \mathrm{~mL}$ (cantidad necesaria para que esté toda la pala agitadora sumergida en el aceite) del aceite A a $80^{\circ} \mathrm{C}$ y se filtró al vacío. A continuación se introdujo en una nevara a $3{ }^{\circ} \mathrm{C}$ durante 24 horas. La idea fue atemperar el aceite a temperaturas bajas para que el descenso de temperatura no fuera tan brusco. Para optimizar los tres parámetros anteriormente citados se realizaron cuatro ensayos:

1. Velocidad de agitación: 40 r.p.m., Temperatura de nucleación: $-20{ }^{\circ} \mathrm{C}$. Observaciones: A los 20 minutos de agitación a $-20{ }^{\circ} \mathrm{C}$, se paró el ensayo porque el aceite estaba completamente solidificado.

2. Velocidad de agitación: 40 r.p.m., Temperatura de nucleación: $-15{ }^{\circ} \mathrm{C}$. Observaciones: A los 25 minutos de agitación, se observó la nucleación de las ceras. Se observó también formación de depósitos en el fondo del vaso. Se propuso aumentar la velocidad de agitación para evitar la formación de dichos depósitos.

3. Velocidad de agitación: 150 r.p.m., Temperatura de nucleación: $-10{ }^{\circ} \mathrm{C}$. Observaciones: No se observó nucleación en la matriz del aceite, pero sin embargo si se observó un aumento de la viscosidad. A las 2 horas de la agitación, se observó formación de aeroemulsión (tipo mahonesa).

4. Velocidad de agitación: 40 r.p.m., Temperatura de nucleación: $-13{ }^{\circ} \mathrm{C}$. Observaciones: Se colocó la pala a $1 \mathrm{~mm}$ del fondo del vaso para evitar en la mayor medida la formación de depósitos. A los 20 minutos se observó la nucleación de los triglicéridos con punto de congelación más alto. Con la agitación se fue observando un crecimiento de los cristales, por lo que se decidió tomar estas como condiciones óptimas para la winterización del aceite A. 


\subsubsection{Proceso de winterización}

Como hemos mencionado anteriormente, la muestra antes de empezar con el proceso de winterización se calentó a $80{ }^{\circ} \mathrm{C}$ y se filtró al vació. Inmediatamente después se introdujo en la nevera a $3{ }^{\circ} \mathrm{C}$ durante 24 horas. Seguidamente se introdujo en el criostato (que estaba a $3{ }^{\circ} \mathrm{C}$ ) y se dejó agitando el aceite durante 20 minutos a una velocidad de 40 r.p.m. A continuación, se bajó la temperatura del criostato hasta $l o s-13^{\circ} \mathrm{C}$ a una velocidad de $0,9^{\circ} \mathrm{C} \cdot \mathrm{min}^{-1}$. Cuando llevaba 20 minutos a $-13{ }^{\circ} \mathrm{C}$, se empezó a observar la formación de pequeños cristales correspondientes a las fracción de triglicéridos que poseen puntos de congelación más elevados (ver figura 115).

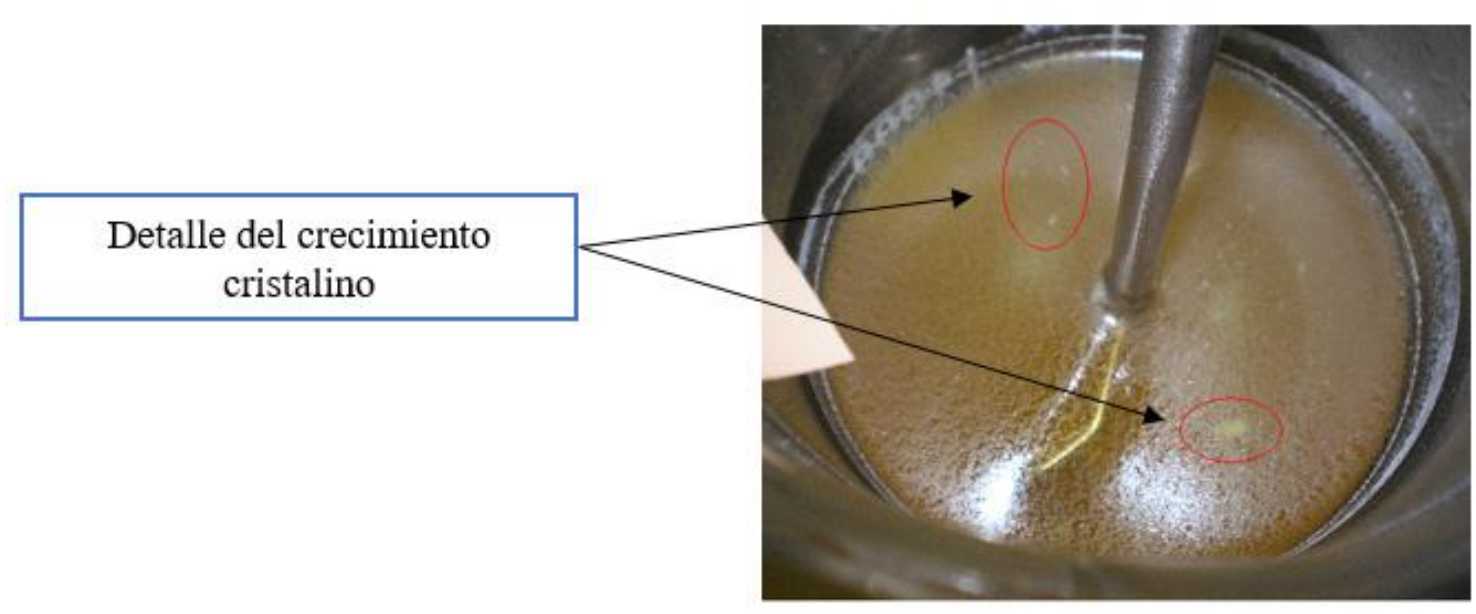

Figura 115: Crecimiento de cristales de parafina durante el proceso de winterización

Se detuvo la agitación y se procedió a la filtración del aceite en frío (a $\left.-13^{\circ} \mathrm{C}\right)$. Se introdujeron unos $50 \mathrm{~mL}$ en el filtro y el resto del aceite se introdujo en el criostato a dicha temperatura para que no se licuaran los cristales formados. Debido a la gran cantidad de fase cristalina formada, la filtración se hizo muy costosa. Después de 2 horas filtrando, se consiguió separar la fase de oleína de la fase de estearina. 

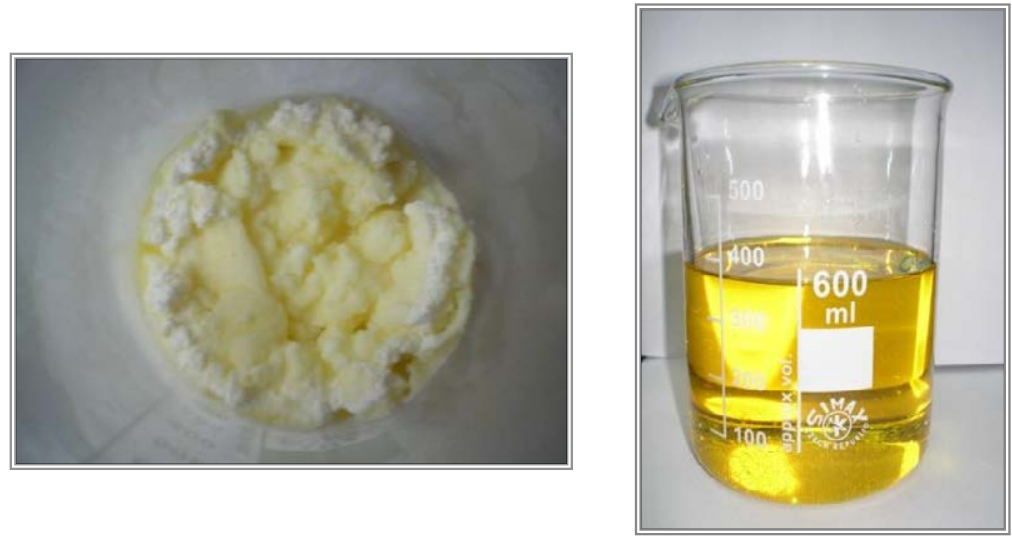

Figura 116: Fracción de estearina (izquierda) y fracción de oleína (derecha)

\subsubsection{Rendimiento del proceso de winterización para el aceite A}

Para calcular el rendimiento del proceso, se pesaron la masa de aceite A que fue winterizado, la fracción de oleína recuperada y la fracción de estearina.

El porcentaje de recuperación de aceite fue de un $90 \%(\mathrm{~m} / \mathrm{m})$ y el rendimiento de recuperación de fracción de oleína fue de un $62 \%(\mathrm{~m} / \mathrm{m})$ mientras que el de estearina fue de un $28 \%(\mathrm{~m} / \mathrm{m})$.

Las principales pérdidas de masa con respecto al proceso de winterización tuvieron lugar durante el filtrado, ya parte del aceite congelado quedó adherido a las paredes del filtro encamisado siendo imposible recuperarlo por diferentes métodos mecánicos. Extrapolando el proceso a escala industrial, económicamente no es un proceso favorable ya que existe un $10 \%$ de pérdidas de masa. 


\subsubsection{ESTUDIO DE LA ACCIÓN DE DEPRESORES DEL PUNTO DE CONGELACIÓN EN EL ACEITE VEGETAL A}

\subsubsection{Comportamiento de varios aceites vegetales en frio}

Se realizó un estudio previo de comportamiento de frío de cuatro aceites sin aditivar para obtener una comparativa del comportamiento en frío de diferentes aceites de origen vegetal. Los cuatro aceites son: aceite $A$, aceite $B$, aceite $C$ y aceite D.

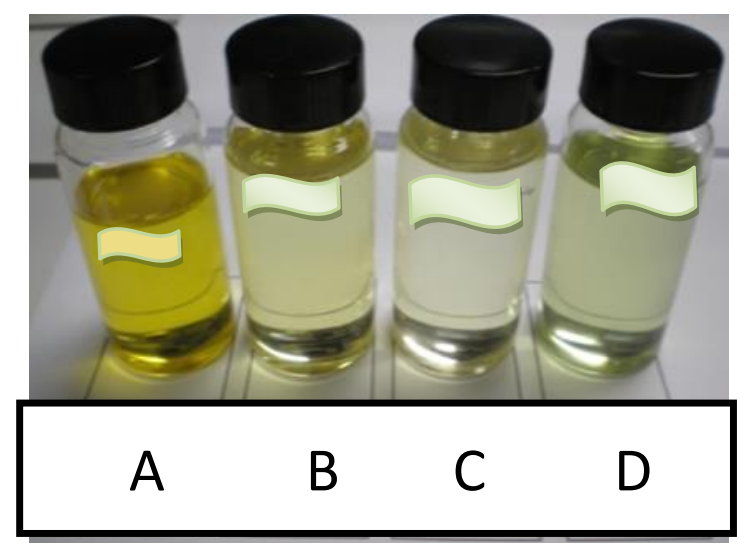

Figura 117: Aceites vegetales sometidos a ensayo

Se introdujeron dichos viales al congelador a una temperatura de $-18{ }^{\circ} \mathrm{C}$. Después de permanecer una hora a dicha temperatura, se observó que el aceite A estaba congelado y que el aceite $\mathrm{C}$ había aumentado mucho su viscosidad. Los otros dos aceites estaban líquidos.
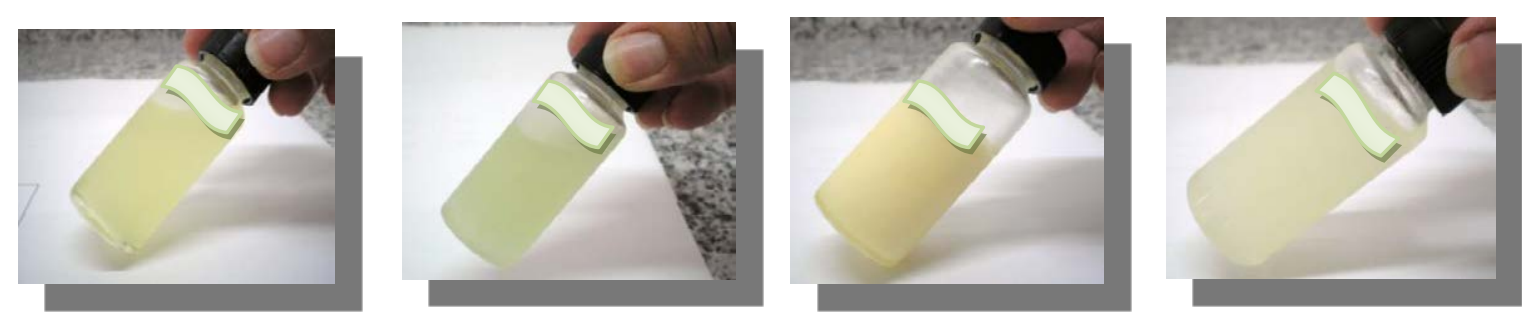

Figura 118: Estado de los aceites B, D, A y C respectivamente después de estar sometidos a $-18^{\circ} \mathrm{C}$ durante 1 hora 
Transcurridas dos horas, se volvió a observar el estado de los aceites. El aceite B tenía una muy elevada viscosidad mientras que el aceite D estaba congelado.
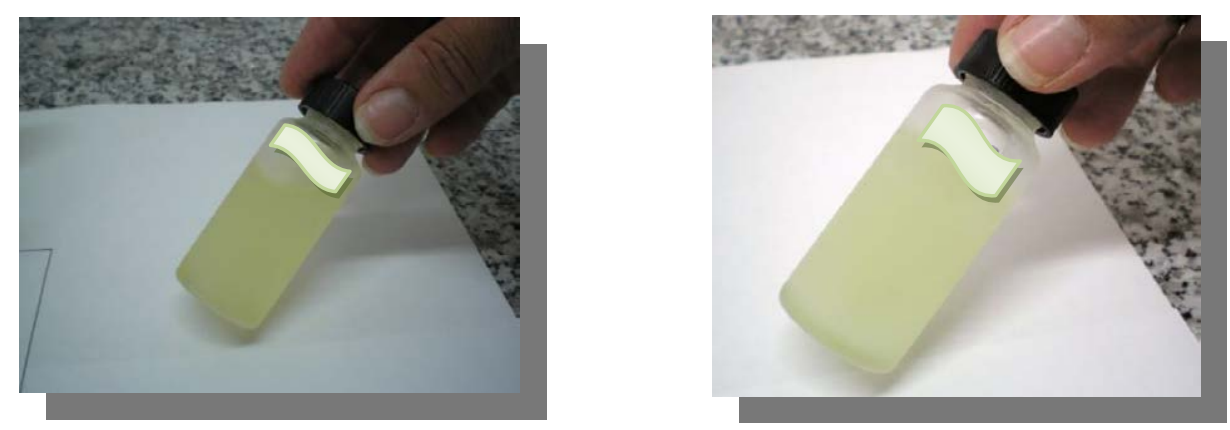

Figura 119: Estado de los aceites $\mathrm{B}$ y C respectivamente después de estar sometidos a $-18^{\circ} \mathrm{C}$ durante 2 horas

El aceite que posee mejor comportamiento en frío es el aceite B y el que peor, el aceite A.

\subsubsection{Depresores de punto de congelación $L$}

Los depresores que han sido evaluados en el laboratorio durante el desarrollo de esta tesis son los F serie 500. Esta serie está formada por 5 depresores (F. 502, F. 503, F. 510, F. 515 y F. 520). Las bases químicas de estos compuestos son principalmente copolímeros de ésteres de estireno-anhídrido maleico.

Dichos aditivos ya fueron evaluados en el laboratorio con el aceite de colza, obteniendo resultados satisfactorios para el F 515. Para evaluar el efecto de dichos depresores en el aceite A, se prepararon cinco disoluciones:

1. $20 \mathrm{~g}$ de aceite $\mathrm{A}+0,5 \% \mathrm{~m} / \mathrm{m}$ F 502

2. $20 \mathrm{~g}$ de aceite $\mathrm{A}+0,5 \% \mathrm{~m} / \mathrm{m}$ F 503 
3. $20 \mathrm{~g}$ de aceite $\mathrm{A}+0,5 \% \mathrm{~m} / \mathrm{m}$ F 510

4. $20 \mathrm{~g}$ de aceite $\mathrm{A}+0,5 \% \mathrm{~m} / \mathrm{m}$ F 515

5. $20 \mathrm{~g}$ de aceite $\mathrm{A}+0,5 \% \mathrm{~m} / \mathrm{m}$ F 520

Se introdujeron dichas muestras en un congelador a una temperatura de $-18{ }^{\circ} \mathrm{C}$ y se observó que transcurrida una hora, todas las disoluciones estaban congeladas.

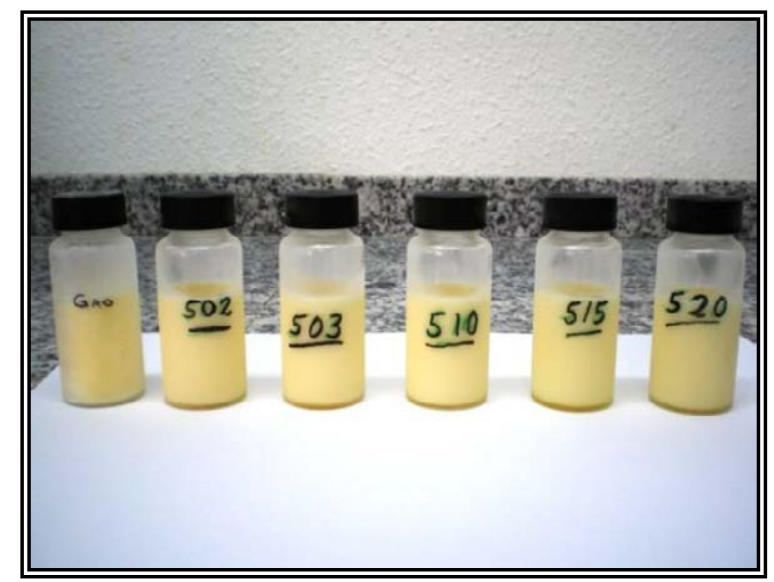

Figura 120: Estado de los aceites después de estar sometidos a $-18{ }^{\circ} \mathrm{C}$ durante 2 horas

Por la tanto, se concluye que dichos aditivos PPD no tienen un efecto depresor del punto de congelación en el aceite A.

\subsubsection{Depresores del punto de congelación I y F}

Otra familia de depresores de punto de congelación que fueron evaluados con el aceite A son los que comercializa I. Se trabajó con tres depresores de dicha marca: Inf. R408, Inf. R458 e Inf. R488. A su vez, se trabajó también con otros dos depresores: el F RD551 y el F RD-557. De los depresores F se sabe que disminuyen el punto de vertido, en el aceite de girasol, unos 20 grados aproximadamente cuando estos están en una proporción del $0,5 \% \mathrm{~m} / \mathrm{m}$ en el aceite. 
Tabla 29: Efecto del RD-557 sobre el punto de vertido de un aceite de girasol

\begin{tabular}{|c|c|c|c|}
\hline & Aceite A $100 \%$ & Aceite $A+0,5 \% R D-557$ & Aceite $A+0,5 \% R D-551$ \\
\hline Punto vertido & $-14{ }^{\circ} \mathrm{C}$ & $-34^{\circ} \mathrm{C}$ & $-34^{\circ} \mathrm{C}$ \\
\hline
\end{tabular}

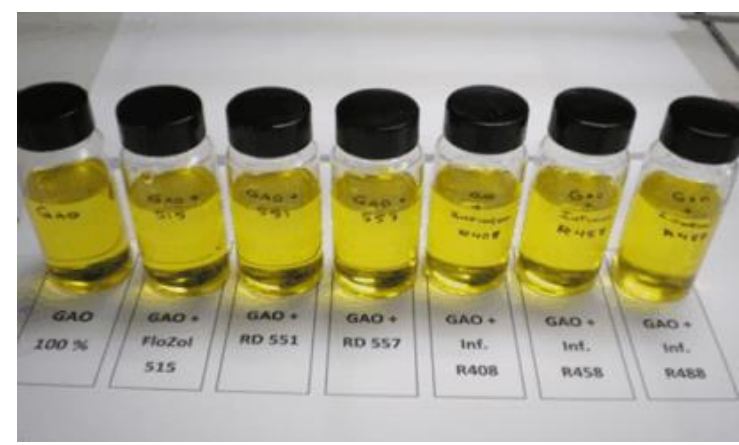

Figura 121: Estado inicial de las alícuotas de aceite A con diferentes aditivos al 0,5\% m/m

Dichas muestras fueron sometidas a las mismas condiciones anteriormente citadas obteniendo resultados muy poco satisfactorios: transcurridos una hora, ya estaban congelados como puede verse en la figura que se muestra a continuación:

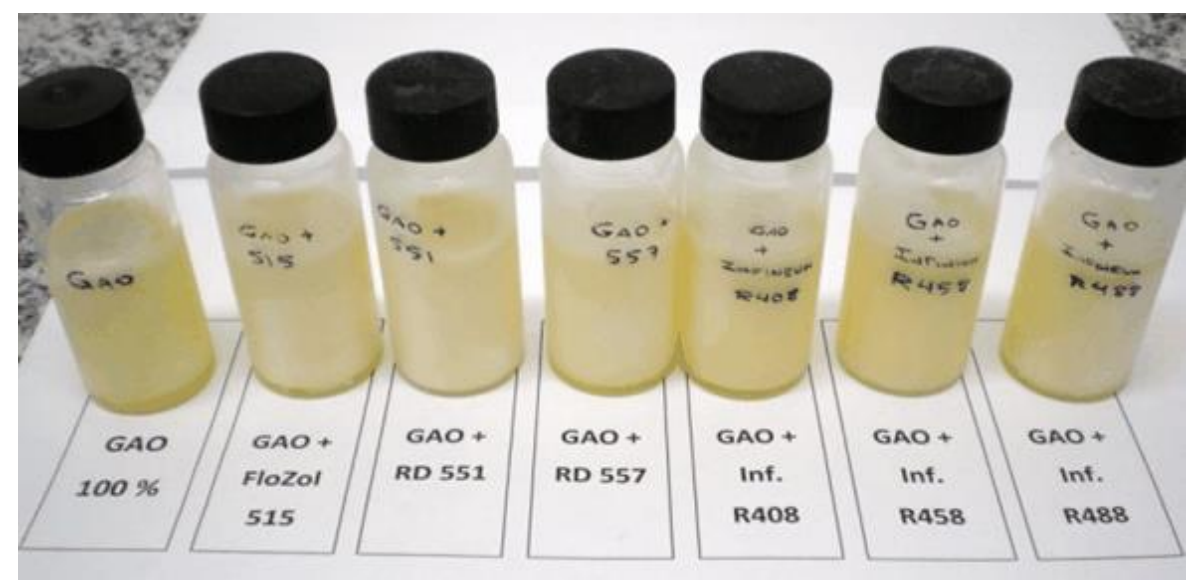

Figura 122: Estado final de las alícuotas de aceite A con diferentes aditivos pasada 1 hora a $-18^{\circ} \mathrm{C}$

Se confirma con esto lo dicho al inicio de este apartado: el aceite A, al poseer un elevado contenido de ácido oleico, cristaliza en bloque haciendo insignificante el efecto depresor de los aditivos. 


\subsubsection{Depresores del punto de congelación: L 4340 FG y L 7671A}

Esto dos depresores del punto de congelación despiertan cierto interés para la presente tesis ya que el L 7671A consigue disminuir el punto de congelación del aceite de Soja Hiperoleica. Por similitud estructural del aceite de soja hiperoleico con el aceite A, podemos intuir que dicho depresor presentará una acción depresora positiva en nuestro aceite.

Para evaluar su acción en el aceite A, se prepararon cinco muestras:

1. $20 \mathrm{~g}$ de aceite A $100 \%$

2. $20 \mathrm{~g}$ de aceite $\mathrm{A}+0,5 \% \mathrm{~m} / \mathrm{m} \mathrm{L} \mathrm{7671A}$

3. $20 \mathrm{~g}$ de aceite $\mathrm{A}+1 \% \mathrm{~m} / \mathrm{m} \mathrm{L} \mathrm{7671A}$

4. $20 \mathrm{~g}$ de aceite $\mathrm{A}+0,5 \% \mathrm{~m} / \mathrm{m} \mathrm{L} 4340 \mathrm{FG}$

5. $20 \mathrm{~g}$ de aceite $+0,5 \% \mathrm{~m} / \mathrm{m} \mathrm{L} 4340 \mathrm{FG}$

Se sometieron a una temperatura de $-18{ }^{\circ} \mathrm{C}$ y se evaluó su estado cada hora. Transcurrida la primera hora, se observó que tanto el aceite A como las disoluciones de aceite A con L 4340 FG están congeladas mientras que las otras dos muestras, formadas por aceite A y L 7671 A siguen líquidas, transparentes y sin opacidad apreciable.

Transcurridas dos horas, se observa el estado de las cinco muestras y esta vez, todas las muestras están completamente congeladas.

Como conclusión de este tipo de depresores del punto de congelación, podemos concluir que el único que actúa en cierto grado sobre el punto de congelación del aceite A es el L 7671A. Su efectividad frente a temperaturas de $-18{ }^{\circ} \mathrm{C}$ no es muy elevada, pero con respecto a los otros depresores evaluados, es el que mejor resultados nos han ofrecido.

Por último, se determinó el descenso del punto de vertido de dicho aceite aditivado con L 7671A mediante la norma ASTM D 97. Los resultados se muestran en la siguiente tabla: 
Tabla 30: Descenso del punto de congelación del aceite A según ASTM D 97

\begin{tabular}{|l|c|c|c|}
\hline Muestra & $\begin{array}{c}\text { Aceite A } 100 \\
\%\end{array}$ & Aceite A+1\% L 7671A & Aceite A + 0,5\% L 7671A \\
\hline Punto de Vertido & $-15 \circ \mathrm{C}$ & $-20 \circ \mathrm{C}$ & $-19 \circ \mathrm{C}$ \\
\hline
\end{tabular}

Si extraemos pequeñas conclusiones acerca del comportamiento del aceite A en frio, podríamos indicar que, según normativa ASTM D 97, si conseguimos que se cumplan las especificaciones para dicho aceite aditivado con L 7671A pero habrá que tener un especial cuidado en el energizado de un transformador lleno de este aceite cuando se encuentre durante largos periodos de tiempo en parada. La congelación de dicho aceite aditivado posee una cinética lenta y por lo tanto, es muy difícil que se llegue a congelar estando el transformador en operación. 


\subsection{PROPIEDADES DE SOLUBILIDAD EN EL ACEITE DIELÉCTRICO VEGETAL}

\subsubsection{DETERMINACIÓN EXPERIMENTAL DE LA TENDENCIA A LA SATURACIÓN DE HUMEDAD}

Para poder determinar la curva de saturación del aceite A y B a una temperatura y una $\mathrm{H}_{\mathrm{R}}$ determinada, se realizó una preparación previa de los aceites. Dichos aceites fueron deshidratamos calentándolos a $65^{\circ} \mathrm{C}$ durante 30 minutos y luego filtrando al vacío con una membrana de nitrocelulosa de $0,8 \mu \mathrm{m}$ de diámetro de poro. A continuación se introdujeron en un desecador hasta que alcanzaron la temperatura ambiente.

Cada 24 horas se analizó por valoración coulumétrica Karl Fischer el contenido de agua de ambos aceites hasta que se alcanzó una saturación de agua en éstos.

Los resultados se indican a continuación:

a) Velocidad de saturación: Para ver gráficamente cuánto tarda cada aceite en saturarse de agua para una temperatura y humedad relativa determinada, se representa la concentración de agua en el aceite (ppm) vs. el tiempo (horas).

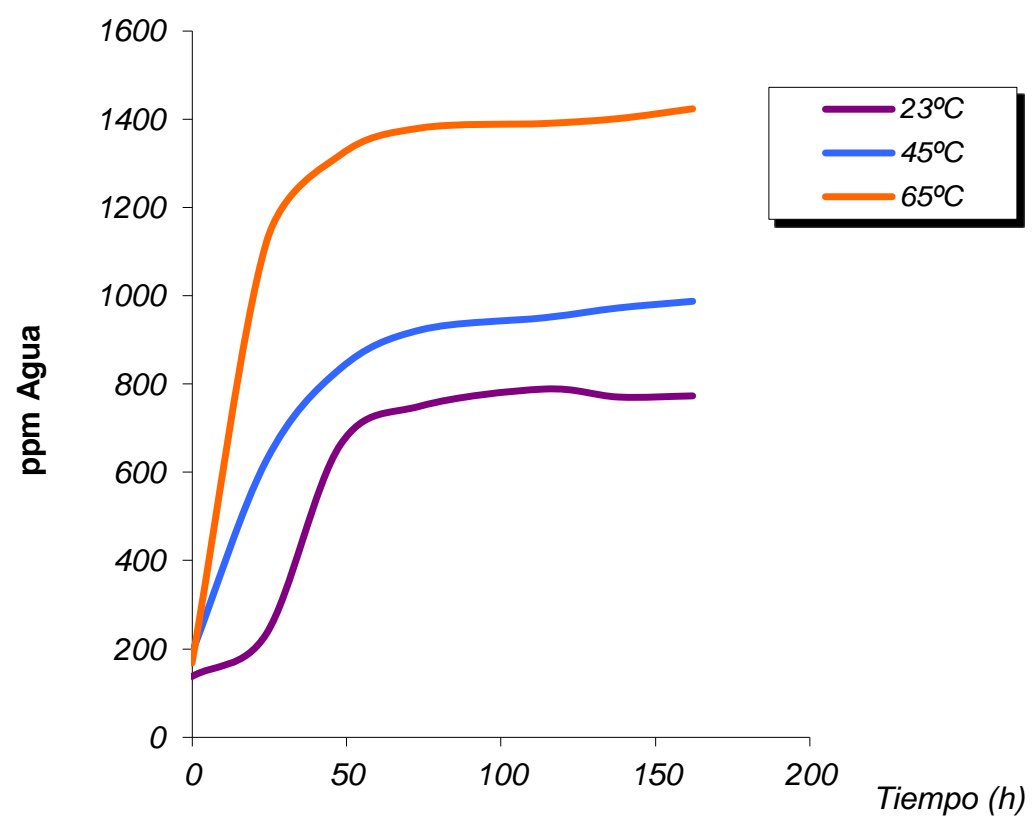

Figura 123: Curvas de saturación del Aceite A para un $43 \%$ de humedad relativa 


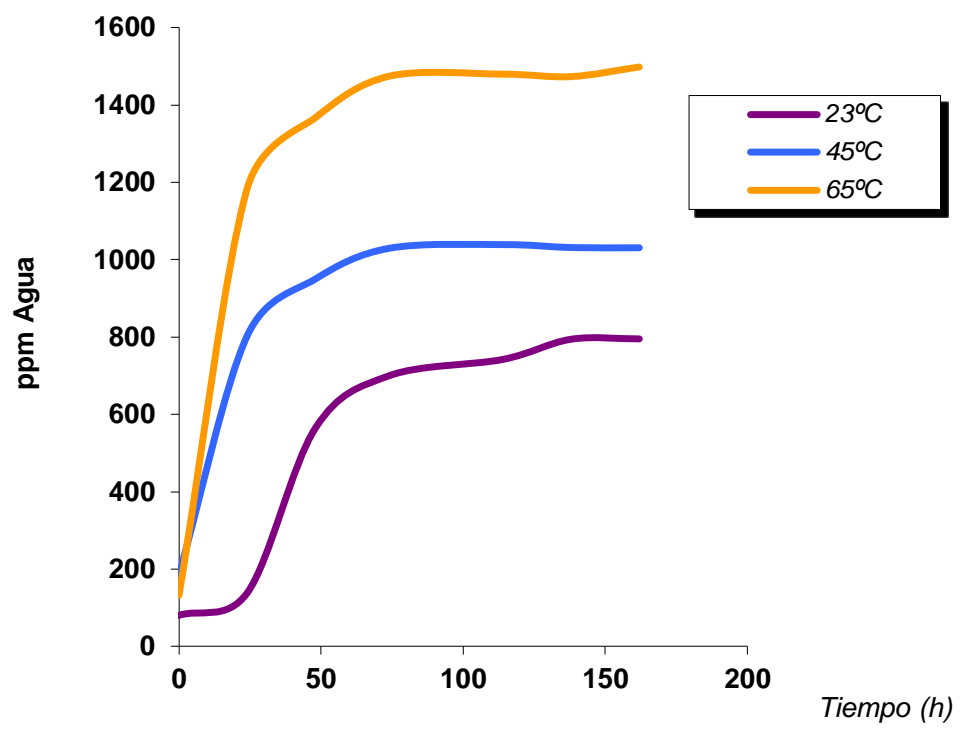

Figura 124: Curvas de saturación del Aceite B para un $43 \%$ de humedad relativa

Para una humedad relativa del $43 \%$, la velocidad de saturación de ambos aceites es prácticamente similar. A $65^{\circ} \mathrm{C}$, el aceite $\mathrm{B}$ se satura con unas $150 \mathrm{ppm}$ más de agua.

A continuación se exponen los gráficos de ambos aceites para una humedad relativa del $80 \%$.

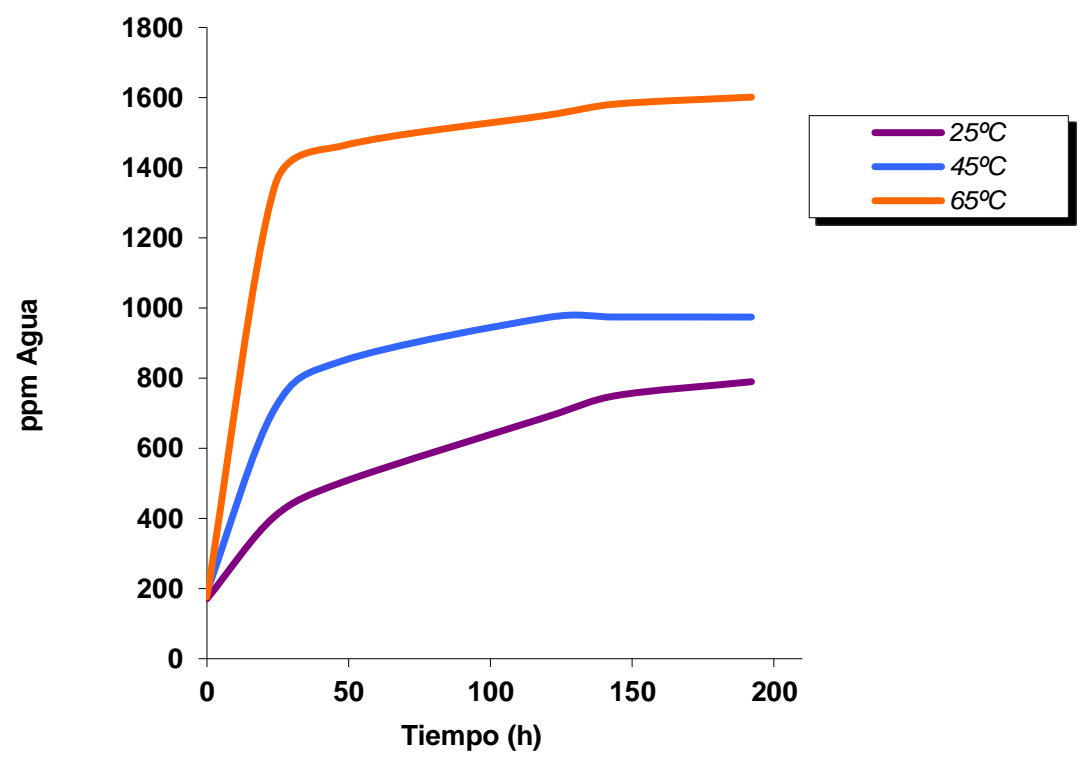

Figura 125: Curvas de saturación del Aceite A para un $80 \%$ de humedad relativa 


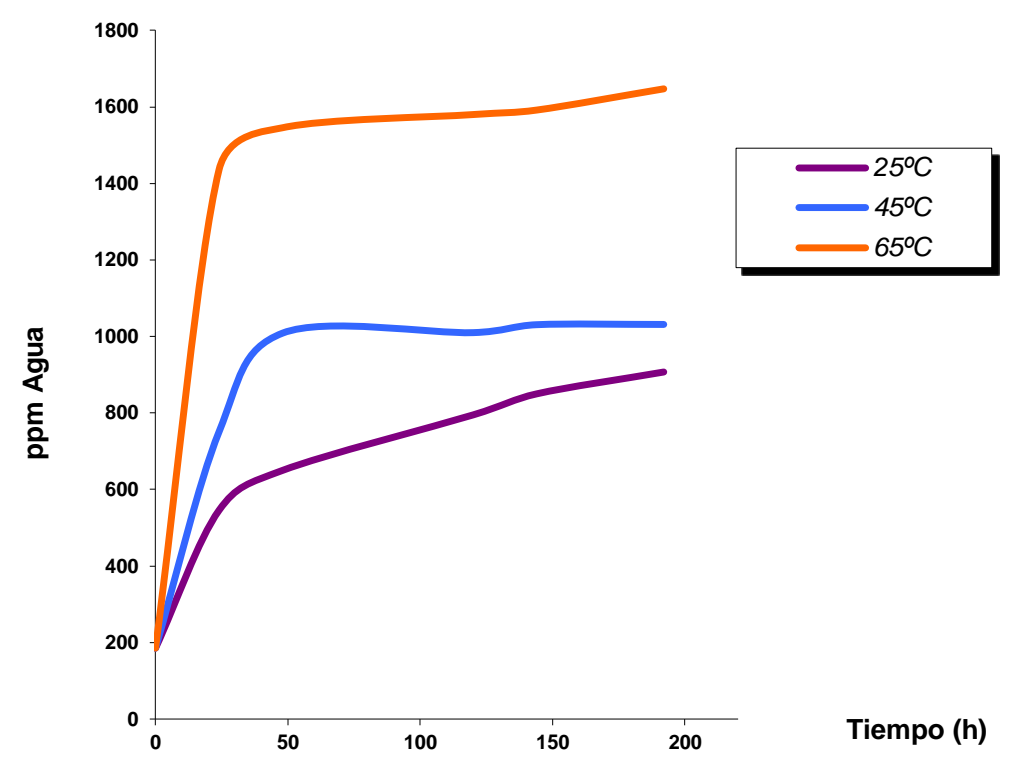

Figura 126: Curvas de saturación del Aceite B para un $80 \%$ de humedad relativa

Para un $80 \%$ de $\mathrm{Hr}$, el comportamiento de ambos aceites es muy similar sin llegar a observar comportamientos dispares entre ellos.

b) Curvas de tendencia a la saturación: Con dichas curvas se puede determinar la saturación de un aceite para una temperatura determinada. Dichas curvas responden a la siguiente ecuación:

$$
\operatorname{Saturación}\left(T^{\mathrm{a}}\right)=10^{\left(A-\frac{B}{(T+273)}\right)}
$$

Donde $A$ y $B$ son parámetros característicos de cada aceite y se determinan experimentalmente. Para obtener experimentalmente estos parámetros, se representan $\log \operatorname{Sat}\left(T^{a}\right)$ vs. 1/T. En el caso anterior, la ecuación sería:

$$
\log \operatorname{Sat}\left(T^{\mathrm{a}}\right)=-\frac{B}{k}+A
$$




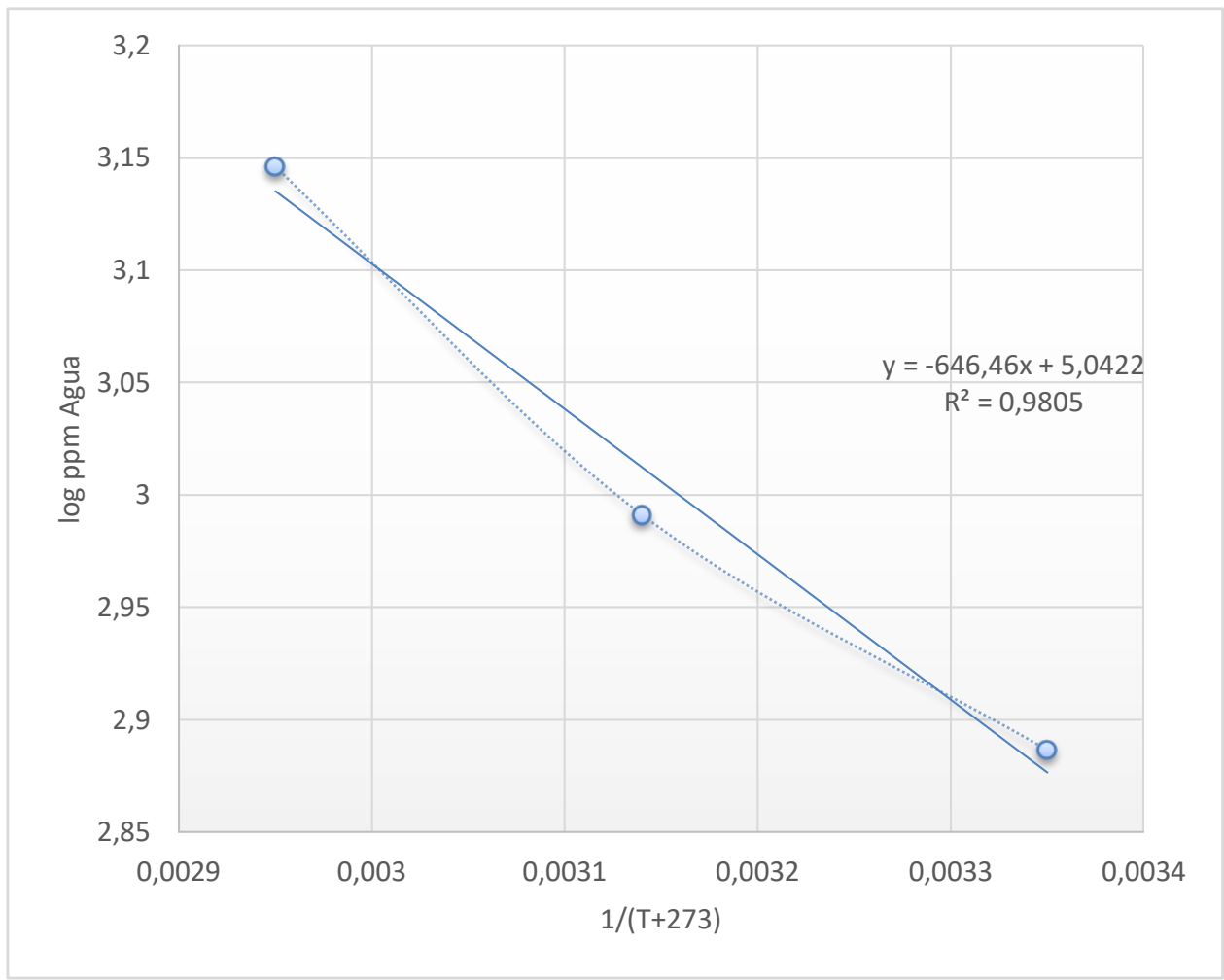

Figura 127: Aceite A para un $43 \%$ de $\mathrm{Hr}$

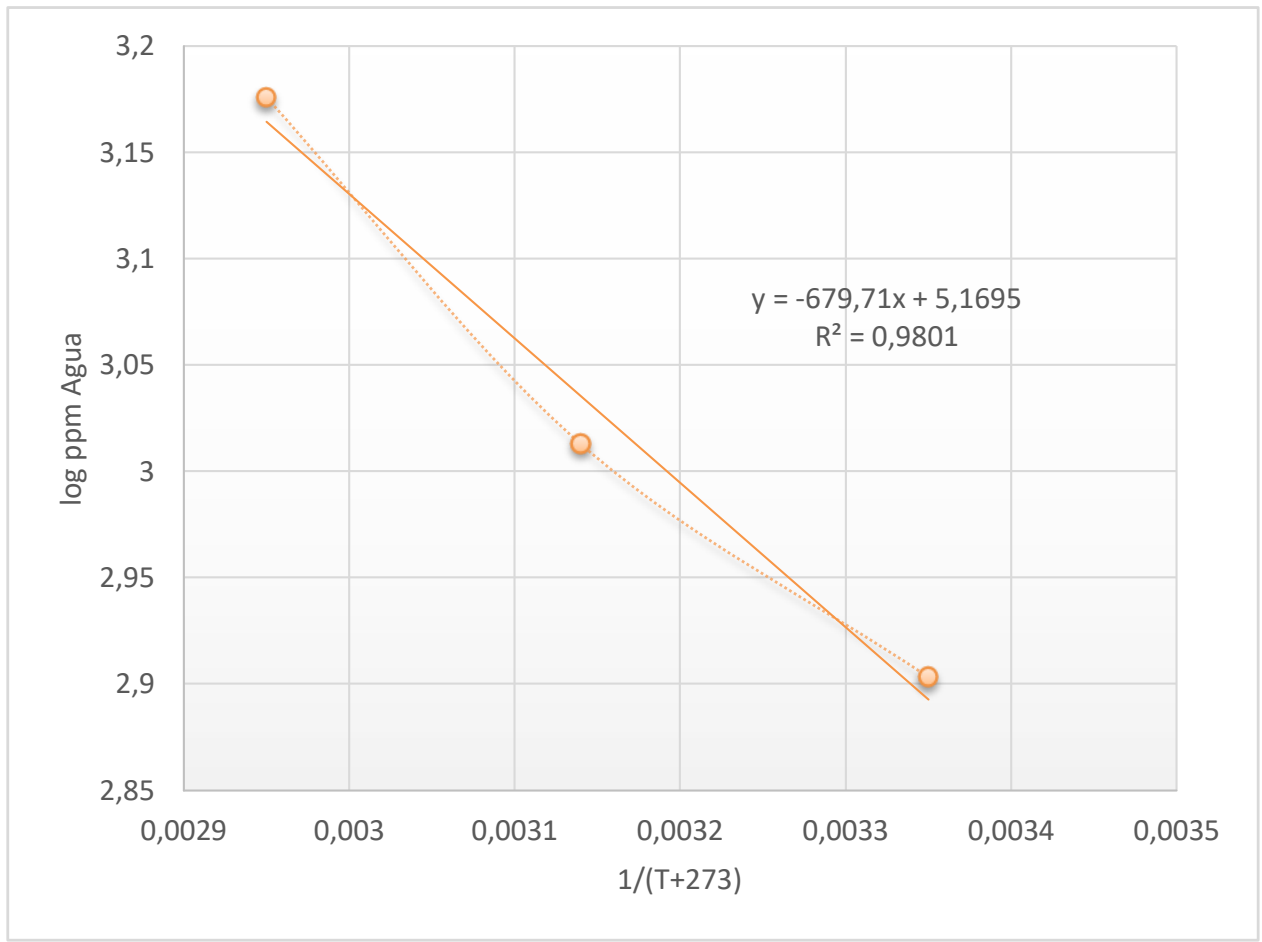

Figura 128: Aceite B para un $43 \%$ de $\mathrm{Hr}$ 


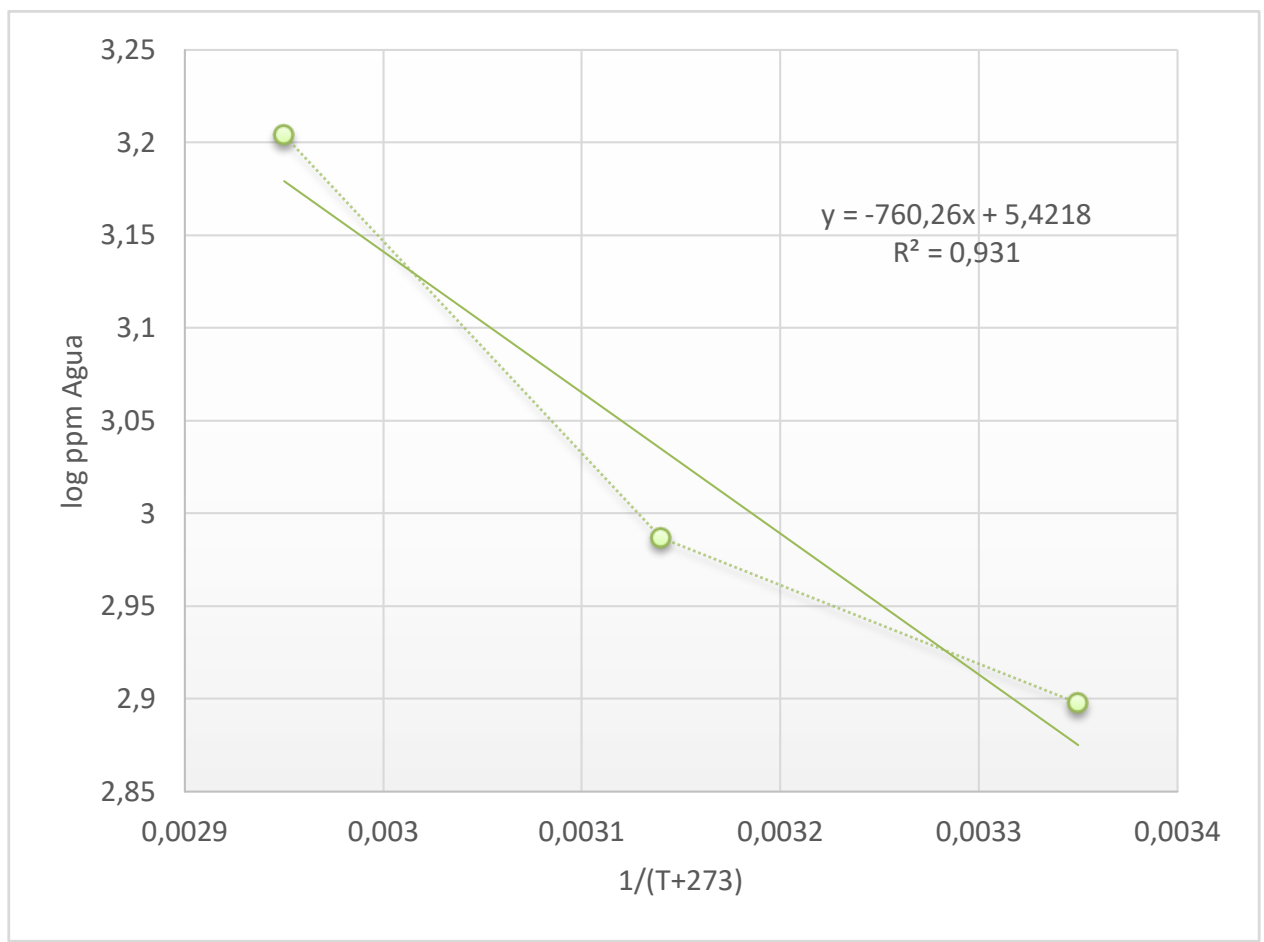

Figura 129: Aceite A para un $80 \%$ de $\mathrm{Hr}$

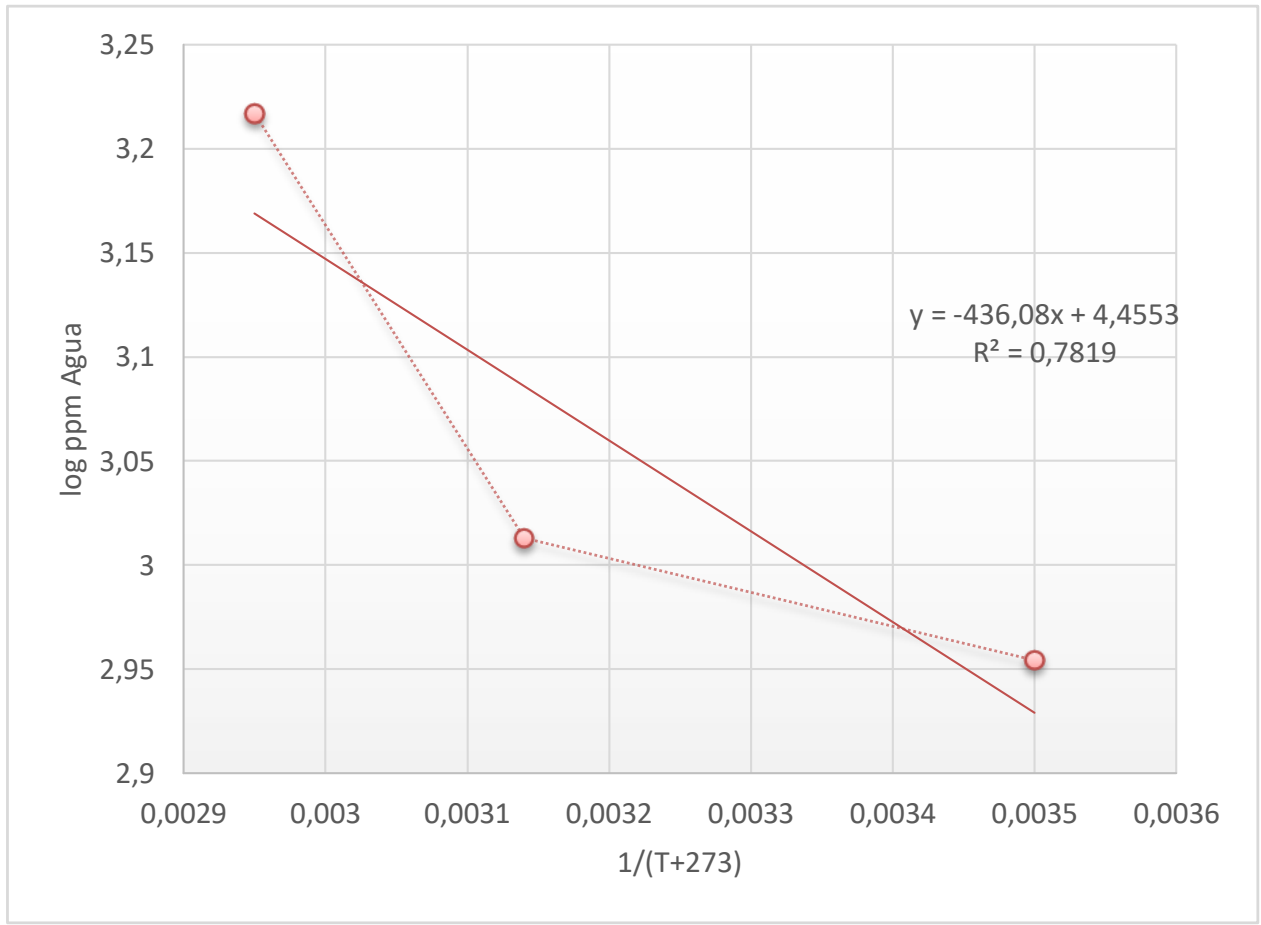

Figura 130: Aceite B para un $80 \%$ de $\mathrm{Hr}$ 
En la figura 130 se observa un índice de correlación bajo $\left(\mathrm{R}^{2}<0,9\right)$ con respecto a las otras tres rectas $\left(\mathrm{R}^{2}>0,9\right)$. Esto es debido a la desviación del dato de saturación del aceite $\mathrm{B}$ a $45{ }^{\circ} \mathrm{C}$. Posiblemente, dicha desviación pueda relacionarse con un error en la preparación de la disolución saturada con sales inorgánicas.

Los parámetros A y B se muestran en la tabla 31:

Tabla 31: Determinación de los parámetros A y B de ambos aceites, experimentalmente

\begin{tabular}{|c|c|c|}
\hline Muestra de aceite & A & B \\
\hline Aceite A 43\% & 5,0419 & 646,46 \\
\hline Aceite B 43\% & 5,1695 & 679,71 \\
\hline Aceite A 80\% & 5,4218 & 760,26 \\
\hline Aceite B 80\% & 5,1051 & 649,53 \\
\hline
\end{tabular}

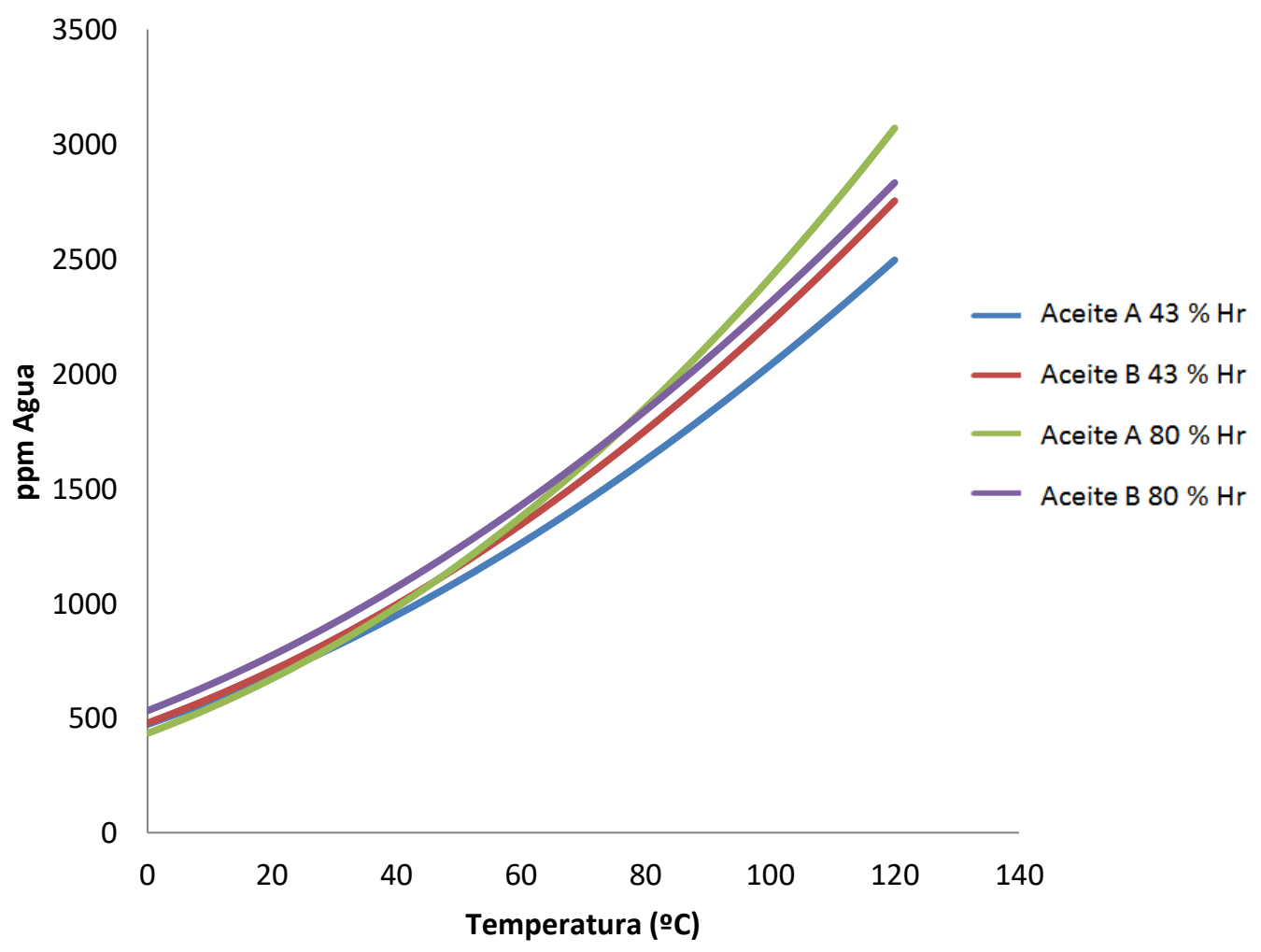

Figura 131: Curvas de tendencia a la saturación 
Como se observa en la figura 131, la muestra de Aceite A presenta variaciones significativas con respecto al cambio de humedad relativa del medio, mientras que el Aceite B muestra un comportamiento muy similar en ambos casos.

\subsubsection{Dependencia de la saturación de agua con el peso molecular del aceite}

Como se ha citado anteriormente en el artículo de Hilder [44], se muestra la relación entre la humedad relativa del medio y la concentración de agua en el aceite. Pero en dicho artículo también se indica la independencia de la naturaleza del aceite con la temperatura y humedad relativa si se expresa la concentración de agua como fracción molar de la disolución.

Para ello determinamos el peso molecular promedio (Pm) y el índice de iodo como valor orientativo al número de insaturaciones de ambos aceites con la distribución de ácidos grasos que se indican en la siguiente tabla:

Tabla 32: Determinación del índice de yodo para el aceite A

\begin{tabular}{|c|c|c|c|}
\hline \multicolumn{4}{|c|}{ Aceite A } \\
\hline Ácidos grados & Porcentaje $\% \mathrm{~m} / \mathrm{m}$ & Factor & Contribución \\
\hline $\mathrm{C}_{18: 1}$ & 91 & 0,860 & 78,26 \\
\hline $\mathrm{C}_{18: 2}$ & 3 & 1,732 & 5,196 \\
\hline $\mathrm{C}_{18: 3}$ & 0 & 2,616 & 0 \\
\hline $\mathrm{C}_{18: 0}$ & 2 & 0 & 0 \\
\hline $\mathrm{C}_{16: 0}$ & 3 & 0 & 0 \\
\hline \multicolumn{2}{r}{} & Índice de Yodo: & $83,5 \mathrm{~g} \mathrm{Iodo} / 100 \mathrm{~g}$ \\
\hline
\end{tabular}

Tabla 33: Determinación del índice de yodo para el aceite B

\begin{tabular}{|c|c|c|c|}
\hline \multicolumn{5}{|c|}{ Aceite B } \\
\hline Ácidos grados & Porcentaje \% m/m & Factor & Contribución \\
\hline $\mathrm{C}_{18: 1}$ & 23 & 0,860 & 19,78 \\
\hline $\mathrm{C}_{18: 2}$ & 52 & 1,732 & 90,064 \\
\hline $\mathrm{C}_{18: 3}$ & 8 & 2,616 & 20,928 \\
\hline $\mathrm{C}_{18: 0}$ & 4 & 0 & 0 \\
\hline $\mathrm{C}_{16: 0}$ & 11 & 0 & 0 \\
\hline & & Índice de Yodo: & $130,8 \mathrm{~g} \mathrm{Iodo} / 100 \mathrm{~g}$ \\
\hline
\end{tabular}


El aceite A tiene un índice de yodo un 22\% aproximadamente menor que el del aceite B. Los pesos moleculares promedios son:

- Aceite A: $886 \mathrm{~g} / \mathrm{mol}$

- Aceite B: $878 \mathrm{~g} / \mathrm{mol}$

Tomamos como datos la concentración de agua a la cual se han saturado los aceites para una humedad y temperatura determinada. Pasamos esos datos a moles y calculamos las fracciones molares. Los resultados se exponen en la siguiente tabla:

Tabla 34: Resultados de saturación de agua en términos de fracción molar

\begin{tabular}{|c|c|c|c|c|c|c|}
\hline HR & \multicolumn{3}{|c|}{$\mathbf{4 3} \%$} & \multicolumn{3}{c|}{$\mathbf{8 0} \%$} \\
\hline Temperatura $\left({ }^{\circ} \mathrm{C}\right)$ & 25 & 45 & 65 & 25 & 45 & 65 \\
\hline Aceite A & 0,034 & 0,043 & 0,061 & 0,034 & 0,042 & 0,068 \\
\hline Aceite B & 0,035 & 0,044 & 0,063 & 0,036 & 0,044 & 0,069 \\
\hline
\end{tabular}

Como se observa en la tabla anterior, efectivamente la dependencia de la naturaleza del aceite con respecto a la saturación de agua se anula cuando dicha concentración de agua se expresa en términos de fracción molar.

\subsubsection{RESULTADOS DE LAS CURVAS DE SOLUBILIDAD DE AIRE EN} ACEITE

\subsubsection{Resultados}

En total, se llevaron a cabo 6 experiencias en el laboratorio, tal y como se muestra en la siguiente tabla resumen: 
Tabla 35: Experiencias llevadas a cabo en el laboratorio

\begin{tabular}{|l|c|}
\hline Aceite, (condiciones del aire de P y T) & Temperatura del aceite \\
\hline \multirow{2}{*}{ Aceite A $\left(150 \mathrm{mbar}, 28^{\circ} \mathrm{C}\right)$} & $30^{\circ} \mathrm{C}$ \\
\cline { 2 - 2 } & $60^{\circ} \mathrm{C}$ \\
\cline { 2 - 2 } Aceite E $\left(150 \mathrm{mbar}, 28^{\circ} \mathrm{C}\right)$ & $80^{\circ} \mathrm{C}$ \\
\cline { 2 - 2 } & $30^{\circ} \mathrm{C}$ \\
\cline { 2 - 2 } & $60^{\circ} \mathrm{C}$ \\
\hline
\end{tabular}

Por lo tanto, se obtuvieron dos curvas de saturación, una para el aceite mineral E y otra para el aceite vegetal A, tal y como se muestra en las figuras 132 y 133 :

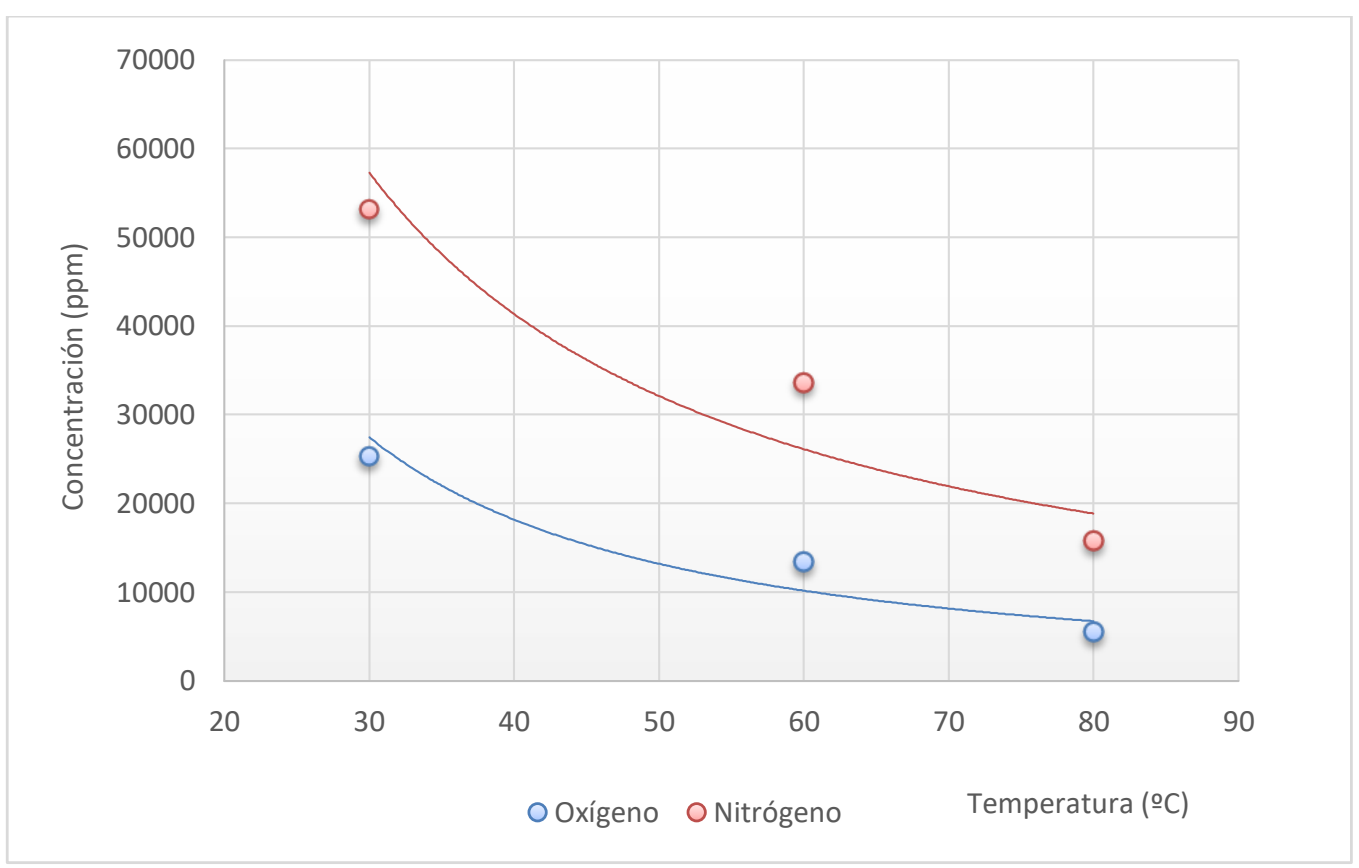

Figura 132: Curvas de saturación de aire para el aceite A 


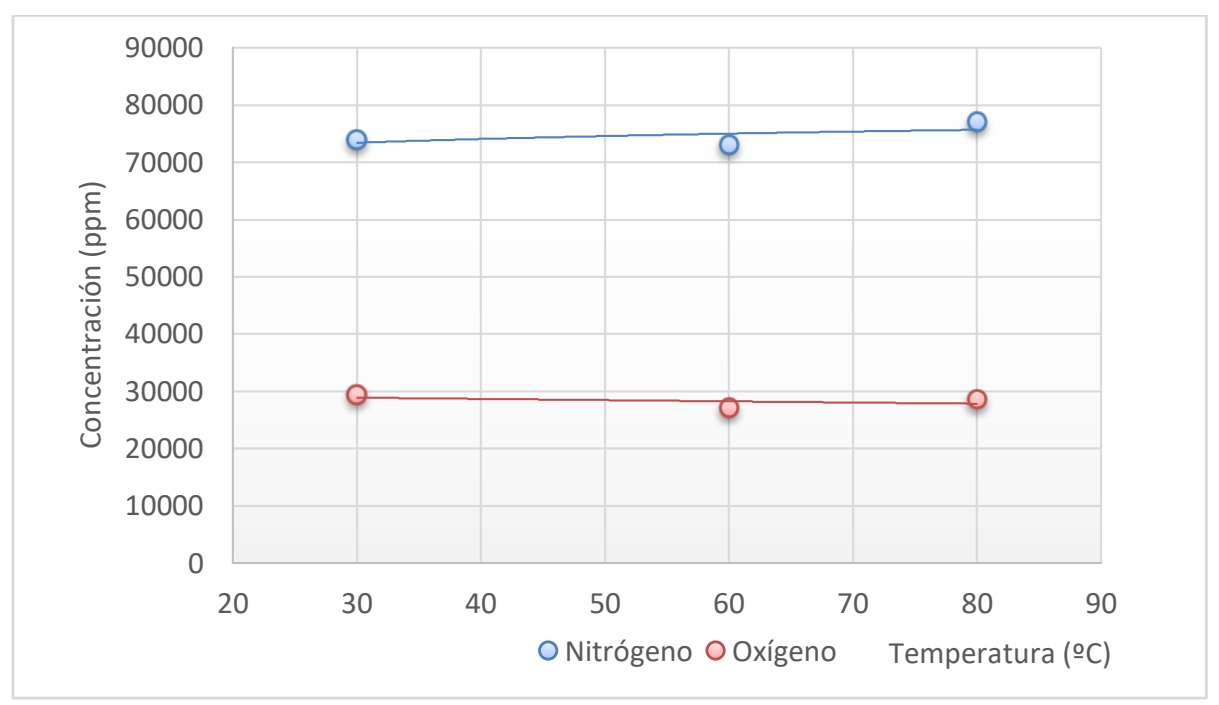

Figura 133: Curvas de saturación de aire para el aceite E

Observando ambas gráficas, podemos indicar que la saturación de aire en aceites minerales con respecto a la temperatura, depende en mucho menor grado que la saturación de aire en aceites vegetales. A $80{ }^{\circ} \mathrm{C}$, la tendencia a quedar ligado el aire a la estructura química del aceite es menor en aceite vegetales que en sus homólogos minerales.

Por último, y para ver el grado de afectación de dicha saturación a las propiedades dieléctricas del aceite, se determinó la rigidez dieléctrica según normativa ASTM D 877 usando una tensión de ruptura de $2 \mathrm{kV} / \mathrm{s}$, electrodos tipo seta separados 1,5 mm entre sí. Los resultados se muestran en el siguiente gráfico resumen:

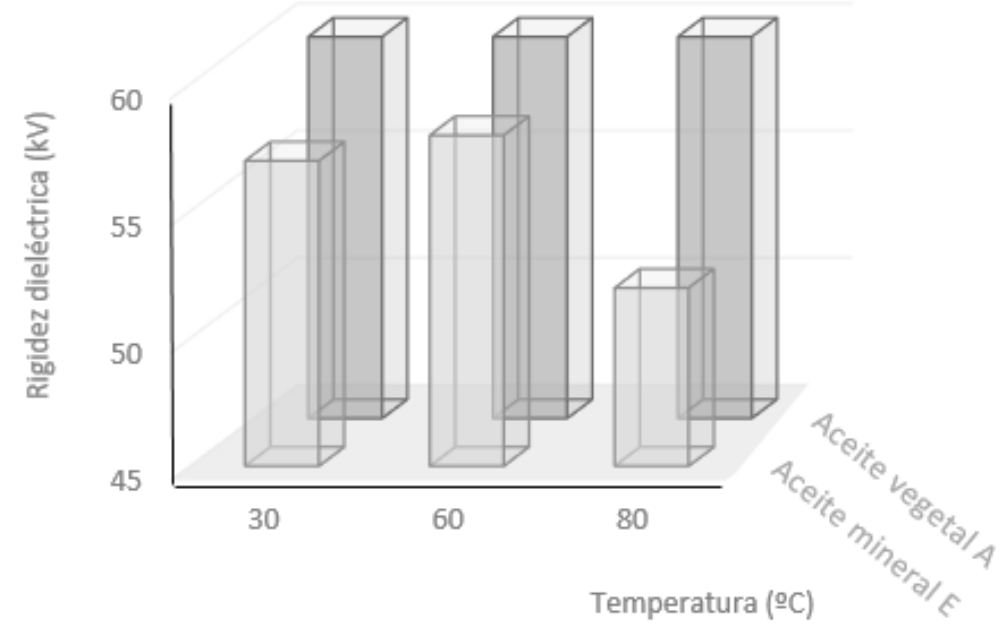

Figura 134: RD frente temperatura de saturación 
Observando los resultados obtenidos, vemos que ninguno de los valores para ambos aceites es inferior a $30 \mathrm{kV}$, valor de rigidez dieléctrica límite para afirmar que un aceite ha perdido todas sus propiedades dieléctricas. Es decir, el valor de rigidez dieléctrica es independiente de la concentración de gases disueltos o ligados químicamente a la estructura interna del aceite y a su vez es mayor en aceites dieléctricos de origen vegetal saturados de aire a las tres temperaturas ensayadas.

\subsection{RESULTADOS DE LOS PROCESOS DE DEGRADACIÓN TÉRMO- OXIDATIVA}

\subsubsection{RESULTADOS OBTENIDOS EN EL ESTUDIO DE LAS PROPIEDADES DE TRANSFERENCIA TÉRMICA}

\subsubsection{Conductividad térmica}

Para determinar el criterio de refrigeración $\mathrm{P}$, se han determinado los valores de conductividad térmica para los aceites:

- Aceite A (Origen vegetal, representado en amarillo)

- Aceite B (Origen vegetal, representado en verde)

- Aceite E (Origen mineral, representado en marrón)

Fueron determinados por el método de los cilindros concéntricos empleando células de conductividad térmica y un calorímetro C80D de la empresa SETARAM (Francia). Estos equipos permiten establecer curvas de evolución de la conductividad térmica en intervalos entre $-30{ }^{\circ} \mathrm{C} \mathrm{y}+190{ }^{\circ} \mathrm{C}$. Se determinaron los valores de conductividad térmica a tres temperaturas: 25,50 y $80^{\circ} \mathrm{C}$. Los resultados se muestran a continuación: 


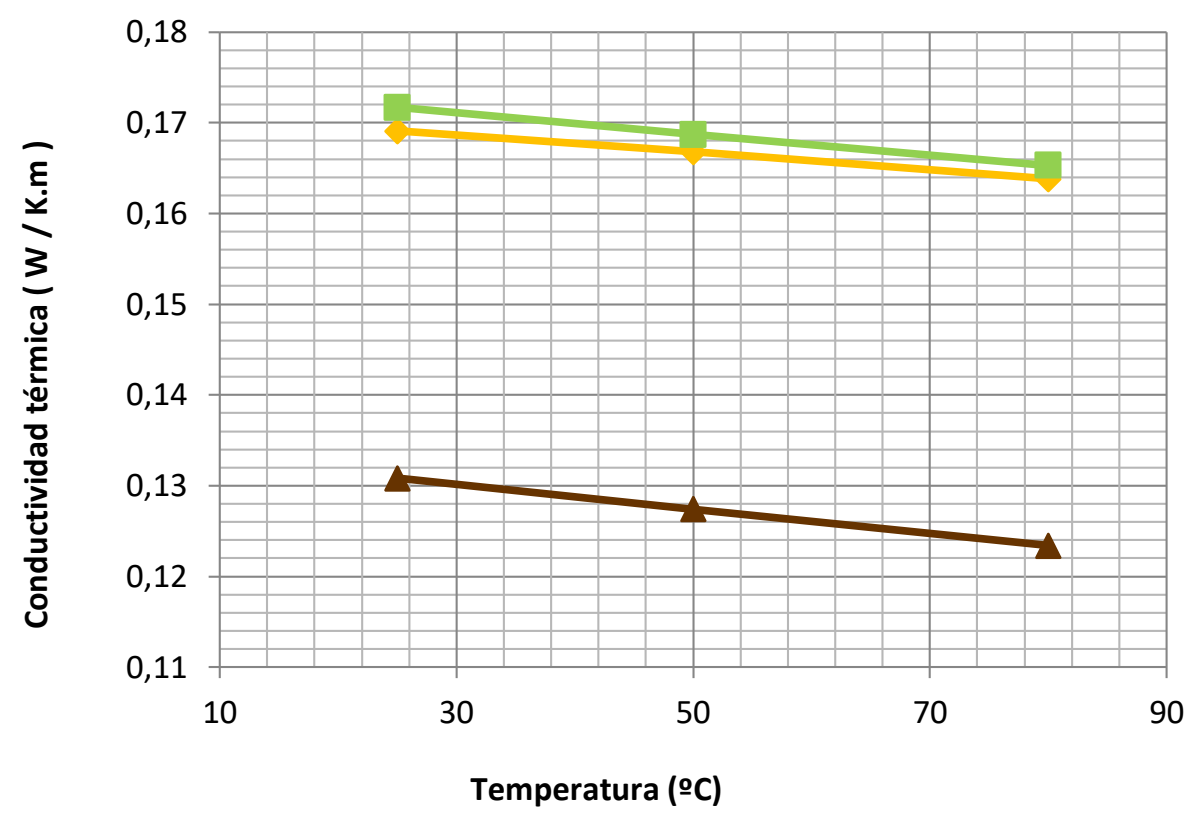

Figura 135: Conductividad térmica frente a la temperatura

Las rectas de regresión que relacionan matemáticamente la temperatura con la conductividad térmica son:

$$
\begin{array}{lll}
\text { Aceite A: } & \lambda=-0,0001 \cdot \mathrm{t}+0,1716 & \mathrm{R}^{2}=0,9994 \\
\text { Aceite B: } & \lambda=-0,0001 \cdot \mathrm{t}+0,1746 & \mathrm{R}^{2}=0,9997 \\
\text { Aceite } \mathrm{E}: & \lambda=-0,0001 \cdot \mathrm{t}+0,1341 & \mathrm{R}^{2}=0,9999
\end{array}
$$

Como se puede observar en la figura 135, la conductividad térmica de los aceites vegetales es mucho mayor que la de sus homólogos minerales. Este fenómeno posiblemente sea debido a la presencia de un mayor contenido en heteroátomos con electrones desapareados (oxígeno, nitrógeno,...) en la estructura química de los aceites vegetales.

\subsubsection{Calor específico}

Los resultados que se muestran a continuación fueron calculados entre 25 y $80{ }^{\circ} \mathrm{C}$ obteniendo más de 13000 puntos para cada aceite. 
Los resultados obtenidos se ajustan, por mínimos cuadrados, a una ecuación de segundo grado para cada uno de los aceites estudiados.

Tabla 36: Resultados experimentales

\begin{tabular}{|c|c|c|c|c|}
\cline { 2 - 5 } \multicolumn{1}{c|}{} & \multicolumn{4}{c|}{$C p\left(\frac{J}{K \cdot g}\right)=a+b \cdot t\left({ }^{\circ} C\right)+c \cdot t\left({ }^{\circ} C\right)^{2}$} \\
\hline Aceite & a & b & c & $\mathbf{R}^{2}$ \\
\hline Aceite A & 1,921251 & 0,001980 & 0,000010 & 0,9993 \\
\hline Aceite B & 1,919008 & 0,001257 & 0,000021 & 0,9995 \\
\hline Aceite E & 1,870029 & 0,003546 & 0,000003 & 0,9996 \\
\hline
\end{tabular}

Debido a que el error experimental del ensayo es del 1\%, podemos eliminar el término cuadrático ya que esto supondría cometer un error del mismo orden que el experimental. Las ecuaciones que relacionan el calor específico con la temperatura, para los tres aceites son:
Aceite A:
$\mathrm{Cp}=1,8963+0,0030 \cdot \mathrm{t}$
$\mathrm{R}^{2}=0,9977$
Aceite B
$\mathrm{Cp}=1,8666+0,0035 \cdot \mathrm{t}$
$\mathrm{R}^{2}=0,9924$
Aceite $\mathrm{E}: \quad \mathrm{Cp}=1,8725+0,0039 \cdot \mathrm{t}$
$\mathrm{R}^{2}=0,9999$

\section{Calor especifico vs. Temperatura}

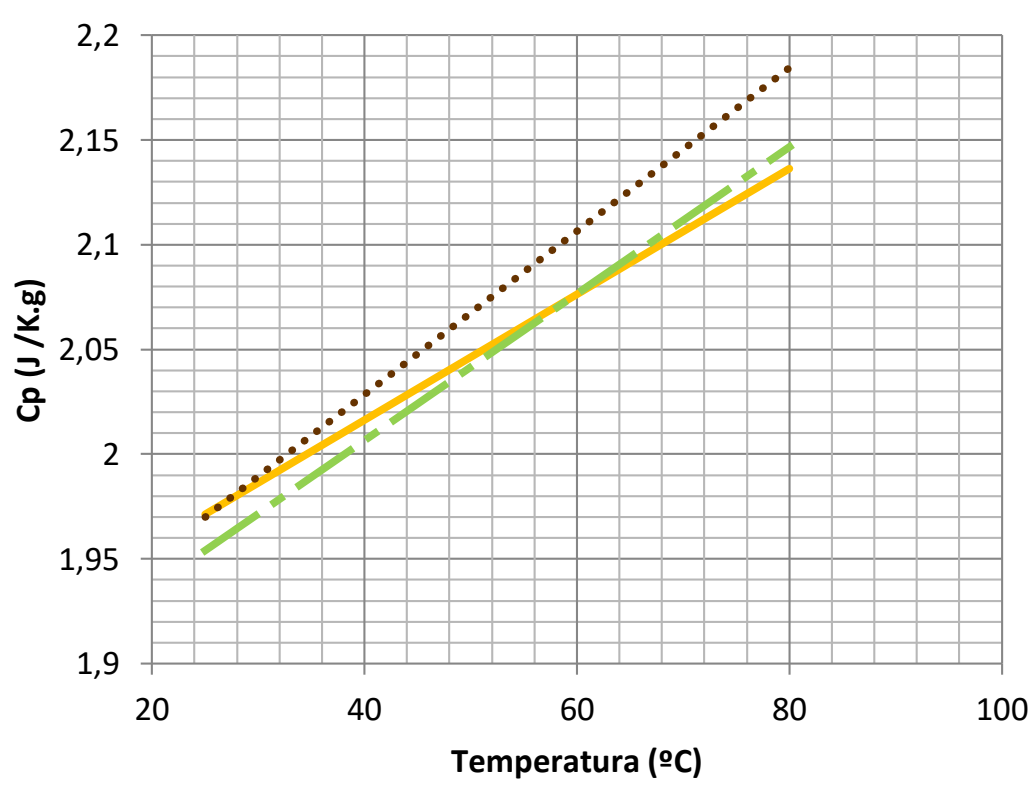

Figura 136: Calor específico frente a la temperatura 
El calor específico de ambos aceites de origen vegetal son prácticamente idénticos y ligeramente inferiores a los del aceite de origen mineral. Esta propiedades es directamente proporcional al valor de refrigeración $\mathrm{P}$ por lo que, a priori, y en igualdad de condiciones con en el resto de parámetros, el aceite mineral tendrá un valor superior de refrigeración que los aceites de origen vegetal.

\subsubsection{Densidad}

Las cinco temperaturas a las que se determinó la densidad para los aceites A, B y E fueron: $0,4,10,30$ y $50{ }^{\circ} \mathrm{C}$. Para llevar a cabo dichos análisis se llevó a cabo la recalibración del densímetro digital en todas las temperaturas citadas con el objetivo de obtener valores de densidad con una elevada precisión y exactitud.

Los resultados se muestran en la tabla siguiente:

Tabla 37: Valor numérico obtenido en el laboratorio

\begin{tabular}{|c|c|c|c|}
\hline \multicolumn{4}{|c|}{ Densidad $\left(\mathbf{g} / \mathbf{c m}^{\mathbf{3}}\right)$} \\
\hline Temperatura $\left({ }^{\mathbf{}} \mathbf{C}\right)$ & Aceite A & Aceite B & Aceite E \\
\hline $\mathbf{0}$ & 0,9266 & 0,9340 & 0,8710 \\
\hline $\mathbf{4}$ & 0,9237 & 0,9311 & 0,8683 \\
\hline $\mathbf{1 0}$ & 0,9197 & 0,9270 & 0,8645 \\
\hline $\mathbf{3 0}$ & 0,9059 & 0,9134 & 0,8517 \\
\hline $\mathbf{5 0}$ & 0,8934 & 0,9008 & 0,8392 \\
\hline
\end{tabular}

A continuación se representó gráficamente las variaciones de las densidades con la temperatura para cada uno de los aceites y se llegó a la expresión matemática que relaciona ambas variables. 


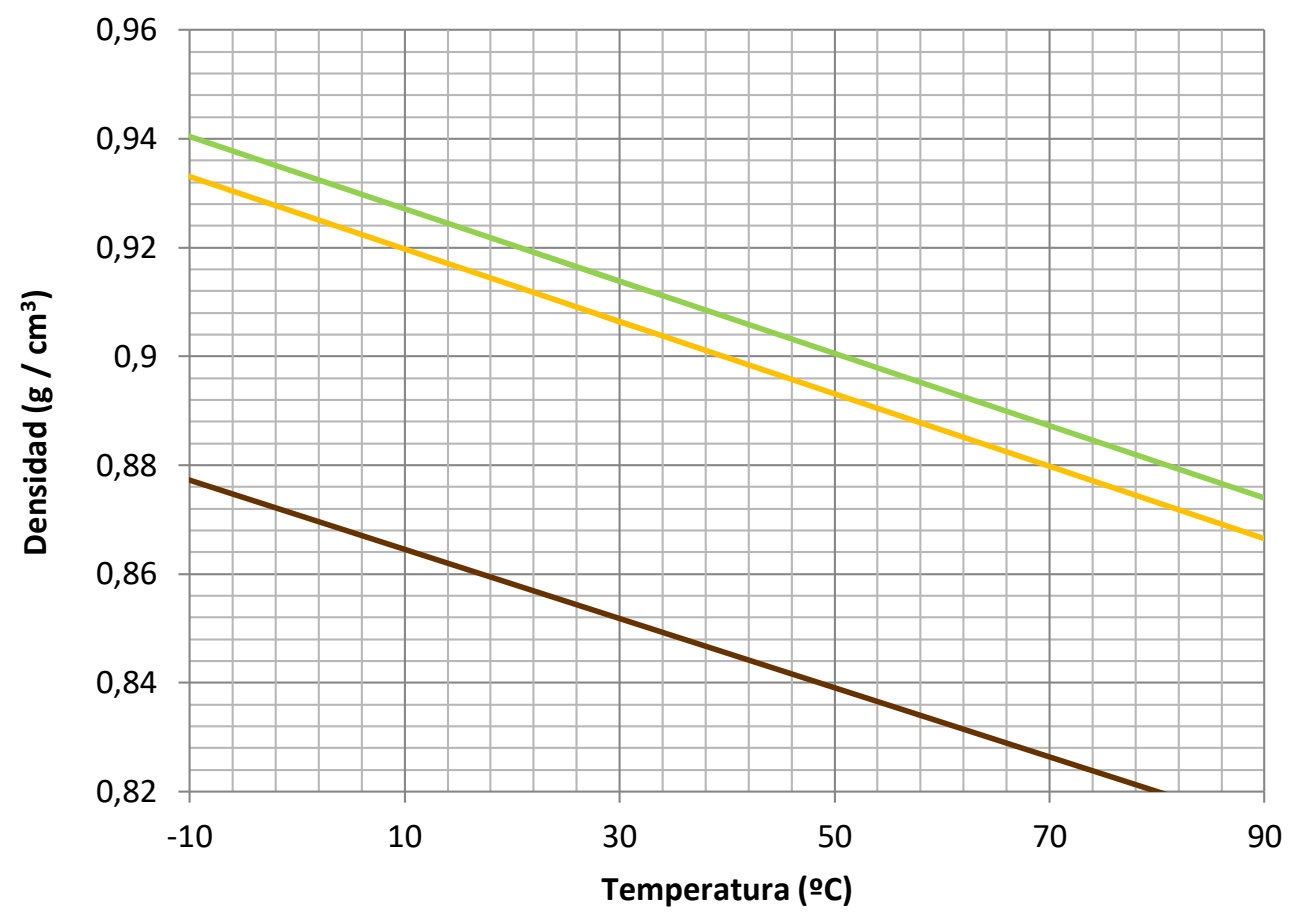

Figura 137: Densidad frente a la temperatura

Las ecuaciones de las rectas ajustadas por mínimos cuadrados, son:

Tabla 38: Ecuaciones comportamiento densidad frente a temperatura

\begin{tabular}{|l|c|c|}
\cline { 2 - 3 } \multicolumn{1}{c|}{} & Ecuación & Índice correlación \\
\hline Aceite A & $\mathrm{D}=-0,0007 \cdot \mathrm{t}+0,9264$ & $\mathrm{R}^{2}=0,9995$ \\
\hline Aceite B & $\mathrm{D}=-0,0007 \cdot \mathrm{t}+0,9338$ & $\mathrm{R}^{2}=0,9996$ \\
\hline Aceite $\mathrm{E}$ & $\mathrm{D}=-0,0006 \cdot \mathrm{t}+0,8709$ & $\mathrm{R}^{2}=0,9999$ \\
\hline
\end{tabular}

Con respecto a la evolución del hielo dentro de un transformador que esté sometido a condiciones climáticas por debajo de $\operatorname{los} 0{ }^{\circ} \mathrm{C}$, efectivamente se puede observar en la Fig. 138 que si el fluido dieléctrico es de origen vegetal, el bloque de hielo a partir de una cierta temperatura, ascendería hacia la parte superior de la cuba del transformador. Sin embargo, si el aceite es de origen parafínico, la densidad del hielo siempre es superior a la del aceite en un amplio margen de temperaturas y por lo tanto, quedaría en el fondo de la cuba del transformador. 


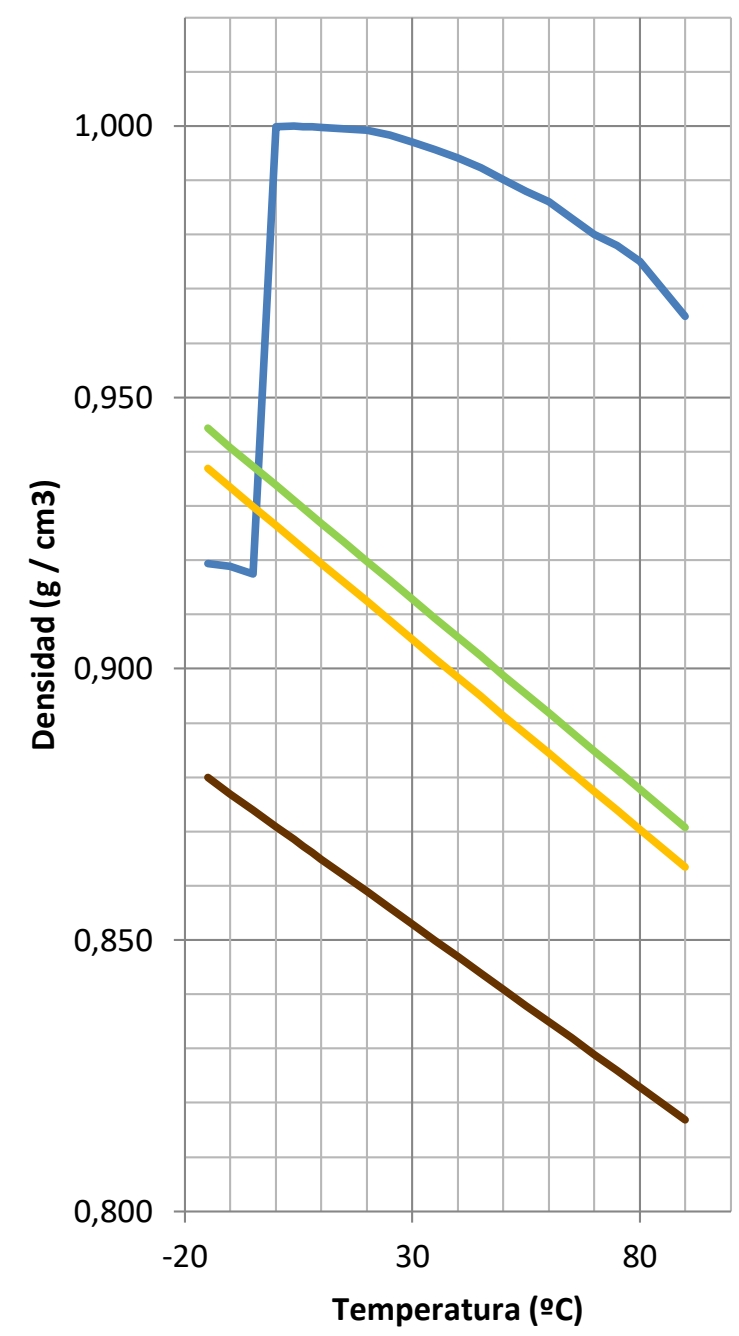

Figura 138: Densidad frente a la temperatura

El mencionado hecho se observa también en las imágenes siguientes donde ambos aceites, A y B, fueron contaminados con agua y enfriados a $-5^{\circ} \mathrm{C}$ aproximadamente. El agua que se había adicionado a los aceites flota sobre éstos en forma de hielo después de un largo período de tiempo. 


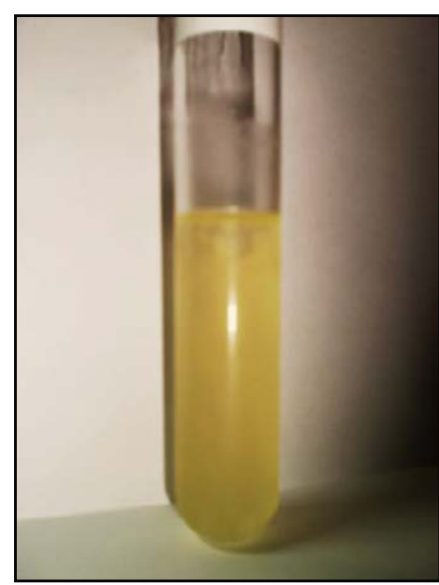

Aceite A

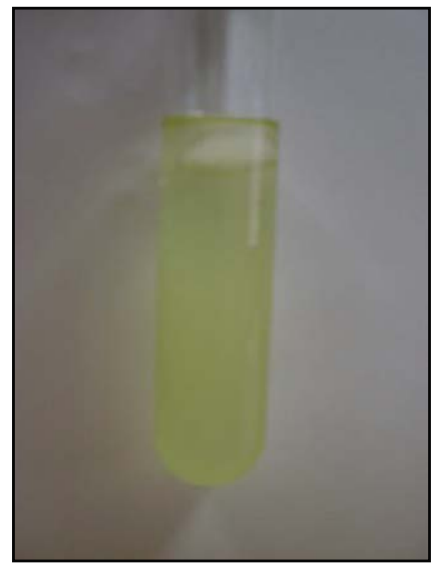

Aceite B

Figura 139: Bloque de hielo flotando sobre el aceite vegetal, a $-5^{\circ} \mathrm{C}$

No obstante a lo anterior, en la situación hipotética de que un transformador con aceite contaminado por agua se enfriase a unas temperaturas de $-5 /-10^{\circ} \mathrm{C}$, el ascenso del hielo hacia la superficie sería un proceso muy lento y claramente dificultado por la alta viscosidad del aceite, que ya se encontraría en proceso de congelación.

\subsubsection{Coeficiente de expansión térmica}

Para calcular el coeficiente de expansión térmica se tomaron como temperaturas $T_{0}=0$

${ }^{\circ} \mathrm{C}$ y $\mathrm{T}_{1}=50{ }^{\circ} \mathrm{C}$ y los valores de las densidades correspondientes a dichas temperaturas para cada aceite obteniéndose los datos siguientes:

- Coeficiente de Expansión Térmica del Aceite A:

$$
\alpha=\frac{(0,9266-0,8934)\left(\frac{\mathrm{g}}{\mathrm{cm}^{3}}\right)}{0,9266\left(\frac{\mathrm{g}}{\mathrm{cm}^{3}}\right) \cdot\left[|0-50|^{\circ} \mathrm{C}\right]}=0,00072 \frac{1}{{ }^{o} \mathrm{C}}
$$

- Coeficiente de Expansión Térmica del Aceite B: 


$$
\alpha=\frac{(0,9340-0,9008)\left(\frac{\mathrm{g}}{\mathrm{cm}^{3}}\right)}{0,9340\left(\frac{\mathrm{g}}{\mathrm{cm}^{3}}\right) \cdot\left[|0-50|{ }^{\circ} \mathrm{C}\right]}=0,00071 \frac{1}{{ }^{o} \mathrm{C}}
$$

- Coeficiente de Expansión Térmica del Aceite E:

$$
\alpha=\frac{(0,8710-0,8392)\left(\frac{\mathrm{g}}{\mathrm{cm}^{3}}\right)}{0,8710\left(\frac{\mathrm{g}}{\mathrm{cm}^{3}}\right) \cdot\left[|0-50|{ }^{\circ} \mathrm{C}\right]}=0,00073 \frac{1}{{ }^{o} \mathrm{C}}
$$

Como puede observarse, todos los coeficientes están relativamente próximos unos de otros sin observar diferencias significativas en los resultados.

\subsubsection{Viscosidad cinemática}

Para la elaboración de esta tesis, se determinaron las viscosidades de los tres aceites a $40{ }^{\circ} \mathrm{C}$ y a $100{ }^{\circ} \mathrm{C}$. Los resultados se exponen en la siguiente tabla:

Tabla 39: Valores de la viscosidad determinados en el laboratorio

\begin{tabular}{|c|c|c|c|}
\hline \multicolumn{4}{|c|}{ Viscosidad $\left(\mathbf{c S t} ; \mathbf{~ m m}^{2} / \mathbf{s}\right)$} \\
\hline Temperatura & Aceite A & Aceite B & Aceite E \\
\hline $\mathbf{4 0}^{\mathbf{}} \mathbf{C}$ & 39,97 & 35,20 & 10,40 \\
\hline $\mathbf{1 0 0}^{\mathbf{}} \mathbf{C}$ & 8,64 & 8,31 & 3,11 \\
\hline
\end{tabular}

La variación de la viscosidad versus temperatura se puede representar con una exactitud razonable siguiendo la norma americana ASTM D 341, la cual usa una relación logarítmica entre ambas variables.

$$
\log _{10} \log _{10}(v-0,7)=A-B \cdot \log _{10}(t+273,15)
$$

(Ecuación 41) 
Donde los parámetros A y B son específicos para cada aceite y se determinan con los valores de la viscosidad cinemática a 40 y $100{ }^{\circ} \mathrm{C}$ obtenidos experimentalmente en el laboratorio.

A continuación se expone una gráfica con los valores de las viscosidades de los tres aceites para un rango de temperaturas comprendida entre 20 y $100{ }^{\circ} \mathrm{C}$.

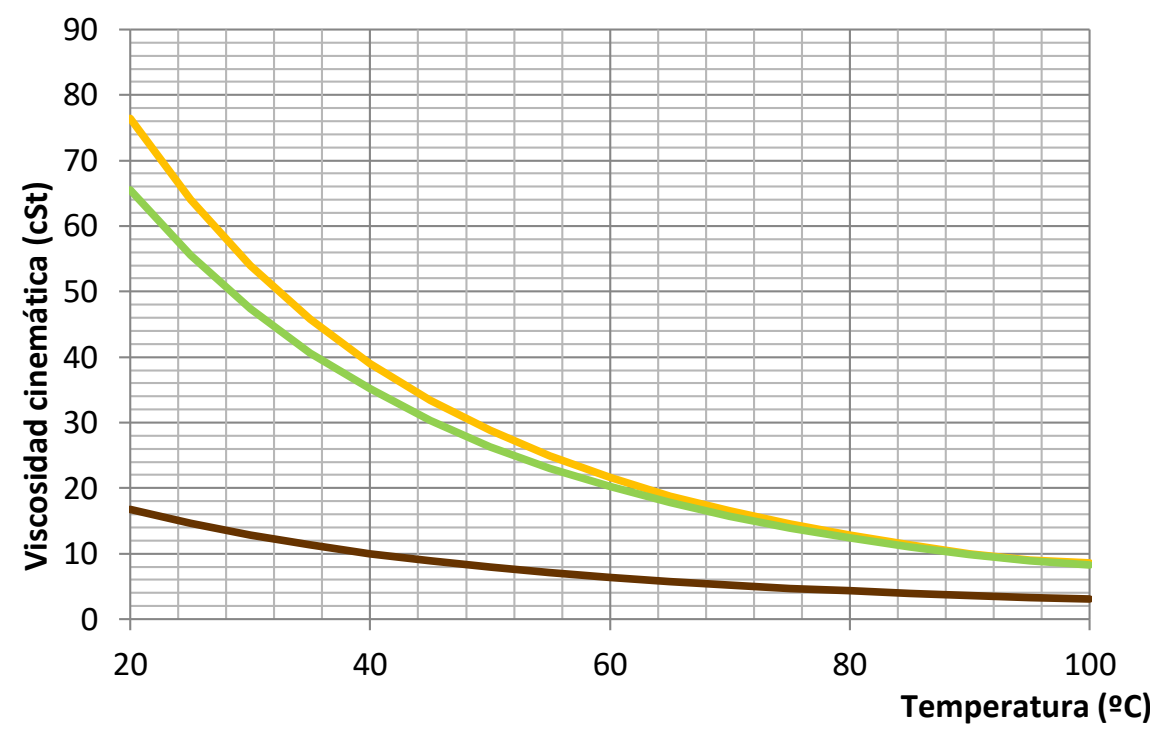

Figura 140: Viscosidad cinemática frente a la temperatura

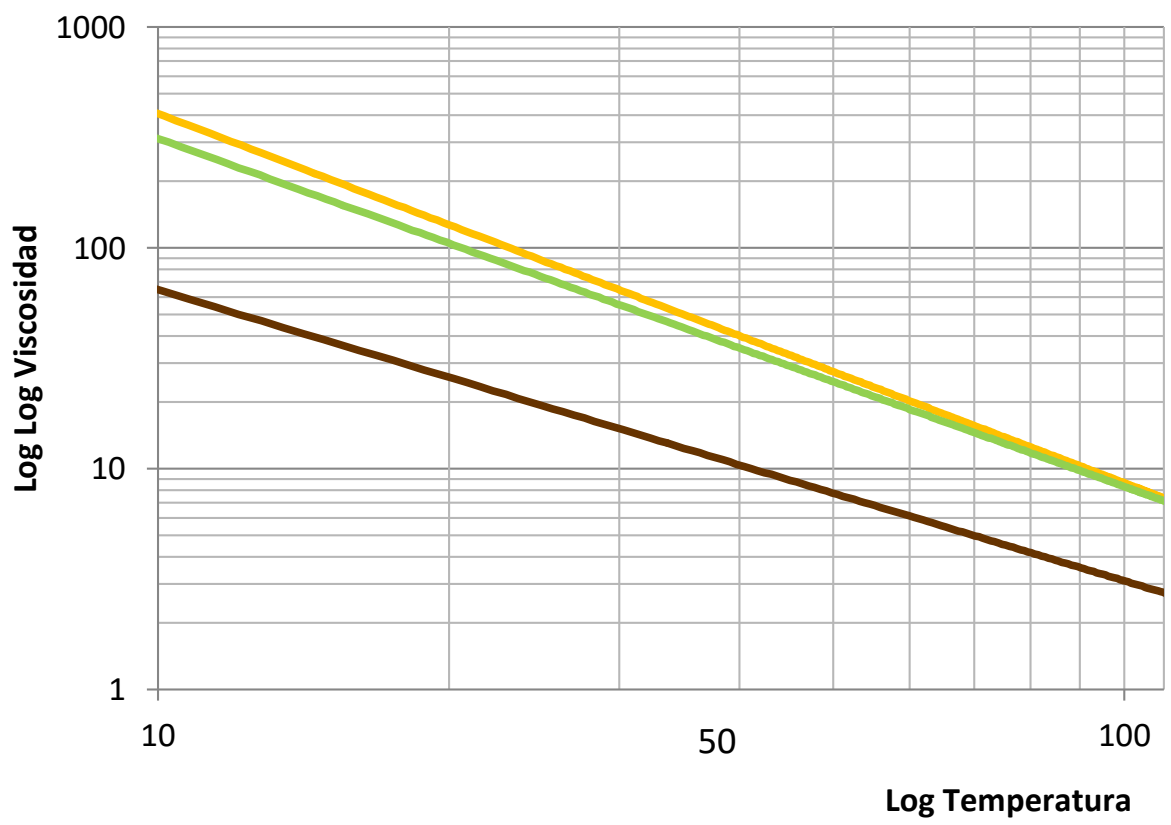

Figura 141: $\log \log$ viscosidad frente al log de la temperatura 
Tal y como se observa en la figura superior, las variaciones de viscosidad cinemática son más notables en aceites de origen vegetal que en los aceites parafínicos. El parámetro Q se usa para determinar los cambios de viscosidad con la temperatura y se define como la relación de dos viscosidades diferentes a dos temperaturas diferentes.

$$
Q=\frac{\vartheta_{1}\left(T_{1}\right)}{\vartheta_{2}\left(T_{2}\right)} \quad T_{1}<T_{2}
$$

Para esta tesis, se calcularon los valores del parámetro $Q$ para una $T_{1}=40{ }^{\circ} \mathrm{C}$ y una $T_{2}=$ $100{ }^{\circ} \mathrm{C}$. Los resultados obtenidos para cada uno de los aceites son:

Tabla 40: Valor de parámetro Q para los tres aceites estudiados

\begin{tabular}{|c|c|c|c|}
\hline Parámetro & Aceite A & Aceite B & Aceite E \\
\hline $\mathbf{Q}_{\mathbf{4 0 / 1 0 0}}$ & 4,62 & 4,24 & 3,34 \\
\hline
\end{tabular}

\subsubsection{Criterio de refrigeración $P$}

Se determinó el valor del parámetro $\mathrm{P}$ en un rango de temperaturas comprendido entre los 20 y los $80^{\circ} \mathrm{C}$. Los cálculos llevados a cabo se muestran en las siguientes tablas:

Tabla 41: Valores del criterio de refrigeración P para aceite vegetal A

\begin{tabular}{|c|c|c|c|c|c|c|}
\hline \multicolumn{7}{|c|}{$P=\frac{C p \cdot \lambda \cdot \alpha}{\vartheta}$} \\
\hline $\boldsymbol{T}\left({ }^{\circ} \boldsymbol{C}\right)$ & Viscosidad & $\boldsymbol{C p}$ & $\lambda$ & $\boldsymbol{\alpha}$ & $\boldsymbol{P}$ & $\boldsymbol{P} \cdot 100000$ \\
\hline 20 & 76,4 & 1,9563 & 0,1696 & 0,0144 & $6,25 \mathrm{E}-05$ & 6,254 \\
\hline 25 & 64 & 1,9713 & 0,1691 & 0,018 & $9,38 \mathrm{E}-05$ & 9,375 \\
\hline 30 & 54 & 1,9863 & 0,1686 & 0,0216 & $1,34 \mathrm{E}-04$ & 13,396 \\
\hline 35 & 45,8 & 2,0013 & 0,1681 & 0,0252 & $1,85 \mathrm{E}-04$ & 18,510 \\
\hline 40 & 39,97 & 2,0163 & 0,1676 & 0,0288 & $2,43 \mathrm{E}-04$ & 24,349 \\
\hline 45 & 33,4 & 2,0313 & 0,1671 & 0,0324 & $3,29 \mathrm{E}-04$ & 32,927 \\
\hline 50 & 28,8 & 2,0463 & 0,1666 & 0,036 & $4,26 \mathrm{E}-04$ & 42,614 \\
\hline 55 & 24,9 & 2,0613 & 0,1661 & 0,0396 & $5,45 \mathrm{E}-04$ & 54,451 \\
\hline 60 & 21,6 & 2,0763 & 0,1656 & 0,0432 & $6,88 \mathrm{E}-04$ & 68,767 \\
\hline 65 & 18,8 & 2,0913 & 0,1651 & 0,0468 & $8,60 \mathrm{E}-04$ & 85,951 \\
\hline 70 & 16,5 & 2,1063 & 0,1646 & 0,0504 & $1,06 \mathrm{E}-03$ & 105,900 \\
\hline 75 & 14,5 & 2,1213 & 0,1641 & 0,054 & $1,30 \mathrm{E}-03$ & 129,639 \\
\hline 80 & 12,8 & 2,1363 & 0,1636 & 0,0576 & $1,57 \mathrm{E}-03$ & 157,274 \\
\hline & & & & & & \\
\hline
\end{tabular}


Tabla 42: Valores del criterio de refrigeración P para aceite vegetal B

\begin{tabular}{|c|c|c|c|c|c|c|}
\hline \multicolumn{7}{|c|}{$P=\frac{C p \cdot \lambda \cdot \alpha}{\vartheta}$} \\
Temper. & Cp & Viscosidad & $\lambda$ & $\alpha$ & $P$ & $P \cdot 100000$ \\
\hline 20 & 1,9366 & 65,5 & 0,1726 & 0,0142 & $7,246 \mathrm{E}-05$ & 7,246 \\
\hline 25 & 1,9541 & 55,5 & 0,1721 & 0,01775 & $1,076 \mathrm{E}-04$ & 10,756 \\
\hline 30 & 1,9716 & 47,4 & 0,1716 & 0,0213 & $1,520 \mathrm{E}-04$ & 15,203 \\
\hline 35 & 1,9891 & 40,6 & 0,1711 & 0,02485 & $2,083 \mathrm{E}-04$ & 20,831 \\
\hline 40 & 2,0066 & 35,2 & 0,1706 & 0,0284 & $2,762 \mathrm{E}-04$ & 27,619 \\
\hline 45 & 2,0241 & 30,3 & 0,1701 & 0,03195 & $3,630 \mathrm{E}-04$ & 36,305 \\
\hline 50 & 2,0416 & 26,3 & 0,1696 & 0,0355 & $4,674 \mathrm{E}-04$ & 46,738 \\
\hline 55 & 2,0591 & 23 & 0,1691 & 0,03905 & $5,912 \mathrm{E}-04$ & 59,117 \\
\hline 60 & 2,0766 & 20,2 & 0,1686 & 0,0426 & $7,384 \mathrm{E}-04$ & 73,836 \\
\hline 65 & 2,0941 & 17,8 & 0,1681 & 0,04615 & $9,127 \mathrm{E}-04$ & 91,268 \\
\hline 70 & 2,1116 & 15,7 & 0,1676 & 0,0497 & $1,120 \mathrm{E}-03$ & 112,032 \\
\hline 75 & 2,1291 & 13,9 & 0,1671 & 0,05325 & $1,363 \mathrm{E}-03$ & 136,294 \\
\hline 80 & 2,1466 & 12,4 & 0,1666 & 0,0568 & $1,638 \mathrm{E}-03$ & 163,815 \\
\hline
\end{tabular}

Tabla 43: Valores del criterio de refrigeración $\mathrm{P}$ para aceite vegetal E

\begin{tabular}{|c|c|c|c|c|c|c|}
\hline \multicolumn{7}{|c|}{$P=\frac{C p \cdot \lambda \cdot \alpha}{\vartheta}$} \\
Temper. & $C p$ & $\lambda$ & Viscosidad & $\boldsymbol{\alpha}$ & $\boldsymbol{P}$ & $\boldsymbol{P} \cdot 100000$ \\
\hline 20 & 1,9505 & 0,1321 & 16,7 & 0,0146 & 0,000225 & 22,526 \\
\hline 25 & 1,97 & 0,1316 & 14,6 & 0,01825 & 0,000324 & 32,407 \\
\hline 30 & 1,9895 & 0,1311 & 12,8 & 0,0219 & 0,000446 & 44,625 \\
\hline 35 & 2,009 & 0,1306 & 11,3 & 0,02555 & 0,000593 & 59,325 \\
\hline 40 & 2,0285 & 0,1301 & 10,4 & 0,0292 & 0,000741 & 74,097 \\
\hline 45 & 2,048 & 0,1296 & 8,9 & 0,03285 & 0,000980 & 97,967 \\
\hline 50 & 2,0675 & 0,1291 & 7,9 & 0,0365 & 0,001233 & 123,321 \\
\hline 55 & 2,087 & 0,1286 & 7,1 & 0,04015 & 0,001518 & 151,772 \\
\hline 60 & 2,1065 & 0,1281 & 6,4 & 0,0438 & 0,001847 & 184,674 \\
\hline 65 & 2,126 & 0,1276 & 5,7 & 0,04745 & 0,002258 & 225,827 \\
\hline 70 & 2,1455 & 0,1271 & 5,2 & 0,0511 & 0,002680 & 267,973 \\
\hline 75 & 2,165 & 0,1266 & 4,7 & 0,05475 & 0,003193 & 319,285 \\
\hline 80 & 2,1845 & 0,1261 & 4,3 & 0,0584 & 0,003741 & 374,121 \\
\hline
\end{tabular}

Para obtener un estudio comparativo, se representaron los valores de los tres aceite sobre un mismo eje de coordenadas: 


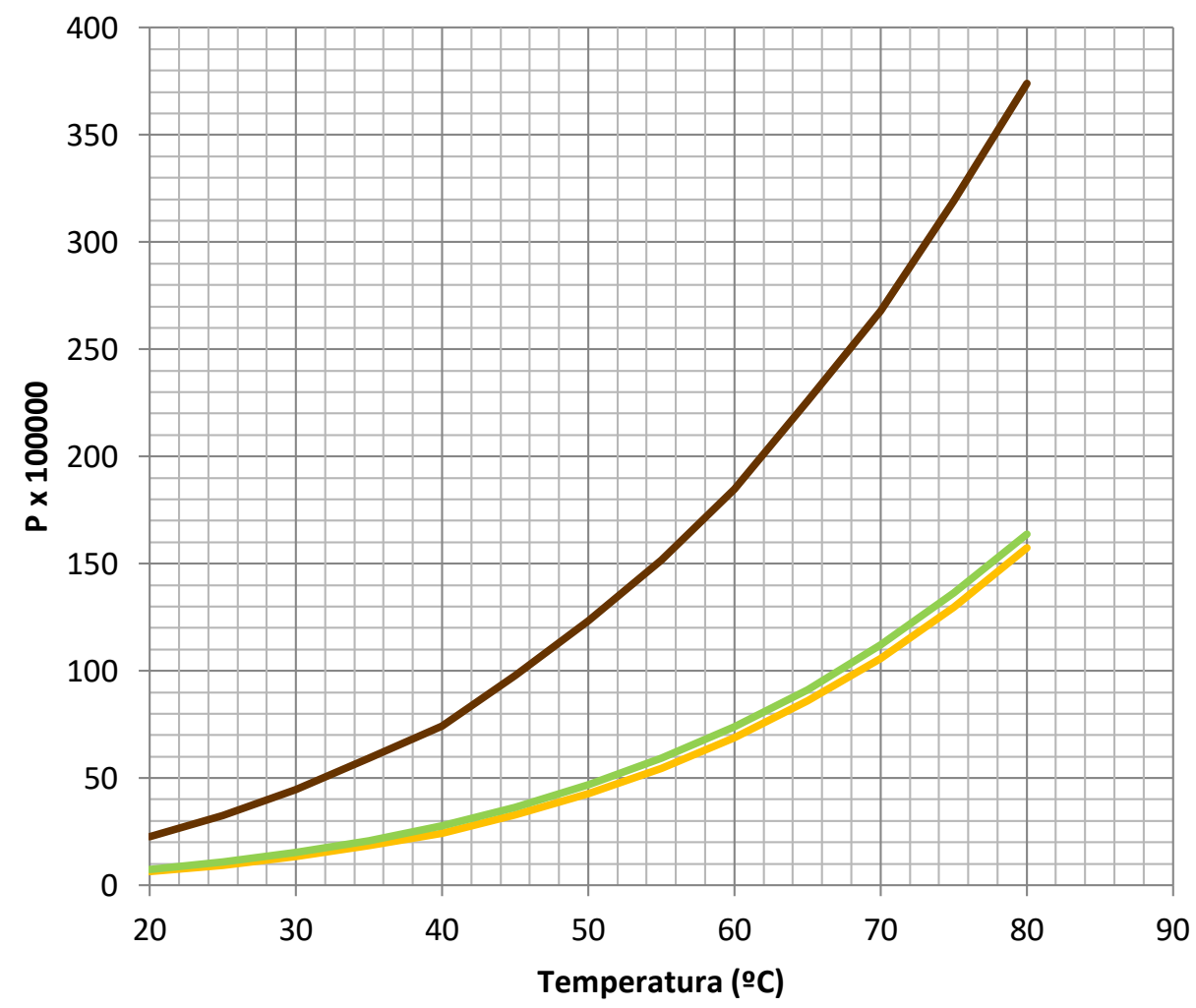

Figura 142: Valor de refrigeración P frente a la temperatura para los 3 aceites estudiados

Se puede observar que, para un rango de temperaturas comprendido entre $\operatorname{los} 20^{\circ} \mathrm{C}$ y los $80{ }^{\circ} \mathrm{C}$, los aceites de origen mineral poseen un valor de refrigeración superior al de los aceites vegetales y que este valor es mucho mayor en aceites minerales a medida que aumenta la temperatura del sistema.

\subsubsection{ESTUDIO DE LA DEGRADACIÓN TÉRMICA DE ACEITES DIELÉCTRICOS DE ORIGEN VEGETAL}

3.3.2.1. Caracterización de la rigidez dieléctrica frente al contenido en agua en aceites de origen vegetal

Para evaluar el efecto del contenido en agua frente a la rigidez dieléctrica en aceites vegetales, se procedió según se ha explicado en el apartado 2.3.2.1.3 (página 171). Inicialmente, ambos aceites presentaban una rigidez dieléctrica superior a $60 \mathrm{kV}$ y un 
contenido en humedad próximo a $100 \mathrm{mg} / \mathrm{kg}$. Se fueron extrayendo muestras cada 24 horas y se determinó la concentración de agua en el aceite así como la rigidez dieléctrica. Los resultados de cada uno de los aceites se muestras a continuación:

- Aceite A

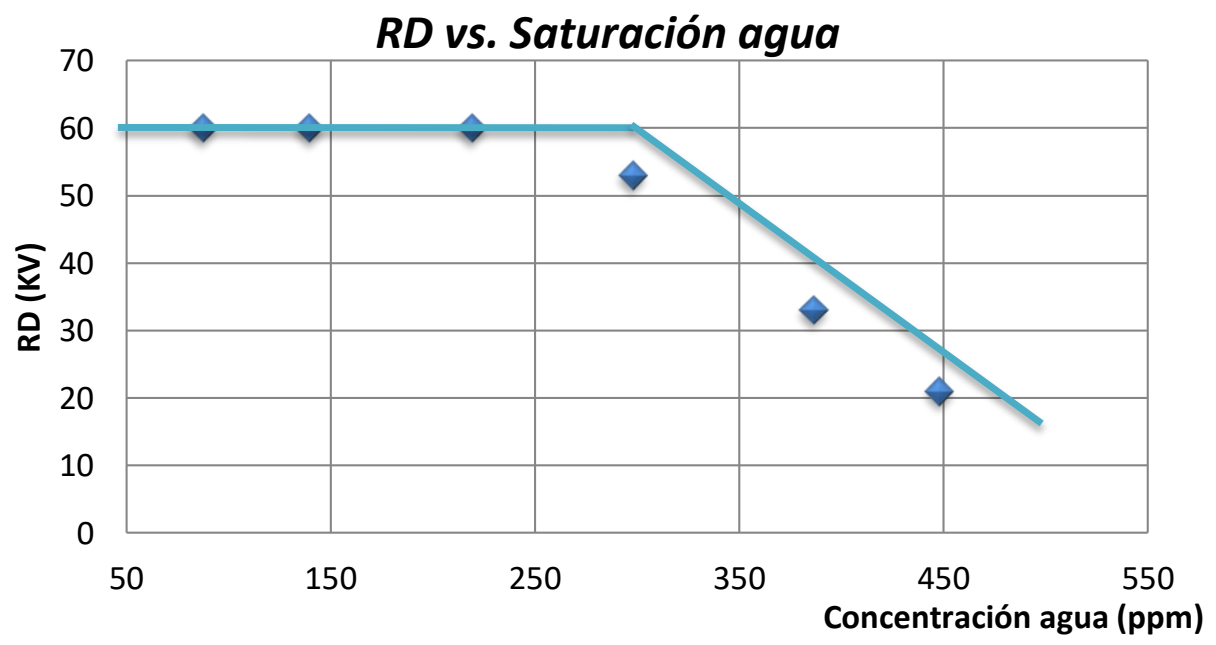

Figura 143: Variación de la RD frente al contenido en agua del aceite A

- Aceite B

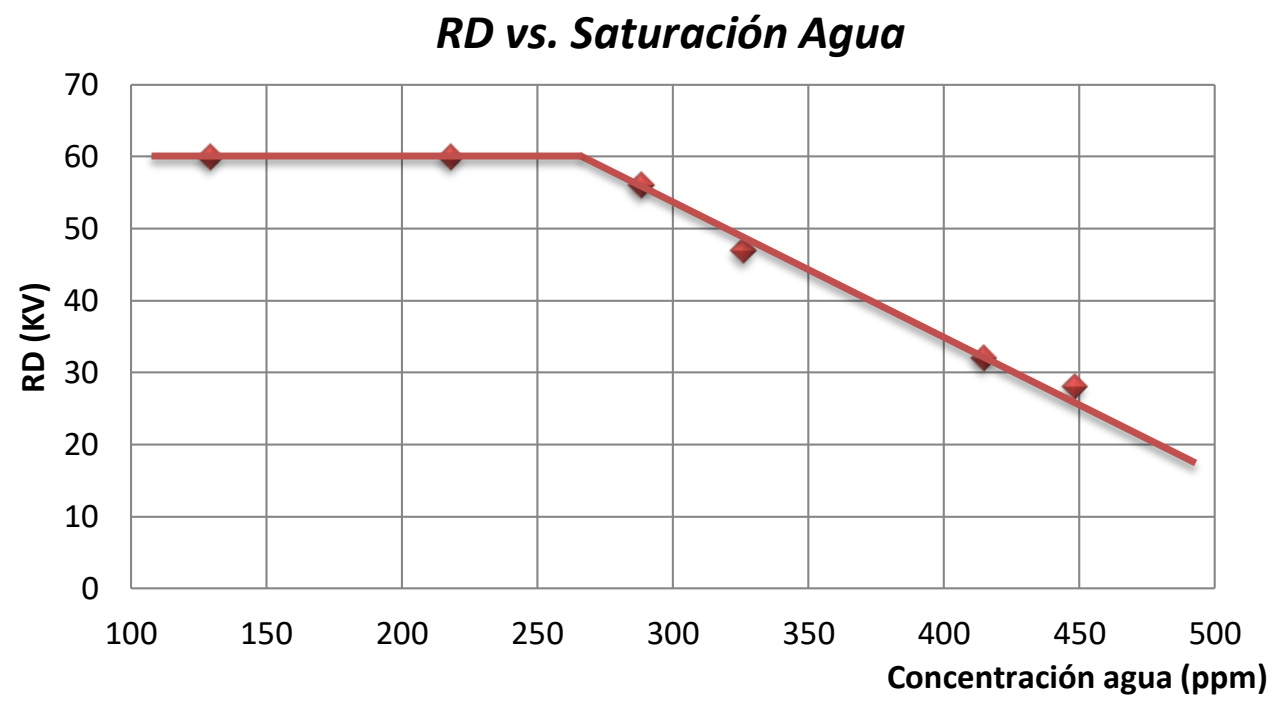

Figura 144: Variación de la RD frente al contenido en agua del aceite B 
Se observa que el aceite A, cuando tiene un contenido en agua de $400 \mathrm{mg} / \mathrm{kg}$ aproximadamente, pierde por completo sus propiedades como material dieléctrico (RD $<30 \mathrm{kV})$ mientras que al aceite B le acurre este fenómeno cuando su contenido en agua es de 425 ppm.

\subsubsection{Caracterización de la rigidez dieléctrica y otras propiedades frente al contenido de índice de acidez en aceites de origen vegetal}

El aceite vegetal que fue evaluado fue el aceite A. El procedimiento operativo de degradación por oxidación ha sido descrito en el apartado2.3.2.2 (página 173). Los resultados obtenidos, después de 120 horas de oxidación se muestran a continuación:

a) Índice de acidez frente el tiempo

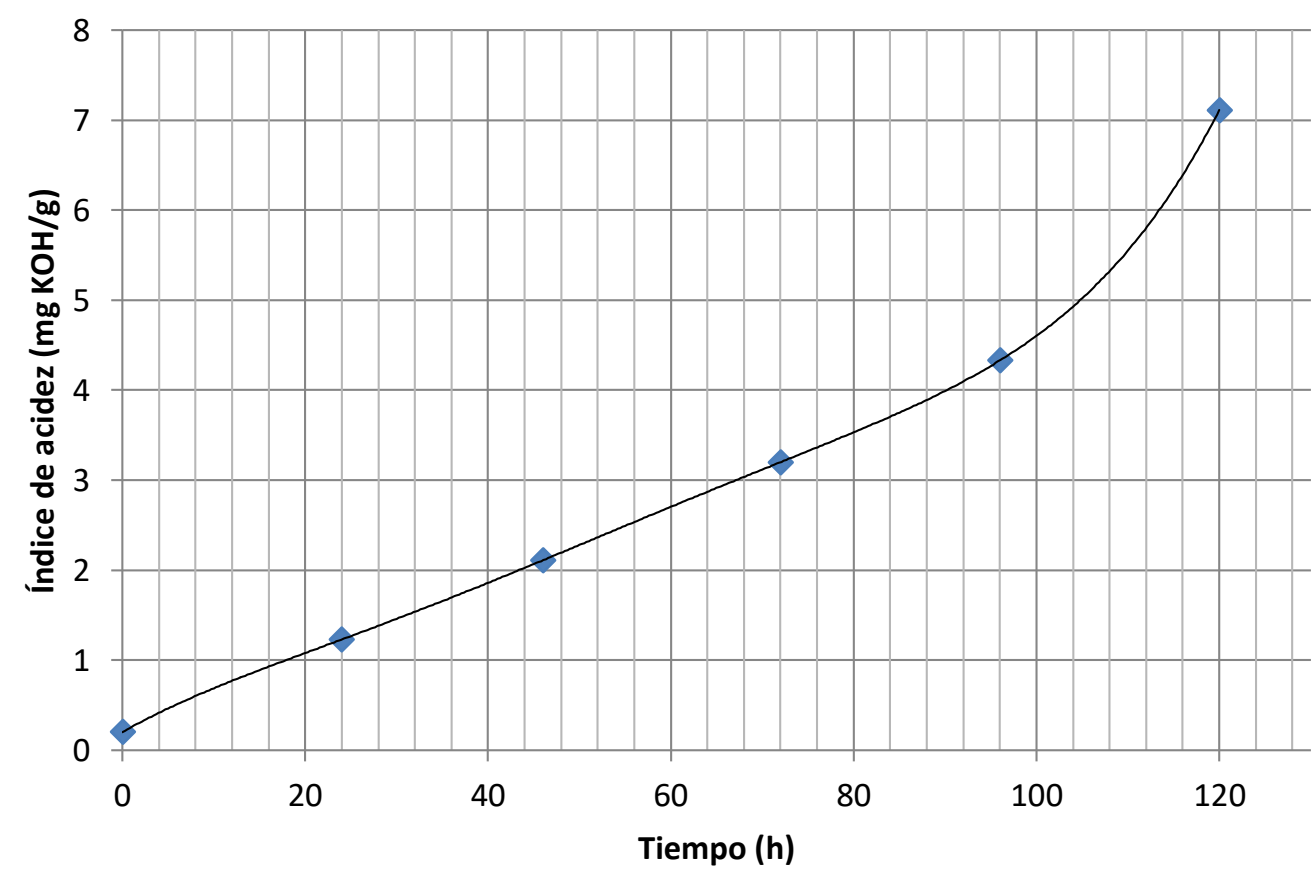

Figura 145: Variación del índice de acidez frente al contenido en agua del aceite A

Se puede observar en la figura 145 que a las 120 horas de oxidación se ha llegado al periodo de inducción del aceite A y a partir de ese tiempo, su índice de acidez crece exponencialmente. En cuanto a la formación de lodos, no se observó en ninguna de las muestras una variación significativa en el peso en las membranas antes y después de 
filtrar las muestras. Además, las muestras no presentaban opacidad ni turbidez apreciable al ojo humano.

b) Contenido en agua frente al tiempo

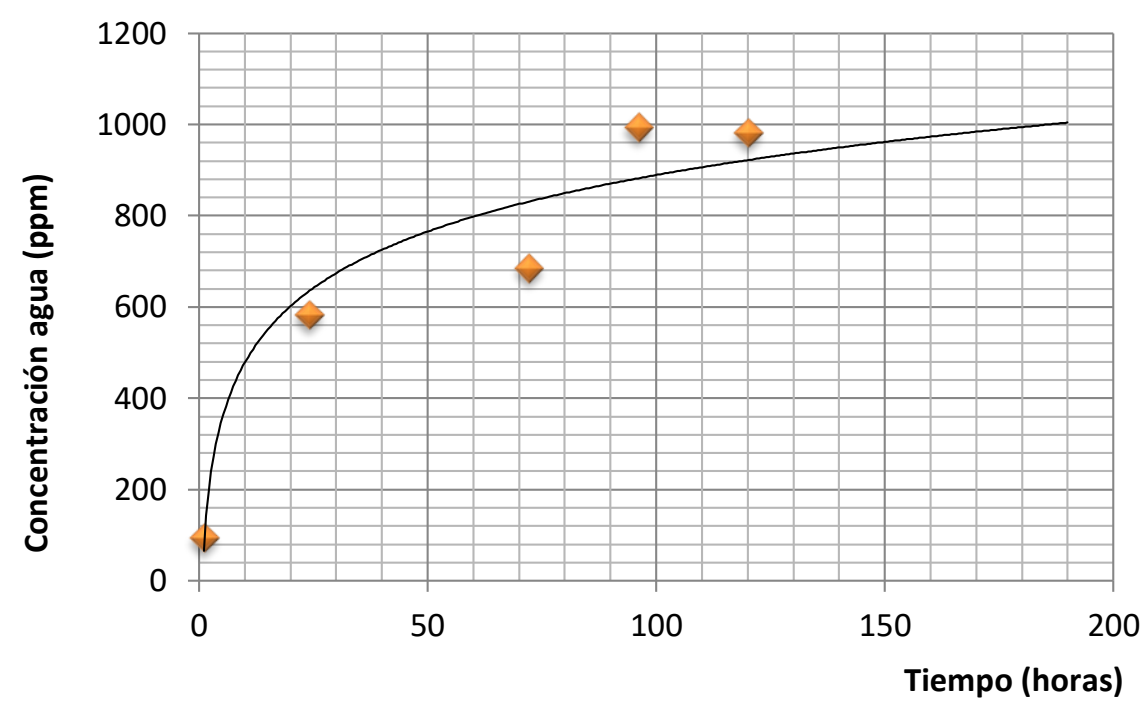

Figura 146: Variación contenido en agua frente a la temperatura para el aceite A

Tal y como se citó anteriormente acerca de la velocidad de saturación de agua en aceite vegetales, a $25^{\circ} \mathrm{C}$ el aceite $\mathrm{A}$ fresco se satura con $800 \mathrm{ppm}$ aproximadamente a las 100 h. En este caso, su límite de saturación es mayor posiblemente debido a la gran cantidad de compuestos polares generados durante el proceso de oxidación y a la posibilidad de que actúen fijando químicamente por absorción cantidades adicionales de agua.

c) Índice de acidez frente a la rigidez dieléctrica

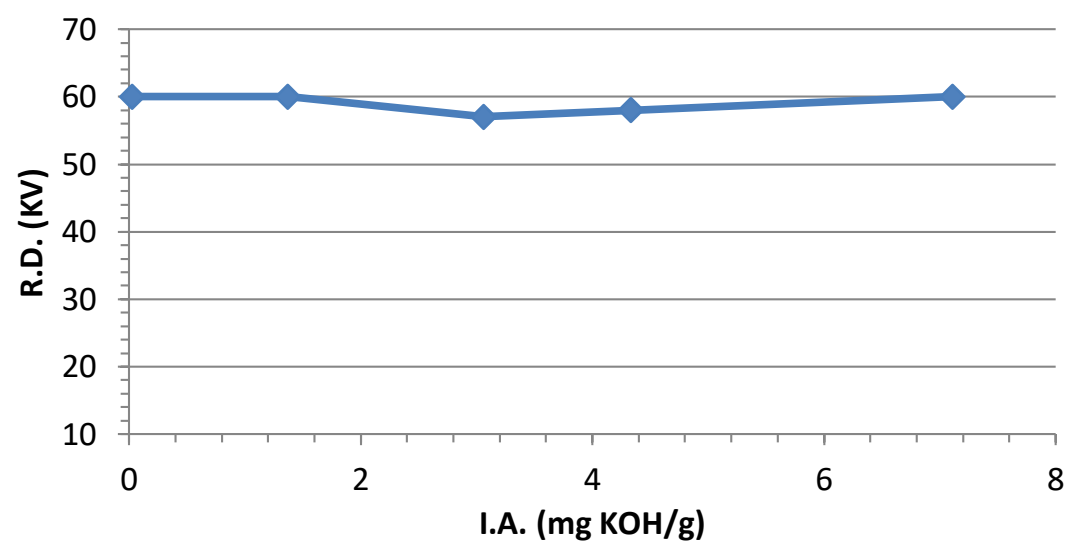

Figura 147: Variación de la RD para IA crecientes en el Aceite A 
Como conclusión, se observa en el gráfico anterior, que una acidez elevada no afecta adicionalmente a la RD en el intervalo de acidez estudiado.

Posteriormente, se decidió repetir el ensayo de oxidación pero ahora sin tener en cuenta el paso de filtración del aceite inmediatamente después de sacarlo del matraz de oxidación. El objetivo de esta modificación fue observar las posibles variaciones en los valores de la rigidez dieléctrica cuando el aceite contiene partículas en suspensión y lodos en su matriz.

Los resultados obtenidos se muestran en la siguiente figura:

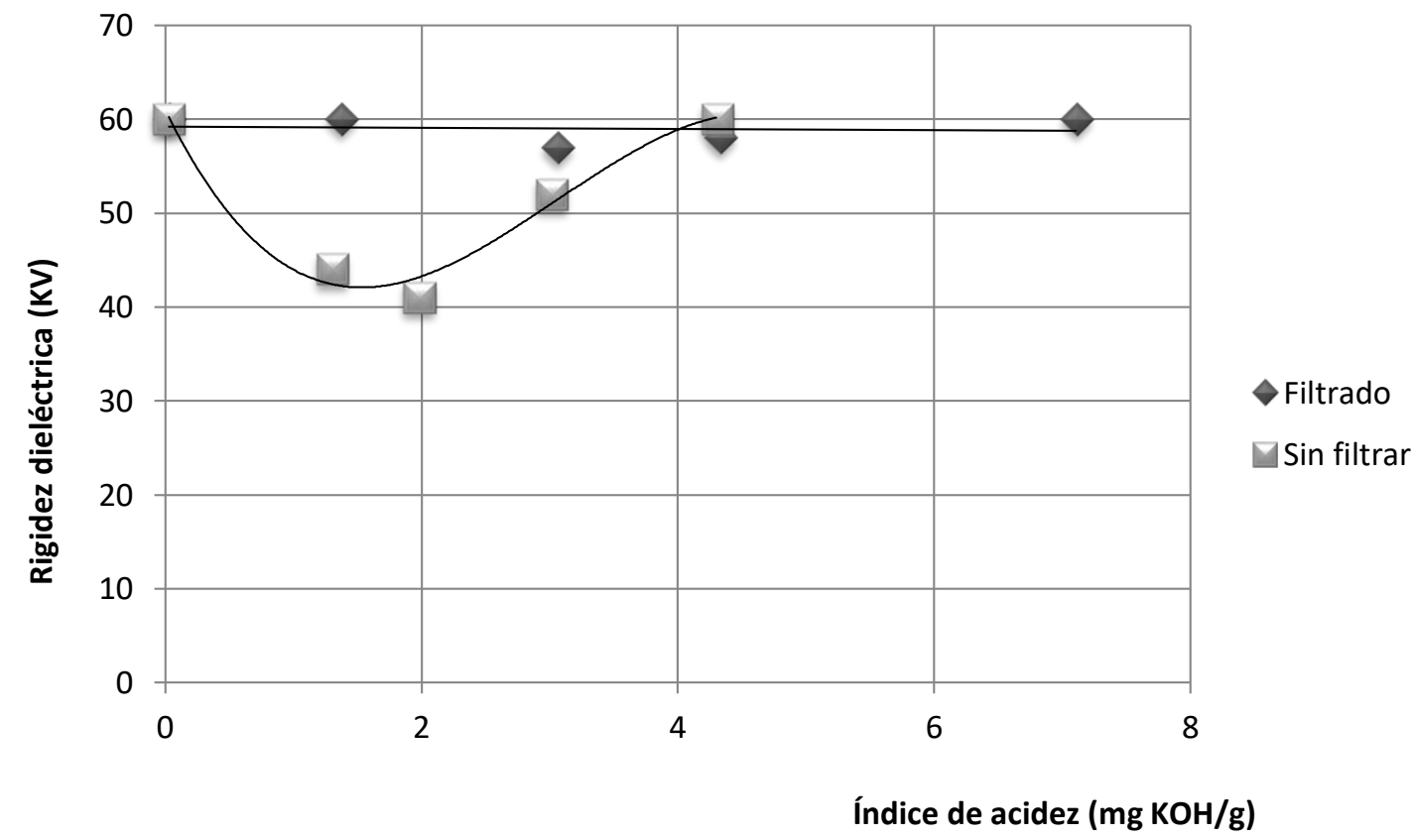

Figura 148: Efecto de la filtración del aceite A sobre el valor de la RD

Tal y como se muestra en la información anterior, a índices de acidez bajos, si el aceite no es filtrado, disminuye su valor de rigidez dieléctrica pero luego, a índices de acidez altos, recupera su valor inicial de $60 \mathrm{kV}$. Este fenómeno puede deberse a que a mayor valor de índice de acidez, mayor cantidad de compuestos polares y por lo tanto, mayor es la capacidad del aceite para disolver el agua en microsuspensión.

Se intentó cuantificar algún tipo de compuesto polar insoluble en el aceite que pudiera ser el causante de la disminución de RD a índices de acidez bajos. Para ello se filtró, en 
membrana de nitrocelulosa de $0,8 \mu \mathrm{m}$ de diámetro de poro, el aceite A que posee un IA de 3,04 $\mathrm{mg} \mathrm{KOH} / \mathrm{g}$ y se cuantificaron los insolubles por variación de pesos de las membranas.

El porcentaje de residuo sólido filtrado es $0,067 \%(\mathrm{~m} / \mathrm{m})$. A simple vista, no se observa ningún tipo de sólido que pueda ser extraído de la membrana para poder realizar un análisis cualitativo de dicho residuo sólido.

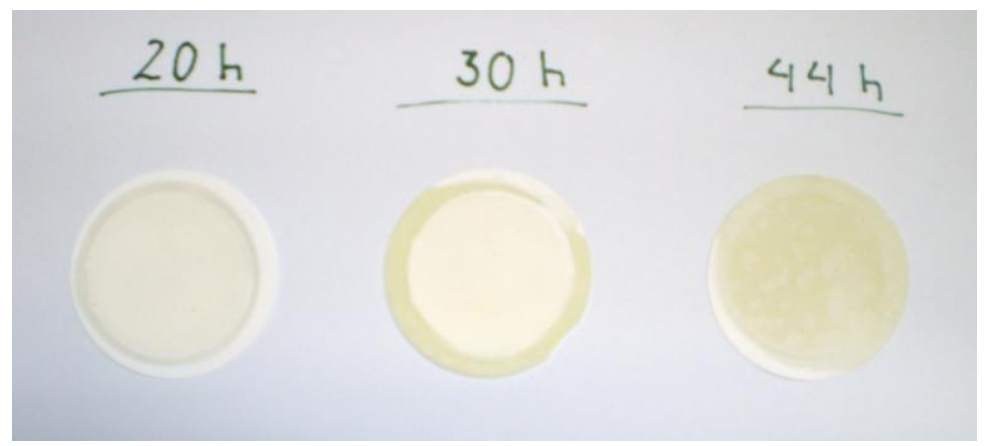

Figura 149: Estado de las membranas de nitrocelulosa

\section{d) Factor de pérdidas dieléctricas frente al tiempo}

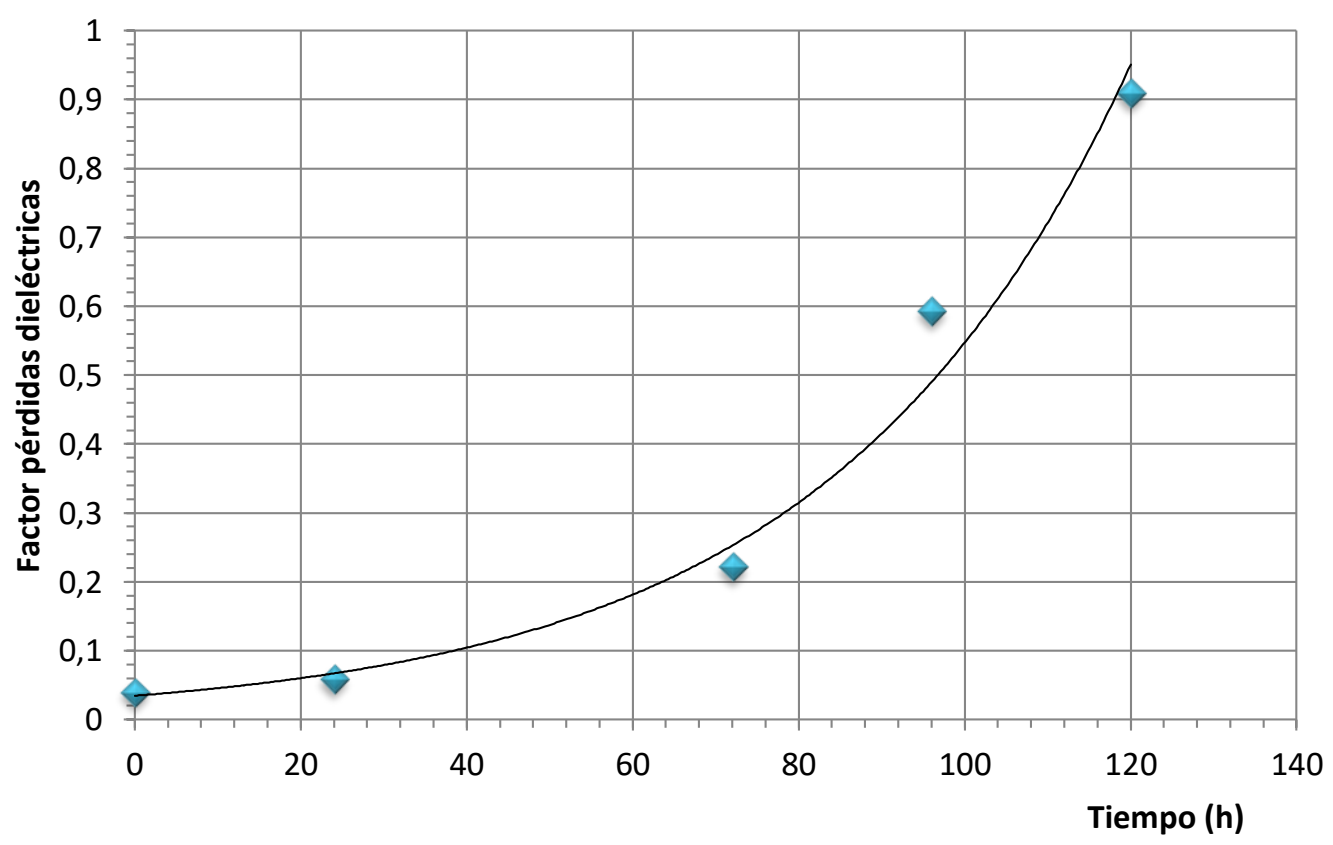

Figura 150: Variación de la tg delta frente a las horas de oxidación 
Tal y como se observa en la figura 150 , el factor de pérdidas dieléctricas a $90{ }^{\circ} \mathrm{C}$ crece exponencialmente con respecto el tiempo. Esto es debido a la formación de compuestos altamente polares en la matriz del aceite durante el proceso de oxidación.

e) Corrosión a la lámina de cobre

El ensayo de corrosión a la lámina de cobre del aceite A oxidado artificialmente se realizó durante 24 horas a $100{ }^{\circ} \mathrm{C}$ no obteniendo una corrosión significativa en ninguna de las láminas.

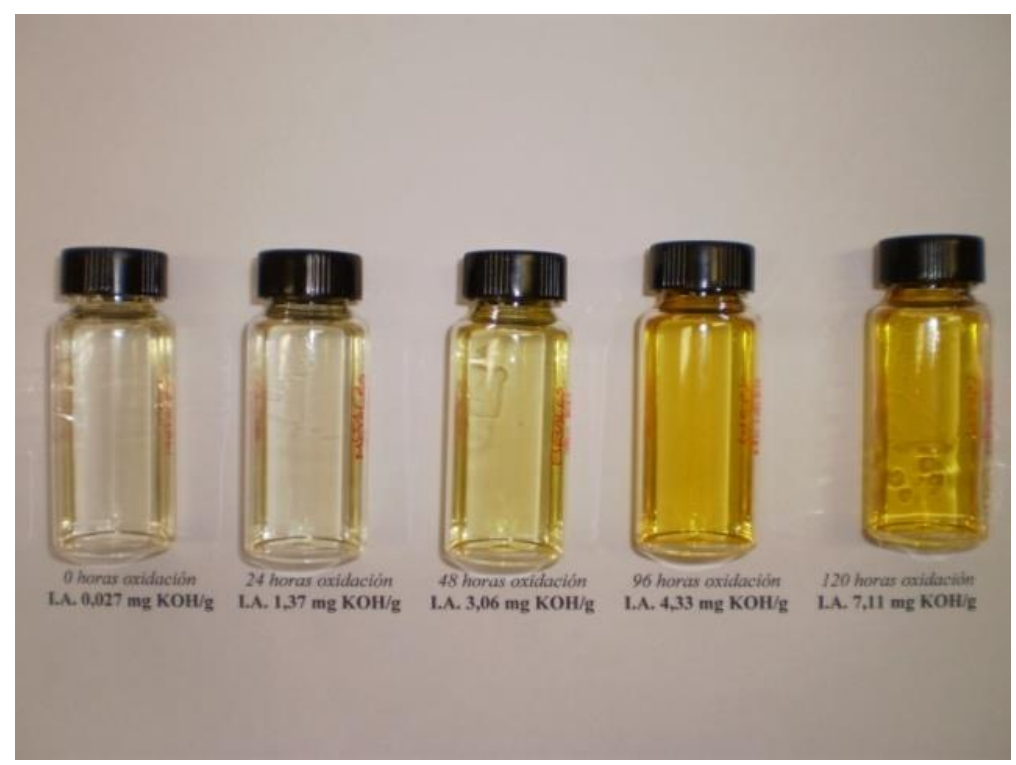

Figura 151: Color de los aceites oxidados. Se observa un oscurecimiento debido a la oxidación del aceite A continuación se muestra una tabla resumen con la escala de corrosión a la lámina de cobre para cada uno de los aceites estudiados, según ASTM D 130.

Tabla 44: Resultados de las probetas de cobre tras ensayo

\begin{tabular}{cc}
\hline Índice de acidez $(\mathbf{m g} \mathbf{K O H} / \mathbf{g})$ & Corrosión Cu según ASTM D 130 \\
\hline 0,03 & $1 \mathrm{a}$ \\
1,37 & $1 \mathrm{a}$ \\
3,06 & $1 \mathrm{a}$ \\
4,33 & $1 \mathrm{a}$ \\
7,11 & $1 \mathrm{a}$ \\
\hline
\end{tabular}




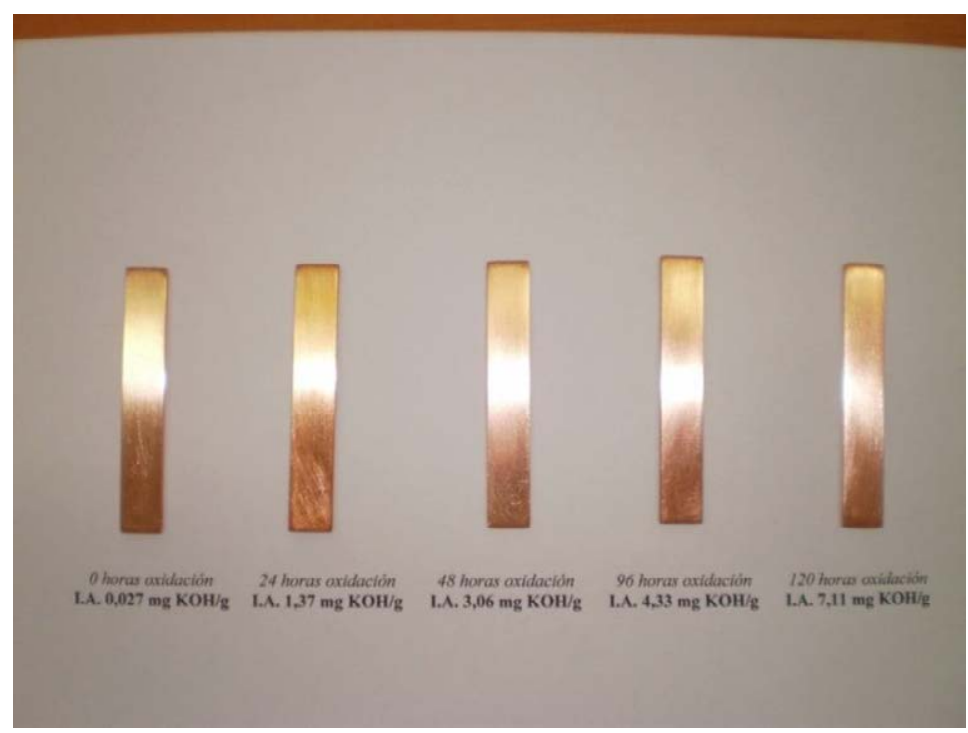

Figura 152: Estado de las probetas tras ensayo de corrosión

La explicación para este fenómeno sería que durante el proceso de oxidación no se han formado compuestos de azufre altamente reactivos con el cobre que dieran una corrosión elevada al metal.

\section{f) Concentración de cobre por ICP-OES}

Se analizaron las muestras del aceite A oxidadas a diferentes periodos de tiempo, después del ensayo de corrosión a la lámina de cobre, para que fuera determinada la concentración de iones $\mathrm{Cu}^{2+}$ disueltos en la matriz del aceite. Los resultados obtenidos por ICP-OES se muestran en la siguiente tabla:

Tabla 45: Valores de contenido en cobre después del ensayo de oxidación

\begin{tabular}{cc}
\hline Muestra & Concentración de Cu (ppm) \\
\hline 0 horas & $<0,1$ \\
24 horas & 0,96 \\
48 horas & 1,41 \\
96 horas & 2,50 \\
120 horas & 2,67 \\
24 horas post corrosión & 10,1 \\
48 horas post corrosión & 5,6 \\
96 horas post corrosión & 5,74 \\
120 horas post corrosión & 3,95 \\
\hline
\end{tabular}




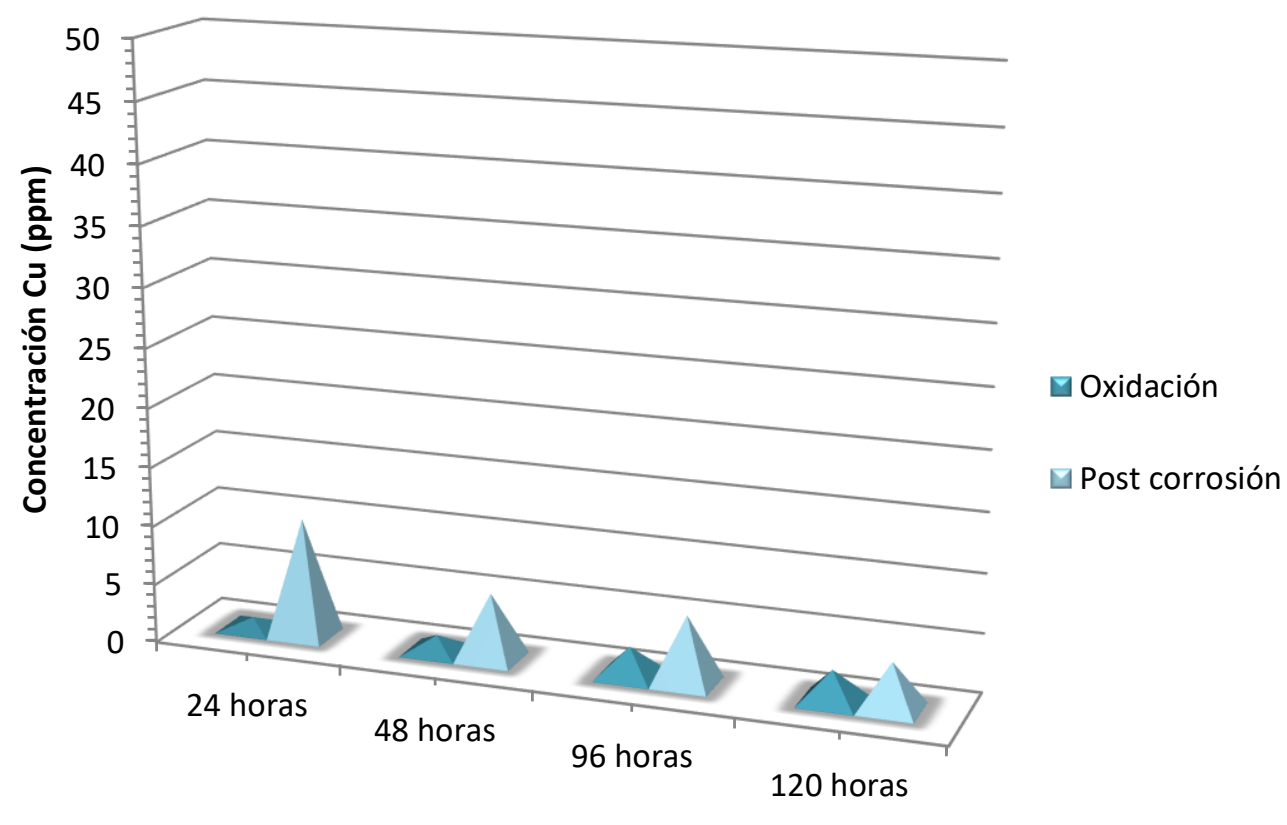

Tiempo

Figura 153: Valores de concentración de cobre, antes y después del ensayo de oxidación

En la figura 153 se puede observar un aumento de la concentración del cobre disuelto en la matriz del aceite A debido a la oxidación del catalizador de cobre usado en el ensayo. Por lo tanto, el aceite A reacciona con el catalizador disolviendo parte de este.

En cuanto a las muestras después del ensayo de corrosión a la lámina de cobre, se observa una disminución de la concentración de iones cobre (II) posiblemente debida a la formación de compuestos organometálicos. Cuanto más compuestos ácidos existan en el aceite, mayor será la capacidad de formación de organocupratos que precipitarán en el seno del aceite, retirando los iones $\mathrm{Cu}^{2+}$ del medio.

\section{g) Espectroscopía infrarrojo por Transformada de Fourier}

Se realizó el espectro infrarrojo a las cinco muestras de aceite A oxidado obteniendo un claro aumento de la absorbancia en las muestras oxidadas. 


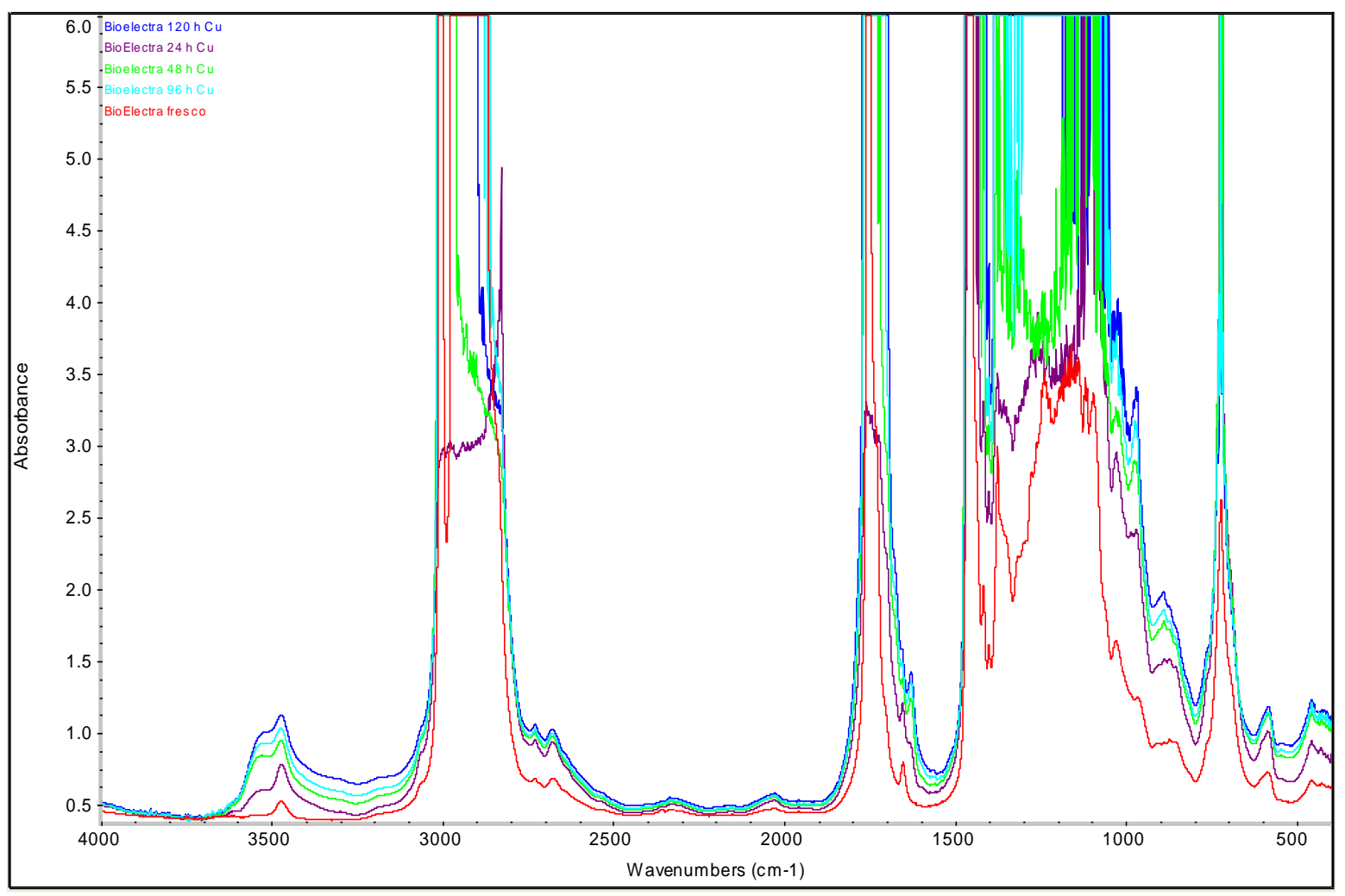

Figura 154: Espectros del aceite A oxidados

En soluciones muy diluidas o poco concentradas, la absorción causada por la tensión del enlace O-H, como la que se presenta en los dímeros, absorbe en la región de 2700-2500 $\mathrm{cm}^{-1}$. Esta banda de absorción constituye un diagnóstico para la presencia del grupo ácido carboxílico y se observa en el espectro FTIR del aceite A oxidado artificialmente.
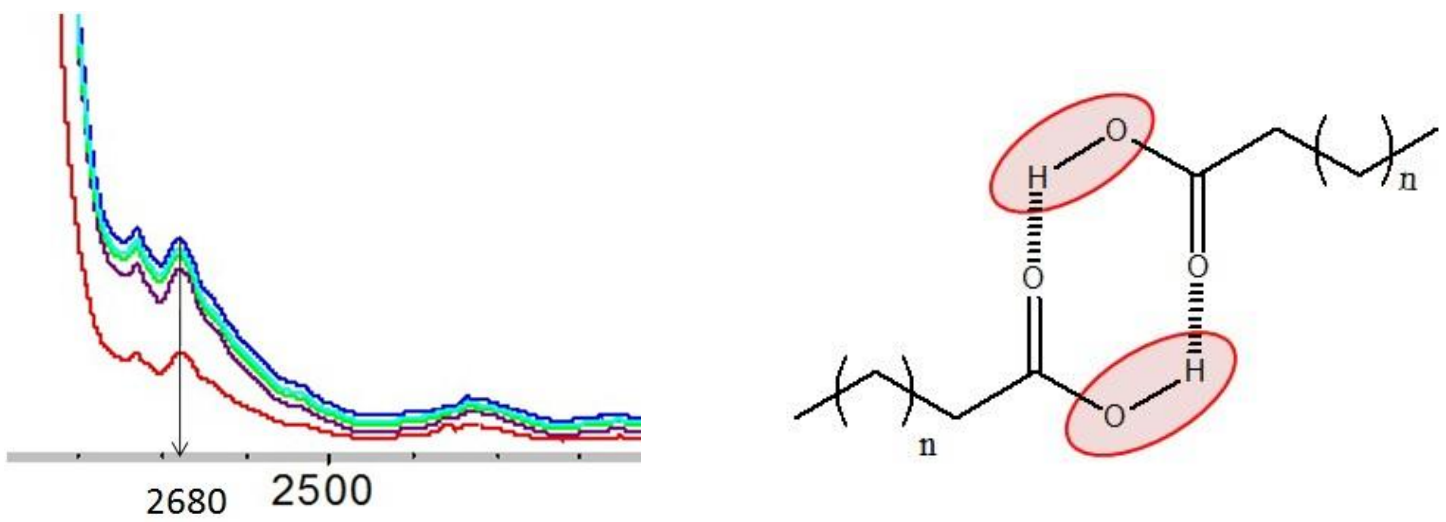

Figura 155: Detalle del espectro FTIR (imagen de la izquierda) y enlace caracterizado en el espectro FTIR (imagen derecha) 


\subsubsection{ENSAYOS DE OXIDACIÓN EN PELÍCULA FINA}

\subsubsection{Resultados}

Se introdujeron dentro de placas Petri (por duplicado) los cuatro aceites a evaluar (dos de origen vegetal y dos de origen mineral), quedando una película de $2 \mathrm{~mm}$ de espesor, tal y como se muestra en la figura 156.
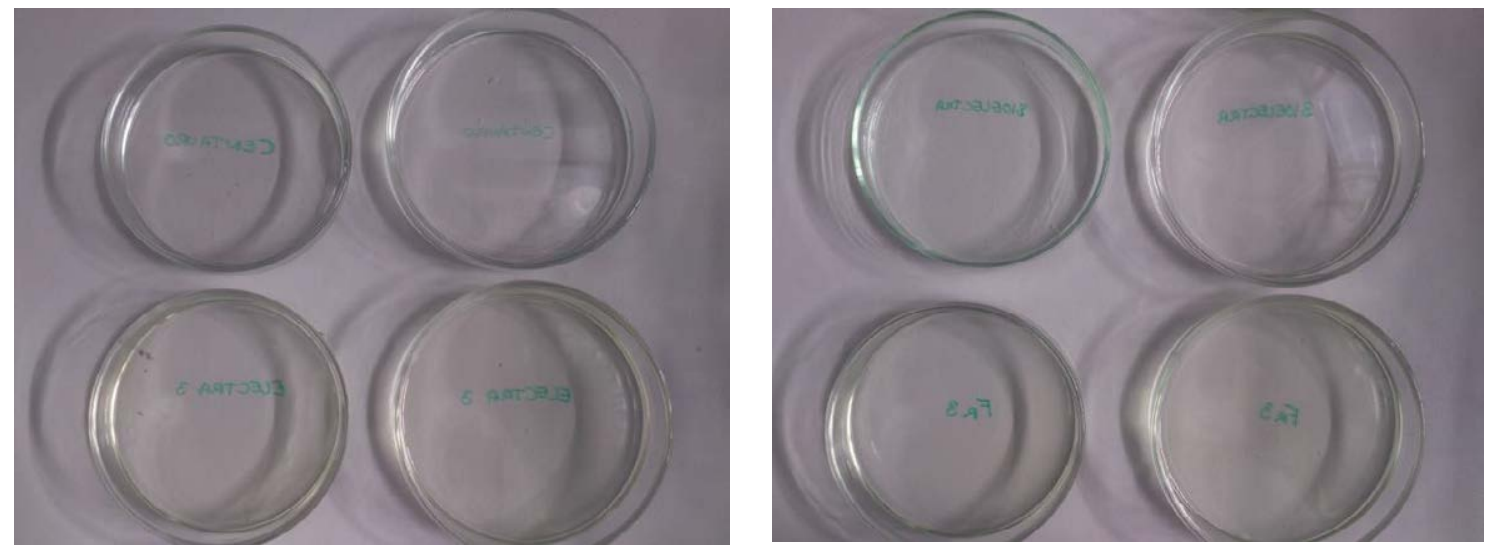

Fig. 156: Estado de los aceites en placas Petri antes del ensayo

Las placas fueron introducidas en la estufa de ventilación forzada a $120^{\circ} \mathrm{C}$ en atmósfera oxidante durante un periodo de tiempo de 168 horas. Después de este periodo, se extrajeron las muestras y se analizaron gravimétrica y visualmente.
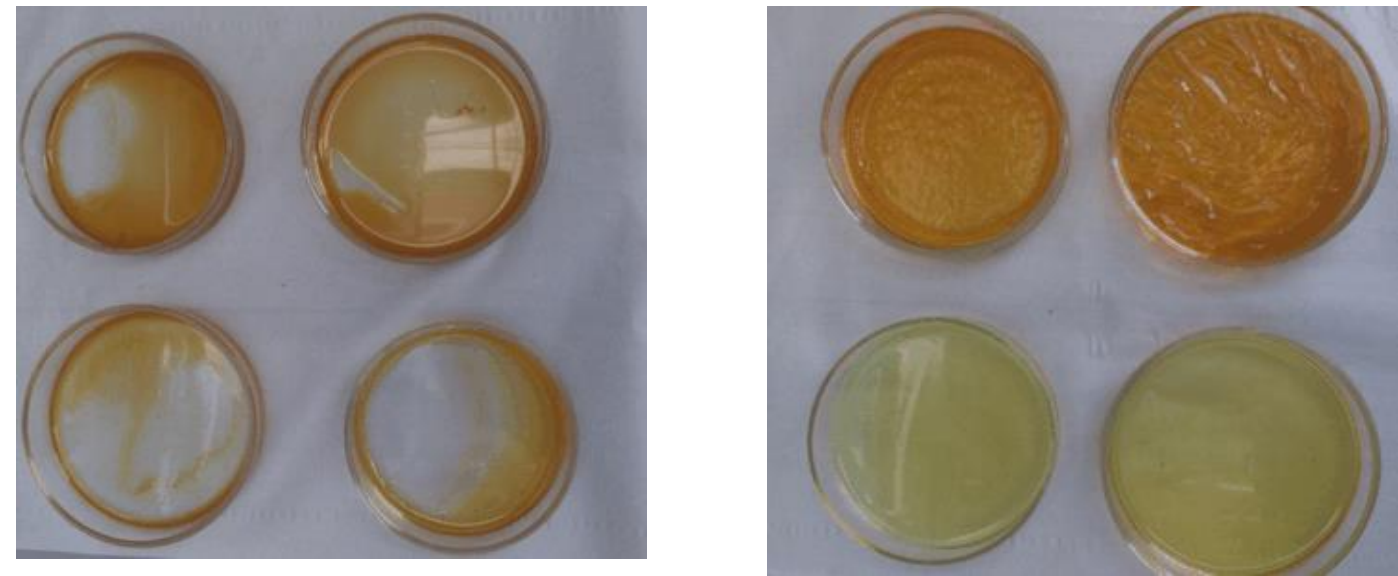

Fig. 157: Estado de los aceites después del ensayo de oxidación: a la izquierda los minerales y a la derecha los vegetales 
En el análisis gravimétrico de las muestras, se observan pérdidas por volatilidad en los aceites minerales, siendo dichas pérdidas las recogidas en la tabla 46.

Tabla 46: Porcentaje de pérdidas por volatilidad

\begin{tabular}{|l|c|c|c|c}
\cline { 2 - 5 } & $\begin{array}{c}\text { Aceite } \\
\text { vegetal A }\end{array}$ & $\begin{array}{c}\text { Aceite } \\
\text { vegetal B }\end{array}$ & $\begin{array}{c}\text { Aceite } \\
\text { mineral C }\end{array}$ & $\begin{array}{c}\text { Aceite } \\
\text { mineral D }\end{array}$ \\
\hline Pérdida de masa (\%) & 1,4 & 1,5 & 5,1 & 9,7 \\
\hline
\end{tabular}

Se observa una clara diferencia entre la tendencia de los aceites vegetales y los aceites minerales. El aceite mineral D es el aceite que más pérdidas por volatilidad a $120{ }^{\circ} \mathrm{C}$ presenta de los cuatro, con una diferencia considerable.

En cuanto al estado físico de las muestras, hay que destacar que las muestras de ambos aceites minerales y el aceite vegetal A se encuentran en estado líquido, con un aumento de su viscosidad con respecto a su viscosidad antes del ensayo. Sin embargo, el aceite vegetal $\mathrm{B}$ ha polimerizado por completo, haciendo imposible su manipulación para caracterizaciones posteriores. Por lo tanto, en caso es encontrarse dicho aceite en un transformador, la pequeña fracción de aceite que estuviera en contacto con el aire polimerizaría pasando a la cuba del transformador y como consecuencia, una disminución de las propiedades dieléctricas y refrigerantes del fluido aislante, ya que dichos polímeros se pueden depositar sobre devanados u obstruyendo la libre circulación de aceite por las diferentes partes del transformador.

\subsubsection{TRIÁNGULO DE DUVAL PARA EL ACEITE A}

\subsubsection{Desarrollo del punto caliente y el análisis de los gases disueltos por micro cromatografía gaseosa}

Como se ha citado en capítulo 2 de la presente tesis, uno de los puntos críticos dentro de un transformador son la generación de puntos calientes o hot spots debido a fallos en la refrigeración de las diferentes partes por las que está formado un transformador.

Existen actualmente potentes herramientas de diagnosis de fallos eléctricos y térmicos dentro de un transformador, como es el triángulo de Duval. Dicha herramienta es útil 
siempre y cuando se compruebe experimentalmente los límites de las áreas que clasifican dichos errores (ver capítulo 2) ya que dichos límites pueden variar de un aceite a otro.

Para comprobar los límites de las áreas que indican fallos térmicos del tipo T1, T2 y T3, se generaron puntos calientes con la planta piloto desarrollada para esta tesis y posteriormente se analizaron por micro cromatografía gaseosa, previa extracción de gases disueltos mediante la técnica Shake Test, los gases originados por el punto caliente generado por el hilo de Kanthal. En la figura 158 se indica un resumen del proceso:

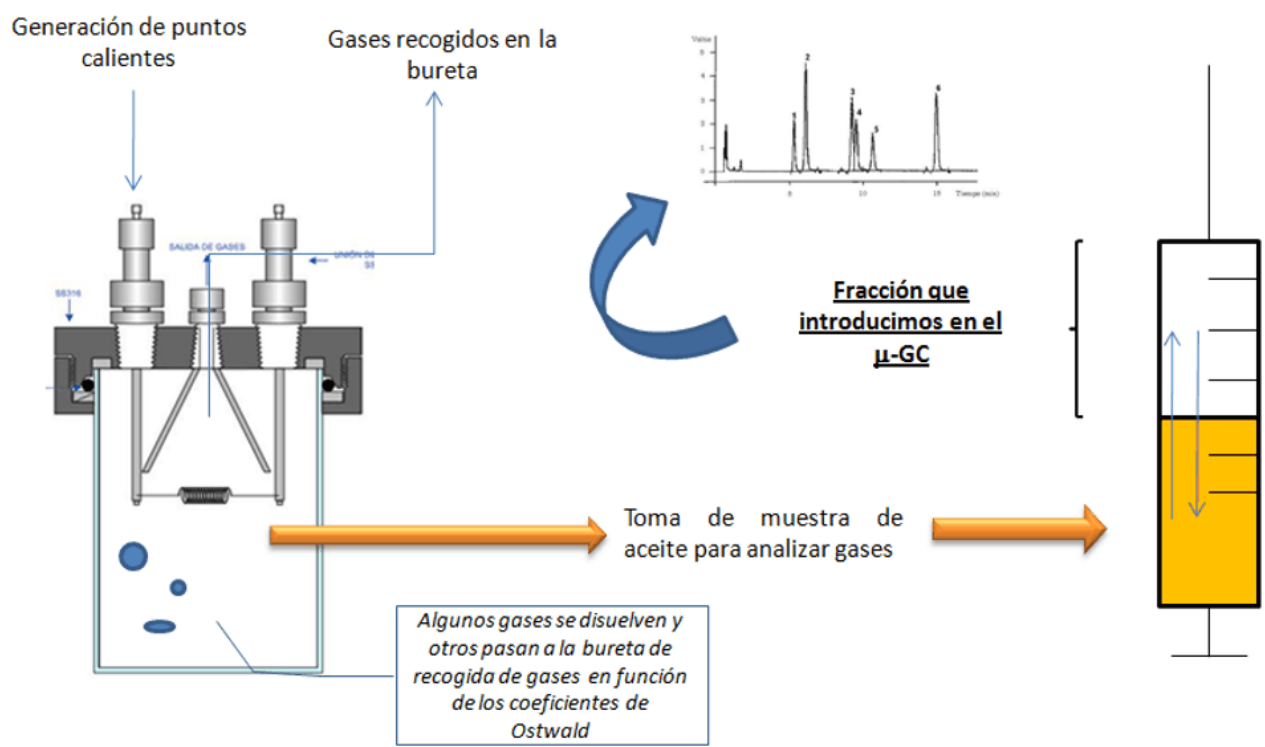

Fig. 158: Esquema proceso de generación puntos calientes y posterior análisis

Como se indica en el esquema anterior, una vez generado el punto caliente, se tomó una alícuota de $100 \mathrm{~mL}$ de aceite con una jeringa especial para análisis de gases disueltos. Posteriormente, se generó un head space de helio en el interior de la jeringa con un sistema automatizado para evitar errores de dilución y mediante un agitador se extrajeron los gases disueltos al head space. Esta fracción gaseosa es la que posteriormente se introdujo en el micro cromatógrafo de gases. 
Los resultados generados por el equipo son las concentraciones de gases en la fracción helio. Posteriormente, seleccionamos la naturaleza del aceite en el software del equipo para que automáticamente, y después de aplicar los correspondientes coeficientes de Ostwald, nos genere la concentración de gases disueltos en el aceite.

\subsubsection{Triángulo de Duval para el aceite A: comprobación de las áreas específicas para fallos térmicos.}

Con el objetivo de llevar a cabo un exhaustivo análisis de las diferentes regiones por fallos térmicos del triángulo de Duval para el aceite $\mathrm{A}$, se llevaron a cabo más de 60 ensayos de generación de puntos calientes (aproximadamente 20 para fallos térmicos $\mathrm{T} 1$, otros 20 para fallos térmicos T2 y finalmente, otros 20 para fallos térmicos T3). El posterior análisis de los gases disueltos y la transformación de dichos valores (de ppm a \%) usando las ecuaciones 28, 29 y 30 generó el siguiente triángulo de Duval:

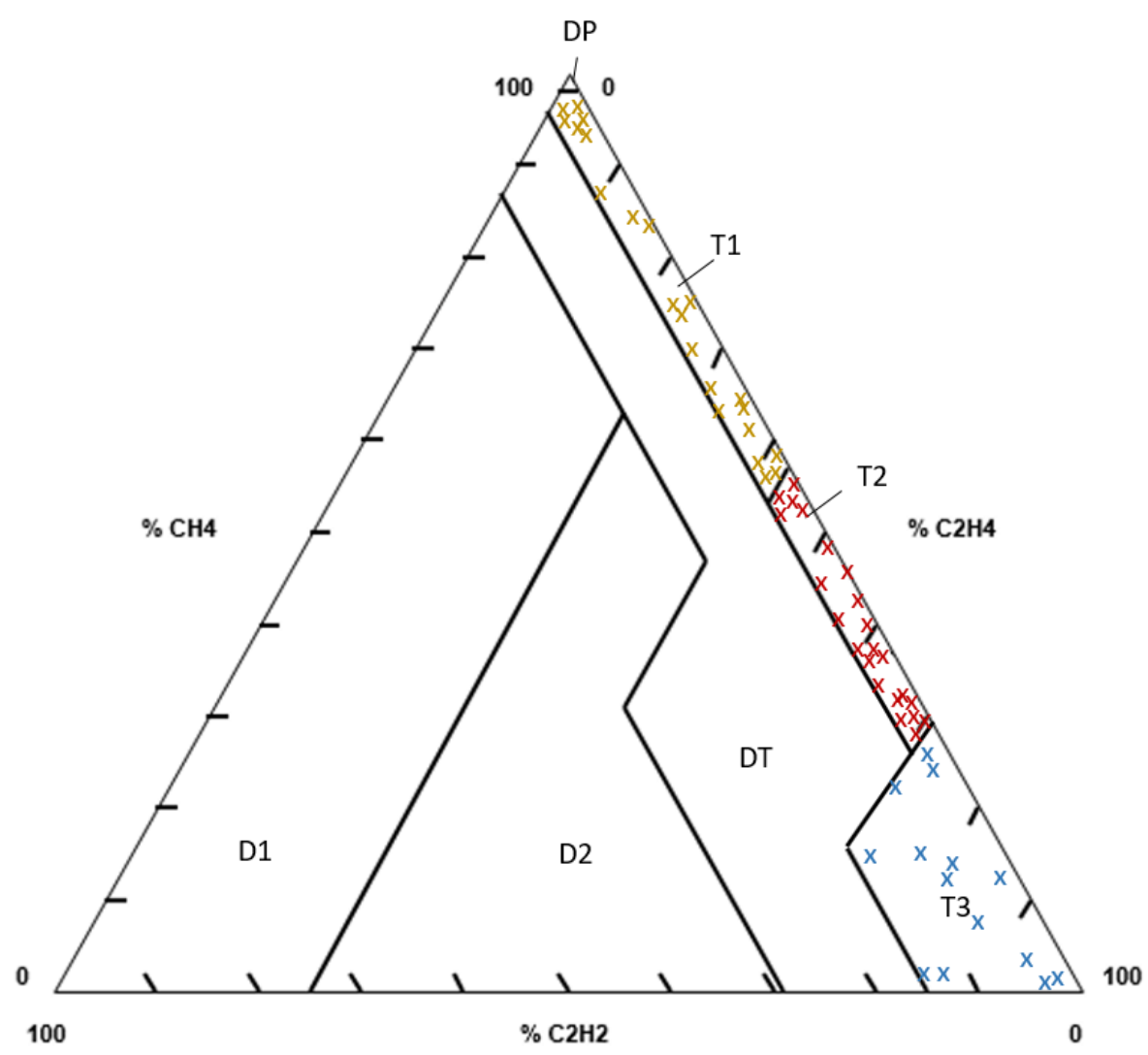

Fig. 159: Representación de DGA generados por fallos térmicos para el Aceite A 
A modo de ejemplo, se muestran a continuación los resultados obtenidos para un fallo térmico de $120^{\circ} \mathrm{C}$. El contenido de gases disueltos, en ppm, es:

Tabla 47: Resultados por micro GC de DGA en un fallo de $120^{\circ} \mathrm{C}$

\begin{tabular}{|l|c|c|c|c|c|c|c|}
\hline Gas & Hidrógeno & $\begin{array}{c}\text { Monóxido de } \\
\text { carbono }\end{array}$ & $\begin{array}{c}\text { Dióxido de } \\
\text { carbono }\end{array}$ & Metano & Etano & Etileno & Acetileno \\
\hline$[\mathrm{ppm}]$ & 17 & 600 & 2377 & 5 & 11 & 3 & 0 \\
\hline
\end{tabular}

Aplicando las ecuaciones 28,29 y 30, obtenemos los siguientes porcentajes:

Tabla 48: Resultados por micro GC de DGA en un fallo de $120^{\circ} \mathrm{C}$

\begin{tabular}{|c|c|c|c|}
\hline Gas & $\mathrm{CH}_{4}$ & $\mathrm{C}_{2} \mathrm{H}_{4}$ & $\mathrm{C}_{2} \mathrm{H}_{4}$ \\
\hline$\%$ & 85 & 25 & 0 \\
\hline
\end{tabular}

Trazando las correspondiente líneas (ver capítulo 2), obtenemos que el diagnostico según el triángulo de Duval es un fallo térmico tipo T1 $\left(\mathrm{t}<300{ }^{\circ} \mathrm{C}\right)$.

La generación de puntos calientes, en el laboratorio, del tipo T1, T2 y T3 ha dado lugar a nuevas zonas o áreas en el interior del triángulo. Los límites entre dichas zonas, para fallos térmicos en el aceite A, se muestran en la tabla 49:

Tabla 49: Nuevos límites para las zonas de fallos térmicos

\begin{tabular}{cc}
\hline Límite entre & Valor \\
\hline $\mathrm{T} 2 / \mathrm{T} 3$ & 71 \\
$\mathrm{DT} / \mathrm{T} 3$ & 15 \\
$\mathrm{DT} / \mathrm{T} 2$ & 4 \\
$\mathrm{~T} 1 / \mathrm{T} 2$ & 20 \\
\hline
\end{tabular}




\subsubsection{Ensayos realizados con equipo INSOIL para la generación de fallos eléctricos}

Se utilizó paralelamente una planta piloto de generación de descargas eléctricas (equipo INSOIL) el cual no podemos mostrar en este documento por motivos de confidencialidad. Se llevaron a cabo ensayos de descargas eléctricas de bajo voltaje y alto voltaje. Se llevaron a cabo 10 experiencias con descargas tipo corona (alto contenido en $\mathrm{H}_{2}$ ) y descargas aplicando un medio/alto voltaje. Los resultados se muestras a continuación:

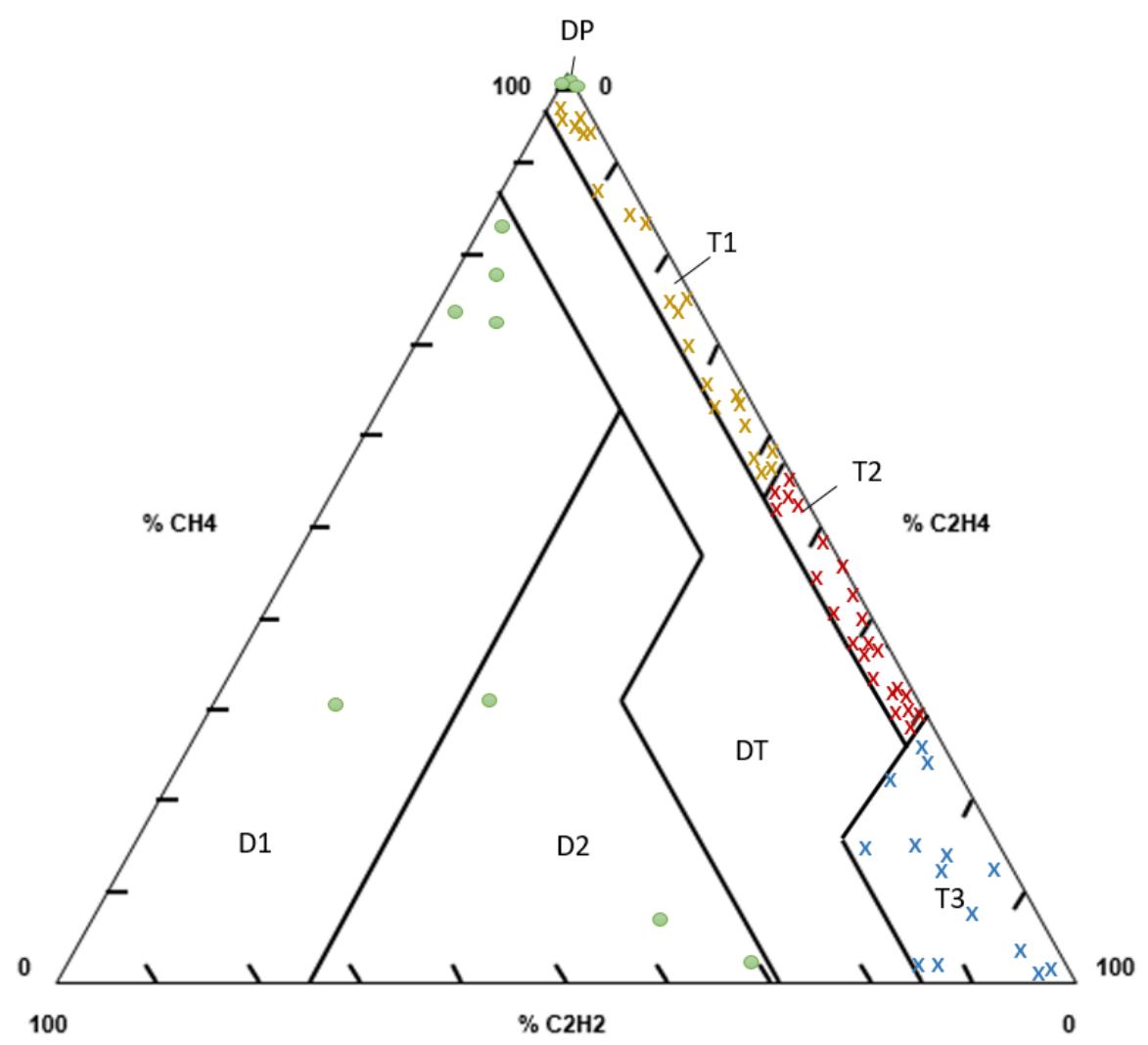

Fig. 160: Representación de DGA generados por fallos térmicos y eléctricos para el Aceite A

Los valores obtenidos de gases disueltos por generación de descargas eléctricas no afectan, según los ensayos llevados a cabo durante la ejecución de la presente tesis, a los límites del triángulo de Duval para fallos D1, D2 y DT (zona o interfase donde pueden coexistir fallos térmicos y eléctricos simultáneamente). 


\subsection{ESTUDIOS DE COMPATIBILIDAD QUÍMICA}

\subsubsection{COMPATIBILIDAD DE ACEITES CON AISLANTES CELULÓSICOS}

\subsubsection{Grado de polimerización medio viscosimétrico}

Se define como grado de polimerización ( $D P$, de sus siglas en inglés) en el polímero de celulosa al número de unidades monoméricas de $\beta$-glucosa. Muy frecuentemente este grado de polimerización es medido por el método viscosimétrico indicado en la norma ASTM D4243 “Standard Test Method for Measurement of Average Viscometric Degree of Polymerization of New and Aged Electrcial Papers and Boards". El valor de DP está críticamente relacionado con la rigidez mecánica del papel.

Durante la fabricación del papel, el DP se encuentra entre 1000 y 1300 aproximadamente. El secado del transformador lo reduce a 950 - 1000 y el envejecimiento en servicio lo reduce todavía más.

Para un DP comprendido entre 950 y 500, la rigidez mecánica (TS) del papel es aproximadamente constante. Pero en el margen de 500 a 200, el valor de TS decrece en proporción directa a su DP. Así por ejemplo, para un valor de DP aproximadamente de 150 , la TS se reduce un $20 \%$ de su valor original y por debajo de esta cifra, el papel no tiene rigidez mecánica alguna.

En la industria, se considera que por debajo de un DP igual a 200, el papel ha perdido sus propiedades mecánicas y el equipo es susceptible a daños.

Por esta misma razón, es de gran importancia estudiar este fenómeno en aceites dieléctricos de nueva generación.

La determinación de DP del cartón prensado que ha estado inmerso en los diferentes aceites, fue determinado según normativa anteriormente citada.

Los resultados obtenidos se muestran en la figura 161, donde se puede observar una caída inmediata del DP con el tiempo de envejecimiento del papel: 


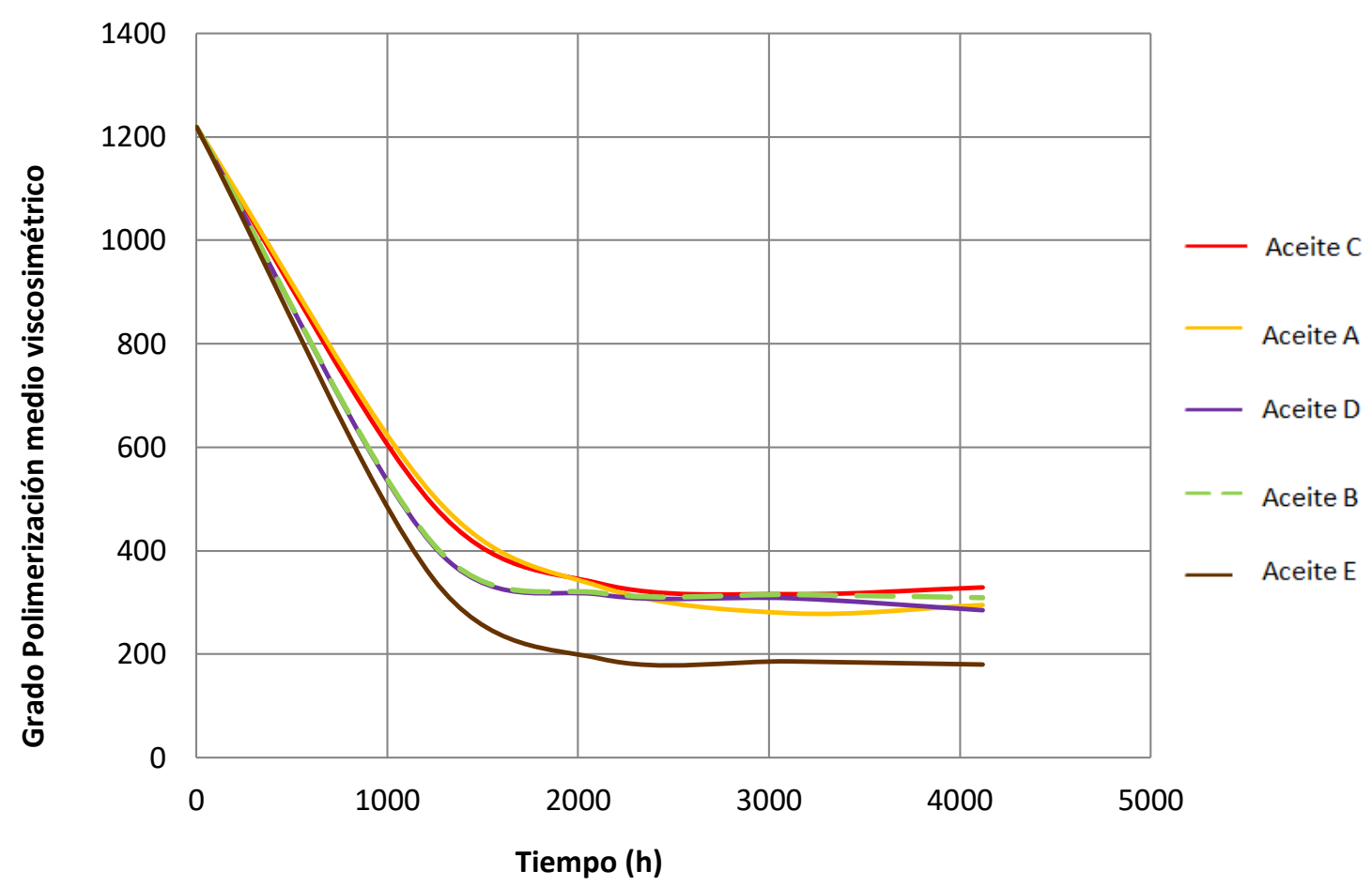

Fig. 161: Representación de DP frente a las horas de degradación térmica del aceite

Como se observa en el gráfico, el comportamiento del material celulósico degradado en los cuatro aceites de origen vegetal es similar, siendo más bajo el $\overline{D P}_{v}$ del cartón sumergido en aceite mineral (aceite E). En ningún caso, el $\overline{D P}_{v}$ en aceite vegetales baja de los 200 .

\subsubsection{Humedad del material celulósico}

Las posibles fuentes de humedad en un transformador son dos: una de origen externo, tal y como es la humedad atmosférica y de origen interno. La humedad de origen interno se debe principalmente a dos causas:

- A la posible humedad que ha quedado retenida dentro del transformador durante la fabricación de este.

- Al proceso de degradación y envejecimiento del material celulósico. 
En nuestro caso en particular, determinamos la humedad en el cartón prensado degradado térmicamente. Seguiremos el procedimiento descrito en la norma UNE EN 60814:99 "Determinación del contenido en humedad por Karl-Fischer". Para determinar la humedad en el cartón, se partió de la muestra completamente desfibrada y triturada. Se introdujeron las muestras en viales de cristal cerrados con septum. Se le pasó una corriente de nitrógeno y a continuación se introdujo un disolvente que sirvió para extraer el agua a la muestra. Luego dicho disolvente, con el agua disuelta, pasó por un tubo directo al recipiente de valoración KF. Así nos aseguramos que no existió contaminación cruzada por parte de la humedad atmosférica en la muestra.

Los resultados de la muestras se exponen a continuación en la figura 162.

Humedad vs. Tiempo

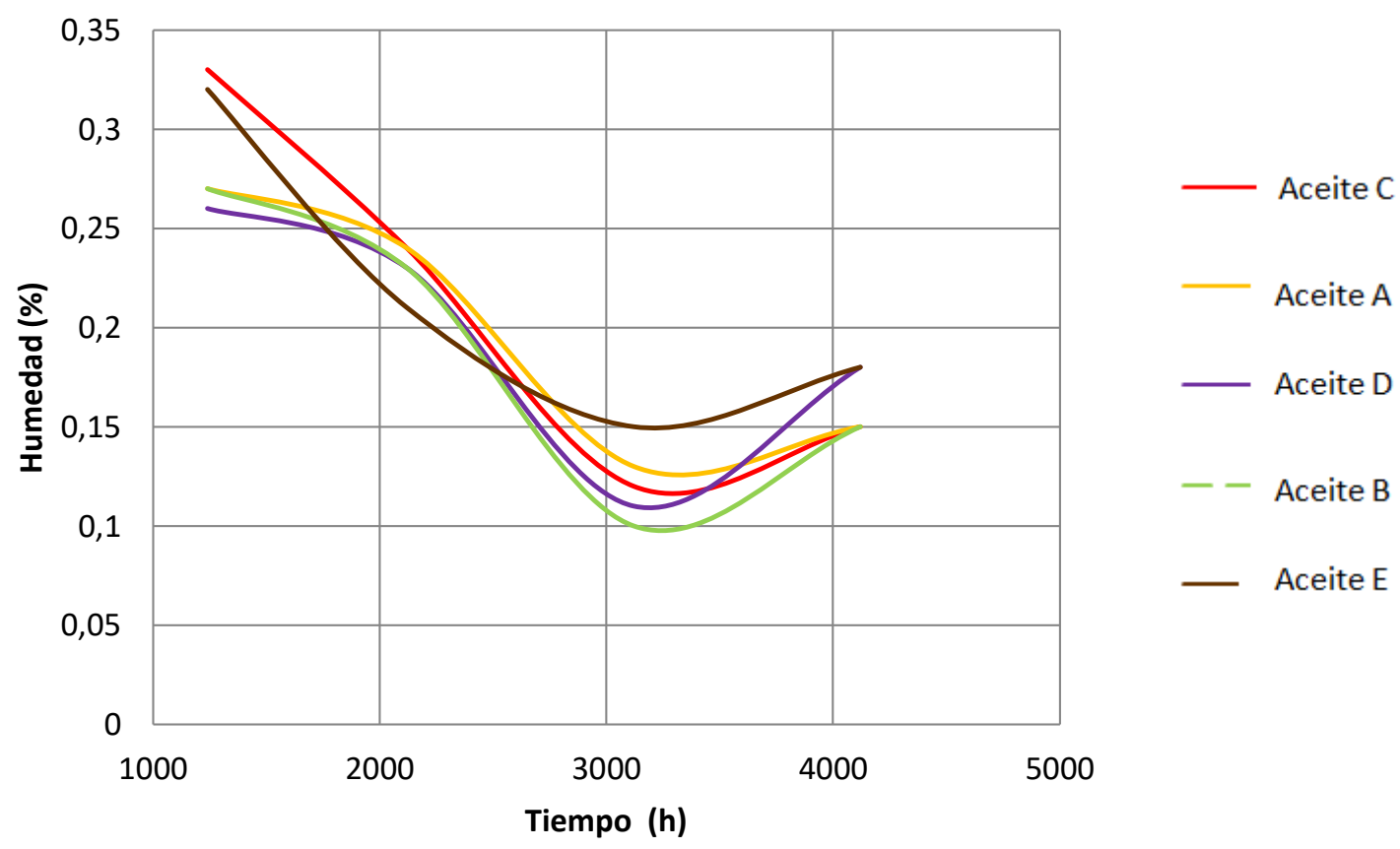

Fig. 162: Representación de la humedad del cartón frente a las horas degradadas

La presencia de humedad dentro de la cuba del transformador puede presentar riesgo a corto plazo ya que la humedad puede dar lugar a formación de burbujas por cambio térmico pudiendo producir descargas parciales, puenteo del aislamiento o incluso "contorneo" del aislante. 


\subsubsection{3. Índice de acidez del aceite}

Una de las vías de degradación del aceite es la vía térmica, es decir, temperaturas de trabajo elevadas durante un largo periodo de tiempo provocan la formación de grupos polares de carácter ácido, incluso, en condiciones muy severas llegan a formarse barros en la matriz orgánica del aceite.

El índice de acidez posee una notable importancia como dato característico del aceite, ya que los productos ácidos afectan a las propiedades dieléctricas del aceite disminuyéndolas. Por otro lado, son agentes que atacan a los materiales del transformador, disolviéndolos y acelerando así su efecto catalizador sobre el envejecimiento del aceite.

Para controlar las variaciones de acidez que presenta un aceite bajo condiciones de degradación térmica, determinamos el índice de acidez según normativa ASTM D 974. Según dicha normativa, la cantidad de muestra varía en función de la acidez esperada.

$$
\text { Aceites usadosu oscuros }\left\{\begin{array}{rr}
\text { IA entre } 0 \text { y } 25 \mathrm{mg} / \mathrm{KOH} \mathrm{g} & 2,0 \pm 0,2 \mathrm{~g} \\
\text { IA entre } 25 \text { y } 250 \mathrm{mg} / \mathrm{KOH} \mathrm{g} & 0,2 \pm 0,02 \mathrm{~g}
\end{array}\right.
$$

En la figura 163, se representa el valor del índice de acidez frente al tiempo que se ha estado degradando el aceite. En esta, se puede observar el comportamiento similar para ambos aceites formulados: el aceite A y el aceite B. Es de notable importancia resaltar la diferencia de acidez que presentan los cuatro aceites de origen vegetal frente al aceite mineral $\mathrm{E}$, que prácticamente se mantiene constante.

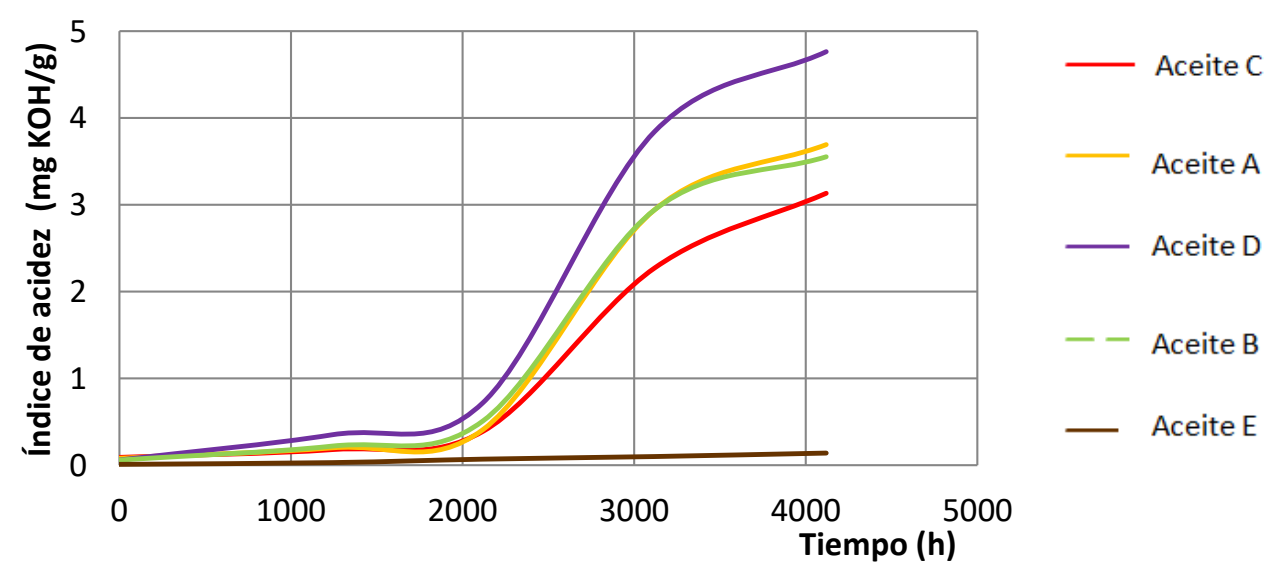

Fig. 163: Representación de la acidez del aceite frente a las horas degradadas 


\subsubsection{Contenido en agua del aceite por Karl- Fischer}

La presencia de agua en el aceite de un transformador es un factor muy importante en el proceso de degradación y por lo tanto, las muestras de aceite y el material aislante celulósico son previamente desecados a vacío en condiciones muy severas en todos los experimentos, tal y como se ha mencionado anteriormente en el capítulo 2 Equipos y métodos de ensayo, salvo en aquellos casos en los que se pretende precisamente estudiar el efecto del contenido en humedad.

Para la realización de esta tesis, se determinó la concentración de agua en el aceite degradado mediante valoración columbimétrica Karl-Fischer. Se realizaron 4 determinaciones para cada uno de los aceites a un tiempo determinado, aunque solo se exponen el valor medio de los cuatro valores obtenidos (ver figura 164).

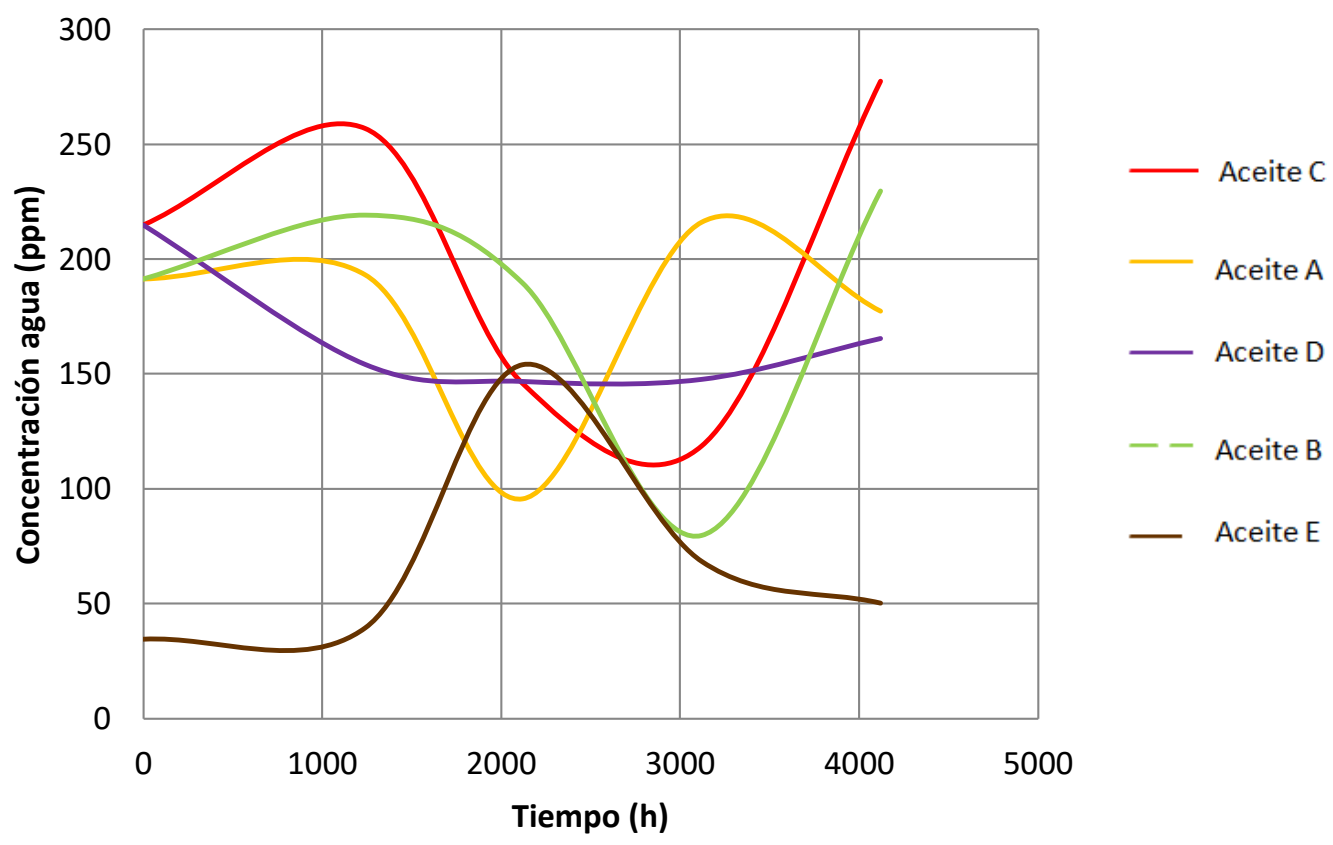

Fig. 164: Representación del contenido en agua en aceite frente al tiempo de degradación

Al contrario de lo esperado, no se ha encontrado una mayor concentración de agua en el aceite a medida que el proceso de envejecimiento transcurre. Esta situación es la misma que la encontrada por otros autores. Una posible explicación a los resultados obtenidos 
podría ser la indicada en el artículo de Saha [53] donde se atribuye la migración de humedad al equilibrio trifásico entre papel/aceite/aire en el sistema experimental, tal y como se indica a continuación.

En un sistema cerrado, el contenido en humedad de los tres medios tiende siempre hacia una posición de equilibrio. Es decir, las moléculas de agua tenderán a fluir desde el medio que tenga las concentraciones más altas de humedad hacia el medio que tenga las concentraciones más bajas. Al principio del ensayo y debido a la naturaleza del aceite y del aire dentro del reactor, el contenido en agua en estos dos medios es inferior al contenido en agua para la fase papel. Por lo tanto, siempre habrá una migración de humedad del papel hacia el aire y el aceite.

Debido a la elevada temperatura a la que se llevó a cabo el ensayo, la presión de vapor del agua fue elevada y como consecuencia se produjo una redistribución de las moléculas de agua en las tres fases con el objetivo de alcanzar el equilibrio químico y termodinámico en el sistema.

La tendencia natural sería que las moléculas de agua en fase vapor del cartón migraran hacia la fase aceite a medida que este se va envejeciendo, debido a la formación de productos de carácter altamente polar. Posteriormente y con el paso del tiempo, las moléculas de agua pasarían a la fase aire. Pero esta migración también se verá afectada por el gradiente de concentración relativa de humedad entre el papel, el aceite y el aire.

Por lo tanto, el efecto de la migración de humedad desde el papel hacia el aceite puede hacer disminuir las reacciones de hidrólisis en el papel y como consecuencia, se puede obtener valores de DP superiores a los esperados con respecto a los periodos de envejecimiento establecidos.

\subsubsection{Tangente del ángulo de pérdidas dieléctricas}

El valor cuantitativo de la tangente del ángulo de pérdidas dieléctricas o tg $\delta$ para un aceite dado, aumenta con la temperatura y también con la degradación o envejecimiento del aceite. 
Dado que el aceite puede fallar como dieléctrico por inestabilidad térmica cuando las pérdidas dieléctricas son elevadas, es importante ver la evolución de dicho parámetro con respecto al proceso de degradación térmica.

La tangente del ángulo de pérdidas puede verse fuertemente afectada por trazas de contaminantes disueltos o partículas coloidales. Los ésteres son más sensibles a la contaminación que los hidrocarburos debido a su mayor polaridad, lo que resulta a cambio un mayor poder disolvente y capacidad de disolución. Por tanto éstos requieren comparativamente un mayor cuidado en su manipulación que los hidrocarburos de origen mineral.

La representación gráfica de la tg $\delta$ frente al tiempo se muestra en la figura siguiente:

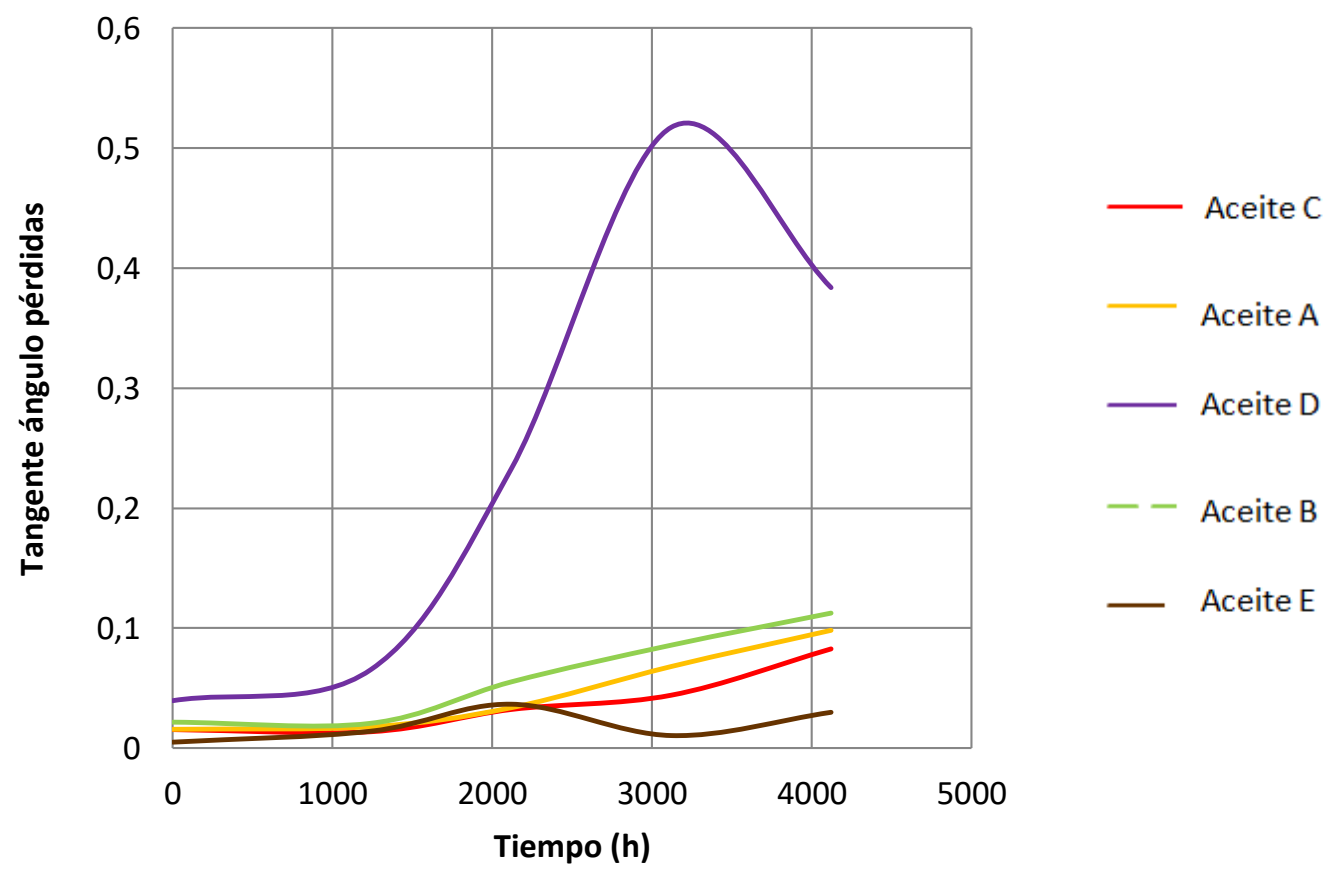

Fig. 165: Representación del valor de la tg delta frente al tiempo de degradación

En cuanto al comportamiento del aceite $\mathrm{D}$ frente al aceite $\mathrm{C}$ (ambos sin aditivar) se observa que la tangente del ángulo de pérdidas es mucho más baja para el C que para el D. Esto puede ser debido a una contaminación externa en la muestra de aceite D. El comportamiento del resto de aceite es similar. 


\subsubsection{2-Furfural $y$ familia de furanos}

Cuando se degrada el papel aislante ubicado en el interior del transformador, el valor del grado de polimerización disminuye y como consecuencia de estas rupturas de enlace, se producen monóxido de carbono, dióxido de carbono y furanos, entre otros compuestos.

Al presentarse una sobretemperatura en el devanado del transformador, ya sea por una sobrecarga o por la presencia de fallas recientes, se han encontrado cantidades considerables de compuestos furánicos disueltos en el aceite. Las temperaturas a las cuales ocurre la degradación de la celulosa y la presencia de niveles anormalmente altos de oxígeno y humedad, determinan que compuestos son formados, tomando en consideración que el mecanismo de hidrólisis oxidativa es la fuente más importante del furano tipo 2-furfural (2-FAL) en transformadores en operación.

Aun así, la degradación de materiales celulósicos conduce a la formación, además, de 5hidroximetil-2-furfural, 2-furfurilalcohol, 2-acetilfurano y 5-metil-2-furfural.

Dichos compuestos se determinan por cromatografía líquida de alta resolución (HPLC), según norma UNE EN 61198, previa extracción con acetonitrilo (Método A) o con cartuchos de gel de sílice (Método B). Con el método A, aparte de extraerse los cinco compuestos, se extraen muchos más compuestos saponificables del aceite vegetal, por lo que se opta por el método B. Como detector se usa un detector UV de diodos (DAD) que permite obtener cromatogramas simultáneos para diferentes longitudes de onda (220 nm para detectar el 2 FOL y $276 \mathrm{~nm}$ para detectar el resto de analitos). El tipo de columna es una $\mathrm{C}_{18}$ de fase inversa con tamaño de partícula de $5 \mu \mathrm{m}$ y $150 \mathrm{~mm}$ (es más pequeña que la de la norma, pero el número de platos teóricos es similar). Los eluyentes que se usan son agua y metanol calidad HPLC. 
Los resultados obtenidos se muestran en la siguiente tabla:

Tabla 50: Concentración de 2-furfural en aceites degradados térmicamente

\begin{tabular}{|c|c|c|c|c|c|}
\hline \multicolumn{7}{|c|}{ Concentración de 2-furfural (ppm) } \\
\hline Tiempo (h) & Aceite C & Aceite A & Aceite D & Aceite B & Aceite E \\
\hline 0 & 0 & 0 & 0 & 0 & 0 \\
\hline 1240 & 0,2 & 0,1 & 0,2 & 0,6 & 8,8 \\
\hline 2120 & 0,5 & 0,6 & 0,4 & 0,7 & 38,6 \\
\hline 3120 & 1,5 & 1,8 & 1,0 & 1 & 41,2 \\
\hline 4120 & 2 & 1,9 & 0,9 & 1,2 & 46,9 \\
\hline
\end{tabular}

La variación de la concentración de 2-furfural con el tiempo viene representada en la figura 166 que se expone a continuación, pero la concentración de 2-FAL en el aceite mineral se ha omitido debido a que, al ser tan elevada, no se apreciaba con claridad las variaciones de 2-FAL en los otros aceites.

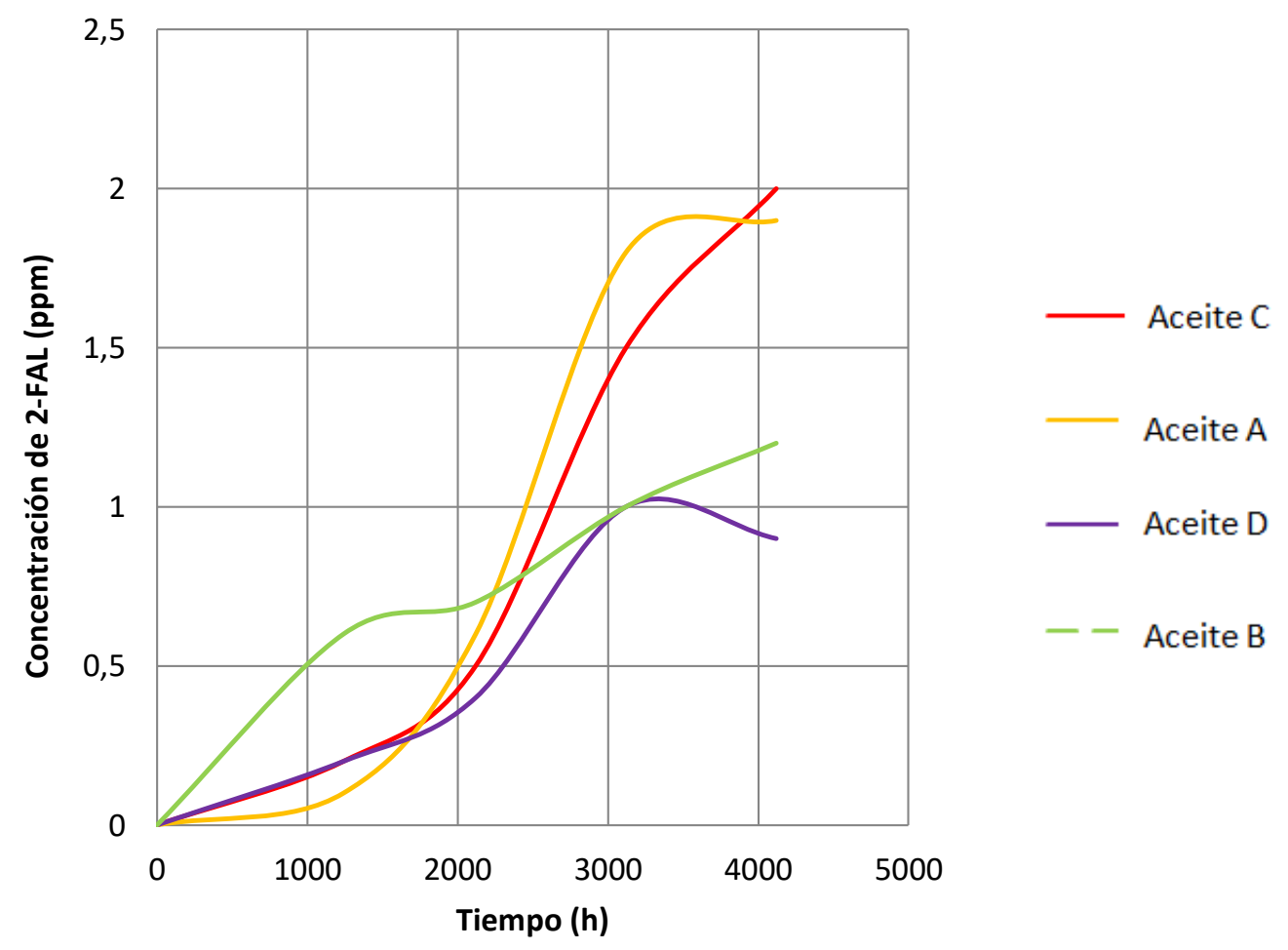

Fig. 166: Representación del contenido en 2-furfural frente al tiempo de degradación 
Se observa, en los valores obtenidos, un contenido en 2-furfural elevado en el aceite mineral con respecto a los valores encontrado de dicho analito en los aceites vegetales. Estos valores están en concordancia con los obtenidos en el DP el papel celulósico.

\subsubsection{Espectroscopía FT-IR}

Uno de los parámetros que nos puede aportar información acerca de los cambios que se producen en la matriz del aceite dieléctrico de origen vegetal en el ensayo de degradación térmica es el valor del PAI (Peak Area Increase) de la banda de vibración del enlace $\mathrm{C}=\mathrm{O}$ (primer sobretono) de los ésteres.

El incremento del área del pico del carbonilo se mide entre 1800 y $1670 \mathrm{~cm}^{-1}$. Realizando esta operación, observamos que las bandas de absorción se van fuera de escala. Se procedió a realizar diluciones 1:10 en n-heptano para poder observar el incremento de dicho picos. El problema con el que nos encontramos es que las variaciones del PAI son tan pequeñas con respecto a la intensidad de la banda, que una dilución de la muestra no permite cuantificar esos incrementos. Por eso se pensó en otra alternativa.

Debido a que el enlace $\mathrm{C}=\mathrm{O}$ se comporta como un oscilador armónico, el sobretono de dicha frecuencia de oscilación aparecerá a $n=2, n=3 \ldots$ Por lo tanto, como la banda de vibración del enlace carbonilo aparece entre $1750-1735 \mathrm{~cm}^{-1}$ el primer sobretono debe aparecer entre los 3500 y $3470 \mathrm{~cm}^{-1}$. Efectivamente y como se observa en las figuras que se muestran a continuación, aparece el incremento del área del pico consecutivo con el tiempo que ha estado el aceite degradándose térmicamente.

Tabla 51: Incremento del PAI y del PLI en el aceite A

\begin{tabular}{|c|c|c|c|c|c|}
\hline \multicolumn{5}{|c|}{ Peak Area Increase (PAI) / Peak Length Increase (PLI) del aceite A } \\
\hline Tiempo (h) & Área & Altura & Paso óptico & PAI & PLI \\
\hline 0 & 5.201 & 0.126 & 0.087 & 0 & 0 \\
\hline 1240 & 6.487 & 0.143 & 0.087 & 14.78 & 1.95 \\
\hline 2120 & 8.380 & 0.165 & 0.087 & 36.54 & 4.48 \\
\hline 3120 & 9.959 & 0.183 & 0.087 & 54.69 & 6.55 \\
\hline 4210 & 11.593 & 0.206 & 0.087 & 73.47 & 9.20 \\
\hline
\end{tabular}


A modo de ejemplo, se mostrará la superposición de los espectros de las 5 muestras analizadas, con el objetivo de observar el incremento de absorción en la banda del primer sobretono del enlace $\mathrm{C}=\mathrm{O}$.

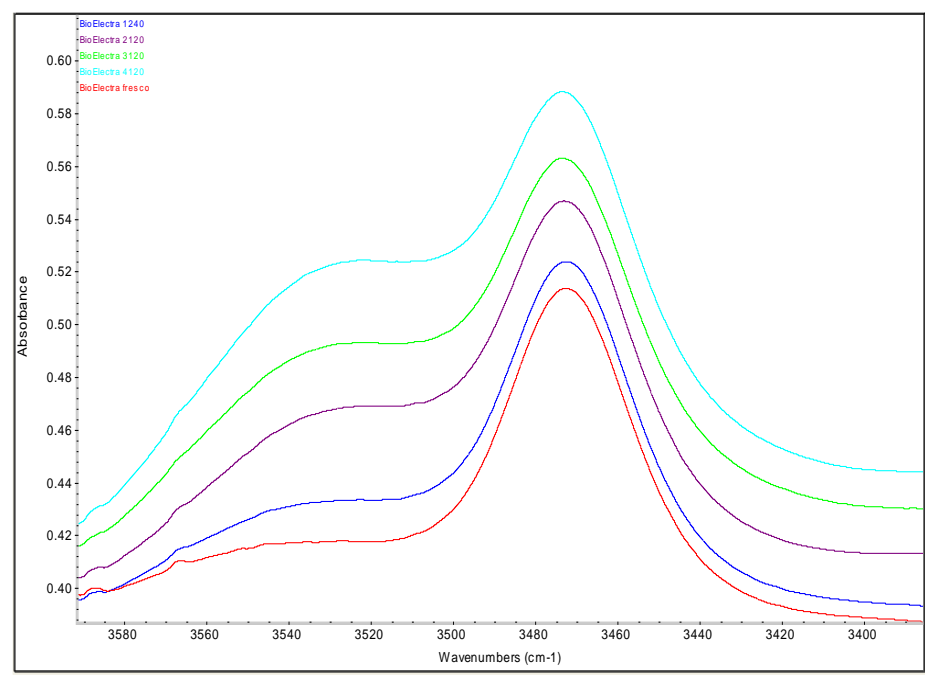

Fig. 167: Aumento de la intensidad de la banda de absorción frente al tiempo de degradación

Tabla 52: Incremento del PAI y del PLI en el aceite B

\begin{tabular}{|l|c|c|c|c|c|}
\hline \multicolumn{5}{|c|}{ Peak Area Increase (PAI) / Peak Length Increase (PLI) del aceite B } \\
\hline Tiempo (h) & Área & Altura & Paso óptico & PAI & PLI \\
\hline 0 & 3.303 & 0.132 & 0.087 & 0 & 0 \\
\hline 1240 & 4.415 & 0.145 & 0.087 & 12,78 & 1,49 \\
\hline 2120 & 6.608 & 0.175 & 0.087 & 37,98 & 4.94 \\
\hline 3120 & 6.606 & 0.173 & 0.087 & 37,97 & 4,71 \\
\hline 4210 & 7.436 & 0.195 & 0.087 & 47.51 & 7,24 \\
\hline
\end{tabular}

Tabla 53: Incremento del PAI y del PLI en el aceite C

\begin{tabular}{|c|c|c|c|c|c|}
\hline \multicolumn{5}{|c|}{ Peak Area Increase (PAI) / Peak Length Increase (PLI) del aceite C } \\
\hline Tiempo (h) & Área & Altura & Paso óptico & PAI & PLI \\
\hline 0 & 5.506 & 0.135 & 0.087 & 0 & 0 \\
\hline 1240 & 5.805 & 0.143 & 0.087 & 3.44 & 0.92 \\
\hline 2120 & 7.352 & 0.153 & 0.087 & 15.35 & 2.07 \\
\hline 3120 & 8.330 & 0.180 & 0.087 & 32.46 & 5.17 \\
\hline 4210 & 9.302 & 0.193 & 0.087 & 43.63 & 6.67 \\
\hline
\end{tabular}


Tabla 54: Incremento del PAI y del PLI en el aceite D

\begin{tabular}{|l|c|c|c|c|c|}
\hline \multicolumn{5}{|c|}{ Peak Area Increase (PAI) / Peak Length Increase (PLI) del aceite D } \\
\hline Tiempo (h) & Área & Altura & Paso óptico & PAI & PLI \\
\hline 0 & 8.871 & 0.157 & 0.087 & 0 & 0 \\
\hline 1240 & 12.772 & 0.199 & 0.087 & 44.84 & 4.83 \\
\hline 2120 & 13.189 & 0.208 & 0.087 & 49.63 & 5.86 \\
\hline 3120 & 16.670 & 0.236 & 0.087 & 89.64 & 9.08 \\
\hline 4210 & 17.370 & 0.245 & 0.087 & 97.69 & 10.11 \\
\hline
\end{tabular}

Tabla 55: Incremento del PAI y del PLI en el aceite E

\begin{tabular}{|c|c|c|c|c|c|}
\hline \multicolumn{5}{|c|}{ Peak Area Increase (PAI) / Peak Length Increase (PLI) del aceite E } \\
\hline Tiempo (h) & Área & Altura & Paso óptico & PAI & PLI \\
\hline 0 & 1.043 & 0.056 & 0.087 & 0 & 0 \\
\hline 1240 & 1,043 & 0.056 & 0.087 & 0 & 0 \\
\hline 2120 & 3.453 & 0.204 & 0.087 & 27.71 & 17.25 \\
\hline 3120 & 1.092 & 0.056 & 0.087 & 0.58 & 0 \\
\hline 4210 & 1.386 & 0.073 & 0.087 & 4.03 & 2.30 \\
\hline
\end{tabular}

En cuanto a la medida de absorbancia para el aceite E, si se ha medido directamente sobre la banda del carbonilo (entre $1750-1800 \mathrm{~cm}^{-1}$ ) ya que en este caso no se nos iba fuera de escala la banda de absorción de dicho enlace.

Con respecto al dato del aceite E a las 2120 horas, no lo tendremos en cuenta a la hora de la evaluación de los datos, ya que es completamente anómalo por no seguir la tendencia de sus sucesivas alícuotas. A la hora de representarlo gráficamente, se ha omitido dicho valor y únicamente se ha procedido al ajuste de los datos por mínimos cuadrados de los datos de 0 horas, 1240 horas, 3120 horas y 4210 horas.

A continuación se representa gráficamente los valores obtenidos de PAI para cada aceite ajustando los valores, de cada aceite, a una recta por mínimos cuadrados. 


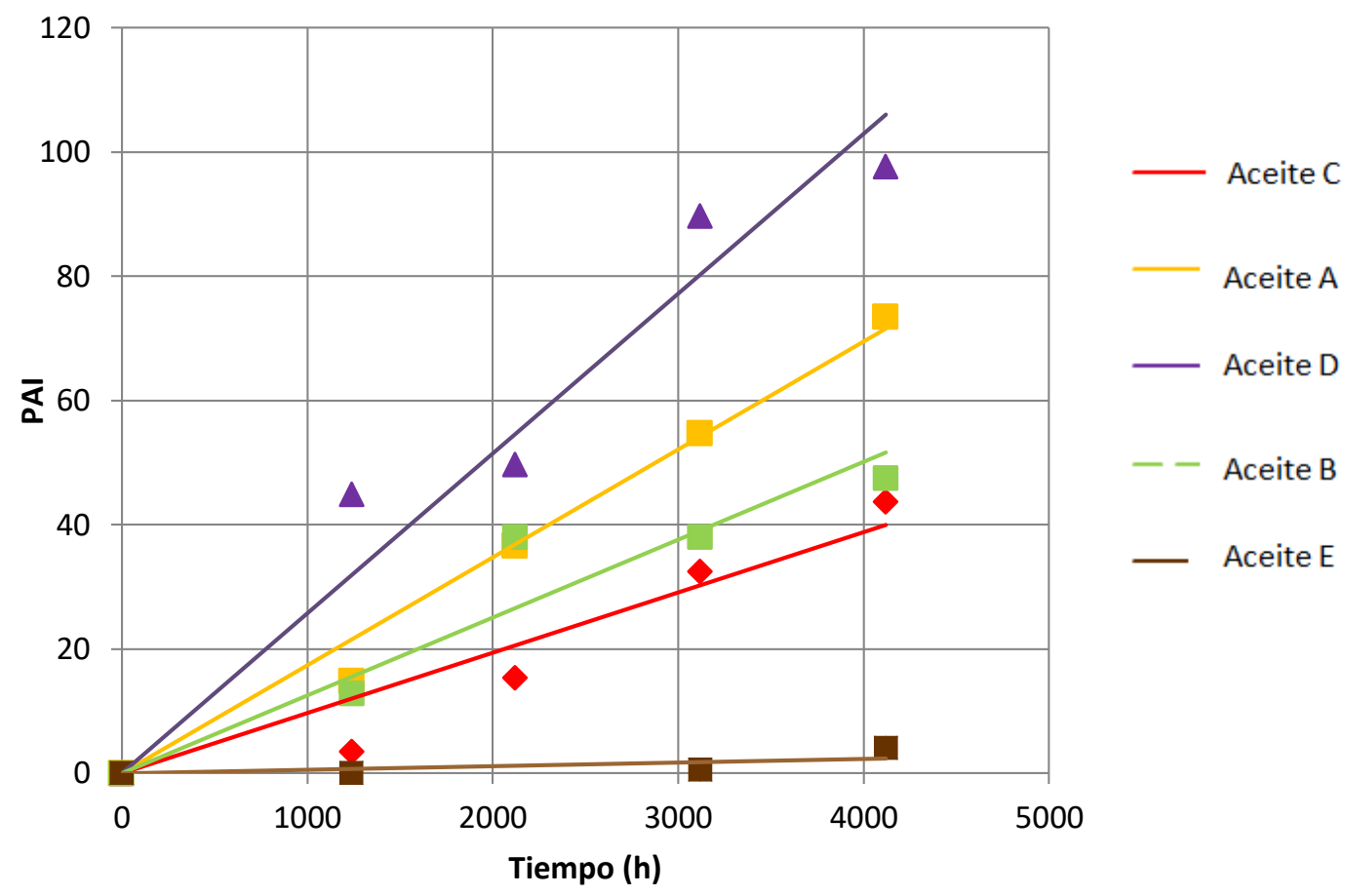

Fig. 168: Aumento del PAI (ajustado a una recta) frente al tiempo de degradación

Las ecuaciones de las líneas de tendencia de cada uno de los aceites con sus correspondientes índices de correlación se muestran a continuación en la siguiente tabla resumen.

Tabla 56: Correlación del PAI frente al tiempo de degradación

\begin{tabular}{|c|c|c|}
\hline & \multicolumn{3}{|c|}{ Incremento del área del pico del enlace carbonilo } \\
\hline Aceite & Ecuación lineal & Índice de correlación \\
\hline A & $\mathrm{PAI}=0,0174 \cdot$ Tiempo & $\mathrm{R}^{2}=0,9858$ \\
\hline B & $\mathrm{PAI}=0,0117 \cdot$ Tiempo & $\mathrm{R}^{2}=0,9248$ \\
\hline C & $\mathrm{PAI}=0,0100 \cdot$ Tiempo & $\mathrm{R}^{2}=0,9622$ \\
\hline D & $\mathrm{PAI}=0,0257 \cdot$ Tiempo & $\mathrm{R}^{2}=0,9435$ \\
\hline E & $\mathrm{PAI}=0,0006 \cdot$ Tiempo & $\mathrm{R}^{2}=0,9953$ \\
\hline
\end{tabular}

Dichos incrementos en las bandas de oxidación estudiadas por FTIR se encuentran en relación directa con los valores de índice de acidez estudiados para la presente tesis. 


\subsubsection{COMPATIBILIDAD DE LOS ACEITES VEGETALES CON LOS}

\section{MATERIALES DEL TRANSFORMADOR}

\subsubsection{Resultados}

Los resultados obtenidos al final del ensayo se dividen en dos bloques:

a) Resultados de los aceites vegetales

b) Resultados de los materiales del transformador

a) Resultados de los aceites vegetales

Los dos aceites vegetales ensayados, A y B, fueron llevados a temperatura ambiente dentro de un desecador, después de haber estado expuestos durante $672 \mathrm{~h}$ a $130{ }^{\circ} \mathrm{C}$. Los aceites no fueron filtrados al vacío antes de caracterizarlos, con el fin de alterar lo menos posible la muestra y así recrear, en el mayor grado posible, su comportamiento en un transformador.

Tabla 57: Resultados químicos y físico químicos del aceite $\mathrm{A}$

\begin{tabular}{lccc}
\hline \multicolumn{1}{c}{ Parámetro } & Antes ensayo & Después ensayo & $\boldsymbol{\Delta}$ Variación \\
\hline Rigidez dieléctrica (kV) & 60 & 60 & 0 \\
Agua K-F (ppm) & 80,16 & 277,87 & 197,71 \\
Índice acidez (mg KOH/g) & 0,04 & 0,14 & 0,10 \\
Tg $\boldsymbol{\delta}$ (adimensional) & 0,00539 & 0,42741 & 0,42202 \\
[Cu] (ppm) & $<0,3$ & $<0,3$ & $0^{(*)}$ \\
\hline
\end{tabular}

(*) No se puede determinar la variación en la concentración de cobre porque los dos datos, antes y después de ensayo, están por debajo del límite de detección del equipo.

En los resultados obtenidos experimentalmente se puede observar un aumento del índice de acidez debido a la formación de compuestos polares que aumentan el valor del índice de acidez.

Se observa también que dicho incremento en la acidez del aceite no provoca una disminución de la rigidez dieléctrica, tal y como se demostró en apartados anteriores. En cuanto al factor de pérdidas dieléctricas, un incremento de este valor indica un 
incremento en la formación de compuestos polares o en la cantidad de agua microemulsionada.

Tabla 58: Resultados químicos y físico químicos del aceite B

\begin{tabular}{lccc}
\hline \multicolumn{1}{c}{ Parámetro } & Antes ensayo & Después ensayo & $\Delta$ Variación \\
\hline Rigidez dieléctrica (kV) & 60 & 60 & 0 \\
Agua K-F (ppm) & 95,46 & 190,73 & 95,27 \\
Índice acidez (mg KOH/g) & 0,06 & 0,15 & 0,09 \\
Tg $\boldsymbol{\delta}$ (adimensional) & 0,02169 & 0,35003 & 0,32834 \\
[Cu] (ppm) & $<0,3$ & $<0,3$ & $0^{(*)}$ \\
\hline
\end{tabular}

(*) No se puede determinar la variación en la concentración de cobre porque los dos datos, antes y después de ensayo, están por debajo del límite de detección del equipo.

El comportamiento del aceite $\mathrm{B}$ es similar al comportamiento del aceite $\mathrm{A}$, produciéndose un aumento en el índice de acidez del mismo orden de magnitud que con el aceite A. El incremento de la tg $\delta$ es provocado por el motivo citado anteriormente.

Ambos aceites vegetales se comportan similarmente cuando son sometidos a elevadas temperaturas y están en contacto con materiales de los que está construido el transformador.

b) Resultados de los materiales del transformador

A continuación se irán exponiendo y discutiendo los resultados obtenidos para cada uno de los materiales evaluados.

\section{1.b. Núcleo del transformador}

El núcleo del transformador generalmente suele estar formado por chapas de ferrita (o $\alpha$-hierro), forma alotrópica del hierro que posee propiedades magnéticas. Se utiliza dopada con níquel, zinc o manganeso, ya que con estos quedan eliminadas prácticamente las Corrientes de Foucault. 
El ataque producido por parte de ambos aceites a la superficie del núcleo del transformador es casi imperceptible para el ojo humano tal y como queda reflejado en la imagen siguiente, donde se muestra el estado de las probetas de núcleo después del ensayo de compatibilidad.

Aceite A

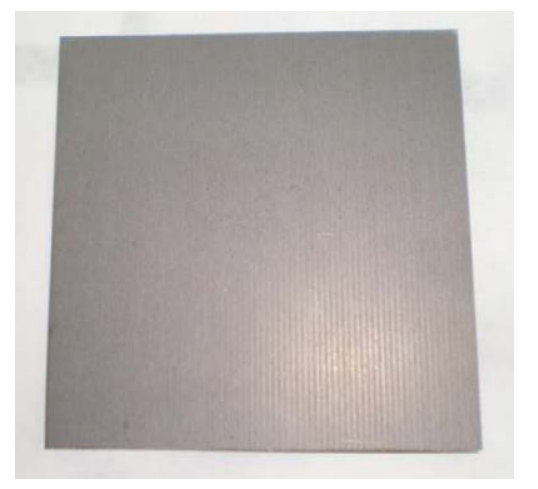

Aceite B

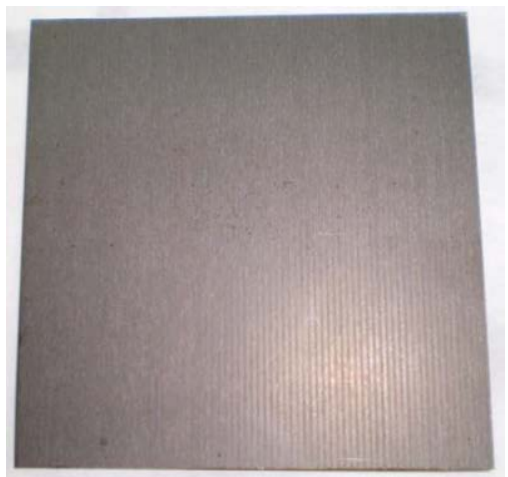

Fig. 169: Estado de las probeta del núcleo del transformador, después del ensayo.

En cuanto a su variación másica, como cabría esperar, es prácticamente nula.

Tabla 59: Variaciones másicas de las probetas de acero

\begin{tabular}{lccc}
\hline & Masa antes $(\mathrm{g})$ & Masa después $(\mathrm{g})$ & $\Delta$ Variación $(\mathrm{g})$ \\
\hline Aceite A & 13,1905 & 13,1906 & $\mathbf{0 , 0 0 0 1}$ \\
Aceite B & 13,4441 & 13,4444 & $\mathbf{0 , 0 0 0 3}$ \\
\hline
\end{tabular}

La variación másica es inferior a la incertidumbre de la balanza analítica con la que se realizó la pesada $\left(\mathrm{U}_{\mathrm{e}}= \pm 0,0005 \mathrm{~g}\right)$. 


\section{2.b. Corcho laminado}

El corcho natural aglomerado posee unas excelentes propiedades de estanqueidad y evita que se pueda derramar el aceite fuera de la cuba del transformador cuando se produzca una expansión térmica del fluido por solicitaciones térmicas o eléctricas. Por esa misma razón, es importante caracterizar el comportamiento del corcho en condiciones de máxima severidad de operación.

Se sometieron a ensayo probetas de corcho de 5 x 5 x $0,4 \mathrm{~cm}^{3}$. Una vez terminado el ensayo, se dejaron enfriar hasta la temperatura ambiente e inmediatamente se sumergieron en vaso de precipitados con $100 \mathrm{~mL}$ de $\mathrm{n}$-heptano. El objetivo fue desengrasar al máximo las probetas de corcho para poder estudiar su variación volumétrica cometiendo el menor error posible.

El estado de las probetas después del ensayo se muestra en la figura 170:

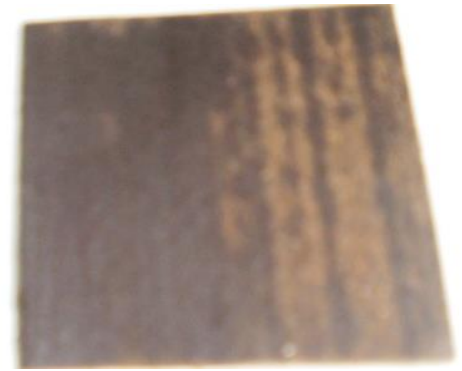

Aceite A

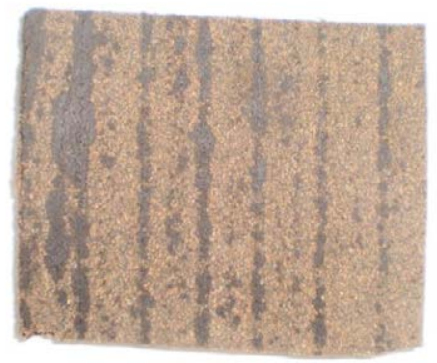

Aceite B

Fig. 170: Estado de las probeta de corcho después del ensayo.

En cuanto a su variación másica, los resultados deben ser tomados con precaución a la hora de ser interpretados porque en este caso estamos pesando también parte de aceite que ha quedado ocluido en los poros internos del corcho y que no ha sido eliminado con los lavados de n-heptano.

Tabla 60: Variaciones másicas de las probetas de corcho

\begin{tabular}{lccc}
\hline & Masa antes $(\mathrm{g})$ & Masa después $(\mathrm{g})$ & $\Delta$ Másica $(\mathrm{g})$ \\
\hline Con Aceite A & 7,6172 & 10,5831 & $\mathbf{2 , 9 6 5 9}$ \\
Con Aceite B & 7,7566 & 11,0827 & $\mathbf{3 , 3 2 6 1}$ \\
\hline
\end{tabular}


Se puede concluir que después del ensayo, la cantidad de aceite que queda retenida en la estructura del corcho es aproximadamente un $40 \%$ del peso inicial de la probeta. Por lo tanto, es de gran importancia determinar la variación volumétrica del corcho antes y después:

Tabla 61: Variaciones volumétricas de las probetas de corcho para el aceite A

\begin{tabular}{ccc} 
& Antes del ensayo & Después del ensayo \\
\hline $\mathrm{a}=\mathrm{b}(\bar{x}, \mathrm{~mm})$ & 51,1 & 50,8 \\
\hline $\mathrm{c}(\bar{x}, \mathrm{~mm})$ & 3,9 & $\mathbf{9}$ \\
\hline Volumen $\left(\mathrm{mm}^{3}\right)$ & $10.183,72$ & \\
\hline \% Variación Volumen & $\mathbf{- 3 , 7 1}$ \\
\hline
\end{tabular}

Una variación volumétrica negativa indica una contracción de la probeta de corcho al ser sometidas a elevadas temperaturas. Por lo tanto, el volumen final es menor pero la masa es casi un $40 \%$ mayor. Esto significa que el aceite rellena todos los poros que tiene el corcho y que queda retenido en él aun después de ser sometido a lavados con nheptano.

Tabla 62: Variaciones volumétricas de las probetas de corcho para el aceite B

\begin{tabular}{ccc}
\hline & Antes del ensayo & Después del ensayo \\
\hline $\mathrm{a}=\mathrm{b}(\bar{x}, \mathrm{~mm})$ & 51,1 & 51,2 \\
\hline $\mathrm{c}(\bar{x}, \mathrm{~mm})$ & 3,9 & 3,9 \\
\hline Volumen $\left(\mathrm{mm}^{3}\right)$ & $10.183,72$ & 10.22362 \\
\hline \% Variación Volumen & $\mathbf{0 , 3 9}$ \\
\hline
\end{tabular}

Con el aceite dieléctrico $\mathrm{B}$, la variación volumétrica es prácticamente inexistente. La tendencia de ambos aceites es prácticamente similar. 


\section{3.b. Probetas de madera laminada}

La madera laminada, dentro de un transformador, se usa como sujeción de partes fijas. Debido a su naturaleza vegetal, actúa también como aislante dieléctrico. Al igual que el corcho, es indispensable determinar el comportamiento de dicho material cuando se junta con aceite dieléctrico vegetal a temperaturas elevadas.

Se sometieron a ensayo probetas de madera de dimensiones 5 x 5 x 1,5 $\mathrm{cm}^{3}$. Se sacó del reactor y se esperó hasta que alcanzara el equilibrio térmico. Seguidamente se desengrasó usando lavados con n-heptano de 24 horas de duración. El estado de las probetas después del ensayo se muestra en las siguientes figuras:

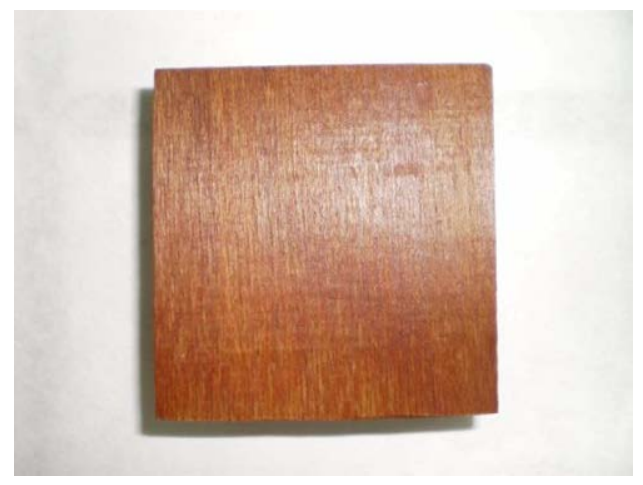

Aceite A

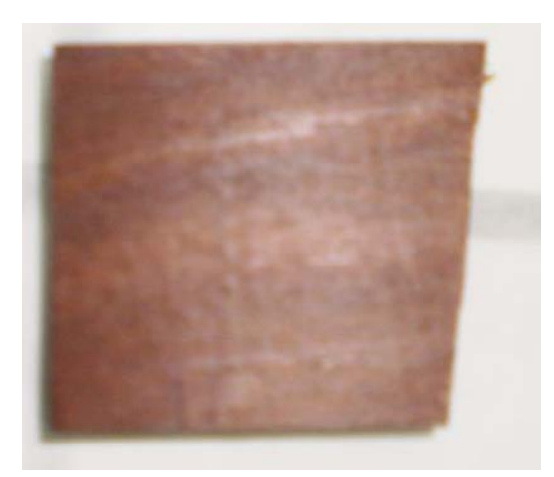

Aceite B

Fig. 171: Estado de las probeta de madera después del ensayo.

En cuanto a los resultados de la variación másica, indicar que se debe tomar el mismo cuidado a la hora de interpretar los resultados que con las probetas de corcho, ya que la madera también ha sido desengrasada pero en las oquedades de su estructura interna puede quedar bolsas con aceite vegetal.

Tabla 62: Variaciones másicas de las probetas de madera

\begin{tabular}{lccc}
\hline & Masa antes $(\mathrm{g})$ & Masa después $(\mathrm{g})$ & $\Delta$ Másica $(\mathrm{g})$ \\
\hline Con aceite A & 36,6622 & 44,8732 & $\mathbf{8 , 2 1 1 0}$ \\
Con aceite B & 33,2036 & 41,3260 & $\mathbf{8 , 1 2 2 4}$ \\
\hline
\end{tabular}

Los resultados obtenidos indican una clara evidencia del similar comportamiento de la madera frente a ambos aceites de origen vegetal. Un $22 \%$ aproximadamente de aceite 
queda retenido en el interior de la madera, después de haber sido desengrasado con nheptano. La variación volumétrica de la madera después del ensayo se puede observar en la figura 63:

Tabla 63: Variaciones volumétricas de las probetas de madera en aceite A

\begin{tabular}{ccc}
\hline & Antes del ensayo & Después del ensayo \\
\hline $\mathrm{a}=\mathrm{b}(\bar{x}, \mathrm{~mm})$ & 49,7 & 49,7 \\
\hline $\mathrm{c}(\bar{x}, \mathrm{~mm})$ & 15,1 & $36,904,34$ \\
\hline Volumen $\left(\mathrm{mm}^{3}\right)$ & $37.298,36$ & $\mathbf{- 1 , 3 2}$ \\
\hline
\end{tabular}

Una variación de tan pequeña magnitud puede estar generada en cierto modo por el error del equipo de medida. En cualquier caso, aparece una variación volumétrica negativa, lo que implica una disminución en el volumen final de la probeta de madera, es decir, una contracción volumétrica.

La variación volumétrica para el aceite B se muestra en la tabla 64 .

Tabla 64: Variaciones volumétricas de las probetas de madera en aceite B

\begin{tabular}{ccc}
\hline & Antes del ensayo & Después del ensayo \\
\hline $\mathrm{a}=\mathrm{b}(\bar{x}, \mathrm{~mm})$ & 50,0 & 49,9 \\
\hline $\mathrm{c}(\bar{x}, \mathrm{~mm})$ & 15,1 & $\mathbf{3 6 , 8}$ \\
\hline Volumen $\left(\mathrm{mm}^{3}\right)$ & $37.750,00$ & \\
\hline \% Variación Volumen & $\mathbf{- 2 , 3 8}$ & \\
\hline
\end{tabular}

La tendencia de la madera frente al aceite dieléctrico B es igual que la del A. Con los resultados obtenidos en ambos ensayos, se puede concluir que el volumen de la madera al aplicarle calor para ambos aceites disminuye, es decir, se contrae y que la madera tiene una capacidad de retención de aceite del $22 \%$ para ambos aceites. 


\section{4.b. Hilo esmaltado de cobre}

El cobre se usa dentro de un transformador como material conductor. Para que no sea atacado por aislantes líquidos o por lodos o partículas en suspensión, el hilo conductor que va en los arrollamientos de un transformador está recubierto de un esmaltado o barniz aislante. Por esta misma razón, para someterlos a ensayo no hemos lijado la superficie del hilo de cobre con cinta abrasiva, ya que si no, eliminaríamos el barniz con el que realmente se encuentra dentro de un transformador.

En la figura 172 se muestra el estado del hilo de cobre después de haber sido sometido a ensayo:

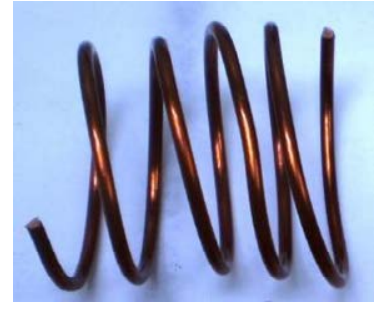

Aceite A

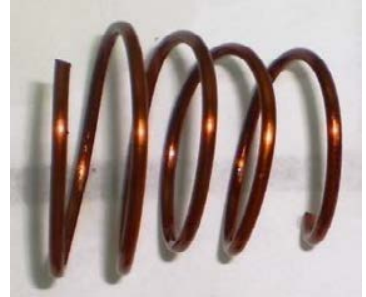

Aceite B

Fig. 172: Estado del esmaltado y del cobre después del ensayo

Los dos únicos fenómenos físicos de degradación que le puede suceder a un hilo de cobre es que sea atacado por ácidos, desprendiéndose de la superficie iones $\mathrm{Cu}^{2+}$ que actúen de catalizador en reacciones de oxidación o que se produzcan fenómenos de corrosión en la superficie. La primera opción queda descartada porque la concentración de cobre en disolución no aumenta antes y después del ensayo tal y como ha sido demostrado con el análisis cuantitativo de cobre por ICP-OES. Con respecto a la segunda opción, existe la normativa ASTM D 130, que nos indica según una escala fijada, la corrosión de cobre después de haber sido sometido a ensayo.

Tabla 65: Corrosión del cobre antes y después del ensayo

\begin{tabular}{ccc}
\hline Antes del ensayo & \multicolumn{2}{c}{ Después del ensayo } \\
\hline 1a & Aceite A & $1 \mathrm{a}$ \\
$1 \mathrm{a}$ & Aceite B & $1 \mathrm{a}$ \\
\hline
\end{tabular}


Como se puede observar en la tabla anterior, ninguno de los dos aceites provoca corrosión en el hilo de cobre esmaltado.

\section{5.b Chapa de cobre}

Al igual que el hilo esmaltado conductor, la chapa de cobre es unos de los materiales que se usa en la fabricación del transformador que actúa de material conductor.

Las probetas que se ensayaron tenían una dimensión de $10,6 \times 10,6 \mathrm{~cm}^{2}$. Al igual que el hilo de cobre, los dos únicos ensayos que se pueden realizar al cobre antes y después del ensayo es la corrosión según escala ASTM D 130 y la concentración de iones cúpricos disueltos en el aceite aislante.

La segunda opción queda descartada por la misma razón indicada en el apartado anterior, ya que la única fuente de iones cúpricos dentro de un transformador son la chapa de cobre o el hilo de cobre esmaltado.

El estado de las probetas de cobre después de realizar en ensayo se muestra a continuación:

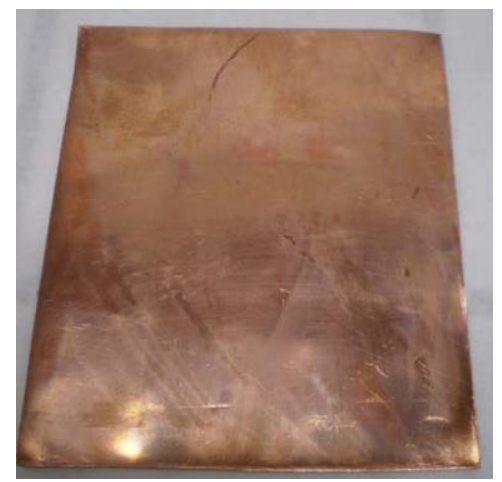

Aceite A

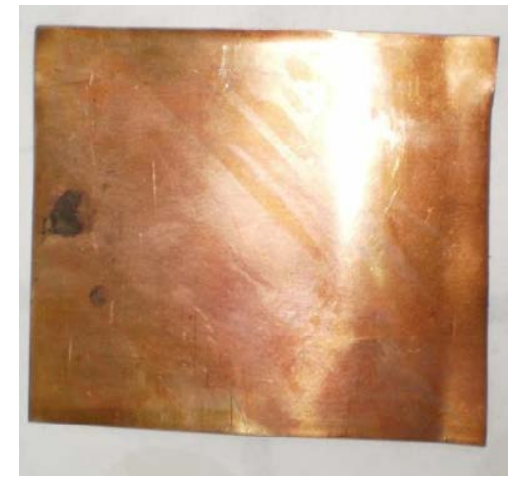

Aceite B

Fig. 173: Estado de las probetas de cobre después del ensayo

Comparando el estado de las probetas de chapa de cobre antes y después del ensayo para cada uno de los aceites estudiados, podemos afirmar que no existe corrosión en su superficie.

Por lo tanto, el comportamiento de ambos aceites vegetales frente al cobre es similar. 


\section{6.b. Cintas autoadhesivas}

Las cintas autoadhesivas son una parte importante en la construcción del transformador debido a su elevada resistencia eléctrica y mecánica. Para este ensayo hemos usado dos tipos de cintas adhesivas que una empresa de construcción de transformadores española suele incluir en sus transformadores.

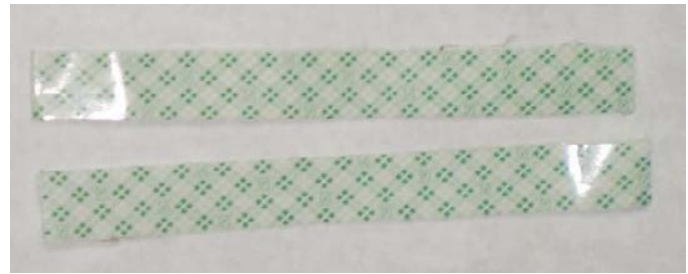

Cinta A

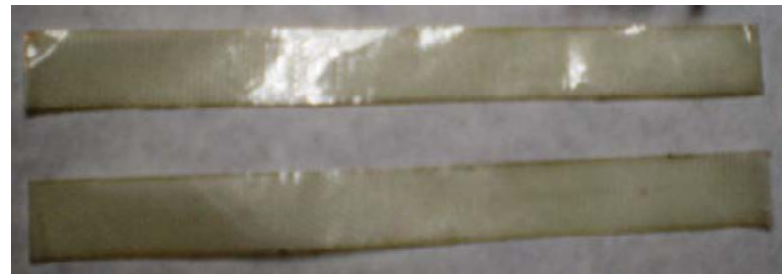

Cinta B

Fig. 174: Estado de las cintas autoadhesivas antes del ensayo

La cinta A está formada por dos capas: una de polímero y otra capa de pegamento. Sin embargo, la cinta B está formada por una capa más, una red entrecruzada que le proporciona a la cinta una elevada resistencia mecánica.

Se sometieron a ensayo los dos tipos de cintas con los dos tipos de aceite. El estado de las cintas después de extraerlas del reactor y eliminar el aceite superficial se muestra a continuación:

\section{Aceite A}

Cinta A

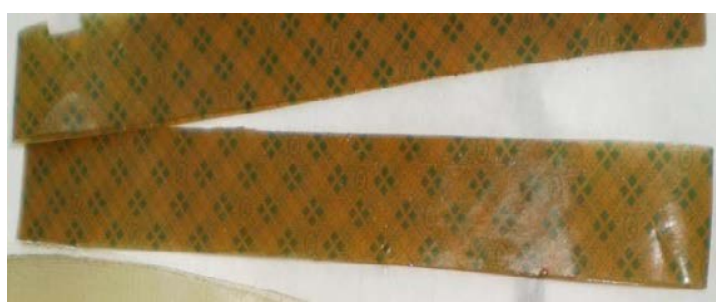

Cinta B 


\section{Aceite B}

Cinta A

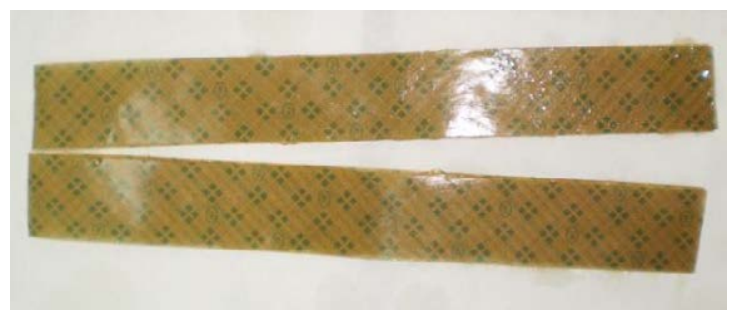

Cinta B

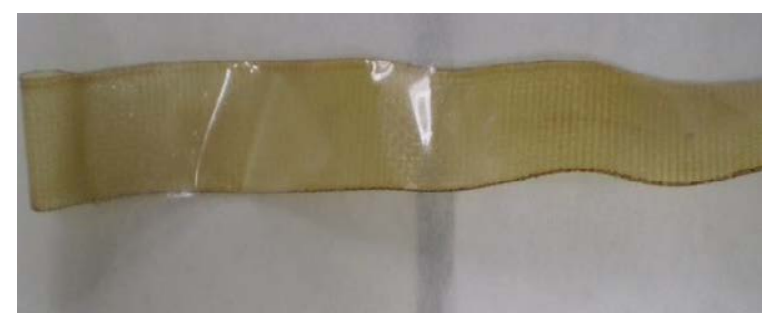

Fig. 175: Estado de las cintas autoadhesivas después del ensayo

Como se observa para ambos aceites, con respecto a la cinta A, la capa de pegamento se separa de la capa de polímero y se aglutina tal y como muestra el detalle de la figura 176, disminuyendo así las propiedades de adhesión. Con respecto a la cinta B, la propiedad de adhesión no la pierde con el tiempo pero si se produce una separación entre capas tal y como se muestra en la cinta B del aceite A.

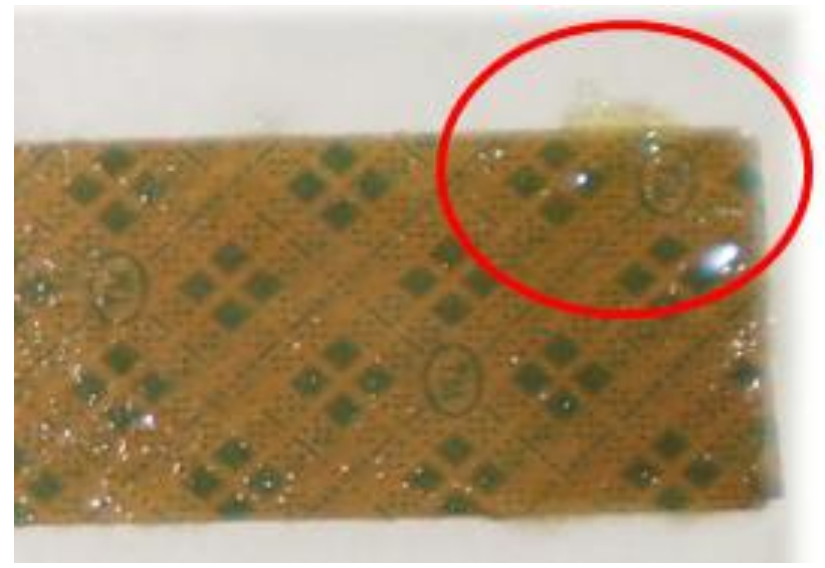

Fig. 176: Detalle del aglutinamiento del adhesivo de la cinta A

\section{7.b. Canutos de material celulósicos}

Los canutos de material celulósico se emplean dentro de un transformador para aislar los arrollamientos de hilo de cobre esmaltado y evitar así que el hilo conductor entre en contacto con otras partes de la cuba y se pueda producir algún fallo eléctrico. 
Los canutos de material celulósico son planchas de papel enrolladas que forman cilindros huecos donde irá ubicado el hilo conductor.

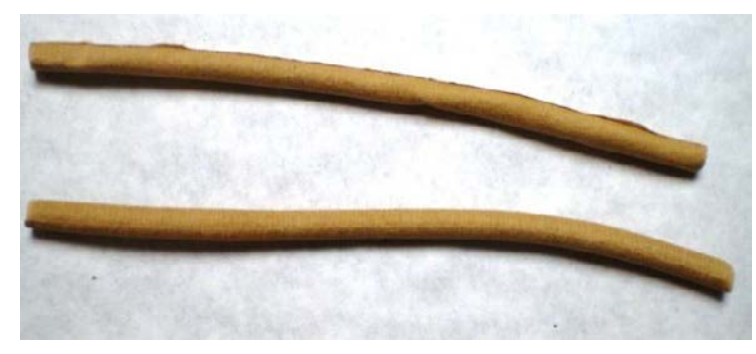

Fig. 177: Canutos de cartón prensado antes del ensayo

Fueron sometidas a ensayo dos probetas de $15 \mathrm{~cm}$, una en cada uno de los aceites, con el objetivo de evaluar una posible disminución en las propiedades mecánicas de la celulosa. El aspecto de los canutos después de estar un mes a $130{ }^{\circ} \mathrm{C}$ se muestra a continuación:

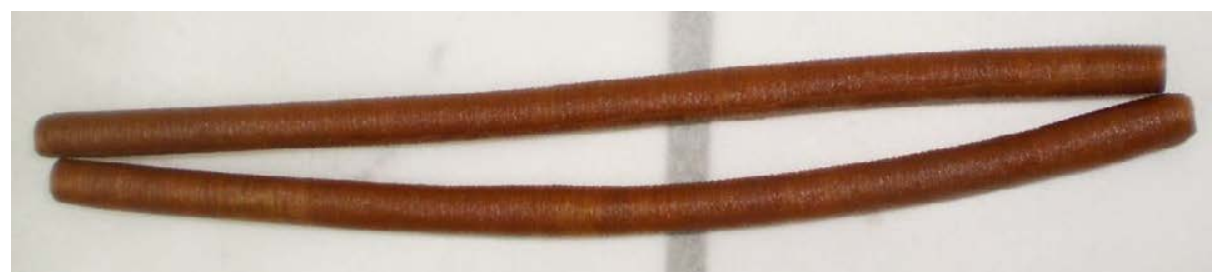

Fig. 178: Canutos de cartón prensado después del ensayo para el aceite A y B

Visualmente, no se observa ningún cambio en la estructura externa de la muestra. Se tomaron medidas de las circunferencias externas antes y después del ensayo, se calcularon los intervalos de confianza para un $95 \%$ y se calculó el porcentaje de variación:

Tabla 66: Variación del diámetro de la circunferencia para el aceite A

\begin{tabular}{lccc}
\hline & Antes ensayo $(\mathrm{mm})$ & Después ensayo $(\mathrm{mm})$ & $\%$ Variación \\
\hline Aceite A & $6,02 \pm 0,15$ & $6,02 \pm 0,14$ & $\approx 0$ \\
Aceite B & $6,28 \pm 0,12$ & $6,28 \pm 0,10$ & $\approx 0$ \\
\hline
\end{tabular}


No se observó ningún cambio en el diámetro de los canutos de material celulósico por lo que se puede concluir que no se expanden dimensionalmente al entrar en contacto con el aceite.

Para evaluar la hidrólisis de las cadenas de celulosa, se han determinado las propiedades de tracción con un equipo Instron. Las condiciones de ensayos fueron las siguientes:

$\square \quad$ Probetas cilíndricas de $150 \mathrm{~mm}$ de longitud

๑ Distancia entre mordazas: $100 \mathrm{~mm}$

Velocidad de tracción: $20 \mathrm{~mm} / \mathrm{min}$

Se evaluaron los parámetros de módulo de Young, carga en la rotura y porcentaje de deformación por tracción.

Tabla 67: Variación de propiedades mecánicas de canutos sumergidos en aceite A

\begin{tabular}{lccc}
\hline & Antes ensayo & Después ensayo & \% Variación \\
\hline Modulo Young (MPa) & 84,36 & 101,15 & $\mathbf{1 9 , 9 0}$ \\
Carga Rotura (N) & 80,91 & 32,01 & $-\mathbf{6 0 , 4 4}$ \\
Deformación (\%) & 27,03 & 8,40 & $-\mathbf{6 8 , 9 3}$ \\
\hline
\end{tabular}

Tabla 68: Variación de propiedades mecánicas de canutos sumergidos en aceite B

\begin{tabular}{lccc}
\hline & Antes ensayo & Después ensayo & \% Variación \\
\hline Modulo Young (MPa) & 84,36 & 65,59 & $-\mathbf{2 2 , 2 5}$ \\
Carga Rotura (N) & 80,91 & 28,52 & $-\mathbf{6 4 , 7 5}$ \\
Deformación (\%) & 27,03 & 8,30 & $-\mathbf{6 9 , 2 9}$ \\
\hline
\end{tabular}

Observando los valores obtenidos de porcentaje de variación en carga y deformación, para ambos aceites, podemos concluir que el ataque químico que se produce sobre los canutos de material celulósico son de igual magnitud cuando trabajamos con aceite dieléctrico B o con aceite dieléctrico A. Con respecto al módulo de Young, existe una gran diferencia de valores entre los obtenidos para el aceite A y B. El módulo de Young 
nos indica cuan "rígido" se ha vuelto el material. Observando que el porcentaje de deformación es similar en los canutos sumergidos en ambos aceites, podemos concluir que el valor del módulo de Young para el aceite B es un valor anómalo calculado por el software del equipo.

\section{8.b. Juntas de cartón}

Otro de los materiales con los que se fabrica un transformador son juntas de cartón prensado. En nuestro caso, para poder ensayar este material hemos preparado probetas microhalterio de dichas juntas y las hemos sometido a ensayo dentro del reactor.

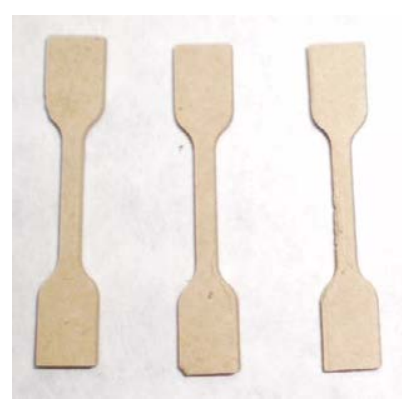

Fig. 179: Probetas microhalterio de cartón prensado antes del ensayo

Para evaluar la pérdida de propiedades mecánicas, en este caso se ensayaron también a tracción las probetas microhalterio y se determinaron el módulo de Young, carga a la rotura y el porcentaje de deformación.

Tabla 69: Variación de propiedades mecánicas de probetas de cartón sumergidos en aceite A

\begin{tabular}{lccc}
\hline & Antes ensayo & Después ensayo & \% Variación \\
\hline Modulo Young (MPa) & 4411,41 & 5200,49 & $\mathbf{1 7 , 8 9}$ \\
Carga Rotura (N) & 145,05 & 92,07 & $\mathbf{- 3 6 , 5 3}$ \\
Deformación (\%) & 5,53 & 1,69 & $-\mathbf{6 9 , 4 4}$ \\
\hline
\end{tabular}



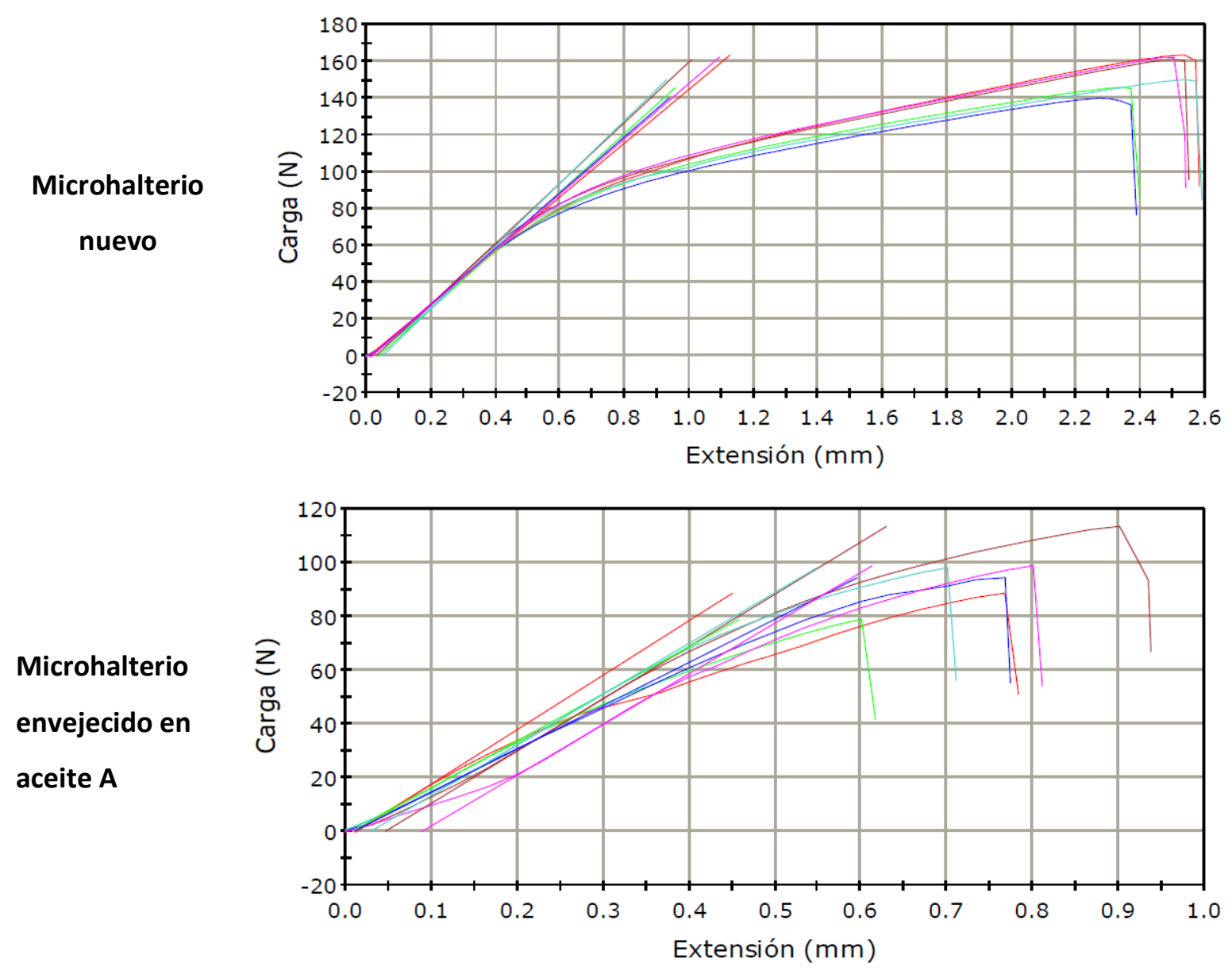

Fig. 180: Gráfico de carga frente a extensión en probetas sumergidas en aceite A

Tal y como muestran los resultados obtenidos, después de un mes a 130 horas, el material celulósico se ve altamente dañado observando tal efecto en la disminución de la capacidad de deformación en un $70 \%$.

Tabla 70: Variación de propiedades mecánicas de probetas de cartón sumergidos en aceite B

\begin{tabular}{lccc}
\hline & Antes ensayo & Después ensayo & \% Variación \\
\hline Modulo Young (MPa) & 4411,41 & 5277,55 & $\mathbf{1 9 , 6 3}$ \\
Carga Rotura (N) & 145,05 & 94,72 & $\mathbf{- 3 4 , 7 0}$ \\
Deformación (\%) & 5,53 & 1,70 & $\mathbf{- 6 9 , 2 3}$ \\
\hline
\end{tabular}




\section{Microhalterio \\ nuevo}

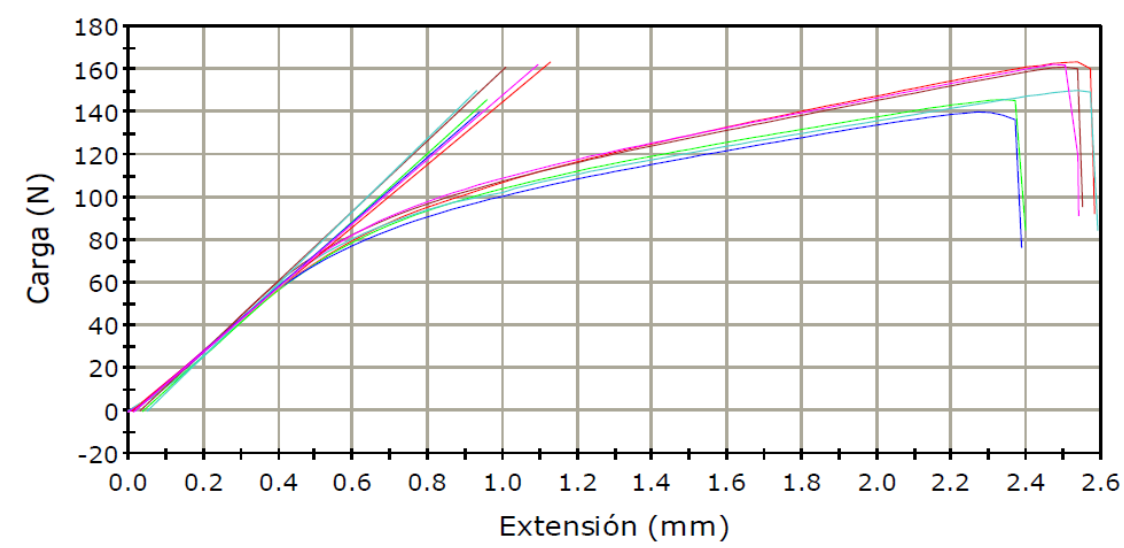

Microhalterio

envejecido en

Aceite B

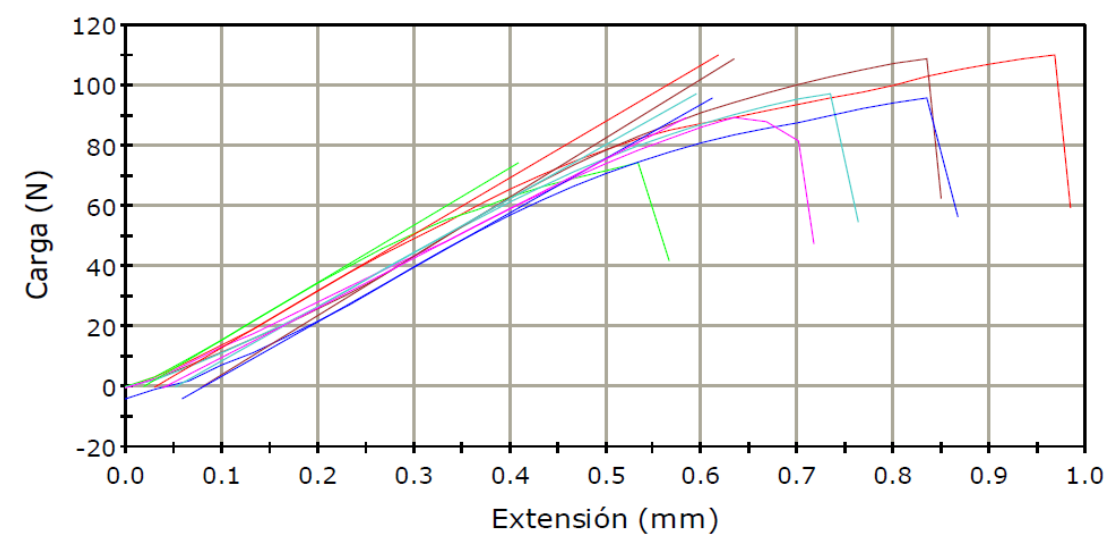

Fig. 181: Gráfico de carga frente a extensión en probetas sumergidas en aceite B

Cuando el fluido dieléctrico es el B, la disminución de las propiedades de tracción son exactamente iguales que cuando se trabaja con aceite dieléctrico A. Por lo tanto, se puede concluir que los aceites atacan en igual grado al material celulósico incluido dentro de la cuba del transformador. Este ataque es muy severo si tenemos en cuenta los valores netos de variación, antes y después, de cada una de las propiedades evaluadas.

\section{9.b. Juntas de goma}

El transformador de distribución sumergido en aceite es un equipo que, generalmente, opera bajo condiciones ambientales a la intemperie, por lo tanto estará sometido a cambios de temperatura, contaminación ambiental, lluvia, luz solar además de las 
condiciones propias de operación del transformador como variación de temperatura por solicitaciones eléctricas. De acuerdo con estas características, se deduce que el diseño y construcción de un transformador debe ser tal que no permita que la parte interna del mismo esté sometida a la acción de agentes externos debido a las fluctuaciones del medio ambiente.

Teniendo en cuenta lo anterior, encontramos que las juntas elastoméricas por su función y ubicación, son elementos con alta probabilidad de permitir el ingreso de humedad al interior del transformador o fugas de aceite del tanque causadas por el deterioro del material de empaquetamiento o deficiencias en el diseño del sello.

Adicionalmente, las juntas de empaquetamiento pueden convertirse en un elemento contaminador del aceite por descomposición y/o, en algunos casos, conductor ayudando a producir fallas o descargas a tierra. Este funcionamiento anómalo es causado por la calidad misma del aislante utilizado, la cual depende del proceso de fabricación y materiales empleados en su elaboración.

Debido a este motivo, se han sometido a ensayo de envejecimiento acelerado, las juntas poliméricas usadas en dichos empaques con el objetivo de determinar la pérdida de propiedades mecánicas, pérdida de masa... Para ello, se han preparado probetas microhalterio de material elastomérico y se han introducido en el interior del reactor.

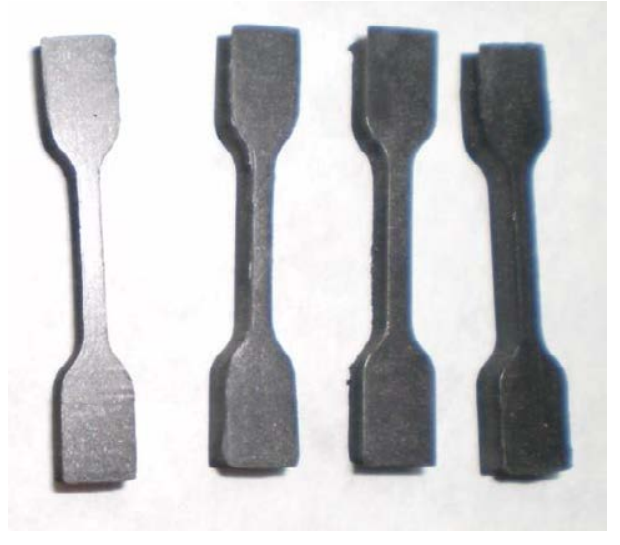

Fig. 182: Probetas microhalterio de caucho antes del ensayo 
El que se vean mermadas las propiedades mecánicas de las probetas, será un factor importante a tener en cuenta en el mantenimiento de los transformadores, ya que si las juntas se deterioran y dejan pasar la humedad y radiaciones ambientales, la velocidad de oxidación del fluido dieléctrico se puede ver incrementado considerablemente.

Se determinaron las propiedades de carga a la rotura, porcentaje de elongación y módulo de Young.

Tabla 71: Variación de propiedades mecánicas de probetas de caucho sumergidas en aceite A

\begin{tabular}{lccc}
\hline & Antes ensayo & Después ensayo & \% Variación \\
\hline Modulo Young (MPa) & 5,41 & 9,24 & $\mathbf{7 0 , 7 9}$ \\
Carga Rotura (N) & 84,49 & 73,82 & $\mathbf{- 1 2 , 6 3}$ \\
Deformación (\%) & 127,40 & 24,61 & $\mathbf{- 8 0 , 6 8}$ \\
\hline
\end{tabular}

Tabla 72: Variación de propiedades mecánicas de probetas de caucho sumergidas en aceite B

\begin{tabular}{lccc}
\hline & Antes ensayo & Después ensayo & \% Variación \\
\hline Modulo Young (MPa) & 5,41 & 15,23 & $\mathbf{1 8 1 , 5 1}$ \\
Carga Rotura (N) & 84,49 & 47,89 & $\mathbf{- 4 3 , 3 2}$ \\
Deformación (\%) & 127,40 & 1,32 & $\mathbf{- 9 8 , 9 6}$ \\
\hline
\end{tabular}




\section{Microhalterio}

nuevo

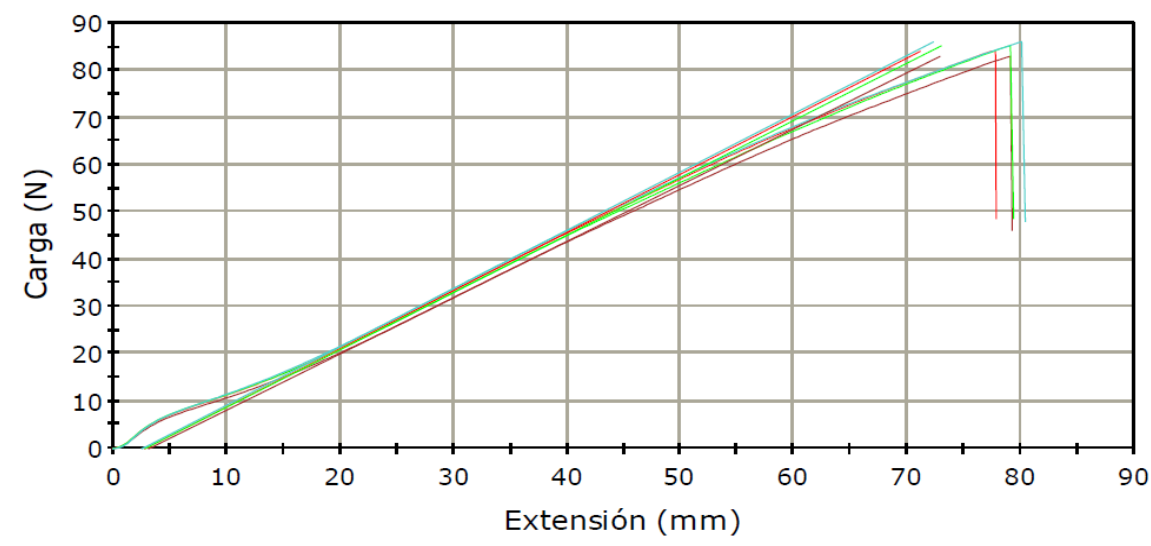

Microhalterio envejecido con

Aceite A

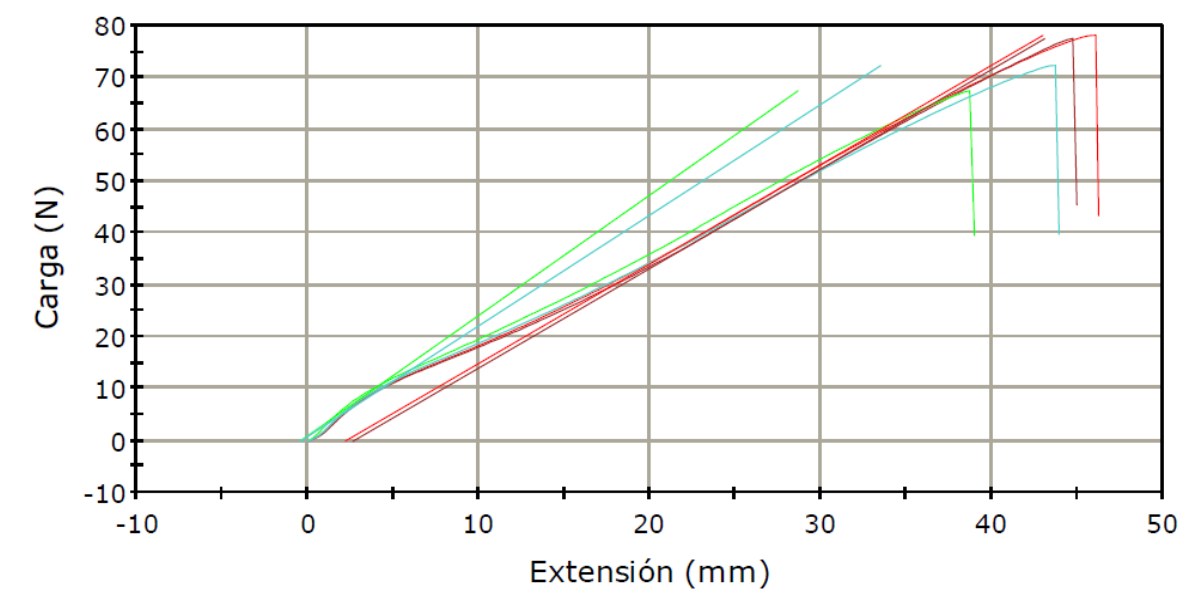

Microhalterio envejecido en Aceite B

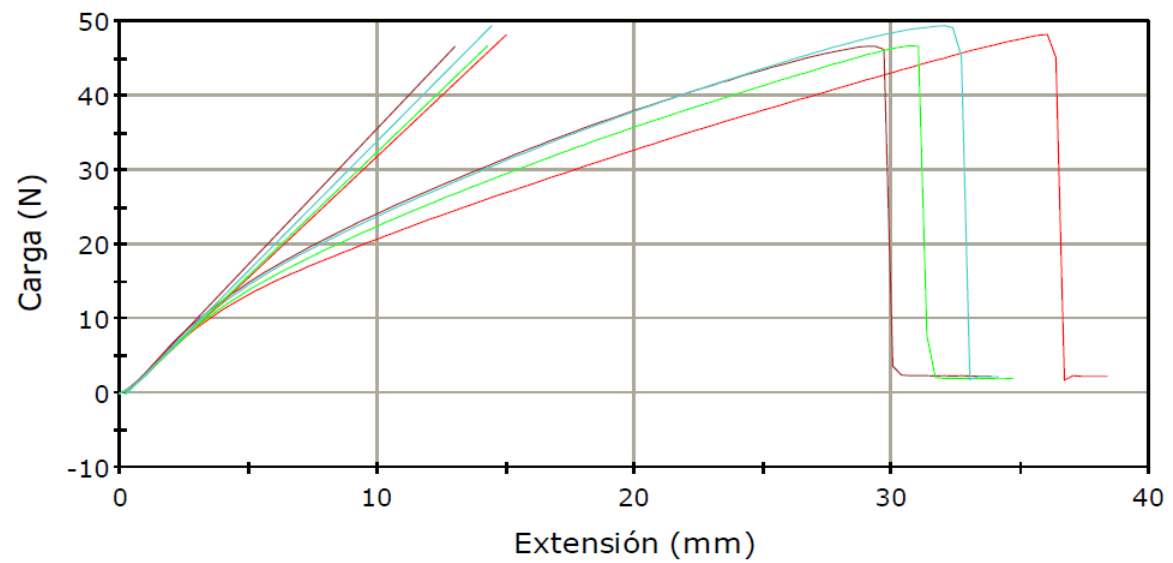

Fig. 183: Representación de la carga frente a la extensión de las probetas de caucho 
Como se puede observar en los gráficos anteriores y en los datos de porcentaje de variación de las diferentes propiedades mecánicas, para ambos aceites, dichas variaciones son muy elevadas, por lo que sería preciso un estudio más exhaustivo para conocer las causas de dichas variaciones.

\subsubsection{COMPATIBILIDAD EN PRESENCIA DE ÁCIDOS GRASOS}

\subsubsection{Resultados del papel Nomex}

Tal y como se ha citado anteriormente, el papel Nomex en un polímero sintético cuyo monómero es la aramida. Dicho polímero, debido a su estructura química, es muy difícil de hidrolizar o que sufra ataques químicos de analitos presentes en la matriz del reactor, por lo que le confiere unas propiedades de tracción óptimas para ser usado como material aislante dentro de un transformador.

A continuación se muestra una imagen del estado de las probetas de papel Nomex después de ser sometidas a ensayo. Como se aprecia en la imagen, ninguna de las probetas ensayadas ha sufrido cambios en su tonalidad o ataque químico sobre su superficie.

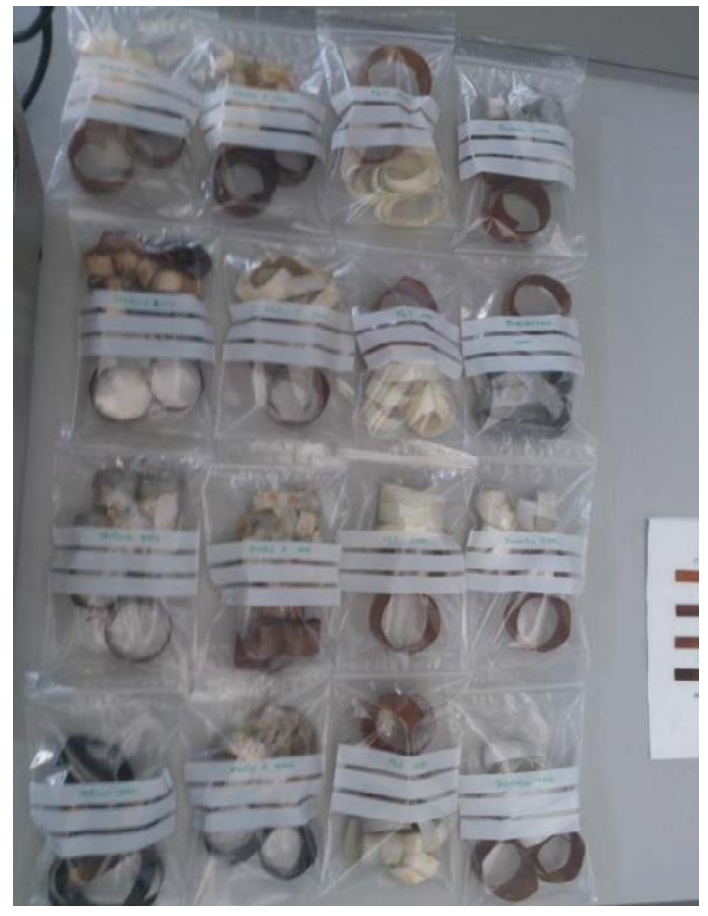

\begin{tabular}{|c|c|c|c|}
\hline Aceite F & Aceite E & Aceite B & Aceite A \\
\hline $1000 \mathrm{~h}$ & $1000 \mathrm{~h}$ & $1000 \mathrm{~h}$ & $1000 \mathrm{~h}$ \\
\hline Aceite F & Aceite E & Aceite B & Aceite A \\
\hline $2000 \mathrm{~h}$ & $2000 \mathrm{~h}$ & $2000 \mathrm{~h}$ & $2000 \mathrm{~h}$ \\
\hline Aceite F & Aceite E & Aceite B & Aceite A \\
\hline $3000 \mathrm{~h}$ & $3000 \mathrm{~h}$ & $3000 \mathrm{~h}$ & $3000 \mathrm{~h}$ \\
\hline Aceite F & Aceite E & Aceite B & Aceite A \\
\hline $4000 \mathrm{~h}$ & $4000 \mathrm{~h}$ & $4000 \mathrm{~h}$ & $4000 \mathrm{~h}$ \\
\hline
\end{tabular}

Fig. 184: Estado de las probetas de papel Nomex y cartón prensado después del ensayo 
El aceite $\mathrm{F}$ es un nuevo aceite sometido a estudio cuyas propiedades físico químicas y su composición química es similar a las del aceite E.

La única observación a tener en cuenta es la presencia de lodos sobre la superficie de las probetas de Nomex que han estado sumergidas en aceite dieléctrico mineral. Dichos lodos son productos de degradación oxidativa del aceite dieléctrico mineral y su deposición sobre la superficie del material aislante no afecta en sus propiedades mecánicas, tal y como se indicará a continuación.

\section{a) Resultados de elongación vs. Tiempo de degradación}

Observando la figura 185, podemos asegurar que la estructura química de la poliaramida no ha sufrido ningún tipo de craqueo u oxidación tanto si ha estado en contacto con aceites vegetales como si lo ha estado con aceites minerales. Además, la presencia de ácidos grasos libres y altas temperaturas no provoca ningún cambio químico en la estructura del polímero.

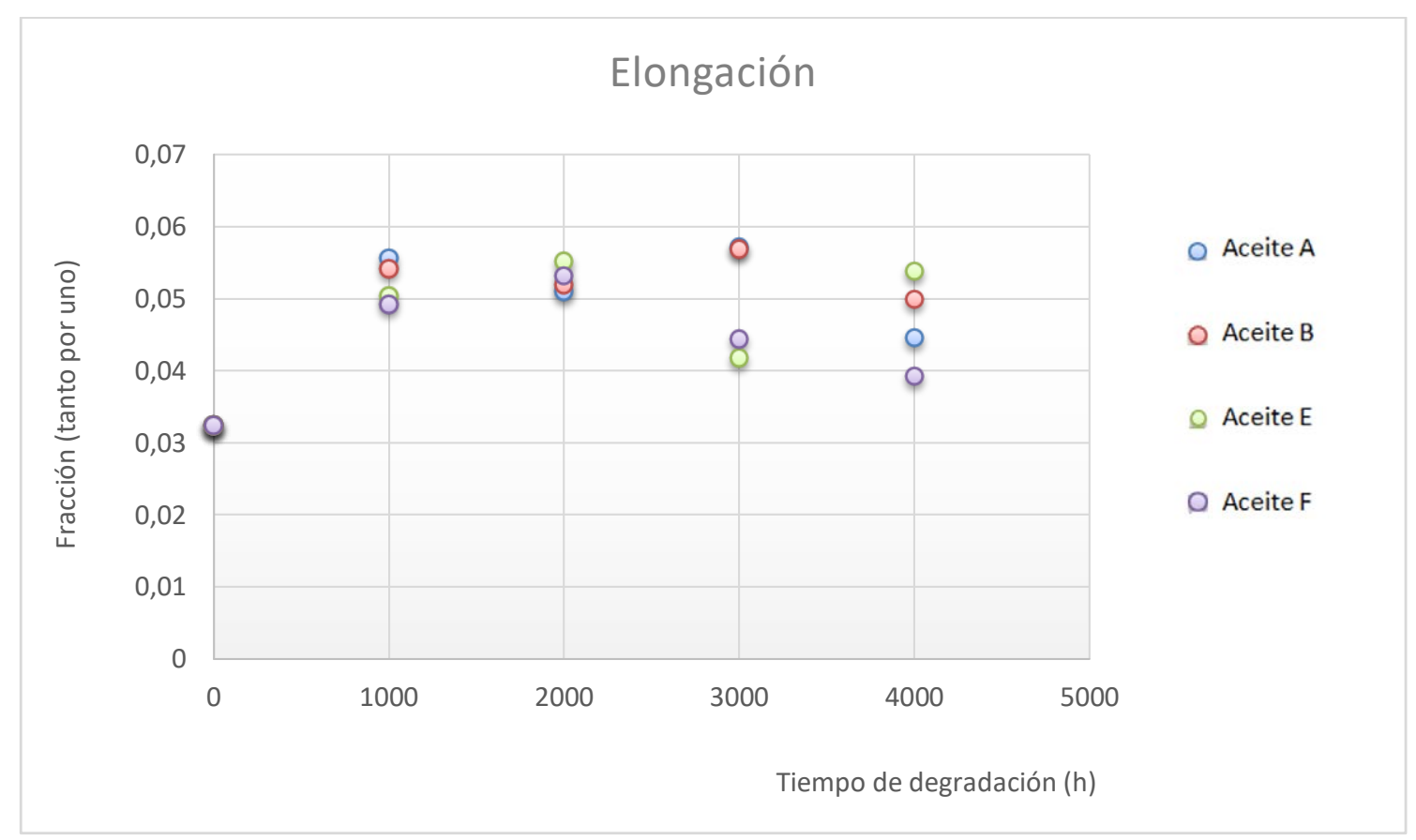

Fig. 185: Elongación vs tiempo para papel Nomex 
Cada resultado que se muestra en el gráfico de la figura 185 es la media aritmética del ensayo de tres probetas de papel Nomex. Cada probeta ensayada tenía una longitud de $20 \mathrm{~cm}$.

b) $\underline{\text { Resultados de tracción vs. tiempo de degradación }}$

En los resultados obtenidos en dicho ensayo, se observa un fenómeno contrario al esperado: no solo la carga a la ruptura de las probetas Nomex no disminuye con el tiempo en ninguna de sus combinaciones, sino que esta carga a la ruptura aumenta un $50 \%$ su valor neto inicial. Una posible explicación es que la resina epoxi que posee la superficie de dicho polímero se activase con el calor, provocando un aumento en las propiedades de tracción y duplicando el valor neto de carga máxima.

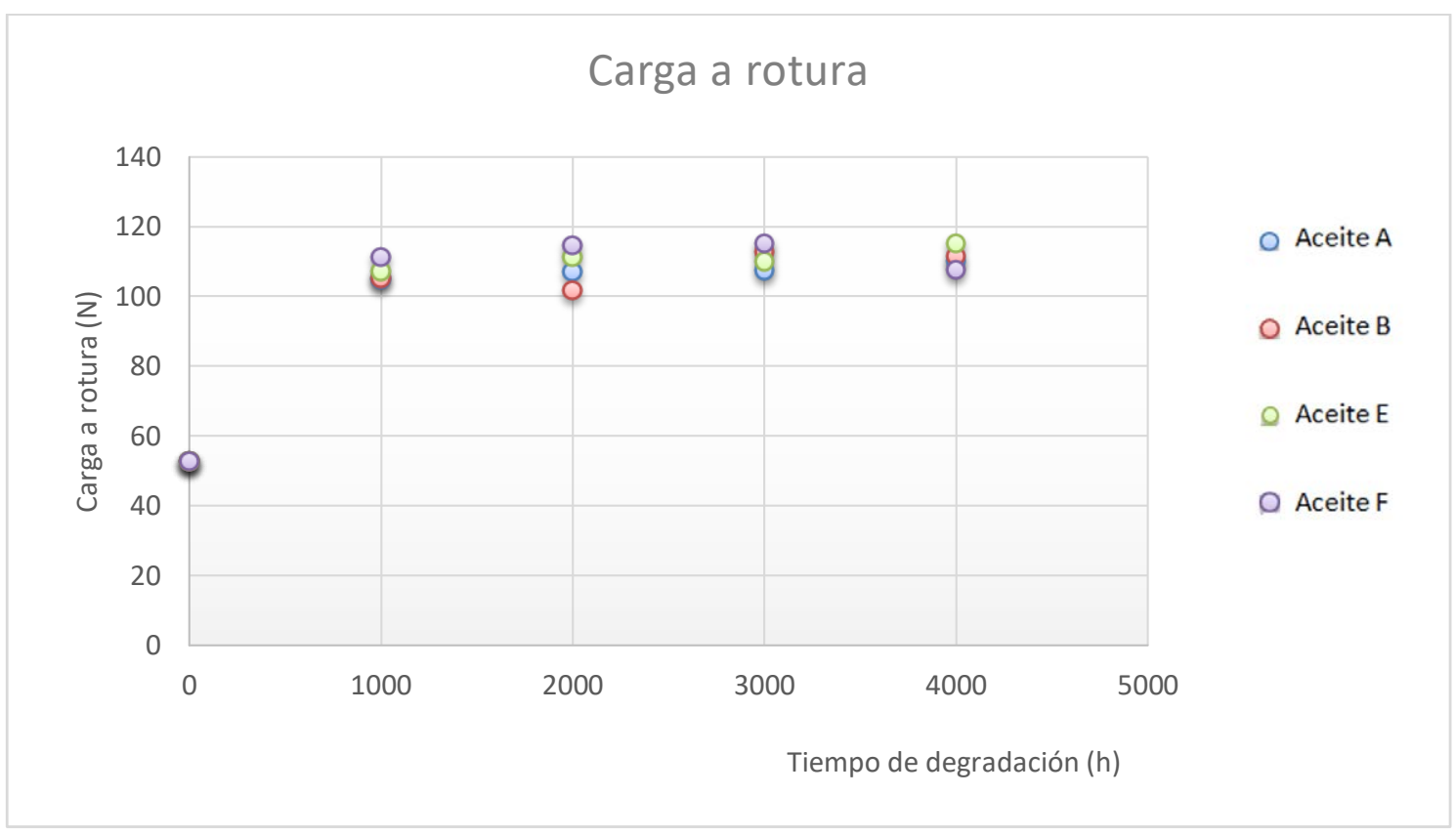

Fig. 186: Carga vs tiempo para papel Nomex

\subsubsection{Resultados del cartón prensado}

Según se ha indicado en la figura 184, el estado visual de las probetas de papel prensado difiere notoriamente con respecto al estado de las probetas de papel Nomex. En este 
caso, se observa un ataque químico sobre la superficie del cartón. Para los aceite minerales, se observan depósitos de lodos sobre la superficie del cartón. Además, las probetas que han estado sumergidas en aceite $\mathrm{F}$ están degradadas térmicamente. Su rigidez se ha visto incrementada hasta tal punto que dichas probetas se han roto al extraerlas del reactor de vidrio.

\section{a) Resultados de elongación vs. tiempo de degradación}

Al contrario que el fenómeno observado para las probetas de papel Nomex, en esta ocasión la estructura química de la celulosa ha sufrido reacciones de hidrólisis y craqueo térmico ya que su porcentaje de elongación ha disminuido progresivamente con el tiempo.

Observando los resultados, podemos ver que las probetas que han estado sumergidas en aceite mineral poseen un porcentaje de elongación ligeramente menor con el tiempo que sus homólogas que han estado sumergidas en aceite vegetal. Por lo tanto, la presencia de ácidos grasos libres provoca un aumento en la cinética de degradación del material celulósico, viéndose intensificado dicho fenómeno cuando el cartón está sumergido en aceites minerales. La presencia de ácidos grasos en una aceite proviene de la hidrólisis del triglicérido ocasionada por la presencia de moléculas de agua en el medio.

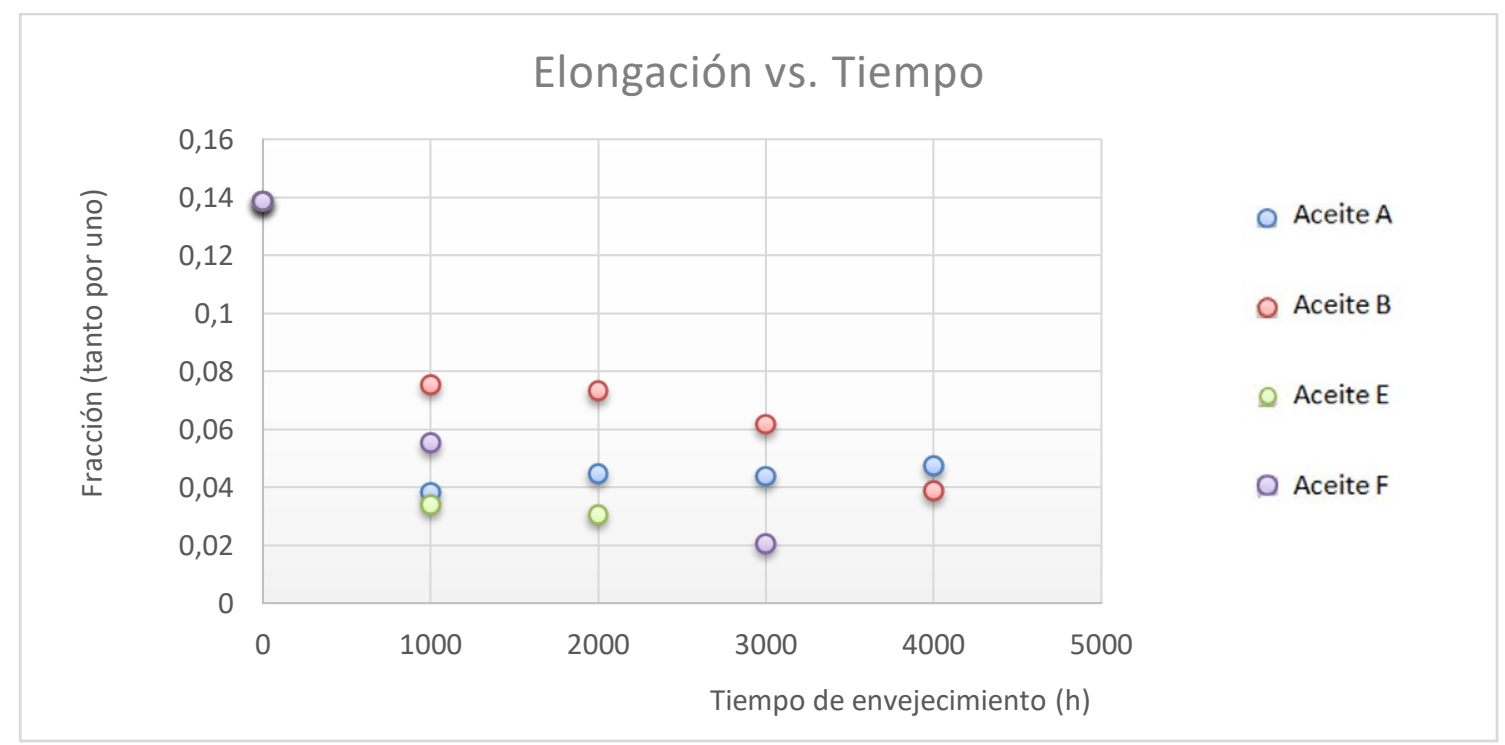

Fig. 187: Elongación vs. Tiempo de envejecimiento en papel celulósico 
c) Resultados de tracción vs. Tiempo de degradación

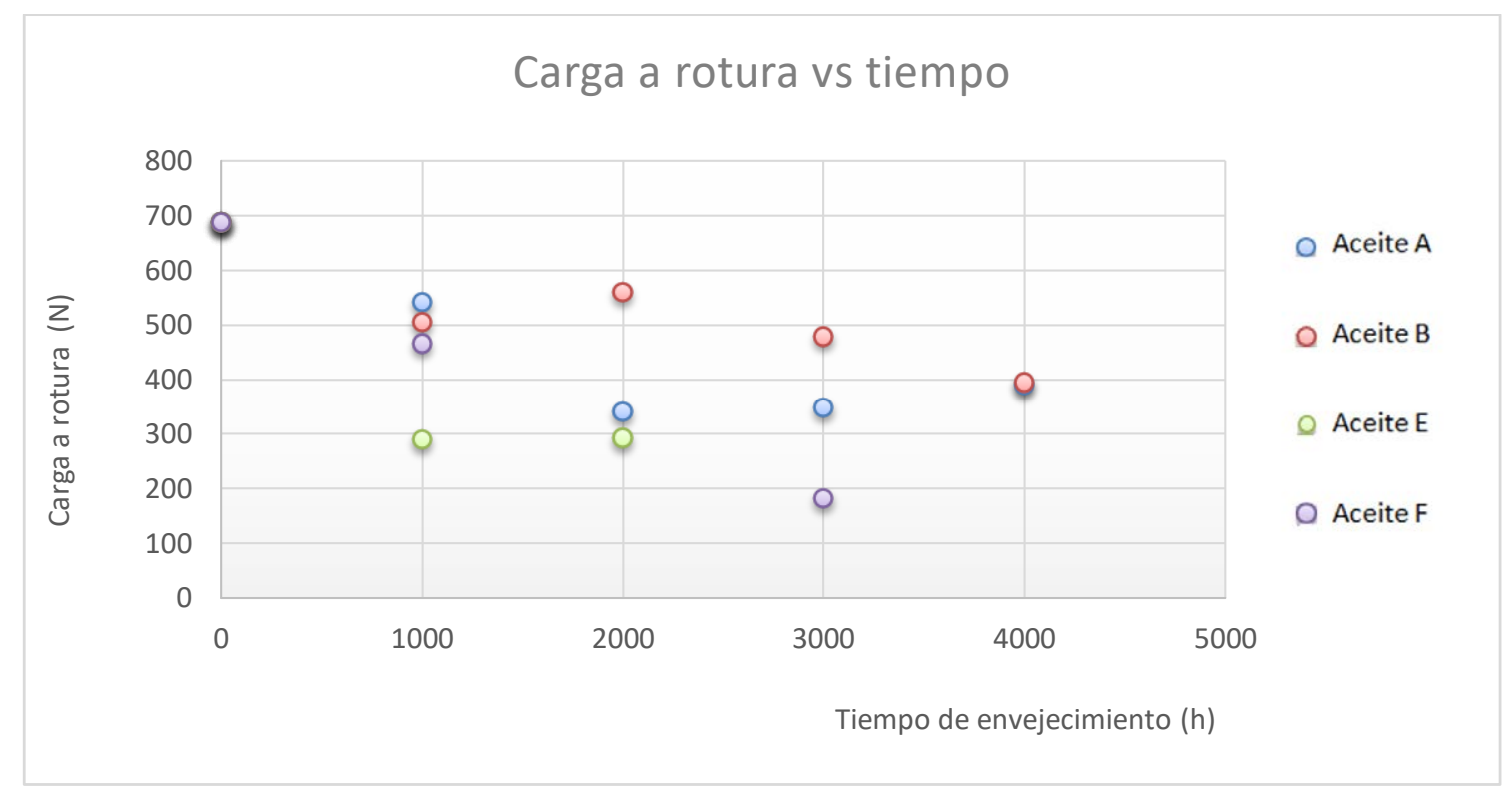

Fig. 188: Carga vs. Tiempo de envejecimiento en papel celulósico

El mismo fenómeno observado que en las propiedades de elongación, se repite en las propiedades de tracción. Existe una disminución de la carga máxima de rotura con el tiempo. Dicho fenómeno nos indica que ha habido un craqueo en las estructuras de la celulosa y hemicelulosa de la que está formada la probeta de material celulósico.

La disminución en la carga máxima de rotura se ve ligeramente intensificada cuando las probetas han estado sumergidas en aceite mineral que cuando han estado sumergidas en aceite vegetal.

\subsubsection{Resultados del catalizador de cobre}

Para evaluar el estado de las probetas de catalizador de cobre, se hizo un estudio visual acerca de la corrosión de su superficie.

A continuación se muestra un cuadro resumen con las imágenes de las 16 probetas de cobre: 


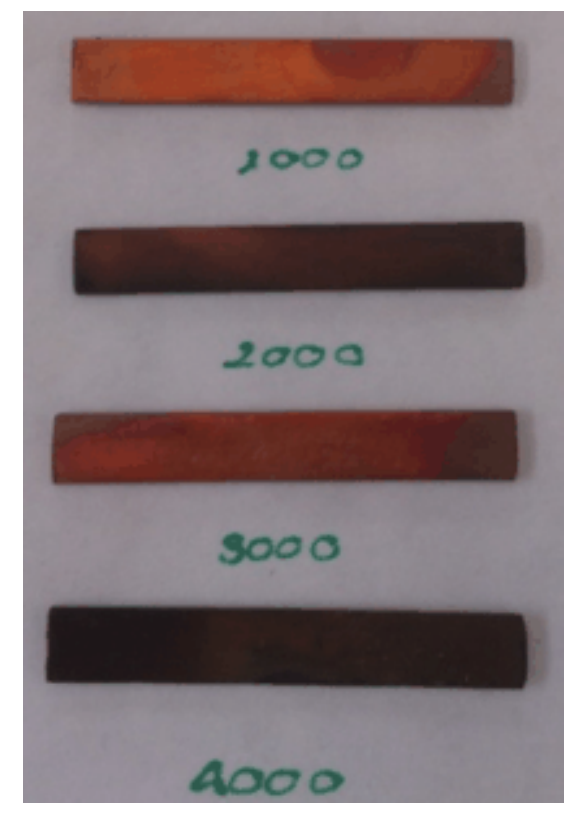

Aceite E

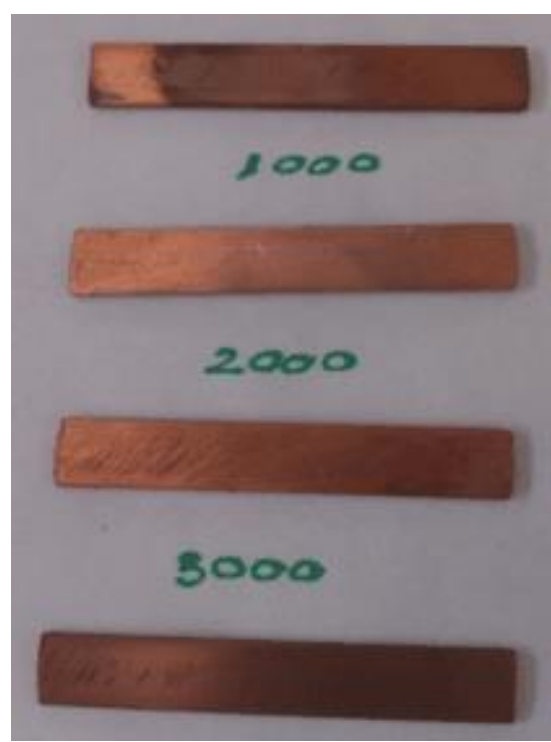

Aceite F

Fig. 189: Estado de las probetas de cobre después del ensayo

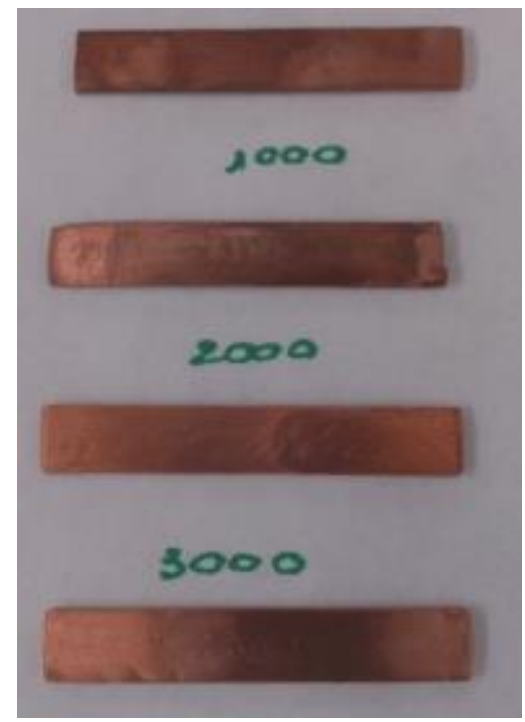

Aceite A

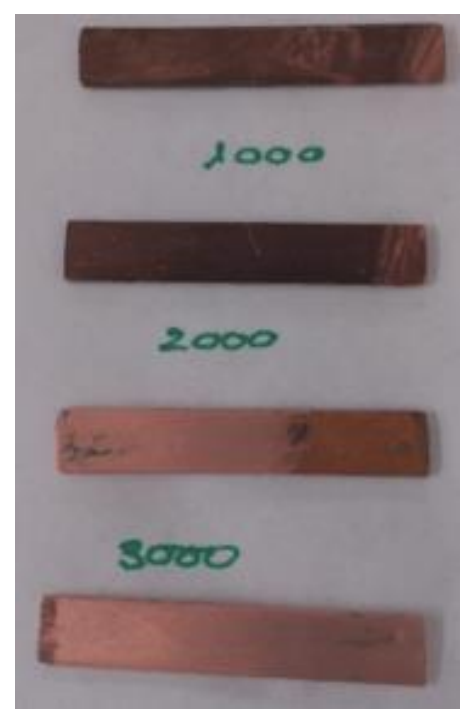

Aceite B

Fig. 190: Estado de las probetas de cobre después del ensayo

Observando las imágenes podemos afirmar ciertas premisas:

\& Las probetas de $\mathrm{Cu}$ en el aceite $\mathrm{E}$ poseen una mayor corrosión superficial que sus homólogas de F, A y B, y además, este fenómeno se intensifica con el tiempo de degradación. 
\& Las probetas de $\mathrm{Cu}$ que han estado sumergidas en el Aceite $\mathrm{E}$ poseen una corrosión a la lámina de cobre de tipo 2 .

\& En las probetas de 3000 y 4000 horas de degradación tanto del aceite A como del aceite $\mathrm{B}$ se ha observado la formación de sales pasivadoras de cobre que han evitado la corrosión de la superficie metálica de las probetas.

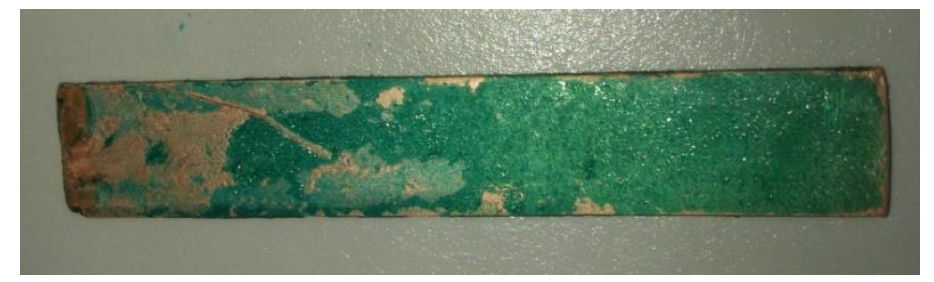

Fig. 191: Formación de sales pasivadoras en el aceite A

En el mecanismo de formación de dichas sales intervienen las bases conjugadas de los ácidos grasos presentes en la matriz (bases conjugadas del ácido oleico y láurico) y los iones de $\mathrm{Cu}^{2+}$ presentes en la matriz cuyo origen es la oxidación de la superficie metálica de la probeta de cobre.

$$
\begin{gathered}
2 \mathrm{Cu}+\mathrm{O}_{2} \rightarrow 2 \mathrm{CuO} \\
4 \mathrm{Cu}+\mathrm{O}_{2} \rightarrow 2 \mathrm{Cu}_{2} \mathrm{O} \\
2 \mathrm{R}^{\prime} \mathrm{COOH}+\mathrm{Cu}_{2} \mathrm{O} \rightarrow 2 \mathrm{Cu}\left(\mathrm{R}^{\prime} \mathrm{COOH}\right)+\mathrm{H}_{2} \mathrm{O} \\
4 \mathrm{R}^{\prime} \mathrm{COOH}+2 \mathrm{CuO} \rightarrow 2 \mathrm{Cu}\left(\mathrm{R}^{\prime} \mathrm{COO}\right)_{2}+2 \mathrm{H}_{2} \mathrm{O}
\end{gathered}
$$

Estas sales evitan que la superficie metálica sufra procesos de corrosión por presencia de hidroperóxidos, aldehídos o cetonas... productos de degradación del aislante líquido. 


\subsubsection{Resultados de las propiedades de los aceites dieléctricos}

El material dieléctrico líquido, tal y como se conoce por experiencias anteriores en el laboratorio, sufre procesos de degradación termo-oxidativa. Dicho fenómeno se ve intensificado en presencia de iones cúpricos. La degradación del aislante provoca una disminución en las propiedades aislantes del fluido. Según la guía de mantenimiento de transformadores (UNE EN 60422:2013), existen unos valores a partir de los cuales, un aceite ha perdido por completo todas sus propiedades como aislante líquido y deberá ser reemplazado dentro del transformador.

A continuación se irán analizando, uno a uno, los parámetros cuantificados para cada una de las 16 muestras de aceite dieléctrico obtenido:

\section{a) Variación de la viscosidad cinemática con el tiempo de degradación}

La viscosidad de un aceite dieléctrico es un parámetro que debe ser meticulosamente cuantificado, ya que incrementos de dicho parámetro provoca disminuciones en las propiedades de aislamiento (mayor dificultad para penetrar en los devanados del transformador y disminución de la velocidad de evacuación del calor del interior del transformador hacía el exterior).

En este caso, y sin tener en cuenta la muestra de Aceite A a 2000 h, la viscosidad se han mantenido constante durante todo el proceso de degradación. No ha habido cambios sustanciales en el valor neto de dicho parámetro con respecto a sus valores iniciales.

La muestra de Aceite A 2000 no se debe tener en cuenta ya que dicho valor de viscosidad disminuye a las 3000 horas y se mantiene constante a las 4000 horas. 


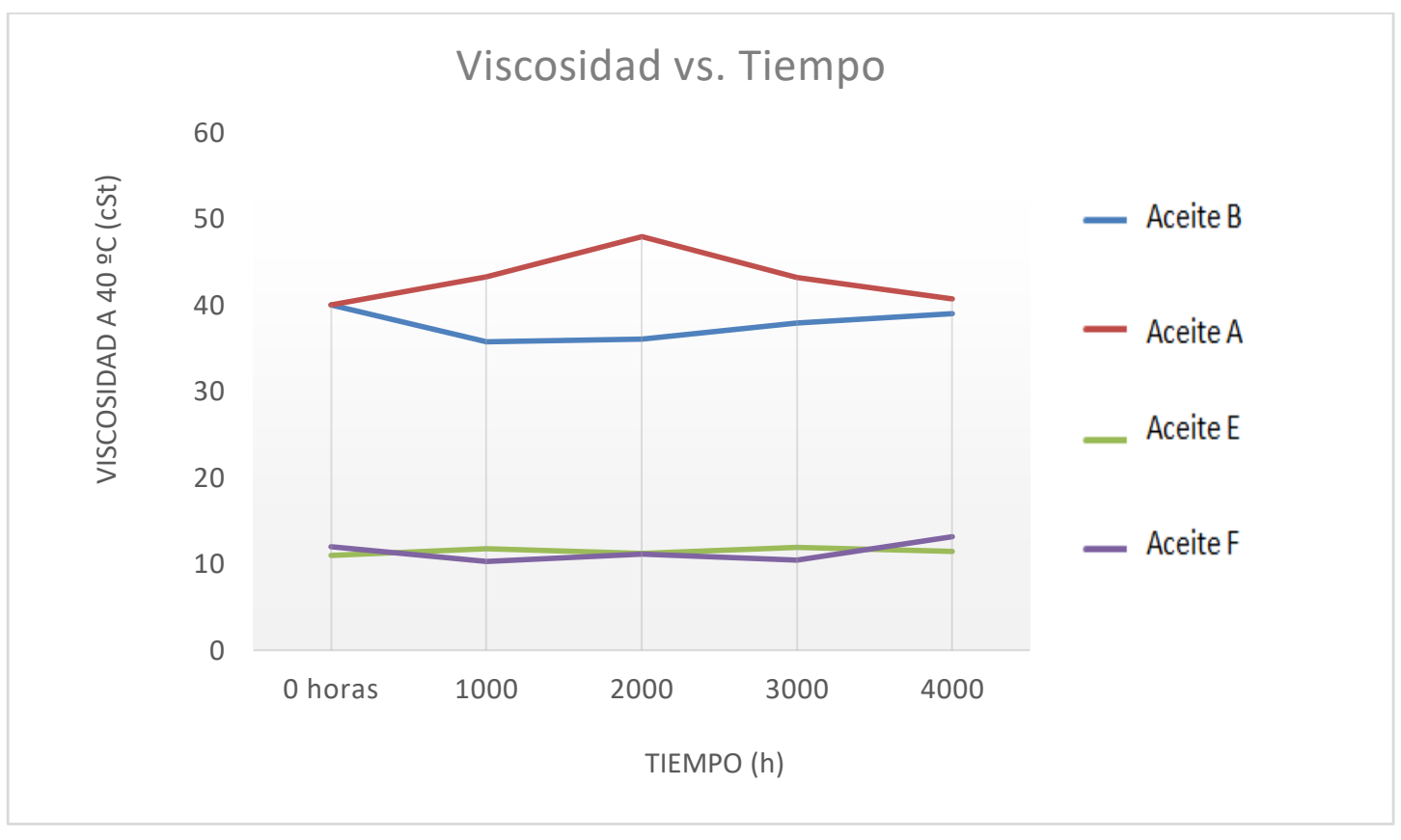

Fig. 192: Viscosidad cinemática a $40{ }^{\circ} \mathrm{C}$ vs. Tiempo de degradación

b) Análisis de gases disueltos versus tiempo de degradación

Cuando un fluido dieléctrico, independientemente de su naturaleza química, se encuentra sometido a fatigas térmicas durante un periodo prolongado de tiempo, se produce un craqueo térmico de su cadena hidrocarbonada dando lugar a gases de bajo peso molecular pero altamente inflamables. En función de si la tendencia del aceite es a absorber el gas producido o a repelerlo (gass absorbing/gass evolving) se generará una presión interna en la cuba del transformador. Si la generación de gases por craqueo térmico es elevada, se puede llegar a alcanzar presiones internas lo suficientemente elevadas como para reventar la cuba del transformador.

Se analizaron los gases disueltos (DGA) en las muestras extraídas a las 1000 y 2000 horas ya que en las de 3000 y 4000 horas, el material particulado presente era tan elevado, que era imposible la toma de muestra con la jeringa especial para gases (no se pueden filtrar las muestras ya que sufren un proceso de desgasificación cuando atraviesan el filtro de nitrocelulosa). Se analizaron los siguientes gases por microcromatografía gaseosa: nitrógeno, oxígeno, metano, etano, etileno, acetileno, monóxido de carbono y dióxido de carbono. Para verificar que no ha habido problemas en la toma 
de muestra que pudieran falsear los resultados, se hizo un diagnóstico del aceite haciendo uso del triángulo de Duval.

A continuación se muestran los resultados del DGA para las muestras degradadas 1000 horas a $120^{\circ} \mathrm{C}$ :

Tabla 73: Resultado del DGA para las muestras degradadas 1000 horas

\begin{tabular}{|l|c|c|c|c|c|}
\hline [DG] ppm & Fórmula & Aceite $\mathrm{F}$ & Aceite $\mathrm{E}$ & Aceite A & Aceite B \\
\hline Hidrógeno & $\mathrm{H}_{2}$ & 34 & 0 & 20 & 0 \\
\hline Metano & $\mathrm{CH}_{4}$ & 355 & 43 & 7 & 16 \\
\hline CO & $\mathrm{CO}$ & 629 & 708 & 679 & 177 \\
\hline CO2 & $\mathrm{CO}_{2}$ & 4082 & 1178 & 2110 & 3710 \\
\hline Etileno & $\mathrm{C}_{2} \mathrm{H}_{4}$ & 36 & 6 & 3 & 5 \\
\hline Etano & $\mathrm{C}_{2} \mathrm{H}_{6}$ & 767 & 11 & 6 & 773 \\
\hline Acetileno & $\mathrm{C}_{2} \mathrm{H}_{2}$ & 0 & 0 & 0 & 0 \\
\hline Nitrógeno & $\mathrm{O}_{2}$ & 21267 & 26374 & 17524 & 17837 \\
\hline Oxígeno & $\mathrm{N}_{2}$ & 75280 & 68457 & 53192 & 55787 \\
\hline Diagnosis & - & $\mathbf{T 1}$ & $\mathbf{T 1}$ & $\mathbf{T 1}$ & $\mathbf{T 1}$ \\
\hline
\end{tabular}

Según el triángulo de Duval, en todos los casos se han producido fallos térmicos tipo $\mathrm{T} 1$, es decir, los aceites han sido expuestos a temperaturas inferiores a los $300^{\circ} \mathrm{C}$.

A continuación se muestra la tabla resumen con los resultados obtenidos de DGA para las muestras sometidas a 2000 horas de degradación: 
Tabla 74: Resultado del DGA para las muestras degradadas 2000 horas

\begin{tabular}{|l|c|c|c|c|c|}
\hline [DG] ppm & Fórmula & Aceite $\mathrm{F}$ & Aceite E & Aceite A & Aceite B \\
\hline Hidrógeno & $\mathrm{H}_{2}$ & 0 & 0 & 17 & 0 \\
\hline Metano & $\mathrm{CH}_{4}$ & 33 & 414 & 5 & 16 \\
\hline CO & $\mathrm{CO}$ & 444 & 1044 & 600 & 204 \\
\hline CO2 & $\mathrm{CO}_{2}$ & 1251 & 4616 & 2377 & 1681 \\
\hline Etileno & $\mathrm{C}_{2} \mathrm{H}_{4}$ & 6 & 20 & 2 & 6 \\
\hline Etano & $\mathrm{C}_{2} \mathrm{H}_{6}$ & 14 & 792 & 11 & 662 \\
\hline Acetileno & $\mathrm{C}_{2} \mathrm{H}_{2}$ & 0 & 0 & 0 & 0 \\
\hline Nitrógeno & $\mathrm{O}_{2}$ & 25704 & 28668 & 25026 & 21356 \\
\hline Oxígeno & $\mathrm{N}_{2}$ & 64230 & 81650 & 83830 & 62344 \\
\hline Diagnosis & - & $\mathbf{T 1}$ & $\mathbf{T 1}$ & $\mathbf{T 1}$ & T1 \\
\hline
\end{tabular}

Del mismo modo que en la remesa de muestras anteriores, la interpretación de los resultados indica que todos los aceites han sido sometidos a temperaturas inferiores de los $300^{\circ} \mathrm{C}$, es decir, el DGA refleja fallos de tipo térmico T1.

\section{c) Índice de acidez}

Es conocido en química orgánica, que la acidez de los ácidos carboxílicos es mayor que la de los homólogos alcohólicos, debido a que el carbono carbonílico es deficitario electrónicamente y como consecuencia, tenderá a atraer hacia él el par de electrones del enlace $\mathrm{C}-\mathrm{O}$ y como consecuencia, debilitar el enlace $\mathrm{O}-\mathrm{H}$, de ahí su relativa fuerza ácida. Este fenómeno provoca que tanto el oleico como el láurico tengan $\mathrm{pK}_{\mathrm{a}}$ cercanos a los 4,5, generando de por sí un ambiente ácido de partida.

Por otro lado, la degradación termo-oxidativa de los triglicéridos de partida de los aceites vegetales predispone a que este tipo de matriz rompa los enlaces glicerol-acetato dando lugar a ésteres de ácidos grasos que a su vez sufren reacciones de acidificación, obteniéndose el correspondiente ácido graso y como consecuencia, elevando más la acidez de la matriz. Este fenómeno no se ve tan intensificado en los aceites de origen 
mineral, ya que su estructura química consta principalmente de anillos aromáticos, cicloalcanos o compuestos nafténicos y parafinas sin grupo funcional.

A continuación se muestran los resultados obtenidos en cada una de las muestras sometidas a ensayo:

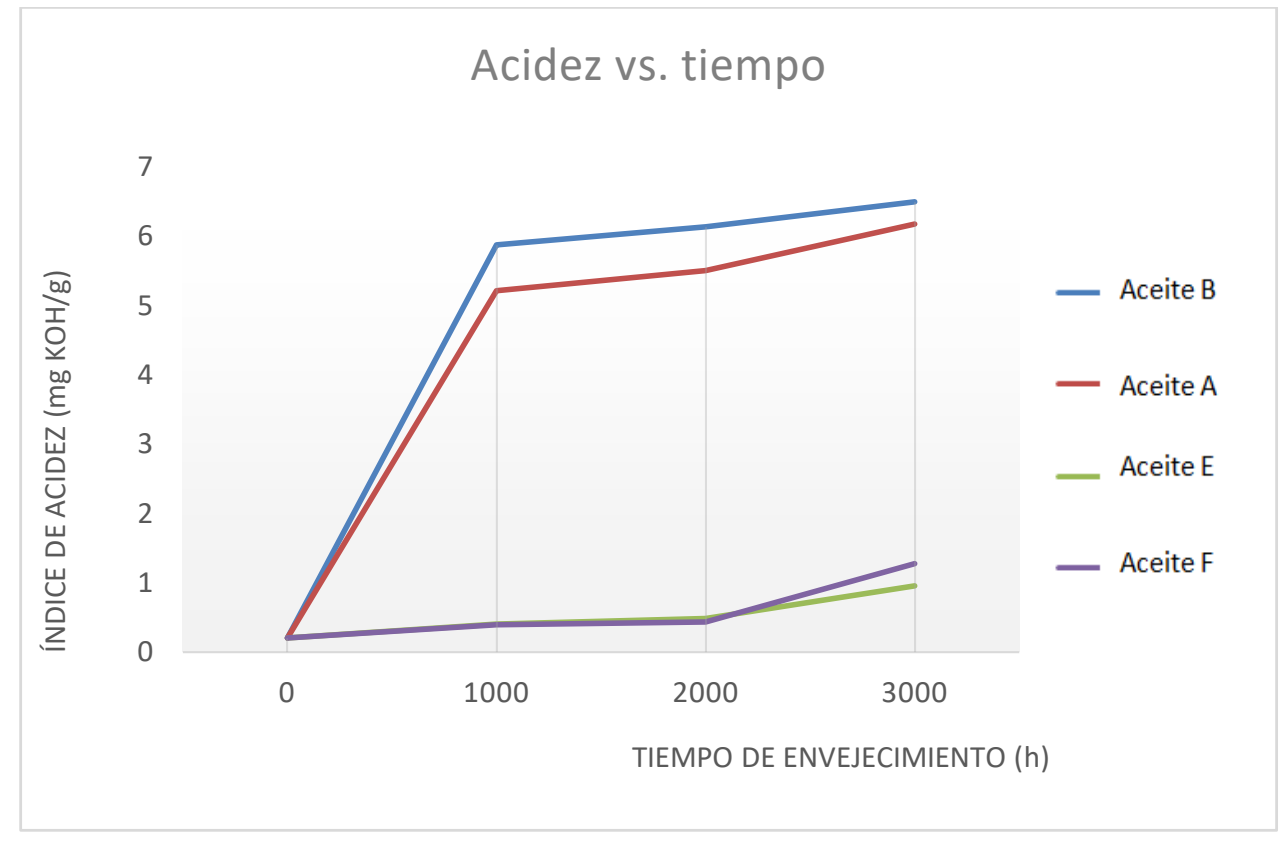

Fig. 193: Representación de la acidez vs. Temperatura de degradación

Como se puede comprobar, el índice de acidez de los aceites vegetales es 6 veces mayor aproximadamente que sus homólogos minerales. Esto es debido al fenómeno explicado anteriormente. Lo importante de estos resultados es que por muy elevado que sea el índice de acidez de las muestras, el ataque que sufre el material aislante celulósico es menor en los aceites vegetales que en los aceites minerales, por lo que una vez más, queda corroborado que el tamaño de la cadena es un factor de mucho peso a la hora de determinar el potencial de ataque de un aceite al material celulósico.

\section{d) Contenido en agua por Karl-Fischer}

El contenido en agua dentro de un sistema trifásico aceite/cartón/aire, tal y como se vio en experiencias anteriores, hace imposible seguir el estado del fluido dieléctrico basándonos únicamente en dicho parámetro, ya que en función de cuando tomemos la muestra, puede ser que haya más agua en la fase cartón que en la fase aire o en la fase 
aceite, y viceversa. Por lo tanto, a las 1000 horas podemos tomar muestra de aceite y obtener $1500 \mathrm{ppm}$ de agua disuelta en el aceite y volver a tomar muestra a las 3000 horas y obtener $50 \mathrm{ppm}$ disueltas, cuando la tendencia natural sería un incremento de agua disuelta en el medio. Este fenómeno ocurre debido a las elevadas temperaturas a las cuales se está llevando a cabo el experimento (temperaturas superiores a la temperatura de ebullición del agua).

Aun así, se determinó el contenido en agua por Karl-Fischer a las 16 muestras degradadas térmicamente. Los resultados obtenidos se muestran en la siguiente gráfica resumen:

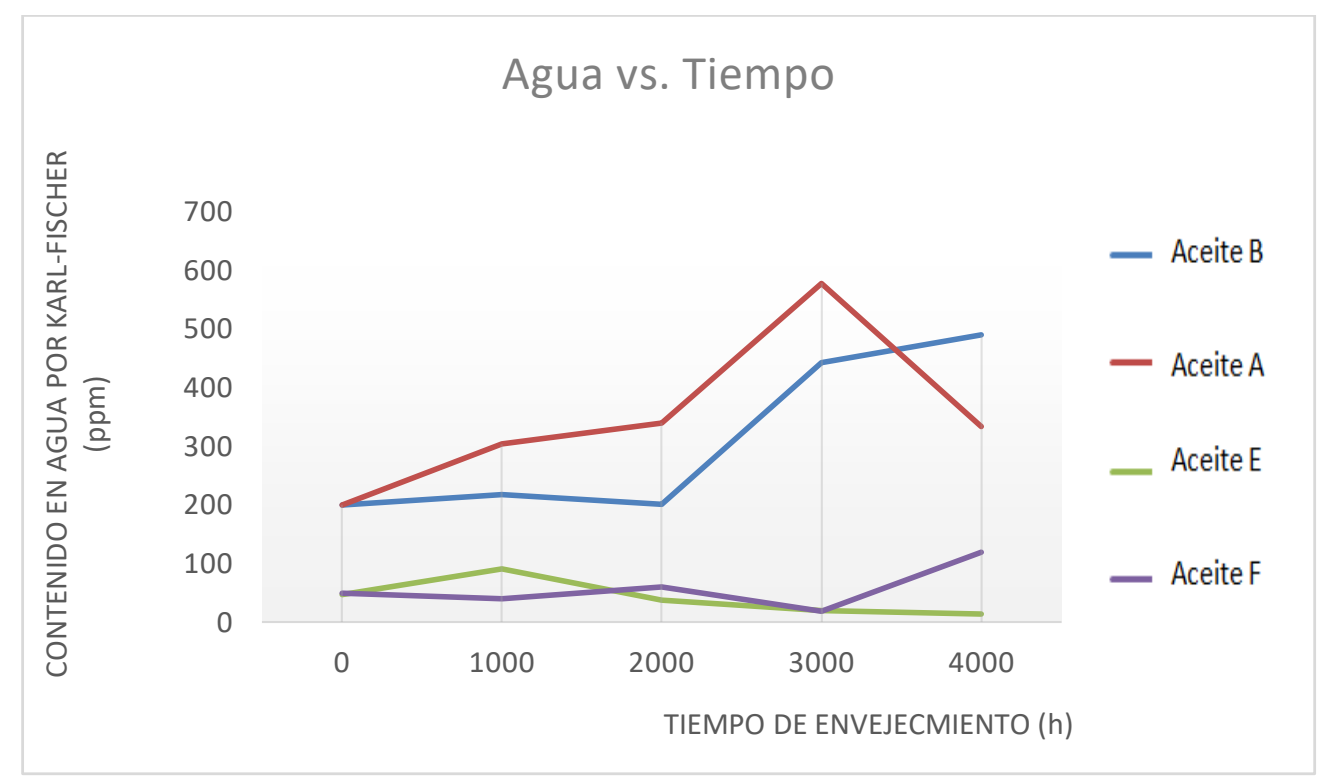

Fig. 194: Contenido en agua por Karl Fischer frente al tiempo de degradación

Se observa una clara diferencia entre los aceites minerales y los aceites vegetales: los aceites vegetales, debido a su estructura química formada por heteroátomos (oxígeno) tiene capacidad de "disolver" mayor cantidad de agua que los aceites minerales. Por lo tanto, en los aceites vegetales habrá menor cantidad de agua disponible para atacar a la superficie metálica del cobre, fenómeno observado en los resultados expuestos de los catalizadores de cobre. 


\subsection{ESTUDIO DE ECOTOXICIDAD EN LOMBRICES Y LECHUGA COMÚN}

\subsubsection{Resultados de la toxicidad aguda en Eisenia foetida según OECD 207}

A continuación se presentan los porcentajes de mortalidad presentados por las lombrices a los 7 días y a los 14 días cuando fueron sometidas a ensayos de ecotoxicidad frente al aceite A.

Tabla 75: Resultado de mortalidad de lombrices según OECD 207

\begin{tabular}{|c|c|c|}
\hline $\begin{array}{c}\text { Concentraciones }(\mathbf{m g} / \mathbf{k g} \\
\text { sustrato seco) }\end{array}$ & Día 7 [Mortalidad, \%] & Día 14 [Mortalidad, \%] \\
\hline Control & 0 & 0 \\
\hline $\begin{array}{c}\text { Control + sustancia } \\
\text { auxiliar }\end{array}$ & 0 & 0 \\
\hline $\mathbf{1 2 , 3 5}$ & 0 & 0 \\
\hline $\mathbf{3 7 , 0 5}$ & 0 & 5 \\
\hline $\mathbf{1 1 1 , 1 5}$ & 0 & 0 \\
\hline $\mathbf{3 3 3 , 4 5}$ & 0 & 0 \\
\hline $\mathbf{1 0 0 0 , 3 5}$ & 0 & 0 \\
\hline
\end{tabular}

El dato anómalo de mortalidad a la dosis de $37,05 \mathrm{mg} / \mathrm{kg}$ a los 14 días se puede concluir que no ha sido consecuencia de la dosis del producto, ya que para concentraciones superiores no ha habido mortalidad.

El CL50 o concentración que produciría una mortalidad del $50 \%$ en los organismos de ensayo, no se puede determinar ya que en ningún caso se ha superado el $50 \%$ de mortalidad en ninguna de las concentraciones ensayadas. Se puede afirmar que el $\mathrm{CL}_{50}$ es superior a los $1000 \mathrm{mg} / \mathrm{kg}$.

Se concluye que el aceite A no presenta efectos tóxicos en Eisenia foetida. 


\subsubsection{Resultados de la toxicidad aguda en Lactuca sativa según OECD 208}

En este caso, la especie sometida a ensayo es la lechuga común. Por lo tanto, los especímenes son semillas de Lactuca sativa inmersas en un sustrato con concentraciones crecientes de aceite A. Se evaluaron los efectos fitotóxicos visibles. No se observaron ningún efecto como clorosis, necrosis, malformaciones, marchitamiento... en las hojas y tallos de ninguna de las plantas germinadas.

En cuanto a la germinación de las semillas, esta ha sido superior al $70 \%$ y la supervivencia de las plantas fue superior al $90 \%$ durante el periodo de ensayo.

Por lo tanto, se puede concluir que el aceite A no presente efectos tóxicos en la especia Lactuca sativa a las concentraciones ensayadas. 
CAPÍTULO 4: CONCLUSIONES Y TRABAJOS FUTUROS 


\subsection{CONCLUSIONES}

Durante el trascurso de la presente tesis, se ha desarrollado una metodología de trabajo en el laboratorio específica para evaluar el comportamiento, tanto químico como físico químico de un aceite dieléctrico de origen vegetal. El objetivo era por tanto, diseñar herramientas de diagnosis que nos devolvieran resultados acerca del comportamiento del aceite vegetal A cuando este se encuentra en condiciones de operación reales. Para ello, se he analizado en profundidad la estructura química y los aditivos, tantos naturales como sintéticos, por los que está formado la matriz del aceite. Un buen entendimiento de su composición nos permitió diagnosticar comportamientos a largo plazo y nos permitió diseñar experimentos que reflejaran resultados de interés para tener un pleno conocimiento del comportamiento de dicho fluido.

Para ello, se diseñaron metodologías para estudiar el comportamiento a bajas temperaturas, se estudiaron sus propiedades de transferencia térmica en todo el rango de temperaturas de operación del aceite en el transformador, se diseñaron metodologías de evaluación de saturación de humedad, oxígeno y nitrógeno recreando las mismas condiciones que tiene el aceite dentro del transformador, se rediseñaron herramientas existentes como el triángulo de Duval para diagnosticar fallos en función de la concentración de gases disueltos y por último, se llevó a cabo un análisis completo de compatibilidad del nuevo fluido con los materiales por lo que está formado el transformador y con los que estará en contacto durante toda su vida útil.

Las conclusiones a las que se ha llegado durante la ejecución de la presente tesis se agruparan por grupos de ensayo, debido al elevado volumen de resultados obtenidos, con el objetivo de facilitar la comprensión de los mismos.

Con respecto a las propiedades o comportamiento en frío, se concluye que el aceite A presenta un bajo rendimiento de separación mecánica por winterización debido a la composición química del mismo. Por esa razón, se optó con trabajar con depresores de punto de congelación. Únicamente hubo uno, el L 7671A cuya composición química son copolímeros de ésteres de estireno-anhídrido maleico que consiguió retrasar la cinética de congelación del aceite y que hizo disminuir el punto de congelación del aceite, según ASTM D 97. 
En cuanto a la determinación de las curvas de saturación de humedad, se observó una cinética de saturación similar a la de otros aceites de origen vegetal presentes en el mercado. Se encontraron relaciones entre el índice de yodo de los aceites y su capacidad de saturación de agua, tanto a media como a elevada temperatura. En los resultados obtenidos con respecto a la curva de tendencia a la saturación, se observan diferencias significativas de la capacidad de saturación de agua en el aceite A cuando trabajamos con humedades relativas diferentes, a elevadas temperaturas. El uso de este aceite en aplicaciones electrotécnicas requerirá de un control, de la temperatura y humedad relativa del medio exhaustivo con el objetivo de evitar la presencia de agua microemulsionada en la matriz del aceite que pudiera mermar las propiedades dieléctricas que posee el mismo.

Como hemos indicado al principio del presente documento, la función principal del aceite A es la de actuar como dieléctrico, pero otra de sus funciones principales es la de disipar el calor generado en diferentes partes de la cuba del transformador, ya sea por fallos térmicos o eléctricos de baja intensidad o por un sobrecalentamiento de alguna parte de núcleo. Para ello, es importante que sus propiedades de transferencia térmicas sean óptimas. Después de llevar a cabo el estudio de sus propiedades principales y de compararlas con otros aceites de diferente origen, concluimos que en cuanto a la densidad y los coeficientes de expansión térmica, los resultados son congruentes y también acordes con los que indica la bibliografía de aceites vegetales. Se deberá tener especial precaución se emplear estos tipo de aceites vegetales en transformadores que puedan estar desconectados largos periodos de tiempo en condiciones de baja temperatura.

Un valor alto del parámetro de refrigeración $\mathrm{P}$ indica una mejor transferencia térmica del aceite. Mediante dicho parámetro, en el rango de temperaturas comprendido entre 20 y $80{ }^{\circ} \mathrm{C}$, se ha podido comparar la eficacia en la transferencia térmica de los aceites vegetales y minerales, siendo la de los minerales superior a la de los vegetales. Este fenómeno es debido a que la viscosidad de los aceites vegetales es superior a la del mineral. Los ésteres son, en general, de mayor viscosidad que los aceites minerales ocasionando eficiencias inferiores en cuanto a su transmisión de calor y que no siempre será compensada por sus valores más altos de densidad y calor específico. 
Por otro lado, otro de los objetivos a alcanzar durante la ejecución de la tesis era ver si el aceite dieléctrico de origen vegetal perdía sus propiedades como dieléctrico cuando este era sometido a ensayos de envejecimiento acelerado. Para condiciones de acidez elevada, la rigidez dieléctrica del aceite era en todos los casos superior a $60 \mathrm{kV}$, no perdiendo en ningún caso sus propiedades como dieléctrico. Tampoco se veían afectadas la corrosividad del cobre por formación de ácidos carboxílicos en el seno de la matriz ni la presencia de cobre disuelto en el aceite crecía exponencialmente con la acidez. Por lo tanto este tipo de aceites, debido a su estructura química, presentan valores elevados de acidez debido a la formación de ácidos grados por hidrólisis del triglicérido, pero se he demostrado que estos valores no afectan a parámetros dieléctricos críticos para el buen funcionamiento del transformador debido a que los ácidos grasos formados son de cadena larga.

El aceite dieléctrico, debido a fallos térmicos y eléctricos generados en el interior del transformador, sufre craqueo en su estructura molecular generando moléculas de bajo peso molecular, es decir gases, que se quedan disueltos en la matriz del aceite (propiedad de gass absorbing). El triángulo de Duval es una herramienta de diagnosis excelente que nos permite evaluar los fallos ocurridos en el transformador analizando el contenido de gases disueltos en el aceite. Para la presente tesis, se ha desarrollado metodologías de generación de puntos calientes con el objetivo de rediseñar los límites del triángulo de Duval para el aceite vegetal A.

En cuanto a la compatibilidad química del aceite $\mathbf{A}$ con el material aislante celulósico con el que va a estar en contacto íntimo durante su periodo de vida útil, se observa que la degradación de la celulosa cuando está presente un aceite vegetal es menor que cuando está presente un aceite mineral: el grado de polimerización medio viscosimétrico del material celulósico es mayor cuando está en contacto con el aceite A que cuando está en contacto con un aceite mineral. En cuanto al contenido en 2-furfural disuelto en aceite, la concentración de dicho analito es mucho mayor en aceites de origen mineral que en aceites de origen vegetal, señal inequívoca de que la degradación de la celulosa en el aceite mineral es mayor.

Pero como hemos indicado al comienzo del presente capítulo, es de elevada importancia evaluar el comportamiento del aceite a elevadas temperaturas cuando se encuentra en contacto con los diferentes materiales por los que está formado el transformador. Los 
resultados obtenidos en cuanto a cambios en las propiedades dieléctricas del fluido aislante, son satisfactorias ya que la variación de parámetros tales como el índice de acidez o la rigidez dieléctrica apenas se han modificado. En cuanto a la variación de propiedades físicas de los materiales, los resultados obtenidos con el aceite B son exactamente igual que las producidas por el aceite A, por lo que se puede concluir que ambos aceites vegetales se comportan de forma similar cuando son sometidos a ensayos durante un mes a $130{ }^{\circ} \mathrm{C}$ y en contacto permanente con los materiales por los que está formado el transformador.

Pero con el objetivo de esta tesis, hemos querido dar un paso más allá y evaluar el efecto que tiene la presencia de ácidos grasos sobre las propiedades de tracción mecánica del material aislante sólido. Haciendo un análisis de los datos obtenidos durante todo este experimento, podemos concluir que los aceites vegetales poseen mayor capacidad de disolución de agua que los aceite minerales, por lo que en el sistema habrá más agua químicamente ligada al aceite y menor cantidad de agua disponible para el ataque de superficies metálicas. También se ha observado que en aceites vegetales predomina la formación de sales pasivadores de cobre disminuyendo así el grado de corrosión del cobre presente en el sistema. En cuanto al material aislante sólido, el porcentaje de elongación y tracción en papel celulósico prensado disminuye con el tiempo de degradación debido a la hidrólisis de sus cadenas de celulosa y hemicelulosa, mientras que el porcentaje de elongación y resistencia a la tracción aumenta con el tiempo en papel Nomex, posiblemente debido a la activación de las resinas epoxi que refuerzan la superficie del polímero de poliaramida. También se ha vuelto a demostrar que una elevada acidez no significa un mayor ataque sobre el aislante sólido, ya que para índices de acidez altos (aceites vegetales), el ataque al material aislante es menor y viceversa, por lo que se confirma que el tamaño de cadena del ácido graso presente en la matriz es un factor determinante del grado de polimerización del polímero de celulosa.

Y para finalizar las conclusiones extraídas de los resultados obtenidos, es de máxima importancia que el fluido desarrollado para esta tesis sea "amigable con el medio ambiente", es decir, que sea biodegradable y con baja ecotoxicidad acuática y terrestre. Con los datos facilitados, se ha demostrado empíricamente que el aceite no presenta ecotoxicidad aguda para concentraciones inferiores a los $1000 \mathrm{mg} / \mathrm{kg}$. 


\subsection{TRABAJOS FUTUROS}

Los trabajos desarrollados para la presente tesis se enfocaron al desarrollo y evaluación de herramientas de diagnosis para aceites dieléctricos de origen vegetal que estarán presentes en transformadores de distribución, es decir, con demandas térmicas y eléctricas de media y baja intensidad y en ausencia de aire. El siguiente paso sería ver qué cambios habría que llevar a cabo en el dieléctrico líquido cuando cambiamos de un transformador de distribución a un transformador de potencia. A priori, este cambio implica dos nuevos requisitos:

- Una elevada estabilidad a la oxidación, ya que en transformadores de potencia existe una cámara de expansión que se usa para soportar cambios del volumen aislante, la cual contiene aire en su interior. Entre el aire y el dieléctrico se genera una interfase la cual está sometida a reacciones de oxidación.

- Alta capacidad aislante frente a fallos en el transformador. Un transformador de distribución opera típicamente entre los $25 \mathrm{kVA}$ hasta un MVA y con una tensión de entrada desde $1 \mathrm{kV}$ hasta los $36 \mathrm{kV}$. Sin embargo, los transformadores de potencia operan desde 5 MVA hasta 500 MVA con una tensión de entrada superior a los $36 \mathrm{kV}$. Por lo tanto, y debido a la diferencia en la potencia de operación, las demandas térmicas y eléctricas que tiene que asumir el aislante líquido en estos transformadores es mucho mayor que las asumidas en un transformador de distribución.

Por lo tanto, es necesario llevar a cabo una serie de pruebas a escala laboratorio que nos den información acerca del comportamiento del aceite A cuando está sometido a condiciones térmicas y eléctricas tan severas. Una propuesta de pruebas en el laboratorio podría ser la evaluación del impacto del aire a elevadas temperaturas, estudio del fenómeno de migración del agua en el sistema aire/aislante sólido/líquido, estudio del efecto de antioxidantes de origen biológico tal como los tocoferoles, ácido ascórbico,... y una última tarea consistente en estudiar el efecto que tiene sobre las propiedades dieléctricas, el grado de refino del fluido dieléctrico. 
BIBLIOGRAFÍA 


\section{BIBLIOGRAFÍA}

[1] Tutoriales de lubricación. Transformadores. www.brettis.com (2012)

[2] Raymond A. Serway. Electricidad y magnetismo. Editorial Mac Graw Hill. $3^{\mathrm{a}}$ edición revisada (1996)

[3] Pedro Avelino Pérez. Transformadores de distribución: teoría, cálculo, construcción y pruebas, Editorial Reverté. 2a edición (2009)

[4] NYNAS. Manual de aceites de transformador. www.nynas.com/naphtenics (2010)

[5] C. Perrier, A. Beroual y J-L. Bessede.Improvement of Power Transformers by using mixtures of mineral oil with synthetic esters. IEEE Transactions on dielectrics and electrical insulation Vol. 13, No. 3. Pp.556-564 (June 2006).

[6] V.V. Sokolov \& Z. Berler. Transformer is gassing-What to do. Scientific and engineering center ZTZ-Service Company. pp. 1-24 (Ucrania)

[7] H. Borsi, K. Durnke \& E. Gockenbach. Relation between Faults and Generated Gases in Transformer Liquids. IEEE Conference 25 July 1999. (Beijing, China)

[8] Imad-U-Khan, Z. Wang \& I. Cotton. Dissolved Gas Analysis of Alternative Fluids for Power Transformers. IEEE Electrical Insulation Magazine Vol. 23, No. 5. Pp. 195198. (Sept-Oct 2007)

[9] L.R. Lewand \& P. Griffin. Gassing Characteristics of Transformer Oil Under Thermal Stress. NETA World. International Electrical Testing Association Inc. 2005

[10] H. Miyao, E. Mori S. Isaka. The Electrostatic Charging Tendency of In-service Oils and the Investigation of Application Method to the Flow Electrification Diagnosis of the Transformer. Dielectric liquids, 1999 (ICDL 99) IEEE International Conference. (Nara, Japón).

[11] Static electrification in power transformers. CIGRE SC12 - Technical Brochure, Product Id 170 (2000)

[12] W. Rottenberg, J. Fleszynski A. Beroual. Influence of thin layers on static electrification phenomena of materials for power transformers. Conference record of the 1998 IEEE International Symposium on electrical insulation, Arlington, Virginia, USA, June 7-10, 1998. 
[13] P.M. Mitchinson. An experiment to evaluate the benefits of processing aged transformed oil. Conference record of the 2006 IEEE International Symposium on Electrical Insulation. Pp 89-92.Reino Unido.

[15] E. Gockenbach H. Borsi. Performance and new application of ester liquids. Dielectric liquids, 2002 (ICDL 02) IEEE 14 ${ }^{\text {th }}$ International Conference Hannover, Alemania).

[16] Norma ASTM. Standard test method for measurement of average viscosimetric degree of polymerization of new and aged electrical papers and boards. Standar ASTM D 4243-16; ASTM International: West Conshohocken, PA. 2016.

[17] Norma española. AENOR UNE EN 60450:2004. Medida del grado de polimerización medio viscosimétrico de los materiales aislantes celulósicos nuevos y envejecidos para uso eléctrico.

[18] D. J. T. Hill T. Saha. A study of degradation of cellulosic Insulation in Power Transformers - Part 1. Molecular weight study of cellulose insulation paper. ELSEVIER Polymer degradation and stability 48 (1995) pp.79-87.

[19] R. Wicks, B. Glenn \& R. M. DuPont. Industry Standards for liquid-filled Transformers Insulation Systems -New Model Test. Seminar 2006 New Mexico. Weidmann Solution.

[20] A. J. Kachler \& I. Holhein. Aging of Cellulose at Transformer Service Temperatures.Part 1\&2. IEEE Electrical Insulating Magazine Vol 21,nº 3. Pp. 15-24 Mar-Apr 2005.

[21] Z. T. Yao \& T.K. Saha. Separation of Ageing and Moisture impacts on Transformers insulation degradation by polarization measurements. The University of Queensland (Australia) CIGRÉ, Session 2002

[22] C. Patrick MacShane. Aging of Paper Insulation in Natural Ester dielectric fluids. 2001 IEEE/PES Transmission and distribution conference \& exposition, Oct. 28-Nov. 02; 2001. Atlanta GA.

[23] M. Darveniza, D.J.T. Hill \& T.K. Saha. Chemical Degradation of Cellulosic Insulation Paper for Power Transformers Part 1" $4^{\text {th }}$ International Conference on properties and applications of dielectric materials. July 3-8, 1994, Brisbane, Australia.

[24] M. Darveniza, D.J.T. Hill \& T.K. Saha. Chemical Degradation of Cellulosic Insulation Paper for Power Transformers Part 2. $4^{\text {th }}$ International Conference on properties and applications of dielectric materials. July 3-8, 1994, Brisbane, Australia.

[25] A. M. Emsley, X. Xiao \& M. Ali. Degradation of cellulosic insulation in power transformers.Part 1. IEEE Proc. Sci. Meas. Technol. Vol. 147 No. 3, 2000 [Pág. 105$109]$. 
[26] A. M. Emsley, X. Xiao \& M. Ali. Degradation of cellulosic insulation in power transformers.Part 2. IEEE Proc. Sci. Meas. Technol. Vol. 147 No. 3, 2000 [Pág. 110$114]$.

[27] A. M. Emsley, X. Xiao \& M. Ali. Degradation of cellulosic insulation in power transformers.Part 3. IEEE Proc. Sci. Meas. Technol. Vol. 147 No. 3, 2000 [Pág. 115$119]$.

[28] A. M. Emsley, X. Xiao \& M. Ali. Degradation of cellulosic insulation in power transformers.Part 4. IEEE Proc. Sci. Meas. Technol. Vol. 147 No. 3, 2000 [Pág. 120124].

[29] W. L. McNutt, R. L. Provost \& R. J. Whearty. Thermal Life Evaluation of High Temperature Insulation Systems and Hybrid Insulation Systems in Mineral Oil, IEEE Trans. Power Del. Vol. 11, 1391-1399, 1996 [Pág. 1391-1399]

[30] Mineral insulating oils in electrical equipment - Supervision and maintenance guidance. Project number IEC 60422 Ed. 4 (2010).

[31] Workshop Abinee/S.Paulo 2-3 june 2005

[32] Z. Leibovitz \& C. Ruckenstein, Winterization of Sunflower Oil.. Ltd., P.O.B. 193, PetahTikva 49101, Israel (1994)

[33] Pushpinder S. Puri.Winterization of Oils and Fats, Best Foods Research and Engineering Center, Union, NJ 07083 (1980)

[34] W. Herbert Morrion \& James A. Robertson. Solvent Winterization of Sunflower Seed Oil, Agricultural Research Center, Athens, Georgia 30604 (1975).

[35] D. G. McConnell, C. D. Evans \& J. C. Cowan. Solvent Winterization of Partially Hydrogenated Soybean Oils, Northern Regional Research Laboratory, 2 Peoría, Illinois (1965).

[36] Richard E. Boucher and Evald L. Skau. Phase Relations Pertaining to the Solvent Winterization of Peanut oil in Acetone-Hexane Mixtures., Southern Regional Research Laboratory, New Orleans, Louisiana (1951).

[37] Richard E. Boucher and Evald L. Skau. Phase Behavior in the Solvent Winterization of Crude Cottonseed oil in 85-15 Acetone-Hexane Mixture as Related to Reduction in Refining Loss and Color. New Orleans, Louisiana. The Journal of the American Oil Chemist's Society. Vol. 32, 497-501 (1955).

[38] C. H. Mack, R. N. Moore, I and W. G. Bickford. Effect of Winterization on the Composition and Stability of Cottonseed Oil. New Orleans, Louisiana. The Journal of the American Oil Chemist's Society. Vol. 29, 14-16 (1952). 
[39] N.V.,Weena. Fraccionamiento de aceites triglicéridos. UNILEVER 455,3013 AL Rotterdam, NL (2000).

[40] W.G. Mertens, L.J. Rubín, and B.F. Teasdale. The Production of Salad oil by Fractional Crystallization With Solvents. Canadá Packers Ltd., Toronto, Canadá. The Journal of the American Oil Chemists Society VOL. 38, pág 286 (1960)

[41] I. Fofana \& V. Wasserberg. Challenge of Mixed Insulating Liquids for Use in HighVoltage Transformers, Part 1. IEEE Electrical Insulation Magazine Vol. 18, No.3 May/June 2002 [Pág. 18-31].

[42] I. Fofana \& V. Wasserberg. Challenge of Mixed Insulating Liquids for Use in HighVoltage Transformers, Part 2. IEEE Electrical Insulation Magazine Vol. 18, No.4 May/June 2002 [Pág. 5-16].

[43] Xiaohu Li, Jian Li and Caixin Sun. Properties of Transgenic Rapeseed Oil Based Dielectric Liquid. IEEE 0-4244-0169-0/066 2006

[44] M. H. Hilder. The Solubility Water in Edible Oils and Fats. The journal of the american oil chemist's society. Vol.45 pág. 703-707 (1968).

[45] Esteban Lantos. Mantenimiento proactivo de transformadores, 2006. Dr. Lantos Laboratorios

[50] M. Duval. Disolved Gas Analysis and the Duval triangle. Doble, 99 1-20,2006.

[51] J.T. Sarria-Arias. Estado del arte del análisis de gases disueltos en transformadores de potencia" Revista de facultad de ingeniería (Jun. 2014), Vol. 23 No. 36 pp. $105-122$

[52] Victor V. Sokolov. Impact of oil properties and characteristics on transformer reliability. International Technical Conference. New Zeeland (2006).

[53] T. K. Saha and P. Purkait. Understanding the Impacts of Moisture and Thermal Ageing on Transformer's Insulation by Dielectric Response and Molecular Weight Measurements, IEEE Transactions on dielectrics and electrical insulation Vol. 15, No. 2, pp.568-582 (2008).

[54] Norma ASTM. Standard terminology relating to electrical insulating liquids and gases. Standar ASTM D 2864-17a; ASTM International: West Conshohocken, PA, 2017. United States.

[55] R. Ferguson, A. Lobeiras \& J. Sabau. Suspended particles in the liquids insulation of aging power transformer. IEEE Electrical Insulation Magazine. Vol. 18, No.4, pp.1723 (July 2002). 
[56] Bechir Baccouri et al. Application of solid-phase microextraction to the analysis of volatile compounds in virgin olive oils from five new cultivars. Food Chemistry Vol. 102 pp.850-856 (2007).

[57] Norma española. AENOR UNE EN 60814:1999. Determinación del contenido en agua por valoración culométrica automática de Karl-Fischer en líquidos aislantes y papeles y cartones impregnados en aceite.

[58] Norma española. AENOR UNE EN 60599:2000. Equipos eléctricos impregnados en aceite en servicio. Guía para la interpretación de los análisis de gases disueltos y libres.

[59] A. Schat \& S. Eeckhoudt. Applicability of metanol as a new marker for paper degradation in power transformer. IEEE Transactions on dielectrics and electrical insulation Vol. 18, No. 2, pp. 533-540 (April 2011).

[60] F. Scatiggio, M. Pompili \& R. Bartnikas. Effects of metal deactivator concentration upon the Gassing characteristics of transformer oils. IEEE Transactions on dielectrics and electrical insulation Vol. 18, No. 3, pp.701-706 (June 2011).

[61] K. Yasuda, S. Arazoe, T. Igarashi \& S. Yanabu. Comparison of the insulation characteristics of environmentally-friendly oils. IEEE Transactions on dielectrics and electrical insulation Vol.17, No. 3.pp. 791-798 (June 2010).

[62] S. Bhumiwat. Performance of oil and paper in transformers base on IEC 61620 and dielectric response techniques. IEEE Electrical Insulation Magazine. Vol. 26, No. 3. Pp. 16-23 (May/June 2010).

[63] R.J. lia, C. Tang. Y. Feng \& C. X. Sun. Influence of the copper ion on aging rate of oil-paper insulation in a power transformer. IET Electrical application, 2009, Vol. 3, Iss. 5, pp. 407-412.

[64] M. Jovalekic, D. Kolb \& S. Tenbohlen. A methodology for determining water saturation limits and moisture equilibrium diagrams of alternative insulation systems. 2011 IEEE International Conference on dielectric liquids. (Stuttgart, Alemania)

[65] I. Höhlein. Unusual cases of Gassing in transformers in service. IEEE electrical Insulation Magazine. Vol. 22, No.1.pp. 24-27 (2006)

[66] Y. Bicen et al. An assessment on aging model of IEEE/IEC standars for natural and mineral oil-inmersed transformer. 2011 IEEE International Conference on dielectric liquids. (Stuttgart, Alemania).

[67] P.M. Mitchinson. An experiment to evaluate the benefits of processing aged transformer oil. Conference record of the 2006 IEEE International Symposium on electrical insulation (Reino Unido) 
[68] N. Lelekakis, D. Martin \& W. Guo. Comparison of dissolved gas-in-oil analysis methods using a dissolved gas-in-oil standard. IEEE Electrical insulation magazine. Vol. 27, No. 5. Pp. 971-798 (2010)

[69] J. Sabau, I. Fofana \& M. Farzaneh. An environmentally friendly dissolved oxygen and moisture removal system for freely breathing transformer. IEEE Electrical insulation magazine. Vol.26, No.3. pp. 35-43 (May 2010)

[70] Norma ASTM. Standard test method for analysis of gases dissolved in electrical insulating oil by gas chromatography. Standar ASTM D 3612-02; ASTM International: West Conshohochen, PA 19428-2959, United States.

[71] N.J. Fox \& G.W. Stachowiak. Vegetable oil-based lubricants- A Review of oxidation. Elsevier. Tribology International 40 (2007) 1035-1046.

[72] R. Artiaga, J. Lopez-Beceiro \& S. Naya. Oxidation stability of soy and palm based biodiesels evaluated by pressure differential scanning calorimetry. Journal of ASTM International, Vol. 7 No. 4. Pp.1-10 (2010).

[73] M. Augusta, G. Martins \& A. Gomez. Experimental study of the role played by dibenzil disulfide on insulating oil corrosivity-Effect of passivator Irgamet 39. IEEE Electrical Insulation magazine. Vol. 26, No. 4. Pp. 27-32 (2010).

[74] K.J. Rapp, C.P. McShane \& J. Luksich. Interaction mechanisms of natural ester dielectric fluid and kraft paper. 15th International Conference on Dielectric Liquids, 2005 (Coimbra, Portugal) 